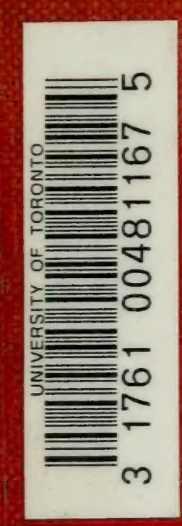

Univ. of TonarTo LIBRARY 


VERGLEICHENDE ANATOMIE DES NER VENSYSTEMS. 


\section{Vergleichende Anatomie des}

Nervensystems

VON

C. U. ARIÊNS KAPPERS

UND

Æ. B. DROOGLEEVER FORTUYN.

ดด

ด๐ 


\section{VERGLEICHENDE ANATOMIE DES NERVENSYSTEMS.}

ERSTER TEIL:

\section{DIE LEITUNGSBAHNEN IM NERVEN. SYSTEM DER WIRBELLOSEN TIERE}

VON

A. B. DROOGLEEVER FORTUYN

Lector der Histologie. Reichs-Universität Leiden.

Mit 116 Abbildungen im Tekst.

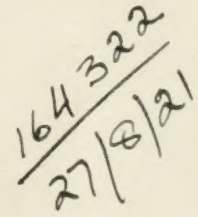

HAARLEM

DE ERVEN F. BOHN

1920. 




\section{VORWORT \\ zum ersten Teil.}

Veranlassung zum Schreiben dieses Buches war, daß Dr. C. U. ARIËxs KAPPERS den Wunsch aussprach, es möge in Anschluß an seinem Werke über die Vergleichende Anatomie des Nervensystems der Wirbeltiere und des Menschen eine Uebersicht über das Nervensystem der Wirbellosen geschrieben werden.

Schon bald nachdem Dr. Ariëns KaPPERs mit diesem Wunsche zu mir gekommen, war es mir klar, daß ich denselben nur zum Teil zu erfüllen im Stande sein würde.

Eine Uebersicht zu geben über den ganzen äußern und inneren Bau des Nervensystems der Wirbellosen, war mir nicht möglich. Doch schien es mir gewünscht eine Zusammenfassung zu geben von dem, was über die Leitungsbahnen im Nervensystem der wirbellosen Tiere bekannt ist, umsomehr, da es über diesen Teil des Baues des Nervensystems keine Sammelwerke gibt, wie solche über den äußern Bau desselben bestehen und weiter, weil dieser Teil in Verbindung mit der Physiologie des Nervensystems wohl der wichtigste genannt werden darf.

Die kritische und vergleichende Literatur-Uebersicht über die Leitungsbahnen der Evertebraten, die in folgendem gegeben wird, ist dadurch ein Werk geworden, das nicht nur durch die Behandlungsweise, worin ich mich nicht mit Dr. KAPPERS würde vergleichen wollen, sondern auch durch den Aufbau deutlich sich von dem Buche Dr. Kappers unterscheidet. Daß dieser trotzdem bereit ist, es unter gemeinschaftlichem Titel erscheinen zu lassen, ist etwas, für das ich ihm auch an dieser Stelle herzlich danke.

Die Niederschrift dieses Buches war Ende 1916 bereits einmal abgeschlossen, doch verhinderten damals die Verhältnisse den Druck.

Inzwischen hatte mein Lehrer, Prof. Dr. C. Pr. Sluiter, Professor der vergleichenden Anatomie in Amsterdam, die Giite, die Arbeit durchzusehen, wofür ich ihm sehr dankbar bin.

Die von ihm erhaltenen Anweisungen, wie die seitdem erschienene Literatur habe ich benutzt, gewisse Teile des Werkes umzuarbeiten und ihnen die vorliegende Form zu geben.

Es muß weiter noch erwähnt werden, daß die Herausgabe des Werkes sehr erleichtert worden ist durch eine staatliche Subvention, für deren 
Zuwendung auch ich S. Exz. DE VISSER, dem Ninister für Unterricht, Kunst und Wissenschaften meinen Dank ausspreche.

Daß außerdem die Firma de Erven F. Bohn in Haarlem auf Dankbarkeit meinerseits Anspruch machen kann, ist selbstverständlich.

Ich habe beabsichtigt die hier folgende Literatur-Uebersicht so vollständig, wie möglich zu machen. Es ist aber selbstredend daß darin noch Lücken vorkommen. Ich werde es sehr schätzen, wenn der Leser mir auf diese Lücken aufmerksam machen will oder mir andere zweckdienliche Angaben zugehen läßt.

A. B. Droogleever Fortuyn.

LeIden, Anatomisches Kabinet, Mai, 1920. 


\section{EIN LEITUNG.}

Die Kenntnis des Weges, welchen der vom tierischen Körper empfangene Reiz durchläuft, ist zum völligen Verständnis der Funktion des Nervensystems unentbehrlich. Deshalb hat die mikroskopische Anatomie des Vertebratenhirns in den letzten Dezennien so viel Interesse erweckt, daß sie für eins der in letzterer Zeit am meisten bereicherten Gebiete der Anatomie gelten darf.

Dasselbe kann man nicht sagen von der mikroskopischen Anatomie des Nervensystems der Evertebraten. Dafür sind mancherlei Gründe anzuführen und wenn in diesem Buche versucht werden wird eine Literaturübersicht. nicht über die ganze mikroskopische Anatomie des Evertebratennervensystems, sondern nur über den Verlauf der Leitungsbahnen zusammenzustellen und dabei die lückenhafte Ausarbeitung dieses Gebietes gar zu sehr zu Tage treten wird, ist es vielleicht nützlich und angebracht diese Gründe, so weit ich sie' sehe, hier mitzuteilen.

Das Problem des Verlaufs der Leitungsbahnen besteht bei Vertebraten namentlich für das Zentralnervensystem. Im peripheren Nervensystem ist man darüber entweder genugsam unterrichtet oder, wie im symphathischen Nervensystem, die ganze Reizleitung ist so diffus, daß es uns bis jetzt nicht darauf ankommt bestimmte Bahnen zu kennen. Anders bei den Evertebraten. Was man hier anatomisch gesprochen gewöhnlich Zentralnervensystem nennt, ist bei weitem nicht so scharf, wie bei den Vertebraten vom peripheren Nervensystem zu trennen. Bei den Echinodermen z.B, bestehen Kontroversen darüber, ob man nur den Nervenring oder auch die Radialnerven oder selbst die letzten allein als nervöses Zentrum anzusehen hat. Und ruft man den mikroskopischen Bau der betreffenden Organe zu Hilfe, so verschwindet der Gegensatz zwischen zentralem und peripherem Nervensystem immer mehr, am meisten freilich bei den niederen Wirbellosen. Ich habe es daher für notwendig gehalten im frolgenden die Leitungsbahnen des ganzen Nervensystems zu betrachten.

Die Anatomie des Nervensystems der Wirbeltiere bietet nach zwei Richtungen Anhalte für das Studium der Leitungsbahnen. Erstens weiß man dort doch im allgemeinen bestimmt ob ein Organ ein Nerv ist oder nicht und wieviele solcher Nerven dem Gehirn entspringen. Nicht also bei den Evertebraten. Widersprüche über die Zahl der Nerven, welche dem Hirnganglion der Insekten entspringen, sind gar nicht selten und die Homologisierung der DROOGLEEVER FORTUYY. 
verschiedenen Nerven wird dadurch sehr erschwert und doch gehören dic Insekten zu den Wirbellosen, welche das spezialisierteste Nervensystem aufweisen, dessen Unterteile also am besten erkennbar sind. Bei den Coelenteraten aber ist es noch heute sehr schwer Nerven und Ganglienzellen als solche zu erkennen und sind oft, wie man später sehen wird, grobe Fehler begangen. Ich glaube, daß solches weniger auf Rechnung eines Entbehrens spezifischer Nerkmale zu schreiben ist, als eines Entbehrens geeigneter Darstellungsmethoden. Sind doch die meisten üblichen histologischen Färbungsmethoden an Vertebraten gefunden und den Wirbeltiergeweben angepaßt. Ob noch zu findende, besonders für diese oder jene Gruppe von Evertebraten brauchbare Methoden die Elemente ihres Nervensystems einmal besser darstellen werden oder nicht, heute ist jedenfalls bei vielen Wirbellosen das Studium des Nervensystems technisch bei weitem schwieriger als bei Vertebraten.

Ein zweiter Umstand, welcher das Studium des Vertebratennervensystems dem der Evertebraten gegenïber erleichtert, ist die geringe Zahl der 'Typen, wonach dasselbe gebaut ist. Wenn man spricht von einem Säugerhirn oder einem Vogelhirn, so mag man darunter noch ziemlich weit aus einander gehende Gebilde zu verstehen haben, man braucht doch nicht sehr tief in die Zoologie eingedrungen zu sein um von der Form und den Verhältnissen der 'Teile einen allgemeinen Begriff zu haben. Wiederum anders bei den Wirbellosen, insbesondere bei Würmern, Mollusken und Arthropoden. Die Ganglien, welche hier das Zentralnervensystem zusammensetzen, sind in so abwechselnder Weise vorhanden und zeigen so mancherlei Anordnungen und gegenseitige Verhältnisse, daß man bei den Arthropoden z.B. zwar sagen-kann, daß sie einen Bauchstrang und Schlundring besitzen, aber daß man dann ja noch gar nicht weil, wie diese Teile gebildet sind. Ohne Zweifel erschweren die vielen anatomischen Grundtypen des Evertebratennervensystems dessen Studium und das Erhalten einer Grundlage für mikroskopische Untersuchungen erheblich. Daher auch der relativ geringe Zusammenhang, welchen man zwischen den bis jetzt publizierten Arbeiten findet und der Mangel an allgemeinen oder iibersichtlichen Resultaten.

Auch histologisch bestehen, besonders was den Verlauf der Leitungsbahnen anbelangt, bei den Wirbellosen viel größere Schwierigkeiten als bei den Wirbeltieren, weil die Neuronen hier gewiß nicht die einzig rorkommenden Formelemente des Nervensystems sind, wie man auch darüber bei den Wirbeltieren denken mag. Der histologische Begriff einer nervösen Leitungsbahn entstammt zweifelsohne dem Reiche der Wirbeltiere. Dort, wo man in jedem \%entralnervensystem dicke Bündel Nervenfasern größere Strecken rerfolgen und experimentell den alleinigen Wegfall eines einzelnen Bündels hervorufen liann, tut sich histologiseh der Begrifi einer bestimmten von dem Reiz durchlaufenen Leitungsbahn auf, so gut wie man auch in der Physiologie diesen Begrifi nicht entbehren kamn. Aber es läßt sich fragen, ob es auch bei ITirbellosen diese festen Leitungsbahnen gibt und eine kurze, prinzipielle Beantwortung dieser Frage darf gewil nicht unterlassen werden in sinem Buche, worin eine Uebersicht über das hinsichtlich dieser Bahnen Bekamnte gegeisen werden soll. 
Da sei denn zuerst die Bemerkung gemacht, daß unter den Wirbellosen die Evolution des Nervensystems, wie man es bei den Vertebraten findet, stattgefunden haben muß und da ist es schon von vornherein recht unwahrscheinlich, daß ein so spezialisiertes Ding wie eine Vertebratenganglienzelle (Neuron) ist, die einfachste Form einer Nervenzelle sein würde. Tatsächlich findet man auch, und darüber sind alle Forscher einig, bei niederen Wirbellosen wie Coelenteraten Ganglienzellen, welche bi-oder multipolai sind, aber zwischen deren Fortsätzen (mit Ausnahme des Falles, daß sie sich bisweilen direkt den Sinnesnervenzellen oder Muskelzellen anschließen) kein Unterschied besteht, woran man also auch keine Dendriten und keinen Neurit unterscheiden kann und welche mittels ihrer protoplasmatischen Verzweigungen mit ihren nächsten Nachbarn zusammenhängen, wobei die Fortsätze breit und unstreitig direkt in einander übergehen (Fig. 4, S. 13). In diesen Fällen kann man nicht von bestimmten Leitungsbahnen sprechen, weil der Reiz ebensogut nach dem einen wie nach dem anderen Nachbarn der gereizten Zelle abfließen kann.

Aber sobald man höhere Wirbellose, wie Arthropoden oder Mollusken oder Würmer studiert, so findet man auch hier Nervenfaserbündel größere Strecken zurücklegen und es läßt sich fragen, ob man berechtigt ist hierin auch Leitungsbahnen zu sehen.

Da soll man zuerst Stellung nehmen gegenüber der Neuronenlehre, wie sie von Retzius, CaJAL u.a. auch im Gebiete der Wirbellosen angewandt worden ist. Die Neuronenlehre umfaßt zwei Hauptsätze. Erstens : die Neuronen sind die Formelemente des Nervensystems und zweitens: die Neuronen sind nicht unmittelbar durch ihre feinsten Fortsätze mit einander verbunden. Ich glaube nun, daß die Ganglienzelle mit oder ohne ihren speziellen Charakter als Neuron tatsächlich überall das histologische Element des Nervensystems ist, daß es aber in der Literatur viele Beweise dafür gibt, daß der zweite Satz bei den Wirbellosen nicht gilt. Aber sie hat für unsere Kenntnis der Leitungsbahnen nur einen untergeordneten Wert, denn der Reiz setzt sich jedenfalls von dem einen Fortsatz oder Neuron auf den anderen fort. Vor allen APATHY, welcher als erster den ununterbrochenen Zusammenhang aller Neurofibrillen im Nervensystem entdeckt hat, aber auch HALLER und bisweilen Bethe, welche ebenfalls die Fortsätze der Nervenzellen in einander übergehen lassen, sehen im Zentralnervensystem der Wirbellosen ins besondere im neuropilema (oder Leydigs Punktsubstanz) ein diffuses System von Leitungsbahnen, das heißt, der Reiz, in einem bestimmten Punkte diesem diffusen Netze zugeführt, kann nicht einem oder höchstens einigen wenigen Wegen folgen, sondern von diesem Punkte mit oder ohne Durchgang von einem oder mehreren Ganglienzellkörpern jeden beliebigen anderen Punkt des Nervensystems erreichen. Wenigstens wären dagegen keine histologischen, nur eventuell physiologische 'Tatsachen anzuführen und dabei könnte also von einer histologischen Erforschung der Leitungsbahnen nicht die Rede sein.

Ich glaube, daß man sich den Bau des Nervensystems so vorzustellen hat, daß da, wo das Reagieren auf Reize des 'Tieres nicht mehr oder weniger 
unbestimmt ist, wo auch eine diffuse Reizleitung genugen würde, wie so oft bei Coelenteraten und im sympathischen Nervensystem, sondern der Reiz freilich sehr viele, aber doch deutlich erkennbare Reaktionen zur Folge hat, ein gruppenweiser Zusammenhang der Ganglienzellen besteht, wie dieses von Dogrel, dem später andere folgten, schon immer und schon an vielen Stellen seit langem hervorgehoben worden ist. Diese (ruppen sind keineswegs völlig gegenseitig unabhängig, sondern in bestimmter Weise mit einander, wenn man will zu Gruppen höherer Ordnung, verbunden und das ganze Nervensystem wird schließlich oft nur eine Gruppe sein. Jede Ganglienzelle darin ist aber nur mit wenigen anderen Ganglienzellen unmittelbar verbunden und durchaus nicht mit fast jeder beliebigen Ganglienzelle des ganzen Nervensystems. Bei solcher Auffassung sind die Resultate der Forscher, welche Fortsätze verschiedener Ganglienzellen in einander übergehen sahen, anerkannt, aber auch die Vorteile, welche die Neuronenlehre betreffs der Reizleitung bietet, gewürdigt. BeтHe (1903) vertritt in seinem Buche über die „Allgemeine Anatomie und Physiologie des Nervensystems" (S. 44) Ansichten, womit die soeben gegebenen übereinstimmen, welchen aber von anderen Stellen und einigen seiner Figuren (Fig. 41) widersprochen wird.

Ich werde also im Folgenden, falls nicht anders gemeldet wird, besonders in den Schemata mit Neuronen arbeiten, dabei aber immer voraussetzen, daß ihre Fortsätze mit einander anastomosieren können.

Von den vielen Weisen, worauf man bei Vertebraten Leitungsbahnen dem Auge sichtbar machen kann, entbehren wir bei den Evertebraten die hexuemstc, die Markischeidenfärhung nach WEIGERT, weil Markischeiden nicht. oder nur in sehr seltenen Fällen den Nervenfasern der Wirbellosen zugefügt

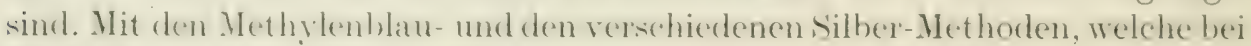
Wirbellosen erheblich mehr Schwierigkeiten bieten als bei Wirbeltieren, sind nur die mehr rezenten Resultate erreicht. Die älteren und auch manche der neueren Ergebnisse sind mittels sehr verschiedener Arbeitsmethoden errungen, welche nicht spezifisch dem Nervensystem angepaßt sind.

Im allgemeinen habe ich nur dann eine Leitungsbahn oder ein Nervenfaserbündel hier wiedergegeben, falls der Beginn der Nervenfaser (die Ganglienzelle), oder ihr Ende, oder beide bekannt sind. Dabei habe ich fast nie Angaben ïber das Enden oder Anfangen von Nervenfasern in einer Ganglienzellgruppe als der Vermeldung wert betrachtet, weil man dann ohne weiteres noch nicht weil3, ob die Fasern wirklich aus den Zellen dieser Gruppe hervorgehen, oder ob sie diese mit ihren Endverästelungen umspinnen, oder endlich ob sie einfach die Ganglienzellgruppe durchsetzen. Ich hoffe so manchen falschen Behauptungen über den Verlauf der Nervenfasern entgangen zu sein.

In dieser Einleitung sei noch bemerkt, daß ich mich befleißigt habe, wo nötig, lateinische Namen für besondere anatomische oder histologische Unterteile zu gebrauchen. Diese gute Gewohnheit scheint in dieser Zeit, wo viele immer mehr nach einer Weltsprache streben in Vergessenheit zu geraten. Es ist gar nicht selten, daß man, besonders in Arbeiten ïber das Insektenhirn eine ganze Seite mit Synonymen, wie z.B. Folgendes sieht: Pilzkörper = 
corps pédonculé $=$ mushroom-body. Da wählt man meiner Meinung nach wohl besser einen allgemeinverständlichen lateinischen Namen, der zwar meistens auch besteht, aber nicht gebraucht wird.

Was meine schematischen Figuren anbelangt, so sei darüber bemerkt, daß ich mich nirgends bemüht habe die relative Größe der Ganglienzellen auszudrücken und ich fast immer gepaarte, symmetrisch gelegene Ganglienzellen nur entweder rechts oder links in der Figur abgebildet habe.

Man wird vielleicht manchmal beim Lesen der folgenden Seiten enttäuscht sein über die dürre Nebeneinanderstellung meistens unzusammenhängender Tatsachen, wo man gemeint hat eine übersichtliche Darstellung der Leitungsbahnen des ganzen Nervensystems und die daraus folgenden physiologischen Rückschlüsse erwarten zu können. Niemand wäre dieser Erwartung so gern entgegengekommen wie ich. Aber ich glaube, weder dasjenige was uns jetzt über die anatomischen Leitungsbahnen der Evertebraten, noch dasjenige was uns über die physiologischen Leitungsbahnen tatsächlich bekannt ist, ließe sich dazu verwenden. Dafür ist uns noch zu wenig bekannt oder wenigstens noch zu viel unbekannt. Und die Fantasie darf in diesem Gebiete, wo jeder Tag neue Tatsachen mit sich bringt, nur zu Arbeitshypothesen, nicht zur künstlichen Zusammenfügung der einzelnen Teile zu einem Ganzen verwandt werden. Bei diesem Sachverhalt kann.ich nur hoffen, daß die Sammlung der bekannten Tatsachen der Hodologie eine zukünftige wissenschaftliche Schilderung der Struktur und Funktionen des Nervensystems der Evertebraten erleichtern möge. 


\section{PORIFERA.}

Es ist sehr wahrscheinlich, daß die Schwämme, welche als Parazoa zwischen die Protozoen und die Metazoen eingereiht werden, kein Nervensystem und keine Ganglienzellen besitzen. Zwar hat Vox LExDExFELD (1885 $a$ und b) bei einigen australischen Kalkschwämmen, z.B. Ascandra arborea und Leucandra conica ein mesodermales Nervensystem beschrieben, dessen multipolare Ganglienzellen mittels ihrer Fortsätze mit rings um die Poren stehenden Sinneszellen in Verbindung stehen, aber VosiraER (1887) erwähnt in seiner sehr vollständigen Arbeit kein Nervensystem der Porifera.

CHus (1897) ist zehn Jahre später der Meinung, daß Vox Lexdexfends Angaben näherer Bestätigung bedürfen und auch neuerclings behauptet Parker (1910), daß den Schwämmen eigentliche Nerrenzellen abgehen. Doch hảben sie typische Muskelfasern, welche unmittelbar erregbar sind und Parker erblickt darin den ersten phylogenetischen Anfang eines Nervensystems. Nach ihm sollen sich erst bei den Coelenteraten sensibele Nervenzellen entwickeln und erst in dritter Instanz neben Rezeptoren oder sensibelen Nervenzellen und Effektoren oder Muskelzellen auch diese beiden verbindende Ganglienzellen. Wir werden später bei den Coelenteraten andere, mehr begründete Auffassungen über das erste Auftreten der Elemente des Nervensystems kennen lernen.

Obgleich die ,Muskelfasern" der Porifera ihrer crhöhten Erregbarkeit wegen vielleicht physiologisch den ersten Infang cines differenzierten Nervensystems darstellen können, so muß man doch anatomisch, falls Vox LENDENFELD Angaben nicht noch nachher Bestätigung erfahren, den Schwämmen jedes Nervensystem absprechen.

\section{I'T'E R A T'U R.}

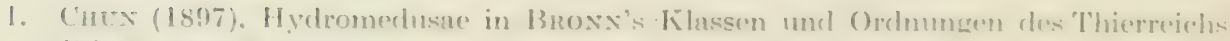
Brl. 2. Aht. 2.1897 .

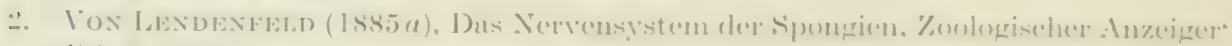
lict. s. Issis.

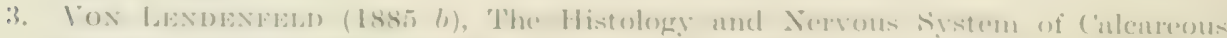

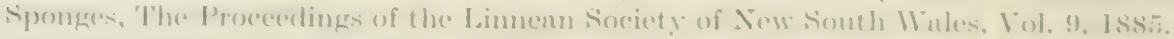

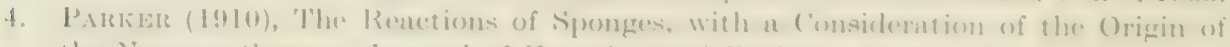

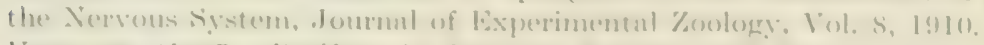

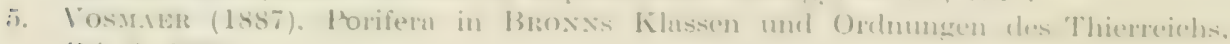
Bd. 2, 1887 . 


\section{OELENTERATA.}

Im allgemeinen kann man sagen, daß die Coelenteraten ein Nervensys tem besitzen, welches hauptsächlich aus einem subepithelialen Plexus von Ganglienzellen besteht, welche mit breiten Fortsätzen anastomosieren, während einige ihrer Fortsätze zur Innervation der Muskelfasern dienen und andere unmittelbar übergehen in die basalen oder zentripetalen Fortsätze der zum Epithel gehörigen Sinneszellen.

Man sieht also am Anfange der Leitungsbahnen eine Sinnesepithelzelle vom Typus, wie sie in den Sinneszellen der Riechschleimhaut der Vertebraten bekannt sind, eine Zelle, deren peripheres Ende ein Sinneshaar oder einen Sinnesfortsatz trägt und welche basal in einer Nervenfaser endigt, welche sich den Fortsätzen der Ganglienzellen anschließt. Der Anschluß ist hier wohl immer ein direkter Uebergang.

Wir begegnen hier zum ersten Male der Zellart der Sinnesepithelnervenzelle (wenn wir alle ihre Qualitäten in einem Worte zusammenfassen), welcher wir bei allen Evertebraten immer wieder begegnen werden. Bei Vertebraten wird diese Zellart repräsentiert von den olfaktorischen Epithelzellen und den Stäbchen- und Zapfenzellen der Retina, ist aber meistens ersetzt durch die Sinnesepithelzelle, welche selbst keine nervösen Fortsätze trägt, sondern von Nervenfasern, Fortsätzen einer Ganglienzelle, umfaßt wird. Solches trifft man hingegen bei den Evertebraten sehr selten an.

Ich werde immer die Terminologie Bethes anwenden, welcher im Jahre 1895 vorgeschlagen hat das Wort Sinnesnervenzelle, schon 1892 von RETzIUS gebildet, immer für eine Sinneszelle anzuwenden, welche selbst eine Nervenfaser als Fortsatz besitzt, während Sinneszelle (wahre Sinneszelle) nur eine Sinneszelle ohne Nervenfortsatz, aber umsponnen und innerviert durch die Fortsätze einer Ganglienzelle bezeichnen sollte.

Wenn man in Gedanken den Reiz durch die Sinnesnervenzelle bis zur ersten Ganglienzelle verfolgt hat, so gelingt es in den allermeisten Fällen bei Coelenteraten nicht histologische Belege für einen bestimmten weiteren Verlauf zu finden. Die Fortsätze, welche die Ganglienzellen verbinden, sind einander ganz gleich und der Reiz könnte also eben so gut auf die eine wic auf die andere Nachbarzelle ïbergehen. Nur diejenigen Fortsätze, welche sich den Muskelfasern nähern, um diese zu innervieren, sind als solche crkennbar 
und der letzte Abschnitt der Reizleitungsbahn ist also manchmal wiederum bekannt. Nur selten sind, wie wir weiter unten sehen werden, die Maschen des von den Ganglienzellen gebildeten Netzes in einer Richtung ausgezogen, wobei die meisten Fortsätze einander parallel gerichtet werden und nur dann ist im Plexus die Richtung der Leitungsbahn angedeutet, aber gar nicht mehr nachgewiesen wie, wenn das Netz nach allen Richtungen gleich ausgespannt ist.

Da die Coelenteraten jetzt die niedrigsten mit einem Nervensystem versehenen Tiere sind, hat man Anlaß die phylogenetische Entstehung des Nervensystems in dieser Gruppe zu vermuten und kann man hier versuchen diese zu erforschen. Die Behandlung dieser Frage ist fiir unseren Zweck deshalb wichtig, weil daraus erhellt, was man bei diesen 'Tieren noch als zum Nervensystem gehörig betrachten soll.

Es sind vor allen Kleinenberg (1872) und die Gebrider Hertwig (1S7S, 1879-1880) gewesen, welche uns über die erste Phylogenese des Nervensystems wichtige Ansichten mitgeteilt haben.

Fig. 1.

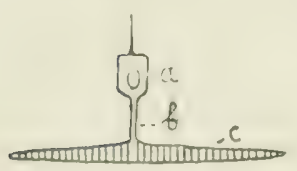

Neuromuskelzelle

a - Zellkörper im Epithel gelegen.

$b=$ Fortsatz, welcher den Zellkörper mit der kontraktilen Faser verbindet. $c=$ kontralitile Faser.

Kleinenberg sah in seinen Neuromuskelzellen die erste Anlage eines Nervensystems. Eine Neuromuskelzelle, auch Epithelmuskelzelle genannt, ist eine Epithelzelle, welche ein Sinneshaar tragen kann und basal sich in einen Fortsatz verjüngt, welchem eine kontraktile Faser quer aufsitzt (Fig. 1). Solche Zellen kommen oft bei Coelenteraten, aber auch bei höheren Evertebraten vor.

Er war nun der Ansicht, daß aus dieser \%elle sich die kontraktile Faser zu einer Muskelzelle entwickelt haben wïrde und der Rest zu einer Sinnesnervenzelle welche ins besondere dazı befähigt wäre, Reize aufzunehmen und zur Vuskelzelle zu leiten. In dieser

Weise würden sich aus einer Zellart zwei hoch differenzierte Gewebe entwickelt haben. Nach O. und R. Hertwig (1850) aber wäre KLEINExBERGs Hypothese so zu verstehen, daß die Neuromuskelzelle sich sogar in drei 'Teile differenziert hätte und zwar eine Sinneszelle aus dem eigentlichen Zellkörper (Fig. 1, a), eine Muskelzelle aus der kontraktilen Faser $(c)$ und einc Nervenfaser aus dem diese beiden Teile verbindenden Fortsatz. (b).

Die Gebriider Hertwig (1878, 1880) haben einige schwache Seiten der KLENExBergschen Hypothese ins Licht gestellt. Von ihren Bemerkungen sind meines Erachtens die folgenden die wichtigsten. Erstens läßt sich gegen KLenENBerg anführen, daß die histologische Spezialisation eine Folge der Spezialisierung der Zelle als Ganzes sein muß und nicht der 'Trennung und des Selbständigwerdens der 'Teile. Was wäre z. B. das Los des liernes bei diesem Prozeß3? Sollte er ohne weiteres eine Zwei- oder Dreiteilung rollfihlt und nachher die hochspezialisierte Zelle sich in die zwei oder drei ungleiche Teile zerlegt haben? Dafur geht uns jede Analogie ab. Auch spätere Forscher wie WoLfF (1904) stellen sich in dieser Hinsicht anf die Seite Hentwigs. 
Und weiter würde Klemexbergs Annahme zwar die Entwicklung des Nervensystems, so weit es die unmittelbare Leitungsbahn zwischen einer Sinneszelle und einer Muskelzelle ist, erläutern, aber nicht so weit es assoziative Funktionen hat und mehrere weit von einander entfernte Zellen verschiedener Art des Körpers unter einander verknüpft. Und doch hat man darin eine Hauptfunktion des Nervensystems zu erblicken.

O. und R. Hertwig haben nicht nur die KLEIsexbergsche Hypothese kritisiert, sondern auch eine andere und, wie ich glaube, weit bessere $\mathrm{Hy}_{\mathrm{y}}$ pothese aufgestellt. Sie weisen darauf hin, daß bei den Coelenteraten die Sinnesnervenzellen, das heißt die Sinneszellen mit nervösem Fortsatz, nicht immer mit ihrem kernhaltigem Zellkörper im Epithel liegen (Fig. 2, a), sondern, daß dieser Zellkörper mehr oder weniger tief unter dem Epithel versunken sein kann (Fig. 2, b). Dabei braucht der periphere Sinnesfortsatz der Zelle nicht iiber die Oberfäche des Epithels hervorzuragen und kann der'zentrale Nervenfortsatz sich einmal oder wiederholt teilen. Eine solche Sinnesnervenzelle ist nun an und für sich nicht zu unterscheiden von einer wirklichen Ganglienzelle (Fig. 2,d), wie sie bei Coelenteraten unter dem Epithel vorhanden sind, welche aber ihrerseits durch einen Fortsatz mit einer Sinnesnervenzelle im Epithel (Fig. 2,c) zusammenhängt, woraus ihre wahre Natur als Ganglienzelle erhellt. Es werden also alle denkbaren Zwischenstufen zwischen einer Sinnesnervenzelle im Epithel (Fig. 2,a) und einer Ganglienzelle (Fig. 2, d) tatsächlich gefunden und die Gebrüder Hertwig sind der Meinung, daß die Ganglienzelle sich auf diesem Wege phylogenetisch aus der Epithelsinnesnervenzelle entwickelt hat, womit dann weiter die

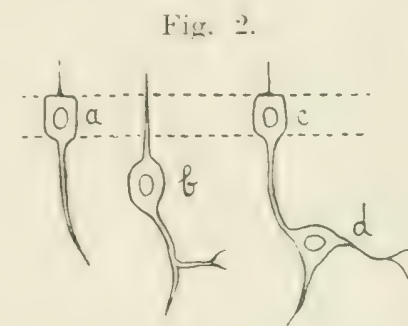

Schema zur Erläuterung der Hertwigschen Hypothese über die phylogenetische Entwick lung der motorischen oder assoziativen Ganglienzelle.

$a$ : Sinnesnervenzelle mit ihrem Zellkörper im Epithel.

b Sinnesnervenzelle mit ihrem Zellkörper unter dem Epithel und verzweigtem zentralem Fortsatz ; Uebergangsstufe zwischen $a$ und $d$.

c. Sinnesnervenzelle, welche mit

d. einer motorischen oder asso. ziativen Ganglienzelle in Verbindung steht

Entwicklung des Nervensystems auch gegeben wäre. Denn man könnte sich ohne Mühe das ganze Nervensystem durch bloße Vermehrung der Ganglienzellen entstanden denken, während dessen assoziativen Fähigkeiten von den vielen Fortsätzen der Ganglienzelle oder Sinnesnervenzelle herzuleiten seien. So wird wenigstens diese Schwierigkeit der KLEINEvBERGschen Hypothese vermieden.

Es sind, soweit mir bekannt, keine überwiegenden Bedenken gegen die HERTWig'sche Hypothese geäußert worden. Wohl aber wird sie gestuitzt durch die Tatsache, daß der vorausgesetzte phylogenetische Vorgang einige Male in der Ontogenie zum Teile wahrgenommen worden ist (so von K. C. Schyeider (1890) bei Hydra (S. 14) und von Vox Lexdexfeld (1882) bei Cyanea (S. 20) ) und die tatsächliche Uebereinstimmung einer tief unter das Epithel gesunkenen Sinnesnervenzelle mit einer Ganglienzelle läßt sich nicht 
leugnen. Man könnte nur bemerken, daß auch innerhalb der Gruppe der Mollusken, wie wir weiter unten sehen werden, Sinnesnervenzellen in oder unter dem Epithel und subepitheliale Ganglienzellen neben einander da sind und wir also, falls die Mollusken die niedrigsten uns bekannten Tiere mit Nervensystem wären, auf ebenso triftigen Gründen wie jetzt bei den Coelenteraten, dann bei den Mollusken die Phylogenese des Nervensystems an diesen Zellen erläutern könnten, ohne das Richtige getroffen zu haben.

liig. 3.

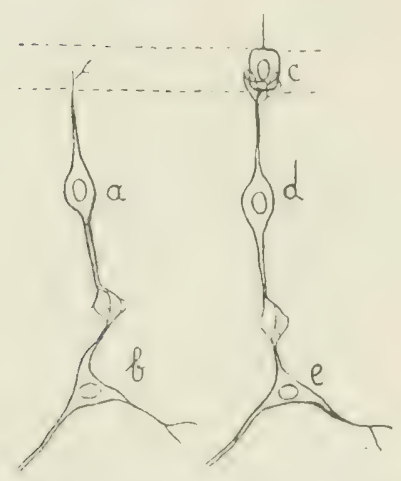

Die beiden sensibelen Cianglienzelltypen

$a$ - sensibele Ganglienzelle mit frei im Epithel endendem, rerzwrigtem. peripherem Fortsats;

b anschliebencle motorische oder assoziative Gianglienzelle;

$c$ : wahre Sinneszelle im Epithel ;

d. sensibele (ianglienzelle, welche mit ihem peripheren Fortsatz die Sinneszelle innerviert ;

$c=$ anschliebende motorische oder assozintive (ianglienz.elle.

Es läßt sich mit anderen Worten nur fragen, ob wirklich innerhalb der Gruppe der Coelenteraten, wo wir doch schon Ganglienzellen neben deren Vorstufen antreffen, die erste Phylogenese des Nervensystems sich voll zogen hat und nicht bei uns unbekannten Vorfahren der Coelenteraten. Das bleibt eine offene Frage.

Wenn man sich genau Rechenschaft darüber gibt, welche Typen von Ganglienzellen in ihrer phylogenetischen Entstehung von der HerTwigschen Hypothese erklärt werden, so ergibt sich, daß es nur motorische und assoziative Ganglienzellen sind. Nun sind diese beiden Ganglienzelltypen zwar die einzigen, welche bei den Coelenteraten vorhanden sind, aber man weiß, daß bei den Vertebraten überdies sensibele ${ }^{1}$ ) Ganglienzellen angetroffen werden und zwar solche, deren peripherer Fortsatz frei, das heißt ohne Zusammenhang mit Sinneszellen im Epithel oder im Bindegewebe endet (Fig. 3,a), und solche (Fig. 3, l), welche mit ihrem peripheren Fortsatz eine wahre Sinneszelle (Fig. 3,c), innervieren. Die wahren Sinneszellen unterscheiden sich also von den Sinnesnervenzellen, indem ihr Zellkörper nicht selbst in einen Nervenfortsatz ausläuft, sondern durch den peripheren Eortsatz einer Ganglienzelle innerviert wird. Die sensibelen Ganglienzellen sind meistens bipolar wie in meinen Fïguren.

Wie hat man sich die phylogenetische Entstehung der sensibelen Ganglienzellen zu denken? Um diese Frage beantworten zu liönnen, hat man

1) Ieh nenne dabei sensibel nur jene Zelle. Welche selbst den Reiz empfängt oder diesen von einer waluen simneszolle ïbernimmt. Einen 'Peil der assnzintiven Bahnon sensibel oflep motorisch zu nemen, wic mun bei den lertobruten tut, hat nur sinn, wemn der eine 'Teil des Nervensystems dem anderen gnnz untergeordnet

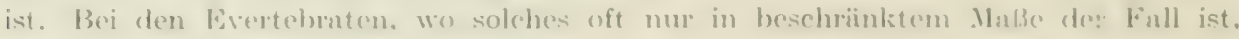
meirlet man besser diese Ausclriele oder spricht nun höchstens ïber sensibelassozintiv und motorisch-assoziativ. 
zuerst zu wissen, bei welchen Evertebraten man diesen sensibelen Ganglienzellen begegnet. Ich habe diesen Punkt genau erforseht (man wird weiter in diesem Buche die Belege finden) und dabei trat die sehr wichtige Tatsache ans Licht, daß die beiden Typen sensibeler Ganglienzellen phylogenetisch nicht gleichen Alters sind.

Die Sinnesnervenzellen kommen im ganzen 'Tierreich vor. Sie wurden im Jahre $1865 \mathrm{zu}$ gleicher Zeit von BaBuchrs und Hexsex bei Mollusken entdeckt, 1877 von GreefF bei den Würmern, 1878 von den Gebriidern Hertwig bei den Coelenteraten, 1879 vor Grenacher bei den Arthropoden und 1883 von Hamans bei den Echinodermen. Bei den Vertebraten gehören die Stäbchen- und Zapfenzellen der Retina und die Riechzellen der Nasenhöhle dazu.

Sensibele Ganglienzellen mit freien Nervenendungen wurden bei den Mollusken von Edinger (1877) entdeckt, bei den Arthropoden, wo sie allerdings selten zu sein scheinen, von Viallaines (1882), bei den Würmern von Surnow (1894). Bei den Echinodermen sind sie nicht bekannt, was aber vielleicht unzulänglicher Untersuchung zuzuschreiben ist; bei den Vertebraten bilden sie oft Tastorgane und sind freie Nervenendungen im Epithel wohlbekannt.

Man kann also sagen, daß man der sensibelen Ganglienzelle mit freien Nervenendungen bei allen Tiergruppen mit Ausnahme der Coelenteraten (und Echinodermen?) begegnet und weil sie schon bei den niedersten Würmern, den Turbellarien, vorgefunden wurden, hat man sich ihre phylogenetische Entstehung innerhalb dieser Tiergruppe, (oder bei. unbekannten Vorfahren der Turbellarien) zu denken.

Ganz anders steht es mit der sensibelen Ganglienzelle, welche mit ihrem peripheren Fortsatz eine wahre Sinneszelle innerviert. Dieser Typus ist uns bei den Vertebraten wohlbekannt, denn wahre Sinneszellen wurden in manchen Tastkörperchen, in den Geschmacksknospen, im Gehörorgan und im statischen Organ beschrieben. Unter den Evertebraten weisen nur die Arthropoden sie auf und hier sind sie von VIaLlanes (1882) entdeckt worden. Wohl ist es mir bekannt, daß Retzius (1895b) bei einem höheren Wurm, Nereis, wahre Sinneszellen beschreibt (S. 81), aber dieser einzige Ausnahmefall wäre näher zu prüfen, zumal, weil Retzius das ganz Besondere dieser Sache gar nicht betont. Bei den Mollusken stellt Pattex (1886) seine „Retinophoren” im Auge als wahre Sinneszellen vor (S. 120), aber er wird darin wohl mit Recht bestritten, wie ich an geeigneter Stelle beweisen werde.

Sind also die sensibelen Ganglienzellen mit freien Nervenendungen phylogenetisch jünger als die Sinnesnervenzellen, noch viel jünger sind die sensibelen Ganglienzellen, welche wahre Sinneszellen innervieren und diese Sinneszellen selbst, denn damit sind nur die beiden höchsten 'Tiergruppen, welche ebenfalls die höchste psychische Entwicklung aufweisen, die Arthropoden und Vertebraten ausgestattet.

Es fragt sich nun, welche Vorstellung man sich am besten über die Phylogenese der sensibelen Ganglienzelle mit freien Endverästelungen bilden kann. Da glaube ich, es ließe sich der Gedankengang der Gebrüder HerTwiG mit Erfolg aufs Neue anwenden und ihre Hypothese iiber die Phylogenese 
des Nervensystems noch weiter ausdehnen. Im Geiste der Hertwigschen Hypothese setze ich voraus, daß die sensibele Ganglienzelle Fig. 3, $a$, von der Sinnesnervenzelle Fig. 2,c, abzuleiten sei, indem dieselbe phylogenetisch bei den primitivsten Würmern ebenso unter das Epithel versunken wäre, wie die assoziative oder motorische Ganglienzelle Fig. 2, $d$, welche von der Sinnesnervenzelle Fig. 2, $a$, hergeleitet wurde. Der im Epithel oder anderswo frei endende Fortsatz ist und bleibt dabei der Sinnesfortsatz.

Ich bin also der Meinung, daß während der Stammesgeschichte zweimal Sinnesnervenzellen in die Tiefe gerückt sind. Einmal geschah es bei den Coelenteraten und hier wurden sie, wie die Gebrüder HerTwig uns lehrten, zu motorischen und assoziativen Ganglienzellen. Ein zweites Mal geschah es bei den niedersten Würmern und hier entstanden sensibele Ganglienzellen mit freien Nervenendungen daraus.

Als Belege für meine Hypothese kann ich in ähnlicher Weise wie die Gebrüder HerTwig, auf Uebergangsformen zwischen einer Sinnesnervenzelle und einer sensibelen Ganglienzelle mit freien Nervenendungen weisen, welche man bei einigen Evertebraten gefunden hat. Vergleichen wir eine Sinnesnervenzelle wie Fig. 2, b mit einer sensibelen Ganglienzelle wie Fig. 3, a so unterscheiden sich die beiden nur in zwei Hinsichten : der periphere Fortsatz der Sinnesnervenzelle ist unverzweigt und erreicht die Körperoberfläche, jener der sensibelen Ganglienzelle ist verzweigt und er erreicht nie die Oberfläche des Körpers. Es sind nun von Havet (1900h) bei Distomum, von Samassa (1894) bei Helix, namentlich aber in sehr schöner Weise von VERAtTi (1900) bei der Molluske Limax (S. 153) Sinnesnervenzellen mit verzweigtem peripheren Fortsatz beobachtet worden, dessen Seitenäste frei endeten. Diese Zwischenstufen zwischen einer typischen Sinnesnervenzelle und einer sensibelen Ganglienzelle brauchen nur ein wenig zu versinken, sodaß auch der periphere Fortsatz selber nicht mehr die Oberfläche erreicht, um typische sensibele Ganglienzellen zu werden.

Die wahren Sinneszellen sind meiner Meinung nach phylogenetisch am ersten bei den Arthropoden und unabhängig davon bei den Vertebraten aus indifferenten Epithelzellen hervorgegangen. Sie haben sich mit sensibelen Ganglienzellen in Verbindung gestellt, welche damit ihren Charakter geändert haben, indem ihr peripherer Fortsatz nicht mehr frei endete, sondern die Sinneszelle innervierte. Die wahren Sinneszellen sind also eine neue Generation von Epithelzellen, welche sich dem Nervensystem angeschlossen hat. ${ }^{1}$ )

[ch darf nicht verschweigen, daß in der Literatur Gedanken geäußert werden, womit meine obenerwähnten Anschaungen Uebereinstimmung zeigen, aber sie enthalten m.E. alle wichtige Fehler. Es ist schon lange her, daß Patrex (1886) wirklich schon behauptet hat, daß die sensibele Gang-

1, Man begegnet diesem letzten Ciedanken in der 'Trnité d'Histologie von Prenaxt, Bouix und IIAllard (190.4) 'lome I S. 317, wo übrigens die Phylo. genese der Elemente des Nervensystems eine andere Darstellung als die obige erlangt. Die Autoren nennen die waluren Sinneszellen ,cellules pseudo-sensorielles on sensorielles accessoires", Weil sie glauben, dul sie nicht wirklich sensibel sind. WVeil ich gerade das Gegenteil amnehme, kann ich diesen Namen nicht beibehalten. 
lienzelle eine Sinnesnervenzelle sei, die sich gesenkt habe. Es war aber seine von keinen Tatsachen unterstützte Hypothese, daß dieser Prozeß sich in der Ontogenese der Mollusken abspiele und er hat es nicht als einen phylogenetischen Prozeß bei den Würmern betrachtet, wie ich (vergl. S. 125). Später hat PATTEx gesagt, daß während der Phylogenese des zusammengesetzten Auges der Arthropoden in die Tiefe gerückte Sinnesnervenzellen $\mathrm{zu}$ sensibelen Ganglienzellen geworden seien und daß diese eine neue Generation von Sinnesnervenzellen oder Sinneszellen innervierten (vergl. S. 206). Auch das ist im Grunde nicht wahr ; die sensibelen Ganglienzellen sind nicht bei den Arthropoden, die Sinneszellen nicht im Auge der Arthropoden, sondern anderswo entstanden.

Vox Lexhossek (1892 und 1895) hat den Gedanken geäußert, daß die sensibele Spinalganglionzelle der Vertebraten von einer aus dem Epithel in die Tiefe versunkenen Sinnesnervenzelle von Lumbricus abzuleiten wäre. Auch mit dieser Anschauung hat meine Erweiterung der HeRTwiGschen Hypothese gewisse Uebereinstimmung, unterscheidet sich aber in mancher Hinsicht davon, wie ich bei der Besprechung der Vos LExHosSEKschen Arbeit (S. 94) erläutern werde.

Nach diesen phylogenetischenAuseinandersetzungen schreite ich zur Beschreibung der bei den Coelenteraten nachgewiesenen Leitungsbahnen.

Fangen wir an mit den $\mathrm{Hy}$ drozoen und unter diesen mit Hydra, einem Tier, womit mehrere Forscher sich befaßt haben. KLeInenberg. $(1872)$, welcher, wie wir gesehen haben, die von ihm entdeckten Epithelmuskelzellen als Vorstufe eines Nervensystems betrachtete, sprach Hydra jede Spur eines besonderen Nervensystems ab. Einige Jahre später erwähnte KoRotNEFF (1876) in den Tentakeln einen Ganglien. zellplexus, das heißt ein Netz von multipolaren Ganglienzellen, welche Fig. 4 .

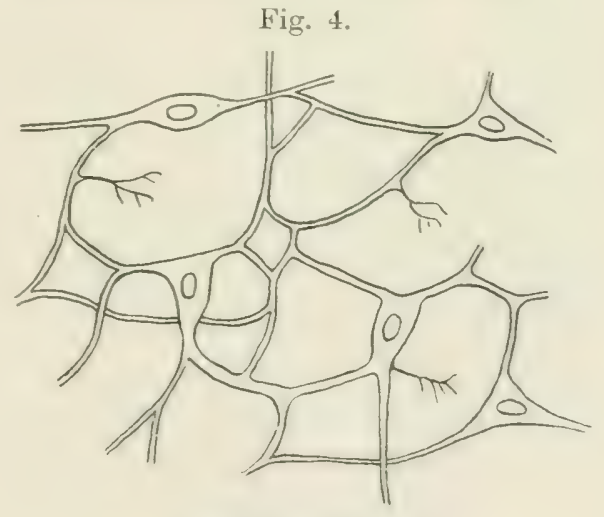

Ganglienzellplexus.

Kopie einer Figur Bethes, (1904) Die verzweigt endenden Fortsätze innervieren die . Muskeln.

mit ihren Fortsätzen anastomosie-

ren, und 1881 zeigte Rouget (zitiert nach WoLfF (1904) einen ebensolchen im allgemeinen unter dem Ektoderm. Solchen Ganglienzellplexus findet man ganz allgemein bei den Coelenteraten und es sind oft von verschiedenen Autoren Teile davon abgebildet worden. Die Figur 4 ist der Arbeit BeTHEs (Deutsche Medizinische Wochenschrift, Bd. 30, 1904) entlehnt. Das breite Zusammenhängen der Ganglienzellen mit ihren Nachbarn und die Fasern zu den Muskeln treten dabei ans Licht. In einem solchen Gewebe lassen sich, wie schon bemerkt, anatomisch keine bestimmten Leitungsbahnen nachweisen.

Der bei Hydra unter dem Ektoderm gelegene Ganglienzellplexus wurde 
von SCHNEIdER (1890) bestätigt, nachdem JiCkeli (1883) erst noch einmal das Dasein von Ganglienzellen an dieser Stelle erwähnt hatte. Er sah auBerdem einen ebensolchen Plexus unter dem Entoderm. Schxeider konnte Epithelzellen des Entoderms, welche Simnesnervenzellen ähnlich waren. ontogenetisch sich senken und sich in subepitheliale Ganglienzellen umbilden sehen. Eine ontogenetische Verwirklichung der HerTwigschen Hypothese also. Die ektodermalen Ganglienzellen bilden sich jedoch aus indifferenten subepithelialen Zellen, was SCHxeider wohl mit Recht als sekundär betrachtet.

Die Angaben Schxemers fanden zum Teil ihrerseits Bestätigung durch die Untersuchungen HADzis (1909). Dieser Autor arbeitete mit Hydra fusca und viridis und wandte neben Isolierung der Gewebeselemente auch die EHRLichsche vitale Methylenblau-Methode und Schnittserien an. Er fand im Ektoderm des Körpers und der Mundscheibe epithelial oder subepithelial gelegene Sinnesnervenzellen, welche mit ihren Nervenfortsätzen mit einem Plexus multipolarer Ganglienzellen zusammenhängen, welche unter oder zwischen den Bases der Epithelzellen liegen. Ein solcher Plexus befindet sich auch in den Tentakeln. Seine Beschreibung davon stimmt völlig mit Fig. 4. Die meisten Fortsätze verbinden die Ganglienzellkörper unmittelbar, aber einige innervieren die Muskelfasern. In diesem Plexus sind keine Leitungsbahnen nachzuweisen, bloß in den Tentakeln laufen die Fortsätze der Ganglienzellen meistens der Länge nach und in der Fußscheibe und auch etwas in der. Mundscheibe streben die Fortsätze zur Bildung eines Ringes. Hier sind also die Leitungsbahnen in dem Plexus angedeutet, aber keineswegs unumgänglich gegeben. HADZI traf auch Ganglienzellen unter dem Entoderm, aber nach ihm gibt es deren zu wenig und haben sie zu kurze Fortsätze zur, Bildung eines Plexus. Die Sinnesnervenzellen des Entoderms sind ebenfall.; spärlich.

Außerhalb der Siphonophoren werden die ïbrigen Hydrozoenordnungen hier gemeinschaftlich behandelt werden.

Das Bestehen eines Nervensystems bei den Coelenteraten ist zuerst von Agassiz bei Hydromedusen konstatiert worden.

Diese Tiere bestehen aus einer gallertigen Glocke, an welcher man eine Außenseite, die Exumbrella (Fig. 5, ex.) und eine Innenseite, die Subumbrella unterscheiden kann. Vom Glockenrande, in dem sich die Sinnesorgane befinden, hängen die 'Tentakeln $(t$.$) herab und hier ist an der Innenseite das$ Velum (v.) ausgespannt, welches die Höhlung der Glocke teilweise verschließt. Eine zentrale Ausstiilpung der Subumbrella, das Manubrium (m.) führt vom Munde zum Magen und dieser setzt sich fort in die Radialkanäle $(c, v$.). welche durch einen Ringkanal (c. c.) verbunden werden, in den auch die Kanäle der 'Tentakeln einminden. Vom Nervensystem sind in die Fig. 5 nur der subumbrellare Plexus $(p l$. s.) und die beiden Nervenringe $(a, n$. e. und a. $n$. i.) eingetragen worden.

Es war der Ringnerv im Glockenrande mit seinen Seitennerven, welcher zuerst die Aufmerlisamkeit Agassizs fesselte. Die Gebrüder Hertwig 
(1877) waren aber die ersten, welche eine richtige Anschauung der Struktur dieser Nerven hatten. Wie weit man vorher davon entfernt war, zeigt die Bemerkung HaEckels (1866), daß dasjenige, was Fritz MüLler als Nervenring betrachtete, ohne Zweifel der „Knorpeling”" unter dem Nervenringe und nicht dieser selbst sei. Und HAECKEE (1866) selbst teilt uns mit, wie bei Glossocodon, einer Geryonide, der eigentliche Nervenring aller Ganglienzellen entbehre, während diese nur in acht dem Nervenringe eingeschal tete Ganglien angehäuft liegen sollten. Derartige ,Ganglien” waren im Nervenringe auch schon von Agassiz und Fritz Müller beobachtet worden und HAECKEL sah sie auch an anderen Stellen. Spätere Untersuchungen haben aber den Gebrüdern Hertwig (1877) Recht gegeben, wenn sie uns lehrten, daß der (doppelte) Ringnerv (Fig. 5, a.n.e. und a.n.i.) der kraspedoten Medusen aus Nervenfasern und vielen im Nerven verbreiteten Ganglienzellen zusammengesetzt ist und daß es weder im Nervenring, noch anderswo besondere Ganglien in den Nerven gibt. Daß zerstreute Ganglienzellen in den. Nerven außerhalb des Nervenringes auftreten können, hatte übrigens auch schon HAECKEL (1866) mitgeteilt.

BoeHuI (1878) beobachtete zerstreute Ganglienzellen im Nervenringe des Glockenrandes der Leptomedusen, ist also in dieser Hinsicht mit den beiden Hertwig im Einklang.

Eiver (1878) erkannte die Doppelnatur des Nervenringes der Geryoniden und sah bei jedem Sinnesorgane des Glockenrandes einen Teil des Ringnerven beiderseits

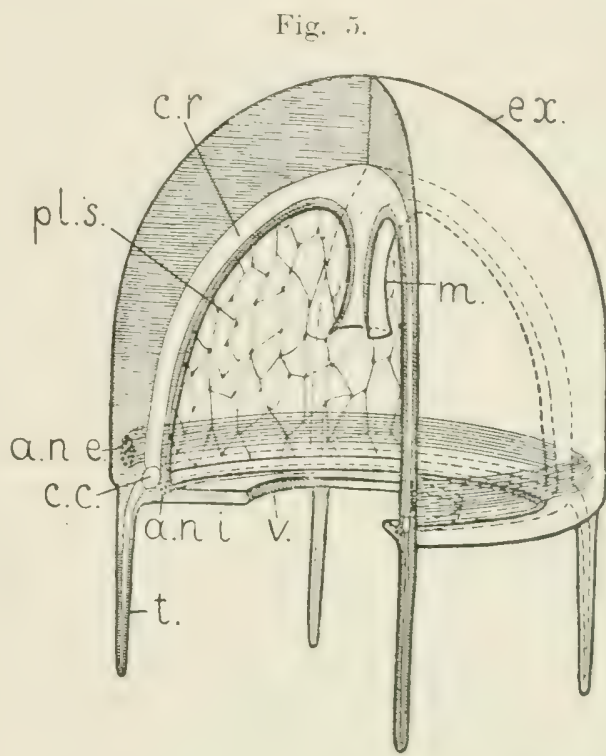

Das Nervensystem einer Hydromeduse. Abgeändert nach Bütschli (1912), Fig. 314. Der linke vordere Quadrant des Tieres durch zwei Radialschnitte, die bis zur Achse gehen, herausgeschnitten.

a. n. e. = annulus nervosus externus, äußerer Nervenring.

a. n. $i$. = annulus nervosus internus, innerer Nervenring.

c. c. $=$ canalis circularis.

c. $r .=$ canalis radialis.

ex. $=$ exumbrella.

$m . \quad=$ manubrium.

pl.s. = plexus subumbrellaris.

t. $=$ tentaculum.

v. $\quad=$ velum.

darin abbiegen. Er leugnete schon einige der von HAECKEL (1866) beschriebenen Ganglien, bestätigte aber andere. Die Struktur des Ringnerven anlangend, meldete er darin überall Ganglienzellen, welche aber auch neben dem Nervenringe zerstreut lägen.

Viel weiter bringt uns die ausgezeichnete Arbeit der Gebrüder HerTwIG im Jahre 1878, die erste, welche uns über einen Teil der Leitungsbahnen der Hydromedusen Auskunft gibt. O. und R. Hertwig untersuchten Aeginidae, Trachynemidae Geryonidae, Vesiculatae und Ocellatae. Die folgende Ueber- 
sicht mag für unseren Zweck genügen. Bei allen Arten findet man im Glockenrande einen doppelten Nervenring, einesteils über, andernteils unter dem Velum (Fig. $5, v$.) gelegen. Beide Ringnerven bestehen aus Nervenfasern und darunter gemischten Ganglienzellen, welche besonders im unteren Ringnerven zahlreich sind. Nach den Gebrüdern HERTwig wechseln die beiden Ringnerven Fasern aus durch die Stützlamelle des Velums hindurch, aber das wird für Carmarina von SchNeIder (1892) verneint. Im Epithel, welches den Nervenring bekleidet, sind Sinnesnervenzellen, welche ihre basalen Fortsätze in den Nervenring hinein senden (Aeginidae, Vesiculatae). Es ist also der Anfang dieser Leitungsbahn bekannt. Der Nervenring sendet einen Nerven zu jeder der Tentakeln (Fig. 5, t.) (Aeginidae, Trachynemidae, Geryonidae) und den Sinnesorganen des Glockenrandes (Vesiculatae). Bei den Geryoniden aber tritt von beiden Seiten ein Nerv auf das Sinnesorgan zu, geradeso, wie auch Enmer (1878) es beschreibt und die Sinnesorgane der Aeginiden sitzen dem Nervenringe unmittelbar auf. Dabei zeigt der Nervenring an dieser Stelle eine Anschwellung, aber Ganglien im Sinne von Ganglienzellanhäufungen, wie HAECKEL (1866) es will, gibt es nicht, ebenso wenig wie bei den Geryoniden. Es laufen schließlich noch vom Nervenringe abzweigende Nerven die Radialkanäle (Fig. 5, c. r.) entlang (Geryoniden), wie mehrere Forscher schon eher gemeldet hatten.

Neben diesen Nerven erwähnen O. und R. HerTwig bei den Aeginiden unter dem Epithel der Subumbrella einen Plexus (Fig. 5, $p l$. s.), wie wir ihn schon von Hydra kennen und dessen Ganglienzellen dem Ringnerven Fortsätze abgeben. Ein solcher Plexus befindet sich auch in den 'Tentakeln. Die Geryoniden und Vesiculaten sind ebenfalls mit einem solchen subepithelialen Plexus ausgestattet.

In den nächsten Jahren wird der subepitheliale Ganglienzellplexus auch unter dem Ektoderm der. Hydroidpolypen entdeckt. So fand JickeLI (1882) diesen bei Eudendrium. Vox LexDexfeld (1883) beobachtete Ganglienzellen in der 'Tentakelbasis der Campanularidae und an anderen Stellen unter dem Ektoderm und Entoderm. Er sagt nicht bestimmt, ob diese Ganglienzellen mittels ihrer Fortsätze zu einem Plexus vereinigt sind, sondern er lenkt die Aufmerksamkeit auf einen oralen Ringnerven von entodermalen Ganglienzellen gebildet, welcher bei den Hydromedusen kein Inalogon hat. Im selben Jahre fand Jickelr (1883) Ganglienzellen in oder unter dem Ektoderm von Tubularia und anderen Hydroidpolypen und beschrieb er mehr vollständig den ektodermalen Plexus bei Eudendrium, wo er besonders in den 'Tentakehn und um den Vund herum entwickelt ist, während an der Basis des Hydranthenkörpers ein Nervenring gebildet wird. Ls hat aber ScHseIDER (1890) diese Arbeit kritisiert und die Heinung geäußert, daß Jickeur keine (tanglienzellen erkannt habe.

Daß es aber jedenfalls Hydroidpolypen mit ektodermalem Ganglienzellplexus gibt, läßt sich der Arbeit Hardys (1891) entlehnen. Dieser Forscher entdeckte bei Myriothela phrygia zwischen dem Liktoderm und den darunter gelegenen Muskelfasern einen Plexus von Nervenfasern, womit unten zwischen den Ektodermzellen gelegene Ganglienzellen verbunden waren. 
Außerdem würden Fasern dieses Nervenfaserplexus zwischen den Ektodermzellen aufsteigen und dort einen zweiten oberflächlichen Plexus bilden. Diese, in Anbetracht dessen, was uns vom Nervensystem der Coelenteraten bekannt ist, sonderbare Angabe bedarf meines Erachtens näherer Bestätigung.

Die Innervation der pigmentierten Epithelzellen oder Augen der Hydromedusen wird uns in der Arbeit Livkos (1900) kennbar gemacht. Vordem hatten dio Gebrüder Hertwig (1878) in den Augen der Ocellaten zwar Pigmentzellen, Sehzellen und Ganglienzellen wahrgenommen, aber der Zusammenhang der Sehzellen mit den Ganglienzellen war ihnen verhiillt geblieben. LINko nun versuchte vergebens die Grougrsche Methode und die EHrLichsche Methylenblau-Methode anzuwenden. Es gelang ihm aber auf andere Weise in den Augen von Staurostoma arctica neben Pigmentzellen spindelförmige Sinnesnervenzellen zu eruieren, deren peripherer Fortsatz sich bis zum Glaskörper fortsetzt, während der basale Fortsatz sich in den Nervenfaserplexus des Nervenringes, welchem die Augen aufsitzen, versenkt. In diesem Nervenringe bipolare Ganglienzellen. Bei Codonium sitzen die Augen nicht dem Nervenringe unmittelbar auf, sondern es ist unter dem Auge ein Polster aus Nervengewebe, welches ein mit bipolaren Ganglienzellen ausgestatteter Nerv mit dem Ringnerven verbindet. Die Bipolarität der Ganglienzellen macht diesen Nerv zu einer bestimmten Leitungsbahn vom Polster zum Ringnerven. In den Augen auch hier bipolare Sinnesnervenzellen.

Hippocrene superciliaris hat mehr zusammengesetzte Sinnesorgane. Es schließt sich hier dem Auge ein Sinneswulst an, welcher aus Sinnesnervenzellen und Ganglienzellen.mit Nervenfasern zusammengestellt ist. Im Auge selbst sind wiederum bipolare Sinnesnervenzellen, deren Fortsätze sich ins Nervengewebe unter dem Epithel begeben. Von da leitet ein Nerv mit bipolaren Ganglienzellen zum Nervenringe in welchem ebenfalls bipolare Ganglienzellen vorhanden sind. Es sind hier also die Leitungsbahnen der optischen Reize in ihrem Anfang angedeutet, aber nicht genau erwiesen.

Sarsia mirabilis hat nach LINko im Auge bipolare Sehzellen, deren zentrale Fortsätze sich in einen Plexus von Nervenfasern und Ganglienzellen unter dem Auge fort setzen. Von dieser Stelle schreiten zwei Nerven, den Radialkanal umfassend, zum Ner venringe, welcher dort verdickt ist und neben bipolaren auch multipolare Ganglien zellen enthält. LINko nennt diese Anschwellung ein Ganglion, aber mit wenig Recht, da der Nervenring auch anderswo von Nervenfasern und Ganglienzellen gebildet wird.

In letzter Zeit hat Krasinska (1914) abermals Carmarina hastata untersucht und dabei die Angaben der Gebrüder Hertwig bestätigt und erweitert. Sie entdeckte überall im Epithel der Subumbrella und des Nanubriums Sinneszellen, deren Basis sich in einen Nervenfortsatz verjüngte. Unter dem Epithel ein Plexus mit Ganglienzellen, welche Krasinska als motorisch betrachtete, da sie wahrscheinlich die Myoblasten oder Epithelmuskelzellen innervierten. Mit dieser Meinung steht das oben Gesagte und Fig. 4 in Einklang. Weiter sah sie solche Sinnesnervenzellen auch den unteren aber nicht den oberen Nervenring entlang und die Nerven, welche die Radialkanäle begleiten, enthalten nach ihr nicht nur Nervenfasern, sondern auch Ganglienzellen. Ein subepithelialer Nervenfaserplexus wurde auch unter dem Entoderm des Magens und des Manubriums gefunden.

Ueber das Nervensystem der Siphonophoren wird uns von CHUN (1881) eine kurze Mitteilung gemacht. Er sieht den für.Coelenteraten typischen Nervenfaserplexus mit Ganglienzellen unter dem Ektoderm.

Kurz nachher erscheint die vielbestrittene Arbeit Korotsefrs (1884). Er erwähnt 
bei Forskalia ophiura dorsal im Stamme einige Reihen von Zellen, welche er Ganglienzellen nennt, denen die nervöse Natur aber wohl mit Recht von SchaEpri (1898) abgesprochen wird. Glïcklicher war KonotnefF, als er bei Physophora in der Blase zivischen Pneumatophor und T'astern einen Nervenfaserplexus mit Ganglienzellen beschrieb und auch Ganglienzellen in dem Pneumatophor anzeigte. Als er aber das Bestehen eines Nervenrings in den Schwimmglocken verneinte, sollte er darin von CHUN (1897) und SchaEPri (1898) berichtigt werden. Die ontogenetischen und phylogenetischen Auseinandersetzungen ïber das Nervensystem, welche sich den Ansichten KLEINENBERrs anschließen, sind mir ebenso wie anderen z.B. Schnerder (1892) sehr unglaubwürdig, weshalb ich sie hier übergehen will.

Die SchNeIDERsche Arbeit (1892) brachte uns nur so um viel weiter, daß jetzt bei Velella und anderen Siphonophoren multipolare Ganglienzellen sowohl unter dem Entoderm als unter dem Ektoderm bekannt waren, aber ScmNeiden beschreibt nicht ihren Zusammenhang zu einem Plexus.

Nach SchAEPPI (1898) sollen auch nur die ektodermalen Ganglienzellen einen Plexus bilden und nicht die zwischen oder unter den Entodermzellen gelegenen, wie sie im Stamme der Kolonie auftreten. Nicht ̈̈berall läßt sich unter dem Ektoderm ein Nervenfaserplexus nachweisen, z.B. nicht in der Subumbrella der Schwimmglocken, aber wohl ist dies der Fall im Stamme und in der Exumbrella der Schwimmglocken. Dazu gesellt sich in den Schwimmglocken ein Nervenring in der Subumbrella in der Nähe der Abgangsstelle des Velums, wie bei Hydromedusen, dessen Zusammenhang mit dem exumbrellären Nervensystem nicht auffindbar war. Der exumbrelläre Nervenring der' Hydromedusen geht aber den Schwimmglocken der Siphonophoren ab. ScHAEPri sah das Nervensystem des Stammes mit dem der Schwimmglocken nur verbunden im ,,spin. delförmigen Organ" im Gipfel der Glocke, wo neben Epithelzellen auch Grnglienzellen sichtbar waren. Weiter beobachtete er auch, wie Fortsätze der Gianglienzellen den Körper. der Epithelmuskelzellen, aber nicht die Muskelfaser selbst innervierten. Es ist also be? Siphonophoren im allgemeinen der letzte Abschnitt der Leitungsbahnen wieder bekannt, sonst aber nichts.

Ist es möglich aus den Angaben über die Hydrozoen ein einigermaßen vollkommenes Bild des Nervensystems zu rekonstruieren? Ich glaube, man wird dabei zu Folgendem gelangen. Ueber den ganzen Körper befindet sich unter dem Ektoderm und bisweilen auch unter dem Entoderm ein nervöser Plexus von multipolaren Ganglienzellen, welche mit ihren Fortsätzen zusammenhängen. In diesem Plexus sind anatomisch keine besonderen Leitungsbahnen nachweisbar, aber wohl kann man sagen, daß der Reiz von den

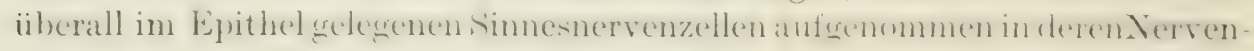
fortsätzen dem Plexus zugeleitet wird, während andrerseits besondere Fortsätze der multipolaren Ganglienzellen den Reiz der Epithelmuskelzelle übermitteln.

Der Ganglienzellplexus breitet sich meistens in allen Richtungen gleich aus, aber er kann sich an gewissen Stellen (vergleiche Hydra) verdichten, wobei gewöhnlich die Maschen des Netzes in einer Richtung ausgezogen werden. Ich glaube nun, daß, wenn dieser Prozeß sich extrem fortsetzt, die sogenannten Nerven und Ringnerven der Hydromedusen und Siphonophoren sich bilden. Allerdings, so lange die Ganglienzellen darin multipolar sind - was nach CHUx (1597) beim unteren, subumbrellären Ringnerven der Hydromedusen der Fall ist - hat der Nerv zwar den Anschein den Reiz. seiner Länge nach zu geleiten, aber braucht er dies doch absolut nicht zu tun. wie auch CHus bemerkt. Wenn aber im Nerven nur bipolare Ganglienzellen 
auftreten, deren Fortsätze in der Richtung des Nerven laufen, so ist damit der Nerv histologisch weit mehr zur Leitungsbahn geprägt. Dies nun ist der Fall mit vielen Nerven der Sinnesorgane der Hydromedusen, wie wir oben sahen und nach CHun (1897) ebenfalls mit dem oberen Nervenring der Hydromedusen und den Radialnerven der Geryonidae.

Bei den Hydrozoen mit höher entwickeltem Nervensystem kommen also neben dem allgemeinen Ganglienzellplexus Nerven vor, welche die Fortsätze vieler Sinnesnervenzellen, die auch gelegentlich zu Sinnesorganen vereinigt sein können, aufnehmen. So weit sie bipolare Ganglienzellen besitzen, ist die Reizleitung ihrer Länge nach anatomisch bevorzugt; sie hängen aber auch seitwärts mit dem allgemeinen Ganglienzellplexus zusammen.

Ich kann nicht umhin hier nachdrücklich zu betonen, daß nach vielen Autoren, in letzter Zeit noch u.a. WolfF (1904) und Krasinsia (1914), bei den Hydrozoa und im allgemeinen bei den Coelenteraten sehr viele nervöse Leitungsbahnen physiologisch nachweisbar sind, ohne daß sie auch histologisch nachweisbar wären.

Es folgen jetzt die Skyphozoen, deren Skyphomedusen von den Hydromedusen durch das Fehlen eines Nervenrings abweichen.

Die erste Mitteilung, welche uns eine Andeutung über die Natur der Leitungsbahnen gibt, ist von KorotnefF (1876) und hat Beziehung auf Lucernaria. KonotnefF ent. deckte in den Tentakeln einen Ganglienzellplexus, aber Kassranow (1901) ist der Meinung, daß dieser Plexus kein Teil des Nervensystems hat sein kömnen und gibt vom Nervensystem an dieser Stelle eine andere, unten folgende Beschreibung.

Nachdem die Gebrüder HerTwig schon im Jahre 1877 verkündigt hatten, daß die akraspeden Medusen (Skyphomedusen) keinen Nervenring besäßen, fügten sie später (1878) hinzu, daß zwar im Epithel der Sinnesorgane des Glockenrandes Sinneszellen mit Nervenfortsätzen, also Sinnesnervenzellen, zu sehen, daß aber im Glockenrande keine Ganglienzellen nachweisbar seien, sodaß jedes Sinnesorgan an und für sich ein Nervenzentrum bilde. Ganglienzellen fänden sich nach ihnen nur in der Subumbrella und sie verneinten den Nervenfaserplexus mit Ganglienzellen ${ }^{1}$ ), welcher von EnrER und von Cr.AUs außerhalb der Sinnesorgane beschrieben worden war.

Es sind diese Angaben offenbar sehr lïckenhaft, aber auch Enmer (1878) zeigt uns weiter nichts als einen allgemeinen Nervenfaserplexus im Körper der Skyphomedusen und das Fehlen eines Nervenringes im Glockenrande. Schatefer (1878), welcher ebensowenig einen Randnerven entdecken konnte, beschrieb bei Aurelia aurita einen subumbrellären Nervenfaserplexus. Da er aber sagt, daß dieser Plexus von bipolaren Zellen gebildet wird, deren Fortsätze meistens unverzweigt sind und nicht gegenseitig zusammenhängen, sondern in bestimmter Entfernung des Zellkörpers frei und spitz enden, so darf man wohl daraus folgern, daß SсHAEFER die Fortsätze nicht bis zum linde hat verfolgen können. Daß er wirklich Nervenelemente zu. Gesicht bekommen hat, wird von HessE!(1895) so sehr bestätigt, daß man daran nicht zweifeln darf.

Von Lendexfeld (1882) gelang es bei Cyanea Annaskala die Resultate seiner Vorgänger zu verbessern. Er sah im Ektoderm der Exumbrella Sinnes-

1) Wenn der Zusammenhang der Nervenfasern und Ganglienzellen nicht genau beobachtet worden ist, spreche ich über einen Nervenfaserplexus mit Ganglienzellen statt Ganglienzellplexus. 
nervenzellen, deren basale Fortsätze sich mit den Ganglienzellen cines Plexus unter dem Epithel vereinigten, welche Ganglienzellen ihrerseits Fortsätze zu den Epithelmuskelzellen sandten. Also die uns schon von den Hydromedusen bekannte Lage. Daneben fand Von Lendenfeld Ganglienzellen unter dem Sinnesepithel der Randsinnesorgane, unter dem Epithel der Tentakeln und der Mundlappen und unter dem Epithel der Subumbrella sogar so viele Ganglienzellen und Nervenfasern, daß sie eine Schicht bildeten. Nach ihm setzen sich auch die Nesselzellen in Nervenfasern fort, welche sich dem Ganglienzellplexus anschließen. Es läßt sich aber dies bezweifeln, da spätere Forscher (u.a. Kassianow (1901)) die Nesselzellen der Coelenteraten im allgemeinen zwar mit verjüngtem basalem Ende, aber ohne Beziehung zum Nervensystem gefunden haben. Vox LENDENFELD konnte auch beobachten, wie bei jungen Tieren die Ganglienzellen und Nervenfasern zwischen den Epithelzellen gelegen waren, während sie bei älteren Tieren darunter lagen.

Fig. 6 .

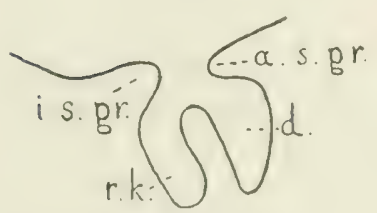

Schematischer Längsschnitt eines Sinnesorgans des Glockenrandes von Rhizostoma Cuvieri. Nach Hesse (1895). a.s.gr. = äußere Sinnesgrube. d. $=$ Decklappen i.s.gr. = innere Sinnesgrube. $r . k_{0}=$ Randlsörper. Er erblickt darin den ontogenetischen Beweis für die S. 9 genannte Hertwigsche Hypothese.

In sehr schöner und zuverlässiger Weise ist das Nervensystem von Rhizostoma Cuvieri von Hesse (1895) studiert worden. Ich meine seine Resultate, so weit sie uns hier interessieren, nicht ohne Hilfe eines, Schemas (Fig. 6) kurz wiedergeben zu können. Die Figur stellt sehr schematisch einen Längsschnitt durch ein Sinnesorgan des Glockenrandes dar. Man begegnet darin dem Randkörper $(r . k$. $)$ vom Decklappen $(d$. überdeckt. Der Decklappen ist durch die äußere Sinnesgrube $(a . s . g r$.) vom Glockenrande getrennt, so wie der Randkörper durch die innere Simnesgrube (i.s.gr.).

Im Epithel des Randkörpers gibt es Sinnesnervenzellen neben Stützzellen. Die Nervenfortsätze der Sinnesnervenzellen bilden einen Filz zwischen den Basen der Stützzellen, welche sich tiefer unter der Oberfläche fortsetzen als die Körper der Simnesnervenzellen. Es liegt also dieser Filz, in dem sich auch Ganglienzellen befinden, tatsächlich noch im Epithel und nicht darunter. Der Filz, wegen der Ganglienzellen meines Erachtens wahrseheinlich ein Ganglienzellplexus wie bei anderen Coelenteraten, ist an einigen Stellen verdickt und es häufen sich hier die Ganglienzellen an. Eine Folge davon ist die von Hesse beobachtete 'Tatsache, daß viele Nervenfasern diesem l'unkte zustreben und so wird anscheinend ein '/entralorgan gebildet.

Auch in der äußeren Sinnesgrube begegnet man einem Nervenfilz unter dem Epithel, welcher mit dem der inneren Sinnesgrube verbunden ist, was Anlaß sein kann in dieser Verbindung eine bestimmte Leitungsbahn zu sehen. Cotylorhiza, wo die äußere Sinnesgrube fehlt, hat deshalb selbstverständlich auch nicht diese Bahn. Alle Nervenfasern der äußeren Sinnesgrube laufen konzentriseh dem Boden der Grube zu, was man bei einer Besehreibung der Nervenbahnen nicht vergessen darf. 
Rhizostoma hat unter der inneren Sinnesgrube viele Ganglienzellen, welchen die Nervenfasern wie einem nervösen Zentrum zustreben. Bisweilen begeben sich Nervenfasern in die Gallerte unter den Sinnesgruben.

Ein peripherisches Nervensystem hat Rhizostoma in der Subumbrella. Es setzt sich aus bipolaren Ganglienzellen und Nervenfasern zusammen, welche zwischen den Epithelzellen gelagert sind und ist mittels vieler Nervenfasern mit beiden Sinnesgruben und mit den Nervenzentren verbunden. Manche Nervenfasern laufen den Radialkanälen und auch dem Ringgefäße parallel. Sie bilden hier also bestimmte Leitungsbahnen und neben dem Ringgefäße eine Ringbahn, welche aber nach Hesse nicht dem Ringnerven der Hydromedusen vergleichbar ist. Mit dem letztgenannten würde eher die Reihe der inneren Sinnesgruben übereinstimmen. Die Muskeln der Subumbrella werden von Nervenfasern der Ringbahn und der radialen Bahnen innerviert und es gibt auch Fasern, welche von dem einen Randkörper zum anderen übergehen.

Man sieht, Hesse weiß viele Leitungsbahnen anzudeuten, aber es bleiben auch hier noch Lïicken auszufüllen.

Kassiaxow (1901) hat sich mit den Lucernariden und unter diesen vor allen mit Craterolophus tethys beschäftigt. Unter dem Ektoderm der Exumbrella beschreibt er einen Plexus von bipolaren Ganglienzellen, worin die Nervenfortsätze der Sinnesnervenzellen übergehen. Die bipolaren Ganglienzellen haben nur selten verzweigte Fortsätze. Was Kassianow uns aber weiter an Einzelheiten bekannt macht, scheint etwas sonderbar. Erstens setzen sich nach ihm auch die gemeinen Epithelzellen in langen, dünnen Fortsätzen fort, welche in seinen Abbildungen nicht immer von Nervenfasern unterschieden werden können. Weiter gibt es Ganglienzellen, welche einen ihrer Fortsätze einer Epithelzelle anlegen, wo er ein wenig verdickt endet. Auch sollen Sinnesnervenzellen bisweilen unmittelbar eine oder mehrere Epithelzellen mit ihrem Fortsatz innervieren. Ich gestehe, daß ich die Bedeutung dessen nicht einsehe und ich bezweifele die Richtigkeit der KAssiaNowschen Angaben.

Die nervösen Elemente sind in den Armspitzen, wo die Tentakeln abgehen, angehäuft. Es gibt auch in den Tentakeln Sinnesnervenzellen, Ganglienzellen und eine Nervenfaserschicht, aber Kassianow konnte ihren genauen Zusammenhang nicht ermitteln. Anders war es im Rande des Bechers, wo die Sinnesnervenzellen ihre basalen Fortsätze zwischen die dortigen Muskelfasern senden. Doch dürften nach KassIANow auch hier noch Ganglienzellen in dieser Leitungsbahn eingeschaltet sein. Unter dem Ektoderm der Subumbrella ist an manchen Stellen eine breite Nervenfaserschicht. Es sind hier im Epithel gewisse Zellen, deren basale Fortsätze sich in die Nervenfaserschicht begeben, welche nach KASsIANow keine Sinnesnervenzellen wären, sondern motorische Zellen einerseits mit Sinnesnervenzellen der Armtentakeln, andrerseits mit Armmuskeln verbunden. In der Subumbrella des Bechers und der Arme sind Nesselbatterien, welche von Sinnesepithel mit kreisrunder Nervenfaserschicht umgeben sind. Die basalen Fortsätze der Nesselzellen führen den Kern und sind keine Nervenfasern. 
Endlich fand Kasstanow auch im Entoderm Sinnesnervenzellen und Ganglienzellen.

In letzter Zeit hat nur noch Krasinska (1914) bei Pelagia noctiluca im Epithel der Meduse Sinnesnervenzellen gefunden, deren Fortsätze manchmal unmittelbar in Fortsätzen der Ganglienzellen eines subepithelialen Nervenfaserplexus $\mathrm{zu}$ verfolgen waren.

Ein Teil des S. 18 von den Hydrozoen Behaupteten gilt auch für die Skyphozoen, aber im allgemeinen sind uns die Leitungsbahnen der Skyphozoen noch weniger als jene der Hydrozoen bekannt.

Schon O. und R. Hertwig (1879) entdeckten unter den Anthozoa bei den Aktinien im allgemeinen einen Ganglienzellplexus unter dem Ekto- und Entoderm, welcher mit den Sinnesnervenzellen in Verbindung steht. So hat Sagartia parasitica in der Mundscheibe und den Tentakeln teils zwischen den Basen der ektodermalen Epithelzellen, teils darunter einen nervösen Plexus, welcher aus bi- oder multipolaren Ganglienzellen besteht, mit welchen die ektodermalen Sinnesnervenzellen zusammenhängen. Die Ganglienzellen sind nicht gleichmäßig über den ganzen Körper verteilt. So sind die Ganglienzellen selten im Nervenfaserplexus des Stomodaeum-Elitoderms, und in der Fußscheibe und im Stamm des Körpers konnten die Gebriider Herrwig sogar keinen Plexus beobachten. Die Ganglienzellen des subentodermalen Plexus der Septen sind schwer aufzufinden, aber auch sic sind mittels ihrer Fortsätze kontinuirlich mit den dortigen Sinnesnervenzellen verbunden. Ein Nervenfaserplexus wird auch in den Akontien gefunden und im Mittellappen der Gastralfilamente — an letzter Stelle neben Sinnesnervenzellen - aber die Seitenlappen der Gastralfilamente entbehren sowohl Sinnesnervenzellen als Ganglienzellen.

Der ektodermale und entodermale Plexus vereinigen sich nur in den Gastralfilamenten und die beiden HERTwIG sind der Meinung, daß hier vielleicht auch bestimmte Leitungsbahnen zwischen beiden Plexus verlaufen. Man vergleiche dafür aber hierunten Groseb.J.

Nachdem HAvet (1901) und Schnerder (1902) die Existenz eines Nervenfaserplexus bei den Aktinien bestïtigt hatten, jedoch darin lecine Bahnen näher hatten bestimmen können, kiundigte WoLfF (1904) das Bestehen eines Nervenrings um den Mund an, damit wieder eine mögliche Bahn angebend.

Weit mehr bietet uns die GroselJsche Arbeit (1909), welche sich auf die vitale Methylenblau-Nethode stiitzt. Grosel.J untersuchte versehiedene Arten von Aktinien und fand dabei das Nervensystem zusammengesetzt aus epithelial oder subepithelial gelegenen Sinnesncrvenzellen mit einem oder mehreren basalen Nervenfortsätzen und bi- oder multipolaren Ganglienzellen. Die Fortsätze der Sinnesnerven- und Ganglienzellen bilden unter dem Elitoderm, wie unter dem Entoderm eine in ihrer Stärke variabele Schicht. Grosfint sah niemals die Ganglienzellen netzartig gegenseitig verbunden und auch nicht mit den Nervenfortsïtzen der Simnesnervenzellen. Es ist wohl nicht zu gewagt, dies der Methylenblau-Methode zuzuschreiben, welche doch immer nur hier und dort einen 'leil des Nervensystems färbt. 
GroselJ gibt den Gebrüdern Hertwig Recht, wenn sie sagen, daß auch die Nesselzellen sich in Nervenfasern verjüngen. Ich glaube nicht, daß er solches hat beweisen können.

Eine interessante allgemeine Bemerkung GroseuJs ist noch, daß die bipolaren Ganglienzellen lange Fortsätze haben, welche bestimmte Bahnen bilden können, während die tri- oder multipolaren nur mit kurzen Fortsätzen ausgestattet sind.

Von den spezielleren Angaben muß ich hier wiedergeben, daß bei Cerianthus alle Sinnesnervenzellen der Tentakeln ihre Nervenfortsätze zur Tentakelbasis senden, was zur Bildung einer bestimmten Leitungsbahn Anlaß gibt. Das gleiche ist der Fall mit den meisten Nervenfortsätzen der Tentakelsinnesnervenzellen von Bunodes. Bei diesem Tiere ist die Mehrzahl der Nervenfasern im parietalen Blatt des Körpers der Körperachse parallel gerichtet, während sie in der Fußscheibe ganz regellos laufen. In der Mundscheibe laufen die Nervenfortsätze der Simmesnervenzellen radial. Besonders viele Sinnesnervenzellen gibt es im Schlundrohr (Stomodaeum), zumal in der Schlundrinne. Größtenteils laufen ihre Nervenfortsätze dieser Rinne parallel Auch beobachtete GroseuJ hier viele bipolare Ganglienzellen, welche ihre Fortsätze ebenfalls unter der Rinne in dieser Richtung senden und so bildet sich hier eine deutliche Bahn für die Reizleitung. Diese Bahn ist zugleich die wichtigste Verbindung des ektodermalen und entodermalen Nervensystems.

GroselJ behauptet, daß unter dem Ektoderm des Stomodaeums der zentrale Teil des Nervensystems gelegen ist, weil von dieser Stelle die meisten Leitungsbahnen ausstrahlen, denn, wie er ganz zutreffend sagt, zentral soll jener Teil des Nervensystems heißen, welcher am meisten durch Leitungsbahnen unmittelbar mit verschiedenen Körperteilen verbunden ist.

Der erste Forscher, welcher bei Korallen einen Plexus von Ganglienzellen zeigte und damit zuerst uns näheres über die Leitungsbahnen mitteilte, war meines Wissens Korotxeff (1887). Er entdeckte bei Veretillum, einer Oktokorallinee, im Becher der Polypen zwischen Epithel und Muskelschicht bipolare und multipolare Ganglienzellen, welche einen Plexus bildeten.

Ihm folgt Hicksox (1895), welcher bei Alcyonium digitatum unter dem allgemeinen Ektoderm der Kolonie nur dann und wann Ganglienzellen, aber keine Nervenfaserschicht beobachtet, sondern unter dem Tentakelektoderm Ganglienzellen, welche cinen gehörigen Nervenfaserplexus bilden, welcher den Muskelfasern aufliegt. Weiter sieht er unter dem Entoderm einen Nervenfaserplexus, dessen bi- und multipolare Ganglienzellen mittels ihrer Fortsätze zusammenhängen und auch befindet sich nach ihm in der Nesogloea ein solcher Nervenfaserplexus, welcher unzweifelhaft mit dem entodermalen zusammenhängt.

Diese letzten Angaben wurden für Xenia Hicksoni bestätigt von AsHworth (1899), welcher an manchen Stellen der Nesogloea einen Nervenfaserplexus verbunden mit kleinen bi- oder multipolaren Ganglienzellen sah. Dieser Plexus hängt zusammen mit einem Plexus mit Ganglienzellen unter dem Entoderm und wahrscheinlich befindet sich ein derartiger Plexus auch unter dem Ektoderm. 
Aleyonium digitatum ist abermals Gegenstand einer Untersuchung durch KASSIANOW (1908), der sich aber auch mit anderen Alcyonaria beschäftigte. Es wird in dieser Arbeit absichtlich nach bestimmten Reizleitungsbahnen gesucht. Kassianow konnte nicht entscheiden, ob das Nervensystem der ganzen Alcyonarienkolonie zusammenhänge, aber er achtet dies nicht wahrscheinlich. Er beobachtete Ganglienzellen unter dem Ektoderm und unter dem Entoderm, aber nicht in der Mesogloea, und er ist der Meinung, daß KorotnefF und AsHwortu in ihren oben zitierten Arbeiten, so wie auch andere Forscher, Zellen der Gallerte als Ganglienzellen angesehen haben.

In den Tentakeln befinden sich Sinnesnervenzellen im Ektoderm der oralen und der aboralen Seite. Ihre Nervenfortsätze treten in eine von Nervenfasern und Ganglienzellen gebildete Schicht zwischen dem ektodermalen Epithel und den Muskelfasern. Also abermals die für Coelenteraten bekannte Lage. An der aboralen Seite der Tentakeln sind nur sehr wenige Ganglienzellen und Nervenfasem zu finden, aber an der oralen Seite ist das Nervensystem weit besser entwickelt.

Die Mundscheibe stimmt, was das Nervensystem betrifft, mit der oralen 'Tentakelseite überein, nur sind die Ganglienzellen und Nervenfasern nicht gleichmäßig verteilt, sondern in einer Weise angehäuft, welche man im Artikel selbst nachschlagen muß. An der Abgangsstelle eines Septums laufen die Nervenfasern einander parallel vom Munde zum Rand der Mundscheibe und KASSIANow meint zwar, daß diese Nervenfaserbündel den Reiz ihrer Länge nach geleiten, aber so lange die ununterbrochene Fortsetzung der Fasern in diesem Bündel noch nicht erwiesen ist und auch hier vielleicht. nur ein in die Länge gezogener Ganglienzellplexus ist, ist die Bahn mehr scheinbar als wirklich gefunden. Kassiaxow konnte im allgemeinen feststellen, daß die Menge der Ganglienzellen und Nervenfasern (auch der radialen Bündel) mit jener der Muskelfasern korrelativ war und dies in den Tentakeln wie in der Mundscheibe.

Ein starker Nervenfaserplexus mit Ganglienzellen umgibt den Mund und

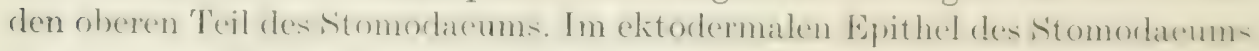
tragen einige Zellen Haare und verjüngen sich basal in einen Fortsatz. Sie sind zweifelsohne Sinnesnervenzellen. In der Siphonoglyphe sind nur wenige Nervenfasern und in der parietalen Körperwand vermochte KAssiaxow nicht mit aller Gewißheit ein Nervensystem zu entdecken.

Unter dem Entoderm bilden die nervösen Elemente keine Schicht, sondern höchstens einen dünnen Plexus. In den Gastralfilamenten waren gar keine Nervenelemente sichtbar.

Aus dem oben Mitgeteilten läßt sich schließen, daß die Anthozoen. wie andere Coelenteraten, einen nervösen Plexus von Ganglienzellen besitzen, welche mit einigen ihrer Fortsätze die Muskeln innervieren und mit anderen in Simmesnervenzellen des Epithels ïbergehen. In einigen Stellen laufen die meisten Nervenfascrn einander parallel, wodurch dort der infang cines histologisch sichtbaren Systems bestimmter Leitungsbahnen gegeben ist. 
Keine Gruppe der Coelenteraten hat so große Schwierigkeiten bei der Untersuchung des Nervensystems bereitet und von keiner lauten die Angaben so widersprechend wie von der Gruppe der Ctenophoren.

Das so sehr in die Augen fallende aborale Sinnesorgan hat schon längst dazu genötigt mit demselben verbundene Nervenelemente oder sogar ein Nervenzentrum in seiner Nähe zu suchen. Claus (1864) und Enier (1S73) gelang dies aber nicht und, obgleich CHUs (1879) ganz willkürlich das aborale Sinnesorgan zum Zentralnervensystem erklärte, kann man behaupten, daß noch heute völlig unbekannt ist, ob und wie die Sinneszellen des Aboralorgans sich. dem Nervensystem anschließen.

Emine (1873) war aber der erste, welcher in der Gallerte des ganzen Körpers Nervenfasern mit Kernen und außerdem multipolare Ganglienzellen nachwies und zwar war Beroe ovatus dabei das Objekt seiner Studien. In den acht Radien des Körpers sind nach ihm die Nervenfasern angehäuft, ohne dabei Nerven zu bilden. Die mit Ganglienzellen ausgestattete Gallerteschicht unter dem ektodermalen Epithel, welche am aboralen Pole die größte Dicke hat, soll nach EIMER das Zentralnervensystem sein. Meinens Erachtens fehlt uns dafür jeder Beweis. Was Emer von der Innervation der Muskelfasern behauptet, nämlich, daß die Muskelfasern als solche nichts anderes als die unmittelbare Fortsetzung der Nervenfasern sind, muß wohl im Vergleich mit dem uns über andere Coelenteraten Bekannten als Fantasie betrachtet werden. R. Hertwig (1880), welcher die Emersche Behauptung nicht bejahen konnte, meinte, daß Ermer von der Kleinexbergschen Neuromuskeltheorie irregeführt worden sei.

CHux (1879) unterwirft die Emensche Arbeit einer Kritik und sagt, daß Emer nicht immer die wahre Natur seiner Nervenfasern und Ganglienzellen beweise. Auch ältere Forscher hätten wohl Muskelfasern für Nervenfasern angesehen. Aber CHUs, der das Aboralorgan zum Zentralnervensystem erklärt und die acht Flimmerreihen zu Nerven, entgeht seiner eigenen Kritik nicht.

Nachdem schon die Gebrüder HeRtwig (1879) die Existenz eines perjpheren Nervenfaserplexus bei den Ctenophoren behauptet und uns damit zum ersten Male einigermaßen über die Art der Leitungsbahnen Auskunft erteilt hatten, erschien im nächsten Jahre die Arbeit R. Herwwigs (1880). Er sah bei einigen Ctenophoren einen subepithelialen Nervenfaserplexus mit Ganglienzellen unter dem Ektoderm des Körpers, womit aber die fadenförmigen Sinneszellen des Aboralorgans nicht durch Fortsätze verbunden sind. Auch setzen sich die Zellen der Wimperbüschel des aboralen Poles nicht in Fasern fort. Ein derartiger subepithelialer Ganglienzellplexus befindet sich auch im Magen, welcher dem Stomodaeum anderer Coelenteraten vergleichbar ist und deshalb mit Ektoderm bekleidet wird. Es gibt vielleicht auch in den Tentakeln subepitheliale Ganglienzellen, aber jedenfalls befindet sich in der Tentakelachse ein Nervenstrang mit Ganglienzellen in seinem Verlauf. In wiefern sein feinerer Bau ihn weiter zur Leitungsbahn prägt, ist unbekannt. In der Achse der Senkfäden liegt ebenfalls ein Nervenstrang, welcher sich jenem Nervengewebe anschließt, welches sich in einer Schicht unter 
der Medianlinie des Tentakels ausbreitet. Sehr interessant ist die Beobachtung Hertwigs, daß die Tentakeln einiger Ctenophoren mit Sinnesnervenzellen ausgestattet sind, welche sich in Nervenfasern fortsetzen. Hier ist also wenigstens der Anfang der Reizleitungsbahn bekannt, eine Tatsache, welche bei Ctenophoren noch immer meines Wissens einzig dasteht.

Hertwig konnte die Nervenfasern in der mesodermalen Gallerte, welche von EIMER entdeckt worden waren, bei Beroe und anderen Ctenophoren zurückfinden. Nach ihm innervieren sie die Muskelfasern, aber in anderer Weise als Ermer meinte und bilden einen Plexus, welcher - wie, sagt er nicht - mit dem Epithel zusammenhängen soll. HERTwiG leugnet die Anwesenheit von Ganglienzellen in der Gallerte und teilt die Kerne der Nervenfasern einem Neurilemma zu. Die Figuren Hertwigs würden aber meiner Meinung nach eher Emer Recht geben, welcher wohl Ganglienzellen in der Gallerte anerkennt. Auch Hertwig fand, wie Enmer, in der Gallerte unter dem aboralen Sinneskörper besonders viele Nervenfasern. Am Ende des Trichters bildet das Nervengewebe zwei Polster und in der Gallerte unter den Wimperrinnen der Meridianstreifen bilden die Nervenfasern wahre Stränge, welche Meridiannerven genannt werden. Hertwig erzählt uns, wie die letzten schon im Jahre 1844 von WiLt beobachtet wurden.

Unter dem Entoderm keine Nervenelemente.

Die später publizierten Mitteilungen ïber das Nervensystem der Ctenopohoren haben uns nicht viel weiter geführt. ScHNeIder (1892) gestand Emer zu, daß es in der Gallerte der Ctenophoren Ganglienzellen gibt. SAMASSA (1892) aber leugnet das ganze Nervensystem der Ctenophoren, was immer andere Forscher dafïr gehalten haben mögen. Nirgendwo ist nach ihm ein Nervenfaserplexus vorhanden. Nur bei Beroe sollen Epithelzellen unter die Flimmerplättchen gesunken und zu Ganglienzellen mit Fortsätzen umgebildet worden sein.

Betue (1895). weleher die Arbeiten Ermers, Hertwigs und SAMAssas kennt, sprioht sich gegen SAmASSA aus und erkennt bei Ctenophoren den subepithelialen Nervenfaserplexus an. Ausdrieklich betont er, wie der Plexus von kontinuirlich mit ihren Fortsätzen zusammenhängenden Ganglienzellen gebildet wird. Er übertrifft R. HERTwIG in der Hinsicht, dia or auch unter dem entorlermalen Epithel einen Nervenfaser. plexus beobachtete.

Zusammenfassend kamn man sagen, daß uns bei den Ctenophoren die Reizleitungsbahnen noch weit weniger bekannt sind als bei den anderen Gruppen der Coelenteraten. Festgestellt ist nur das Bestehen eines subepithelialen Ganglienzellplexus, aber die Hertwigsche Arbeit gibt uns Hoffnung, daß es möglich sein wird, auch hier andere, mehr bestimmte Leitungsbahnen kennen zu lernen. Wie schwierig solehes sein wird, ergibt sich aus dem Mangel an diesbeziiglichen Mitteilungen in den letzten zwanzig Jahren und weiß ich aus eigener Anschaumg. Der Nervenfaserplexus in der mesodermalen Gallerte, weleher zur Innervation der Muskelfasern dient, ist, wie schon R. HerTwig (1880) bemerkte, ein 'Teil des Nervensystems, welcher sich im besondern bei den Ctenophoren unter den Coelenteraten entwickelt hat. 


\section{I T E R A T U R.}

1. Asmworth (1899), The Structure of Xenia Hicksoni, nov. sp., with some Observations on Heteroxenia Elizabethae, Quarterly Journal of Microscopical Science, Vol. 42, 1899.

2. Bethe (1895), Der subepitheliale Nerrenplexus der Ctenophoren, Biologisches Centralblatt, Bd. 15, 1895.

3. Boенu (1878), Helgolander Leptomedusen, Jenaische Zeitschrift fuir Naturwissenschaft, Bd. 12 ( N. F. 5), 1878.

4. Büтschli (1912), Vorlesungen über vergleichende Anatomie, 2te Lieferung, 1912.

5. Chư (1879), Das Nervensystem und die Nuskulatur der Rippenquallen, Abhandlungen herausgegeben von der Senckenbergischen naturforschenden Gesellschaft, Bd. 11,1879 .

i. Chun (1881), Das Nervensystem der Siphonophoren, Zoologischer Anzeiger, Bd. 4,1881 .

7. Chux (1897), Hydromedusae, Broxis Klassen und Ordnungen des Tierreichs, Bd. 2, Abt. 2, 1897 .

$\therefore$ Claus (1864), Bemerkungen über Ctenophoren und Medusen, Zeitschrift für wissenschaftliche Zoologie, Bd. 14, 1864.

1. Emier (1873), Zoologische Studien auf Capri, I, Leber Beroe ovatus, 1873.

11. Enrer (1878), Die Medusen physiologisch und morphologisch auf ihr Nervensystem untersucht, 1878 .

11. GroselJ (1909), Untersuchungen über das Nervensystem der Aktinien, Arbeiten aus den zoologischen Instituten der Lniversität Wien, Bd. 17, 1909.

1:. Hadzi (1909), Leber das Nervensystem von Hydra, Arb. a. d. zoolog. Instit. der Univ. Wien, Bd. 17, 1909.

13. HaEckel (1866), Die Familie der Rüsselquallen (Medusae Geryonidae), Jenaische Zeitschr. f. Naturwiss., Bd. 2, 1866.

14. HARDY (1891), On some Points in the Histology and Development of Myriothela phrygia, Quart. Journ. of Nicr. Seience, Yol. 32, 1891.

1.j. Havet (1901), Contribution à l'étude du système nerveux des actinies, La Cellule, Tome 18, 1901.

1i. R. Hertwig (1880), Ueber den Bau der Ctenophoren, Jenaische Zeitschr. f. Naturwiss., Bd. 14, (N. F. 7), 1880.

17. O. und R. Hertwig (1877), Leber das Nervensystem und die Sinnesorgane der Medusen, Jenaische Zeits. f. Naturwiss., Bd. 11 (N. F. 4), 1877.

1:. O. und R. Hertwig (1878), Das Nervensystem und die Sinnesorgane der Medusen, 1878.

19. O. und R. Hentwig (1879-1880), Die Actinien, Jenaische Zeits. f. Naturwiss., Bd. 13, 1879. Bd. 14 (N. F. 7), 1880 .

21. Hesse (1895), Ueber das Nervensystem und die Simmesorgane von Rhizostoma Cuvieri, Zeits. f. wiss. Zoologie, Bd. 60, 1895.

21. Hicksox (1895), The Anatomy of Alcyonium digitatum, Quart. Journ. of Mier. Science, Vol. 37, 1895.

:-2. JiCkel (1882), Vorläufige Mittheilung über das Nervensystem der Hydroidpolypen, Zoolog. Anzeiger, Bd. 5, 1882.

23. Jickel (1883), Der Bau der Hydroidpolypen, Morphologisches Jahrbuch, Bd. $8,1883$.

21. Kassianow (1901), Studien über das Nervensystem der Lueemariden, Zeits. f. wiss. Zoologie, Bd. 69, 1901.

9.;. Kassixow (1908), Untersuchungen über das Nervensystem der Aleyonaria, Zeits. f. wiss. Zoologie, Bd. 90, 1908.

2) f. Kleisenberg (1872), Hydra, 1872.

27. Korotweff (1876), Histologie de l'Hydre et de la Lucernaire, Arehives de zoologie expérimentale, 'Tome 5, 1876. 
2:. KonotweF (1884), Zur Histologie (ler Siphonophoren, Nitheilungen aus der zoologisehen Station zu Neapel, Bd. 5, 1884.

2!). Korotneff (1887), Zur Anatomie und Histologie des Veretillum, Zoolog. Anzeiger, 13.1. 10, 1887.

:․) Krasinska (1914), Beiträge zur Histologie der Medusen, Zeits, f. wiss. Zoologie, Bd. 109, 1914.

:3. Von Lendenfeld (1882), Ueber Coelenteraten der Südsee, Zeits, f. wiss. Zoologie, Bil. 37, 188\%.

:3:. Von Lendenfeld (1883), Ueber das Nervensystem der Hydroidpolypen, Zoolog. Anzeiger, Bd. 6, 1883.

3:3. Lrnko (1900), Ueber den Bau der Augen bei den Hydromedusen, Mémoires de l'académie impériale des sciences cle St. Pétersbourg, 8me série, tome 10, 1900.

:3. SAmassa (1892), Zur Histologie der Ctenophoren, Archiv für mikroskopische Anatomie, Bd. $40,1892$.

3.;. Schaterer (1878), Observations on the Nervous System of Aurelia aurita, Philosophical Transactions of the Royal Society of London, Vol. 169, 1879.

36. SchaepPI (1898), Untersuchungen über das Nervensystem der Siphonophoren, Jenaische Zeits. f. Naturwiss., Bd. 32, (N. F. 25), 1898.

37. K. C. Schneider. (1890), Histologie von Hyclra fusca init besonderer Berücksichtigung des Nervensystems der Hydropolypen, Archiv. f. mikr. Anatomie, Bid. 35,1890 .

:3. K. C. Scmpeider (1892), Einige histologische Befunde an Coelenteraten, Jenaische Zeits. f. Naturwiss., 13d. 27 (N. F. 20), 1892.

39. K. C. SchneIDFr (1902), Lehrbuch der vergleichenden Histologie der Tiere, 1902.

40. WolfF (190!), Das Nervensystem der polypoiden Hydrozoa und Seyphozoa, Zeitschrift für allgemeine Physiologie, Bd. 3, 1904. 


\section{VER $\mathrm{F}$ 成.}

Der Bau des Nervensystems ist in den verschiedenen Klassen und Ordnungen der Würmer so wenig übereinstimmend, daß es nicht möglich ist, davon ein allgemeines Bild $\mathrm{zu}$ entwerfen.

Nur einige allgemeine Bemerkungen möchte ich am Anfang dieses Abschnitts machen. Es treten bei den Wïrmern zum ersten Male echte Ganglien auf, welche, abgesehen von Stützgeweben sehr oft aus einem peripheren Belag von Ganglienzellen und einem inneren Gewebe von Nervenfasern bestehen. Die Ganglienzellen der Würmer sind nicht nur bipolar oder multipolar, wie bei den Coelenteraten, sondern sehr oft unipolar. Auch sind die Fortsätze der Ganglienzellen nicht immer mehr einander gleichwertig. Unter den multipolaren Ganglienzellen treten typische Neuronen, das heißt Ganglienzellen mit vielen Dendriten und einem Neurit auf, ganz wie bei den Wirbeltieren. Der Körper der unipolaren Ganglienzelle hat nur einen einzigen Fortsatz, welcher sich aber bald verzweigt (Fig. 7). Ich will in üblicher Weise, wie z.B. auch VoN LENHosseK (1895) es tut, den einzigen Fortsatz Stammfortsatz (Fig. 7,s) und seine Verzweigungen Nebenfortsätze nennen. Unter den Nebenfortsätzen kann man in manchen Fällen Dendriten unterscheiden, welche sich in der Nähe des Zellkörpers aufsplittern (Fig. $7, d$ ) und einen Neurit (Fig. 7,n), welcher unter Abgabe von Kollateralen (Fig. $7, c$ ) längere Strecken zurücklegt und schließlich mit zahlreichen, feinen Verzweigungen endet. Es ist mir selbstverständlich nachher nicht möglich den Lauf aller Dendriten und Kollateralen $\mathrm{zu}$ beschreiben. Meistens

Fig. 7.

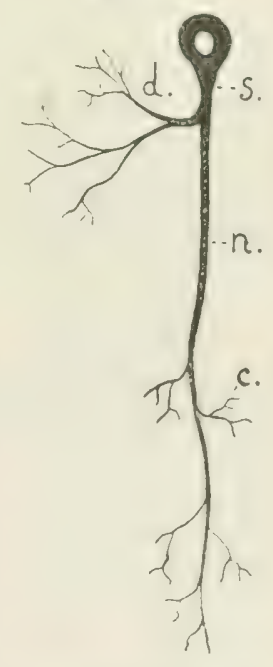

Schema einer unipolaren Ganglienzelle.

$s=$ Stammfortsatz

$d=$ Dendriten

$n=$ Neurit.

$c=$ Kollateralen. reicht es hin, den Lauf der Neuriten anzugeben, wenn man den Verlauf der Leitungsbahnen im Nervensystem darstellen will.

Die Dendriten und Kollateralen der Ganglienzellen bilden im Inneren der Ganglien ein Gewebe, welches von Leydig Punktsubstanz genannt wurde, obgleich er selber schon richtig wußte, daß die Punkte durchgeschnittene 
Fasern waren. Das Wort Punktsubstanz ist leider im Anfang nicht von einem den klassischen Sprachen entlehnten Worte ersetzt worden und hat in Arbeiten, welche in allerhand Sprachen geschrieben sind, Anwendung gefunden. Erst später haben HIS und anderen statt dessen auch „Neuropil” oder „Neuropilem" gesagt. Das erste Wort ist eine Uebersetzung des griechischen „neuropilos" oder Nervenfilz, das zweite enthält das griechische ,pilema”, welches "das dicht zusammen gepackte" bedeutet. Ich glaube, man soll das letzte Wort bevorzugen. Es bietet zwei Vorteile. Erstens drückt es nicht wie Punktsubstanz oder Neuropil die Struktur des davon angedeuteten Gewebes aus, welche heute noch immer vielumstritten ist. Zweitens kann es eben "so gut statt „Punktsubstanz” wie statt „Punktsubstanzballen”, das heißt eines besonderen Abschnitts der Punktsubstanz angewendet werden. Ich will also in der Folge nur das Wort Neuropilem gebrauchen, ein Wort, welches internationale Anwendung finden kann.

Ueber die Struktur des Neuropilems sind verschiedene Ansichten verbreitet, welche sehr nahe zusammenhängen mit den Ansichten der Autoren über die Neuronentheorie. Meine Ansicht ist, wie auch in der Einleitung S. 4 erläutert wurde, nicht, daß die Verzweigungen der verschiedenen Ganglienzellfortsätze immer ganz frei von einander sind, wie die Neuronentheoretikern behaupten, auch nicht, daß sie ein einziges Netz bilden, wobei alle Fasern kontinuirlich in einander übergehen, wie die Antineuronentheoretikern meinen, sondern, daß die Fasern in bestimmter, sei es auch nicht genau bekannter Weise teils in einander iibergehen, teils ohne Zusammenhang durcheinander geflochten sind. Von den Autoren, welche das Neuropilem eingehend studiert haben, wird beides mit großer Bestimmtheit be. hauptet. Nur die Verallgemeinerung ihrer Befunde wäre meines Erachtens fehlerhaft.

Im allgemeinen sind in den Nerven der Würmer immer an manchen Stellen Ganglienzellen eingelegt. Daraus ergibt sich, daß der Nerv als solcher keine einfache Leitungsbahn ohne weiteres zu sein braucht. Der Reiz, im Körper einer Ganglienzelle angelangt, braucht durchaus nicht in derselben Richtung im Nerven weiter geleitet $\mathrm{zu}$ werden. Ich werde daher niemals einen Nerven nennen, wenn nicht außerdem der Faserverlauf im Nerven bekannt ist. Ich möchte immer so in den Nerven, wie in den Ganglien nur was uns über die Neuronenketten bekannt ist, wiedergeben.

Von manchen Autoren wird kein Unterschied gemacht zwischen den Konnektiven oder Längenverbindungen der Ganglien und den Kommissuren oder Querverbindungen, das heißt, es werden auch die Konnektive als Kommissuren bezeichnet. Ich glaube, daß man allen Grund hat Irrtümer zu vermeiden und mit SPExGEL, welcher nach EIsig (1S87) dies am ersten täte, Konnektive und Kommissuren zu unterscheiden. Ich werde in Uebereinstimmung mit der Terminologie der Vertebraten den Ausdruck Kommissur reservieren für alle Nervenfasern, welche die Medianlinie des Körpers überschreiten ohne Rücksicht ob sie solches innerhalb oder außerhalb eines Ganglion tun. 
Nach diesen allgemeinen Bemerkungen nehme ich mein eigentliches Thema wieder auf und fange an mit der Klasse der Plathelminthen und unter diesen mit der Ordnung der Turbellaria.

Die Gestalt des Nervensystems bei diesen Tieren kann Fig. S erläutern, welche das Nervensystem einer Planaria schematisch darstellt. Im Vorderende des zungenförmigen Körpers befindet sich das Hirnganglion (g.c.), welches sich in zwei nach hinten laufende Seitenstränge (s.str.) fortsetzt. Diese sind durch Kommissuren (c.) verbunden und sie entsenden die peripheren Nerven. Die Mundöffnung und der Pharynx liegen bei diesen Tieren fast in der Mitte des Körpers. Aus dem Hirnganglion treten die Hirnnerven, von denen einige zu den Augen (o.) gehen.

Der erste Forscher, welcher uns Angaben über den Lauf einiger Nervenfasern verschafft, ist LAxG (1879). Er arbeitete mit marinen Dendrocoelen, meistens Polycladen und bemerkt vielsagend, daß vor dem Jahre 1868, als KefERsters im Hirnganglion Ganglienzellen und Nervenfasern nachwies, das Nervensystem oft mit dem Blut- oder Wassergefäßsystem oder mit den Geschlechtsorganen verwechselt wurde. Vorn im Kopfe der Dendrocoelen liegt das symmetrisch gebaute, aus peripheren Ganglienzellen und zentralen Nervenfasern zusammengesetzte Hirnganglion, welches neben vielen Nerven zwei starke seitliche Nervenstränge nach hinten abgibt, welche den ganzen Körper durchziehen und zahlreiche periphere Nerven aussenden. Im Hirnganglion sind Nervenfasern, welche die Medianlinie kreuzen und deshalb eine Kommissur bilden und LATg konnte wahrnehmen, wie die Fortsätze einiger Ganglienzellen des Hirnganglions in die Nerven austraten. Hier sind also einige Teile der Leitungsbahnen schon angegeben. Alle Nerven enthalten Ganglienzellen und gehen bald in einen Nervenplexus über. Dabei ist zu beachten, daß dieser Nervenplexus sich von dem NervenfaserFig. 8.

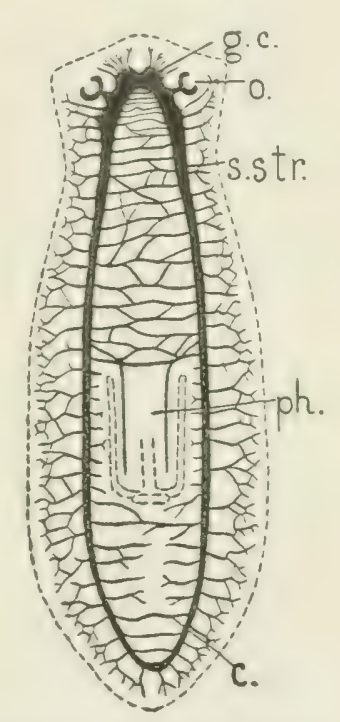

Schema des Nervensys. tems einer Planaria. Nach Bütschli (1912), Fig. 320.

c. = commissura.

g.c. = ganglion cerebrale.

o. $=$ oculus.

ph. = pharynx.

s.str. = Seitenstrang, plexus der Coelenteraten unterscheidet durch seine Zusammensetzung an manchen Stellen aus Bündeln von Nervenfasern, nicht nur aus einzelläufigen Nervenfasern. Daraus kann man schließen, daß, wenn auch die Nerven des Plexus sich verzweigen und kontinuirlich in einander übergehend ein Netz bilden, die in den Nerven enthaltenen Nervenfasern ganz gut ungeteilt und ohne gegenseitigen Zusammenhanu darin fortlaufen können, was hinsichtlich der Reizleitung sehr wichtig ist. Ob auch die Nervenfasern einen Plexus bilden, wie bei den Coelenteraten, hat LANG nicht gesehen. Wo solches der Fall ist, werde ich es weiter immer erwähnen.

Drei Jahre später (1882) untersuchte LANG auch das Nervensystem der 
Tricladen. Er fand die seitlichen Nervenstränge durch viele Ksmmissuren bunden und auch das Hirnganglion scheint ihm der Heuptsache nach eine Kommissur, zumal da es bei den Landtricladen durch einige dünne Kommissuren ersetzt ist. LANG erblickt in den beiden seitlichen Nervensträngen mit ihren Kommissuren die erste Anlage des Bauchstranges der Anneliden. Ich meine wir können ihm darin Recht geben.

Nachdem also LAxG einige zentrale Teile der Leitungsbahnen aufgefunden hatte, wurden von Bowmug (1891) im Körperepithel von Monoophorum striatum und anderen Arten einzelstehende oder in Gruppen vereinigte Tastsinneszellen beschrieben und abgebildet. Sie liegen an allen Orten aber besonders in der Kopfregion, tragen ein peripheres Tasthaar und setzen sich basal in einer Nervenfaser fort, sind also echte Sinnesnervenzellen.

Ohne Zweifel ist nicht Vox LexHossek, wie mancher meint, der erste gewesen, welcher bei einem Wurme im Körperepithel zerstreute Sinnesnervenzellen erkannt hat, sondern haben GREEFF und BoEHuI oder vielleicht Walter oder Heckert (vergl. S. 35) die Priorität. Jedoch ist es wahr, daß erst Vox LExHossek, welcher diese Zellen im nächsten Jahre (1892) bei Lumbricus entdeckte, ihrem Vorkommen allgemeine Bekanntheit gegeben hat.

Hesse (1897a) gelang es einen anderen peripheren Teil der Leitungsbahnen zu beobachten. Er war nämlich der erste, welcher unzweideutig sah, daß die Sehzellen im Auge verschiedener Planaria-Arten mit Fortsätzen ausgestattet sind, welche zum Hirnganglion schreiten. Es sind also Sinnesnervenzellen. Ebensolche Zellen fand Hesse im Auge von Dendrocoelum lacteum, Derostoma und Leptoplana.

Die GoLGI-Methode hat auch bei den Turbellarien weitere nervöse Leitungsbahnen zu Tage gefördert. Schon Brocmux (1895) hatte mit Hilfe dieser Methode bei Dendrocoelum lacteum einen dorsalen, peripheren, sube pithelialen Nervenplexus crkannt, dessen multipolare Ganglienzellen neben anderen Fortsätzen solche besitzen, welche mehrfach verzweigt, trei im Epithel enden. Man ist also berechtigt diese Zellen sensibele Ganglienzellen zu nennen, da ihr peripherer Fortsatz von dem Sinnesfortsatze einer Sinnesnervenzelle durch seine Verzweigungen und die Tatsache, daß diese nicht die Oberfläche des Epithels erreichen, viel weniger darüber hervorragen, zu unterscheiden ist.

Fräulein Moxti (1897) war aber im Stande die von Blocmux errungenen Resultate weiter zu fuihren. Sie arbeitete mit Dendrocoelum lacteum, Planaria torva und montana und mit Polycoelis brunnea, welche in ihrem Bau ïbereinstimmten. Wie schon bekannycoelis brudas Nervensystem am zwei Seitensträngen, welche vorn im Körper zum Hirnganglion anschwellen, das eine große Kommissur zwischen beiden Seitensträngen bildet. AuBerdem sind die Seitenstränge durch zahlreiche, im ganzen Körpergelegene Kommissuren verbunden und auch ihr hinteres Ende bildet eine Kommissur. Die Seitenstränge und auch die Kommissuren entsenden periphere Nerven, welche teils in den Muskeln enden, teils einen nicht nur dorsal, sondern auch rentral gelegenen peripheren Nervenplexus bilden. In den Seitensträngen 
findet man neben Nervenfasern auch unipolare, bipolare und multipolare Ganglienzellen. Ebenso gibt es Ganglienzellen in allen peripheren Nerven und auch in den Kommissuren, wo sie dann aber meistens bipolar sind.

Ueber den Lauf der einzelnen Nervenfasern kounte Moxtr Folgendes beobachten. Unter dem Epithel der Haut befindet sich eine Muskelfaserschicht, worin große, multipolare Ganglienzellen liegen mit vielen Dendriten, welche sich zwischen den Zellen des Epithels verzweigen und dort frei enden und mit einem Neurit, welcher in einem peripheren Nerven und diesen entlang in einem Seitenstrang zu verfolgen war. Ein zweiter Ganglienzelltypus ist bipolar. Er liegt entweder in der. Nuskelschicht oder in den peripheren Nerven der Seitenstränge oder in diesen selbst. Sein peripherer Fortsatz läuft zum Epithel der Haut, wo er sich verästelt und frei endet. Sein zentraler Fortsatz. geht in die peripheren Nerven oder den Seitenstrang. Eine dritte Ganglienzellart gleicht der zweiten in allem; nur besitzt diese Zelle außerdem einen Fortsatz zu einem Muskel, zum Parenchym des Körpers oder abermals zum Seitenstrange, wo er dann verzweigt endet.

Weiter beobachtete Moхтi in den Seitensträngen auch multipolare Ganglienzellen deren Neurit in den Muskeln endet, während sich die Dendriten in der Nähe des Zellkörpers rerzweigen.

Daneben wurden Nervenfasern unbekannter Herkunft in den Seitensträngen gefunden, welche aus diesen hervortraten und im Hautepithel mit freien Verzweigungen endeten. Sie waren besonders zahlreich im vorderen Körperabschnitt.

Fasern der Kommissuren, welche nach Austritt zu den Hoden oder Darmdivertikeln gehen um dort zu enden sind, NIохтI nicht entgangen.

Nicht ganz klar war mir ihre Beschreibung bipolarer, in den Seitensträngen oder in der Muskelfaserschicht gelagerter Ganglienzellen, welche einen Fortsatz ins umringende Gewebe senden und den anderen, den Neurit, in irgendwelches Nervenfaserbündel. Auch ist mir nicht deutlich, wo die unipolaren Ganglienzellen sind, deren Fortsatz in den peripheren Nerven und weiter in dem Seitenstrang zu verfolgen wäre.

Soll es der Launenhaftigkeit der GoLgischen Methode zugeschrieben werden, daß Moхті nicht die von BoeHuig entdeckten Sinnesnerrenzellen im Epithel wiederfand?

Einige Jahre später hat Moxtr (1900) wiederum mittels der GoLGIschen Nethode Planaria montana (oder alpina) untersucht, sich aber jetzt mehr ins besondere dem Hirnganglion (ganglion cephalicum) zugewandt. Es befinden sich hier verschiedenartige Ganglienzellen. Erstens bipolare, deren einer Fortsatz das Ganglion verläßt und zum Epithel der Haut geht um sich dort zu verzweigen, deren anderer Fortsatz aber in dem Seitenstrang zu verfolgen ist, wo er Kollateralen entsendet, welche bisweilen in die Kommissuren treten. Der zentrale Fortsatz dieser Zellen braucht jedoch nicht so lang zu sein, sondern er kann sich auch schon in der Nähe des Zellkörpers verästeln und dort enden.

Neben diesen bipolaren Ganglienzellen gibt es im Hirnganglion auch multipolare Ganglienzellen mit vielen zentralen Fortsätzen, welche sich in

DROOLIFEVER FORTEYN. 
der Nähe verzweigen und einen peripheren Fortsatz zum Ektoderm. Weiter sind im ganglion cephalicum große, unipolare Ganglienzellen, welche ihren Fortsatz in den Seitenstrang senden, wo er Kollateralen bildet. Schließlich beschreibt Monti noch zwei besondere Typen von bipolaren Ganglienzellen im Hirnganglion. Der erste Typus sendet den einen Fortsatz zum Ektoderm der einen Körperseite, wo er sich frei verzweigt; der andere Fortsatz aber teilt sich und der eine Zweig läuft zentralwärts, der andere geht zur Peripherie und zwar zum Ektoderm der anderen Körperseite. Der zweite Typus hat einen peripheren Fortsatz, welcher sich im Epithel verzweigt und einen zentralen, welcher im Hirnganglion die Medianlinie kreuzt und in den Seitenstrang der anderen Körperseite übergeht.

Am Rande der Seitenstränge erwähnte Moxri noch Ganglienzellen mit einem frei und verzweigt im Körperepithel endenden Fortsatz und daneben einem im Strange aufsteigenden und einem absteigenden Fortsatz. Diese beiden letzten senden Kollateralen aus, welche teils zur Muskulatur gehen, teils wiederum zum Epithel, wo sie mit freien Verzweigungen enden.

Ich habe der großen, zusammenstellenden Arbeit Vox GRAFFs (1904), welche erst 1908 abgeschlossen wurde, keine weiteren für meinen Zweck verwendbaren Angaben entlehnen können. Sollte also nach dem Jahre 1900 wirklich nichts weiteres über den Lauf der Reizleitungsbahnen im Nervensystem der 'Turbellarien publiziert worden sein, so kann ich nur VON GRAFF beistimmen, wenn er sagt, daß unsere Kenntnis der Histologie des Nervensystems dieser 'Tiere Spezialforschungen noch sehr bedarf.

Vom Nervensystem der 'l'rematoden gibt LAxg (1881) uns eine Beschreibung, der auch BRAUN (1892) der Hauptsache nach gefolgt ist. Oberhalb des Pharynx liegt das Hirnganglion, von dem nach vorn laufende Nerven abgehen, welche untereinander durch einen Nervenring verbunden sind. Nach hinten gehen zwei seitliche Nervenstränge, welche mit den sie verbindenden Kommissuren eine Art Strickleiter zusammensetzen. Sie entsenden periphere Nerven, welche einen Plexus bilden. Allen Nerven sind Ganglienzellen eingelagert. Das Hinganglion stimmt in seinem Wesen mit einer Kommissur der Seitenstränge überein; es ist aber eine zusammengesetzte und an Ganglienzellen reiche Kommissur. Man findet nach LAxG im Himganglion mehrere Bündel von Kommissurfasern und genau symmetriseh gelegene Ganglienzellen.

Der erste, welcher nach LAxG wenigstens einen Teil der Reizleitungsbahnen sah, war Blochisix (1595), welcher bei Trematoden einen ebensolchen subepithelialen Nerronplexus beobachtete mit multipolaren Ganglienzellen, welche Fortsätze mit freien Endungen ins Epithel der Körperoberfläche sandten, wie bei Dendrocoelum.

Hesse (1897a) sah bei Trematoden wie Tristomum und Polystomum, wie die Sehzellen der Augen sich in Nervenfasern fortsetzen, welche bis ins Hirnganglion zu verfolgen waren. Es sind also wiederum Sinnesnervenzellen.

Sinnesnervenzellen bei 'Trematoden wurden auch von BETTExdorf (1897) an verschiedenen Stelien aufgefunden. Er arbeitete mit vielen Arten und 
seine Resultate haben daher wohl eine allgemeinere Bedeutung. Meistens war es die Methylenblau-Methode, welche ihm Neues zu entdecken gestattete. BETTExdorF erwähnt, wie schon WALTER im Jahre 1858 und Looss 1894 bei Trematoden Sinnesnervenzellen beobachteten, während HECKERT sie im Jahre 1889 in den Saugnäpfen von Distomum macrostomum und anderswo wahrnahm. Ich konnte leider diese Angaben nicht rerifizieren. Sind sie richtig, so hat auch GREEFF nicht als erster die Sinnesnervenzelle der Wïrmer entdeckt (vergl. S. 32).

Nach Bettexdorf, dessen Beschreibung sehr gut durch Fig. 9, eine Wiedergabe des Nervensystems der Larve von Distomum caudatum nach BüTschLi (1912) beleuchtet werden kann, ist das Hirnganglion (Fig. 9, g.c.) eigentlich ein Paar durch eine Kommissur vereinigte Ganglien dorsal zwischen Mundsaugnapf (m.s.n.) und Pharynx (ph.) gelegen. Sie sind Ursprung vieler peripheren Nerven und drei Paar longitudinale Nervenstränge entfernen sich davon dorsal, lateral und ventral nach hinten (d. str., l. str. und $v$. str.) und werden alle durch kreisförmige Querverbindungen $(q$.) und Kommissuren (c.) verbunden. Die peripheren Nerven, welche vom Hirnganglion nach vorne ziehen, enthalten die Nervenfortsätze von Sinnesnervenzellen $(s, n, z$.). Weiter besteht überall im Körper unter der peripheren Muskulatur ein Nervenplexus mit Ganglienzellen und die Sinnesnervenzellen der Körperoberfläche senden ihre basalen fortsätze in diesen Plexus hinein.

In den beiden Saugnäpfen hat sich dieser Plexus weiter differenziert. Er ist hier mehr oder weniger kreisförmig und dabei hat eine Tren-

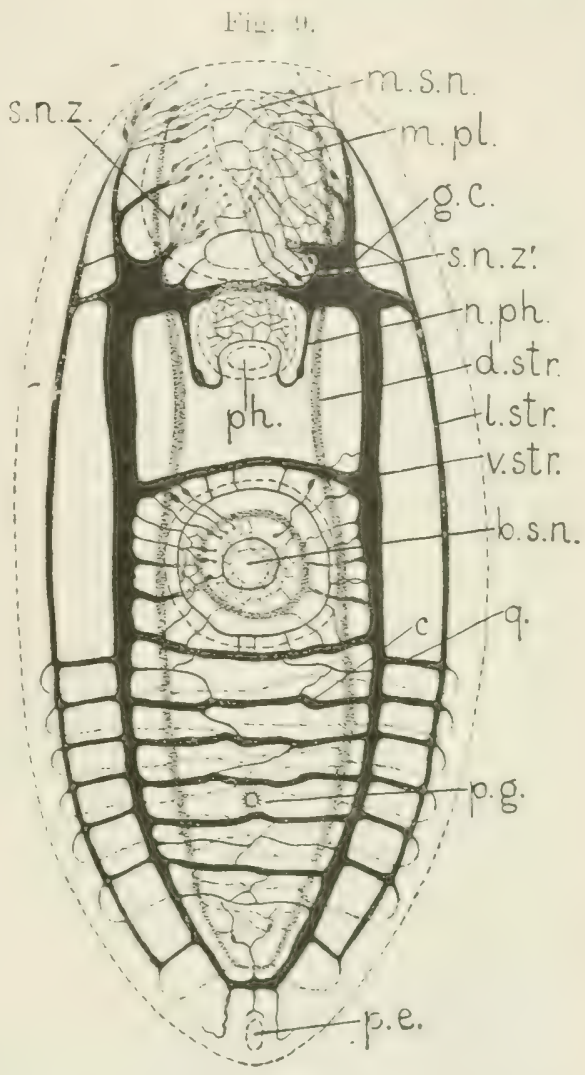

Schema des Nervensystems der Larre von Distomum caudatum von der vent ralen Seite gesehen. Nach Büischul ((1912), Wi i..323.

$$
\begin{aligned}
& \text { b.s.n.=Bauchsaugnapf. } \\
& c .=\text { commissura. } \\
& \text { d.str.=dorsaler Nervenstrang. } \\
& \text { g.c. = ganglion cerebrale. } \\
& \text { l. str. = lateraler Nerrenstrang. } \\
& m . p l=\text { motorischer Plexus } \\
& m . s . n .=\text { Mundsaugnapf. } \\
& n . p h .=\text { nerrus pharyngeus } \\
& \text { p.e. }=\text { Excretionsporus } \\
& p . g .=\text { Genitalporus. } \\
& p h .=\text { Pharynx } \text {. } \\
& \eta .=\text { Querverbindung } \\
& \text { s.n.z. = Sinnesnervenzellen. } \\
& \text { s.n.z.' = Sinnesnervenzellen. } \\
& r \text { str. = ventraler Nervenstrang. }
\end{aligned}
$$

nung stattgefunden in einen oberflächlichen, mehr sensibelen Plexus und einen 
tieferen, rein motorischen, welcher aller Ganglienzellen entbehrt ( $m . p l$.). Die motorischen Nervenfasern haften sich im allgemeinen entweder an die Muskelfaser oder an ihren Myoblast. Auch in den Saugnäpfen beobachtete BETTENDORF Sinnesnervenzellen mit peripherem in die Cuticula eindringendem Fortsatz und zentralem Fortsatz, welcher in den Nervenplexus sinkt. Ueberdies gibt es in dem Mundsaugnapf Sinnesnervenzellen, deren basaler Fortsatz unmittelbar ins Hirnganglion eintritt $\left(s, n . z .^{\prime}\right)$. Seitenäste dieser Fortsätze bilden gegenseitige Verbindungen und es kommt so ein Plexus zustande, aber jetzt ein wahrer Nervenfaserplexus, nicht nur ein Nervenplexus, wie unter der peripheren Muskelschicht. Im Bauchsaugnapf ist beständig ein Paar große Sinnesnervenzellen deren basaler Fortsatz in den Bauchnerv geht, ohne aber vorher sich mit einem Plexus zu vereinigen.

Manches von Bettexdorf Beobachtete wurde auch von Havet (1900b) gesehen. Er wählte Distomum hepaticum (Fasciola hepatica) als Objekt und sah auch die Sinnesnervenzellen im Körperepithel. Er erzählt uns, dass deren Zellkörper sich oft tief gesenkt hat und auch der periphere Fortsatz. Seitenäste tragen kann.

Man findet hier also eine Zwischenstufe zwischen einer im Epithel befindlichen Sinnesnervenzelle mit ungeteiltem Fortsatz und einer tiefen sensibelen Ganglienzelle mit freien verzweigten Endungen im Epithel, wie wir solche auch bei der Molluske Limax kennen lernen werden, und gerade so eine, wie meine Erweiterung der Hertwigsehen Hypothese (S. 12), welche die Phylogenese der sensibelen Ganglienzelle erläutern soll, als phylogenetische Uebergangsform bedingt.

Die Basis der Sinnesnervenzelle setzt sich in einen oder zwei Nervenfortsätze fort, welche Kollateralon abgeben und zusammen einen Plexus bilden. Dann treten sie ein in den dorsalen, lateralen oder ventralen longitudinalen Nervenstrang oder überschreiten erst die Medianlinie des Ǩ̈rrpers. Einige Sinnesnervenzellen senden sogar einen Fortsatz in den linken und einen in den rechten Nervenstrang. Sehr interessant ist die HAvETsche Beobachtung, daß die Fortsätze gleich nach Ankunft im Nervenstrange sich teilen in einen nach vorn und einen nach hinten zichenden Ast. Man hat oft etwas ähnliches bei anderen Würmern gesehen, wie wir später erfahren werden.

Neben den Nervensträngen liegen Ganglienzellen, welche ihre Fortsätze zu den Muskeln oder in den Nervenstrang hineinsenden.

Im Hirnganglion entricelite HAVET zuerst Kommissurzellen, welche ihren Fortsatz zum Ganglion der anderen Seite senden. HAvET erklärte also den Ursprung wenigstens einiger der von Laxg beobachteten Kommissurfasern. Andere Zellen des Hirnganglion senden einen Fortsatz in den Nervenstrang hinein oder zum Pharynxi in dessen Muskeln wieder andere Ganglienzellen zerstreut liegen. Endlich sagt uns Haviz, daß cinige Siunesnerrenzellen des Epithels der Saugnïpfe Fortsätze in den Saugnapf selbst senden, wo auch schon multipolare Ganglienzellen vorhanden sind. In diesen

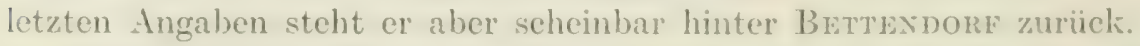

Der Leberegel, Distomum hepaticum, war abermals Gegenstand einer Untersuchung ron Seiten Marcixowsis (190:3). Er wendete seine Auf- 
merksamkeit ins besondere der Innervation des Pharynx und Oesophagus zu und fand beide von Ganglienzellgruppen umgeben, welche dort ein diffuses Nervensystem, ich vermute einen sympathischen Ganglienzellplexus, bildeten. Der Pharynxnerv( Fig. 9, $n$. ph.) welcher dem Hirnganglion entspringt führt Nervenfasern, welche, wie oben gesagt, Havet entdeckte und welche nach Marcivowski in den Ganglienzellgruppen des Pharynx, aber auch in denen des Oesophagus enden.

So viel ich weiß, sind der MARCINowskischen Arbeit nur zwei andere gefolgt welche hinsichtlich der Reizleitungsbahnen noch einige, wenn auch weniger bedeutende Fingerzeige enthalten. Avdre (1910) studierte die Augen von Polystomum integerrimum und fand, daß jedes der vier Augen eine einzige Sinnesnervenzelle, die Sehkolbe, enthielt. Diese setzt sich unmittelbar in eine Nervenfaser fort, welche zu der iiber dem Pharynx gelegenen Kommissur des Hirnganglions geht und darin weiter verläuft. ANDre konnte also die Hesseschen Angaben etwas genauer wiederholen. Dort wo die Fortsätze der beiden linken und rechten Augen sich zum „Augennerven" neben einander legen, werden sie von einigen Ganglienzellen umgeben, ohne damit in Verbindung zu stehen.

LINTON (1910) endlich bestätigt, sei es auch in wenig überzeugender Weise für Graffila gemellipara das Bestehen des schon bei anderen Trematoden bekannten Nervenplexus mit Ganglienzellen unter dem Epithel der Haut.

Das Nervensystem der Cestoden besteht hauptsächlich aus zwei longitudinalen Nervensträngen, den Seitensträngen oder nervi laterales, welche in den Proglottiden durch Kommissuren verbunden sind und welche im Scolex in zwei durch eine Kommissur verbundene Ganglien, zusammen das Hirnganglion oder ganglion cephalicum genannt, übergehen. Vom Hirnganglion und ron den Seitensträngen werden die peripheren Nerven abgegeben.

Die Seitenstränge und peripheren Nerven sind mit Ganglienzellen belegt, was also wiederum die Frage des Verlaufs der Nervenfasern darin erschwert. Ich meine, daß LAсzко (1850) der erste ist, welcher behauptet diesen Ganglienzellenbelag der Nerven bei Tetrarhynchen beobachtet zu haben, zugleich mit der Unipolarität der Ganglienzellen. Aber LAxg (1881) ist der Meinung, daß sich unter den LAczKoschen Ganglienzellen Drüsenzellen befinden. Dennoch erwähnt er auch selber die Ganglienzellen, welche den Nerven des Hirnganglions und den Seitensträngen der Tetrarhynchen anhaften, während KaHANe (1SS0) ihr Bestehen in den peripheren Nerven von Taenia perfoliata leugnet.

Die ersten Angaben, welche sich unmittelbar auf den Verlauf der Leitungshahnen beziehen, stammen von NIEnIIEC (1888). Er beobachtete, wie bei Ligula die beiden Anschwellungen der Seitenstränge, welche gewöhnlich als Hirnganglion bezeichnet werden aller Ganglienzellen entbehrten und hier also nicht Ganglien genannt werden dürfen. Dagegen sah er in der wichtigsten Kommissur dieser Anschwellungen viele multipolaren Ganglienzellen, welche Fortsätze in die Seitenstränge hinein abgaben. Auch Karrane (1880) hatte schon bei Taenia Ganglienzellen in der Hirnkommissur erwähnt und NIEMIEC behauptet, daß, obgleich gewiß andere Cestoden als Ligula in den Anschwellungen der Seitenstränge Ganglienzellen besitzen, die Hirnkommissur doch immer mehr von diesen Zellen hat.

Botriocephalus hat eine ebensolche Hirnkommissur mit Ganglienzellen wie Ligula und auch hier treten Fortsätze dieser Ganglienzellen in die Seitenstränge.

Im Vorderende des Scolex der Taenien begegnete NiExIEC acht nach hinten laufenden Nerven, jeder mit einem Ganglion anfangend, welehe unter dem Hakenkranz durch einen Nervenring verbunden waren; aber den Faserverlauf darin schildert er uns nicht. 
Das Jahr 1895 bringt uns zwei Arbeiten, bei denen die modernen Färbungen des Nervensystems, die Golgische Methode und die Ehruichsche Methylenblau-Methode angewandt worden sind. Die erste bot uns Blochuaxix (1895). Sein Material bestand aus mancherlei Cestoden. Er entdeckte im Scolex und dessen Halse bipolare Sinnesnervenzellen und subepithelial einen Nervenplexus mit eingestreuten Ganglienzellen. Die frejen Nervenendungen, welche neben den Sinnesnervenzellen im tief unter der Cuticula gelegenen Epithel gesehen wurden, waren oft das Ende ron Fortsätzen der Ganglienzellen des Plexus. Doch war dieser nicht rein sensibel, denn er hatte auch Verbindung mit den Myoblasten oder Sommer-LAxDoIsschen Zellen : multipolaren Zellkörpern, deren Fortsätze teilweise erst in die eigentlichen Muskelfasem iibergehen.

Der Befund BLochuarss wurde völlig bestätigt durch die schönen und wichtigen Untersuchungen, welche ZERNECKE (1895) anstellte und worin

Fig. 10.

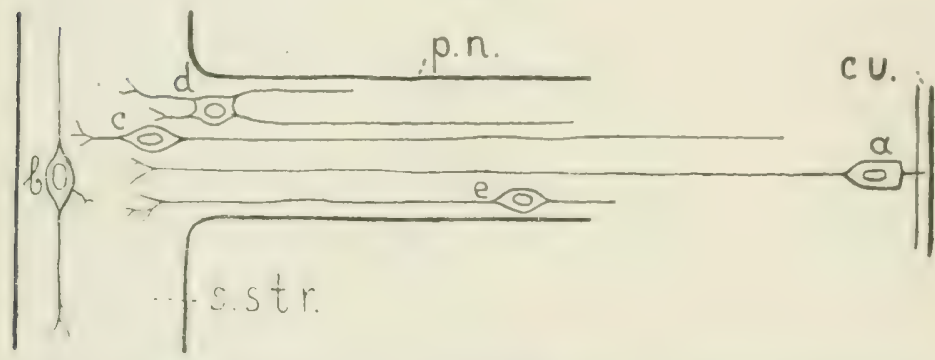

Einige Leitungsbahnen der' ('estorlen nach der Beschreilumer ZERNECKE's schematisch clargestellt.

$$
\begin{aligned}
c u . & =\text { cuticula. } \\
p . \mu_{0} & =\text { peripherer Nerv. } \\
\text { s.str. } & =\text { Seitenstrang. }
\end{aligned}
$$
noch weit mehr iiber den Nervenfaserverlauf $z u$ Tage gefördert wurde. Auch ZARNECKE hat verschiedene ('estodenarten bearbeitet.

Dic bipolaren, spindelförimigen Sinnesnervenzellen wurden auch von ZERNECKE gesehen und zwar

iiber den ganzen Körper zorstreut. Diese Zellen (Fig: 10, a) sind tief unter der C'uticula gelegen, aber ihr peripherer Eortsatz endet in derse!ben. Ihr zentraler Fortsatz geht immer in den longitudinalen Seitenstrang iiber und endet hier verästelt, aber er entsendet bisweilen ein Jestchen. welches frei außcrhalh des Zentralnervensystems endet. Juf seinem Woge passiert er einen unter den Sinnesnervenzellen grelegenen, subepithelialen Nervenplexus, an welchem sich auch multipolare Ganglienzellen heteiligens. Viele Fortsitze dieser Ganglienzellen enden mit freien Verzweigungen unter der ('uticula, gerade so wie auch Buocumasy uns lehrt. Viele Nervenfasern dieses Plexus anastomosicren wie solches auch im Ganglienzell. plexus der ('oelenteraten der Fall ist, aber nicht alle. Einige Fasern des sub. epithelialen I'lexus entstammen dem Zentralnervensystem, also den Seitensträngen oder dem Gehirn. ZERAECKE erzählt uns auch noch wie die meisten Nervenfasem des Plexus zirkular um den Körper herumlaufen.

Auch die Wege der motorischen Innervation blieben Zl:nxwere nicht ganz verborgen. Wie schon ohen gesagt wurde, findet man bei den ('estoden 
multipolare Myoblasten. Einige ihrer Fortsätze bilden die Muskelfasern. andere, und das gilt besonders für die äußeren Ringmuskeln, setzen sich kontinuirlich in Fasern des subepithelialen Nervenplexus fort und übermitteln also den motorischen Reiz. Es gibt aber auch Nervenfasern im Plexus, welche Blochisaxs nicht nennt und welche sich unmittelbar mit der kontraktilen Faser vereinigen. Muskelfasern anderer Systeme als die äußere Ringmuskellage werden bisweilen direkt vom Seitenstrange her innerviert, wobei die zu diesen motorischen Nervenfasern gehörigen Ganglienzellen wohl ebendaselbst zu suchen sind.

So weit über das periphere Nervensystem der Cestoden. Zervecke hat uns aber auch über die Leitungsbahnen im Seitenstrange und die davon abgehenden Nerven gewisse Aufschlüße gegeben. Ich werde sie hier liurz wiederholen in Anlehnung an das Schema Fig. 10 in dem allerdings die richtigen Verhältnisse der Entfernungen und Größen nicht berücksichtigt werden konnten.

Die meisten Ganglienzellen, welche iiberall verbreitet in den Seitensträngen und den peripheren Nerven liegen, sind bipolar, aber bisweilen entfernt sich ein kleiner dritter Ast vom Zellkörper (Fig. 10, b). Niemals biegen Längsfasern des Seitenstranges in einen peripheren Nerven ab, eine merkwürdige Tatsache, wodurch die Cestoden von anderen Würmern abweichen. Die bipolaren Ganglienzellen im Seitenstrange richten ihre beiden Fortsätze entweder in der Längenrichtung des Stranges (Fig. 10,b), oder senkrecht darauf, aber dann tritt auch der eine Fortsatz in einen peripheren Nerven aus und geht zum peripheren Nervenplexus (Fig. 10, c. Der Plexus konnte in der Figur nicht eingezeichnet werden). Dicht neben dem Seitenstrang werden oft multipolare Ganglienzellen (Fig. 10, d) beobachtet, welche cinige ihrer Fortsätze in den Seitenstrang senden, wo sie verzweigt enden, andere aber durch den peripheren Nerven hindurch in den Körper schicken. Die peripheren Nerven sind außerdem mit weit vom Nervenstrang entfernten bipolaren Ganglienzellen (Fig. 10,e) ausgestattet, deren zentraler Fortsatz, bis in den Seitenstrang zu verfolgen ist, wo man ihn verzweigt enden sieht. Andere im Seitenstrang endende Fasem der peripheren Nerven sind Fortsätze der schon vorher beschriebenen Sinnesnervenzellen (Fig. 10, a) der Haut.

Während ZERxECKE uns nichts mitteilt über den Lauf der Nervenfasern im Hirnganglion der Cestoden ist gerade dieses Gegenstand einer Untersuchung Towers gewesen. Tower (1900) hat mit Moniezia expansa, einer Taenie, gearbeitet. Die vitale Methylenblau-Methode und die Golgische Methode gelangen ihm anfänglich nicht, aber er hat doch nachher seine in anderer Weise eroberten Resultate mit diesen Methoden kontrolliert.

Das ganglion cephalicum oder Hirnganglion der Moniezia besteht aus zwei Hälften, welche einander in der Medianlinie berühren (Fig. 11). Jede enthält eine zentrale Gruppe von Ganglienzellen, in der Figur mit einer punktierten Linie umgrenzt. Daß die Ganglienzellen hier nicht peripher im Ganglion angehäuft sind, darf als eine Seltenheit bezeichnet werden. Jede Hälfte des Ganglions ist seitwärts und nach vorn in einen Zipfel ausgezogen, welche von Tower cornu anterius (Fig. 11, c.a.) und cornu exterius (Fig. 11, c.e.) 
genannt werden. Letzterer biegt nach hinten in den Scitenstrang um.

Es hat sich ergeben, daß die beiden Ganglionhälften innerlich durch eine Kommissur verbunden sind. Tower entdeckte darin drei Fasersysteme. Das erste geht von der einen zentralen Gruppe von Ganglienzellen zur anderen (siehe Fig. 11). Tower erwähnt nicht bestimmt die Ursprungszellen dieses Systems und wir wissen deshalb auch nicht, ob es doppelläufig ist, obgleich solches nicht unwahrscheinlich ist. Ein künftiger Forscher möge besonders beachten, ob die zentralen Ganglienzellen auch wirklich die gesuchten Kommissurzellen sind. Die zentrale Ganglienzellanhäufung verläßt noch ein anderes Bündel Kommissurfasern. Sie überschreiten die Medianlinie, durchsetzen das Ganglion und das cornu exterius und gehen in den nervus lateralis oder. Seitenstrang über (Fig. 11,a). Ihre Ursprungszellen sind wiederum unbekannt, aber vielleicht sind es die zentralen Ganglienzellen und dan wäre es vielleicht dieselbe Bahn, welche bei Ligula und Botriocephalus von

Fig. 11.

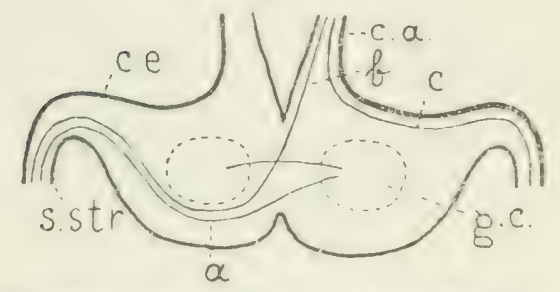

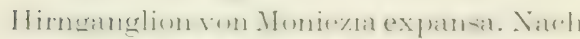

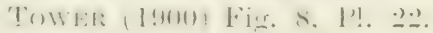

c. $a .=$ cornu anterius.

c.e. $=$ cornu exterius.

g.c. = Ganglienzellanhäuf ung.

s.str. $=$ Seitenstrang. Niemec entdeckt wurde. In meiner Figur 11 habe ich, wie ich oft tun werde, einfachheitshalber nur die eine Hälfte des bilateralsymmetrischen Systems miedergegeben.

Dem eben besprochenen Nervenfaserbündel schließen sich andere Nervenfasern an, welche aus dem cornu anterius kommen; wie 'I'OWER vermutet aus weiter nach vorn gelegenen Ganglien. Ich habe dieses ebenfalls bilateralsymmetrische System in Fig. 11 mit $b$ bezeichnet.

Aus dem Vorderhorn strömen auch Nervenfasern in den Seitenstrang derselben Seite (Fig. 11, c). Sie sind also keine Kommissurfasern. Auch ihr Beginn- und Endpunkt ist unbekannt.

Neben den erwähnten Fasern des Hirnganglions wurden von Tow wr weiter noch Ganglienzellen im ganglion posterius laterale beschrieben. welche ihren Neurit in den Seitenstrang senden. Das ganglion posterius laterale ist ein Ganglion im Halse des Wurms, dessen Lage hier nicht näher umschrieben zu werden braucht.

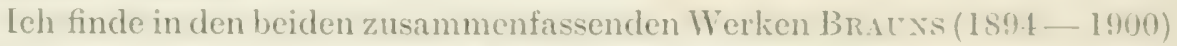
und Schnemers (1902) nichts weiter, was meinem Zwecke dienen kann und beende also die Gruppe der C'estoden.

Unsere Kenntnis der Leitungsbahmen oder des Nervenfaserverlaufs im Nervensystem der Nemertinen ist relativ nicht gering, aber dennoch meine: Wissens in diesem dahrhundert nicht bereichert worden.

Das Nervensystem besteht auch hier im grolen Ganzen aus zwei durch eine rom Rüisel (Fig. 12, r.) durchbohrte Kommissur rerbundenen Hirn- 
ganglien, welchen sich zwei nach hinten laufende und durch Kommissuren verbundene Seitenstränge (Fig. 12, s. str.) anschließen. Himganglien und Seitennerven bilden wieder den Ursprung der peripheren Nerven.

Dewoletzky (1888) ist der erste, welcher auf einen kleinen Teil des Nerrenfaserverlaufs hindeutet, wenn er sagt, daß die Flimmerzellen der Wand des Seitenorgans (Fig. 12, s. o.) der Nemertinen durch Fasen mit den Zellen des Ganglions, welches das Organ umgibt, in Verbindung stehen. Da man aber bei Dewoletzk nicht genau ermitteln liann, ob die Fasern Fortsätze der Flimmerzellen oder der Ganglienzellen sind. soll seine Angabe näher geprüft werden. Die Ganglienzellen sind nach DEwoLETzKY ihrerseits wiederum durch ein Nervenfaserbündel mit dem Gehirn verknüjft. Nach Bürger (1895) sind diese Nervenfasern, renigstens bei Carinella, Fortsätze von Ganglienzellen, welche im dorsalen Teile des Hirnganglions ihren Platz'finden.

Weniger wichtig ist auch die in einer später noch oft zu zitierenden Arbeit HALLERs (1889) geäußerte Bemerkung, daß bei Cerebratulus in der Peripherie des Gehirns mul-

Fig. 12.

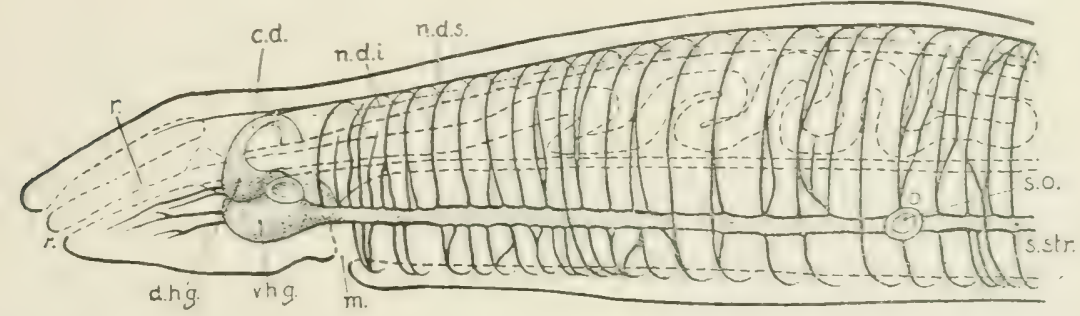

Linksseitige schematische Ansicht des Torderteiles des Nerrensystems einer Nemertine. Nach Bürschm. (1912), Fig. 327, A.

$c . d .=$ cornmissura dorsalis. $\quad d . h . g_{0}=$ dorsales Hirnganglion. $\quad m .=$.Iund. n.d.i. = nervus dorsalis inferior. n.d.s. = nervus dorsalis superior.
$r_{0}=$ Rüssel.

v.h.g. = ventrales Hirnganglion.

tipolare Ganglienzellen angehäuft seien, deren Fortsätze entweder zum Neuropilem schritten oder die Ganglienzellen unmittelbar gegenseitig verbänden. Letzteres ist rlie auch bei anderen Evertebraten von HALLER beobachtete Lage, welche aber von vielen anderen. Gelehrten verneint wird. Nur dessen ist man gewiß, daß, falls jede der genannten Ganglienzellen mit allen ihren Nachbarn zusammenhängt, ron bestimmten, histologisch nachweisbaren Leitungsbahnen in diesem Gebiete nicht die Rede scin kann. Besonders für Cerebratulus verneint Moxtgomery (1S97) die von HALLER erwähnte Multipolarität der Ganglienzellen und betrachtet sie als unipolar. Auch Büircier verkïndet in seiner zusammenfassenden Arbeit (1897-1903), daß sämtliche Ganglienzellen der Nemertinen unipolar sind.

Die besten Mitteilungen über den Nervenfaserverlauf der Nemertinen erteilt uns Bürger in einer Reihe von Arbeiten (1890, 1591, 1595 und 1897 - 1903). Er ist aber leider nicht immer leichtverständlich und überzeugend.

IVir begegnen hier zum ersten Male den Neuralkanälen oder Neurochorden oder Kolossalfasern oder wie sie weiter genannt werden mögen und es sei darum hier kurz über ihre Natur berichtet. Die Kolossalfasern oder neurochordae sind nicht nur bei Nemertinen, sondern auch bei Anncliden, C'rus- 
tacea und sogar bei Amphioxus anwesend. Man hat, nachdem Kow ALEwsky im Jahre 1871 damit vorgegangen war, oft ihre nervöse Natur verneint und ihnen dann z.B. Stiitzfunktionen zugeschrieben. Ohne die verschiedenen Auf-

Fig. 13.

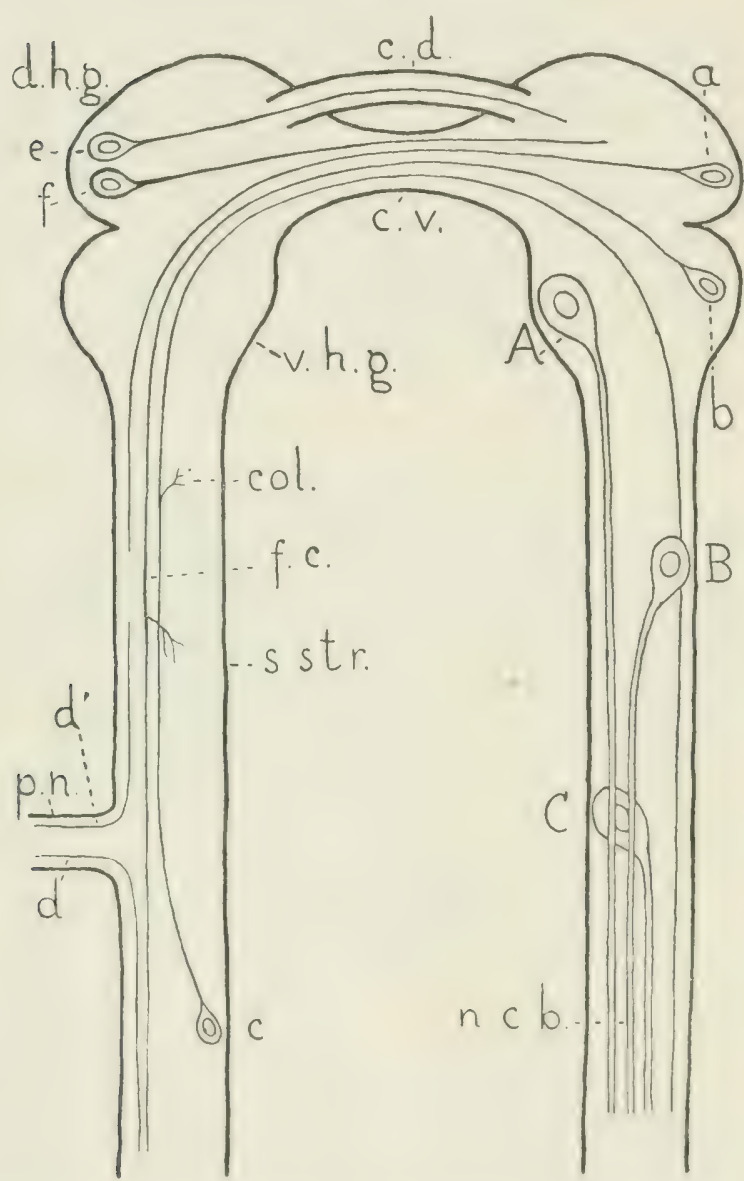

Cerebratulus marginatus, Zentralnervensystem nach BïRGER (1895).

r.d.= commissura dorsalis. col. Kollaterale.

c. v. = commissura ventralis.

d.h.g. clorsales Hirnganglion.

t.c. $=$ fasciculus centralis.

n.c.b. $=$ Neurochorthïndel. p.n. peripherer Nerv.

s.str. = Seitenstrang.

r.h.g. = ventrales Hirnganglion.

sale und eine ventrale Kommissur (Fig. 13, c.d. und c.v.) verbunden. Die ventralen Hirnganglien gehen in die Seitenstringe (Fig. 13, s.str.) iiber, welche die peripheren Nerven abgeben (Fig. 13, p.n.).

In den Seitensträngen liegen peripher Ganglienzellen, aber zentral sind kann man sagen, daß, sobald ihr Zusammenhang mit riesigen im Nervensystem gelegenen Zellen bekannt wurde - und es war nach Bürger (1895) SPENGEL (1882), welcher zum ersten Male dies an Polychaeten erwies - die Ansicht, daß es sich um kolossale Ganglienzellen mit überaus langen und dicken Nervenfortsätzen handele, sich immer weiter verbreitete. Argumente, wie das von Vox LExHOSSEK (1892) erwähnte, daß die Neurochorden sich niemals mit der GoLGischen Methode färben lassen, fallen dabei weniger ins Gewicht und ich meine nicht fehl zu gehen, wenn ich die Neurochord\%ellen mit ihren Kolossalfasern auch in diesem Buche als reizleitend betrachte.

Die Nemertine, wo die Wege der Nervenfasern am besten bekannt sind, ist wohl Cerebratulus marginatus. Jedes der beiden Hirnganglien besteht aus einem dorsalen und einem ventralen dbschnit. dem dorsalen und ventralen Himganglion (Fig. 13, d.h.g. und v.h.g.). Die beiden Hirngangrien sind durch eine dor-

fassungen alle mitzuteilen 
sie aus Neuropilem gebaut. Bürger konnte in ihnen zwei longitudinale Systeme von Nervenfasern beobachten, das später zu beschreibende Neurochordbündel (Fig. 13, n.c.b.) und das von ihm mit dem. Namen Wurzelbündel oder Zentralstrang belegte Bündel, das ich deshalb fasciculus centralis (Fig. 13, f.c.) nennen möchte. Von der fasciculus centralis biegen sich Seitenbündel $a b$ zur Peripherie. Sie bilden die peripheren Nerven (Fig. 13, p.n.). Das Wurzelbündel als Ganzes betrachtet (nicht jede seiner Fasern) tritt durch die ventrale Kommissur und wird zum Wurzelbündel der anderen Seite.

Der fasciculus centralis wird von verschiedenartigen Nervenfasern gebildet. Erstens sind im dorsalen Hirnganglion umipolare Ganglienzellen (Fig. $13, a)$, welche ihren Fortsatz in das Wurzelbündel senden. Sie durchziehen die ventrale Kommissur und steigen in dem Seitenstrang der anderen Körperhälfte ab. Derartige Zellen befinden sich auch im ventralen Hirnganglion (Fig. 13, b) und überall in den Seitensträngen (Fig. 13, c). Die Fasern der letzten aszendieren in dem einen Seitenstrang und deszendieren im anderen und so ist der ganze fasciculus centralis doppelläufig. (In Fig. 13 habe ich wiederum jede Zellart entweder rechts oder links eingetragen. Der wahre Zustand ist symmetrisch). Die Fasern des Wurzelbündels können Kollateralen abgeben (Fig. 13, col.).

In den Seitenbiindeln der peripheren Nerven traf BüRGER Nervenfasern, welche sich dem Wurzelbündel beimischten, entweder darin auf- oder darir ahsteigend (Fig. 13, $\left.d, d^{\prime}\right)$. Obgleich BürGER den exakten Beweis schuldig blieb, ist es doch wohl sehr wahrscheinlich, daß wenigstens ein Teil dieser Fasern Fortsätze der ebengenannten Ganglienzellen sind. Er selbst (1S97 _ 1903 ) ist wenigstens dieser Meinung.

Das Neurochordbündel des Seitenstranges besteht aus Neurochorden, welche Fortsätze der Neurochordzellen, der größten aller Ganglienzellen sind. Ein Paar dieser Neurochordzellen (Fig. 13, A) befindet sich ventral im Hirnganglion, die vielen anderen, von denen in der Figur 13 nur zwei $(B$ und $C$ ) angegeben sind, liegen in der Peripherie des Seitènstranges. Das Neurochordbündel ist nur absteigend. Die Kolossalfasern verlassen den Seitenstrang nicht und auch sind sie nach BürGER (1895) unverzweigt, wiewohl er zuvor (1890) das Gegenteil behauptet hatte.

Das eben über den Verlauf der Fasern der Wurzel- und Neurochordbündel Gesagte wurde später von Bürger (1891) mit Hilfe der MethylenblauMethode bestätigt, aber Moxtgomery (1897) entdeckte bei einer Cerebratulusart drei Paar Neurochordzellen im Gehirn, statt eins. Thre Neurochorden laufen in den Seitensträngen analwärts. Wie die Neurochorden der weiteren Neurochordzellen verlaufen, sagt er nicht, aber wohl hat er die dichotomische Zweiteilung der Kolossalfasern beobachtet und schließt sich deshalb der früheren Meinung BüRgers an.

Im Jahre 1895 konnte Bürger neben den genamnten Bahnen noch andere im Gehirn von Cerebratulus wahrnehmen. So befinden sich in den dorsalen Hirnganglien kleine, dunkelkernige Ganglienzellen (Fig. 13, e), deren Fortsätze in der dorsalen Hirnkommissur nach den dorsalen Hirnganglien der anderen Seite gehen, während die Fortsätze anderer Ganglienzellen (Fig. 13, f) 
dazu die ventrale Kommissur benutzen. Auch befinden sich atußerhalb des Gehirns unter den Kopfspalten Gruppen von Ganglienzellen, deren Fortsiitze ebenfalls die dorsale Kommissur anwenden, um zur anderen Seite zu gelangen. Außerdem deutet BüßGER (1895) noch auf weitere Leitungsbahnen hin, aber er beschreibt sie nicht in klarer Weise, weshalb ich sie iibergehen möchte.

Langia formosa gleicht Cerebratulus in manchen Hinsichten, aber andere Nemertinen zeigen erhebliche Untersehiede. Es gibt Nemertinen ohne Neurochordzellen, wie \%.B. Eupolia, Hubrechtia und Carinella nach Bürger (1895) oder Lineus gesserensis nach Moxtgonery (1897). Drepanophorus und Amphiporus haben deren nur ein Paar welches ron der Zelle A (Fig. 13) repräsentiert werden könnte mit dem Ǔntersehied aber, daß ihr Neurochord erst durch die ventrale Hirnkommissur kreuzt und sich dann in den Seitenstrang bis zur Analkommissur fortsetzt. Bei Drepanophorus wurde von BiiRGER (1890) auch der fasciculus centralis ganz wie bei Cerebratulus wahrgenommen,

Amphiporus und Drepanophorus sind auch in ihren peripheren Leitungsbahnen teilweise von BürGER aufgeklärt worden.

Fig. 14 .

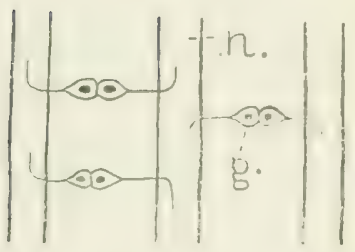

Amphiporus. Drei longitudinale Rüsselnerven mit ihren gepaarten Ganglienzellen.

Nach Bürgetr (1891). $n_{*}=$ Nerv. $g .=$ Ganglienzelle.
Amphiporus wurde von ihm (1891) mittels der Methylenblau-Methode erforscht. Er sah im Rüssel sechzehn longitudinale Nerven mit darin eingelegten Ganglienzellen. Ein Teil von drei solchen Nerven ist in Fig. 14 (n.) schematisch dargestellt. Zwischen jedem Paare dieser Nerven befinden sich zahlreiche unipolare Ganglienzellen (Fig. 14, g.), welche paarweise zusammenliegen, dabei sich mit ihren fortsatzfreien Enden aneinanderlegend. Ihre Stammfortsätze senden sie in die Nerven hinein, wo dieselben sich entweder nach vorn oder nach hinten umbiegen. Im hinteren Teil des Rüssels sind die gepaarten Ganglienzellen durch einen Plexus ersetzt. Auch andere bewaffnete Nemertinen (Metanomertinen) stimmen mit Amphiporus in diesen Merkmalen iiberein und BüraER (1595) konnte später noch seine Mitteilungen ïber den Faserverlauf der Riisselnerven vervollständigen mit der Angabe, daß3 Nerventasern der sechzehn Rüsselnerven zur Ringmuskellage des Rüssels schreiten, dabei sich in mancherlei WVeisen zu Längenbündeln gruppierend. Auch sehmiegen sich Nervenfasern der Rüssehnerven der Metanemertinen den Zellen der Rüsselpapillen an, aber ihr gegenseitiges Verhältnis, das heilst. ob die Papillenzellen Simnesnervenzellen oder indifferente Epithelzellen oder sogar Simncszellen sind, ist unbekannt.

Bei Drepanophorus wurde der Bau der Räckennerven näher untersucht (Bürger 18!5). Der obere Rückennerr (Figr. 1:- n.d.s.) geht aus dem Hirn hervor und zwar aus der dorsalen Rommissur. Er ist mit mipolaren Ganglienzellen belegrt und diese senden ihre Fortsälze ins Innere des Nerven. Daneben laufen Nerrenfasern vom Gehim oder von den Seitensträngen herriihrend. Der untere Riickennerv (Fig. 12, n.l.i.) wird gehildet von Nervenfasern. welche aus dem oherem allmählich hinter vinander austreten und sich dann wieder zu einem Nerven vereinigen. Der obere liaickennerv ist durch 
Seitennerven mit den Seitensträngen verbunden (Fig. 12) und diese werden unter anderen von Nervenfasern durchzogen, welche sich vom Seitenstrange zum oberen und von diesem weiter zum unteren Rückennerven begeben. Auch fand Bürger Fasern, welche vom Seitenstrange zum oberen Rückennerven zogen und diesen an der entgegengesetzten Seite verließen. Es ist nur schade, daß BÜRGER nicht die Ursprungszellen aller dieser Nervenfasern erwähnt aber diese werden hoffentlich später von einem anderen Forscher entdeckt werden.

Ueber die Sinneszellen von Drepanophorus ist ron BürGER (1895) nur eine einzige Bemerkung gemacht worden, welche uns hier dienen könnte. Er sagt die Stäbchenzelle (Sehzelle) im Auge setzt sich in eine Faser fort, welche mit einem Fortsatz einer bipolaren Ganglienzelle zusammenhängt, deren anderer Fortsatz zum Hirnganglion läuft. Außerdem wäre zwischen der Sinnesnervenzelle und der bipolaren Ganglienzelle noch ein rätselhafter „Zwischenkern" zu finden.

Als aber zwei Jahre später Hesse (1897a) das Auge von Drepanophorus untersuchte, erkannte er wohl, daß die Sehzelle darin den Typus einer Sinnesnervenzelle hatte, aber die bipolare Ganglienzelle sah er nicht, denn er sagt, daß der Nervenfortsatz der Selizelle selbst hirnwärts zieht und im Hirn zu verfolgen ist. Eupolia bot ihm die gleichen Verhältnisse. Es besteht also zwischen BürGER und Hesse ein Gegensatz, welcher noch immer nicht beseitigt worden ist.

Die unbewaffneten Proto-, Meso- und Heteronemertinen haben nach BürGER (1895) nicht sechzehn Rüsselnerven, wie die Metanemertinen, sondern nur zwei, welche sich von der ventralen Hirnkommissur abzweigen. Sie sind mit Ganglienzellen versehen und enthalten vom Gehirn herstammende Nervenfasern. Zwischen den beiden Nerven ist ein Nervenplexus ausgespannt, welchem unipolare Ganglienzellen aufsitzen. Eupolia besitzt basal neben den Rüsselpapillenzellen Ganglienzellen, welche alle ihren Fort. satz zum Rüsselnerven senden, bisweilen aber läuft ein zweiter Fortsatz die Papillenzelle entlang. Also eine andere Lage, als diejenige der Metanemertinen, welche oben erwähnt wurde, aber auch hier keine ganz leichtverständliche.

Zuletzt will ich noch sagen, daß BürGer (1895) auch entcleckte, wie die Oesophagealnerven der Heteronemertinen Nervenfasern der eigenen Ganglienzellen neben Nervenfasern des Gehirns einschließen.

Wir verlassen jetzt die Klasse der Plathelminthen und gehen zu jener der Chaetognathen ïber. Das Nervensystem (Fig. 15) besteht hier aus zwei Ganglien, einem Kopf- oder Hirnganglion '(h.g.) und einem Bauchganglion $(b . g$.$\left.) , welche durch lange Konnektive (s. l_{\text {. }}\right)$ verbunden sind, welche Schlund- 
konnektive heißen sollen, weil sie wie die Schlundkonnektive der Anne-

Fig. 16.

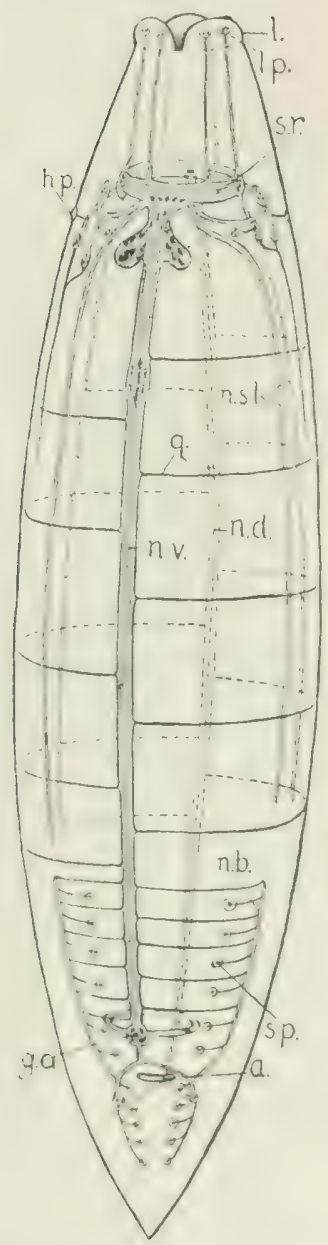

Schema des Nervensys. tems von Ascaris von rler Bauchseite gesehen. Abgeänclert nach ВӥтSCHLI (1912), Fig. 328.

$$
u_{0}=\text { unus. }
$$

y. $a_{0}=$ ganglion amale.

h.p.= Halspapille.

l. = I ippe.

$l . p,=$ I ippenp

n.b. = nervus bursalis.

$n . d .=$ nervus dorsalis.

n.s.l.= nervus sublateralis

u.r.=nervus ventralis.

$\%$ = Querverbindung.

$s . \nu_{0}=$ Sehwanzpapille.

$s . r .=$ Schlundring. liden den Darm (d.) umfassen. Aus den beiden Ganglien gehen die peripheren Nerven hervor.

O. Hertwig (1880) beobachtete in den Ganglien periphere Ganglienzellen und ein zentrales Neuropilem, aber in Bezug auf den Nervenfaserverlauf bemerkt er nur. daß in den Schlundkonnektiven sowohl Fasern vom Bauchganglion zum Kopfganglion, als zum Vorderkörper ziehen. Im Kopfe fand er im Zusammenhang mit dem Kopfganglion ein peripheres Nervensystem in dessen Nerven auch Ganglien vorkamen.

BRANDES (1899) bringt es ein wenig weiter in der Kunst die Wege der Leitungsbahnen zu enträtseln. Er erzählt uns, wie Fortsätze der Ganglienzellen des Bauchganglions zur entgegengesetzten Seite des Ganglions wandern und dort in einen peripheren Nerven austreten. Ein Paar vom Bauchganglion nach hinten ziehende Nerven bildet im Hinterteil des Körpers einen Nervenplexus mit eingelagerten Ganglienzellen, worin also wahrseheinlich keine bestimmten Bahnen aufzufinden sein werden und lateral und nach vorn austretende Nerven tun dasselbe. Auch Scirverder (1902) hat in seinem Lehrbuch das Bestehen dieses peripheren Nervenplexus anerkannt.

Wie man sieht, wartet die Hodologie der Chaetognathen auf neue Forschungen.

Unter den Nemathelminthen ist hauptsächlich das Nervensystem der Nematoden und unter diesen vor allen das Nervensystem von Asearis Gegenstand einer histologischen Untersuchung gewesen, aber statt der gegenseitige nStiitze und Ergänzung, welche bei ande: ren Tiergruppen die frïheren und späteren Forschungren bieten, haben bei Ascaris, wie wir sehen werden. die Arbeiten der letzten Zeit sich so schroff widersprochen, daß erst die Zukunft Auskunft geben kann, welche den rechten Wegr eingeschlagen hat.

Befassen wir uns erst mur mit Ascaris. Ascaris lumbricoides und megalocephala sind heide, oft von denselben Autoren, studiert worden und auch in den Einzelheiten des feineren Banes des Nervensystems haben sie so wenige Unterschiede aufgewiesen, daß sie nicht getrennt besprochen zu werden brauchen. 
Das Nervensystem von Ascaris besteht aus einem Nervenringe (Fig. 16 , s.r.), welcher den Oesophagus umfaßt und welcher nach vorn und hinten longitudinale Nerven abgibt. Nach vorn gehen sechs Nerven zu den Lippenpapillen (Fig. 16 ; vergleiche auch Fig. 17). Nach hinten ziehen in den dorsalen und ventralen Medianlinie zwei starke Nerven, der nervus dorsalis (Fig. 16 , n.d.) und der nervus ventralis (n.v.). Diese beiden Nerven sind durch asymmetrische Querverbindungen (Fig. 16, q.) verbunden. Neben den Seitenlinien laufen die wenigen dicken Sublateralnerven (Fig. 16, n.s.l.) rom Nervenring nach hinten. Noch andere Nerven gehen zu den Halspapillen (h.p.). Der nervus ventralis endet in dem vor dem After (a.) gelegenen Analganglion $(g . a$.$) und$ steht in der in Fig. 20 näher beleuchteten Weise mit dem nervus bursalis (n.b.) und den Schwanzpapillen (s.p.) in Verbindung.

Die bequemste Weise zur Darstellung der wichtigsten Nerven behufs ihres Faserverlaufs ist wohl diese, daß man sich den Nervenring an einer Stelle durchschnitten und nachher in einer Ebene platt liegend denkt. So ist das Schema der Figuren 17 und 19 angefertigt worden, nach dem Bei-

Fig. 17 .

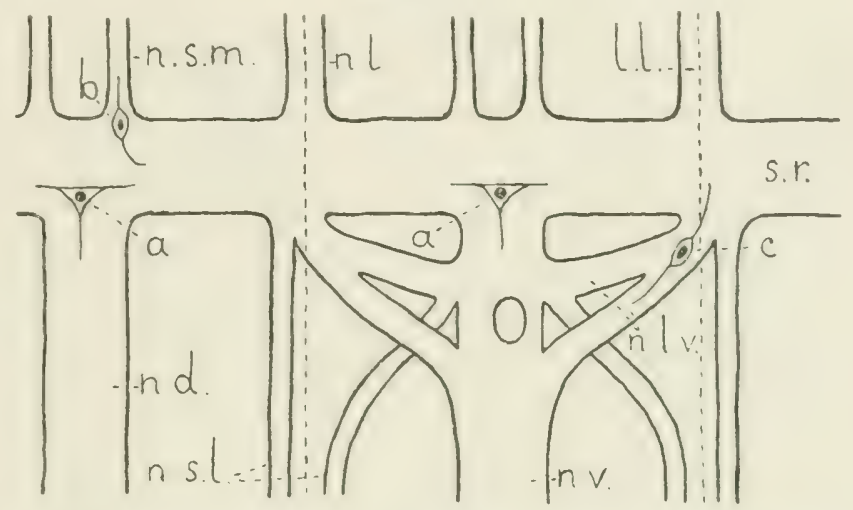

Ascaris. Nervenring mit einigen daraus hervortretenden Nerven. Schema, abgeändert nach Hesse (1892).

$$
a, b, c=\text { Ganglienzellen. } \quad l . l .=\text { linea lateralis. }
$$
$n . d_{0}=$ nervus dorsalis. $\quad n . l .=$ nervus lateralis. $n . l . v .=$ nervus lateroventralis n.s.l. = nervus sublateralis. n.s.m. = nervus submedianus. $\quad n_{*} v_{0}=$ nervus ventralis s. $r .=$ Schlundring. spiel, welches Hesse (1892) gegeben hat.

Als allgemeine Bemerkung kann hier auch die ganz merkwürdige Tatsache erwähnt werden, daß die motorischen Nervenfasern nicht zu den Muskeln schreiten, sondern, daß aus diesen letzten der Innervation dienende Fortsätze zu den Nerven hervorgehen.

Schon in der 1863 erschienenen Arbeit A. Schnerders, welche auf Zupfpräparaten basiert, wird der Lauf einiger Nervenfasern geschildert. Ascaris megalocephala war das Versuchstier. Vom oesophagealen Nervenringe (Fig. 17, s.r.) zweigen sich sechs Nerven nach vorn ab, welche die drei Lippen innervieren. Es sind zwei starke nervi laterales (Fig. 17, n.l.) unter den Seitenlinien (Fig. 17, l.l.) gelegen und vier dünnere nervi submediani (Fig. 17, n.s.m.) neben der Nedianebene des Körpers gelegen. Nach hinten gehen aus dem Schlundringe in der Medianebene ventral der starke Bauchnerv (nervus ventralis, Fig. 17, n.v.) und dorsal der dicke Rückennerv (nervus dorsalis), (Fig. 17, n.d.) hervor. 
In erster Linie beobachtete A. SchNEIDER nun in den submedianen Nerven bipolare Ganglienzellen mit einem Fortsatz oralwärts und einem caudalwärts gerichtet und dancben unipolare Ganglienzellen, welche in einem Fortsatz nach vorn auslaufen. Die Fasern der Lateralnerven stammen aus Ganglienzellen, welche vor, neben oder hinter dem Schlundringe liegen. Die letzten sind meistens unipolar und senden also ihren einzigen Fortsatz nach vorn. Ueberdies biegen Fasern unbekannter Herkunft aus dem Nervenringe in die Lateralnerven ab. Zu beiden Seiten neben den Bauchnerven begegnete SCHNEIDER sechs besonderen Ganglienzellen. Fünf von ihnen sind unipolar und senden ihren Fortsatz zu einer Ganglienzellgruppe, von ScHxeIDER ganglion medianum genannt, welche hinter dem Ringnerven im nervus ventralis gelegen ist. Die sechste ist bipolar. Ein Fortsatz gesellt sich zu den fünf ebengenannten und zieht zum ganglion medianum; der andere zur Muskulatur. Da, wo der Bauchnerv und der Rückennerv den Schlundring verlassen, entdeckte SchNeIDer eine tripolare Ganglienzclle mit einem Fortsat in dem genannten Nerven und zwei im Oesophagealringe (Fig. 17, a,a).

Bütschli (1874), welcher nach SchхeIder Ascaris, bearbeitete, sah in allen Nerven Ganglienzellen einverleibt, ảber meistens sind seine Angaben ïber die Wege ihrer Fortsätze zu unbestimmt um hier wiedergegeben werden zu können. Er erwähnt an der Abgangsstelle des Bauchnerven und des Rïckennerven Ganglienzellen, welche ihre Fortsätze in den Schlundring senken. Um dem Oesophagus herum beobachtete er viele Ganglienzellen, welehe mit den Nerven, welche den Schlundring nach vorn verlassen, in Verbindung stehen. eine 'Tatsache, welche Josepr (1882) bestätigte, als er die Fortsätze der circumoesophagealen Ganglienzellen in den genannten Nerven entweder nach vorn oder nach hinten zum Schlundringe verfolgen konnte. Fortsätze noch anderer Ganglienzellen um den Oesophagus schlagen nach JosEPI eine seitliche Richtung ein, kreuzen den Nervenring und bilden zusammen mit. Fasern des Nervenringes und der nach vorn laufenden Nerven eine Verbindung zwischen diesen Nerven und den lateralen Wurzeln des nervus ventralis (Fig. $17, n . l . v$.). Derartige Verbindungen erwähnt JosepH auch zwischen den oralwärts gehenden Nerven und dem nerrus dorsalis.

ROHDE (1855) bezeichnete zwar in seiner ersten Arbeit bei Ascaris megalocephala und lumbricoides einige Reizleitungsbahnen, aber er begründete seine Behauptungen nicht. Das hat sich zum 'Teil geändert in einer anderen Ascaris-Publikation (RoHDE 18926), worin er bekannt macht, daß3 außerhalb des Schlundringes sich nur der nervus ventralis und dorsalis und die Sublateralnerven mit den Muskeln verbinden. Auch sah er Fasern der Dorsalund Ventralnerven (Rompes Mediannerven) unmittelbar in Nervenfasern des Schlundringes übergehen.

HEsse (1892) fügt seiner Ascaris-Arbeit, welche mich nicht so glänzend wie manche andere seiner Forschungen dïnt, eine schematische Figur des vorderen Teils des Nervensystems hinzu, welche mir das Modell für Figur 17 geliefert hat. Ueber den Verlauf der Nervenfasern sagt er nicht viel. Er verneint das Vorkommen unipolarer Ganglienzellen. wie ScHremer sie beobachtete, aber er zeichnet, wie dieser, tripolare Ganglienzellen im Schlundringe 
an der Stelle, wo die Bauch- und Rückennerven daraus hervorgehen (Fig. 17, $a, a)$, während er sagt, daß oft Nervenfasern des Schlundringes in diese Nerven eintreten. An der Abgangsstelle der sechs nach vorn zu den Lippen gehenden Nerven beschreibt Hesse kleine Ganglienzellen und er zeichnet sie bipolar mit einem Fortsatz im Lippennerven und einem im Schlundringe (Fig. 17, b). In Höhe der Laterallinie (Fig. 17, l.l.) biegt sich ein Nerv rom Schlundringe ab, welcher bald eine Ganglienzellgruppe umfasst und sich dann in zwei zum Bauchnerven schreitende, lateroventrale Nerven (Fig. 17, n.l.v.) spaltet. Hesse zeichnet diese Ganglienzellen bipolar mit einem Fortsatz im Schlundringe und dem anderen im Lateroventralnerven (Fig. 17, c). Weiter beschreibt er noch Fasern der Lateralnerven, welche nicht in den Schlundring übergehen, sondern diesen passierend nach hinten laufen. Was die Beginn- und Endpunkte der Reizleitungsbahnen anbelangt, so meldet er freie Nervenendungen in den Lippen und bestätigt die RoHDEsche Angabe, daß die Sublateralnerven die Muskeln innervieren.

Braxdes (1899) will in den eben beschriebenen lateralen Ganglienzellgruppen den Zentralteil des Nervensystems sehen, aber, was uns hier mehr interessiert, er fand darin wie Hesse Ganglienzellen, welche ihre Fortsätze teils in den Schlundring, teils in die lateroventrale Nerven bis zum Bauchnerven senden. Daneben beobachtete er, wie der Bauch- und Rückennerrv von den lateralen Ganglien herstammende Nervenfasern auch aus dem Schlundringe empfing.

So weit sind die Angaben der Autoren noch ziemlich mit einander in Uebereinstimmung zu bringen, aber die Jahre 1908 - 1910 bringen uns die Arbeiten Demekas (1908) und Goldschinds (1908, 1909 und 1910), deren Resultate unvereinbar sind. Da später zwar Dogiel, der Lehrer Derseras, einen leider auch persönlichen Angriff auf die GoLDscmmDTschen Untersuchungen gerichtet hat als Antwort auf die leider auch persönliche Kritik, welcher Goldschund die Forschungen Deinekas unterworfen hatte, aber so viel ich weiß, keine neuen Tatsachen dieser Streitfrage hinzugefügt worden sind, will ich beider Ansichten über den Nervenfaserverlauf von Ascaris nebeneinander referieren, der Zukunft die Entscheidung überlassend. Ich werde mich dabei. wie fast immer in dieser Literaturübersicht, aller Kritik enthalten. möchte aber nur bemerken, daß ich die DersekAschen Arbeitsmethoden denjenigen GoLdschmists als überlegen ansehen würde, wenn nicht GoLDSCHMIDT damit so besondere Einzelheiten konstant hätte auftreten sehen. Sagt doch Goldschmot (1910), daß er Hunderte vonExemplaren untersucht und nur sehr selten Variationen in den Zellen und Fasern gesehen habe.

Goldschmint beabsichtigte behufs der Physiologie bei wenigstens einem Tiere in den Aufbau des Nervensystems einzudringen und alle Leitungsbahnen desselben kennen zu lemen, ein Ziel, welches auch andere Forscher sich mit mehr oder weniger Glück gestellt haben. Im ersten 'Teile seiner Arbeit gibt Goldschmid (1908) eine komplizierte Beschreibung der Morphologie des Nervensystems von Ascaris (hier lumbricoides, aber megalocephala weicht nicht davon ab), dabei darauf hinweisend, daß3 eine oder zwei Ganglienzellen ein Ganglion und eine Nervenfaser einen Nerven bilden kann. In man- 
cher Hinsicht gibt er eine genauere Beschreibung des Nervensystems al: friihere Autoren.

Das Nervensystem von Ascaris ist nach GoLdscmud aus einer kon stanten Anzahl Ganglienzellen aufgebaut, wie auch andere Organsysteme dieses Tieres eine konstante Zellenanzahl besitzen. So bilden 162 Ganglienzellen das ganze ,Zentralnervensystem”, das heißt, den Vorderteil des Nervensystems. Die meisten Ganglienzellen sind gepaart, aber einige sind in der Medianebene gelegen und zwei befinden sich nur rechts. Das Nervensystem ist also nicht ganz symmetrisch gebaut, wie solches auch aus den asymmetrisch gestellten Querverbindungen der Nerven (Fig. 16, q.) erhellt, worauf schon z.B. Hesse (1892) unsere Aufmerksamkeit gelenkt hat.

Unter den Ganglienzellen gibt es nach GoLdschud multipolare Zellen, welche jedoch nur zwei nervöse Fortsätze

Fig. 18.

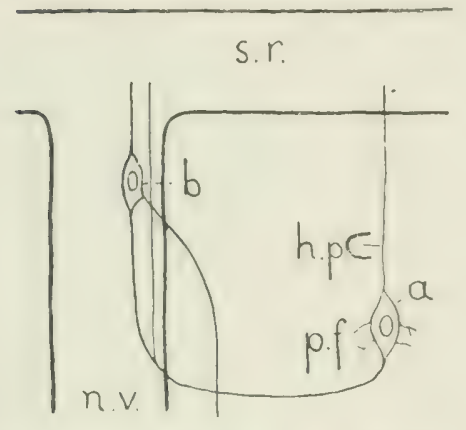

Zwei Ganglienzellen von Ascaris.

Nach Got.dschmint (1908. $a, b=$ Ganglienzellen.

$h \cdot p_{0}=$ Halspapille.

$n \cdot v .=$ nervus ventralis.

$p . f_{0}=$ Plasmafortsätze.

$s . r .=$ Schlundring. haben, während die anderen ,plasmatisch" sind (Fig. 18, p.f) und nicht der Reizleitung dienen. Die Ganglienzellen hängen mit ihren dicken Fortsätzen unmittelbar zusammen. Das ist eine Tatsache, welche bei Ascaris, anderen Evertebraten gegenüber, besonders in die Augen fälit, denn auch RoHDE (1892b) hat sie uns schon mitgeteilt und Hesse (1892) bildet sie ab. Goldscmimd hat aber entdeckt, daß auch alle Verbindungen dieser Nervenfasern lionstant sind und überdies, daß an der Verbindungsstelle zweier Nervenfasern die innere Struktur der Fasern verschieden sein kann, sodaß zu sehen ist, welche Nervenfaser sich fortsetzt und welche sich nur der anderen anschließt.

Goudschum t beschreibt für sehr viele der 162 Ganglienzellen den Verlauf des

ersten Teiles der Fortsätze. Man wird es mir hoffentlich nicht iibel nehmen, wenn ich die zahlreichen, detaillierten Schilderungen hier nicht wiederhole, sondern dafür nach dem Originale verweise. Es werden immer nur Bruchteile der Leitungsbahnen verfolgt. Verlangt man ein Beispiel, so möchte ich das in Figur 18 schematisierte geben.

Das Sinnesorgan der Halspapille (Fig. 1s, h.p.) wird von einer frei endenden Nervenfaser innerviert, welche sich unterhalb des Urgans 'T-förmig tellt. Der eine Ast zieht unmittelbar zum Schlundringe (Fig. 18, s.r.), der andere zu ciner multipolaren Ganglienzelle (Fig. 18, a), welche neben Plasmafortsätzen (Fig. 18, p.f.) noch einen langen Nervenfortsat $\%$ aufweist. Diese Nervenfaser schreitet zum Bauchnerven (Fig. 18, n.v.), wo ein zum Schlundringe verlaufender Ast aus ihr hervorgeht, wihrend sie selbst sich kontinuirlich in einen Fortsatz einer tripolaren Ganglienzelle $b$ fortsetzt. Von deren beiden anderen Ausläufern taucht der eine in den Schlundring ein und der 
andere (Goldschmid 1909) begibt sich in den Subventrainerven. Es stehen also dem von der Halspapille empfangenen Reize drei Tege zum Schlundringe offen, ohne daß man bis jetzt aus anatomischen Gründen entscheiden könnte, welchen der drei der Reiz durchläuft oder was daraus weiter folgt. Auch die Simnesorgane der Lippenpapillen entbehren der Sinneszellen, sind aber mit freien Nervenendungen ausgestattet. Diese setzen sich in die Ausläufer bipolarer Ganglienzellen fort, deren andere Fortsätze in den Nervenring treten. Weitere Details im Originale.

Nach Goldschmot verlassen die Endteile der motorischen Nervenfasern ïberhaupt nicht die Längsnerven, worin sie sich befinden, sondern jede Muskelzelle sendet einen Fortsatz zum Längsnerven, wo er mit einer Nervenfaser in Verbindung tritt.

Der Schlundring und zwar jener von Ascaris mègalocephala, wird hauptsächlich im zweiten Teile der GoLDschmmotschen Arbeit (1909) besprochen. Es senden alle Ganglienzellen einen Fortsatz in den Nervenring und dic meisten Neuronen treten nur hier mit einander in Verbindung. Die Fasern des Schlundringes laufen meist einander parallel, sind aber durch Seitenäste breit verbunden. GoLDschмm selber konnte nicht alle diese Verbindungen erforschen, weil ihm dies auch bei diesem einfachen Nervensystem zu umständlich war und wer die Schwindel erregenden schematischen Abbildungen des von ihm untersuchten Teils des Nervensystems gesehen hat. wird begreifen, daß seine Resultate im Rahmen dieses Werkes nicht wiedergegeben werden können, sondern dafür das Original nachgeschlagen werden muß.

Der dritte Teil der GoLDSchmidsschen Untersuchungen (1910) berücksichtigt hauptsächlich die Zytologie der Ganglienzellen und nicht sosehr die Wege der Leitungsbahnen. Nur wird darin das sympathische Nervensystem erwähnt, welches, in der muskulösen Oesophaguswand gelegen, rechts und links nur durch eine Nervenfaser, einen Fortsatz der Ganglienzelle 64, mit dem Zentralnervensrstem verbunden ist.

Das von GoLdschump erreichte Resultat ist trostlos, insofern das richtige Verständnis der Physiologie des Nervensystems von Ascaris nicht durch die genaue Kenntnis des Nervenfasernverlaufs im Schlundringe gefördert wird. Wenn wirklich, wie GoLdschump sagt: ,Alles im Nerven ringe in letzter Linie mit allem zusammenhängt", kann man hier anatomisch keine Reizleitungsbahnen mehr auffinden. Hat GoLDscmud sich nicht an diese Konsequenz gewagt, als er später die auch von mir (S. 4) gemeinte Stelle Bethes zitierte, wo das diffuse Netzwerk der Nervenfasern verneint. aber das Bestehen lokaler Netzwerke wahrscheinlich erachtet wird und als er am Schluß seiner Arbeit mögliche Reflexbogen behandelt, welche aber, meines Erachtens, durchaus nicht notwendig gegeben sind?

Es sollen jetzt die Resultate DEIxEKAs (1908) besprochen werden, welche mit Hilfe der vitalen Methylenblau-Methode errungen sind und die so sehr von dem Gompcumintschen Befund abweichen.

DEINEKA hat zuerst die Innervation der Sinnespapillen untersucht. Diese sitzen nicht nur dem Kopfe und Halse auf, sondern man begegnet 
Fig. 19.

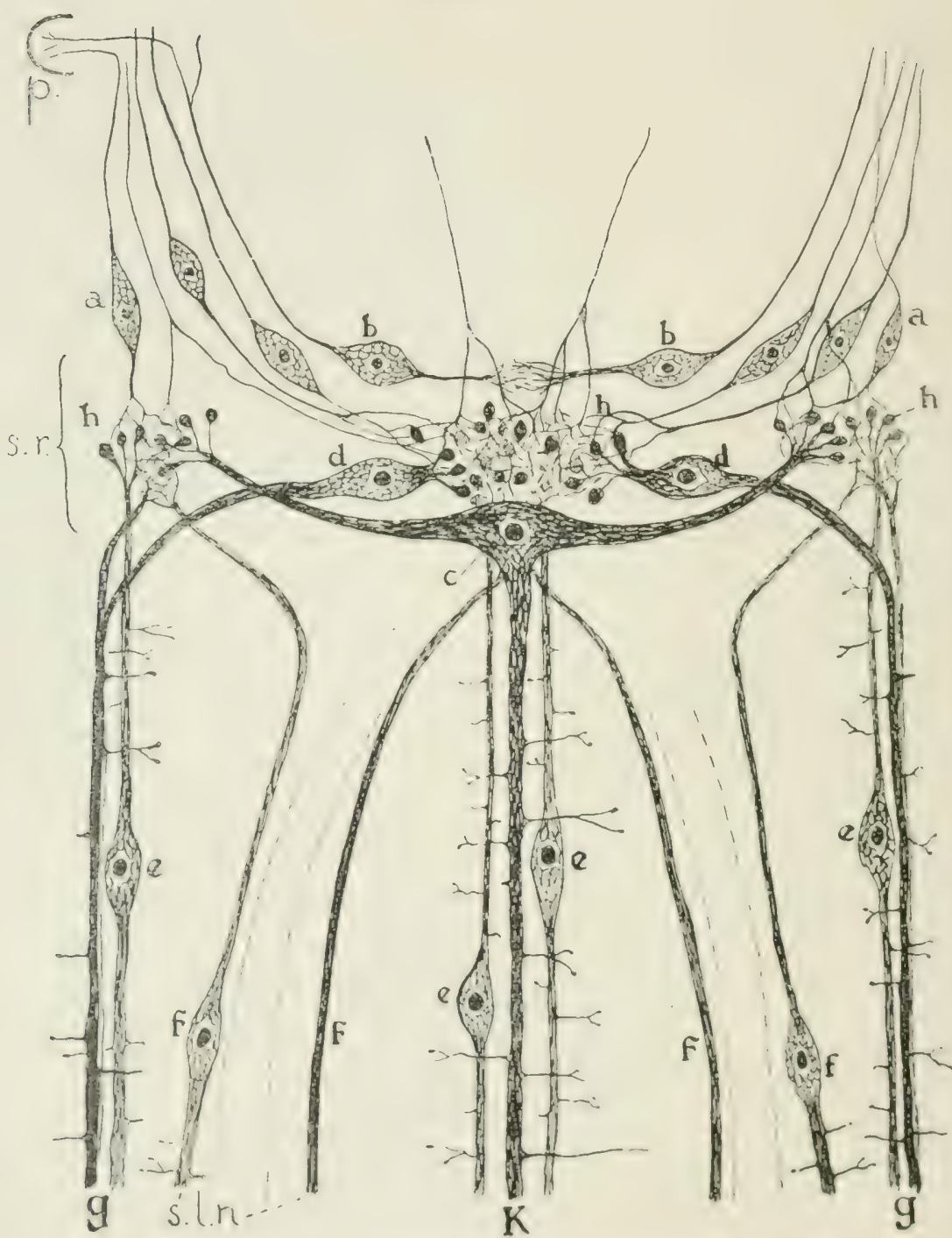

Schema der gegenseitigen Beziehungen ${ }^{-}$der Ganglienzellen im Schlundringe von Asearis. Abgeandert nach DeINeKa (1908), Textfigur 7. Der Schlundring ist auf der Höhe des Riiekennervs (g durehschnitten und flach ausgebreitet. $\alpha=$ sensibele cianglienzelle erster Art. $b=$ sensibele Cianglienzelle zweiter Art. $c=$ motorische (ianglienzelle zweiter Art. $d=$ motorische Ganglienzelle erster Art. $e=$ motorische Ganglienzelle dritter Art.

$f=$ motorische Gianglienzelle vierter Art. $g=$ kïckennerv. $h=$ Plexus sensibeler Nervenfasern mit den Dendriten der motorischen Ganglienzellen verbunden. $k=$ Bauchnerv. $p_{,}=$P'upille.

s. $l . n_{0}=$ sublateralnerv. s. $r .=$ Schlundring. 
ihnen beim Männchen auch am Schwanzende. In jede dieser Papillen treten nach ihm zwei verschiedene Nervenfasern, die Fortsätze zweier der Form nach verschiedenen, sensibelen Ganglienzellen ein. Die sensibelen Ganglienzellen der Lippenpapillen liegen in oder neben dem Schlundringe (Fig. 19, $a, b)$, die übrigen in einiger Entfernung ihrer Papille, wie dies auch GouDsснилтт über die sensibele Ganglienzelle der Halspapille mitteilt (Fig. 18, a). Die sensibelen Ganglienzellen der ersten Art (Fig. 19, a) sind bisweilen multipolar, aber meistens bipolar. Der eine Fortsatz tritt in die Sinnespapille $(p$.$) ,$ der andere in den Schlundring (s.r.) oder in den Bauchnerven (k, ). Diese bipolaren Zellen sind wohl dieselben, welche auch A. SchNeider, Hesse und Goldschmot in den sechs Lippennerven oder an deren Abgangsstelle im Schlundringe sahen, während vielleicht auch die von GOLDSCHIIDT beschriebene Ganglienzelle $a$ der Fig. $18 \mathrm{zu}$ den sensibelen Ganglienzellen erster Art gehört.

Die sensibelen Ganglienzellen zweiter Art (Fig. 19,b) haben einen langen peripheren Fortsatz und mehrere kurze zentrale. Der lange Fortsatz tritt in die Sinnespapille ein und verästelt sich dort, aber er hat auch schon vordem Aeste abgegeben, welche bisweilen frei enden. Die zentralen Fortsätze dieser Zellen hängen bisweilen mit Dendriten benachbarter Ganglienzellen zusammen. Die sensibelen Ganglienzellen zweiter Art liegen ebenfalls in oder neben dem Schlundringe oder auch in der Subcuticula. Die motorischen Ganglienzellen von Ascaris (z.B. Fig. 19,e) sind durch ihre Endverästelungen nur mit dem zentralen Fortsatz der sensibelen Ganglienzellen erster Art, niemals mit Zellen zweiter Art verbunden.

GoLDSCHMidT (1910) hat sich bestrebt nachzuweisen, daß diese sensibelen Ganglienzellen zweiter Art gar keine Ganglienzellen seien, sondern Stützzellen, welche das Methylenblau in den DeineKaschen Präparaten zufällig mitgefärbt habe. Ich kann aus Mangel an eigenen Beobachtungen nicht versuchen eine Entscheidung zu treffen, möchte nur bemerken, daß, falls die sensibelen Ganglienzellen zweiter Art Stützzellen sind, die Derserasche Behauptung, daß sie niemals mit motorischen Ganglienzellen verbunden sind, alles Sonderbare verliert.

Unter den sehr großen motorischen Ganglienzellen kann man nach Detneka vier Typen mit konstanter Lage unterscheiden. Jede motorische Ganglienzelle steht meistens in Beziehung zu mehreren Muskelzellen. Der erste Typus unter den motorischen Ganglienzellen hat einen langen und einen kurzen Fortsatz (Fig. 19, d), der zweite aber einen langen und zwei kurze Fortsätze (Fig. 19,c). Der Zellkörper und die kurzen Fortsätze liegen im Schlundringe, der lange Fortsatz in einem vom Schlundringe nach hinten abgehenden Nerven. Die Zellen des zweiten Typus sind wohl die auch von A. SchNeIder und Hesse beobachteten tripolaren Ganglienzellen. Ihre kurzen Fortsätze oder Dendriten sind mit den Endverästelıngen der sensibelen Ganglienzellen verbunden (Fig. 19, h), ihre langen, die Neuriten, mit den motorischen Endorganen.

Im Bauchnerven entdeckte DeINeKA motorische Ganglienzellen des dritten Typus (Fig. 19, e). Sie haben einen langen und einen kurzen Fortsatz, 
welche beide mehr oder weniger den Charakter eines Neurits mit Kollateralen haben. Die Fortsätze enden oft im Nervenringe oder im Analganglion am Ende des Bauchnerven. In der der Dexwekaschen Arbeit entlehnten Figur 19 sind auch im Dorsalnerven $(g)$ einige motorische Ganglienzellen des dritten'Typus $(e)$ eingezeichnet worden, da dieser Nerv in seinem Baue vorne mit den Vorderteile des Bauchmerven ïbereinstimmt, hinten aber nur aus motorischen Zellen des dritten 'Typus besteht.

Der vierte 'Typus der' motorischen Ganglienzellen (Fig. 19, f) hat ebenfalls einen langen und einen kurzen Fortsatz, aber dessen Seitenäste enden mit scharfen Spitzen und nicht mit kleinen Keulen. Die vier Sublateralnerven (von DExEKA Lateralnerven genamnt) sind aus motorischen Gạnglienzellen des vierten 'Typus zusammengestellt, welche ihre Dendriten in den Schlundring hineinsenden (Fig. 19, f).

GoLdschmot (1910) konnte von diesen rier motorischen Ganglienzelltypen nur den zweiten anerkennen. Dieser ist nach ihm wirklich eine tripolare Ganglienzelle; die anderen Typen blieben ihm völlig unbegreiftich.

Neben den genamnten Zelltypen findet man im Schlundringe noch Ganglienzellen, deren Fortsätze den Ring nicht verlassen.

DexakA erkennt zwar den kontinuirlichen Zusammenhang vieler Ganglienzellfortsätze an, hat aber oft auch nur Kontakt beobachtet.

DEnEKA hat auch den Hinterteil des Nervensystems studiert, aber es sind ihm darin Joseph, RoHDE und Hesse vorangegangen und ich will also erst ihre Resultate, soweit sie die Hodologie anbelangen, referieren.

Josepr (1882) war der Ansicht, daß bei der männlichen Ascaris der Bauchnerv sich vor dem Anus teile in einen sehwachen medianen Nerven und zwei starke laterale Nerven, die nervi bursales. Die Bursalnerven stiegen hinter dem Inus dorsalwärts und bögen damn nach vorn um, sodaß die Bursalnerven nervi recurrentes des Ventralnerven wären (vergl. Fig. 16), eine Ansicht, welche auch von RowDE geteilt wird, aber doch jetzt durch - die Untersuchungen Dexisas in einem anderen Licht erscheint. In der Ursprungsstelle der beiden Bursalnerven liegen nach Josepri drei Ganglienzellen im Bauchnerven, welche wohl meiner Meinung nach dem Analganglion des Bauchmervs anderer Autoren entsprechen und deren mittelste zwei .. Nerven" (das ist Fortsïtze) zur Subcuticularschicht sendet. Wenn die Bursalnerven oralwärts umgebogen sind, werden sie nach Jostry durch Fasern verstärkt. welehe teils aus dem Ventralnerven herstammen. teils fiortsätze ron Ganglienzellen sind, welche sich dem Bursalnerven cingelagert haben. Auch meldet er, daß uni- und bipolare Ganglienzellen, welche den Bursalnerven begleiten, fortsätze in den Rückennerven senden. Dic Schwanzpapillen sah er innerviert durch Fasern des Ventralnerss. aber auch durch Ganglienzellen, welche in der Nähe neben der Seitenlinie lagen. Wie wir bald sehen werden, hat Joseph allem Anschein nach sehr vieles vom Bau des: circumanalen Nervensystems in unbestimmter Weise gesehen, aber fast nichts davon genau erforseht. Zweifelsohne wird ("r aber anch so seinen Nachfolgern geholfen haben.

Rompe (1892b) hatte von der Innervation der Schwamzapillen schon 
eine andere und wohl richtigere Vorstellung als JosEPH. Er beobachtete, wie jede Schwanzpapille innerviert wird durch eine Nervenfaser, welche dort frei in der Cuticula endet und ein Fortsatz einer Ganglienzelle des Bursalnerven ist. Aus dem Beobachteten leitete er ab, daß der von der Papille empfangene Reiz im Bursalnerven angelangt nach hinten läuft und so in den motorischen Ventralnerven kommt, dessen nervus recurrens nach ihm der Bursalnerv ist. Vom Bauchnerven würde der Reiz durch Querverbindungen auch in den Dorsalnerven gelangen können. Aber RoHDE konnte seine Behauptungen nicht beweisen und erst DErNEKA hat, wie wir sehen werden gezeigt, daß der Reiz der Schwanzpapille wirklich vom Bursalnerven in den Ventralnerven übergeht, sei es auch in anderer Weise als ROHDE es sich dachte (Vergl. Fig. 20).

Hesse (1892) hat den hinteren Teil des Nervensystems bei beiden Geschlechtern von Ascaris untersucht und gesehen, daß beim Weibchen zwar Fasern des Ventralnervs in den Sublateralnerven übergehen, ein Bursalnerv aber nicht gebildet wird. Auch beobachtete er, daß beim Männchen der Bursalnerv kein eigentlicher nervus recurrens des Bauchnervs ist, sondern ein Teil des unteren Sublateralnervs, welcher durch Fasern des Bauchnervs, welche sich dahin begeben, verstärkt wird. Das stimmt schon recht gut mit dem was Deineka uns später lehrte (Vergl. Fig. 20). Ebenso wie Rohde erzählt uns Hesse, daß die Schwanzpapillen vom Bauchnerven aus innerviert werden, aber er sah auch, von RoHDE abweichend, daß viele Nervenfasern in jede Papille eindringen, was später von DeInekA (Fig. 20,g) und Goldschmid (1910) bestätigt wurde. Hesse zitiert dabei Совв, welcher bei einer anderen Ascaris-Art als Ascaris megalocephala, nämlich A. Kükenthalii, an der Papillenbasis eine Ganglienzelle nachgewiesen hat, welche einen Fortsatz in die Papille sandte. Es ist also möglich, daß hier ein Artunterschied vorliegt. Hesse erwähnt im Bursalnerven auch tripolare Ganglienzellen mit einem Fortsatz zur Papille und zwei anderen im Nerven. Ich glaube, es wäre nicht unmöglich, daß HEsse damit die Dernekaschen sensibelen Ganglienzellen zweiter Art (Fig. 20,b) meinte, in welchem Falle er aber nicht gesehen hätte, daß sie dem Bursalnerven mehr als zwei Fortsätze abgeben.

DeñEKA (1908) entdeckte, daß auch die Schwanzpapillen der männlichen Ascaris durch Fortsätze zweier Arten sensibeler Ganglienzellen (Fig. 20, $a$ und b) innerviert werden, wie wir schon von den Kopfpapillen wissen. Die peripheren Fortsätze dier meist bipolaren Ganglienzellen erster Art haben hier aber Seitenäste, welche zwischen den Muskelfasern oder anderswo ein freies Ende haben. Ihre zentralen Fortsätze (Fig. 20, $a, a^{\prime}$ ) laufen teilweise zum Analganglion, womit der Ventralnerv endet (Fig. 20,c) und wo sie terminale Netze bilden. Wie aus der Figur abzuleiten fällt, dürften diese Fasern zu der Meinung geleitet haben, daß der Bursalnerv ein nervus recurrens des Ventralnerven sei, so wie zu der Meinung Josepus, daß eine Ganglienzelle des Bauchnerven zwei Fortsätze zur Peripherie aussende (die Fasern zu $a^{\prime}$ der Figur 20).

Die zentralen Fortsätze anderer sensibeler Ganglienzellen erster Art 
(Fig. 20,a") ziehen erst im Bursalnerven ein wenig oralwärt sund verlassen diesen Nerven dann um einzeln zum Ventralnerven abzubiegen, wo sie ihre Endnetze bilden. Diese Fasern bilden die Querverbindungen orler sogenannten „Kommissuren" der Autoren, deren Ursprungszellen JosepH und Hesse im

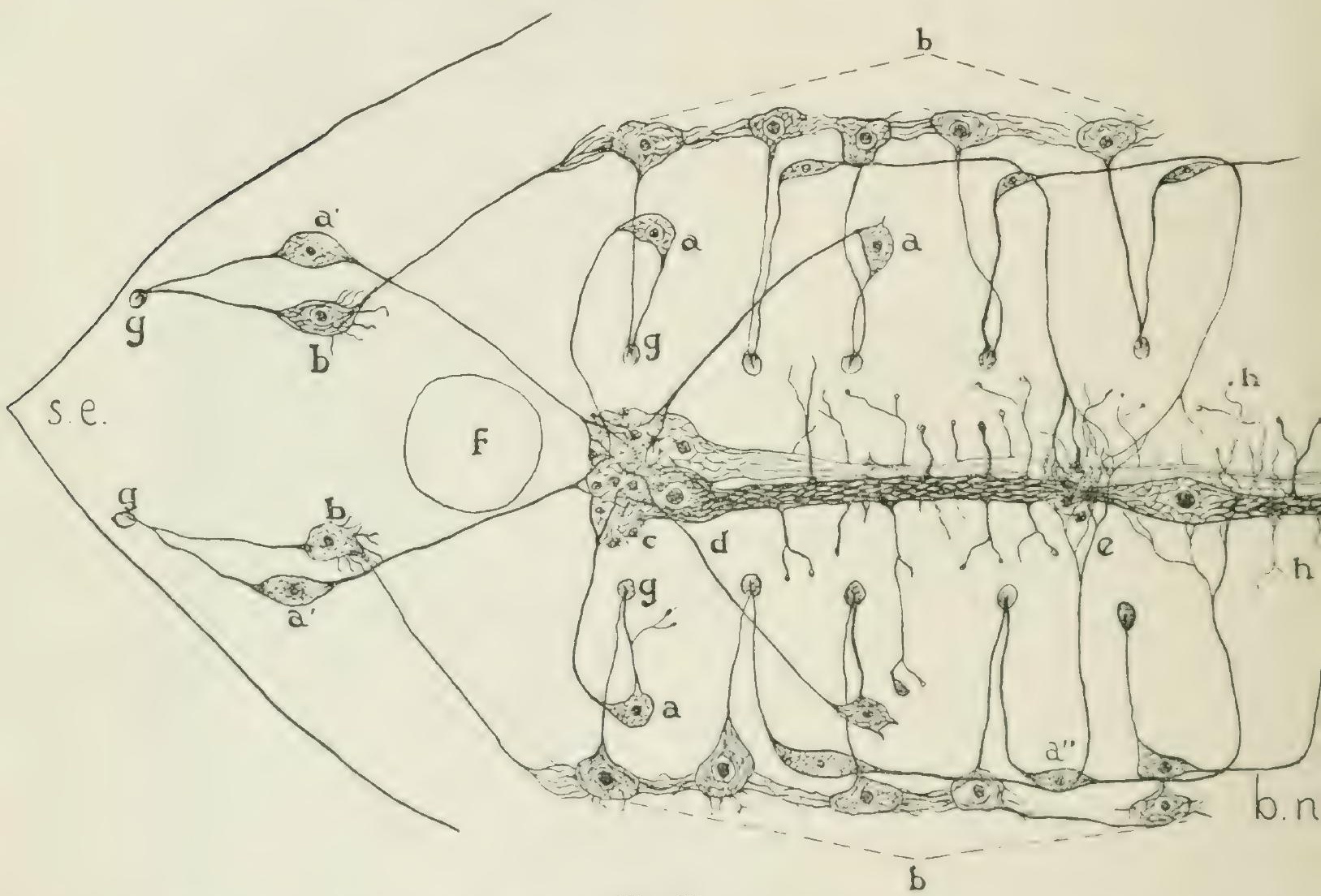

Fig. 20 .

Schema der gegenseitigen Beziehungen dex Ganglienzellen in Schwanz dex Asearis-

Mämohen. Nach Derweka (190S Trxtfigur 6. $a, a^{\prime}, a^{\prime \prime}=$ sensibele Ganglienzellen erster Art.

$b=-$ sensibele Ganglienzelle zwiter Art.

$c=$ Analganglion.

$d=$ motorische (iauglienzelle des Analganglions.

$e=$ Bauchnerv. $f=$ Anus. $\quad y=-$ Simmespmpille.

h-motoriseher Endapparat. b.h.--[Bursalnerv.

s.e. = Schwanzende.

Bauchnerven gesucht haben. Der. Wear. wethen der Reiz von der Schwanzpapille zum Batuchnerven zurickzuleren hat und welcher von Roune greahnt

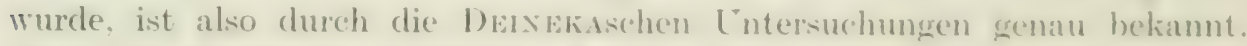
Wenn die fasern der vordersten Schwanzpapillen zum Banchnerven abgehogen sind, ist damit auch der Bursalner nach form beendet. Im Bursalnerven befinden sich weiter noch die Zellkörper und zentrifugalen Fortsitze 
der sensibelen Ganglienzellen zweiter Art (Fig. 20, b), welche GoLdschumt (1910), wie schon gesagt, als Stiitzzellen betrachtet.

Was die motorischen Ganglienzellen betriftt, so kann ich noch sagen, daß DeINEKA im Analganglion den ersten und zweiten Zelltypus, welche oben beschrieben wurden vorfand. Sie schicken ihre Neuriten in den Bauchnerven (Fig. 20, d), behalten aber ihre Dendriten im Analganglion.

Ueber andere Nematoden als Ascaris sind mir nur die Untersuchungen, welche Braxdes (1899) publiziert hat, bekannt. Er befaßte sich mit Gordius einer Gordiacee. Das Tier hat in seiner ganzen Länge einen Bauchstrang, welcher hinten eine Anschwellung hat (welche aber kein Ganglion ist) und vorn den Oesophagus umfaßt mit einem Schlundringe, welcher aber ebensowenig wie derjenige des Ascaris dem der Anneliden homolog ist. Unten im Bauchstrange (Fig. 21, b.str.) befindet sich in der ganzen Länge eine ununterbrochene Schicht basaler, unipolarer Ganglienzellen. Dieselben (Fig. 21, b.g.) senden ihren Fortsatz nach der dorsalen Seite, wo sie sich verästeln, nachdem sich schon vorher Kollateralen abgespaltet hatten. Lateral liegen segmentale Gruppen lateraler, unipolarer Ganglienzellen (Fig. 21. l.g.), deren Fortsätze die Medianlinie kreuzen und sich dann verzweigen.

Die Mitte des Bauchstranges wird von Neuropilem eingenommen, aber unter den basalen Ganglienzellen sah Braxdes noch eine Reihe großer, ungepaarter, medianer Ganglienzellen (Fig. 21, m.g.). Die Zellen sind multipolar. Sie dringen mit vielen Fortsätzen in den Bauchstrang ein, aber ein Fortsatz tritt aus an der ventralen Seite des Stranges. Entweder erreicht er unmittelbar die Hypodermis, oder er läuft erst in einem ventralen, medianen Nerven der Hypodermis (Fig. $21, n$.), von BRAxdes nicht sehr glücklich Neuro-

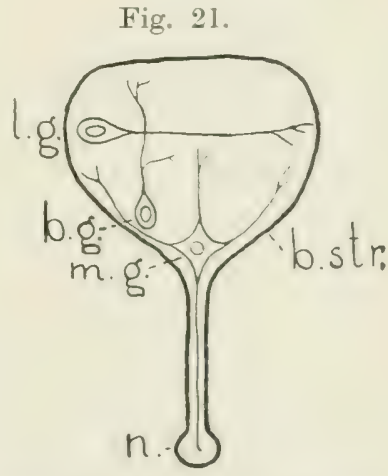

Querschnitt des Bauchstranges von Gordius.

Nach BRANDES (1899, fig. 5 . b.g. = basale Ganglienzelle. b.str. = Bauchstrang.

l. g. = laterale Ganglienzelle

m. $g .=$ mediane

$n .=$ Neurochord. chord genannt, obgleich er gar keine Kolossalfaser einer Neurochordzelle ist.

Neben den Nematoden sind auch die Acanthocephalen den Nemathelminthen unterzuordnen. Es ist wiederum nur BRANDES (1899), welcher einige Angaben der Leitungsbahnen liefert und zwar von Echinorhynchus gigas. Beim Hinterende der Riisselscheide liegt ein groß3es, flachovales Ganglion, worin Brandes 86 periphere Ganglienzellen zählte. deren Fortsätze ins Neuropilem ziehen und entweder sich dort verästeln, oder die Medianlinie kreuzen und in die peripheren Nerven austreten. Acht periphere Nerven verlassen dieses Ganglion. Einer, der vordere Mediannerv, besteht nur aus vier Nervenfasern, welche die Fortsätze von vier vorn im Ganglion gelegenen Ganglienzellen sind. Nach Brandes wïrden zwei dieser Nervenfasern. die Retractormuskeln innervieren und zwei ein 'Tastorgan vorn im Kopfe, aber seine Darstellung hat mich nicht davon iiberzeugt. Die beiden vorderen Lateralnerven entspringen aus Zellen des Seitenrandes des Ganglions und sie innervieren die lateralen Vortoßmuskeln. Aus der ligur 7 der BRANDEssehen Arbeit würde erhellen, daß das hintere Paar Lateralnerven gekreuzte Fortsätze von fianglienzellen dieses Cianglions bekäme, aber der Text schweigt dariber. 
Wir gehen nun zur großen und überans wichtigen Gruppe der Anneliden über.

Den eigentlichen Anneliden gehen die Archiauneliden voran. Ihr Nervensystem setzt sich wie dasjenige aller Anneliclen (siehe Fig. 22) zusammen aus emem ganglion supraoesophageum (oberes Schlundganglion oder Hirnganglion) und einem ganglion infraoesophageum (unteres Schlundganglion), welche durch die beiden Schlundkonnek-

Fig. 22.

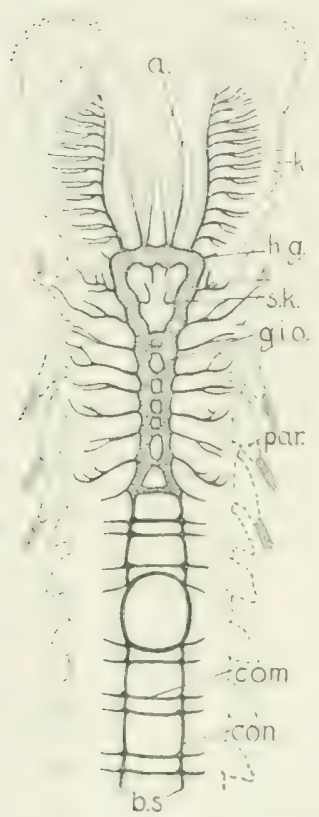

Vorderer' Tetl der Nervensystems einer Polychaete. Nach Bürschlit (1912), Fig. 336 .

$a_{0}=$ Antennr.

b.s.= Bauchst rang.

rom. $=$ Kommissur.

com. = Konncktiv.

?.i.o. = ganglion infraoesophageum.

h.!.= Hirnganglion.

$k=$ Kieme.

!uli. pritriputimum.

$\therefore k$ = Sichlundknnmoktiv tiven zum Schlundringe verbunden sind. Dem unteren Schlundganglion schließt sich bei den Anneliden im al!ge. meinen eine Doppelreihe durch Kommissuren und Konnels. tive verbundener Ganglien an, der Bauchstrang (Kig. 2:2) oder das Bauchmark. Nur bei den Archiamneliden und einigen Amneliden ist der Bauchstrang noch nicht in einzelne Ganglien differenziert. Aus allen Ganglien entspringen periphere Nerven.

Fraiposi (1884) war der erste. welcher einen Teil der Leitungsbahmen des Nervensystems der Archianneliclen zu Gesicht bekam und zwar bei Polygordius. Er beobachtete im Hirnganglion ein zentrales Neuropilem und fünf Gruppen peripherer Ganglienzellen, zwei rom, eine in der Mitte und zwei hinten. Aus den beiden vorderen Gruppen sah er die Tentakeluerven entspringen. Frarpoxt behauptet auch, (laB. Epithelzellen von Polygordius Fortsätze in das Hirn. ganglion senclen, also wohl Simnesnervenzelien wären, aber seine Figuren erregen $Z$ wreifel über diese Angaben. Zweifel. haft auf Grund seiner Abbildungen ist auch Frarost: Witteilung, daß die Zellen der Wimpergruben von Pro. todrilus sich zu Fortsätzen verjüngten, welche mit (ianglienzellen des Hinterteils des Gehims in Verbindung ständen.

Br.xnE: (1899) sah bei Polygordius die Hypodermider Bauchlinie verdickt durch den Bauchstrang, bestehend aus einer ventralen Ganglienzellschicht und einer dorsalen Nerrenfaserechicht. dem Neupopilem. Die Ganglienzellen senden $z u$ beiden Seiten der Vitte ihre Fortsiuze in einem Bimdel dorsalwärts, weshalb das Neuropilem dreiteilig ist.

Dic eigentlichen Anneliclen sind sehr oft und mit viclem Erfolge Gegenstand hodologischer Untersuchungen gewesen. Namentlich die Chaetopoden und Hirudineen unter ihnen gehören zu den 'Jieren, deren Reizleitungsbahnen uns am besten bekannt sind. Es haben denn auch viele der größßsten Gelehrten diesem Thema ihre kräfte gewidmet.

Fangen wir an mit den ('haetoporlen und unter diesen wieler mit den Polyehaeten.

Eine Lebersicht iiber das Nervensystem liefert die Fig. 20. Man sieht dort den lorderteil eines 1 urmes, das heil3t den Kopf mit den Kiemen (li.) und Antennen- (a.) und die ersten Körpersegmente mit ihren borstentragenden Parapodien (per.). Im Kopte befindet sich das Hirngranglion (h.g.), durch die Schlundkonnektive (s.k.) mit dem unteren sehlundganglion (!y.i.o.) verbunden. Diesem schließt sich der Banchstrang (b.s.) an. zwei Reihen von Ganglien mit Kommissuren und Konnektiven dazwischen. Hinsichtlich der Fig. 2.2 
sei nur bemerkt, daß sehr oft neben den zwei lateralen Konnektiven ein drittes medianes anwesend ist.

Wie bei so manchen anderen Evertebraten besteht das Innere der Ganglien au* Jeuropilem, welches von einer Rinde aus oft unipolaren Ganglienzellen umgeben wird. IIir können bis zum Jahre 1862 zurückgehen um die vielbestätigte, allgemeine Angabe geäußert zu sehen, daß die peripheren Ganglienzellen ihren Fortsatz ins Neuropilem senden und zrrar ist es LEYDIf (1862), welcher, so viel ich weiß als erster, diese: für die Anneliden behauptet hat und damit die erste allgemeine Mitteilung über einen Teil der Reizleitungsbahnen der Polychaeten gibt.

Es dauerte manches Jahr ehe CrReEFF (187:) wiederum eine Leitungsbalnn bei Polychaeten entcleckte. Er untersuchte die Augen der Alciopiden und erkannte bei manchen Arten in der Retina Sehzellen, deren kernhaltiger Zellkörper sich nach außen in ein Stäbchen, nach innen in eine Jerrenfaser des Sehnerven fortsetzte. Die GreEffsche Entdeckung ist später. von Hesse (1899) bestätigt worden. Damit ist (GREefF also clen erste, welcher die Sehzellen der Alciopiden als Sinnesnervenzellen erkannt hat, aber zugleich hat er damit als erster iiberhaupt bei einem II urme Sinnesnervenzellen gesehen und kann er als ihr Entdecker bei dieser Tiergruppe gelten (vergl. S. II und 32).

Greeff teilt uns mit, wie aus dem Zellkörper der Sehzelle eine ,Nervenfaser hervorgeht, welche in der Mitte des Stäbchens fortschreitet, aber da hat er wohl keine Nervenfaser, sonclem eine Neurofibrille beobachtet.

Einige Jahre später erscheint die Arbeit MEYERs (1882). Sie bezieht sich auf Pol!ophthalmus pictus und, obgleich der Lauf der Nervenfasern mehr erraten, als exakt erwiesen wurde, enthält sie sehr viel gutes.

Im Hirnganglion ron Polyophthalmus entdeckte MEYER drei Paar Gruppen von meistens unipolaren Ganglienzellen, welche drei Paar Nervenfaserbündel abgeben. Dic erste Gruppe liegt oben vorn im Hirnganglion. Sie umschließt eine Achse von Nervenfasern, welche Fortsätze ihrer Ganglienzellen sind. Die Fortsätze treten in einen peripheren Nerven ein, welcher zum Becherorgan geht, das sich zu beideu Seiten des Koufes neben den Flimmergruben befindet. Hier setzen sich die Ausläufer kontinuirlich fort in die Nervenfortsätze der fadenförmigen Sinnesnervenzellen, welche man im Becherorgan unter der Cuticula sieht. Die Fasern passieren dabei ein peripheres Ganglion, womit sie aber, wenn ich MEYER gut begreife, nichts zu schaffen haben. Das bedarf wohl näherer Bestätigung.

Die zweite Gruppe ist hinten unten dem Hirn eingelagert und die meisten Fortsätze ihrer Zellen begeben sich in die Schlundkonnektive. Die dritte Gruppe ist oben hinten im Gehirn zu finden und sie entsendet einen Nerven zum peripheren Ganglion des Flimmerorgans, wohin die Bases der fadenförmigen Flimmerzellen sich auch begeben Der richtige Nervenfaserverlauf bleibt peripher also noch festzustellen.

Die beiden zweiten Gruppen sind durch eine Kommissur verbunden ; auch kann man cin Paar Längsbündel im Hirnganglion von vorn nach hinten ziehen sehen, welche noch nicht genannt wurden. Die L'rsprungszellen dieser Fasern waren MEYER nicht genau bekannt.

Neben den beschriebenen unipolaren Ganglienzellen beobachtete MErER im oberen Schlundganglion auch andere, welche oft bipolar sind, ebenfalls gruppiert sind und mit ihren Fortsätzen die sechs Ganglienzellgruppen und die Faserbïndel untereinander verbinden. IIEYER nannte sie Kommissurzellen, einen Namen, welchen ich nicht beibehalten kann, weil ich damit nur Ganglienzellen, deren Fortsätze die Merlianlinie kretızen, bezeichnen möchte. Vielleicht lassen sie sich eben so gut Assoziationszellen nennen, wic ich vorläufig tun werde.

Die erste Gruppe der Assoziationszellen ist an der Vorderseite des Ciehirns gelegen. Sie steht in Verbindung mit ren beiden ersten Gruppen unipolarer Ganglienzellen, mit den Längsbündeln und durch diese hindurch mit den beiden dritten (iruppen unipolaver Ganglienzellen, sowie mit vier anderen Grupıen dssoziationszellen.

Von der zweiten und dritten Cruppe der Assoziationszellen, in der Witte des Hirngranglions und unten im Hirn gelegen, meldet MEYER die Bahnen nicht. 
Die vierte Gruppe ist gepaart. Sie liegt neben den Längsbündeln und steht mit den Fortsätzen ihrer Ganglienzellen mit diesen, mit der Kommissur und mit den drei Paar Gruppen unipolarer Ganglienzellen in Verbindung.

Die Fasern der Schlundkonnektive setzen sich fort in den Bauclistrang, wo diese longitudinalen Nervenfasern noch in viele Bïndel verteilt werden. Manche dieser Nervenfasern des Bauchmarks biegen sich nach der Peripherie des Körpers, das heißt zu den Seitenaugen oder den Muskeln und bilden so die peripheren Nerven, zwei Pąar zu jedem Körpersegment.

Neben den Fasern befinden sich nach MEYER im Bauchstrange unipolare Ganglienzellen, welche in drei ununterbrochenen Säulen, zwei dorsolateralen und einem ventro. medialen, angehäuft liegen. Das Bauchmark von Polyophthalmus ist also innerlich gar nicht und äußerlich nur wenig gegliedert. Im unteren Schlundganglion wird nur die ventromediale Ganglienzellgruppe wahrgenommen, da hier die beiden dorsolateralen noch nicht aufgetreten sind. NExer hat in diesen Hinsichten aber später keine Bestätigung gefunden.

Fig. 23.

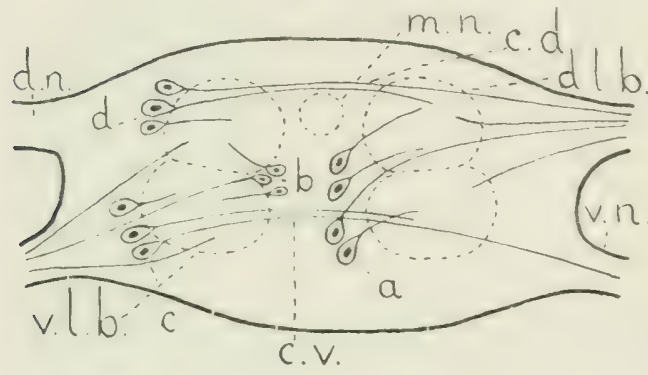

Querschnitt eines Bauchganglions von Travisia. Nach Kükexthal (1887).

$a, b, c, d=$ Ganglienzellgruppen.

$c . d .=$ commissura dorsalis.

c.v. = commissura ventralis.

d.l.b. = dorsales Längsbündel.

$d_{n .}=$ nervus dorsalis.

$m . n .=$ nervus medianus.

$\varkappa . l . b .=$ ventrales Längsbiindel.

$v \cdot n .=$ nervus ventralis

Meyer erwähnt endlich noch, daß von den drei Kopfaugen das unpaare in die zweite und die beiden gepaarten in die beiden vierten Assoziationszellgruppen einverleibt sind, aber ob sie auch davon innerviert werden, konnte er nicht erforschen. Wohl sah er. daß neben den drei Kopfaugen drei Statocysten sind, die unpaare von der zweiten Assoziations zeligruppe, die beiden anderen durch Kommissurfasern innerviert.

Das Jahr 1887 ist reich an Nitteilungen ïber die Hodologie der Polychaeten. Da haben wir zuerst KüкExTHAL (1Ss7), welcher die Opheliaceen als Objekt erwählt. Am vollständigsten wird Travisia beschrieben. Es besteht hier ein oberes Schlundganglion aus Neuropilem mit umringenden Ganglienzellgruppen. Zwei dieser

Gruppen sind aus unipolaren Ganglienzellen zusammengesetzt, welche ihren Fortsatz zu den Hypodermiszellen neben den Flimmergruben des Kopfes senden.

Das Hirnganglion ist mittels der Schlundkonnektive mit dem Bauchmark verbunden und diesen Schlundkonnektiven sitzt ein Ganglion auf, worin man drei Gruppen von Ganglienzellen, welche ihre Fortsätze in die Konnektive schicken. beobachten kann.

Im Bauchstrange sind die Ganglienzellen nicht gleichmäßig verteilt, sondern sie sind in den Ganglien angehäuft, während sie in den Konnektiven weniger zahlreich sind. Ein dorsales und ein ventrales Par Nerven verlassen jedes Ganglion. Wie nach KüкеxтицL ein Bauchganglion gebaut ist, wird am besten durch die schematische Figur 23 beleuchtet.

Die Fasern der beiden Schlundkonnektive setzen sich im Bauchstrange 
in zwei Längsfaserbündel fort, welche von einem bindegewebigen Septum in einen dorsalen Teil (Fig. 23, d.l.b.) und einen ventralen Teil (v.l.b.) zerlegt werden. Das dorsale Längsbündel (d.l.b.) selbst wird noch weiter zerlegt. Das stimmt also mit dem, was Meyer bei Polyophthalmus beobachtete.

In jedem Ganglion entdeckte Küкеxтнац vier Paar Ganglienzellgruppen. Die erste Gruppe (Fig. 23, a) befindet sich median zwischen den Längsbündeln und vorwiegend ventral. Ihre unipolaren Zellen senden ihre Fortsätze in das ventrale Längsbündel, in das dorsale Längsbündel und zwar auch dort ventral oder dorsal und in den dorsalen peripheren Nerven (Fig. 23, d.n.).

Die zweite Gruppe (Fig. 23, b) umfaßt kleine unipolare Ganglienzellen, welche medial in der Rinne zwischen dem dorsalen und dem ventralen Längsbündel gedrängt liegen. Die Fortsätze dieser Zellen dringen in eins der beiden Längsbündel ein, oder sie ziehen in den ventralen Nerven (Fig. 23 links).

Die dritte Gruppe (Fig. 23, c) wird lateral neben dem ventralen Längsbündel gefunden. Thre unipolaren Ganglienzellen fügen ihre Fortsätze dem ventralen Längsbündel bei, oder dieselben kreuzen die Medianlinie, bilden also die ventrale Kommissur (Fig. 23, c.v.) und ziehen nun entweder in dem ventralen Nerven oder im ventralen Längsbündel weiter.

In entsprechender Weise verhalten sich die Ganglienzellen der vierten Gruppe (Fig. 23,d). Diese liegt lateral neben dem dorsalen Längsbündel und die Ausläufer ihrer Ganglienzellen gehen in das dorsale Längsbündel derselben oder der gekreuzten Seite oder in den dorsalen Nerven der anderen Seite, dabei die dorsale Kommissur (Fig. 23, c.d.) bildend. (Man muß sich die Zellen der Fig. 23 wiederum symmetrisch an der anderen Seite gelegen denken.).

Zur Bildung des dorsalen Nerven tragen neben Fortsätzen von Ganglienzellen der Gruppen $a$ und $d$ auch Fasern bei, welche aus den Längsbündeln darin abbiegen (Fig. 23 rechts), während solche Fasern auch den ventralen Nerven verstärken (Fig. 23 links), welcher übrigens von Fortsätzen der Zellgruppen $b$ und $c$ gebildet wird. Diese in die Seitennerven abbiegenden Fasern der Längsbündel hatte auch schon MEyer, wie wir oben sahen, bei Polyophthalmus erwähnt.

Dorsal in der Mitte des Bauchstranges befindet sich der sogenannte Mediannerv (Fig. 23, m.n.), welcher aber meiner Ansicht nach besser das mediane Konnektiv genannt würde. Jedes Bauchganglion enthält in der Mitte zwei große, multipolare Zellen, die Medianzellen, welche einige Fortsätze in die Mediannerven senden, wie Kükexthal uns mitteilt. Wenn diese Medianzellen, welche auch bei anderen Chaetopoden vorhanden sind, wirklich mit den Medianzellen der Hirudineen homolog sind, sind es keine Ganglienzellen, sondern Gliazellen. Ich bilde sie deshalb in der Figur 23 nicht ab.

So weit über Travisia. Ophelia hat den Bauchstrang ebenso gebaut wie Travisia und auch hier sind die Schlundkonnektive von Ganglienzellen umgeben, deren Fortsätze sich den Konnektiven beimischen.

KїкENTHAL beschreibt in wenig klarer Weise einige Leitungsbahnen im Hirn von Ammotrypane. Hier stimmt die Struktur der Schlundkonnelitive mit jener anderer Arten überein und auch die Bauchganglien sind wie bei Travisia gebaut, nur sind die 
dorsale und die ventrale Kommissur zu einer einzigen vereint. Armandia hat aber wiederum zwei Kommissuren in jedem Ganglion.

IVie MEYER, so hat auch KüKENTHAt das obere Schlundganglion von Polyophthalmus untersucht. Er fand darin neben anderen Zellgruppen eine gepaarte, laterale Gruppe unipolarer Ganglienzellen, deren Fortsätze teils in einen lateralen Nerven lau. fen, teils eine Kommissur bilden. Die Gruppe ist nicht ohne weiteres mit einer von MEYER entcleckten Ganglienzellgruppe zu identifizieren. Küкшмтиац beobachtete auch eine mediane dorsale Gruppe bipolarer Ganglienzellen, ron MFYER weniger richtig Kommissurzellen genannt, welche ihre Fortsätze in einen dorsalen, medianen Nerven zur Rük-

Fig. - -4 .

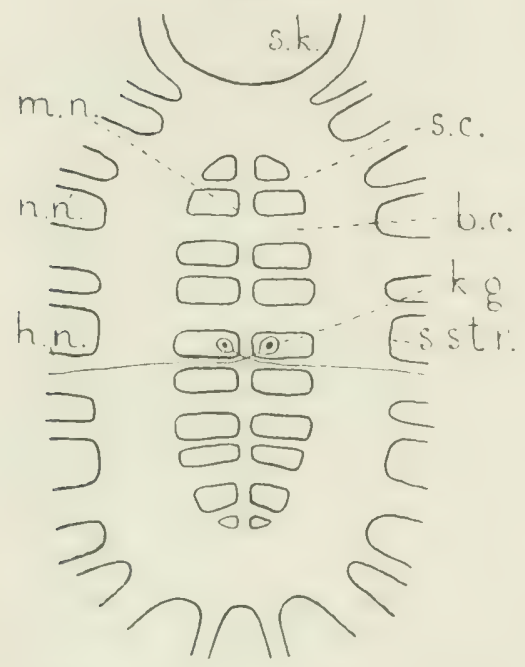

Bauchstrang von Myzostomum giganteum.

Nach NANSEN (1887).

b. $c .=$ breite Kommissur

h. $n$. = Hauptnerv

k. g. = kolossale Ganglienzelle oder Neurochordzelle

$m_{0} n_{0}=$ Mediannerv

n. $n_{0}=$ Nebennerv

s. $c$. = schmale Kommissur

s. $k$. = Schundkonnektiv.

s. str. = Seitenstrang kenseite des Kopfes senden. Ob dies die zweite vón MEyer beschriebene Gruppe ist?

Lateroventral neben den Schlundkonnektiven konnte KüкENThaL zwei Ganglienzellgruppen wahrnehmen, welche Zellen einen Teil ihrer Fortsätze quer dureh das Konnektiv hindureh in einen Nerven zum Integument senden.

Der Bauchstrang von Polyophthalmus hat nach KüKenthaL den sehon von anderen Opheliaceen bekannten Bau : zwei Kommissuren und vier Yaar Ganglienzellgruppen in jedem Ganglion. Er weicht in dieser Angabe ab von MEYER, welcher im Bauchmark keine innerliche Gliederung entrlecken konnte.

Im selben Jahre wie Küкmistua die Opheliaceen hat Naxsen (1887) die Myzostomen, vor allen Myzostomum giganteum, untersucht. Sie weichen in ihrem Nervensystem erheblich von den Opheliaceen ab. Das Hirnganglion wird gebildet von wenigstens vier Paar Ganglienzellgruppen mit unipolaren oder multipolaren Ganglienzellen. Das Hirnganglion bildet mit den Schlundkonnektiven (Fig. 224, s.1.), welche das Ganglion mit dem Bauch-

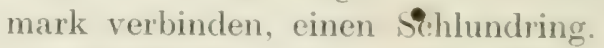

Der Schlundring empfängt Fortsätze von Ganglienzellen des Hirnganglions und entsendet einige Nerven zum Rüssel, welche diesen ebenfalls mit einem Ringnerven, dem ,'Tentakelnervenring" umgeben. Auch in diesem Ringe sind Ganglienzellen eingelagert, welche diesem ihre Fortsätze abgeben.

Der Bauchstrang von Myzostomum giganteum ist sehr kurz und gedrängt (Fig. 24). Im Gegensat\% zu den Opheliacen sind die beiden Konnektive oder Seitenstränge wie NAxskx sie nennt, weil ihnen die Ganglien abgehen, nicht mit einander verwachsen, sondern nur durch Kommissuren verbunden. Infolgedessen hat auch der Mediannerv (Fig. -24, m.n.) (besser das Mediankonnektiv) größere Selbständigkeit. Die Kommissuren sind nicht alle gleich dick, sondern man unterscheidet abwechselnd schmale und breite 
Kommissuren (Fig. 24, s.c. und b.c.). Deutliche Ganglien im Bauchstrange gibt es nicht, aber die peripheren Nerven verlassen den Bauchstrang an regelmäßigen Stellen, welche wie die Kommissuren auf Segmentierung hindeuten. Wahrscheinlich hat der Bauchstrang sechs Segmente, obgleich seine Ganglienzellgruppen dieses nicht ausweisen. Unter den peripheren Nerven beobachtet man dicke Hauptnerven (Fig. 24, h.n.) und schwache Nebennerven (Fig. $24, n . n$.).

Der Nervenfaserverlauf des Bauchstranges, wie er von NAxSEx erforscht worden ist und in überzeugender Wëise dargestellt wird, wird am bequemsten erläutert an einem Querschnitt durch eine breite Kommissur (Fig. 25).

Median sind darin die Fasern des Mediannerven $(m . n$.$) angeschnitten,$ welcher selbstverständlich in den Kommissuren nicht frei liegt (vergl. Fig. 24). Lateral sieht man zu beiden Seiten das Neuropilem der Seitenstränge (Fig. 25,neur.), das sich in mancher Hinsicht mit den Längsbündeln der Opheliaceen (Fig. 23) vergleichen ließe.

Auf der Höhe einer breiten Kommissur konnte NANSEx nun die folgenden, das Neuropilem umringenden Ganglienzellgruppen beobachten. Zuerst eine einzige, mediane

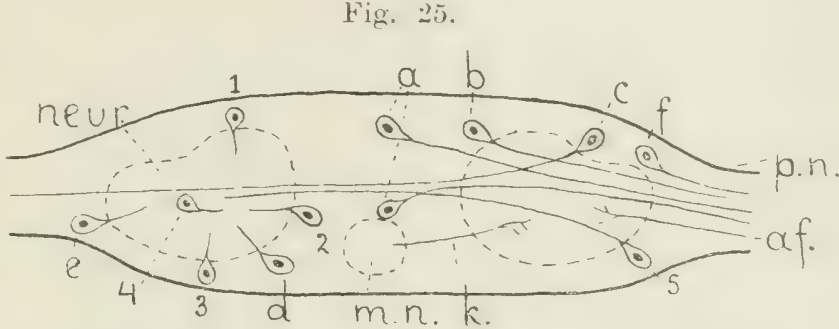

Querschnitt der Bauchstranges von Myzostomum giganteum durch eine breite Kommissur. Nach $\cdot$ NANSEN . (1887).

$a, b, c, d, e, f=$ Ganglienzellgruppen

af. $=$ afferente Nervenfaser

$k$. = Kollaterale

$m . n_{0}=$ Mediannerv

neur. $=$ Neuropilem des Seitenstranges

$p_{.} n_{0}=$ Peripherer Nerv

Gruppe, welche teils

$1,2,3,4,5=$ Ganglienzelle

dorsal und über den

Kommissurfasern, teils ventral darunter gelegen war (Fig, 25, a). Die meisten Fortsätze dieser Ganglienzellen treten in einen peripheren Nerven ein.

Die zweite Gruppe (Fig. 25, b) ist gepaart und hat eine dorsale Stellung. Aus ihren Zellen entspringen Fortsätze zu einem peripheren Nerven der gleichen Seite.

Die dritte Gruppe (Fig. 25, c) befindet sich ebenfalls an der dorsalen Seite, aber die Fortsätze ihrer Zellen ziehen in einen peripheren Nerven der anderen Seite, dabei also eine Kommissur bildend.

Die vierte und fünfte Gruppe (Fig. 25, $d$ und $e$ liegen ventral, e lateral und $d$ medial und ihre Ganglienzellen sind mit Fortsätzen ausgestattet, welche in das Neuropilem eindringen.

Die sechste Gruppe endlich (Fig. 25, f) ist wiederum eine dorsale, welche wie Gruppe $a$ von Ganglienzellen gebildet wird, welche ihre Ausläufer einem peripheren Nerven derselben Seite zusenden, aber ihre Stellung ist ganz lateral neben Gruppe $c$. 
Neben diesen Ganglienzellgruppen erwähnt NAxsex noch das Vorkommen von fünf charakteristischen, einzelstehenden Ganglienzellen. Die dorsale Zelle 1 (Fig. 25) und die ventralen Zellen 2 und 3 dringen mit ihren Fortsätzen in das Neuropilem ein. Die vierte (Fig. 25,4) ebenso, aber ihr Zellkörper liegt zentral, mitten im Neuropilem. Die fünfte (Fig. 25, 5) ist eine wahre Kommissurzelle. Thr Zellkörper ist ventral gelegen, ihr Fortsatz kreuzt die Medianlinie und taucht in das Neuripilem der anderen Seite ein.

Die peripheren Nerven enthalten nicht nur austretende Nervenfasern der genannten Ganglienzellen, sondern auch eintretende, afferente Nervenfasern (Fig. 25, af.), welche im Neuropilem des Seitenstranges ihre Endverästelungen haben.

Das Verhältnis des Mediannerven zu den Seitensträngen besteht nach NANSEx darin, daß die Fasern des Vediannerven Kollateralen zu ihrem Neuropilem entsenden (Fig. 25, $/ i$.).

Es bleibt mir jetzt noch ïbrig eine Bemerkung NAxsexs über die kolossalen Ganglienzellen des Nervensystems von Myzostomum mitzuteilen.

NANSEx ist nicht der erste, welcher über die Kolossalzellen der Polychaten oder den Lauf von ihren Neurochorden berichtet. SPExGEL (1852) hatte schon bei den Euniceen Halla und Arabella im Bauchmark Neurochorde aufgefunden, welche er als Fortsätze kolossaler Ganglienzellen der vorderen Ganglien, der Neurochordzellen, erkannte. Und RoHDE (1886) hatte schon im Jahre 1886 vorläufige Mitteilungen ïber die Neurochorde der Aphroditeen veröffentlicht, welche er uns aber erst 1890 ausgearbeitet überliefert hat und welche ich deshalb erst nachher referieren möchte.

NAxsex nun entdeckte bei Nyzostomum dorsal zwischen jedem l'aar breiter Kommissuren des Bauchmarks ein Paar kolossaler Ganglienzellen (Neurochordzellen), deren Fortsatz die Medianlinie kreuzend in die schmale Kommissur zur anderen Seite des Bauchstranges und weiter in einen Hauptnerven zog (Fig. 24, k.g.).

Die Capitelliden, wiederum eine andere Familie der Polychaeten, wurden von Eisig (1887) bearbeitet und was er in seiner Monographie iiber den Lauf der Nervenfasern im Bauchstrang mitteilt, stimmt in manchen Hinsichten mit den Befunden Kükextuals überein, was ersichtlich ist, wenn man die nachstehenden Angaben mit Fig. 23 vergleicht.

Notomastus ist hier die am besten bekannte Art. EIsIg erwähnt, daß Ganglienzellen des unteren Schlundganglions und der Bauchganglien Fortsätze senden in die Konnektive, welche die Ganglien verbinden und daß andrerseits Nervenfasern der Konnektive in die peripheren Nerven der Ganglien austreten. Beides sieht man auch in Fig. 23, wo die Konnelitive von den Längsbiundeln dargestellt werden. Ganglienzellen der Bauchganglien entsenden auch Nervenfasern in die gleichseitigen peripheren Nerven oder nach Kreuzung in die peripheren Nerven der anderen Hälfte des Ganglions (vergl. Fig. 23) und zwar liegen die ersten lateral im Ganglion, die letzten aber ventral.

Neurochorde sind bei Notomastus anwesend, aber Eisig betrachtet sie auf Grund ihres wässerigen Inhalts als degenerierte Nervenfaserbiundel, 
welche schließlich Stützfunktionen haben und seine Angaben fördern unsere Kenntnis der Leitungsbahnen nicht.

Eisig hat auch versucht im peripheren Nervensystem den Lauf einiger Nervenfasern zu erforschen, aber er hat dabei nur zweifelhafte Resultate erreicht. Die Sehzellen des Auges gehen nach ihm wahrscheinlich mit einem basalen Fortsatz kontinuirlich über in „Kömer", welche ihrerseits durch einen Fortsatz kontinuirlich mit einer Ganglienzelle verbunden sind. Die Sinneszellen der Seitenorgane enden nach Eisig in einer ,Spindel", welche einerseits mit einer Muskelfaser, andrerseits mit einer Nervenfaser in Verbindung steht. Letztere geht zu den „Körnern” des Körnerganglions, von dem weiter gewiße Fasern in die Nerven des Seitenorgans ziehen. Der histologische Wert der genannten Elemente ist nicht klar.

Unter den anderen Capitelliden stimmt Dasybranchus in manchen Hinsichten mit Notomastus überein. Capitella gehen die Neurochorde ab, aber bei Mastobranchus beobachtete Eisig kolossale Ganglienzellen, deren Fortsätze sich den Neurochorden näherten, ohne daß ein direkter Verband wahrgenommen wurde. Eisig betrachtet auch diese Ganglienzellen, ebenso wie die Neurochorde als wahrscheinlich degeneriert, eine Ansicht, welche ich mit Rücksicht auf die Angaben anderer Autoren nicht teilen kann. Behauptet doch Friedlaexder (1889) gerade für Mastobranchus, daß die Ausläufer der Neurochordzellen sich an segmental gelegenen Stellen in die Neurochorde (vielleicht Neurochordbiindel?) fortsetzen und daß die Neurochorde funktionierende Nervenfasern sind, welche alle Segmente des Wurmkörpers in direkte Verbindung setzen.

Haller (1887, 1889) hat sich in zwei Arbeiten mit der Hodologie von Lepidasthenia und Nereis beschäftigt. Die letztere dieser beiden Arbeiten ist die wichtigere und HALLER hat darin versucht auf Grund aus freier Hand geschnittener Präparate zu beweisen, daß die Fasern der peripheren Nerven teils aus Ganglienzellen, teils unmittelbar aus dem Neuropilem der Ganglien entsprängen. Ich glaube mit vielen anderen Autoren, daß die Nervenfasem, von welchen gesagt wird, daß sie im Neuropilem entspringen tatsächlich darin enden und ihren Ursprung in, freilich HALLER unbekannten, peripheren Ganglienzellen oder Sinnesnervenzellen haben. Die HaLlerschen Angaben sind dann auch besser im Einklang mit den Resultaten anderer Forscher und ich werde mir in deren Wiedergabe erlauben keine Nervenfasern im Neuropilem entspringen, sondern sie nur darin enden zu lassen. Haller meint, wie bei den Evertebraten im allgemeinen, so auch hier, daß die Zellkörper einer Ganglienzellgruppe vielfach unmittelbar durch Fortsätze verbunden sind und in diesem Falle wären die Reizleitungsbahnen, einmal in den Ganglienzellgruppen angelangt, anatomisch nicht weiter verfolgbar. Auch abgesehen von diesen letzten Punkten sei bemerkt, daß, meiner Ansicht nach, HaLLER seine Behauptungen nicht immer genugsam begründet.

HaLLer (1889) hat in erster Linie das ganglion supraoesophageum untersucht und dessen Bau bei Lepidasthenia und Nereis übereinstimmend gefunden. Seine Resultate werden am besten in Verbindung mit denjenigen anderer Forscher (S. 78) besprochen. Beim Unterschlundganglion ist so etwas un- 
möglich und daher folge hier gleich die Bemerkung, daß HALLER bei Lepidasthenia eine schwache Kommissur vorn im Unterschlundganglion beobachtete, deren Fasern, wie er sagt, nicht mit Ganglienzellen in Verbindung stehen, sondern von Neuropilem zu Neuropilem gehen. Das verdient jedoch nähere Bestätigung. Die Ganglienzellen sind in fünf Gruppen angehäuft, zwei laterodorsalen, zwei lateroventralen und einer medioventralen und ihre Fortsätze gehen in den peripheren Nerven derselben Seite oder in das Neuropilem des Ganglions. HaLLER wies im unteren Schlundganglion Kolossalzellen nach, aber er erwähnt nicht, wie bei den Bauchganglien, den Lauf ihrer Neurochorde.

Im Bauchmark ist keine Stelle frei von Ganglienzellen und die Ganglien sind also nur durch ihren größeren Gehalt an Ganglienzellen und die austretenden Nerven gekennzeichnet, aber andere Polychaeten als Lepidas-

Fig. 26 .

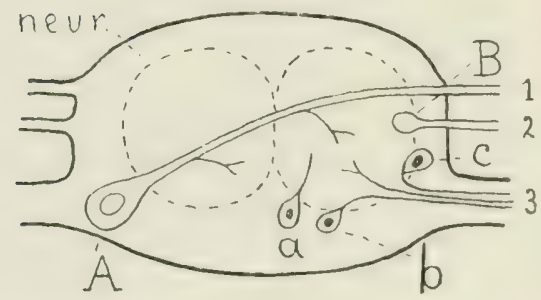

Querschnitt durch das Bauchganglion ron Lepidasthenia.

Nach Halder (1889) Textfigur 1. neur. = neuropilema

$a, b, c=$ Ganglienzellen

$A=$ Neurochordzelle

$B=$ Neurochord

$1,2,3=$ peripherer Nerv thenia haben gewiß Konnektive ohne Ganglienzellen.

In jedem Bauchganglion kann man die fünf oben genannten Ganglienzellgruppen des unteren Schlundganglions wiedererkennen. Thre Zellen schicken Fortsätze ins Neuropilem (Fig. 26 a) oder in die peripheren Nerven (Fig. $26, b, c)$, aber es gibt auch nach $\mathrm{HAL}_{\mathrm{A}-}$ LER Fälle, worin eine Ganglienzelle der ventrolateralen Gruppe mit einer der dorsolateralen Gruppe unmittelbar durch einen Fortsatz verbunden ist. Jedes Bauchganglion hat vier Paar peripherer Nerven (wovon in Figur 26 nur drei gezeichnet wurden), aber nur zwei sind wie gewöhnlich Nervenfaserbiundel und zwar enthalten diese nicht nur Fortsätze der Zellen des Ganglions, sondern auch Nervenfasern, welche im Neuropilem des Ganglions endigen (Fig. 26, 3). Die beiden anderen Nervenpare sind weiter nichts als einzeln austretende Neurochorde.

In jedem Bauchganglion befindet sich lateral und ventral ein Paar Neurochordzellen (kolossaler Ganglienzellen) (Fig. 26, A). Der Fortsatz dieser Ganglienzellen kreuzt, nach HALLER als cinzige Kiommissurfaser des ganzen Bauchganglions, die Medianlinie und verläßt das Bauchmark an der anderen Seite, an und für sich einen peripheren Nerven (Fig. 26, 1) bildend. Zuror aber hat er dem Neuropilem der beiden Banchstranghälften Kollateralen abgegeben.

Neben diesen seitwïrts austretenden Kolossalfasern gibt es rechts und links einen oder mehrere longitudinale Neurochorde im Bauchstrang. Ein ganz lateral dahinlaufender Neurochord (Fig. 26, B) fängt an im dritten Bauchganglion und entsendet dam und wann Seitenäste, aber außerdem spaltet er in jedem Segmente einen dicken Seitenast ab, welcher an und für sich als peripherer Nerv das Ganglion verläßt. (Fig. :26, 2?). 
HALLER betrachtet die beiden Medianzellen, welche jedem Bauchganglion eigen sind, als Ganglienzellen, aber er beschreibt nicht den Lauf ihrer Fortsätze.

So weit über Lepidasthenia. Von allem was Haller über die Polychaete Serpula bemerkt, interessiert uns nur, daß das untere Schlundgang. lion Ganglienzellen besitzt, welche Fortsätze entweder in das Neuropilem oder in das Konnektiv zum ersten Bauchganglion senden. Andere Fasern des Konnektivs enden im ganglion infraoesophageum.

Rohde (1890) hat das Zentralnervensystem der Aphroditeen untersucht und namentlich über den Lauf der Kolossalfasern sehr wichtige Erforschungen mitgeteilt. Einige Aphroditeen, so Aphrodite selbst und Hermione, haben gesonderte Ganglien im . Bauchstrange, aber Sthenelais, Sigalion und Polynoe nicht. Bei ihnen sind die Ganglienzellen überall dem Bauchstrange eingelagert und die Segmente (Fig. 27,s.) sind nur durch die drei Paare peripherer Nerven, zwei dünne und einen dicken, gekennzeichnet. Kommissuren fand Rorde in jedem Ganglion, aber vorwiegènd im unteren Schlundganglion.

RoHDE stellt sich auf die Seite jener Forscher, welche die Neurochorde nicht für Stützgewebe, sondern für wahre Nervenfasern sei es denn von kolossalen Dimensionen, halten und er konnte denn auch in sehr vielen Fällen ihr Hervorspringen aus kolossalen Ganglienzellen beobachten.

Sthenelais hat unter den Aphroditeen besonders viele Neurochorde. Wie sie laufen und wo sie entspringen, zeigt RoHDE in einem Schema, das meiner Figur 27 zu Grunde gelegt wurde. RoHDE erkannte drei Arten kolossaler Nervenfasern, solche, welche im Bauchstrang von vorn nach hinten laufen, solche, welche umgekehrt darin aszendieren und solche, welche in jedem Segmente zur Peripherie des Körpers schreiten.

Fig. :27.

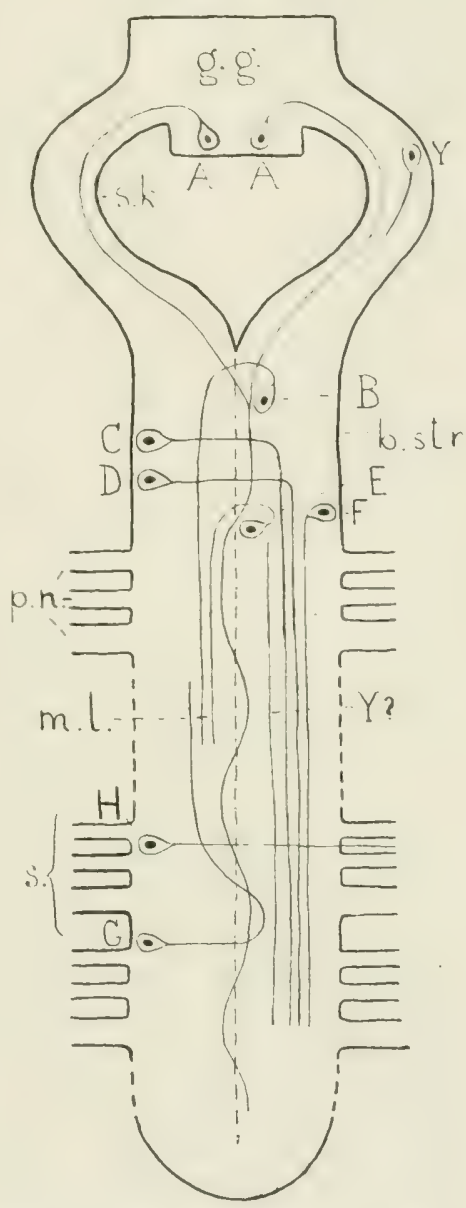

Schematische Darstellung der Neurochorde in Zentralnervensystem von Sthenelais.

Abgeändert nach ROHDE (1890) Fig. 87.

b.str. = Bauchstrang

g. $g .=$ Gehirnganglion

$m . l .=$ Medianlinie

p.n. $=$ peripherer Nerv

$s .=$ Segment

s. k. = Schlundkonnektiv

$A$ bis $H$ und $Y=$ Neurochordzelle

$Y ?=$ Neurochord

Der Bauchstrang ist zweimal unterbrochen bei - -

Am hinteren Rande des Gehirnganglions (Fig. 27, g.g.) entdeckte RондE das erste Paar Neurochordzellen (Fig. 27, A,A). 
Sie senden ihren Fortsatz durch die Schlundkonnektive (Fig. 27, s.k.) in den Bauchstrang (b.str.) hinein. Hier angelangt, vereinigen sich die beiden Neurochorde zu einem einzigen, welcher im Bauchstrange deszendiert, dabei oft die Medianlinie (Fig. 27, m.l.) kreuzend. Wie alle Kolossalfasern entsendet er dann und wann Seitenästchen.

Bald nachdem die Schlundkonnektive sich zum Bauchmark vereinigt haben, treten ventral hinter einander zwei Paar Kolossalzellen (Fig. 27, B und $E$ ) hervor, deren Fortsatz einen Bogen beschreibt, die Medianlinie überschreitet und dicht daneben nach hinten läuft. Er endet noch vor der Mitte des Körpers.

Zwischen $B$ und $E$ aber lateral, liegen zwei Paar Neurochordzellen (Fig. 27, $C$ und $D$ ), deren Fortsätze die Medianlinie kreuzen und nach hinten streben, aber mehr lateral als die Neurochorde $B$ und $E$. Lateral hinter $D$ befindet sich noch eine Kolossalzelle (Fig. 27, F), deren Neurochord in der an der gleichen Seite liegendem Bauchstranghälfte deszendiert.

Im Konnektivalganglion entdeckte RoHDe eine Neurochordzelle (Fig. 27, $Y$ ), aber er konnte deren Fortsatz nicht im unteren Schlundganglion wieder auffinden. Andrerseits war durch die ganze Länge des Bauchmarks bis zum ganglion infraoesophageale ein Neurochord (Fig. 27, $Y$ ?) gelegen, dessen zugehörige Zelle unbekannt blieb und RorDE hält es für nicht unmöglich, daß die Zelle $Y$ und die Faser $Y$ ? zu einarder gehören.

Etwa nach dem sechzehnten Segmente bis ins zweitletzte wurde von Roнde in jedem Ségmente entweder links, oder rechts, aber ohne bestimmte Ordnung lateral vor der Abgangsstelle des ersten Nerven eine Neurochordzelle gesehen (Fig. 27, G). Ihr Neurochord kreuzt die Medianlinie, aber im vorhergehenden Segmente kreuzt er wieder zurück und jetzt tritt die Faser dorsal aus dem Bauchstrange aus und läuft eine Strecke weit nach vorn. Wemn so zu beiden Seiten ïber dem Bauchstrang etwa sieben soleher Kolossalfasern laufen und weitere sich hinzufügen wiurden, kehrt die erste Faser ins Batchmark zurück und zerfasert sich dort im Neuropilem, welchem Beispiel die anderen der Reihe nach folgen. Rompe sah kein Zusammenfließen dieser Neurochorde, wie Spexger solches fiir Halla behauptet.

Zuletzt beschreibt RoHDE noch lateral in der Mitte eines jeden Segments ein Paar Neurochordzellen (Fig. 27, $H$ ), welche seiner Abbildung nach zwisehen den beiden vorderen der drei jedes Segment verlassenden Nerven zu finden sind. Ihr Fortsat\% iberschreitet die Medianlinie und tritt selbständig als peripherer Nerv aus dem Banchstrang. Sein Ende ist unbekannt, abex in der Nähe der Parapodien zu suchen.

Sigalion besitzt nur zwei Paar Neurochordzellen, welche den Zellen A und $C$ von Sthendais homolog sind. Hhe Kolossalfasern deszendieren, aber die beiden Fasern $A$ vereinigen sich nicht und keine kreuzt die Medianlinie.

Polynoe elegans hat jedenfalls die Neurochordzelle $C$, aber wahrscheinlich auch $A$ und zwar in der Modifikation von Sigalion. Auch enthält hier jedes Segment die Neurochordzelle 11 , aber ihr Fortsatz verläßt das Bauchmark nach Krenzung der Medianlinie im hinteren der drei peripheren Nerven des Segments, also nicht sclbständig wie bei sthenelais. 
Aphrodite und Hermione entbehren der longitudinalen Neurochorde.

Fig. 2S.

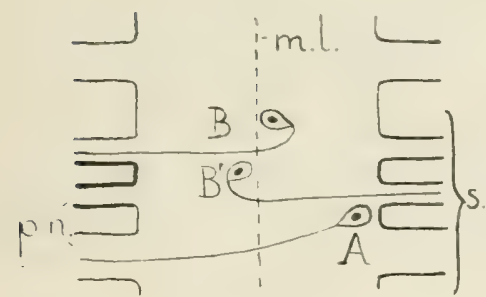

Ein Teil des Bauchmarks von Aphrodite oder Hermione schematisch dargestellt.

Abgeändert nach ROHDE (1890), Fig. 89.

m.. . = Medianlinie

$p \cdot n_{0}=$ peripherer Nerv

$s_{0}=$ Segment

$A, B, B^{\prime}=$ Neurochordzelle
Hingegen treten in jeden der peripheren Nerven Kolossalfasern aus, welche sich aber mehr als gewöhnlich in ihrer Größe den dicken Nervenfasern des Bauchmarks näheren und deshalb meiner. Meinung nach rielleicht nicht mehr Neurochorde zu nemnen sind. Lebrigens hat achon Leydici (1ss6i) betont. daß die Neurochorde mit den größten Nervenfasern durch Uebergänge verbunden sind. In die starken peripheren Nerven treten nach ROHDE acht oder neun Kolossalfasern, welche aus der anderen Seite des Bauchstranges stammen. Ihre Ursprungszellen sind nicht genau bekannt, aber wahrscheinlich lateral gestellt (Fig. 28, A). Die beiden dünnen peripheren Nerven empfangen sechs bis sieben Neurochorde der entgegengesetzten Seite des Bauchmarks. Auch ihre Neurochordzellen sind nicht entdeckt worden, aber Rohde vermutet, daß sie ventral median liegen (Fig. 28, $B$ und $B^{\prime}$ ).

Aphrodite hat nach RoHDE auch in Retzius (1891) einen Forscher ihres Nervensystems gefunden. Retzius hat sich in einer Reihe von Schriften (Retzius 1891, 1892b, 1895b und 1900) mit dem Nervensysteme der Polychaeten okkupiert und dabei als erster die vitale Methylenblan-Methode angewandt, was ihm erlaubte sehr wichtige hodologische Resultate zu erringen. Die Arbeiten Retzius' gehören, wie bekannt, zu den schönsten auf diesem Gebiete.

Retzius (1891) beobachtete bei Aphrodite, wie RoHDE und andere Autoren, deutlich gesonderte, durch Konnektive verbundene Ganglien im Bauchstrang. Figur 29 stellt ein solches Ganglion schematisch, nur nicht so schematisch wie Fig 28, dar. Aus jedem Ganglion gehen drei periphere Nervenpare hervor. Die hinteren peripheren Nerven sind die kräftigsten (Fig. 29, h.p.n.), die mittleren und vorderen sind beide dünn, aber dabei sind die mittleren Nerven (Fig. 29, m.p.n.) nach Retzius noch am wenigsten entwickelt.

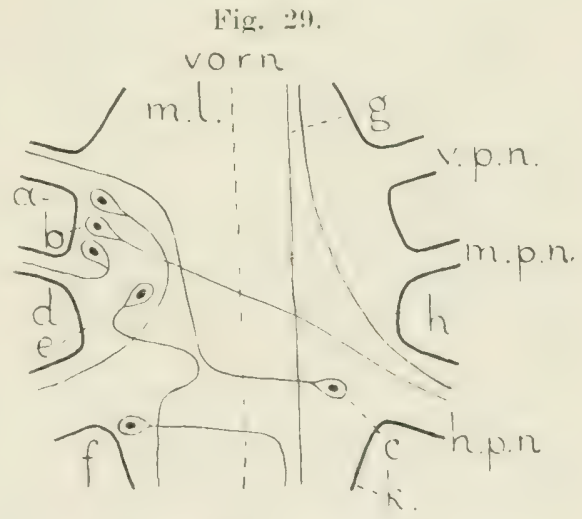

Ganglion des Bauchstranges von Aphrodite.

Nach Retzius (1891).

$a$ bis $f=$ Ganglienzellen

$g, h=$ Nervenfaser

h. p. $n .=$ hinterer peripherer Nerv

$k_{0}=$ Konnektiv

m. $l .=$ Medianlinie

$m . p_{0} n_{0}=$ mittlerer peripherer Nerv

$v . p . n$. $=$ vorderer peripherer Nerv 
Die Ganglienzellen zeigten sich unipolar. Einige (Fig. 29,a) senden ihren Fortsatz in den hinteren peripheren Nerven derselben Seite, andere in jenen der gegenüberliegenden Seite (Fig. 29, b). Den Fortsatz noch anderer Ganglienzellen (Fig. 29, c) sah Retzius die Medianlinie kreuzen und in den vorderen peripheren Nerven verschwinden. Auch solche Ganglienzellen (Fig. 29, d), welche ihren Fortsatz dem dünnen mittleren Nerven derselben Seite zuteilen, fehlten nicht.

Nicht immer treten die Ausläufer der Ganglienzellen in die peripheren Nerven ein. Bisweilen ziehen sie nach hinten und verstärken sie die Konnektive und zwar ohne dabei die Medianlinie zu überschreiten (Fig. 29, e), oder gerade nach dieser Verrichtung (Fig. 29, f).

Während das Ende aller dieser Nervenfasern unbekannt war, blieb auch die Herkunft zweier Nervenfaserarten im Dunkeln. Einige (Fig. 29, g) durchziehen das Ganglion in seiner ganzen Länge, andere, von vorne kommend, verlassen das Ganglion durch den hinteren Nerven (Fig. 2!), $h$ ). Retzius glaubt, daß nicht alle Ganglienzellen gepaart sind, wie es doch meistens im Zentralnervensystem der bilateral-symmetrischen Evertebraten der Fall ist.

Lepidonotus hat nach RETzius die Ganglienzellen nicht zu bestimmten Ganglien gruppiert aber wohl liegen die Ganglienzellen symmetrisch. Einige senden ihren Fortsatz in den nächstliegenden peripheren Nerven derselben Seite, andere in einen Nerven der anderen Seite, welcher damn aber nicht der nächste ist. Noch andere Ganglienzellfortsätze kreuzen die Medianlinie und zichen als longitudinale Nervenfasern nach vorn.

Der dicke Fortsatz einer vierten Zellart krewzt nach der anderen Seite und verläßt selbständig, nicht in einem peripheren Nerven, das Bauchmark. Diese Zelle erinnert also an die Neurochordzelle $H$ (Fig. 27), welche Ronde bei Sthenelais entdeckte, aber RETzIUs betrachtet sie nicht als Kolossalzelle.

Der mächtige Stammfortsatz einer fünften Ganglienzellart verzweigt sich dichotomisch. Beide Aeste ïberschreiten die Medianlinie, aber dann läuft der eine nach vorn, der andere nach hinten in die Länge des Bauchstranges.

Von den Sedentarien unter den Polychaeten untersuchte ReTzivs Arenicola und eine 'Terebellide. Arenicola zeigte Retzius unter allen Ganglienzellen nur zwei Typen. welche unsere Kenntnis der Leitungsbahnen fördem. Es waren Ganglienzellen mit aszendierenden Fortsätzen, welehe entweder die Hälfte des Bauchmarks, worin die Zelle lag, nicht verlielien, oder zur anderen Seite kreuzten.

Die Terebellide besa 3 an der Basis der peripheren Nerven cine (ianglienzelle, cleren Fortsatz die Medianlinie ïberschritt und nach vorn zog. Daneben einen (ianglienzelltypus mit in der entgegengesetzten Seite des Bauchmarks deszendierender Nervenfaser und weiter Ganglienzellen, deren Fortsatz in den peripheren Nerven derselben Seite austrat.

Nephthys hat RETzus wiederum eine reichere Ausbeute an Ganglienzellen mit wenigstens teilweise bekanntem Lauf ihrer Nervenfasem eingebracht. Die Ganglien des Bauchstranges sind scharf umschrieben und zwei Konnektive (Fig. 30,/.), welche nicht wie bei anderen oben beschriebenen Polychaeten mit einander verwachsen sind, sind zwischen den Ganglien ausgespannt. 
Alle Ganglienzellen sind unipolar und meistens bilden sie symmetrisch gelegene Paare. Zwei Paare haben die Gestalt, welche die Zelle $a$ der Figur 30 abbildet, das heißt, der Fortsatz dieser Ganglienzellen läuft nach Ueberschreitung der Medianlinie in das Konnektiv nach vorn. Bevor er kreuzt, hat er aber dem Neuropilem einige Kollateralen abgegeben. Das ist an und fuir sich nichts Besonderes, denn fast alle Ganglienzellen tragen, auch wenn ich es nicht melde, durch Abgabe von Seitenästchen ihrer Fortsätze zur Bildung des Neuropilems bei, aber die Zellen des Typus $a$ sind nur durch das Verhalten ihrer Kollateralen von Zellen des später zu erwähnenden Typus e zu unterscheiden und somit will ich das hier betonen.

Ein drittes Paar Ganglienzellen (Fig. 30, b) hat einen Stammfortsatz, welcher sich dichotomisch teilt. Der eine Ast geht in das Konnektiv derselben Seite nach hinten. der andere kreuzt die Medianlinie und läuft in das Konnektiv nach voln.

Der Stammfortsatz eines vierten Paares (Fig. $30, c)$ sucht erst die andere Hälfte des Ganglions und teilt sich dann in zwei nach hinten und nach vorn ziehende Aeste.

Der Stammfortsatz eines fünften Ganglienzellpaares (Fig. 30, d) tut dasselbe, ohne aber vorher die Medianlinie des Ganglions gekreuzt zu haben.

Das sechste Ganglienzellpaar (Fig. 30,e) weicht im Laufe des Neurits nicht ab von Zellen des Typus $a$, sondern in beiden Hälften des Ganglions spalten sich Kollateralen ab.

Noch andere Ganglienzellen (Fig. 30,f) senden nach Dichotomie ihres Stammfortsatzes einen

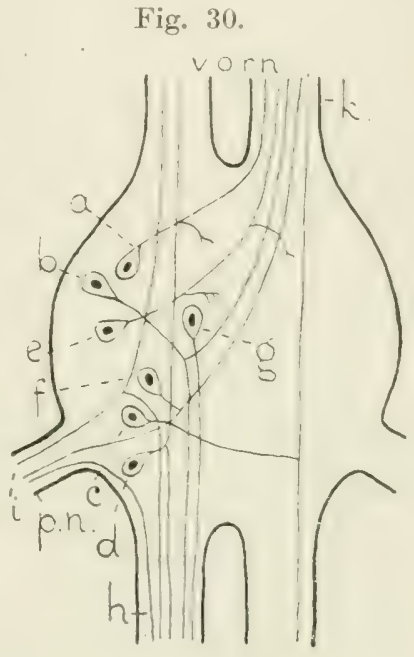

Bauchganglion von Nephthys. Nach Retzius (1891). $a$ bis $g=$ Ganglienzelle $h, i=$ Nervenfaser k. = Konnektiv $p_{0} n_{0}=$ peripherer Nerv Ast in den peripheren Nerven (Fig. 30, p.n.) und den anderen nach vorn in das Konnektiv der anderen Körperhälfte.

Eine Ganglienzelle, deren Gegenstïck Retzius verborgen blieb, ist die Zelle $g$ der Figur 30. Ihr Fortsatz geht in das Konnektiv derselben Seite nach hinten.

Die genannten Ganglienzellen sind alle groß. Sie werden von vielen kleinen Ganglienzellen begleitet, welche ebenso ihre Fortsätze nach vorn, nach hinten oder in die peripheren Nerven senden.

Retzius beobachtete weiter auch, wie Nervenfasern unbekannter Herkunft aus den Konnektiven in die peripheren Nerven abbogen (Fig. 30,h). Andere Nervenfasern unbekannter Herkunft traten mit dem peripheren Nerven ins Ganglion ein und verzweigten sich dort in einen nach vorn und einen nach hinten ziehenden Ast.

Schließlich sei noch erwähnt, daß Retzius bei Nephthys auch Kolossalfasern beobachten konnte, aber die Neurochordzellen und somit die Herkunft dieser Fasern sah er nicht. 
Nereis ist nicht nur im eben angeführten Artikel, sondern wiederholt von Retzus untersucht worden und dieser Gelehrte hat sich dabei nicht auf den Bauchstrang beschränkt, sondern auch andere 'Teile des Nervensystems hinzugezogen. Immer diente ihm das Methylenblau zur Färbung der Ganglienzellen und Nervenfasern. Das Himganglion wird S. 76 beschrieben.

Das untere Schlundganglion von Nereis enthält nach RETzius (1891) wenigstens vier Ganglienzelltypen. Die beiden ersten sind unipolar und ihr Fortsatz zieht nach vorn entweder in derselben Hälfte des Nervensystems bleibend oder nach Kreuzung der Medianlinie in der anderen Hälfte. Der dritte Typus ist ebenfalls unipolar, aber ihr Fortsatz überschreitet die Medianlinie und geht nach hinten. Median befindet sich eine große Ganglienzelle, deren Fortsatz in dem Mediannerven (richtiger Mediankonnektiv) deszendiert. Könnte diese nicht eine Neurochordzelle sein und ihr Fortsatz eine Faser des später auch von HAMAKER (1898) beobachteten Neurochords des Mediankonnektivs? Noch beobachtete Retzius in diesem Ganglion eine bipolare Ganglienzelle.

Nervenfasem aus den Schlundkonnektiven enden im unteren Schlundganglion, wobei ein Teil ihrer teste die Medianlinie iiberschreitet. Leider sind ihre Ganglienzellen unbekannt.

Die Bauchganglien stimmen in manchen Hinsichten mit dem unteren Schlundganglion ïberein. Alle Ganglienzellen sind unipolar und Retzus konnte keine Neurochordzellen dabei entdecken. Die meisten Ganglienzellfortsätze kreuzen die Medianlinie und bilden dabei in jedem Ganglion drei Kommissuren, eine vordere, eine mittlere und eine hintere. Haben sic die Kommissur passiert, so ziehen sie weiter in einen peripheren Nerven, und zwar sind es dann nach Retzius (1892b) motorische Nervenfasem, oder sie biegen frontal oder caudal ab in die Konnektive.

Es gibt aber auch Ganglienzellen mit Fortsätzen, welche nicht die Medianlinie kreuzen, sondern entweder sofort in einen peripheren Nerven austreten oder sich teilen in einen aszendierenden und einen deszendierenden Ast.

In den peripheren Nerven erwähnt Retzius (1891 und 1892b) Nervenfasern, welche im Bauchganglion angelangt sich T-förmig teilen und einen Ast nach vorn, den anderen nach hinten in die Konnektive senden. Retzius (1892b) betrachtet diese Fasern als sensibele Nervenfasern. Wenn aber wirklich, wie er sagt (1891), einer der beiden deste bisweilen mit einer Ganglienzelle verbunden war, so wäre in diesem Falle wohl dieser , Ast " der eigentliche Stammfortsatz und die austretende Nervenfaser nicht sensibel.

Die Sinnesnervenzellen des Epithels stehen nach ReTzius (1900) isoliert oder sie sind in Gruppen geordnet, welche man vielleicht Sinnesorgane nemnen darf. In den Paropodien vereinigen sich ihre Nervenfortsätze in Nerven, welche zum subepithelialen Nervenplexus gehen. Wahrseheinlich stellen diese Nervenfortsätze der Sinnesnervenzellen die oben genannten sensibelen Nervenfasern der peripheren Nerven des Bauchganglions dar.

Neben Retzius hat Biedermaxy (1891) fast zu gleicher Zeit das Bauchganglion einer Nereis-Art und zwar von Nereis pelagrica mit Hilfe der Methylenblau-Methode studiert. Er beschrieb in den Konnektiven Nervenfasern, 
welche jedem der zwei stärksten peripheren Nerven einen Ast übermitteln und solche, welche selbst sich in einen peripheren Nerven hineinkrümmten.

liig. 31

Wie Retzius sah er daneben viele Ganglienzellen, welche ihre Fortsätze mit oder ohne Kreuzung der Medianlinie in einen peripheren Nerven oder in das Konnektiv aussandten.

Die peripheren Nerven führen weiter nach ihm noch Fasern. welche sich im Ganglion verästeln und dort enden, oder aber nach einer 'T-förmigen Teilung in die Konnektive eintreton. In letzter Hinsicht stimmt er abermals mit Retzius iiberein.

Auch HaAAKER (1898) hat sich mit Nereis und zwar mit Nereis virens beschäftigt und manche Leitungsbahnen des Nervensystems, welche schon Retzius beobachtete, bestätigt und dessen Angaben erweitert. Er hat neben anderen Methoden auch die Methylenblau-Methode angewandt.

HAMAKER beschreibt ausfuihrlich die Ganglien und ihre peripheren Nerven in ihrer Lage und ihrem Lauf. Davon interessiert uns hier nur folgendes. Im Bauchstrang werden die Ganglien durch drei mit einander verwachsene Konnelitive, zwei große, laterale (Fig. 31, l.k.) und ein kleines medianes (Fig. 31, m.k.) verbunden. Sie sind ohne Ganglienzellen und enthalten deshal'o nur Nervenfasern und Neuroglia. In jedem Körpersegmente verlassen fünf Nervenpaare (Fig. 31, I- כ) den Bauchstrang. Da aber die Grenzen der Segmente nicht mit den Konnektiven, also den Grenzen der Bauchganglien in gleicher Höhe liegen, gehen zwar auch aus jedem Ganglion fünf periphere Nerven hervor, aber diese gehören zwei Körpersegmenten an. Figur 31, worin

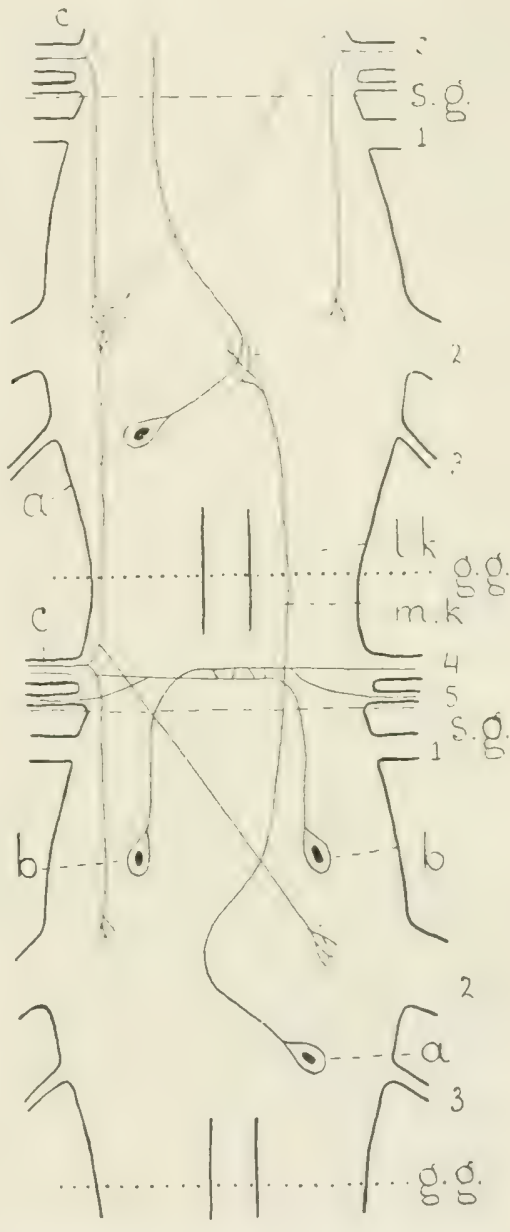

Zwei Ganglien des Bauchstranges von Nereis virens.

Nach Hamarer (1898), 'Taf. 4, Fig. :27.

\%. \%. $=$ (irenze des Ganglions

l. $k$. = laterales Konnektiv

$m . l_{\text {. }}=$ medianes Konnektiv

s. $\% .=$ Segmentalgrenze

1 bis 5 periphere Nerven

$a, b=$ Ganglienzelle

$c=$ Nervenfaser s.g. die Segmentalgrenze, g.g. die Grenze des Ganglions bedeutet, zeigt dies nach Gebühr.

In jeder der drei Konnektive zwischen den Bauchganglien befindet sich, wie auch Schineider (1902) mitteilt, ein Neurochord oder, wie man 
vielleicht besser sagt, ein Neurochordbündel. Ohne Zweifel stchen die Fortsätze mancher Neurochordzellen des unteren Schlundganglions mit dem medianen Neurochorde in Verbindung, aber Haraker selber konnte nicht entscheiden, ob die Fortsätze zu einem einzigen zusammenflössen oder nur dicht neben einander weiter zögen und deshalb ein Neurochordbündel bildeten. Die Neurochordzellen der lateralen Neurochorde sind nicht bekannt. Alle Neurochorde ziehen unverändert bis ins letzte Segment des Körpers; nur werden sie dann und wann von Nervenfasern oder Nervenfaserbiindeln durch. bohrt.

Das Neuropilem der Bauchganglien ist nur ventral und lateral mit Ganglienzellen belegt. HAMAKER schildert die folgenden Leitungsbahnen im Bauchstrang.

Ventral in jedem Bauchganglion trifft man auf der Höhe der Abgangsstelle des dritten segmentalen Nerven ein Paar Ganglienzellen a. (In der Figur 31 ist oben nur eine Zelle $a$ links, unten eine Zelle $a$ rechts gezeichnet). Der Fortsatz dieser Ganglienzelle (Fig. 31, a, rechts), eine starke Nervenfaser, überschreitet die Medianlinie des Bauchmarks anf der Höhe des zweiten peripheren Nerven, kehrt aber gleich in die vorige Hälfte des Bauchmarks zurïck und läuft nun im lateralen Konnektiv weiter nach vorn durch ein oder zwei Segmente um verzweigt zu enden, gerade in der Nähe der Kreuzungsstelle einer Nervenfaser derselben Art (Fig: 31 vorderes Ganglion). Man begegnet diesen Leitungsbahnen in allen Segmenten, mit Ausnahme der zwanzig ersten hinter dem Kopfe, wo sie undeutlich und klein sind.

Halbwegs zwischen den Abgangsstellen des ersten und zweiten Nerven entdeckte HAMAKER in jedem Ganglion ventral ein Paar Ganglienzellen (Fig. 31, b,b), welche ihren Fortsatz frontal senden. Auf der Höhe des vierten segmentalen Nerven angelangt, kreuzt er die Medianlinie und spaltet sich dann in zwei Aeste, welche in die vierten und fünften Nerven austreten. Wo die Fasern von links und rechts die Medianlinie kreuzen, anastomosieren sie nach HAMAKER mittels Seitenästchen. Die Faser $b$ berihrt an einer Stelle die Faser $a$ und ist dort sogar in eine Rinne der Faser $a$ gefasst. Ein wenig weiter, nach ihrer Dichotomie, durchbohrt Faser $b$ den lateralen Neurochord. Wahrscheinlich gehören diese Nervenfasern zu denjenigen, welche REтzius beobachtete (S. 72, Alinea 4).

Eine dritte Nervenfaser in jedem Bauchganglion betrachtet HAMAKER wohl ganz richtig als zentripetal, weil ihre Ganglienzelle nicht im Zentralnervensysteme auffindbar war. Die Faser (Fig. 31, c,c,c) tritt mit dem vierten segmentalen Nerven ins Ganglion ein und spaltet sich sofort in einen aszendierenden und einen deszendiarenden Zweig, wie auch RETzIUs und BIEDERMAN solches an einigen eintretenden Nervenfasern beobachten lionnten.

Der nach hinten ziehende Ast endet rerzweigt im nächsten Segmente auf der Höhe des zweiten Nerven (Fig. 31 links). Der aszendierende Ast hat seine Endverästelungen neben dem zweiten Nerven desselben Segmentes (Fig. 31 links). Nahe bei seinem Anfang spaltet er cinen Seitenzweig ab weleher schräg nach hinten läuft, die Medianlinie ïberschreitet und ebenfalls auf der Höhe des \%weiten Nerven endet (Fig. 31 hinteres Ganglion). Es enden 
also in jedem Ganglion des Báchstranges zu beiden Seiten auf der Höhe des zweiten Nerven drei verschiedene Seitenäste des Nervenfasertypus $c$ und zwar dreier verschiedene Nervenfasern (Fig. 31 vorderes Ganglion). Nach HAMAKER anastomosieren die terminalen Aestchen dieser drei Nervenfasem. Ich weise darauf hin, daß eine Wechselwirkung dreier Neuronen anch bei Homarus besteht (S. 246 und Figur 83).

Der zweite segmentale Nerv schreitet zum Parapodium und bildet in dessen Basis ein Ganglion, das Parapodialganglion (Fig. 32, par.g.). Dieses ist der Ort, wo die vier Parapodialnerven (Fig. 32, I-IV), welche weiter zur Peripherie ziehen, entspringen. Im zweiten Segmentalnerven (Fig. 32, 2) fand Hamaker vier verschiedene Nevenfaserarten. Einige biegen in den ersten oder vierten Parapodialnerven ab, andere enden im Parapodialganglion und noch andere spalten sich dort in zwei Aeste, welche sich in den zweiten und dritten ParapodiaInerven fortsetzen. Fig. 32 zeigt dieses schematisch. Der zweite und dritte Parapodialnerv enthält nach HAmsKER neben motorischen Nervenfasern zu den Muskeln der Bürsten auch sensibele Nervenfasern. Diese letzten sind entweder die Nervenfortsätze bipolarer Sinnesnervenzellen, mit ihren Zellkörpern unter der Hypodermis und mit ihren Sinnesfortsätzen darin, oder die Nervenfortsätze bipolarer, sensibeler Ganglienzellen, welche ihren zweiten Fortsatz zur Umgebung der Bürsten senden, wo er sich verästelt und, wie ich aus der Haunkerschen Abbildung schließe, frei endet. Leider teilt uns HarakER nicht mit, ob die gegabelten Nervenfasern des zweiten und dritten Parapodialnerven (Fig. 32) motorische oder sensibele Fasern seien. Die

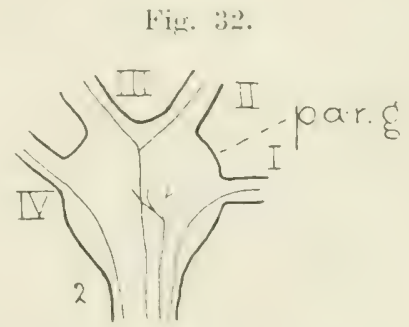

Parapodialganglion von Nereis virens. Abgeändert

nach HAMAKER (1898) Taf. 1, Fig. 8 .

par. $\dot{g} .=$ ganglion parapodiale

$2=$ zweiter cegmentalnerv des Bauchgang. lions.

$I-I V=$ nervi parapodiales Weise der Verästelung spricht dafür, daß es motorische Fasern sind.

Ueber die Reizleitungsbahnen der Polychaeten liegt uns zuletzt noch eine Arbeit Hesses (1899) vor. Hesse beschreibt darin die Augen. Bei den meisten Raubanneliden, sagt er, ist der nervus opticus aus Fortsätzen der Sehzellen (ihrer Natur nach Sinnesnervenzellen) zusammengestellt, welche unmittelbar zum Hirnganglion gehen. Nicht also bei Nereis cultrifera. In den vorderen Augen dieses Tieres liegen viele unipolare Ganglienzellen, welche das ganglion opticum bilden, unter der Retina und ihre lortsätze ziehen ins Gehirn. Wie aber die Verbindung der Sehzellen der Retina mit diesen Ganglienzellen ist, ist nie beobachtet worden.

Bei Hesione sicula erstreckt sich das ganglion opticum vom Auge bis zum Hirnganglion und clamit fällt ein eigentlicher nervus opticus weg. Lysidica viriclis, der PaloloWurm, hat segmental gestellte Bauchaugen. Jede ihrer Sehzellen sendet einen Fortsatz ins Bauchmark hinein.

Die Alciopiden besitzen oft ein ganglion opticum. Bei Vanadis formosa besteht es aus unipolaren Ganglienzellen, aber diese senden ihre Fortsätze nicht zum Gehirn, sondern zur Retina. Wahrscheinlich begegnen diese Fortsätze den Nervenfortsätzen der Sehzellen in einem Faserfilz zwischen Retina und ganglion opticum. Ein langer Nerv 
verbindet hier das ganglion opticum mit dem Gehirn, aber es ist nicht bekannt aus welchen Zellen seine Fasern hervorgehen. Alciopa cantrainii und Asterope candicla entbehren ein optisches Ganglion. Hier ziehen die Fortsätze der Sehzellen ummittelbar ins obere Schlundganglion. Hesse ist dabei im Einklang mit GreEfF (1877).

Die Eunicide Ophrystroche puerilis hat zwei Becheraugen, jedes mit Sehzelle, deren Fortsatz zum Gehirn läuft.

Die Sehzellfortsätze der beiclen Augen von Ranzania schreiten in der Richtung des Schlundringes und wahrscheinlich treten sie darin ein.

Fig. 33

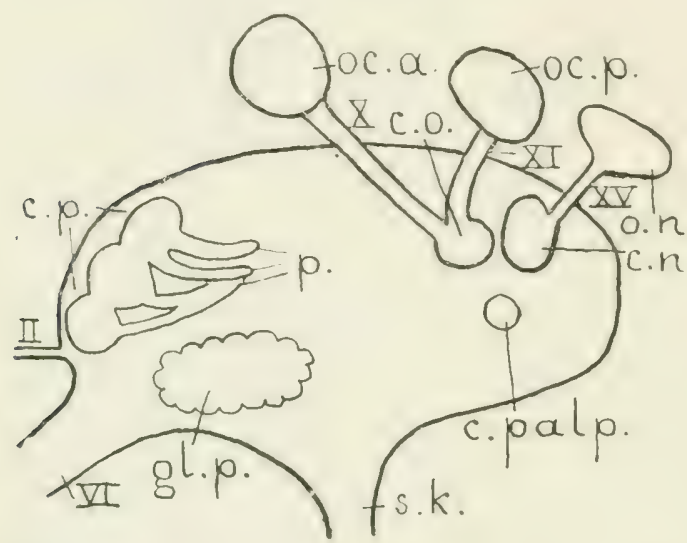

Schema des Ciehims von Nereis von der Seite gesehen. Abgeändert

nach Howarirex (1916) Textfig. 5.

c.n. $=$ commissura nuchalis

c. o. $=$ commissura optica

c. $p .=$ corpus pedunculatum

c. palp. $=$ commissura palpalis

gl. $p .=$ glomeruli palpales

$o . n$. = organon nuchale

oc. $a$. $=$ oculus anterior

oc. p. $=$ oculus posterior

p. = peduneulus

s. k. = Schlundkonnektiv

$I I, Y I, \mathrm{X}, \mathrm{X} I, \mathrm{XV}=$ Nerven
Mit Ausnahme der Angaben ïber das Hirnganglion von Nereis ist das obige alles, was ich über die Polychaeten zu bemerken habe. Es ist ganz merkwiirdig, dals in einer wichtigen Tiergruppe, wie die Polychaeten, die meisten Mitteilungen über die Leitungsbahnen neben einander stehen und sich nicht beriihren, weil entweder das untersuchte 'T'ier' oder die untersuchte Bahn oder beide nicht dieselben waren. Bestätigungen, sowie Verneinungen früherer Angaben werden sehr selten gegeben und daraus erhellt, dal3 auf diesem Gebiete noch viel zu wenig gearbeitet worden ist $u m$ einigermaßen ein iibersichtliches Bild der Leitungsbahnen im Nervensysteme entwerfen zu kïnnen. Nur für das Hirngang-

lion von Nereis werde ich dieses jetzt versuchen.

Daß ich solches tun kamn, ist ausschließlich einer Arbeit Nus Hor.ugrexs (19)16) zu verdanken, in welcher das Hirnganglion von Nereis diversicolor an nicht weniger als 400 Exemplaren auf verschiedene Weisen grïndlich studiert und dessen Bau mit den Angaben anderer Autoren verglichen worden ist. Nach Howngres gehen nicht weniger als 16 Nervenpare aus dem Hirnganglion hervor (vergl. Fig. 33 und 35). "Lwei entspringen dem vorderen Rande (Fig. 35, I und 1I, lig. 333 II) und es befindet sich darunter der von Retzits (1895 b) entdeckte nerrus antemnarius (II). welcher die Antenne (Fig. 35, ant.) innerviert. Sieben Nerven (Fig. 35, III bis IX) verlassen das Gehirn an der vorderen Ecke und gehen meistens zu den Palpen (Fig. $35 p,$.$) . Dannf olgen die beiden Augennerven (Fig. 33, X und XI) zum ror-$ 
deren und hinteren Auge (Fig. 33 und 35, oc. a. und oc. p.). Seitwärts oder nach hinten ziehen fünf Nervenpaare, von denen Fig. 35 den zwölften und dreizehnten zeigt und Fig. 33 den fünfzehnten oder den Nuchalnerven zum Nuchalorgan (o. n.).

Außerdem verlassen das Gehirn die drei Wurzeln des Schlundkonnektivs (Fig. 33 und 35 s.k.), welche sich im Konnektivalganglion vereinigen, bevor sie das Unterschlundganglion erreichen. Zwei dieser Wurzeln sind dorsal, eine ist ventral.

Diese Mitteilungen Holmarexs stimmen noch am meisten mit denjenigen Hayakers (1898) überein, welcher bei Nereis virens 12 Hirnnervenpaare erkannte, während Retzius (1895 b) und HALLER (1889) es nicht so weit brachten. Keiner von ihnen hat die drei Wurzeln des Schlundkonnektivs entdeckt, wohl zwei derselben welche HALLER (1889) das obere und untere Schlundkonnektiv nennt (Fig. 34, o.s.k. und u.s.k.) und welche er, ebenso wie Haxaker (1898), im Kommissuralganglion (besser Konnektivalganglion) zusammenkommen sieht.

Im Inneren des Hirnganglions von Nereis hat schon HaLler (1889) die corpora pedunculata (Fig. 34, c.p.) entdeckt, welche von anderen Autoren unter anderen Namen (Pilzkörper oder globuli) schon bei anderen Polychäten beschrieben worden waren. Es sind dies Ganglienzellanhäufungen, welche im allgemeinen die Form einer an einer Stelle geöffneten Hohlkugel (der Pilzhut) haben. Durch die Oeffnung der Hohlkugel treten die zugehörigen Nervenfasern und bilden so den Stiel des Pilzkörpers oder den pedunculus (Fig. 34, p.). Wir werden den corpora pedunculata auch im Hirn mancher Arthropoden begegnen, wo sie eine höhere Ausbildung als bei den Würmern erlangen. Rohde (1890) bestreitet bei den Aphroditeen die Hallersche Ansicht, daß die Pilzkörper aus Ganglienzellen beständen und behauptet, daß sie aus „Nervenkernen", welche Fortsätze entsendeten, zusammengesetzt seien, aber darin möchte ich doch HALLER beipflichten.

HALler selbst nannte die corpora pedunculata Tentakelganglien, weil er meinte, daß sie besonders mit den Tentakeln oder Antennen in Verbindung ständen, aber Retzius (1895 b) und besonders N. Holıigrex (1916) haben die Unrichtigkeit dieser Meinung betont. N. HoLAGREx, welcher die Gebilde globuli nennt, homologisiert sie mit den corpora pedunculata der Insekten, was HALLER selbstverständlich nicht tun konnte. N. HoLMGREN hat auch als erster die Dreiteilung des Körpers dargetan (Fig. 33, c.p.) und gezeigt, daß die Fortsätze der kleinen, stark chromatischen Ganglienzellen eines corpus pedunculatum sich zu vier Bündeln, welche die Sticle oder pedunculi (Fig. 33 und 34,p.) genannt werden, zusammenlegen. Der hintere der drei Teile des corpus pedunculatum hat 2 Stiele, die beiden vorderen je einen, welche sich aber bald vereinigen (Fig. 33, p.). Die Stiele der corpora pedunculata gehen nach hinten und nach rechteckiger Umbiegung medialwärts und enden, ehe sie noch die Medianlinie des Gehirns erreicht haben.

Die Nervenfasern bilden im Inneren des Hirnganglions wenigstens sechs Kommissuren. Zwei Kommissuren, eine obere und eine untere (Fig. 34, o.k. und $u . k$.) konnte schon HaLLER (1889) unterscheiden neben einer Kommis- 
sur der corpora pedunculata. N. HoLmgrex (1916) kennt zuerst eine Kommissur, welche hauptsächlich aus Fasern des ersten Hirnnerven besteht. Die zweite liegt etwas hinter der ersten. Die dritte ist die große Palpenkommissur (Fig. 33, c. palp.), die vierte gehört zu den Schlundkonnektiven. Die fünfte ist die optische Kommissur der Augennervenfasern (Fig. 33, c.o.). Die sechste Kommissur oder die Nuchalkommissur (Fig. 33, c.n.) hat nach HoumGREx mitunter den Charakter eines Assoziationszentrums, weil Fasern aus anderen Hirnteilen hineindringen. Die Kommissur der beiden corpora pedunculata wird von HoLMGREx nicht erwähnt.

Während Retzius (1895 b) drei und HAMakeR (1898) sechs Ganglienzellgruppen zu beiden Seiten im Hirnganglion unterschied; ist HoLMGREN

Fig. 34 .

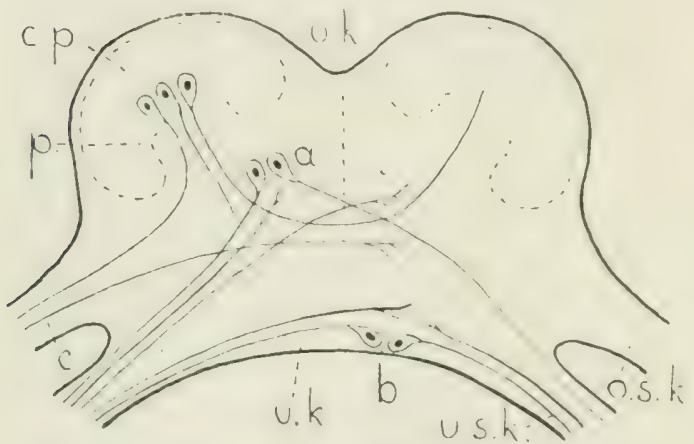

Schnitt durch das Hirnganglion von Nereis.

Abgeändert nach HALLER (1889).

$a, b=$ Ganglionzelle

$\therefore=$ Nervenfaser

c. $p .=$ corpus pedunculatum

o. $k_{0}=$ obere Kommissur

o.s. k. $=$ oberes Schlundkonnektiv

p. $=$ pedunculus

u. k. = untere Kommissur

u.s. $k_{0}=$ unteres Schlundkonnekt iv

(1916) im Stande die Ganglienzellen außerhalb der corpora pedunculata in nicht weniger als 23 Gruppen zu zerlegen. Ich möchte ihre Beschreibung hier nicht wiederholen.

Ueber die Wege der Nervenfasern sei Folgendes mitgeteilt. HaLler (1889) beschreibt im corpus pedunculatum des Gehirns von Nereis drei Ganglienzellarten (Fig. 34). Alle drei senden Fortsätze in die Stiele aus, aber bisweilen schreiten diese ins Neuropilem des Hirnganglions, bisweilen in das obere Schlundkonnektiv, bisweilen auch in eine Kommissur zum corpus peduneulatum der anderen Seite.

HoLMGREx (1916) hingegen bemerkt iiber die Stammfort-

sätze der unipolaren Ganglienzellen der corpora pedunculata, daß sie in die Stiele ziehen und sich dort wiederholt verästeln oder Zweige zu den Palpenglomeruli senden (Fig. 33, gl. p.) Faserknäuel, welche aus Fasern der Palpennerven zusammengesetzt in der Nähe der pedunculi gefunden werden.

Dorsal von der oberen Kommissur fand HaLLer (1889) einige Ganglienzellen (Fig. 3t, a), welche einen Fortsatz entweder in das untere Schlundkonnektiv derselben Seite oder nach Kreuzung der Hedianlinie in der oberen Kommissur in das untere Schlundkonnektiv der anderen Körperseite senden. Andere Fasern des unteren Schlundlionnektivs gesellen sich den ebengenamnten Nervenfasem zu und enden im Neuropilem des Hirnganglions vor oder nach Kreuzung der Medianlinie (sehe Fig. 34).

Die untere Kommissur wird ron einem ebensolehen System ron Nerven- 
fasern gebildet wie die obere, aber die zugehörigen Ganglienzellen sind unten im Hirnganglion gelegen (Fig. 34, b).

Das obere Schlundkonnektiv enthält neben den Fasern des corpus pedunculatum noch Nervenfasern, welche aus dem Neuropilem der entgegengesetzten Hirnganglionhälfte stammen (Fig. 34, c). Von diesen Nervenfasern sind nur die im Hirnganglion endigenden Fasern der Schlundkonnektive mit den von Holugrex entdeckten Fasern $q$ der Fig. 35 zu identifizieren.

Fig. 35.

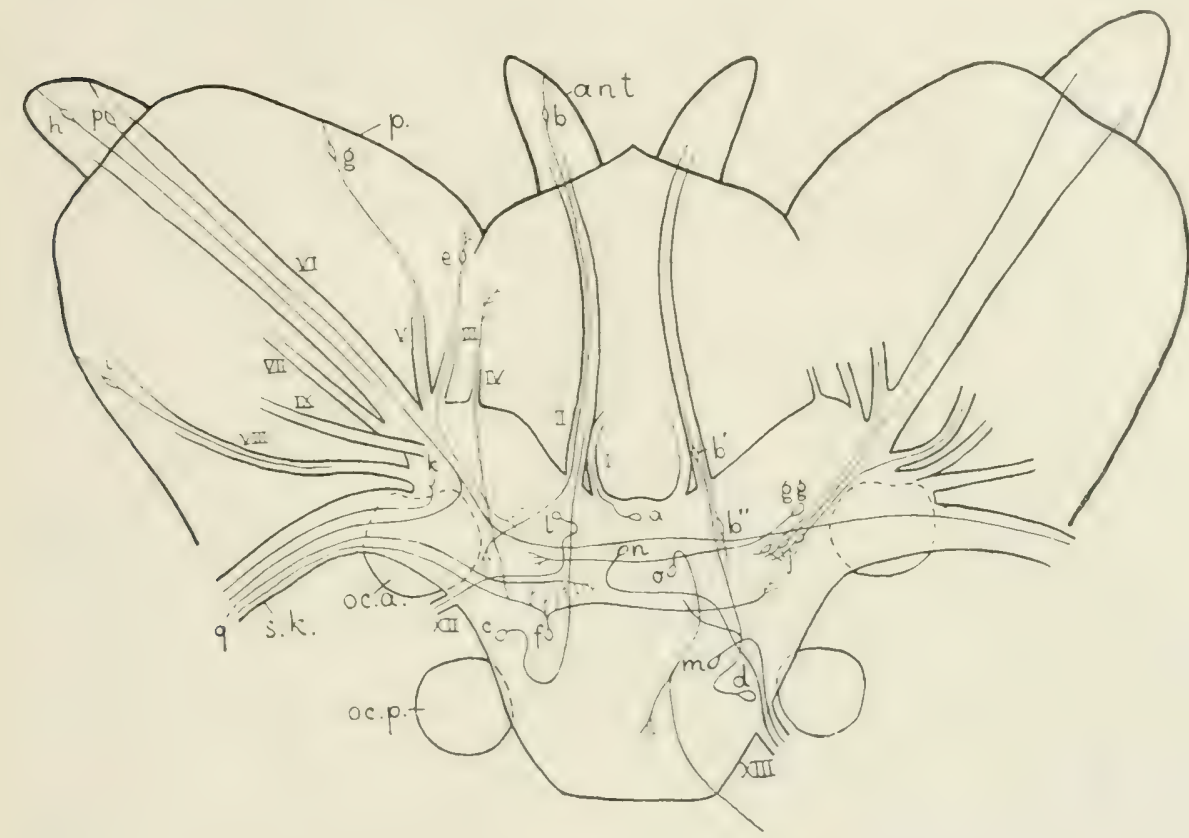

Gehirn und Umgebung von Nereis diversicolor.

Abgeändert nach N. Holimaren (1916) 'Taf. 4.

ant. = Antenne.

oc. $a .=$ oculus anterior.

$o c . p .=$ oculus posterior.

p. = Palpe. s. $k_{0}=$ Schlundkonnektiv.

$$
\begin{aligned}
I-I X, X I I, X I I I & =\text { Hirnnerven. } \\
a-p, b, b ", g g & =\text { Neuronen. } \\
q & =\text { Nervenfaser. }
\end{aligned}
$$

HolMgrex (1916) erwähnt in erste Linie bestimmte Nervenfasern der Hirnnerven. So fand er im ersten Nerven neben weniger gut bekannten zentripetalen Fasern, welche in die erste Kommissur fortschreiten, Fortsaitze unipolarer Ganglienzellen (Fig. 35, a), welche mediodorsal vorn im Gehim gelegen sind.

Schon Retzius (1895 b) hatte in den Antennen Sinnesnervenzellen entdeckt, welche ihre Nervenfortsätze in den nervus antennarius und weiter ins Neuropilem des Hirnganglions senden. HoLmarex sah sie auch, nur komnte er genauer ihr Ende in der Nähe des vorderen Auges wahmehmen (Fig. 35, b) oder beobachten, wie ihre Fasern eine schwache ventrale Kommissur bildeten. Weniger gut bekannte bipolare Zellen des Antennalnerven befinden sich in 
der Nervenbasis (Fig. 35, $b^{\prime}$ ) oder sogar im Hirnganglion (b") Der zweite

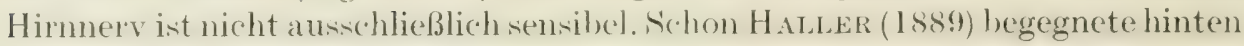
im Hirnganglion einer Ganglienzellgruppe, aus der ein nach vorne laufendes Nervenfaserbündel, welches sich in einen Nerven zum 'Tentakelepithel fortsetzte, zum Vorschein trat. Und auch HoLmGREx (1916) fand zwei unipolare Ganglienzelltypen (Fig. 35, c und $d$ ), welche ihre Fortsätze in den Tentakelnerven sandten.

Die bipolaren Zellen, welche mit ihren zentralen Fortsätzen zum Bau des dritten Hirnnerven beitragen (Fig. 35,e) sind wahrscheinlich keine Sinnesnervenzellen, sondern sensibele Ganglienzellen, weil ihr peripherer Fortsatz sich ziemlich reichlich verzweigt. Ihre Nervenfortsätze enden etwas vor dem hinteren Auge.

Der vierte Hirnnerv ist klein und motorisch. Ganglienzellen des 'Typus $f$ (Fig. 35) senden diesem Nerven einen Fortsatz zu. Es gibt im Ganzen nur ein Paar dieser Ganglienzellen. Sie sind unipolar. Ihr Stammfortsatz teilt sich in einen lateralen, einen medianen und einige kleine, nach vorn gerichtete Aeste. Der laterale Ast teilt sich in eine Faser des Schlundkonnektivs und eine Faser des vierten Hirnnerven. Der mediane Ast kreuzt die Medianlinie und endet verzweigt bei den nach vorn gerichteten Fortsätzen des gleichartigen Neurons der anderen Seite.

Die Nerven V bis VIII sind Palpennerven. Sie gehen frontolateral aus dem Hirnganglion hervor und Retzius (1895 b) hat schon darüber bemerkt, daß diese Nerven einerseits Nervenfortsätze von Sinnesnervenzellen führen, anderseits Fortsätze von Ganglienzellen des Gehirns, welche Muskeln der Palpen innervieren. Die Untersuchungen Howmgrexs haben das bestätigt. Er fand sowohl in der ausstülpbaren Spitze der Palpe (Fig. 35, $h$ ), wie in den übrigen Teilen (Fig. 35, $g$ und i) Sinnesnervenzellen, welche ihre Nervenfortsätze in den fünften, sechsten oder achten Nerven sandten. Diese Nervenfasern endeten an verschiedenen Stellen. Finige Simnesnervenzellen der Palpenspitze (Fig. 35, p) senden ihren Nervenfortsatz mit dem sechsten oder großen Palpennerven ins Gehirn. Bei der ersten dorsalen Wurzel des Schlundkonnektivs angelangt teilt dieser sich in einen Ast, welcher in diese Wurzel iibergeht und einen Ast, welcher kreuzt und in die ventrale Wurzel des Schlundkonnektivs der anderen Seite zieht. Andere Simesnervenzellen der Palpe tun dasselbe, nur daß die zweite dorsale $W$ urzel des Schlundkonnektivs an die Stelle der ersten tritt. Dorsal hinter den corpora pedunculatia entdeckt Howagrex bipolare Ganglienzellen (Fig. 35, j), welche einen Fortsat\% in den fünften, sechsten oder siebenten Nerven schickten und deren anderer Fortsat\% in der Nähe von Fasern des dritten Nerven enden kann. HOLMGREx betrachtet diese Zellen als motorisch.

Der neunte Hirnnerv ist wahrscheinlich nur sensibel. Seine Fasern können in der ersten Kommissur enden.

Der zehnte und elfte Hirnnery sind die Augennerven. Ueber die Augennerven bemerkt Haller (1857), daß die Nerven des hinteren Augenpaares von Lepidasthenia und Nereis aus zwei Arten von Nervenfasern zusammengestellt sind, solchen, welche peripher gelegen sind und aus Ganglienzellen 
des Hirnganglions entspringen und zentralen, welche im Neuropilem des Hirnganglion enden. Im Auge selbst sind nach HatLer (1889) keine Ganglienzellen. Wahrscheinlicher klingt was HoLMGREN (1916) sagt, z.w., daß in der Retina des Auges Sinnęsnervenzellen liegen, deren Nervenfortsätze ins Gehirn eindringen. Fasern der beiden Augennerven bilden die commissura optica.

Der zwölfte, dreizehnte und vierzehnte Hirnnerv gehen in einen Nervenplexus über, welcher neben dem Hirn im Kopfe liegt. Ventral vorn im Hirnganglion befindet sich eine unipolare Ganglienzelle (Fig. 35, l) mit einem Fortsatz, welcher hinter dem vorderen Auge entlang in den zwölften Nerven und nachher in den Plexus schreitet. Der dreizehnte Nerv geht hinter dem hinteren Auge aus dem Gehirn hervor. Einige seiner Fasern überschreiten in einer hinteren Kommissur (Nuchalkommissur ?) die Medianlinie. Andere gehören zu unipolaren Ganglienzellen (Fig. 35, $m$ und $n$ ), welche in derselben oder der entgegengesetzten Hirnhälfte gelegen sind.

Median hinten im Gehirn sind nach HoLmGRex bipolare Ganglienzellen mit peripheren Fortsätzen zum Plexus hinter dem Hirnganglion. In denselben Plexus tritt das Neurit einer unipolaren Ganglienzelle (Fig. 35, o) mit Dendriten, welche sich median hinten im Hirn verzweigen.

Der fünfzehnte Nerv oder der Nuchalnerv war Retzius (1895 b) bekannt. Hinten am Hirnganglion, nahezu im Gehirne selbst, entdeckte er eine gepaarte Gruppe bipolarer Ganglienzellen. Thre zentralen Fortsätze versinken ins Neuropilem des Hirnganglions ; die peripheren aber bilden einen Nerven, welcher hinter dem hinteren Augenpaar herum zu einem peripheren Nervenplexus, aber auch zu einem besonderen Sinnesorgan der Epidermis. dem Nuchalorgan läuft. Die dortigen Sinneszellen werden von den Fasern des Nerven innerviert, aber sie gehen angeblich nicht selbst basal in Nervenfortsätze über, sind also keine Sinnesnervenzellen, sondern wahre Sinneszellen. Wenn Rerzius darin Recht hat, würden wir hier zum ersten Male bei einem Evertebraten sensibelen Ganglienzellen (die bipolaren Ganglienzellen) begegnen, welche nicht wie anderswo freie Nervenendigungen besitzen, sondern wahre Sinneszellen innervieren. Diese sind (vergl. meine Erweiterung der HerTwigschen Hypothese, S. 12) die letzte Stufe der phylogenetischen Entwicklung des sensibelen Nervensystems, weil sie bei den Vertebraten oft, bei den Evertebraten nur regelmäßig bei den Arthropoden beobachtet 'werden. Bei den Würmern würden sie nur in diesem Ausnahmefalle da sein. Das ist sehr befremdend und bei diesem Sachverhalt ist auch einem so vorzüglichen Forscher wie Rerzus gegenüber Zweifel gerechtfertigt.

In diesem Zweifel werde ich bestärkt durch HoLjGREx (1916), welcher sagt, daß der Nuchalnerv aus den peripheren Fortsätzen bipolarer in den hinteren Ecken des Hirnganglions befindlicher Zellen besteht, , welche wohl als in das Gehirn hineingerückte Sinneszellen des Nuchalorgans aufgefaßt werden können" und dann natürlich Sinnesnervenzellen sein würden. Immerhin bleibt es nötig die Sache aufs neue zu untersuchen. Die zentralen Fortsätze der bipolaren Zellen ziehen nach HoLAGREx recht weit nach vorn in das Gehirn. Manche Fasern des Nuchalnerven laufen in die hintere Kommissur, welche somit zur Nuchalkommissur wird. 
Ueber den sechszehnten Hirnnerven bemerkte schon HaMAKER (1898), daß seine Fasern zur dorsalen Oberfläche des Kopfes ziehen und aus Ganglienzellen einer hinten im Hirnganglion gelagerten Gruppe hervorgehen. Nach Houmgrex gleicht der sechszehnte Nerv dem Nuchalnerven in seinen Elementen, aber er geht zum Hinterrande der Kopflappen.

Ueber die Elemente der Hirnmerven ist nichts mehr bekannt, wohl aber über die Fasern der Schlundkonnektive. RETzius (1895 b) beobachtete vorn und lateral im Hirnganglion Ganglienzellen mit Fortsätzen, welche in das obere oder das untere Schlundkonnektiv der gleichen oder der entgegengesetzten Seite übergingen. HAMAKeR (1898) teilt uns über Nereis virens mit, daß unter dem vorderen der beiden Augennerven, seitlich neben dem Gehirn, eine Ganglienzellgruppe sichtbar sei, welchè mit dem ganglion opticum unter dem vorderen Auge zusammenhänge, und deren Zellen dem Schlundkonnektive Fortsätze mitgäben, welche ins Konnektivalganglion eindrängen. Daneben bemerkt er, daß die Neurochorde des Bauchstranges sich in den Schlundkonnektiven in Fasern auflösen, welche anscheinend durch das Konnektivalganglion zum ganglion opticum gingen. Außerdem stellen nach ihm fortsätze von Ganglienzellen des ganglion opticum eine Verbindung dieses Ganglions mit dem Konnektivalganglion her, ohne in Neurochordfasern verfolgbar'zu sein.

Letztgenannte Ganglienzellen sind wahrscheinlich auch von HoLMGREx (1916) bei Nereis diversicolor gefunden worden. Neben dem vorderen Auge befindet sich eine Gruppe von unipolaren Ganglienzellen, welche ihre firtsätze entweder in das dorsale Schlundkonnektiv (Fig. 35, $k$ ) oder in den neben dem Him gelegenen Nervenplexus senden. Diese Ganglienzellgruppe wird von HAMAker das ganglion opticum genannt, aber, wie HoLMGREN richtig bemerkt, mit Unrecht, weil die damit verbundenen Nervenfasern nicht zu den Augen gehen. Der Name ganglion opticum muß daher fallen.

Howmarex (1916) konnte manche andere Nervenfasern der Schlundkonnelitive unterscheiden. Zuerst solche unbekannter Herkunft (Fig. 35, q), welche mit der zweiten dorsalen oder mit der ventralen Wurzel ins Gehirn eintreten und sich dort zentral, besonder's in der Nähe der Ganglienzelle $f$, verzweigen oder auch nach Uebersehreitung der Medianlinie enden.

Vorn im Hirnganglion sind verschiedene unipolare Ganglienzellen, welche einer der Wurzeln der Schlundkonnektive einen Fortsatz zuteilen. Erstens der Typus $r$ der Fig. 36 mit Dendrit zur anderen Seite und Neurit im Schlundkonnektiv derselben Seite. 'Wweitens der 'Typus $s$ (Fig. 36) mit stark gesehlängeltem Neurit im Schlundkonnektiv derselben Seite. Dann der 'Typus $\ell$ (Fig. 36) mit seinem Neurit im Schlundkonnektiv derselben Seite und liurzen lateralwärts gerichteten Dendriten. Die Zelle u (Fig. 36) war nach HowyGREN wahrscheinlich auch RETzus bekannt. Der Stammfortsat\% sendet einen Zweig in die zweite Kommissur und einen anderen in das Schlundkonnektiv derselben Seite. Der Typus v (Fig. 36) besteht in zwei Modifikazionen, uniund bipolar. Einer der beiden Fortsätze oder Zweige des stammfortsatzes geht in die erste Kommissur, der andere in die zweite Kommissur und geht nachher wahrscheinlich ins Schlundkonnelitiv der andere Seite ïher. Die \%elle $u$ : 
(Fig. 36) hat eine andere Stellung als $s$ und ihr Neurit windet sich in anderer Weise, stimmt aber übrigens mit $s$ überein. Typus $x$ (Fig. 36) überliefert ebenso wie $v$ dem Schlundkonnektiv der anderen Seite einen Fortsatz.

Vier andere Neuronen, welche mit dem Schlundkonnektiv in Verbindung stehen, liegen lateral im Hirnganglion beim vorderen Auge. Die Zelle y (Fig. 36) hat einen T-förmig verzweigten Stammfortsatz mit einem Zweige im Schlundkonnektiv. Der Typus $z$ (Fig. 36) hat einen Fortsatz, welcher die Medianlinie ïberschreitet und wieder zurïckkehrt und in das Schlundkonnektiv der gleichen Seite verschwindet. Die Ganglienzelle aa (Fig. 36) sendet

Fig. 36 .

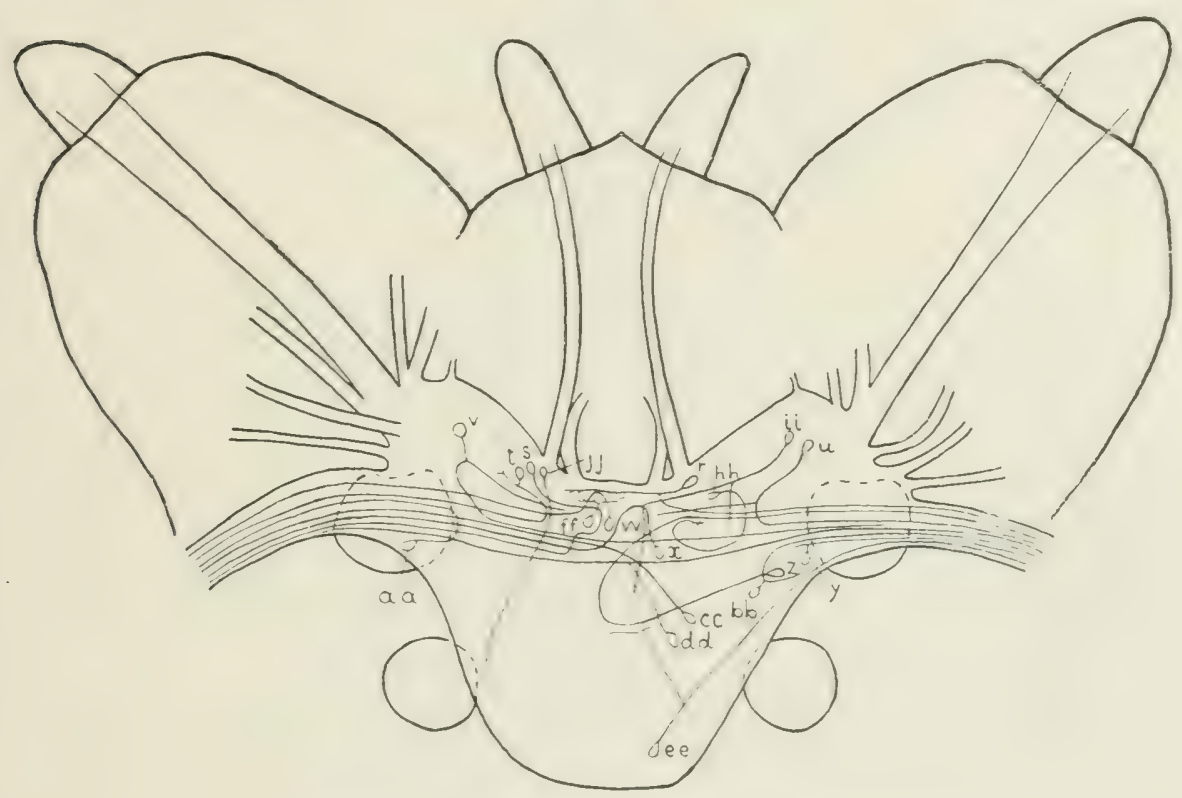

Gehirn und Umgebung von Nereis diversicolor.

Abgeändert nach N. Holugrex (1916) Taf. 4.

V̌ergleiche Fig. 35 .

$r$ bis $z$, aa bis $f f$, $h h$ bis $j i=$ Ganglienzellen

ihren Fortsatz mit einem Bogen ins Schlundkonnektiv der gleichen Seite. Der Typus $b b$ (Fig. 36) besitzt einen dichotomisch verzweigten Stammfortsatz, dessen beide Aeste in der Richtung des Schlundkonnektivs der gleichen Seite laufen, aber nur einer war darin zu verfolgen.

Mitten im Gehirn liegen die Neuronen $c c$ und dd (Fig. 36). Die erste Zelle hat einen Fortsatz, welcher in der zweiten Kommissur kreuzt und in das Schlundkonnektiv der anderen Seite zieht. Die zweite hat einen Fortsatz. welcher bei der zweiten Kommissur angelangt, sich spaltet in zwei Aeste, welche zum rechten und linken Schlundkonnektiv gehen.

Hinten im Hirnganglion befindet sich schließlich noch das Neuron ee (Fig. 36), welches weniger gut bekannt ist, wahrscheinlich aber seinen Neurit 
ins Schlundkonnektiv der gleichen Seite und seine Dendriten ins Gehirn sendet.

Holmgren (1916) beschreibt zuletzt noch fünf Neuronen bei Nereis, welche nicht zum Schlundkonnektiv gehören. Die Ganglienzelle ff (Fig. 36) ist vorn im Hirnganglion zu finden. Sie ist unipolar und der Stammfortsatz verästelt sich sofort in der ersten Gehirnkommissur. Der Typus gg (Fig. 35) ist eine unipolare Kommissurzelle mit einem Fortsatz, welcher kreuzt und in der Nähe der gleichartigen Zelle der anderen Seite endet. Die Zelle $h h$ (Fig. 36) ist unipolar und zeigte nur einen spiralförmigen Fortsatz, war daher wahrscheinlich unvollständig gefärbt. Die Zelle $i i$ (Fig. 36) liegt neben der Zelle $u$ und sendet einen Fortsatz aus, welcher medianwärts zieht und dann nach hinten biegt und mitten im Gehirn endet. Ein Seitenast geht auch nach hinten. Die Zelle $j j$ (Fig. 36) endlich liegt vorn im Hirnganglion und sendet ihren Fortsatz in der Richtung des hinteren Auges.

Ungeachtet der schönen Resultate HowmGRens und der Kenntnis so vieler Neuronen kann man sich über die Wege der Reize im Hirnganglion von Nereis nur sehr ungenaue Vorstellungen bilden.

Das Nervensystem der Oligochaeten gleicht im großen und ganzen demjenigen der Polychaeten, welche gut gesonderte Bauchganglien haben, besteht also aus dem Schlundringe, dem Bauchstrang und den peripheren Nerven.

Es ist wohl bemerkenswert, daß von allen Oligochaeten mit einer Ausnahme (HAVET 1900 a) nur Lumbricus, der Regenwurm, zv hodologischen Untersuchungen verwandt worden ist.

Merkwürdigerweise gehen die ersten Angaben über den Verlauf der Nervenfasern bis auf das Jahr 1856 zurick. Damals hat CLARKr (1856) seine Beobachtungen publiziert, welche er am Nervensystem von Lumbricus terrestris angestellt hatte. Man wird sich nicht wundern, daß manche seiner Behauptungen später nicht bestätigt worden sind. ClArKe macht überhaupt den Eindruck mehr erraten als genau gesehen zu haben, was zweifelsohne auf Rechnung seiner primitiven 'lechnik zu stellen ist. Trotzdem will ich seinen Befund hier zitieren, weil er als erster sich bestrebt hat bei Lumbricus die Reizleitungsbahnen aufzufinden, wie später so mancher Forscher nach ihm getan hat.

CLARKE nun beschreibt im allgemeinen in den peripheren Nerven der Bauchgan. glien Nervenfasern, welche sich in die Ganglien fortsetzen. Vielfach biegen sie sich, im Ganglion angelangt, um und laufen longitudinal nach vorn oder nach hinten. Sio können mun nach CLARK in den nächsten Nerven wieder austreten (was jetzt nicht wahrscheinlich lautet) oder an diesem voriber und einfach weitergehen, oder endlich seitwärt: im Ganglion abbiegen zu den lateralen Ganglienzellgruppen.

Andere Fasern sind Kommissurfasem. Sie treten in einem peripheren Nerven in den Bauchstrang ein, überschreiten die Ifediunlinie und treten wieder in einen peri. pheren Nerven aus oder sie biegen sich um, nach voln oder nach hinten, um sich den longitudinalen fasern beizumischen. Ob) das erstgenannte Verhulten wirklich vorkommt, ist jetzt wenigstens zweifelhaft.

Wiederum andere Nervenfasem der Nerven verbreiten sich in allen Richtungen nach den Ganglienzellen des (ianglions und einige, wber gewil. nicht alle, sincl nach CLARKE auch Fortsätze dieser (iunglienzellen.

CLAнke macht einige Bemerkungen über das Himganglion, aber diese scheinen mir zu wenig zuverläßig um hier referiert zu werden. Lieber möchte ich erwilhnen, daß CLarke schon in der Lngebumg des Oesophagus einen Nervenplexus mit eingelagerten Ganglienzellgruppen enteleckte, also exinen 'Teil des Nervensystems, wo die Reizleitung unbestimmt erscheint. 
Vraxal (1883) hat viele Jahre später denselben Nervenplexus ebenfalls gesehen Er lenkt wenigstens die Aufmerksamkeit auf einen sympathischen Nervenplexus mit eingelagerten Ganglienzellen, welcher den Pharynx umgibt und auch weiter nach hinten den Darm umringt, aber dort aller Ganglienzellen entbehrt.

Die drei Neurochorde von Lumbricus, welche größtenteils iiber den eigentlichen Ganglien und Konnektiven und außerhalb derselben im Bauchstrange laufen, waren schon am Anfang der sechziger Jahre des neunzehnten Jahrhunderts von LEy DiG beob. achtet worden, aber VIGNAL hat ihre Wege studiert und behauptete gesehen zu haben, daß der mediane im ersten Ganglion des Bauchstranges und die beiden lateralen im zweiten anfangen. Sie enden nach ihm in einem der letzten Ganglien des Bauchstranges (in welchem es war, konnte nicht genau nachgewiesen werden) und entsenden Seienäste zu den longitudinalen Nervenfaserbïndeln des Bauchmarks. VIGxaL hat mit diesen Angaben noch nicht das Richtige getroffen und auch die Neurochordzellen noch nicht entdeckt, aber doch hat er gewiß CLAPAREDE (1869) iibertroffen, welcher ehemals behauptet hatte, daß die Neurochorde tatsächlich nicht mit dem Nervensysteme verbunden seien.

FriedLAENder (1888) hat in seiner wichtigen Arbeit über die Leitungsbahnen des Zentralnervensystems von Lumbricus auch unsere Kenntnis der Neurochorde erweitert. Er sah sie dünn im unteren Schlundganglion enden. Der mediane Neurochord war nicht gut in eine Zelle verfolgbar, aber in jedem der hinteren Segmente des Bauchstranges beobachtete er ein Paar Neurochordzellen, deren Fortsätze zusammen die lateralen Neurochorde bildeten. Später (FriedLaExDER 1894) hat er noch hinzugefügt, daß die Neurochordzellen anscheinend immer bipolar sind und daß die lateralen Neurochorde einen Seitenast entsenden auf der Höhe eines jeden zweiten, hinteren, Doppelnerven des Bauchganglions. Dazu muß man wissen, daß, wie wir später noch sehen werden, aus jedem Ganglion drei Nervenpaare, jederseits ein Einzelnerv und mehr nach hinten

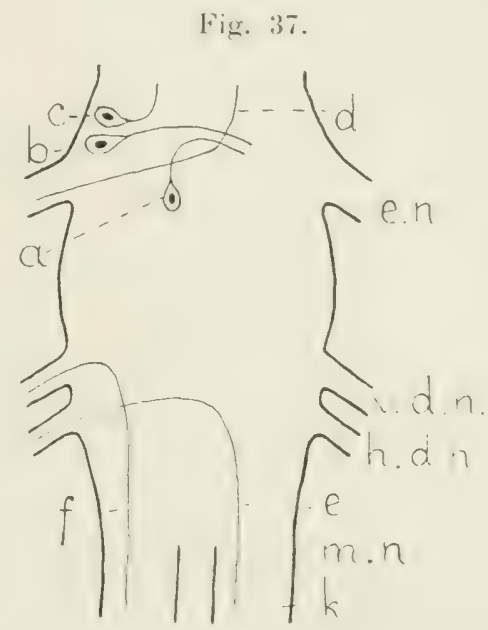

Bauchganglion von Lumbricus Nach Friedlaender (1888).

$a, b, c=$ Ganglienzellen

$d, e, j=$ Nervenfasern

e. $n$. = Einzelnerv

h. d. n. = hinterer Doppelnerv

k. = Konnelitiv

$m . n .=$ Mediannerv

$v \cdot d n$. $=$ vorderer Doppelnerv ein Doppelnerv hervorgehen.

Das obere Schlundganglion, oder Hirnganglion, hat FrtedLA ExDER nicht viele seiner Leitungsbahnen offenbart. Er beobachtete darin zwei dorsale und zwei ventrale Gruppen großer Ganglienzellen, welche meistens ihre Fortsätze zur anderen Seite des Ganglions hinübersandten.

Im unteren Schlundganglion beschreibt FRIEDLA ENDER keine bestimmten Faserbündel, aber wohl tut er das für die Bauchganglien. Die Bauchganglien werden durch zwei Konnektive (Fig. 37, k) unter einander verbunden, aber dazwischen läuft median der Mediannerv (Fig. 37, m.n.) oder das Mediankonnektiv, wie er auch hier vielleicht besser genannt wiirde. Jedes Bauchganglion entsendet, wie gesagt, vorn zu beiden Seiten einen peripheren Nerven, 
den Einzelnerven (Fig. 37, e.n.) und mehr nach hinten einen Doppelnerven (Fig. 37, v.d.n. und h.d.n.).

In jedem Bauchganglion kann man nach FriedLaExder vier Paar Ganglienzellgruppen unterscheiden, zwei laterale und zwei ventrale. Sämtliche Ganglienzellen sind unipolar. Außerdem findet man median die multipolaren Medianzellen, deren nervöse Natur aber meines Erachtens noch nicht festgestellt worden ist. Falls sie mit den Medianzellen der Hirudineen homolog sind, sind es wohl Gliazellen.

Auf der Höhe des Einzelnerven entdeckte FrIEDLAEXDER Ganglienzellen der ventralen Gruppe (Fig. 37,a), welche ihren Fortsatz zur anderen Seite des Ganglions senden und zwar durch die dorsale der beiden Kommissuren, welche jedes Ganglion aufweist und welche, wie aus Figur 38 erhellt, die Fasern des Mediannerven ( $m . n$.) in drei Bündel zerlegen. Einige, laterale Ganglienzellen (Fig. 37, b) senden ebenfalls ihren Fortsatz in die dorsale Kommis-

Fig. 38 .

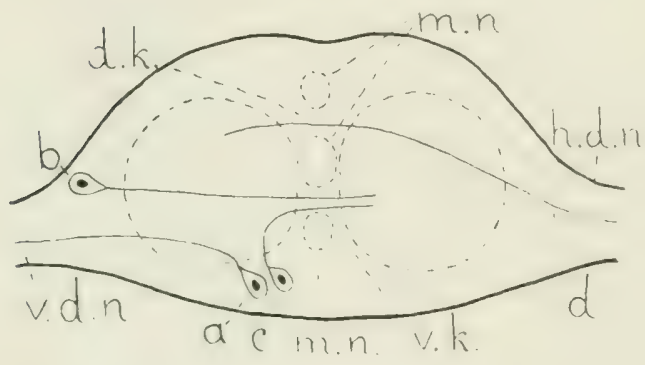

Quersehnitt eines Bauchganglions von Lumbricus.

Nach Friediander (1888).

$a, b, c=$ Ganglienzellen

$d=$ Nervenfaser

d. $f_{\text {: }}=$ dorsale Kommissur

h.d.n. = hinterer Doppeinerv

m. $n .=$ Mediannerv

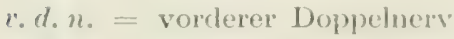

$v: k_{0}=$ ventrale Kommissur sur, während die Fortsätze anderer in das zur gleichen Seite gehörige Konnektiv ziehen (Fig. 37, c).

Neben der Abgangsstelle des Doppelnerven enthält die ventrale Gruppe Ganglienzellen mit einem Fortsatz in den vorderen Doppelnerven (Fig. 38, $a$. In dieser Figur ist links der vordere Doppelnerv (v.d.n.), rechts der hintere Doppelnerv (h.d.n.) angeschnitten gedacht). Die ventrale Kommissur ist die Brïcke zur anderen Seite des Ganglions für Nervenfasern, welche entweder Ganglienzellen der ventralen der beiden lateralen Gruppen entstammen (Fig. 3s, b) oder Ganglienzellen der ventralen Gruppe (Fig. 38, c).

As Nervenfasern unbekann-

ter Herkunft nemut FriedLAExider noch Fasern des hinteren Doppelnerven, welche in der dorsalen Kommissur die Medianlinie kreuzen (Fig. 38, d) und Fasern der Konnektive, welche nach Kreuzung in den Einzelnerven oder den hinteren Doppelnerven, dagegen ohne Kreuzung in den vorderen Doppelnerven übergehen (Fig. $37, d, e, f$ ).

Ich habe hier diejenigen Nervenfasem außer Acht gelassen, von deren Lauf FriedLAENDER nicht gewiß war und auch die verschiedenen Faserbündel der Konnektive will ich nur kurz nennen. weil Friendafider zwardas Bündel als Ganzes, aber nicht das Verhalten der einzelnen Nervenfasern darin erforschen konnte. In den Konnektiven des ganzen Bauchstranges sah FriedLAENDER also ein dorsales und ein ventrales Bündel, welche schon im unteren 
Schlundganglion anfingen; ein laterales Bündel setzte sich aber nicht ganz bis in die letzten Ganglien des Bauchmarks fort.

Haller (1889) hat nach FriedlaExder das Bauchmark von Lumbricus bearbeitet und manche seiner Angaben kritisiert, was aber wohl nicht immer mit Recht geschah. Ich will schon hier darauf hinweisen, daß HALLER später (1910) abermals und mit neuem Erfolg das Bauchmark von Lumbricus untersucht hat. Als ich die in diesem Artikel niedergelegten HALLERschen Resultate betreffs der Leitungsbahnen der Polychaeten wiedergab, bot sich schon die Gelegenheit da zu bemerken, daß HALíer im Gegensatz zu anderen Autoren der Meinung ist; daß fast alle Ganglienzellen multipolar sind und mit ihren Fortsätzen unmittelbar zusammenhängen und daß manche Nervenfasern aus dem Neuropilem der Ganglien entspringen. So auch hier bei Lumbricus, wo ich wiederum mich so ausdrikken will, indem ich sage, daß die letztgenannten Nervenfasern im Neuropilem enden, weil ich glaube, daß solches eher der Wirklichkeit entspricht.

HALLER hat nichts mitzuteilen über den Ursprung der Neurochorde, aber wohl sagt er, daß der große, mediane Neurochord nicht nur dem Neuropilem Seitenästchen iiberläßt, sondern auch bisweilen mit den lateralen Neurochorden zusammenhängt.

Er behauptet, daß die multipolaren Medianzellen des Bauchganglions (Ganglienzellen, wie er meint) Fortsätze ins Neuropilem senden oder kontinuirlich mittels ihrer Fortsätze mit Ganglienzellen in großer Entfernung verbunden sind, verneint aber, daß ihre Fortsätze auch in die peripheren Nerven treten sollten.

Die Ansicht, welche HALLER über den Verlauf der Nervenfasern im Bauchstrang hat und welche die Fig. 39 abbildet, ist wohl sehr einfach und schematisch. Spätere Autoren haben zwar einige seiner Behauptungen bestätigt, und ich werde das jedesmal hervorheben, aber im allgemeinen folgt aus ihren Darstellungen, daß HALLER damals nur halb gesehen und sich den Lauf der Nervenfasern zu einfach vorgestellt hat. (Han vergleiche auch seinen späteren Aufsatz). 
In der Fig. 39 ist ein Bauchganglion schematisch dargestellt und sind die beiden nächsten, wo manche Nervenfasern des Ganglions anfangen oder enden, nur gerade angedeutet worden $(n . g$.$) , wobei die Konnektive (k$.) fortgelassen sind. In die Einzelnerven (Fig. 39, e.n.) treten nach HALLER Nervenfortsätze lateral gelegener Ganglienzellen $(a)$ und Nervenfasern, welche im Neuropilem enden $\left(a^{\prime}\right)$ und beides trifft ebenfalls für die andere Hälfte des Ganglions zu ( $b$ und $\left.b^{\prime}\right)$.

In der von letztgenannten Fasern gebildeten Kommissur sind auch Ganglien żellfortsätze $(l)$, welche die Medianlinie ( $m . l$.) iiberschreiten, aber nicht in einen peripheren Nerven übergehen, sondern im Neuropilem enden. Vielleicht sind diese Zellen (Fig. 39, $l$ ) mit den Zellen $a$ oder $b$ der Fig. 37, welche FriedLAENDER beobachtete, zu identifizieren. Jedenfalls sind es wahre Kommissurzellen.

Die Doppelnerven erhalten, wie HALLER mitteilt, Nervenfasern, welche das Ganglion und ein Konnektiv durchziehen und im nächsten Ganglion entweder im Neuropilem enden $\left(c^{\prime}, l^{\prime}, e^{\prime}, f^{\prime}, g^{\prime}, h^{\prime}, i^{\prime}, j^{\prime}\right)$ oder aus einer Ganglienzelle hervorgehen $(c, d, e, f, g, h, i, j)$. Beide Doppelnerven empfangen aszendierende Fasern $\left(c, c^{\prime}, d, d^{\prime}, e, e^{\prime}, f, f^{\prime}\right)$ und deszendierende $\left(g, g^{\prime}, h, h^{\prime}\right.$, $\left.i, i^{\prime}, j, j^{\prime}\right)$ und Fasern derselben Hälfte des Bauchmarks $\left(c, c^{\prime}, d, d^{\prime}, i, i, j, j^{\prime}\right)$, sowie Fasern, welche die Mittellinie kreuzen $\left(e, e^{\prime}, f, f^{\prime}, g, g^{\prime}, h, h^{\prime}\right)$. Es bilden die genannten Nervenfasern Längsbündel im Ganglion und im Konnektiv, welche oft gesehen wurden. Die einzelnen Faser- und Ganglienzelltypen sind weniger wiedererkannt. Vielleicht stimmt die Faser $f$ der Fig. 37, welche nach Angaben FriedLAEnders angefertigt wurde mit der Faser $i$ oder $i$ ' der Figur 39 überein, sowie die Faser $e$ mit Faser $g$ oder $g$ '.

Kurz nach Haleer hat CerfortaIxe (1892) Mitteilungen iiber die Leitungsbahnen des Zentralnervensystems von Lumbricus terrestris veröffentlicht. So konnte er die FriedlaExdersche Entdeckung, daß die lateralen Neurochorde mit hinten im Körper gelegenen Ganglienzellen verbunden seien, bestätigen. Er selbst fand den medianen Neurochord mit speziellen Ganglienzellen vorn im Bauchstrang verbunden, aber genauer erklärt er deren Lage leider nicht. Weil er sagt, daß die drei Neurochorde sich vom unteren Schlundganglion bis nahe zum Ende des Bauchmarks erstrecken und der mediane noch ein wenig weiter nach vorn rükt als die lateralen, haben wir Grund die Ursprungszellen des medianen Neurochords im ganglion infraoesophageum zu suchen.

Ueberall entsenden die Neurochorde Seitenäste und darunter beobachtete Cerfontaine in jedem Bauchganglion konstant einen Ast jedes der beiden, lateralen Neurochorde hinter dem Einzelnerven, einen ebensolchen hinter dem Doppelnerven und einen Ast des medianen Neurochords in der Ebene des hinteren Doppelnerven. Oft anastomosieren die Seitenäste der lateralen Neurochorde, besonders jene hinter dem Doppelnerven und zwar ïber oder unter dem medianen Neurochord.

Sehr wichtig für meinen Zweck ist in Crrfoxtaxis Arbeit eine kombinierte Abbildung der verschiedenen Ganglienzellypen des Bauchganglions welehe er mit Hilfe der Methylenblau-Mlethode darin entdecken konnte. Eine kurze Erläuterung ist der Figur beigegeben, aber die Ganglienzellarten werden nicht einzeln beschrieben. Ich habe in meiner Figur 40 alle diese Ganglienzellen 
schematisch wiedergegeben, außer denjenigen, welche keine verfolgbaren Fortsätze hatten und einer Gruppe unipolarer und bipolarer Ganglienzellen, welche in der Mitte des Ganglions gelegen, nur dem Neuropilem Fortsätze überliefert.

In die Einzelnerven (Fig. 40, e.n.) treten nach der CerfontaIneschen Abbildung drei Nervenfaserarten aus. Die erste ist Ausläufer einer Ganglienzelle (Fig. 40, b) der anderen Ganglionhälfte. Bevor sie austritt, sendet sie einen Seitenast in das Konnektiv nach vorn. Die zweite kreuzt ebenfalls die Medianlinie und setzt sich in eine bipolare Ganglienzelle $(d)$ fort, deren zweiter Fortsatz nur kurz ist. Die dritte endlich gehört einer unipolaren Ganglienzelle derselben Seite an (Fig. 40,e). Vielleicht ist diese Zellart dieselbe. welche Haller beschrieb und die in der Fig. 39 mit $a$ bezeichnet wurde.

Im vorderen Doppelnerven (Fig. $40, v .(l n$.$) laufen die Fortsätze dreier$ verschiedenen Ganglienzelltypen. Der erste (c) liegt hinter der Abgangsstelle des Einzelnerven und er sendet seinen einzigen Fortsatz schräg durch das Ganglion in den vorderen Doppelnerven der anderen Seite. Der zweite ist ebenfalls unipolar ( $i$ ), aber nahe der Basis jenes vorderen Doppelnerven gelegen, welcher auch seinen Fortsatz enthält. Diese Ganglienzelle hat vielleicht auch FrIEDLAENDER beobachtet und dann ist er in der Figur 38 mit $a$ bezeichnet worden. Der dritte Ganglienzelltypus $(h)$ ist bipolar mit kurzem Dendrit und langem Neurit im vorderen Doppelnerven derselben Seite.

Neben diesen Ganglienzellfortsätzen enthält der vordere Doppelnerv zwei Fig. 40.

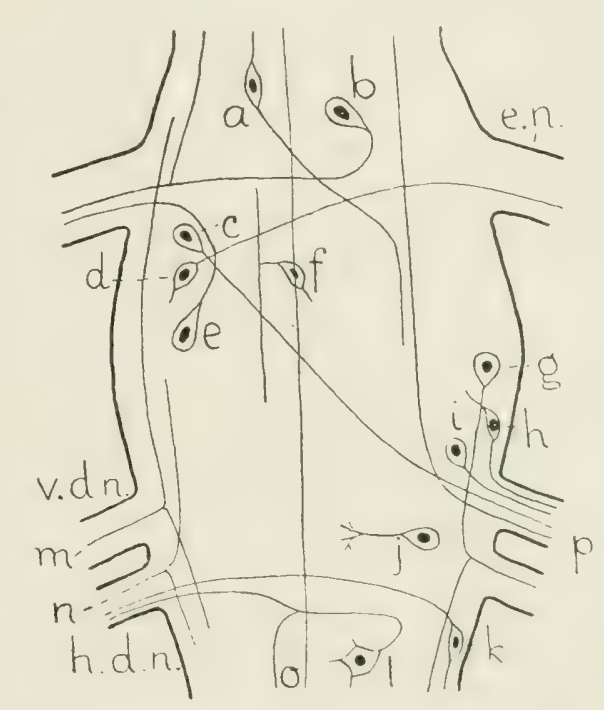

Banchganglion von Lumbricus. Nach Cerfontane (1892) Taf. II, Fig 9.

$a$ bis $l=$ Ganglienzellen

$m$ bis $p=$ Nervenfasern

c. $n .=$ Einzelnerv

h. . $n .=$ hinterer Doppelnerv

v. $d \cdot n$. = vorderer Doppelnerv

Nervenfaserarten unbekannter Her-

kunft, welche den Nerven unmittelbar mit anderen Ganglien in Verbindung stellen. Die Nervenfasern der ersten Art $(m)$ spalten sich sofort nach ihrem Eintritt in einen aszendierenden und einen deszendierenden Ast. Die anderen $(p)$ biegen um nach vorn und verlassen das Ganglion durch das Konnektiv. Diese Fasern hat auch HALLER gesehen und ich habe sie schon in die Figur 39 eingezeichnet ( $c$ oder $c^{\prime}$ ).

Der hintere Doppelnerv (Fig. 40, h.d.n.) wird teilweise gebildet von Nervenfasern unbekannter Herkunft $(n)$, welche in ihrem Verhalten durchaus den Fasern des 'Typus $m$ ähneln. Die Untersuchungen Vox Lexiossexs machen es jetzt wahrscheinlich, daß die Fasern $m$ und $n$ aus Sinnesnervenzellen der Haut hervorgehen. Neben den Fasern des 'Typus $n$ beteiligen sich 
die Fortsätze dreier Ganglienzelltypen an der Bildung des hinteren Doppelnerven. Der erste $(g)$ ist unipolar. Sein Stammfortsatz spaltet sich in den Ast, welcher in den hinteren Doppelnerven austritt und einen Ast, welcher in das Konnektiv nach hinten läuft. Der zweite $(k)$ ist bipolar. Der eine Fortsatz deszendiert im Konnektiv, der andere kreuzt die Medianlinie und verläßt im hinteren Doppelnerven das Ganglion. Der dritte $(l)$ ist multipolar und mit einem Neurit versehen, welcher die Medianlinie überschreitet und nach Dichotomie einen Ast in den hinteren Doppelnerven und einen in das Konnektiv nach hinten schickt.

Die übrigen von Cerfontaine beobachteten Ganglienzellen beteiligen sich anscheinend nicht an den Nerven. Der Zelltypus $a$ der Figur 40 ist bipolar ; ein Fortsatz schreitet nach vorn in das Konnektiv, während der andere kreuzt ind nach hinten geht. Die Zellen des 'Typus $f$ sind bipolar. Der eine Fortsatz ist nur kurz, der andere geht 'T-förmig in eine Längsfaser des Ganglions iiber. Die Zelle $j$ befindet sich auf der Höhe des Doppelnerven und sein Stammfortsatz zerfällt in Fasern des Neuropilems. Und wenn ich nun auch noch gemeldet habe, daß Nervenfasern, wie die Faser $o$ der Figur 40 das Ganglion in seiner ganzen Länge durchziehen, so habe ich, abgesehen von den Kollateralen, den Lauf der von CERFoxtAIxE erforschten Nervenfasern beschrieben.

In demselben Jahre, da Cerfontaine die mit Hilfe der MethylenblauMethode beobachteten Ganglienzellen und Nervenfasern des Bauchganglions von Lumbricus abbildete, hat Retzius (1892a) seine mit der GoLGischen Methode angestellten Untersuchungen desselben Gegenstandes veröffentlicht und es ist erfreulich zu sehen, wie sehr die Resultate der beiden Arbeiten ïbereinstimmen.

Jederseits in den Konnektiven und im Ganglion sah Retzius ein Längsbïndel dicker Nervenfasern, welche Ganglienzellen angehörten, und drei longitudinale Systeme dünner Nervenfasern, welche, aus den peripheren Nerven herstammend, nicht im Bauchstrang mit Ganglienzellen zusammenhingen und deshalb von ihm als eintretende, sensibele Nervenfasern betrachtet wurden, wie Vox LexHossek sie kurz vorher entdeckt hatte. (Den Vox LENHOSSEKschen Befund werde ich bald eingehender besprechen).

Auch ReTzus konnte im Bauchganglion manche Ganglienzelltypen auffinden. Der erste (Fig. 4l, a) ist unipolar. Sein Fortsat schreitet im Längsbïndel nach hinten, verläßt es aber bald $u m$ in den hinteren Doppelnerv überzugehen. Oft geht ein \%weig des Stammfortsatzes im Längsbündel nach vorn und ein zweiter Ast, weleher im Längsbiindel weiter deszendiert, tritt bisweilen in den Einzelnerven des nächsten Ganglions ein. Diese Zellart hat also soviel Aehnlichkeit mit der in Fig. 40 als $g$ bezeichneten Cerroxtarieschen Zelle, daß es wohl erlaubt ist, die beiden zu identifizieren.

Die unipolaren Ganglienzellen des zweiten 'Typus (Fig. 41, b) liegen median. Ihr Stammfortsatz spaltet sich in einen Ast nach vorn ins Längsbiundel und einen caudalen Ast, welcher mit dem vorderen Doppeherven das Ganglion verläßt.

Eine dritte Ganglienzellart (Fig. 4l,c) sendet den Fortsatz ins Längsbündel 
nach vorn und dieser tritt aus in den hinteren Doppelnerven des nächsten Ganglions. Das ist also eine schon von Hallen beobachtete Zelle ( $j$ der Fig. 39).

Auf der Höhe eines jeden der peripheren Nerven Lefinden sich unipolare Ganglienzellen (Fig. 41, d,e,f), deren Fortsätze die Medianlinie kreuzen und in den zugehörigen peripheren Nerven austreten. Die Zelle d hat auch HALLER schon gesehen (Fig. 39, b) und es ist nicht unmöglich, daß auch die Ganglienzelle $d$ der Fig. 40 dieser Kategorie einzuverleiben ist, obgleich Cerfontaine sie als bipolar abbildet.

Ohne Zweifel ist aber die typische Ganglienzelle g der Fig. 41, welche nach Retzius auf der Höhe des Einzelnerven gelagert, ihren Fortsatz schräg durch das Ganglion in den vorderen Doppelnerven der anderen Seite sendet, dieselbe Zelle wie die Zelle $c$ der Fig. 40, welche nach der Abbildung Cerfontaixes angefertigt wurde.

Ebenfalls stimmt die bipolare Ganglienzelle $h$, welche, wie Retzius uns mitteilt, ihren langen. Fortsatz in den vorderen Doppelnerven sendet und ihren kurzen zum Neuropilem, mit der von Cerfontaine abgebildeten Zelle $h$ der Fig. 40 überein.

Alle diese Ganglienzellen tirgen zur Bildung der peripheren Nerven bei und wenn ihre Fortsätze zur Muskulatur gehen, müssen wir RETZIUS beistimmen, wenn er sie motorisch nennt.

Es gibt aber auch noch einen Ganglienzelltypus (Fig. 41, n), dessen Fortsatz T-förmig in eine Längsfaser des Konnektivs übergeht. Das ist wohl eine auch von Cerfostalyes beobachtete Ganglienzelle (Fig. 40, f).

RetziUs erwähnt in jedem Bauchganglion eine einzige multipolare Ganglienzelle, welche vor den Doppelnerven in der Mitte des Ganglions gelegen ist und deshalb wohl eine der

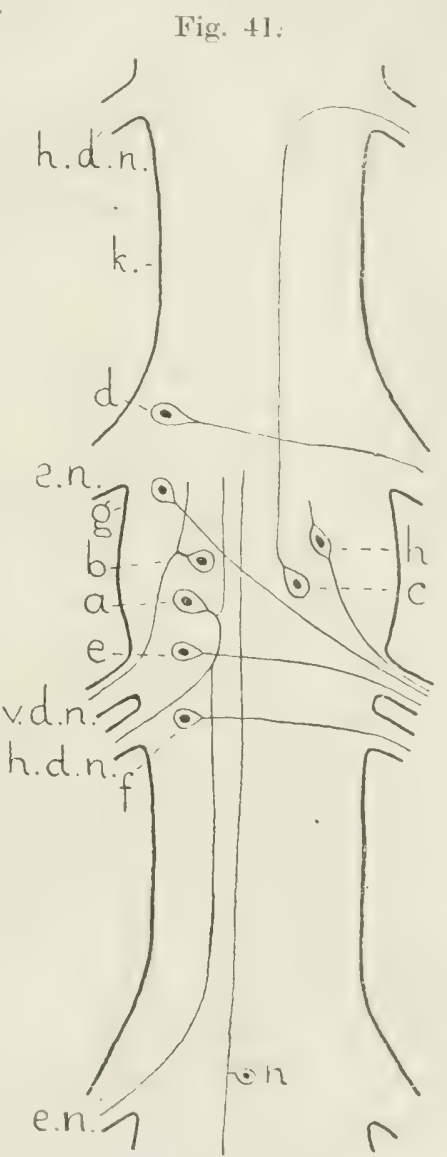

Bauchganglion von Lumbricus. Nach Retzius $(1892 a)$.

$a$ bis $h$ und $n=$ Ganglienzellen e. $n$. = Einzeluerv

h. d. n. = hinterer Doppelnerv

$k_{\text {. }}=$ Konnektiv

v. d. $n$. = vorderer Doppelnerv

Medianzellen anderer Autoren ist. Reтzius verneint, daß ein Fortsatz dieser Ganglienzelle in den Einzelnerven und zwar nach Kreuzung der Medianlinie übergeht, wie Vox LevirosseK (1892 und 1895) behauptet. Er befindet sich dabei mit HALLer im Einklang.

Die dïnnen sensibelen Nervenfasern, welche mit den peripheren Nerven ins Bauchganglion gelangen, spalten sich nach REтz̈IUs fast ohne Ausnahme ' $\mathrm{I}$-förmig in einen aszendierenden und einen deszendierenden Ast und diese longitudinalen Nervenfasern bilden im Ganglion und in den Konnek- 
tiven drei Bündel. Das laterale Bündel (Fig. 42, 1) hat die größte Dicke und es empfängt Fasern der drei peripheren Nerven. Ein dünneres Bündel (Fig. $42,2)$ läuft ein wenig mehr median. Es enthält keine Nervenfasern des hinteren Doppelnerven, wohl aber der beiden anderen Nerven. Das mediane Bündel endlich (Fig. 42,3) besteht nur aus Nervenfasern, welche aus dem vorderen Doppelnerven stammen und ist das dïnnste. Daß auch CERfoxtaIve einige dieser sensibelen Nervenfasern gekannt hat, geht ohne weiteres aus seiner Abbildung hervor (vergl. Fig. 40, $m$ und $n$ ).

Oft schreiten sowohl der aszendierende, wie der deszendierende Ast einer Nervenfaser zum nächsten Ganglion um dort zu enden, häufig neben der Wurzel eines Nerven. Bisweilen aber endet einer der beiden Aeste im

Fig. 42 .

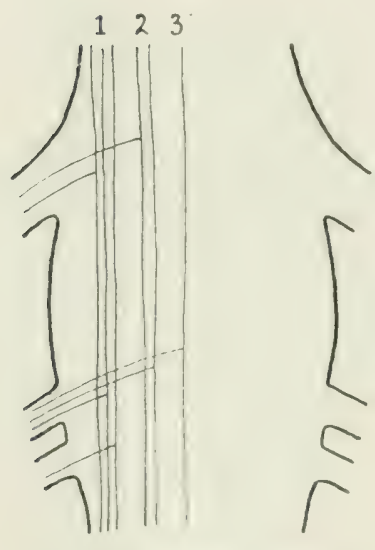

Die sensibelen Nervenfasern im Bauchganglion von Lumbricus.

Nach Retzius (1892 $\alpha$ ), Taf. III, Fig. 2.

$1,2,3=$ longitudinale Faserbündel Ganglion selbst und es scheint auch möglich zu sein, daß beide leste in derselben Richtung fortlaufen oder die Medianlinie kreuzen. Wie auch aus den Forschungen anderer Autoren erhellt, ist das erstgenannte Verhalten das gewöhnlichste.

Die sensibelen Nervenfasern des Bauchmarks des Regenwurmes waren schon kurz bevor Retzit's sie beschrieb und Cerfontañe sie abbildete, von Vox LENHOSsEK (1892) entdeckt worden und es folgt jetzt eine Periode, worin sie die Aufmerksamkeit verschiedener Forscher fesseln und neben ihnen noch sensibele Nervenfasern anderer Art entdeckt werden.

Vox Lexhosser (1892) hat Lumbricus mit der GoLgischen Methode untersucht und dabei nicht nur als erster die oben beschriebenen sensibelen Nervenfasern im Zentralnervensystem und den peripheren Nerven entdeckt, sondern auch wahrgenommen, daß sie aus Sinnesnervenzellen des Hautepithels hervorgehen und somit ihre sensibele Natur festgestellt.

Er sah im Epithel der Haut zwischen andersartigen Zellen Sinnesnervenzellen stehen, deren Nervenfortsätze sich in die peripheren Nerven des Bauchstranges zu einem Ganglion begaben und dort angelangt, sich in einen aszendierenden und einen deszendierenden Ast spalteten, welche im nächsten Ganglion endeten.

Er betont, was RETzus bestätigte, daß die sensibelen Nervenfasern dünner sind als die motorischen und daß die meisten im vorderen Doppelnerven ins Bauchmark eintreten (vergl. lïg. 42). Niemals verästeh sie sich auf ihrem Wege von der Simnesnervenzelle zum Bauchstrang und auch darin haben sie nach ihm keine Kollateralen, was aber Retzius (1592a) nicht immer bewahrheitet fand.

Alle sensibelen Fasem eines Körpersegments treten in dessen Ganglion ein und zwar die linksseitigen alle links, die rechtsseitigen alle rechts. In der 
Peripherie überschreiten sie also niemals die Medianlinie und auch im Zentralnervensystem würden sie das, wenn man Vox LExHossex glauben kann, niemals tun, aber Retzius hatte bisweilen andere Erfahrungen.

Was Vox Lexhossek uns über die anderen Leitungsbahnen des Nervensystems mitteilt, wurde größtenteils von RETzIUs bestätigt und ist schon oben wiedergegeben worden. So meldet er im Bauchganglion laterale und ventrale Ganglienzellen, deren Fortsätze in der dorsalen Kommissur die Medianlinie kreuzen und in die peripheren Nerven austreten. Wahrscheinlich stimmen die Retziusschen Zellen $d$, e und $f$ (Fig. 41), die Hallersche Zelle $b$ (Fig. 39) und auch die Friedlaexderschen Zellen $a$ und $b$ (Fig. 37) damit iiberein.

Die peripheren Nerven werden nach Vox Lexhossek auch von Fortsätzen lateraler Ganglienzellen derselben Seite gebildet und tatsächlich sind wir solchen Zellen auch schon oft bei anderen Autoren begegnet (vergl. Fig. $39,40,41)$.

Ich habe schon oben gesagt, daß Vor Lenhossen behauptet, daß die multipolaren Medianzellen einen ihrer Fortsätze, welcher einen Bogen beschreibt und die Medianlinie kreuzt, in den Einzelnerven senden und ungeachtet des Widerspruchs von Seiten RExzius', beharrt er noch im Jahre 1895 bei seiner Meinung (Vox Lenhossek 1895).

Vox. Lenhossek hatte freie Nervenendungen im Hautepithel von Lumbricus verneint, aber schon zwei Jahre später konnte Surnow (1894) ihr Dasein beweisen. Ohne ihre Ganglienzellen auffinden zu können, entdeckte er Nervenfasern, welche vom Bauchstrange herstammend ihre freie Nervenendungen im Körperepithel oder auch im Darmepithel hatten. Das war also eine zweite Art sensibeler Nervenfasern, wie wir sie oben schon bei anderen Würmern kennen lernten, welche aber SuInxow hier zum ersten Male bei einem Wurm gesehen hat. SmInxow beobachtete ebenfalls die Sinnesnervenzellen der Haut und meldete, daß, bevor ihre Nervenfortsätze ins Bauchmark treten, sie einen subepithelialen Nervenplexus passieren.

Die Suinsowsche Entdeckung wurde bald von Retzius (1895 $a$ ) bestätigt und zu gleicher Zeit von Fräulein LANGdon (1895 $a$ und $b$ ) wiederholt. Auch sie hat die Golgrsche Methode angewandt und Lumbricus agricola als Versuchstier gewählt. Die Sinnesnervenzellen der Epidermis wurden von ihr wiedergefunden, aber dabei wurde entdeckt, daß sie nicht einzeln stehen, wie Vox LENHossek meinte, sondern immer in Gruppen geordnet sind.

In diesen Gruppen werden sie von Stuitzzellen umgeben und es liegen Basalzellen zwischen ihrer Basis, weshalb sie Sinnesorgane darstellen, welche (abgesehen von der Innervierungsweise) den Geschmacksknospen der Vertebraten gleichen. Jede Sinnesnervenzelle trägt ein starres Sinneshaar und setzt sich basal in einen Nervenfortsatz fort, woneben einige kurze, nichtnervöse Basalfortsätze bestehen können. LANGDON bestätigte, daß diese Nervenfortsätze niemals die Medianlinie kreuzen, und durch den subepithelialen Nervenplexus und die peripheren Nerven unverzweigt ins Bauchganglion gelangen, wo sie sich 'T'-förmig teilen und daß jeder der beiden Aeste im nächsten Ganglion endet. 
Diese Sinnesknospen sind zu Zehntausenden ïber den ganzen Körper zerstreut, kommen aber auch in der Mundhöhle vor.

In den peripheren Nerven des Bauchganglions laufen die Nervenfortsätze der Sinnesnervenzellen neben ein wenig dickeren sensibelen Nervenfasern, welche in den subepidermalen Nervenplexus eintreten, sich dort bisweilen verzweigen ohne fast je zu anastomosieren, aber immer zwischen den Epithelzellen der Epidermis mit freien Endverästelungen enden. Niemals dringen sie in die Sinnesknospen ein. Diese frei endenden, sensibelen Nervenfasern sind von LANGDON auch im Epithel der Mundhöhle entdeckt worden, aber da stammten sie nicht von einem Bauchganglion, sondern vom Hirnganglion oder dem Schlundringe her.

Leider blieben auch LANGDON die Ursprungszellen dieser Nervenfasern im Zentralnervensystem unbekannt und diese Lücke in unserer Kenntnis ist, so viel ich weiß, auch jetzt, zwanzig Jahre später, noch nicht ausgefüllt. Fest steht nur, daß die Nervenfasern nicht mit einer Ganglienzelle verbunden sind, ehe sie das Bauchganglion erreicht haben.

Daß LANGDON in den drei peripheren Nerven des Bauchganglions auch motorische Nervenfasern zu den Huskeln unter der Haut beobachtete, braucht uns nach den RETzuUsschen Untersuchungen nicht zu wundern.

Als Von Lenhosseк (1892) die Sinnesnervenzellen im Epithel des Regenwurms entdeckte, hat er gleich die Hypothese aufgestellt, daß die Spinalganglienzellen der Vertebraten phylogenetisch auf diese Zellen zurückzuführen seien und später (1895, S. 272) als nicht nur die Sinnesnervenzellen in oder unter der Epidermis bei Chaetopoden, Mollusken und Arthropoden bekannt waren, sondern auch SmRxow beim Regenwurm die mit freien Verästelungen in der Epidermis endenden Nervenfasern zu Tage gefördert hatte, hat er abermals die Spinalganglienzelle von der Sinnesnervenzelle abgeleitet.

Er stellt sich dabei vor, daß sich die Sinnesnervenzelle immer tiefer unter die Körperoberfläche gesenkt habe, bis sie schließlich in der Nachbarschaft des Zentralnervensystems angelangt sei. Diese Verlagerung hat nach Vox LExHossek die Bildung einer neuen Verbindung mit der Körperoberfläche notwendig gemacht und diese wird nach ihm ermöglicht, indem sich der Zellkörper selbst immer mehr zu einer fadenförmigen Bildung umgestaltet, die, urspriinglich ein Zellbestandteil, bald den Charakter einer Nervenfaser annimmt". Der periphere Fortsatz der Spinalganglienzellen wäre also eine sekundäre Bildung.

Ich glaube, die Vox Lexnosskksehe Hypothese, welche in weitem Kreise Anerkennung fand, enthält einen guten Kern, aber Smrxows Untersuchungen hatten schon damals eine andere Ausarbeitung verlangt und jetzt ist sie wohl völlig umzuabeiten und meiner Lrweiterung der Herwwaschen Hypothese (S. 11) anzusehließen.

Es war der gute Gedanke Vox Lexiossers eine sensibele Ganglienzelle, wie die Spinalganglienzelle ist, als eine Sinnesnervenzelle, welche sich gesenkt hat, zu betrachten. Alles andere war aber falsch. Es geht nicht an, die Spinalganglienzelle der Vertebraten, also einen ganz besonderen und phylogene- 
tisch jungen. Typus der sensibelen Ganglienzelle (das heißt der Ganglienzelle mit frei in der Körperperipherie endendem sensibelem Fortsatze) zurïckzuführen auf die Sinnesnervenzelle der höheren Würmer (Oligochaeten oder Polychaeten).

Wir wissen doch jetzt schon lange (vergleiche BoEmmig und MoxTr S: 32 und 33), daß auch bei den niedersten Würmern wie den Turbellarien nicht nur Sinnesnervenzellen im Körperepithel, sondern auch sensibele Ganglienzellen mit freien Nervenendungen angetroffen werden, also die phylogenetische Bildung nicht bei höheren Würmern stattgefunden haben kann. Fräulein Montr beschreibt außerdem so vielsagend, daß diese sensibelen Ganglienzellen entweder in den Muskeln unter dem Epithel oder in den peripheren Nerven oder endlich in den Seitensträngen, also im Zentralnervensystem, gelagert sind.

Daraus würde man schließen, daß auch in der Phylogenie der Weg von der Körperperipherie zum Zentralnervensystem von der sensibelen Ganglienzelle als solche und nicht nur als Sinnesnervenzelle zurückgelegt worden ist, oder wenigstens zurückgelegt werden könnte.

Ich glaube deshalb, daß die Spinalganglienzelle der Vertebraten nicht eine in die Tiefe gerückte Sinnesnervenzelle der höheren Würmer ist, sondern, wie die sensibelen Ganglienzellen aller Vertebraten und Evertebraten von den sensibelen Ganglienzellen der Turbellarien oder jedenfalls der primitivsten Würmer abzuleiten ist. Hier bei den Turbellarien sehen wir schon die sensibelen Ganglienzellen mit freien Nervenendungen peripher gelegen oder in die peripheren Nerven oder ins Zentralnervensystem eingeschloßen, also an allen möglichen Stellen.

Da die Coelenteraten zwar Sinnesnervenzellen, aber keine sensibelen Ganglienzellen aufweisen, so meine ich weiter, daß bei den niedersten Würmern die sensibele Ganglienzelle aus einer in die Tiefe gerückte Sinnesnervenzelle entstanden ist, wie ich in meiner Erweiterung der HERTwigschen Hypothese dargetan habe. Freilich, einen Vorläufer dieses Gedankens finde ich auch in der Vox LexHossekschen Hypothese.

Daß die Verbindung der sensibelen Ganglienzelle (Spinalganglienzelle) mit der Peripherie eine sekundäre Bildung sein sollte, wie VOx LENHOssek will, ist jetzt auch nicht mehr anzunehmen. Die sensibele Ganglienzelle kann so nahe unter dem Epithel gelegen sein, daß ihr sensibeler Fortsatz gar nicht sehr lang zu sein braucht, gar nicht länger, als der Sinnesfortsatz der Sinnesnervenzelle, von dem wir aus den Untersuchungen VERATTIS (S. 153) wissen, daß er alle Uebergänge zum peripheren Fortsatz der sensibelen Ganglienzelle aufweist. Damit fällt der Grund zur Annahme eines sekundär gebildeten peripheren Fortsatzes der sensibelen Ganglienzelle weg.

Ich will schließlich noch bemerken, daß, falls die Spinalganglienzelle notwendig auf eine Zelle von Lumbricus zurückzuführen wäre (welcher Behauptung ich keineswegs beistimme), sie eher von der freilich nicht genau bekannten Ursprungszelle der Surxowschen sensibelen Nervenfasern als von einer Sinnesnervenzelle abgeleitet werden sollte.

Nach dem Jahre 1895 tritt ein Stillstand in den Lumbricus-Forschungen 
ein. Havet (1900 a) konnte nochmals die Mitteilungen von Vox Lenhossek und Retzius über die Sinnesnervenzellen der Haut und den Weg und die Endungsweise ihrer Nervenfortsätze bei Lumbricus ganz bestätigen. Aber, was wichtiger ist, er hat auch das gleiche Verhalten bei Lumbriculus konstatiert und war damit der einzige Forscher, welcher je eine andere Oligochaete als Lumbricus hodologisch studierte. Die Sinnesnervenzellen der Haut zeigen bei Lumbriculus, wie bei Lumbricus, oft zwei basale Fortsätze und auch hier treten die Nervenfortsätze darunter mit den peripheren Nerven ins Bauchganglion und spalten sich dort in aszendierende und deszendierende Aeste, welche drei longitudinale Nervenfaserbündel bilden (vergl. Fig. 42) und im nächsten Ganglion enden.

HAVET hat mit Hilfe der GougIschen Methode auch einige Ganglienzelltypen im Bauchstrang von Lumbriculus entdeckt, worin aber nur selten Zellen des Regenwurms wiederzuerkennen sind. Zwar ist dies der Fall mit Ganglienzellen, deren Fortsatz die Medianlinie kreuzt und in einen peripheren Nerven austritt, wie sie z.B. auch in der Fig. 41 gezeichnet worden sind und mit Ganglienzellen des Typus $n$ der Fig. 41, aber nicht mit anderen Zellarten.

So fand HAvet Ganglienzellen, welche sich mit einem kurzen Fortsatz einer Längsnervenfaser anschlossen, welche nach der einen Seite verfolgt in einen peripheren Nerven seitwärts bog, nach der anderen Seite aber im nächsten Ganglion endete, bisweilen nachdem noch zuvor ein Ast in einen anderen peripheren Nerven gezogen war.

Andere Ganglienzellen besitzen einen Fortsatz, welcher sich spaltet in einen Ast zum peripheren Nerven und einen Zweig, welcher nach Kreuzung der Medianlinie im Ganglion endet.

Noch andere senden ihren Fortsatz, welcher einen Ast mit unbekannter Bestimmung hat, in einen peripheren Nerven derselben Seite.

Neben der Medianlinie des Bauchstranges war eine Ganglienzelle gelagert, deren Fortsatz mit einem Bogen diese Linie überschritt, aber wieder zurückkehrte und in einem peripheren Verven der gleichen seite das Bauchmark verliels.

Endlich konnte HAVET auch noch Ganglienzellen mit kreuzenden Fortsätzen auffinden. In der anderen Ganglionhälfte angelangt, spaltet sich dieser Ausläufer T-förmig in eine Längsfaser, welche im Ganglion endet und eine Längsfaser, welcher in einen peripheren Nerven weiterzieht. Bei einem Zelltypus, welcher dem vorigen iibrigens ähnlich ist, ist diese austretende Faser nur ein Seitenast der Längsfaser und nicht ihre fortsetzung selbst.

Es ist nur schade, daß HAVET die Lage aller dieser Ganglienzellen so unbestimmt erwähnt und auch die verschiedenen peripheren Nerven nicht unterscheidet.

Kehren wir aber zum Regenwurm zurick.

SCHNEDER (1902) erkennt in seinem Lelubuche der vergleichenden Histologie bei Lumbricus im Bauchganglion motorische (ianglienzellen an, welche ihren Neurit in einen peripheren Neven desselben oder des niichsten Ganglions senden und zwar mit oder ohne Krewzung der Medianlinie. Wir haben schon Beispiele solcher (ianglienzellen kennen gelernt. 
Auch CAJAL (1904) beschreibt im allgemeinen in den Ganglien : on Lumbricus unipolare und multipolare Ganglienzellen, deren Fortsätze die Medianlini berschreiten.

Erst HaLler (1910) hat in letzter Zeit wieder eingehende Bemerkungen über den Nervenfaserverlauf von Lumbricus gemacht und dabei vieles entdeckt, was ihm früher (1889) verborgen geblieben war.

Auch jetzt weicht er in sehr vielem von anderen Autoren ab. So sollen nach ihm die Ganglienzellen des Bauchmarks sämtlich multipolar sein, während doch die meisten von allen Forschern als unipolar beschrieben werden. Nur selten sind diese Ganglienzellen aber nach ihm durch breite Anastomosen verbunden.

Die Beschreibung, welche HALLER von den Neurochorden gibt, stimmt nicht ganz mit der Cerfoxtatseschen überein. Die drei dorsal im Batichstrang liegenden Neurochorde sind nach ihm Ganglienzellfortsätze, welche Seitenäste abspalten und oft damit anastomosieren. Die beiden, lateralen Kolossalfasern stehen nicht nur am Ende, hinten im Bauchstrang, unmittelbar mit Ganglienzellen in Verbindung, sondern auch im Anfang, vorn im Bauchmark. Die mittlere hat Zweige, welche ventral ziehen und sich unmittelbar in ventrale Ganglienzellen des Bauchstrangs, von HaLler Mittelzellen (Fig. 43, m.z., m.z.') genannt, fortsetzen, welche ihrerseits durch andere Ausläufer unmittelbar mit anderen Ganglienzellen zusammenhängen.

Die drei Neurochorde sind mit gemeinsamen Seitenästen versehen, welche in die peripheren Nerven gehen. Jeder dieser Seitenäste gabelt sich und jeder Zweig tritt in einen der beiden Doppelnerven ein. Andere Seitenäste betreten das Hirnganglion und lösen sich auf ins Neuropilem oder setzen sich dort unmittelbar in Ganglienzellen fort. Haller hat in seiner Textfigur 3, S, 604 die Neurochorde schematisch dargestellt. Wenn er Recht hat, ist der Weg des Reizes darin anatoFig. 43.

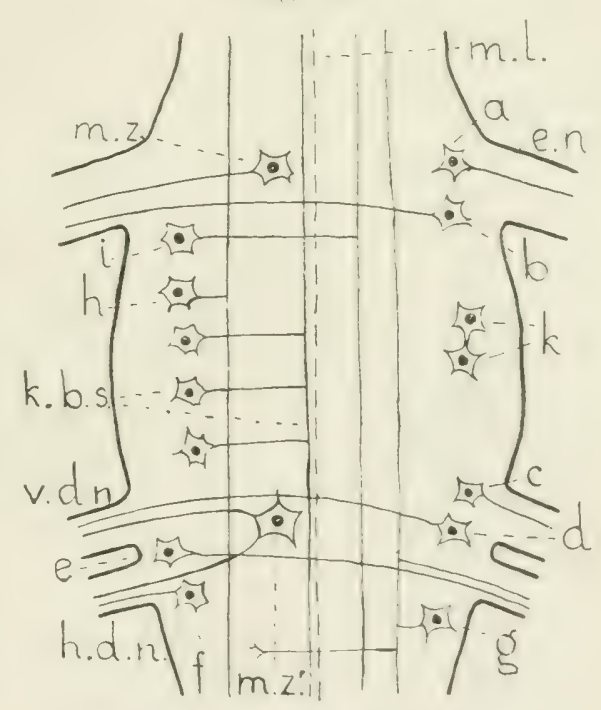

Bauchganglion von Lumbricus. Nach Haller (19J0).

$a$ bis $k=$ Ganglienzellen e. $n_{\text {。 }}=$ Einzelnerv

h. d. n. = hinterer Doppelnerv

k. b. s. $=$ Kettenbahnsystem

m. $s .=$ Medianlinie

$m . z$. und $m \cdot z^{\prime}$. = Mittelzellen

v. $d_{.} n \cdot{ }^{-}=$vorderer Doppelnerv misch nur sehr unvollkommen nachzuweisen, weshalb ich die Figur nicht reproduziere, sondern nur darauf verweise.

Neben den Neurochorden erwähnt HALLER die folgenden Ganglienzellen im Bauchganglion, welche zur Kenntnis der Leitungsbahnen beitragen. Neben den Wurzeln der peripheren Nerven liegen große Ganglienzellen, 
welche ihren Neurit in den Nerven derselben oder der anderen Seite senden (Fig. 43, $a, b, c, d, e, f$ ). Von diesen hatte HaLLer die Zellen des Einzelnerven schon in seiner vorigen Arbeit beschrieben (Fig. 43 und 39, $a, b$ ) und Retzius hatte die Zellen, deren Fortsätze die Medianlinie überschreiten schon gesehen (Fig. $41, d, e, f$ ).

Ventral im Bauchganglion neben der Medianlinie befindet sich auf der Höhe des Einzel- und des Doppelnerven ein Paar Mittelzellen (Fig. 43, m.z. und $m . z . ')$. Diese Ganglienzellen sind schon oben genannt, weil sie durch einen Fortsatz mit dem mittleren Neurochorde verbunden sind. Andere Fortsätze verbinden sie mit anderen Ganglienzellen, aber auch überliefert die vordere Mittelzelle dem Einzelnerven, die hintere dem vorderen und dem hinteren Doppelnerven einen Ausläufer.

Links und rechts im Bauchstrang beobachtete HALLER die schon bekannten longitudinalen Fasersysteme, wobei er ein ventrales und ein dorsales Bündel unterscheiden konnte. Einige dieser Längsfasern gehören zu Ganglienzellen, wie die Zelle $g$ der Figur 43, welche ich als Beispiel beschreiben möchte. Diese Zelle hat einen Fortsatz, welcher mit seiner longitudinalen Faser eine T-Figur bildet. Die Längsfaser selbst verzweigt sich aber auch wieder und zwar gibt es unter den Seitenästen Kollateralen, welche die Medianlinie kreuzen und dann enden; ein Seitenast geht in einen Nerven, hier den hinteren Doppelnerven, zur Peripherie des Körpers. Haller behauptet, aber ohne Grund und mit Unrecht, daß diese Nervenfasern der peripheren Nerven, welche sich im Bauchganglion einer Längsfaser 'T-förmig anschließen, dieselben seien, welche Vox LExHossek fälschlich als Fortsätze der Sinnesnervenzellen des Hautepithels beschrieben habe. Ich meine, entweder sind die von HALLer und die von Vox Lexhossek (und vielen anderen) gesehenen Nervenfasern nicht identisch, oder sie sind wie Vox LENHosseK es will Nervenfortsätze der Epithelsinnesnervenzellen.

HALLER beobachtete im Bauchganglion auch Ganglienzellen mit einem Fortsatz, welcher in eine Längsfaser derselben oder der anderen Bauchmarkshälfte zu verfolgen war (Fig. $43, h, i$ ) ohnedaß aber ein Seitenast in einen peripheren Nerven einträte. Der erste Typus war uns schon bekannt (Fig. 40, $f$, Fig. 4l, $n$ ).

Die fast immer bei Evertebraten von HALLER beobachteten multipolaren Ganglienzellen, welche mit ihren kurzen Fortsätzen nur mit ihren Nachbarn zusammenhängen, habe ich in der lig. 43 mit $l$ bezeichnet.

Ganz vereinzelt dastehend ist nach HALLER das ,Kettenbahnsystem“. Es besteht aus longitudinalen Nervenfasern, medial des dorsalen und ventralen Längsbündels gelegen, welche an regelmäßigen Stellen mit Fortsätzen lateraler Ganglienzellen verbunden sind (lïg. 43, li. l. s. s.).

Obgleich das Banchganglion von Lumbricus mehr als jeder andere 'I'eil des Nervensystems eines Evertebraten untersucht worden ist, so ist, glaube ich, die Zeit noch nicht gekommen, vom Laufe seiner Leitungsbahnen ein iibersichtliches Bild zu entwerfen. Dafür sind die meisten Nervenfasern und Ganglienzellen noch zu wenig häufig und konstant von mehr als einem forscher gesehen worden. 
Ist es nicht sonderbar, daß; wo so viele Reizleitungsbahnen im Bauchganglion des Regenwurms entdeckt worden sind, fast alle Angaben über die Wege der Nervenfasern im Hirnganglion und im unteren Schlundganglion fehlen? Fürwahr eine peinliche Lücke in unserer Kenntnis, welche bald ausgefüllt werden möge.

Mit den Oligochaeten haben wir die Unterklasse der Chaepotoden beendet und können wir jetzt also die Gephyreen unter den Anneliden besprechen, was mit wenigen Worten getan sein wird.

Meines Wissens hat nur HaLler (1889) sich mit den Leitungsbahnen einer Gephrree und zwar von sipunculus beschaittigt. Dieses Tier hat einen Bauchstrang ohne bestimmte Ganglien, welcher die peripheren Nerven aussendet. Zentral im Bauchstrang ist ein Neuropilem, welches von allen Seiten von unipolaren Ganglienzellen umringt wird, während ausschließlich ventral sich noch eine Schicht multipolarer Ganglienzellen zwi-

Nervensystem von Hirudo medicinalis. Nach

Bütschli (1912), Fig. 335.

b. g. = Bauchganglion

b. str. = Bauchstrang

d. = Darm

g. $i . o e .=$ ganglion infra oesophageum

1\%. s. ut. - sanglion $\approx 11$ praoesophageum

$k$. = Konnektiv

p. n. $=$ periphererNerv

$s . k$. = Schlundkonnektiv

s. $n$. = sympathisches Nervensystem schen dem Neuropilem und den unipolaren Ganglienzellen darbietet.

Die unipolaren Ganglienzellen senden alle ihren Fortsatz ins Neuropilem. Die multipolaren Ganglienzellen sind meist gegenseitig durch breite Fortsätze verknüpft. Auch ihre Fortsätze, bisweilen alle, können ins Neuropilem ziehen, aber einige gehen in die peripheren Nerven der gleichen oder der anderen Seite. In den peripheren Nerven werden sie begleitet von Nervenfasern, welche nach HALler dem Neuropilem entspringen, das heißt also wohl darin enden.

Wie man sieht, trifft die Bemerkung Bethes (1903), daß die Histologie des Nervensystems der Gephyreen nur sehr mangelhaft bekannt sei, auch jetzt noch völlig zu.

Die letzte Unterklasse der Anneliden ist jene der Hirudineen. Auch hier begegnet man (Fig. 44) wieder einem Schlundring (oberem Schlundganglion (g.s.oe.), Schlundkonnektiven (s.l.) und unterem Schlundganglion (g.i.oe.), ) welcher sich nach hinten in den Bauchstrang (b.str.) fortsetzt, der aus einer Reihe durch Konnektive ( $k$.) verbundener Ganglien (b.g.) besteht. Jedes Bauchganglion verlassen zwei Paar peripherer Nerven (p.n.).

Ian hat oft versucht die Hodologie der Hirudineen und namentlich von Hirudo medicinalis, des Blutegels, kennenzulernen.

Schon Bruch (1849) hat im Jahre 1849 damit angefangen und er ist daher überhaupt der erste, welcher sich über den Lauf der Leitungsbahnen eines Wurmes Rechenschaft geben wollte. Sehr interessant ist es, daß ihm schon die Darstellung der ganzen topographischen Histologie eines Evertebraten-Nervensystems vor Augen schwebte. Wie mancher hat nach ihm dasibelbe versucht ohne daß es jemandem bis jetzt gelungen ist, dieses Problem zu lösen !

Die Bauchganglien stimmen nach BRUCH im allgemeinen alle in ihrem 
feineren Bau überein. Aus jedem Bauchganglion gehen zwei Paar Nerven hervor, der vordere und der hintere, periphere Nerv (Fig. 45, v.n. und h.n.). Die Ganglien werden durch zwei deutlich getrennte Konnektive (Fig. 45 k.) verbunden, überdies aber durch den Nediannerven, welcher auch hier richtiger Mediankonnektiv genannt wird.

In den Konnektiven sah BRUCH Nervenfasern unbekannter Herkunft, welche das ganze Ganglion der Länge nach durchzogen (Fig. 45, a), andere, welche von vorne herkommend in den vorderen orler den hinteren Nerven der gleichen Seite eintraten (Fig. 45, b, c).

Figr. 4.).

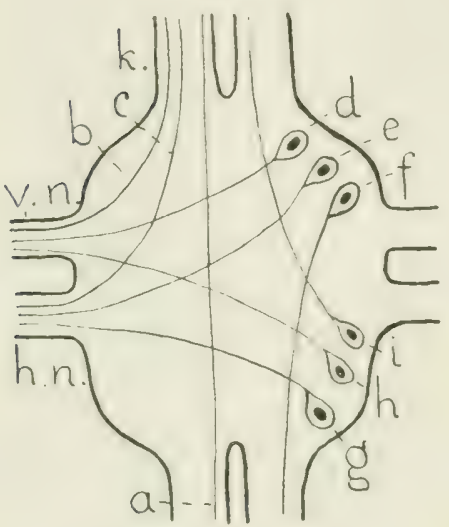

Bauchganglion von Hirudo medicinalis. Abgeändert nach BRUCH (1849).

$a, b, c=$ Nervenfasern

l bis $i=$ Ganglienzellen

h. $n_{\text {. }}=$ hinterer Nerr

l. $=$ Konnektiv

r. n. = vorderer Nerv

In den vier Ecken des Ganglions befinden sich Ganglienzellen. Jene aus der vorderen Hälfte des Ganglions senden ihren Fortsatz in das Konnelitiv derselben Seite nach hinten (Fig. 45, f), oder ihre Fortsätze überschreiten die Medianlinie und ziehen in einen peripheren Nerven, den vorderen oder den hinteren. weiter ( $d$ und $e$ ).

Nicht so deutlich war Bruch der Weg, welchen die Fortsätze der Ganglienzellen in der hinteren Hälfte des Ganglions einschlagen. Wahrscheinlich kreuzen einige die Medianlinie und biegen in die peripheren Nerven ab (Fig. $45, g, h)$; vielleicht auch ziehen andere im Konnektive derselben Seite nach vorn (Fig. 45, i).

Der Weg der Nervenfasern ist, wenn man BRUCII glauben will, in den peripheren Nerven nicht ohne weiteres klar, denn es sind nach ihm überall in die peripheren Nerven Ganglienzellen eingelagert, was aber später, wie wir sehen werden. sowohl verneint, wie bejaht wurde. Der vordere Nerv des Ganglions geht bald in ein Ganglion über, dessen Zellen nach Bruch gewiß apolar, also ohne Fortsätze sind und das gleiche ist für die Seitenäste des vorderen Nerven zutreffend. Es werden oft, besonders von älteren Autoren apolare Ganglienzellen bei Evertebraten erwähnt, aber ich glaube, es ist keinem Zweifel unterlegen, daß diese Zellen, falls sie nicht ganz junge Ganglienzellen, Neuroblasten, sind, entweder Fortsätze besitzen, oder keine Ganglienzellen sind.

Die kleineren teste des vorderen Nerven. sowie der hintere Nerv und seine Aeste enthalten dagegen bipolare Ganglienzellen.

Im Lehrbuche der Histologie, welches LEYDIG 1857 publizierte, finden wir die Ergebnisse BRUCHs und einiger anderen Forscher in einer Figur 93 dargestellt, welche ich hier der Kuriositiit wegen reproduzieren will (Fig. 46). Es ist eine der ältesten Abbildungen des Nervenfaserverlaufs eines Evertebraten. Sie versimnbildlicht nach LEY Dic den mutmaßlichen Faserverlauf von Piscicola, aber eine Vergleichung mit Fig. 45 lehrt, daß dieser Abbildung 
des Bauchganglions die auch im Texte zitierte Bruchsche Arbeit zu Grunde gelegt wurde und darin wurde mit dem ,Blutegel" wahrscheinlich Hivudo und nicht Piscicola gemeint.

Die Beschreibung, welche LEYDIG der Figur beifügte, ist unvollständig, aber die Figur spricht für sich selbst. Es sei namentlich auf die sonderbare Kommissur im Hirnganglion hingewiesen.

Im Jahre 1875 erschien das oft zitierte Buch ,Das Centralnervensystem ron Hirudo medicinalis" von HrRarand. Ich weiß, daß es Angaben ïber die Wege der Nervenfasern enthålt, aber das Buch selbst war mir leider nicht zugänglich. Ich vermute, daß, was HERuIANN richtig beobachtete, nachher schon alles ron anderen Forschern wiedergefunden ist und tröste mich damit über meine Unbekanntheit mit diesem Buche.

HANSEN (1881) war der erste, welcher der Bruchschen Meinung, daß überall in den peripheren Nerven Ganglienzellen eingelagert seien, entgegentrat. Und doch stand BRUCH in dieser Meinung nicht allein, denn auch LEydig, wie Figur 46 beweist, und HERMIAN (nach VIGNAL 1883) erklärten sich (lavon überzeugt. HANSEx num hat einen nicht näher bestimmten Blutegel (Hirudo ?) mit Hilfe einer Goldchlorid-Methode untersucht und dabei wahrgenommen, daß die Terven, welche von den Bauchganglien zu den willkürlichen Muskeln gehen, keine Ganglienzellen enthalten und keinen Plexus bilden, sondern in motorischen Endapparaten enden.

Kurz nachher hat auch VIGNAL (1883)

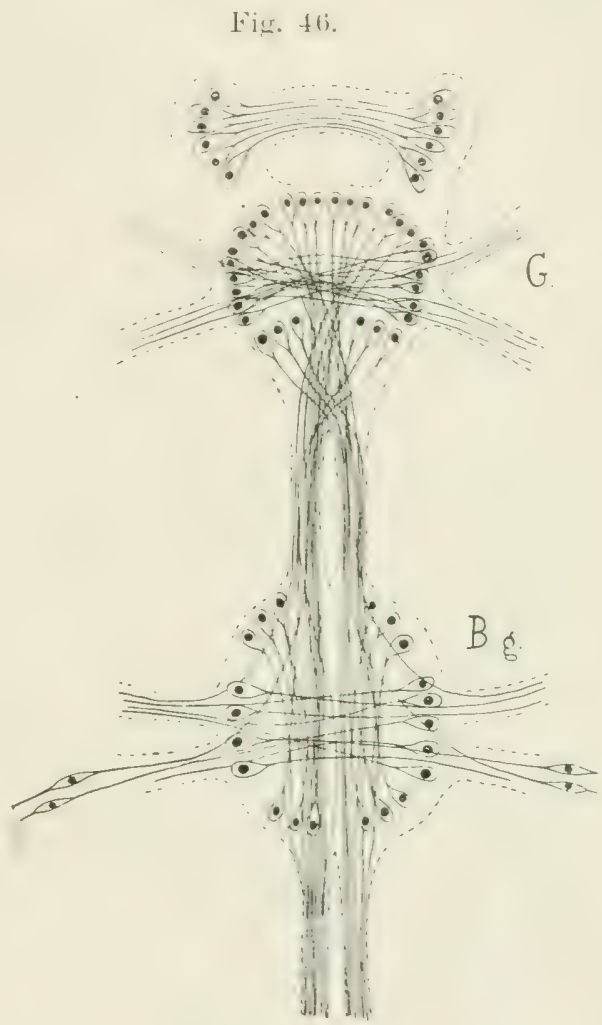

Schema der mutmaßlichen Reizleitungsbahnen in Nervensystem von Piscicola. Kopie der Fig. 93 aus dem LEYDiGschen Lehrbuche (1857).

$\cdot G_{0}=$ Gehim

B. $y_{0}=$ erstes Bauchganglion bei den Hirudineen die ïberall in den

Nerven verbreiteten Ganglienzellen geleugnet und die diesbezüglichen Angaben auf einzellige Parasiten in den Nervenhüllen zurückgefuihrt; wohl aber gibt er zu, claßs jeder Nerv dicht neben dem Bauchstrang ein Lateralganglion passiert. VIGNAL äußert sich auch über das gastrointestinale oder sympathisehe Nervensystem und sagt davon, daß es ein Nervenplexus mit eingelagerten Ganglienzellen ist.

In dieser letzten Mitteilung ging ihm RANviER (1880) voran, welcher beim Blutegel (Hirudo?) in den Darmdivertikeln einen weitmasehigen Nervenplexus beschrieb unit Ganglienzellen, welehe den Nerven eingelagert waren oder mit kurzen Stielchen, den Stammfortsätzen, aufsaßen.

Später hat Apatrर (1897) für Pontobdella festgestellt, claß der Plexus im Darm eir wahrer Ganglienzellplexus ist, wie er so oft bei den Coelenteraten angetroffen wird und also kein Nervenplexus. Es sind dann keine bestimmte Leitungsbahnen darin nuchweisha. 
Unsere Kenntnis der Bahnen im Zentralnervensystem der Hirudineen ist nicht mehr bereichert worden, bis EHRLICH seine Methylenblau-Methode entdeckte. Mit Hilfe dieser Methode wurde im Jahre 1891 Hirudo medicinalis von Biedermann und nebst Hirudo auch Aulastomum von Retzius untersucht.

Biederuani (1891) bestätigte, daß zwei Paar peripherer Nerven (Fig. 47, v.n. und h.n.) aus jedem Bauchganglion hervorgehen und daß die Ganglien von den beiden lateralen Konnektiven $\left(l . k_{*}\right)$ und den Mediannerven

Fig. 47 .

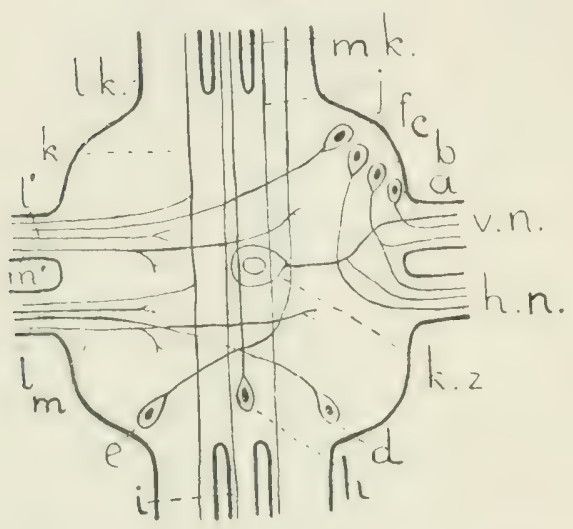

Bauchganglion von Hirudo medieinalis. Nach Biedermiann (1891).

$a$ bis $h=$ Ganglienzellen

$i$ bis $m=$ Nervenfasern

h. n. = hinterer Nerv

li. $z .=$ Kolossalzelle

l. 1. a laterales Konnektiv

m. k. = medianes Konnektiv

v. $n_{0}=$ vorderer Nerv (oder Mediankonnektiv $m . k$. .) verbunden werden. In der Fig. 47 habe ich das Mediankonnektiv eingezeichnet, weil Biedermann auch darin Leitungsbahnen schildert.

Biedermany fand im Ganglion manche Ganglienzelltypen. Zuerst sah $\mathrm{er}^{\circ}$ in oder neben der Medianlinie ein Paar kolossaler Ganglienzellen (Fig. 47 , k.z.). Er erkennt ihnen nur einen Fortsatz zu, welcher nicht gut verfolgbar war, sich aber wahrscheinlich spaltet und jedem peripheren Nerven einen Ast zusendet. Diese beiden Zellen sind auch von anderen Autoren später wiedergefunden, aber niemals, ungeachtet ihre Größe, mit den Neurochordzellen anderer Würmer verglichen worden, was sich doch der Niihe lohmen würde. Neurochordzellen würden den Hirudineen abgehen nach dem heutigen Standpunkte.

Lateral im Ganglion liegen verschiedene Jypen kleiner Ganglienzellen. Ihr Fortsatz verlässt das Ganglion durch den vorderen oder hinteren Nerven oder nach Spaltung durch beide (Fig. 47, a, b, c). Bisweilen aber iberschreitet der Fortsatz die Medianlinie und tritt in einen Nerven der anderen Seite aus (Fig. 47, $d, f$ ). Diese Zellen stimmen also mit von BRUCI gesehenen Ganglienzellen überein (Fig. 45, d, $e, g, h$ ). (In der Fig. 47 ist die Lage der Ganglienzellen $a, b, c, d$ und $f$ willkürlich von mir gewählt worden.) Es gibt auch Ganglienzellen (Fig. 47,e), deren Fortsatz sich nach Kreuzung in das laterale Konnektiv fortsetzt.

Schließlich beobachtete Biedermaxy hinten im Ganglion eine mediane Ganglienzelle (Fig. 47,h), welche einen Fortsatz nach vorn in den Mediannerven (das Mediankomektiv) aussendet. Es ist mir nicht klar, ob diese Zelle mit einer Medianzelle anderer Autoren identifiziert werden darf.

Neben diesen Ganglienzellen und ihren Fortsätzen (die Kollateralen sind wiederum unberïckichtigt gelassen) hat Bredermaxis auch Nervenfasern unbekannter Herkunft gesehen. In jedem peripheren Nerven sind 
Fasern vorhanden, welche im Neuropilem des Ganglions verästelt enden und darunter im vorderen und hinteren Nerven zwei besonders starke Fasern, von denen die eine sich im Neuropilem der Eintrittsseite, die andere auch in der anderen Seite des Ganglions verzweigt (Fig. $47, l, l$ ', $m, m^{\prime}$ ).

In den Konnektiven, in den lateralen so gut wie im medianen, befinden sich Fasern, welche das ganze Ganglion durchsetzen ohne darin andere Aeste als kleine Kollateralen abzuspalten (Fig. 47, $i, j$ ), aber iiberdies ist in jedem lateralen Konnektive eine Nervenfaser (Fig. $47, k$ ), welche in den vorderen und den hinteren Nerven einen. Zweig hineinschickt.

Vielleicht hat Bruch diese Nervenfaser gemeint, als er sagte, daß Fasern des Konnektivs in die Seitennerven abbögen (Fig. 45, $b$ und $c$ ), aber gewiß hat er die Konnektivalfasern, welche das ganze Ganglion durchschreiten, gesehen (Fig. 45, $a$ ).

Retzius (1891) hat, wie gesagt, im selben Jahre wie BIEDERMANN und ebenfalls mit Methylenblau die Hodologie des Bauchganglions von Aulastomum gulo erforscht, aber die Untersehiede mit Hirudo medicinalis sind nach ihm sehr unerheblich, sodaß die hier folgende Beschreibung für beide Arten passt.

Das Bauchganglion von. Aulastomum (Fig. 48) hat im allgemeinen dieselbe viereckige

Fig. 48.

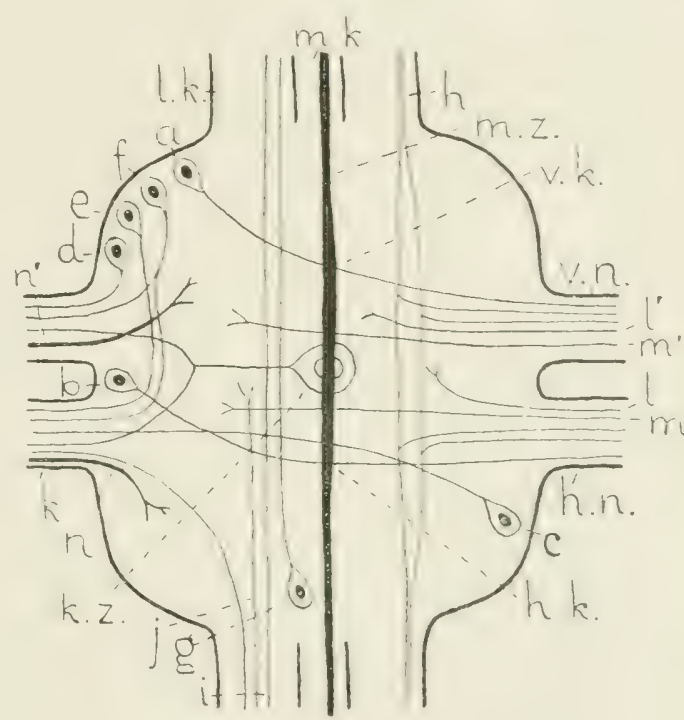

Bauchganglion von Aulastomum gulo. Nach Retzius (1891).

$$
\begin{aligned}
& a \text { bis } g=\text { Ganglienzellen } \\
& h \text { bis } n=\text { Nervenfasern } \\
& \text { h. } k_{0}=\text { hintere Kommissur } \\
& \text { h. } n \text {. = hinterer Nerv } \\
& \text { k. z. = Kolossalzelle } \\
& \text { l. } k \text {. = laterales Konnelstiv } \\
& m . k_{0}=\text { medianes Konnektiv } \\
& m . \% \text {. Medianzelle } \\
& v, k_{0}=\text { vordere Kommissur } \\
& \text { v. } n \text {. }=\text { vorderer Nerv }
\end{aligned}
$$
Gestalt, wie das Bauchganglion von Hirudo. Es gehen daraus seitlich zwei Paar Nerven hervor und vorn und hinten schließt es sich den Konnektiven an, welche hier alle drei (der Mediannerv als Konnektiv gerechnet) mit einandci verwachsen sind.

Die Ganglienzellen, welche ausnahmslos unipołar sind, liegen peripher ums Neuropilem geordnet und zwar bilden sie nach RETziUs acht Gruppen, vier zwischen den Nerven und Konnektiven, zwei zwischen den vorderen und hinteren Nerven und zwei an der Eintrittsstelle der Konnektive. Die beiden 
Hälften des Ganglions werden durch zwei Kommissuren, eine vordere und eine hintere verbunden (Fig. 48, v.k., h.k.).

Retzius konnte acht Ganglienzelltypen unterscheiden. Der erste (Fig. $48, a)$ ist vorn und lateral im Ganglion. Sein Fortsatz geht in die vordere Kommissur und weiter in den vorderen peripheren Nerven. Diese Zellart wurde auch schon von. BRUcH (Fig. 45. d) und wahrscheinlich auch von BIEDERMAxN (Fig. 47, $f$ ) beobachtet, obgleich Retzius, welcher oft auf BiederMANN verweist, solches nicht meldet, wahrscheinlich, weil BIEDERMANN die Lage dieser Zellen nicht genau beschreibt. Retzius glaubt, daß an jeder Seite im Ganglion wenigstens zwei solcher Zellen sind.

Zwischen den beiden Nerven ward eine Ganglienzellgruppe entdeckt, deren Zellen (Fig. 48, b) Fortsätze haben, welche in der hinteren Kommissur die Medianlinie kreuzen und in den hinteren Nerven austreten: Darin stimmen sie mit Ganglienzellen überein, welche hinten im Ganglion liegen (Fig. 48, c) und welche auch schon von Bruch (Fig. 45, g) und, falls ihre Lage dieselbe ist, auch von Biedermaxy (Fig. 47, d) beobachtet wurden.

Vorn im Ganglion sah Rerzius Ganglienzellen, welche ihren Fortsatz in den vorderen oder hinteren Nerven derselben Seite sandten (Fig. 48, $d, e$ ), oder deren Fortsatz sich gabelte und mit einem Ast in beiden Nerven weiterzog (Fig. 48, f). Biederuans hat, wie auch Retzius mitteilt, diese Ganglienzellen in seinen Präparaten gefunden (Fig. 47, $a, b, c$ ).

Noch eine andere Ganglienzellgruppe ist hinten im Ganglion vor dem Konnektive gelegen. Ihre Zellen (Fig. 48, g) besitzen einen Fortsatz, welcher nach vorn in das Konnektiv zieht.

Zuletzt muß ich noch melden, daß Retzius, so gut wie BIEDermaxy, im Ganglion die beiden Kolossalzellen erblickte. Sie sind neben oder hinter einander gestellt in der Mitte des Ganglions oder mehr nach vorn. Auch sie sind unipolar (Fig. 48, li.z.), aber ihr Fortsatz teilt sich dichotomisch und ein jeder Ast tritt in einen peripheren Nerven derselben Seite ein. Bisweilen aber deszendiert nach Retzius ein dritter Ast in das Konnektiv.

Retzius entdeckte im Bauchganglion sieben Nervenfasersysteme von denen ihm die Ganglienzellen unbekannt blieben.

In den Mediankonnektiven laufen zwei überaus breite Fasern (Fig. 48, m.z.), welche das ganze Ganglion durchsetzen und nach Retzius Nervenfasern sind. Bei Hirudo medicinalis bilden sie Anastomosen. REтzius identifiziert diese Fasern mit den , Medianzellen" Hermaxss und, obgleich er darin keine Kerne sah, betrachtet er sie doch als langausgezogene, spindelförmige \%ellen.

Wie mich die Zitate Hallers (1889) und Mexcls (1908) lehren, ist HerMANX der Ansicht, dal3 bei Hirudo alle Medianzellen durch lortsätze zusammenhängen. Jedes Ganglion soll zwei hinter einander liegende Vedianzellen enthalten, welche sechs Fortsätze haben und einer ihrer beiden lateralen Ausläufer soll in einem peripheren Nerven das Ganglion verlassen. Letzteres stimmt nun nicht mit den RETziUsschen Angaben und später hat RonDE (1892 a) Medianzellkörper neben diesen Riesenfasern entdeckt. Retzrus identifiziert seine Riesenfasern also mit Unrecht mit den Hirmaxischen 
Medianzellen oder höchstens sind die Riesenfasern Fortsätze der Medianzellen. Dann aber, wo Mexcl (1908), nachdem zuerst Rohde (1892 a) bei Hirudineen die nervöse Natur der Medianzellen angezweifelt hatte und JosEPH (1902), K. C. Schxemer (1902) und Livaxow (1906) sie als Gliazellen bezeichnet hatten, ihren Charakter als Gliazellen unzweifelhaft erwiesen hat, wage ich es nicht, die sehr breiten Fasern, welche Retzrus fand als Nervenfasern oder Ganglienzellen zu betrachten.

In den Lateralkonnektiven liegen die Fasern, welche auch BiederMans beobachtete (Fig. 47,k), aber nach Retzius nicht genau beschrieb. Das Bündel dieser Nervenfasern (Fig. 48, $h$ ) spaltet sich, wenn es im Ganglion angelangt ist und jedes dieser beiden Bündel liefert jedem peripheren Nerven einen Seitenast.

Die Konnektivalfasern, welche dem Ganglion nur kleine Kollateralen abtreten (Fig. 48, $i$ ) blieben REtzIUs ebensowenig verborgen als BRUCH (Fig. 45, a) und Biedermany (Fig. 47, j). Daneben gibt es Nervenfasern des Konnektivs, welche im Neuropilem des Ganglions enden (Fig. 48, $j$ ) oder in einem peripheren Nerven sich seitwärts krümmen (Fig. 48, k). Fasern des letzten Typus sah auch BRUCH (Fig. $45, b$ ), aber nur in der vorderen Ganglionhälfte.

Die zwei dicken Nervenfasem, welche BIEDERuIAxs in jedem peripheren Nerven erforscht hat und welche zur gleichen Seite oder nach Kreuzung im Neuropilem enden (Fig. $47, l, l^{\prime}, m, m^{\prime}$ ), hat auch Retzius bei Aulastomum wiedergefunden, aber im vorderen Nerven gelang ihm das nur schwer (Fig. $48, l, l$, $\left.m, m^{\prime}\right)$. Hirudo ist aber nach Retzius im hinteren Nerven mit zwei Fasern des Typus $l$ ausgestattet, was BIEDERMiAvs entgangen ist.

Noch stärker als die letztgenannten Fasern sind zwei Fasern, welche mit den beiden peripheren Nerven ins Ganglion eintreten und sich dort verästeln (Fig. $\left.48, n, n^{\prime}\right)$. Sie laufen ventral und kommen in ihrer Dicke den Riesenfasern gleich.

Auch das untere Schlundganglion ist nicht von RETzius vergessen worden und der Bau ist ähnlich bei Aulastomum und Hirudo.

Das Ganglion enthält vier Paar. Kolossalzellen (auch das letzte Ganglion des Bauchstranges hat deren mehr als zwei) und es hat daher vielleicht den Wert von vier Bauchganglien. Aber die Fortsätze des ersten Paares kreuzen die Medianlinie und sind deshalb vielleicht ein andere: Zelltypus.

Hanche Ganglienzellen des ganglion infraoesophageum senden Fortsätze zur anderen Seite des Ganglions oder in die Schlundkonnektive. Dem letzten Beispiel folgen die Medianzellen.

Es darf uns nicht wundern, daß es auch Fasern der Schlundkonnektive und der peripheren Nerven gibt, welche im unteren Schlundganglion enden.

Das Hirnganglion ist nach Retzius einfach gebaut, aber die Wege der Nervenfasern darin beschreibt er nicht.

Rohde (1892 a) hat sich später als Retzrus mit der Histologie des Nervensystems der Hirudineen beschäftigt. Da er aber alle Nervenfibrillen, weil sie nach ihm in die Fibrillen der Nervenhüllen übergehen, als Stuitzgewebe betrachtet und die interfibrilläre Masse als nervös, so wird der Begriff bestimmter Leitungsbahnen an manchen Stellen ganz hinfüllig. Ich kann die 
Ansicht RoHDEs, welche auch von NAxSEx und anderen, neuerdings noch von Goldschmid (1910) vertreten wird, nicht teilen und schließe mich darin gar manchen Gelehrten an.

RoHDE hat besonders Pontobdella muricata und Aulastomum gulo untersucht. Er fertiste Schnittserien und zupfpräparate an, aber die Goborsche Methode wollte ihm nicht gelingen.

Bei Pontobdella beobachtete er im Bauchganglion einige starke Ganglienzellfortsätze, welche in die peripheren Nerven eintreten und derartige dicke Nervenfasern sah er bei Aulastomum in den peripheren Nerven. Auch sah er Nervenfasern im Ganglion van Aulastomum und Pontobdella, welche die Medianlinie kreuzten, konnte aber ihre Ganglienzellen nicht nachweisen.

ROHDE hat auch in einem großen Teile des Bauchmarks die beiden Riesenfasern wahrgenommen, welche Aulastomum im Mediankonnektiv (Mediannerven), Pontobdella hingegen in den lateralen Konnektiven aufweist. Es sind dies die Fasern, welche Rexzius mit den Hermaxxschen Medianzellen homologisierte (Fig. 48, m.z.) ohne ihre Kerne entdecken zu können, aber RонDE beschreibt außerhalb dieser Fasern in jedem Ganglion zwei multipolare, hinter einander gelegene Medianzellen, welche er, wie gesagt, mit Recht, als Stiutzelemente betrachtet. Wenn also die Riesenfasern nicht Fortsätze dieser Medianzellen sind (ROHDE konnte ihre Herkunft nicht entdecken), hat ReTzius (1891) sie mit Unrecht zu den Nedianzellen in Beziehung gebracht und können es sehr gut Nervenfasern sein, wie er anfänglich meinte.

RoHDE bestätigt auch die Bruchsche Angabe über die Gegenwart von Ganglienzellen in den peripheren Nerven, denn er fand darin einige große multipolare Ganglienzellen. Ich weiß nicht wem ich glauben muß: BRUCH und ROHDE, welche Ganglienzellen zu sehen meinten oder HANsEN und VIGNAL, welche sie verneinten. Dennoch ist die Sache für unsere Kenntnis der Leitungsbahnen sehr wichtig.

Mitten in jedem Konnektiv entdeckte RoHDE eine bipolare Zelle, welche er als eine mutmaßliche Ganglienzelle und nicht als eine Gliazelle deutete, aber ich glaube, daß HExcL (1908) später überzeugend dargetan hat, daß diese Konnektivalzellen der Hirudineen Gliazellen sind.

Eine wirkliche Ganglienzelle ist noch die bipolare Zelle, welche zwischen den Wurzeln des vorderen und hinteren Nerven im Bauchganglion liegt und dort von LEYDiG entdeckt wurde. ROIIDE sah, und BRISTOL (1898) hat dies bestätigt, daß sie einem jeden dieser beiden Nerven einen Fortsatz zuteilt. Daß diese Zelle, wie Hermaxy es will, einen dritten Fortsatz ins Zentrum des Ganglions senden sollte, verneint er.

Ich kann es nicht unterlassen an dieser Zelle auch auf die beriihmten Untersuchungen hinzuweisen, welche APATHY (1897) bei Hirudo und auch bei Lumbricus angestellt hat, obgleich, wie bekannt, die Struktur des ganzen Nervensystems nach АPATHY so wäre, daß darin anatomisch keine bestimmten Leitungsbahnen nachzuweisen sind, weil die Fortsaitze der nervösen Zellen ein diffuses Maschenwerk bilden und somit für meinen Zweek diesen Forschungen lieine Angaben zu entlehnen sind. Wic ich mich den APATHYschen Anschaumgen gegeniiber verhalte, habe ich schon in der Einleitung gesagt. 
In den folgenden Jahren findet auch das periphere Nervensystem der Hirudineen wieder Berücksichtigung. Hesse (1897 b) erwies endgültig, daß die Sehzellen des Auges mancher Hirudineen Sinnesnervenzellen sind und daß ihre basalen Fortsätze den Sehnerven bilden, welcher ins Hirnganglion eintritt.

Der erste, welcher sich bewußt war, daß die Sehzellen der Hirudineen sich kontinuirlich in Nervenausläufer fortsetzen und die Nervenfasern sich ihnen nicht nur nähern, ist wahrscheinlich WHIruAN (1889) gewesen, welcher sich dahin äußert, daß die Nervenfaser in die helle Sehzelle an der Seite des Kernes eintritt.

Später hat MaYer (1892) sowohl in Zupfpräparaten wie in Schnitten beobachtet, wie die Sehzellen im Auge sich in Nervenfasern fortsetzen und zwar bei Hirudo, Aulastomum, Clepsine und Piscicola.

Hesse hat also in dieser Hinsicht keine Priorität (was er auch nicht behauptet), aber wohl sah er als erster, daß auch die Zellen einer Sinnesnervenzellgruppe, welche bei Mesobdella gemmata und Haementeria officinalis in der Epidermis vorhanden ist, sich in Nervenfasern fortsetzen, welche sich dem Sehnerven anschließen. Später hat Livaxow (1906) dies für Acanthobdella bestätigt.

Auch Retzius (1898) hat versucht, das periphere Nervensystem der Hirudineen näher bekannt zu machen. Er zeigte mit Hilfe der GolgIschen und der Methylenblau-Methode in der Haut von Clepsine bipolare Sinnesnervenzellen nebst frei endenden Nervenfasern unbekannter Herkunft, also die beiden bei Würmern allgemeingültigen Weisen der sensibelen Innervation.

Bristol (1898), hat in seiner Arbeit über die Metamerie von Nephelis auch manche Leitungsbahnen im peripheren Nervensystem aufgeklärt, wobei ihm u.a. eine Goldchlorid-Methode geholfen hat.

BRIstol entdeckte einen bis dahin unbekannten Nervenring, welcher in einigen Körperringen mit den Ordnungszahlen 5, 8, 11, 13, 16 u.s.w. zwischen den Muskeln gelegen ist und daher von BRIsToL der intermuskulare Nervenring genannt wurde.

Jeder Nervenring sendet Nervenfasern in ein Ganglion des Bauchstranges durch dessen vorderen und hinteren Nerven und empfängt Nervenfasern auf demselben Wege. Diese Nervenfasern innervieren die Muskeln und die Sinnesorgane.

Vom dritten Nervenringe ab liegen halbwegs zweier Nervenringe acht bipolare Ganglienzellen, welche die beiden benachbarten Ringe verbinden, weil sie ihre Fortsätze darin aussenden und zwar gerade an den Stellen, wo auch Aeste des vorderen und hinteren Nerven des Bauchganglions in den Ring eintreten.

Jedem Nervenringe sitzen zehn Ganglienzellgruppen auf, sechs dorsal und vier ventral. BRISTOL nent diese Zellen bipolar, aber aus seinen Abbildungen erhellt, daß es unipolare Ganglienzellen sind, deren Stammfortsatz sich bald 'I'-förmig in zwei Aeste spaltet. Die beiden Fortsaitze laufen im Nervenringe in entgegengesetzten Richtungen. 
Die laterodorsale Gruppe wird von sechs bis acht Ganglienzellen gebildet, die beiden mediodorsalen Gruppen jede von einer einzigen Ganglienzelle. Die lateroventrale Gruppe ist auch tatsächlich nur eine Ganglienzelle, aber die medioventrale weist zwei oder drei Zellen auf. Die Fortsätze dieser Ganglienzellen konnten im Ringe nicht bis zu ihrem Ende verfolgt werden. Es ergab sich nur, daß Fortsätze der medioventralen Ganglienzellen in einen Ast des vorderen Nerven des Bauchganglions traten und also wahrscheinlich den Bauchstrang erreichten.

Bristol ist der Meinung, daß alle diese Ganglienzellen und Fasern des Nervenringes noch weiter mit der GoLgischen oder mit der MethylenblauMethode studiert werden müssen. Teilweise hat HAVET $(1900 a)$ das getan und dabei gesehen, daß die Sinnesnervenzellen der Haut, welche Retzius entdeckte, welche aber Bristol noch nicht bekannt sein konnten, ihre Nervenfortsätze in diesen Ring und weiter ins Bauchganglion senden.

Bristol, welcher voraussetzte, daß die afierenten Nervenfasern der peripheren Nerven, welche Retzrus im Bauchganglion der Hirudineen enden sah, die Fortsätze der Ganglienzellen des Nervenringes scien, kann also jetzt nur noch teilweise Pecht bekommen.

Ebenso glaube ich nicht, daß Bristol Recht hat, wenn er ohne Beweis behauptet, daß3 alle Ganglienzellen der Nervenringe und die zwischenliegenden bipolaren Ganglienzellen zusammen mit den Medianzellen, den Konnektivalzellen und den LEYDIGschen Zellen, wie er die bipolaren Ganglienzellen nennt, welche an der Abgangsstelle der peripheren Nerven gelegen in die beiden Nerven einen Fortsatz senden und welchem wir schon bei Rorde begegnet sind, ein einziges zusammenhängendes System kolossaler Ganglienzellen bilden.

Bristol hat auch das sympathische Nervensystem von Nephelis studiert. Es geht aus dem Schlundringe hervor. Ander Abgangsstelle liegen drei Ganglienzellgruppen, zwei in den Wurzeln des sympathischen Nervensystems und eine im Schlundringe. Thre Zellen haben Fortsätze, welche in die Zweige des sympathischen Nervensystems ziehen. Diese Zwreige bilden einen Nervenplexus um die Mundhöhle, den Oesophagus und den Darm.

Im Plexus um die Mundhöhle, also vor dem Schlundringe sind nur Nervenfasern und keine Ganglienzellen. Diese Nervenfasern stammen von Ganglienzellen her, welche in der Nähe des Schlundringes im sympathischen Nervensysteme angehäuft liegen. Hinter dem Schlundringe aber, also in der Umgebung des Oesophagus und des Darmes, besteht der Plexus aus multipolaren Ganglienzellen und ihren liortsätzen.

Die bipolaren Sinnesnervenzellen der Haut, welehe Retzius bei Clepsine entdeckte, hat HAVET (1900 a) bei diesem $\mathbf{W u r m}$, aber auch bei Nephelis vulgaris und Hirudo mit Hilfe der GoLsischen Methode wiedergefunden, aber außerdem hat er ihre Nervenfortsätze bis zum Ende verfolgt und dabei entdeckt, daß sie sich ebenso wie bei den Oligochaeten verhalten.

Bei Nephelis liegen die Simnesnervenzellen einzeln oder in Gruppen und ihr eigentlicher Zellkörper befindet sich entweder in der Épidermis oder auch tiefer unter der Oberfläche zwischen den Muskeln. Unmittelbar unter 
der Epidermis und auch mehr nach innen zwischen den Muskelschichten befinden sich Nervenfaserbündel, welche die Wege der Nervenfortsätze dieser Sinnesnervenzellen sind, wenn sie sich zu den peripheren Nerven des Bauchmarks und in das Bauchganglion begeben. Die inneren Nervenfaserbündel bilden den BRISTOLschen intermuskularen Nervenring und sie enthalten nach HAVET nicht nur die Fortsätze der Sinnesnervenzellen. sondern auch motorische Nervenfasern zu den Muskeln, wie auch Bristol behauptete.

Die sensibelen Nervenfasern verzweigen sich nicht, ehe sie das Bauchganglion erreicht haben. Dann aber teilen sie sich T-förmig in einen aszendierenden und einen deszendierenden Ast, welche entweder im nächsten Ganglion oder schon im Konnektiv enden. Diese Längsnervenfasern bilden ganz wie bei Oligochaeten drei Bündel und überhaupt sind also, wie man sieht, die epidermalen Sinnesnervenzellen und das Verhalten ihrer Fortsätze, welche die sensibelen Nervenfasern bilden, einander völlig gleich bei Oligochaeten und Hirudineen, denn so wie Nephelis verhalten sich nach Havet auch Hirudo und Clepsine.

Havet ist der Meinung, daß die von Retzius bei Aulastomum beobachteten Nervenfasern $h$ meiner Fig. 48, die eben genannten eintretenden sensibelen Nervenfasern sind. Es mag sein, aber da würde sich nicht nur Retzius, sondern auch Biederians, welcher diese Fasern fast genau so sieht (Fig. 47,k), in seiner Beschreibung geirrt haben und es scheint mir daher vorsichtiger vorauszusetzen, daß das Methylenblau die von Havet entdeck-

Fiu. $+!$.

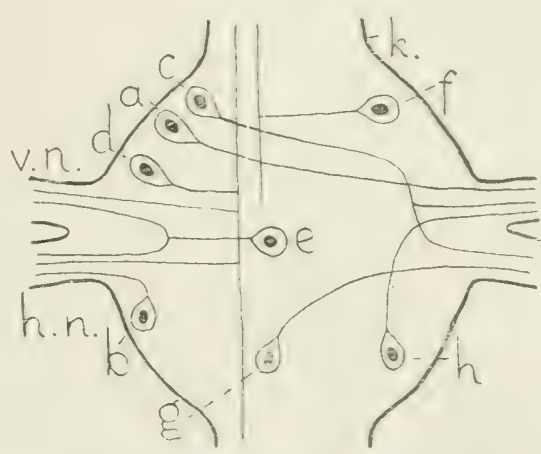

Bauchganglion von Nephelis. Nach Havet (1900a).

$a$ bis $h=$ Ganglienzellen

h. n. = hinterer Nerv

$k$. $=$ Konnektiv

$v$. n. $=$ vorderer Nerr

ten sensibelen Nervenfasern in ihren Präparaten nicht mitgefärbt hat.

Jene Fortsätze der Sinnesnervenzellen, welche ins untere Schlundganglion eintreten, finden daselbst ihr Ende, ohne weiter nach hinten oder zum Hirnganglion zu laufen.

Havet beobachtete bei Nephelis auch Nervenfasern, welche in der Epidermis enden, ganz wie Retzius (1898) bei Clepsine. Aber gegenüber Retzius behauptet er, daß diese keine frei endenden sensibelen Nervenfasern sind, sondern motorische der benachbarten Muskelfasern. Ich kann darin HAVET nicht beistimmen.

Havet hat im Bauchganglion von Nephelis manche verschiedenartigen Ganglienzellen wahrgenommen, welche ich in der Fig. 49 schematisch darstelle. Sämtliche Ganglienzellen sind unipolar.

Es gibt zwei Zelltypen uns schon von anderen Hirudineen bekannt. Der erste, (Fig. 49, a) hat einen Nervenfortsatz, welcher die Medianlinie kreuzt und in einem peripheren Nerven verschwindet. Solche Zellen liegen 
nicht nur vorn im Ganglion, sondern auch an der Abgangsstelle der peripheren Nerven und hinten im Ganglion. Sie tragen bei zur Bildung beider Kommissuren des Ganglions.

Der zweite Typus sendet den Neurit in den peripheren Nerven der gleichen Seite (Fig. 49, b). Eine Modifikation dieser Zellart ist die hinten im Ganglion gelegene Zelle (Fig. 49, $h$ ), deren Fortsatz in den vorderen Nerven der gleichen Seite tritt.

Die dritte Ganglienzellart ist in ihrem Wesen neu für Hirudineen (Fig. $49, c)$. Die Zelle liegt vorn, in der Mitte oder hinten lateral im Ganglion. Ihr Fortsatz kreuzt und spaltet sich, in zwei Aeste, welche für den vorderen und hinteren Nerven bestimmt sind.

Die vierte Ganglienzelle (Fig. 49, d) aus der vorderen Ganglionhälfte war ebenfalls noch unbekannt. Thr Ausläufer setzt sich in eine Längsfaser fort, welche den peripheren Nerven derselben Seite zwei Seitenäste zusendet.

Neben der Medianlinie ist eine Ganglienzelle gelegen, welche auch BIEDERMANy und Retzrus bei ihren Hirudineen beobachteten (Fig. 49, e, Fig. 47 und 48, k.z). Ihr Fortsatz gabelt sich und jeder periphere Nerv bekommt einen Ast. HAvet erwähnt nicht die besondere Größe dieser Ganglienzelle.

Die Ganglienzellen des Typus $f$ der Fig. 49 haben einen Fortsatz, welcher zur anderen Ganglionhälfte übergeht und dort einen aszendierenden und einen deszendierenden Zweig bildet. Eine Zellart, welche ich nicht abbildete, gleicht der Zelle $f$, aber aus der Längsfaser geht ein Zweig zum peripheren Nerven desselben Ganglions hervor und ein anderer zum peripheren Nerven des nächsten Ganglions.

Hinten im Ganglion und neben der Medianlinie befindet sich noch die Zelle $g$ (Fig. 49) mit gekreuztem Fortsatz im hinteren Nerven.

Ich brauche wohl nicht zu sagen, daß ich auch hier alle Kollateralen und Dendriten unerwähnt gelassen habe.

Fast alle bei Nephelis beobachteten Ganglienzellen sollen nach HaveT auch bei Clepsine zu finden sein, aber er bildet nur Zellen des Typus a (Fig. 49) ab. Wie man sieht hat HAVET den bekannten Zelltypen wieder manche neuen zugefügt.

K. C. Schxemer (1902) erwähnt in seinem Buche bei Hirudo unter allen Ganglienzellen des Bauchganglions nur jene, welche ihren Fortsatz in das Konnektiv oder nach Kreuzung in einen peripheren Nerven aussenden.

Branchiobdella parasita ist eine Hirudinee, welche, weniger bekannt als andere Arten, nur von Scmmin (1905) auf ihre Leitungsbahnen untersucht worden ist. Er konnte im ganglion infraoesophageum laterale Ganglienzellen sehen mit Fortsätzen zum Neuropilem der anderen Ganglionhälfte. Auch sah er, daß die peripheren Nerven Nervenfasern aus beiden Ganglionhälften empfingen.

Das Bauchganglion hat nicht zwei, sondern drei Nervenpaare, welche alle Ganglienzellen enthalten. Der vordere Nerv empfängt Fasern aus dem Mediankonnektiv und aus dem Neuropilem der gleichen Seite.

Acanthobdella peledina ist eine Hirudinee, welche in Livaxow (1906) 
einen Forscher ihrer Leitungsbahnen gefunden hat. LTrAxow hat sich nur mit den peripheren Leitungsbahnen beschäftigt.

Er beschreibt im Hautepithel einzelstehende oder gruppierte Sinnesnervenzellen, deren Nervenfortsätze in einen Nerven des Hautmuskelschlauches treten, wahrscheinlich also ebensolche Sinnesnervenzellen, wie HAvET bei anderen Hirudineen beschrieben hat. Die gruppierten Sinnesnervenzellen bilden wahre Simnesknospen, welche ungleichmäßig über den Körper zerstreut liegen. Bisweilen ist den Sinnesnervenzellen einer Knospe eine viel größere Sinnesnervenzelle beigemischt, welche eine Vakuole mit Stäbchensaum enthält und somit eine Sehzelle oder Retinazelle, wie Lrvaxow sich ausdrückt, ist. Auch diese Zelle sendet ihren basalen Nervenfortsatzi den Nerven hinein.

Die drei Paar Augen vorn im Kopfe sind eigentlich ebensolche Sinnesknospen, wie die oben genannten, nur daß sie nicht eine, sondern vier bis sechs Sehzellen enthalten und vorn von einer Kappe aus Pigmentzellen umgeben sind. Jedenfalls sind die Augen der Acanthobdella und der anderen Hirudineen auf Sinnesknospen zurückzuführen, was WHTMAx (1889) schon im allgemeinen behauptet hatte, in welcher Meinung ihm aber später u.a. MAYyer (1892) widerspricht. Die Nervenfortsätze der Sehzellen der Augen laufen, begleitet von jenen der lateralen Sinnesknospen, in den sensibelen Nerven ihres Somits.

In der Kopfregion sah Livaxow viele Borstensäcke, an welche sich einige Muskelfasern heften, die von einer unipolaren Ganglienzelle innerviert werden. Wie aber diese Ganglienzelle den Reiz empfängt, blieb unbekannt.

Lryaxow beobachtete auch die Nervenringe, welchen wir in der BRIsToLschen Arbeit begegnet sind. Sie liegen hier im ersten und letzten Körperringe eines jeden Somits und enthalten Ganglienzellen. Ihre Nervenfasern innervieren nach Lrvaxow die Längsmuskeln des Körpers. Daß sie auch sensibele Nervenfasern führen, sagt er nicht.

MExcL (1908) hat neben seinen wichtigen Erörterungen über die Natur der Median- und Konnektivalzellen, welche ich schon zitiert habe nur noch eine Bemerkung über die Ontogenie der Leitungsbahnen gemacht, welche uns hier interessiert. Er arbeitete mit Clepsine und Nephelis und sah, daß das Nervenfasersystem, welche sich ontogenetisch in erster Instanz im Bauchganglion entwickelt, die Kommissur bildet. Diese Kommissurfasern biegen in der Längsrichtung des 'Bauchstranges um und wachsen als Längsfasern in die Konnektive aus, welche also erst nur gekreuzte Fasersysteme enthalten. Die umbiegenden Nervenfasern schieben teils oberhalb, teils unterhalb der Kommissur.

Die Arbeit Nexcls zeigt, wie sehr auch bei Wïrmern das Studium der Ontogenese des Nervensystems, sogar ohne spezifische Nervenfärbungen, zur Kenntnis der Leitungsbahnen beitragen kann und wirkt daher sehr anregend.

Das sympathische Nervensystem von Hirudo medicinalis ist noch in letzter Zeit von Ascoli (1911) mit Hilfe einer Neurofibrillen-Methode bearbeitet worden. Er fand in der Mundhöhle und im Darm einen Nervenplexus, 
welcher nur mit dem oberen Schlundganglion verbunden war und worin neben Ganglien auch einzelne Ganglienzellen gelagert waren. Im Darmplexus beobachtete er Ganglienzellen, welche mit ihren Fortsätzen die Darmmuskeln innervierten. Sehr interessant ist es aber, daß er im Schlund- und Kieferplexus sensibele Ganglienzellen mit freien Nervenendungen entdeckte. Ascoli nennt sie Sinneszellen, aber er beschreibt sie als Zellen mit einem Sinnesfortsatz, welcher meist verästelt zwischen den Epithelzellen endet und mit einem oder zwei Fortsätzen, welche sich in den Plexus begeben, was also völlig mit dęn sensibelen Ganglienzellen, welche z.B. von Moxti bei Turbellarien entdeckt wurden, übereinstimmt.

Wichtig und ein guter Grund für meine in der Einleitung verkiundeten Ansichten über den Zusammenhang der Neuronen ist auch die Bemerkung Ascolis, daß im Plexus zwar manche Ganglienzellen mit breiten Fortsätzen unmittelbar zusammenhängen, aber daß diese manchmal weit aus einander liegende und nicht gerade benachbarte Zellen sind. Das heißt also, wie bei den Coelenteraten bilden diese Ganglienzellen einen wahren Ganglienzellplexus (nicht nur Nervenplexus), aber schon ist darin die Gruppierung und Verbindung der Ganglienzellen weit mehr verwickelt und werden also viel bestimmtere Leitungsbahnen geschaffen als bei den Coelenteraten. Noch verwickelter könnte dann die Gruppierung und Verbindung der Zellen im Zentralnervensystem geworden sein.

Er bleibt mir noch übrig auf eine sehr umfangreiche Abhandlung hinzuweisen, welche SArchez (1909-12) in letzter Zeit über das Nervensystem der Hirudineen veröffentlicht hat. Leider ist diese spanisch geschrieben, welche Sprache.ich zu meinem Bedauern nicht genug beherrsche, um darin einen Artikel von 300 Seiten durchzuarbeiten. Ich will deshalb nur sagen, daß die Abbildungen mich belehrten, daß SAxchEz manche Leitungsbahnen, teilweise mit den von Retzius entdeckten übereinstimmend, gesehen hat. Wer sich daher mit den Hirudineen beschäftigt, wird diese Arbeit gewiß berücksichtigen müssen.

Ilit den Hirudineen habe ich auch das Kapitel der Würmer überhaupt beendet, da mir keine Reizleitungsbahnen der Rotatorien bekannt sind.

\section{IT E R A T'UR.}

1. ANDré (1910), Die Augen von Polystomum integerrimum, Zcits. f. wiss. Zoologic, BCl. 9:5. 1910.

2. АРАтиу (1897), Das leitende Element des Nervensystems und seine topographisehen Bezichungen zu den Zellen, Mittheil. aus der zoolog. Station zu Neapel, 131. 12, 1897.

3. Ascoli (1911), Zur Neurologie der Hirudincen, Zoolog. Jahrbiicher (Abt. Anat.), 13c1. 31. 1911.

4. Bғтие (1903), Allgemeine Anatomie und Physiologie des Nervensystems, 1903.

5. Beтtendonf (1897). Ueber Mfusculatur und Sinneszellen der 'Trematolen, Zoolog. Jahrbiicher (Abt. Anat.), Bd. 10, 1897. 
6. Biederuaxx (1891), Ueber den L'sprung und die Endigungsweise der Nerven in den Ganglien wirbelloser 'Tiere, Jenaische Zeits. f. Naturwiss., Bd. 25, N. F. 18, 1891.

7. Blochiraxy (1895), Ueber freie Nervenendigungen und Sinneszellen bei Bandwürmern, Biolog. Centralblatt, Bd. 15, 1895.

8. Boенщi (1891), Untersuchungen ïber rhabdocöle 'Turbellarien, II, Plagiostomina und Cylindrostomina, Zeits, f. wiss. Zoologie, Bd. 51, 1891.

9. BRAvdes (1899), Das Nervensystem der als Nemathelminthen zusammengefaßten Wurmtypen, Abhandl. der naturforsch. Gesellschaft zu Halle, Bd. 21, 1899.

11). Braun (1892), Trematodes, Broxiss Klassen und Ordnungen des Thierreichs, Bd. IV, Abt. 1 a, 1879 - 1893.

11. Braun (1894 - 1900), Cestodes, Broxns Klassen und Ordnungen des Thierreichs, Bd. IV. Abt. $1 b, 1894-1900$.

12. Bristor (1898), The Metamerism of Nephelis, Journal of Morphology, Tol. 15, 1899.

13. BRuch (1849), Ueber das Nervensystem des Blutegels, Zeits. f. wiss. Zoologie, Bd. 1, 1849.

14. Buerger (1890), Untersuchungen über die Anatomie und Histologie der Nemer* tinen u.s.w., Zeits. f. wiss. Zoologie, Bd. 50, 1890.

15. Buerger (1891), Beiträge zur Kenntnis des Nervensystems der Wirbellosen. Neue Untersuchungen über das Nervensystem der Nemertinen, Mittheil. aus der zoolog. Station zu Neapel, Bd. 10, 1891 - 1893.

11. Buerger (1895), Die Nemertinen des Golfes von Neapel, Fauna und Flora des Golfes von Neapel, 22ste Monographie, 1895.

17. Buerger (1897 - 1903), Nemertini, Browns Klassen und Ordnungen des Thierreichs, Bd. IV, Suppl., $1897-1903$.

1s. Buetschur (1874), Beiträge zur Kenntnis des Nervensystems der Nematoden, Arehiv f. mikrosk. Anatomie, Bd. 10, 1874 .

19. Buetschli (1912), Vorlesungen über vergleichende Anatomie, 2te Lieferung, 1912.

20. CAJAL (1904), Neuroglia y neurofibrillas del Lumbricus, Trabajos del laboratorio de investigaciones biologicas, Tomo 3, 1904.

21. Cerfontaine (1892), Contribution a l'étude du système nerveux central du Lombric terrestre, Bulletıns de l'Académie Royale de Belgique, Tome 62 (3me série, T. 23), 1892.

2.). ClaPAREDE (1869), Histologische Untersuchungen ïber den Regenwurm (Lumbricus terrestris), Zeits. f. wiss. Zoologie, Bd. 19, 1869.

23. Clarke (1856), On the Nervous System of Lumbricus terrestris, Proceed. of the Royal Soc. of London, Vol. 8, 1857.

24. DeinekA (1908), Das Nervensystem von Ascaris, Zeits. f. wiss. Zoologie, Bd. 89, 1908.

25. Dewoletzky (1888), Das Seitenorgan der Nemertinen, Arbeiten aus dem zoolog. Institute der Univers. Wien, Bd. 7, 1888.

26. Ersig (1887), Die Capitelliden des Golfes von Neapel, Fauna und Flora des Golfes von Neapel, 16te Monographie, 1887.

27. Fraipont (1884), Recherches sur le système nerveux central et périphérique des Archiannélides (Protodrilus" et Polygordius) et du Saccocirus papillocercus, Archives de Biologie, Tome 5, 1884.

28. Friedlatender (1888), Beiträge zur Kenntnis des Centralnervensystems von Lumbricus, Zeits. f. wiss. Zoologie, Bd. 47, 1888.

29. Friedlatender (1889), Ueber die markhaltigen Nervenfasern und Neurochorde der Crustaceen und Anneliden, Mittheil. aus der zoolog. Station zu Neapel, Bd. $8,1889-1891$.

30. Friedlaender (1894), Altes und Neues zur Histologie des Bauchstranges des Regenwurms, Zeits. f. wiss. Zoologie, Bd. 58, 1894.

31. Goldscmint (1908), Das Nervensystem von Ascaris lumbricoides und megalocephala I, Zeits. f. wiss. Zoologie, Bd. 90, 1908. 
3:. Goldschmot (1909), Das Nervensystem von Ascaris lumbricoides und megalocephala II, Zeits. f. wiss. Zoologie Bd. 92, 1909.

3:3. Goldschmid (1910), Das Nervensystem von Ascaris lumbricoides und megalocephala III, Festschrift zum sechzigsten Geburtstag Richard Hertwigs, Bd. 2, 1910.

;4. Ton Grafr (1904 - 1908), Turbellaria, Brovns Klassen und Ordnungen des Thierreichs, Bd. IV, Abt. 1 c, 1904-1908.

3.). GreffF (1877), Untersuchungen úber die Alciopiden, Nova acta academiae caesareae Leopoldino-Carolinae, Bd. 39, 1877.

31i. Haller (1887), Ueber die sogenannte Leydische Punktsubstanz im Central. nervensystem, Morphologisches Jahrbuch, Bd. 12, 1887.

;7. Haller (1889), Beiträge zur Kenntnis der Textur des Centralnervensystems höhereı' Würmer, Arbeiten a. d. zoolog. Institute der Univers. Wien, Bd. 8, 1889.

38. Haller (1910), Ueber das Bauchmark, Jenaische Zeits. f. Naturwiss., Bd. 46, N. 1. 39. 1910.

39. Hanaker (1898), The Nervous System of Nereis virens, Bulletin of the Museum of Comparative Zoology, Vol. 32, 1898.

41. Hansen (1881), Sur la terminaison des nerfs dans les muscles volontaires de la sangsue, Archives de Biologie, T. 2, 1881.

41. Havet $(1900 a)$, Structure du système nerveux des Annélides, La Cellule, 'T. 17, 1900.

4.). Havet $(1900 \quad b)$, Contribution a l'étude du système nerveux des 'Trématodes, Lภ Cellule, T. 17, 1900.

43. O. Hertwit (1880), Die Chaetognathen, Jenaische Zeits. f. Naturwiss,. Bd. 14. N. F. 7, 1880 .

44. Hesse (1892), Ueber das Nervensystem von Ascaris megalocephala, Zeits. f. wiss. Zoologie, Bd. 54, 1892.

45. Hesse (1897 a), Die Augen der Plathelminthen, insonderheit der tricladen 'Turbel larien, Zeits. f. wiss. Zoologie, Bd. 62, 1897.

4ti. Hesse (1897 b), Die Sehorgane der Hirudineen, Zeits. f. wiss. Zoologie, Bd. 62, 1897.

47. Hesse (1899), Die Augen der polychaeten Anneliden, Zeits. f. wiss. Zoologie, Bd. $65,1899$.

4S. N. Holscrex (1916), Zur vergleichenden Anatomie des Gehirns von Polychaeten etc., Kungl. Svenska Vetenskapsakademiens Handlingar, Bd. 56, 1916.

49. Joseph (1882), Vorläufige Bemerkungen ïber Muskulatur, Exeretionsorgane und peripherisches Nervensystem von Ascaris megalocephala und lumbricoides, Zoologischer Anzeiger, Bd. 5, 1882.

i1). Joseph (1902), Untersuchungen über die Stïtzsubstanzen des Nervensystems, U.S.W., Arbeiten a.d. zoolog. Instituten der Univers. Wien, Bd. 13, 1902.

i1. KAHANE (1880), Anatomie von laenia perfoliata Goeze als Beitragzur Kenntnis der Cestoden, Zeits. f. wiss. Zoologie, Bil. 34, 1880.

$\therefore$ Kuekexthal (1887), Leber das Nervensystem der Opheliaceen, Jenaische Zeits. f. Naturwissenschaft, Bd. 20, N. 1\% 13, 1887.

i3. Laczko (1880), Beiträge zur Kenntnis der Histologie der 'l'etrarhynchen, hauptsïchlich des Nervensystems, Zoolog. Anzeiger, Bd. 3, 1880.

$\therefore$ 4. LAxa (1879), Lntersuchungen zur vergleichenden Anatomie und Histologie des Nervensystems der Plathelminthen 1, Das Nervensystem der marinen Dendrocoelen, Mittheil. a. (I. zoolog. Station zu Neapel, Bd. 1, 1879.

$\therefore$ LAxo (1881), Lnters. z. vergl. Anat. und Histol. des Nervens, der Plath. II, Ueber das Nervensystem der 'T'rematoden, III, Das Nervensystem der Cestoden im All. gemeinen und dasjenige dex Totrarhynchen im Besonderen, Mittheil. a. d. zoolog. Station zu Neapel, Bd. 2, 1881.

ini. LAxq (1852), Lnters. zo vergl. Anat. und Hist. des Nervens. der Plath. IV, Das Nervensystem der 'Trieladen, Mittheil. a. d. zoolog. Station zu Neapel. Bd. 3, 1882.

i7. LANGDON (1895a), The Sense Orguns of Lumbricus agricola, Anatomischer Anzeiger Bd. 10, 1895.

is. LAx(adox (1895 b), The Sense Organs of Lumbricus agricola, Joumal of Morphology. Vol. 11, 1895. 
59. VoN LENHOSSEK (1892), Ursprung, Terlauf und Endigung der sensibeln Nervenfasern bei Lumbricus, Archiv. f. mikrosk. Anat., Bd. 39, 1892.

60. Vox Lexhossek (1895), Der feinere Bau des Nervensystems, 2te Aufl. 1895.

61. Leydig (1857), Lehrbuch der Histologie, 1857.

6.2. Lexdig (1862), Ueber das Nervensystem der Anneliden, Arehir fuir Anatomie und wissenschaftliche Medicin, 1862.

63. Lerdia (1886), Die riesigen Nervenröhren im Bauchmark der Ringelwïmer, Zoologischer Anzeiger, Bd. 9, 1886.

64. Lintox (1910), On a New Rhabdocoele Commensal with Modiolus plicatulus, Journal of Experimental Zoology, Tol. 9, 1910.

(i.). Lrvavow (1906), Acanthobdella peledina, Zoolog. Jahrbieher (Abt. Anat.), Bd. 22. 1906.

(iti. Marcixowski (1903), Das untere Schlundganglion ron Distomum hepaticum Jenaische Zeits. f. Naturwiss., Bd. 37, 1903.

1i7. MaYer (1892), Beiträge zur Kenntnis des Hirudineen-Auges, Zoolog. Jahrbiieher (Abt. Anat.), Bd. 5, 1892.

lis. Mexcl (1908), Ueber die Histologie und Histogenese der sogenannten Punktsubstanz LEydigs in dem Bauchstrange der Hirudineen, Zeits. f. wiss. Zoologie, Bd. $89,1908$.

199. E. MEYer (1882), Zur Anatomie und Histologie von Polyophthalmus pictus, Arehiy f. mikrosk. Anat., Bcl. 21, 1882.

70. Montgomery (1897), Studies on the Elements of the Central Nerrous System of the Heteronemertini, Journal of Morphology, Vol. 13, 1897.

71. Moxtr (1897), Sur le système nerveux des Dendrocèles d'eau donce, Archives italiennes de Biologie, T. 27, 1897.

72. Moxtr (1900), Nuove richerche sul sistema nervoso della Planarie, Monitore zoologico italiano, Vol 11, 1900.

73. NAxsex (1887), Anatomie und Histologie des Nervensystems der Myzostomen, Jenaische Zeits. f. Naturwiss., Bd. 21, N. F. 14. 1887.

74. Nremec (1888), Untersuchungen über das Nervensystem der Cestoden, Arbeiten a. d. zoolog. Institute der Lnivers. Wien, Bd. 7, 1888.

75. RAxvier (1880), Leçons d'Anatomie générale, Appareils nerveux terminaux, 1880.

7i. Retzius (1891), Zur Kenntnis des centralen Nervensystems der IViirner, Biologische Untersuchungen, N. F. Bd. 2, 1891.

7. Retzius (1892 a), Das Nervensystem der Lumbricinen, Biolog. L'nter's., N. F' Bd. 3, 1892 .

7๙. Rexzius (1892 b), Das sensibele Nervensystem der Polychaeten, Biolog. Unters., N. F. Bd. 4, 1892.

79. Retzius (1895 a), Die Sumpowsehen freien Nervenendigungen im Epithel des Regenwurms, Anatom. Anzeiger, Bd. 10, 1895.

81). Retzius (1895 b), Zur Kenntnis des Gehirnganglions und des sensibelen Nervensystems der Polychaeten, Biolog. Unters., స. F. Bcl. 7, 1895.

81. Retzius (1898), Zur Kenntnis des sensibelen Nervensystems der Hirudineen, Biolog. Unters., N. F. Bd. 8, 1898.

8.2. Retzius (1900), Zur Kenntnis des sensibelen Nervensystems der Wïrmer und Mollusken, Biolog. Unters., N. F. Bd. 9, 1900.

8:3. ROHDE (1885), Beiträge zur Kenntnis der Anatomie der Nematoden, Zoologische Beiträge, Bd. 1, 1885.

44. ROHDE (1886), Histological Investigations upon the Nervous system of the Chato. poda, The Annals and Magazine of Natural History, Vol. 18, 1886. (Lebersetzt aus den Sitzungsberichten der $k$. preussischen Acadernie der Wissenschaften, 1886.)

85. Roude (1890), Histologische Untersuchungen über das Nervensistem der Poly. chaeten, Zoologische Beiträge, Bd. 2, 1890.

86. ROHDE (1892 a), Histologische Untersuchungen über das Nervensystem der Hirudineen, Zoolog. Beiträge, Bd. 3, 1892.

87. RoHDE (1892 b), Muskel und Nerw, I, Ascaris, Zoolog. Beitr. Bd. 3, 1892. 
88. SANChez (1909-1912), El sistema nervioso de los Hirudineos, Trabajos del laboratorio de investigaciones biologicas T. 7, 1909, T. 10, 1912.

89. Schмпт (1905), Zur Anatomie und Topographie des Zentralnervensystems von Branchiobdella parasita, Zeits. f. wiss. Zoologie, Bd. 82, 1905.

90. A Schneider (1863), Neue Beiträge zur Anatomie und Morphologie der Nemato. den, IV, Das Nervensystem, Archiv f. Anat., Physiol. und wiss. Medicin, 1863.

91. K. C. Schneider (1902), Lehrbuch der vergleichenden Histologie der Tiere, 1902.

12. Sulrnow (1894), Ueber freie Nervenendigungen im Epithel des Regenwurms, Anat. Anzeiger, Bd. 9, 1894.

93. Spenget (1882), Oligognathus Bonelliae, eine schmarotzende Eunicee, Mittheil. a. d. zoolog. Station zu Neapel, Bd. 3, 1882.

94. Tower (1900), The Nervous System in the Cestode Moniezia expansa, Zoolog. Jahrbücher, (Abt. Anat.), Bd. 13, 1900.

9). Vignal (1883), Recherches histologiques sur les centres nerveux de quelques invertébrés, Archives de Zoologie expérimentale, 2me Série, T. 1, 1883.

9). Whitiax (1889), Some New Facts about the Hirudinea, Journal of Morphologr, Vol. 2, 1889.

97. Zarnecke (1895), Untersuchungen über den feineren Bau der Cestoden, Zoolologische Jahrbiicher (Abt. Anat.), Bd. 9, 1896. 


\section{MOLLUSCA.}

Das Nervensystem der Mollusken ist im allgemeinen aus deutlich gesonderten Ganglien zusammengesetzt, welche, insofern sie nicht mit einander verwachsen sind, durch Kommissuren und Konnektive verbunden sind und woraus die Nerven hervorgehen. Ich kann hier nicht jedesmal auf die Anatomie des Nervensystems eingehen. Sie ist in den zoologischen Lehr- und Handbüchern bequem nachzuschlagen, falls dies zum besseren Verständnis der nachfolgenden Beschreibung der Leitungsbahnen im Nervensystem noch nötig ist.

Nur die Amphineuren, die primitivste Klasse der Mollusken, haben noch keine Ganglien, wie die anderen, sondern ein Zentralnervensystem, das sich demjenigen der Plathelminthen anschließt und aus einem Hirnganglion mit zwei Paar daraus hervorgehenden, longitudinalen Seitensträngen, den Pedalsträngen und den Pleurovisceralsträngen (oder Lateralsträngen) besteht. Zwischen den beiden Pedalsträngen sind zahlreiche Kommissuren ausgespannt, sodaß uns wiederum das Bild einer Strickleiter vor Augen geführt wird. Auch werden die beiden Pleurovisceralstränge von einer über dem Darm gelegenen analen Kommissur verbunden und außerdem werden sie durch Querverbindungen, welche ich nicht Kommissuren nennen möchte, weil sie nicht die Medianebene des Körpers durchschreiten, mit den Pedalsträngen in Verbindung gesetzt.

Ueber die Wege der Nervenfasern in diesem Zentralnervensystem ist fast nichts bekannt. Peripher in den Nervensträngen und selbstverständlich auch dort, wo diese noch einigermaßen zu Ganglien verdickt sind, liegen überall Ganglienzellen, während die Nervenfasern zentral angehäuft sind. Das lehrt uns schon HaLLer (1882 - 1884) bei Chiton, für welches Tier Schneider (1902) es wiederholt und Siмrotr (1892 — 1894) behauptet, daß es im allgemeinen bei den Amphineuren der F'all ist.

Auch WIRÉN (1892) gibt nicht mehr als eine Bestätigung dieser Allgemeinheit. Er konnte im Hirnganglion von Chaetoderma nitidulum zwar Nervenfasersysteme unterscheiden, aber nicht ihren Anfang oder ihr Ende und er meldet auch nicht genau den Lauf der Nervenfasern.

Die Kommissuren der Pedalstränge sind bei Chiton ohne Ganglienzellen und bestehen also nach HALLER (1882 - 1884) nur aus Nervenfasern, welehe vom einen Strange zum anderen übergehen. 
Im peripheren Nervensystem der Amphineuren ist uns wenigstens ein Teil der Leitungsbahnen bekannt.

HALLER (1881) hat als erster bei einer Amphineure und zwar bei Chiton Sinnesnervenzellen aufgefunden, als er beobachtete, daß die Zellen eines Sinnesorgans unter der Radula sich in Nervenfasern fortsetzten. Die Sinnesnervenzellen sind ein weit verbreiteter Zelltypus der Mollusken. Hensen (1865), BABUchin (1865) und Flemming (1870) haben sie bei den Weichtieren gefunden, noch ehe sie bei den Coelenteraten bekannt waren. Fleming, welcher nicht wie Hensen und BABUChin Sehzellen, sondern Zellen eines anderen Sinnes studierte, nannte die von ihm wahrgenommenen Zellen Pinselzellen, weil sie ein Büschel Sinneshaare trugen und dieser Name ist bei den Mollusken sehr eingebürgert. Ob sie aber ein oder mehrere Sinneshare tragen, es sind immer Sinneszellen, welche sich basal in eine Nervenfaser fortsetzen und sie gehören deshalb zur Kategorie der Sinnesnervenzellen.

In seiner nächsten Arbeit hat Haller (1882 - 1884) ausgedehntere Angaben ïber das Subradularorgan bei Chiton gemacht. Die Sinnesnervenzellen kommen neben zwei anderen Zellarten im Epithel vor. Ihre Nervenfortsätze gehen kontinuirlich über in Ausläufer von multipolaren Ganglienzellen, welche unter dem Epithel gelagert sind. Andere Fortsätze dieser Ganglienzellen anastomosieren gegenseitig und so bilden diese Zellen einen wahren Ganglienzellplexus (nicht Nervenplexus), wie wir solchem bei den Coelenteraten begegnet sind. Noch ein anderer Fortsatz dieser Ganglienzellen zieht in die Nerven, welche, aus dem Subradularorgan hervorgehen.

Die Zellen des Subradularorgans sind nicht die einzigen Sinnesnervenzellen, welchen HALLER bei Chiton begegnete. Er sah auch die FLEmmvgschen Pinselzellen, also Sinnesnervenzellen mit einem Bïschel Sinneshaare und einem basalen Nervenfortsatz und zwar im Epithel der Munclhöhle. Sie standen dort neben Geschmacksknospen, in denen ebenfalls Simesnervenzellen, aber ein wenig anders geformte anwesend waren.

In der Herzwand beobachtete HALLER schließlich einen Ganglienzellplexus, dessen kleine, multipolare Zellen inittels ihrer Fortsätze kontinuirlich verbunden waren, wiederum also wie es bei Coelenteraten Regel ist. Diese kleinen Ganglienzellen standen aber auch kontinuirlich mit großen, walurscheinlich bipolaren Ganglienzellen in Verbindung.

BLUMRICH (1891) war so glïcklich bei Chiton laevis und siculus Sinnesnervenzellen im Epithel der Kiemenhöhle nachzuweisen. Das Epithel ist hier stellenweise verdicht und es besteht da aus Drisenzellen und Fadenzellen dawisehen. Diese Fadenzellen sind Simesnervenzellen, dem Nervenfasern des Kiemeneingeweidenerven, ,setzen sich daran", wie Buumrici sagt, was wir wohl als, gehen daraus hervor" zu verstehen haben. BLumicn meint, dieses Epithel sei Riechepithel.

Freie Nervenendungen in Epithel der Haut wurden bei Amphineuren von WIRÉN (1892) entdeckt. E. sah bei Chaotoderma nitidulum zahlreiche Nervenfasern in die Zwischenräune zwischen den indifferenten Epithelzellen der Haut eindringen und sich dort verzweigen und offenbar frei enden. Oft umschlingen sie die Epithelzellen; bisweilen dringen sie atuch in die Cuticula hinein.

Die Scaphopoden werden, obgleich ihre systematische Stellung unsicher ist, oft den Amphineuren angeschlossen und so will ich es auch machen. Sie sind mit scharf unschriebenen Ganglien, wie die Mollusken mit Ausnahme der Amphineuren besitzen, ausgestattet.

Das C'erebralganglion hat nach For. (1889) bei Dentalium entalis große, unipolare (ianglienzellen in seiner Rinde. welche ihre Fortsätze ins Neuropilem senclen, aber weiter waren sie nicht zu verfolgen.

PLATE (1592) hat bei Dentalium dentule wahrseheinlich Sinnesnervenzellen beob. achtet. Das 'lier besitzt eine große Zahl kleiner, keulenförmiger 'Tentakeln. Darin befindet sich eine Zeligruppe, Welche PLATE mit dem Namen Ganglienzellgruppe belegt, welche aber der Besehreibung nach wohl aus sinnesnervenzellen besteht. Die "Ganglienzellen" haben doch Fortsätze, Endkolben, wie PLATE sie nemnt, welele mit einem Stifte aus der Cuticula des 'Tentakels hervorragen und wahscheinlich 'Tastorgane sind. Diese Angaben PLATEs laten weniger befremdend, wenn man die (ianglienzellen als Sinnesnervenzellen betrachtet. Ihr Zusammenhang mit dem Nerven in der Achse des 'Tentakels oder mit dem (ianglion, worin dieser Nerv übergeht, war nicht nachzuweisen. 
Das Nervensystem der Lamellibranchia besteht aus den Cerebral-, Pedalund Visceralganglien, (Fig. $50, g . c ., g \cdot p$. und $g . v$.), welche durch lange Konnektive (Fig. 50, c.p.k. und c.v.k.) und, wenn sie nicht paarweise ganz verwachsen sind, durch kurze, auswendig sichtbare, andernfalls durch innere Kommissuren verbunden sind. Die Ganglien entsenden die peripheren Nerven.

Die Lamellibranchier werden in Protoconchae und Heteroconchae eingeteilt, welche beide Ordnungen ich nach einander besprechen will.

Fleming (1870) hat im Jahre 1870 bei der Protoeonche Mytilus dargetan, daß die von ihm entdeckten Pinselzellen Sinnesnervenzellen sind, das heißt also, daß es Epithelsinneszellen sind, welche selbst sich in einen Nervenfortsatz oder eine Nervenfaser verjüngen. Er beobachtete ja im Mantelrande von Mytilus Sinneszellen mit einem Büschel Sinneshaare, Pinselzellen also, zwischen den Epithelzellen zerstreut und sah, daß sie sich in Nervenfasern fort. setzten, welche einen tiefer gelegenen Nervenplexus bildeten, worin auch Ganglienzellen auftraten.

Ich bekam oft den Eindruck, daß man meint, daß F'LEMIING hier in seinen Pinselzellen einen ganz nenen Zelltypus entdeckt hätte. Das ist nicht wahr. Noch ehe Fleming in seinen Pinselzellen Sinnesnervenzellen erkannte, hatte schon $\mathrm{BABU}$ CHIN (1865) die Stäbchen-

zellen in der Retina der Pulmonaten und im selben Jahre Hexsex (1865) die Sehzellen oder Stäbchenzellen im Auge der Cephalopoden und von Pecten ganz deutlich als Sinnesnervenzellen mit basalem Nervenfortsatz beschrieben. Sie waren also in der Erkennung der Sinnesnervenzellen bei den Mollusken allen voraus. Ich komme auf ihre Arbeiten noch zurïck.

Ein anderer Teil des peripheren Nervensystems wurde von Docirel (1877) studiert. Er verküindete das Dasein apolarer Ganglienzellen zwischen den Muskelfasern des Atriums des Herzens von Pecten maximus, also einer Art Ganglienzellen, welche nicht zur Kenntnis der Leitungsbahnen beitragen würde. Aber, wie ich schon einmal bemerkte, soll man wahrscheinlich solehe Zellen, wenn iberhaupt als Ganglienzellen, als Neuroblasten betrachten.

Das Jahr 1886 bringt uns die Arbeit PATTExs (1886), in der, soviel ich weiß, zum ersten Male die Innervationsweise der Augen der Lamellibranchier geschildert wird. Der Artikel ist eine seltene Nischung richtiger und falscher 
Beobachtungen und enthält daneben sehr wichtige theoretische Anschauungen. Ich glaube, es verdient den Vorzug erst die PATtexschen Beobachtungen, immerhin soweit sie sich auf meinen Gegenstand beziehen, und die Resultate späterer Forscher desselben Objekts zu besprechen und nachher seine theoretischen Anschauungen zu prüfen.

Bevor ich hier die speziellen Angaben Pattens wiedergebe, will ich zu ihrer Erläuterung sagen, daß dieser amerikanische Forscher vom Bau der Sehzellen der Mollusken- und Arthropodenaugen ganz andere Vorstellungen hat, als wir später noch bei anderen Gelehrten kennen lernen werden. Vorgreifend kann ich sagen, daß sie allgemein in den Sehzellen oder Retinazellen oder wie sonst die Zellen, welche den Lichtreiz empfangen, bezeichnet werden, Sinnesnervenzellen erblicken, das heißt also Sinneszellen, deren Zellkörper sich kontinuirlich in eine Nervenfaser fortsetzt, welche also einen Nervenfortsatz haben.

Nicht also Patten. Er betrachtet die Strukturelemente der Retina, welche das Licht empfangen, Retinophoren, wie er sie nennt, nicht als einheitliche Zellen, sondern als paarweise verwachsene Zellen. Von den beiden Kernen bleibt in der Retinophore nur einer erhalten. Die Nervenfasern der Retina sind nach ihm nicht Fortsätze der Retinophoren, sondern Fortsätze unbekannter Ganglienzellen, welche die Retinophoren umschlingen. Eine Nervenfaser, die axiale Nervenfaser, welche in der Achse der Retinophore läuft, scheint sich im Inneren einer Zelle zu befinden, aber tatsächlich ist es nach Pattex eine Nervenfaser, welche ursprünglich zwischen den beiden Zellen gelegen war, woraus die Retinophore hervorgegangen ist und welche später bei der Verwachsung der beiden Zellen zu einer Retinophore innerhalb derselben aufgenommen wurde. Diese axiale Nervenfaser (dieselbe, welche auch von anderen Autoren gesehen wurde, aber m. E. als Neurofibrille der Sehzelle zu deuten ist), geht allmählich in die Retinophore uber und täuscht also vor, ein Fortsatz der Retinophore zu sein, was aber, wie man begreifen wird, nach PATTEx durchaus nicht der Fall ist.

Sehen wir nun, was PATTEx besonders bei den protoconchen Lamellibranchiern beschreibt. Er befaßt sich zuerst mit Arca Noae, wo drei Augenarten gefunden werden : die zusammengestellten Augen, die invaginierten Augen und die pseudolenticulaten Augen, welche eine Zwischenstufe zwischen den beiden vorigen biklen.

Die Retinophoren der zusammengestellten Augen tragen ein Stäbchen an ihrer Oberfläche, das PATTEN besonders als zur Sinnesfunktion dienend betrachtet, weil es reichlich innerviert ist. Die Retinophore wird in zweierlei Weisen innerviert. Erstens dureh die axiale Nervenfaser, welehe sich bis ins Stäbchen fortsetzt und sich verzweigt. Diese Nervenfaser geht ganz allmählich in das spitze untere Ende der Retinophore ïber, ja selbst driickt Pattex sich so aus, daß er sagt: die Spitze der Retinophore verlängert sich in eine Nervenfaser. Zweitens wird die Retinophore innerviert durch manche Nervenfasern, welche in der Länge neben den Retinophoren ziehen und neben den Stäbchen schlingenartig anastomosieren, was aber nicht in Schnitten, sondern nur in Mazerationspräparaten zu beobachten war. 
Nicht nur die Retinophoren des Auges werden innerviert, sondern PATTEN sah auch Nervenfasern an den Pigmentzellen des Auges und sogar an indifferenten Epithelzellen enden. Da war aber der Uebergang der Nervenfaser in die Zelle niemals allmählich sondern immer abrupt. PAtrex sah die Nervenfaser oft verzweigt.

Das Epithel der Einsenkungen der invaginierten Augen, die Retina, besteht aus Pigmentzellen und pigmentlosen Zellen. Beide sind nach PATTEx mit einer dicken Cuticula bedeckt. In den unteren Schichten derselben verzweigen sich manche Nervenfasern, welche zwischen den Retinazellen hindurch ins Bindegewebe darunter zu verfolgen, dann aber schwer von Bindegewebsfasern zu unterscheiden sind. Wer die Richtigkeit der PATTExschen Angaben bezweifelt, kann in diesem Bekenntnis einen Grund finden zur Annahme, daß PATTEx nur Bindegewebsfasern beobachtet hat. Aber PATTEx selber ist überzeugt, daß es Nervenfasern sind, welche die Retinazellen umspinnen und in der Cuticula enden.

Die Innervierung der pseudolenticulaten Augen endlich weicht nicht ab von derjenigen der beiden anderen Augenarten.

Die Innervierung des Pecten-Auges stimmt nach Patтex in manchen Hinsichten mit derjenigen des Arca-Auges überein. Das Auge selbst ist sehr kompliziert gebaut, wofür ich den Leser auf die Arbeiten ïber dieses Thema verweise. Ich hoffe wenigstens solches tun zu können ohne der Dentlichleit meiner Auseinandersetzungen zu schaden. Nur möchte ich bemerken, daß das Auge invertiert ist, die Sehzellen der Retina also vom Lichte abgewendet sind und daß der Sehnerv, bevor er ans Auge herantritt, sich teilt in einen inneren oder basalen und einen äußeren oder lateralen Ast. Der nervus opticus ist selber ein Zweig des nervus circumpallialis.

Pattex beobachtete auch bei Pecten in der Retina Retinophoren. Wie bei Area sind sie mit einer axialen und mit manchen sie umschlingenden Nervenfasern ausgestattet. Die axialen Nervenfasern setzen sich alle kontinuirlich in Nervenfasern des inneren Sehnerven fort. Sie sind nicht scharf begrenzt gegen der Retinophore, denn PatTex sagt, die Retinophore bildet sich an ihrer Basis in die Nervenfaser um. Die axialen Nervenfasern durchschreiten die Retinophoren und ihre Stäbchen und treten dann wieder aus um sich gegenseitig mit Schlingen zu verbinden.

Die Nervenfasern, welche die Retinophoren umgeben, bilden 'Terminalnetze an ihrer Oberfläche, oder sie verästeln sich wiederholt dichotomisch und dringen wahrscheinlich auch in die Retinophoren ein. Sie anastomosieren gegenseitig und wahrscheinlich auch mit den axialen Nervenfasern. Diese Nervenfasern können die unmittelbaren Fortsetzungen von Nervenfasern des äußeren Sehnervenastes sein, aber meistens sind sie das nicht. Dann sind sie entweder Fortsätze multipolarer Ganglienzellen, welche hier und dort zwischen den Retinophoren liegen und welche einen anderen Ausläufer in den äußeren Sehnerven senden oder sie sind Fortsätze multipolarer Ganglienzellen, welche in einer Schicht an der der Linse zugekehrten Seite der Retinophoren liegen und ebenfalls nach PATTEx einen oder mehrere Fortsätze in den äußeren Sehnerven schicken. 
Die axialen Nervenfasern bilden also den einen, die Nervenfasern zwischen den Retinophoren den anderen Opticusast. Das ist wenigstens was PATTEN behauptet. .

Es sei hier gleich bemerkt, daß3 die Abbildungen, welche PATTEx von beiden Ganglienzellarten gibt, geeignet sind großen Zweifel über die angebliche Natur dieser Zellen zu erregen.

Das Pecten-Auge war schon vor PATtex oftmals in seinem Bau untersucht worden, aber, so viel ich weiß, hat nur HExsex (1865) bestimmte Mitteilungen über die Innervierung gemacht. Er beschrieb in der Retina zwei Zellschichten. Die erste ist die Ganglienzellschicht PATtexs, die zweite ist die Sehicht der Pattenschen Retinophoren.

Es ist nun sehr merkwïrdig, daß Hexsex schon in klarer Weise"gesehen hat, daß die Zellen der zweiten Schicht der Retina sich kontinuirlich fortsetzen in die Nervenfasern des inneren Sehnerven, denn, obgleich Pattex ihn darin bekämpfte, hat er von späteren Autoren völlig Recht bekommen, wie wir sehen werden.

Die Zellen der ersten Retina-Schicht, über deren Natur Hexsex sich nicht äußert, setzen sich nach ihm in die Nervenfasern des äußeren Sehnerven fort. PATTEX stimmt ihm darin bei, erkennt aber, wie wir sahen, nicht wie Hexsex, daß alle diese Nervenfasern Fortsätze der Zellen der Ganglienzellschicht sind.

Wie haben nun spätere Forscher die obengenannten Resultate PATTENs beurteilt?

Rawitz (1888) konnte bei Pecten viele PatTexschen Angaben über die Histologie der Retina bestätigen, aber gerade nicht jene, welche die Innervierungsweise betreffen. Er nennt die Retinophoren Stäbchenzellen und betrachtet sie als gewöhnliche, einheitliche Sinneszellen, welche sich basal ununterbrochen in Nervenfasern fortsetzen; also als Simnesnervenzellen. Die Nervenfaser setzt sich zwar innerhalb der Zelle in eine axiale Nervenfaser fort, aber diese endet dort und verläßt nie das Stäbchen, verzweigt sich nicht und hängt nicht mit anderen axialen Nervenfasern zusammen. Auch RawiT\% komnte, eben so wie PATtes beobachten, daß diese Nervenfasern unmittelbar in den inneren Ast des Sehnerven eintreten, wo sie nach ihm bisweilen in multipolare Ganglienzellen iibergehen.

Was aber tun nach RAwrtz die Nervenfasem des äußBeren Opticuszweiges? Auch or betrachtet in Uebereinstimmung mit PATTEx die multipolaren Zellen zwischen den Stäbchenzellen und jene, welche in einer Schicht an der der Linse zugekehrten Seite der Stäbehenzellen gelagert sind als Ganglienzellen, obgleich die erstgenannten Zellen fast zytoplasmafrei und in den RAwrTzschen Figuren durchaus nicht ganglienzellähnlich sind. RAwrT mun teilt uns mit, daß die Nervenfasern des äußeren Opticus alle Fortsätze der Zellen der Ganglienzellschicht sind. Diese multipolaren Ganglienzellen sind ummittelbar mit einander verbunden durch andere Fortsätze, aber auch senden sie einen Ausläufer zu den multipolaren Ganglienzellen zwischen den Stäbchenzellen. Die Fortsätze der letztgenannten Ganglienzellen bilden ihrerseits ein Flechtwerk um die Stäbehenzellen und dringen bisweilen darin ein, ohne je mit der axialen Nervenfaser zu anastomosieren. 
RAwitz erkennt also in Uebereinstimmung mit PATTEN die doppelte Innervation der Stäbchenzellen an, aber im Gegensatz zu ihm meint er, daß die die Stäbchenzellen umschlingenden Nervenfasern nur Fortsätze der zwischenliegenden Ganglienzellen sind und nicht dreierlei Ursprung haben. Ich gestehe aber, daß die Rawrtzschen Untersuchungen mir nicht ganz zuverlässig scheinen.

CARrière (1889), welcher von PATTEx wegen seiner Studien der Molluskenaugen bekämpft worden war, kehrt, dazu veranlaßt durch die RAwITzsche Arbeit, noch einmal zu diesem 'Thema zurïck. Auch jetzt macht er nicht auf mich den Eindruck ganz klare Vorstellungen über die Innervierung der Sehzellen zu haben. So sagt er über das zusammengesetzte Auge von Arca Noae, daß die Sehzelle, welcher er, wie alle andere Autoren, die Doppelnatur abspricht, nach innen sich in zahlreiche Fasern fortsetze, welche sich vielleicht mit Nervenfasern verbänden oder selbst Nervenfasern seien. welche an die Zelle heranträten. Er konnte die Nervenfasern, welche nach PATTEx die Sehzellen umspinnen sollen, nicht beobachten.

Bei Pecten sah CARrière wohl den Achsenfaden in der Sehzelle (Stäbchenzelle), aber er weiß nicht, ob er sich verästele und ob es ein Nervenfaden sei. Betreft's der Innervierung der Stäbchenzelle steht nur fest, daß sie verbunden ist mit einer Nervenfaser des inneren Sehnervenastes.

Während CARrière also die umschlingenden Nervenfasem der Sehzellen ganz verneint, streiten seine Beobachtungen nicht mit der Ansicht, daß die Sehzellen Sinnesnervenzellen sind.

Rawitz hat die Augen von Area Noae erst in der Fortsetzung seiner eben erwähnten Arbeit (RAwitz 1890) besprochen. Er teilt uns mit, daß im zusammengesetzten Auge von Arca Noae, Arca barbata, Arca tetragona und Pectunculus glycimeris kegelförmige Sehzellen sichtbar sind, deren spitzes unteres Ende sich in eine Nervenfaser fortsetzt, welche im Augennerven weiterzieht. Diese Beschreibung schildert also die Sehzellen als wahre Sinnesnervenzellen. Die die Sehzellen umschlingenden Nervenfasern, welche PATtEx erwähnte, existieren nicht nach RawiTz.

Zehn Jahre nach Rawitz hat auch Hesse (1500) die Augen einiger Lamellibranchier studiert. Bei Lima squamosa fand er die Sehzellen als Sinnesnervenzellen ausgebildet, das heißt, ei beobachtete, wie die Zellen sich basal kontinuirlich in Nervenfasern fortsetzen, welche zum Ringnerven des Mantels ziehen.

Aber auch Pecten und Spondylus hat Hesse seine Aufmerksamkeit gewidmet und ich glaube die glänzenden Resultate dieses Forschers über alle vorigen stellen zu können. Hesse spricht es abermals offen aus, daß die Sehzellen der Retina sich in Nervenfasern verjüngen, welche sich zum inneren oder basalen Ast des nervus opticus vereinigen. Aber Nervenfasern, welche die Sehzellen umschlingen, sieht er nicht und betrefi's der multipolaren Ganglienzellen, welche PATTEN und RAwtTz annahmen, hat er ganz andere Ansichten. Die Zellen, welche in einer Schicht den Sehzellen aufliegen, nennt er Distalzellen. Ihre wahre Natur konnte er leider nicht entscheiden, aber er hat ganz überzeugend dargetan (man sehe seine Abbildungen), dalo es keine 
Ganglienzellen sind und er leugnet auch jede Verbindung dieser Zellen mit Nervenfasern.

Die Zellen, welche zwischen den Stäbchenzellen liegen und welche von PATtex und RAwitz ebenfalls als multipolare Ganglienzellen betrachtet wurden, nennt er Zwischenzellen und er glaubt, es seien optische Sinneszellen, weil sie jede einen Fortsatz aussenden, welcher eine Nervenfaser des äußeren Sehnerven wird. Solche Zwischenzellen kommen aber auch vereinzelt zwischen den Distalzellen vor.

Statt Stäbchenzellen mit doppelter Innervation, sieht Hesse also im Pectenauge zwei Arten von Sinneszellen (Stäbchen- und Zwischenzellen), jede nach dem Typus der Sinnesnervenzelle gebaut und jede einen besonderen Zweig des Sehnerven bildend.

Kehren wir jetzt zu der Arbeit Pattexs (1886) zurück um darüber zu urteilen. Da will ich betonen, daß PATTEx im Auge der Lamellibranchier keine Sinnesnervenzellen erkennt, aber gerade die zwei anderen Weisen der sensibelen Innervation zu sehen glaubt, nämlich frei, zwischen indifferenten Epithelzellen endende Nervenfasern — so im Auge, wie im Körperepithel und wahre Sinneszellen, die Retinophoren, die von Nervenfasern, welche Fortsätze (sensibeler) Ganglienzellen sind, umgeben und durchsetzt werden. Spätere Untersuchungen haben aber meines Erachtens unzweifelbar ergeben, daß die Sehzellen jedenfalls Sinnesnervenzellen sind, welche nicht von Nervenfasern umgeben sind, sondern nur sich ganz einfach in einen Nervenfortsatz verlängern.

Pattex hat also mit Unrecht gemeint in der Retina andere Nervenfasern als die basalen Fortsätze der Sehzellen (und bei Pecten auch der Zwischenzellen) zu sehen und da bleibt es leider zweifelhaft, ob wir ihm glauben können, wenn er behauptet, im indifferenten Epithel endende sensibele Nervenfasern beobachtet zu haben, obgleich solche vor ihm von EdxaER (1877) und später von anderen Forschern tatsächlich im allgemeinen bei Hollusken gefunden sind, was nicht von wahren Sinneszellen mit herantretenden Fortsätzen sensibeler Ganglienzellen, wie doch die Retinophoren sein würden, gesagt werden kann. Es verlangt deshalb die Vorsicht, daß die PATTExschen Angaben über frei von allen Sinneszellen endende Nervenfasern noch genau, dạs heißt an derselben Stelle desselben 'Tieres Bestätigung erlangen, ehe wir ihm in diesem Punkte Glauben beimessen.

Ich bin jetzt bei der Besprechung der theoretischen und hypothetischen Anschauungen PATtexs angelangt.

PATTEx glaubt im allgemeinen bei Mollusken in der Existenz sensibeler Ganglienzellen, welche frei von Sinueszellen zwischen indifferenten Epithelzellen endende Nervenfasem aussenden und gewiß mit Recht, sei es denn, daß er selber oder nur andere vor und mach ihm diese Zellen und Nervenfasern nachgewiesen haben. Er hat sich nun ïber die ontogenetische Entwicklung dieser Ganglienzellen bei Mollusken Vorstellungen gebildet, womit meine Anschaumgen ïber die phylogenetisehe Entwicklung dieser Ganglienzellen bei den Würmern bis in Einzelheiten übereinstimmen. Ich habe diese Ansichten schon S. 11 als Erweiterung der HerTwigschen Hypothese niedergelegt. 
Nach Pattex gibt es im Epithel ,junge Ganglienzellen" mit bipolarem Zellkörper, welcher sich einerseits in einen peripheren Fortsatz mit Sinneshaar, andrerseits in eine Nervenfaser fortsetzt. Das sind also Zellen. wie die Flemmingschen Pinselzellen, welche schon vor PATTex bekannt waren, oder Sinnesnervenzellen, wie ich sie allenthalben nenne. Der Zellkörper dieser Zellen kann auch unter das Epithel gerückt sein und nach PATTEx auch weitere Umwandlungen erfahren. Die Zelle würde ihr Sinneshaar verlieren können, der periphere Fortsatz würde sich verästeln zwischen den indifferenten Epithelzellen, der Zellkörper würde immer tiefer versinken und multipolar werden, wonach aus der , jungen Ganglienzelle" eine multipolare, sensibele Ganglienzelle mit freiem, sich im Epithel verästelndem Fortsatz entstanden sein wiirde.

Es ist mir nicht klar, auf welchen Tatsachen diese Hypothese PATTExs fußt, nur ist deutlich, daß seine, junge Ganglienzellen" Sinnesnervenzellen sind und PATTEx hat also schon vor sehr langer Zeit, zu einer Zeit, wo die Sinnesnervenzellen der Evertebraten zwar schon lange bekannt waren, aber die Möglichkeit, daß daneben wie bei den Vertebraten, so auch bei Evertebraten sensibele Ganglienzellen, unabhängig von Sinneszellen, vorkommen konnten, sich gerade auftat, in erstaunlicher Weise die gegenseitigen Beziehungen dieser beiden Zellarten geahnt.

Jetzt, wo unsere Kenntnis mit sovielen Tatsachen bereichert worden ist, erlaube ich mir die PatTexschen Gedanken in etwas anderer IVeise anzuwenden und wie man weiß die Hypothese aufzustellen, daß die sensibelen Ganglienzellen nicht ontogenetisch bei den Mollusken - über die Ontogenie dieser Zellen bei den Mollusken ist mir nichts bekannt - aber phylogenetisch bei den Würmern von Sinnesnervenzellen herstammen. Daß man den betreffenden sensibelen Ganglienzellen auch schon bei den niederen Würmern begegnet, konnte freilich PATTEx damals noch nicht bekannt sein. Die Zwischenstufen zwischen beiden Zellarten sind später bei Mollusken von VERATTI in sehr schöner Weise dargetan (Vergl. S. 153).

Pattex hat noch weitere allgemeine Betrachtungen über die Reizleitungsbahnen geäußert, welche sich aber nicht bewahrheitet haben. So glaubte er, daß sich niemals Nervenfasern des Zentralnervensystems unmitttelbar mit Sinneszellen der Epidermis vereinigten, sondern daß immer periphere Ganglienzellen dazwischen geschaltet seien und daß Sinnesnervenzellen wahrscheinlich immer unmittelbar Muskelfasern innervierten ohne Vermittlung des Zentralnervensystems.

Kehren wir jetzt wieder zu den tatsächlichen Mitteilungen ïber Leitungsbahnen zurück.

RAwitz hat in drei umfangreichen Artikeln (RAwITz 1888, 1890 und 1892) das Resultat seiner Studien ïber den Mantelrand der Lamellibranchier niedergelegt und dabei auch bei den Protoconchen an manchen Stellen Sinnesnervenzellen, vercinzelte oder in Sinnesorgane gruppierte, wahrgenommen. Ich werde nur jene Fälle nennen, wo RAwitz nachdrücklich den Uebergang der Zelle in eine Nervenfaser betont. Besonders haben Zupfpräparate RAwirz gute Dienste geleistet.

Bei Anomia ephippium ist der Mantelrand links und rechts nicht ïbereinstimmend 
gebaut. Rechts fand RAwitz Sinnesnervenzellen im Epithel mit zwei Fortsätzen. Jener, welcher nach RAwiTz halbwegs der Zellhöhe an den Kern herantritt, soll die Nervenfaser sein. Tch finde aber keinen Anlaß heute noch an aus dem Kerne hervorgehende Nervenfasern zu glauben und meine deshalb, daß diese Faser ein Zellfortsatz ist. Links im Mantelrande gibt es zwei Sinnesnervenzellarten, beide mit einem basalen Fortsatz, welcher eine Nervenfaser ist. Alle Sinnesnervenzellen tragen Sinneshaare. Auch ins Epithel der 'Tentakeln des Mantelrandes sind Simnesnervenzellen gestellt.

Im Mantelrande von Anomia befindet sich ein Kingnerv, der nervus pallialis circula:i, welcher multipolare Ganglienzellen enthält. Seine Seitenäste innervieren nach RAwitz die Sinnesnervenzellen, was wir wohl so zu verstehen haben, daß ihre Nervenfortsïtze zusammen diese Aeste bilken.

Ostrea echlis, die Auster, hat zweiorlei Sinnesnervenzellen im Mantelrande und in den Tentakeln, beide mit basalem oder aus dem ,Kerne" hervorgehendem Nervenfortsatz. Das Verhalten dieser Nervenfasern zum Ringnerven ist dasselbe, wie bei Anomia.

Lima hians und inflata haben neben Simmestentakeln anch Driisententakeln. Beide, aber besonders erstere, haben Sinnesnervenzellen oder Pinselzellen, wie FuEmurng sagen wïrde, in ihrem Epithel. Sie besitzen nach RAwiTz (1888) einen basalen Haftfortsatz und halbwegs der Zelle fängt ein Nervenfortsatz im Keme oder im nucleolus an. Diese Nervenfortsätze bilden ein Bündel im Tentakel, welches ein Seitenast des Ringnerven ist. Der Ringnerv enthält multipolare Ganglienzellen, nicht also die 'Tentakelnerven.

Manche Pecten-Arten und auch Spondylus gaederopus sind mit Sinnesnervenzellen in den Tentakeln des Mantelrandes ausgestattet. Diese tragen Sinneshaare und haben nur basale Nervenfortsätze, welche wiederum in Seitenäste des Ringnerven eintreten.

Die Arcacea wurden in zweiten 'leile der RAwitzschen Untersuchungen beschrieben (1890). Hier wurden bei Area Noae, barbata und tetragona, ebenso wie bei Pectunculus glycimeris Simesnervenzellen im Mantelrande aufgefunden. Die Mytilacea waren schon von Freming nachgeforscht worden, welcher bei Mytilus edulis Sinnesnervenzellen in der Gestalt der Pinselzellen entdeckte. RAwitz konnte dies bestätigen und sah solche Zellen auch im Mantelrande von Modiola barbata und Lithodomus dactylus. Später (RAwitz 1892) hat er Pinselzellen, wie F'Lemmng sie fand und also mit basalem Nervenfortsatz auch in den Siphopapillen und dem Mantelrande von Dreissenia polymorpha gemeldet.

Die Lucinacea fanden im dritten 'Teile der RAwitzschen Arbeit (1892) Erwähnung. Bei Cardita sulcata gibt es Pinselzellen mit basalem Nervenfortsatz im Mantelrande und diese Nervenfortsätze ziehen wiederum in den Ringnerven des Mantelrandes. Astarte fusca und Lucina spinifera stimmen offenbar mit Cardita iiberein.

In denselben Jahren als RAwiTz seine Untersuchungen veröffentlichte, hat auch THInLe (1889) Simnesnervenzellen zu entdeeken gemeint und zwar in den abdominalen Sinnesorganen der Lamellibranchia. Die -inneszellen im Epithel setzten sich in eine Nervenfaser fort, welche wahseheinlich mit einer bipolaren Gunglienzelle verbunden war. Fest steht aber, daß der zweite Fortsatz dieser (innglienzelle sich in den Nerven des Organs begab.

Jetzt bin ich fast am Ende mit der Behandlung der Protoconchae und noch habe ich nichts ïber das Zentralnervensystem dieser 'Tiere erzählt. Ich habe tatsächlich nur eine einzige Arbeit iiber dieses 'T'hema ausfindig machen können; das ist aber eine sehr gute, obgleich es keine unnütze 'Tat sein würde. die darin niedergelegten Resultate mit modernen, spezifischen Untersuchungsmethoden näher zı priifen.

Die Arbeit, welche ich meine, ist der Aufsatz RAwity' (1857), in dem die Wege der Nervenfasern im C'erebral-, Pedal- und Visceralganglion von Mytilus beschrieben werden. Es ist jedoch schade, daß RAwitz nur selten sich 
bestimmt darüber äußert, ob die Nervenfasern Fortsätze der Ganglienzellen des Ganglions, oder ob es im Ganglion endende Nervenfasern sind, welche aus anderswo gestellten Ganglienzellen hervorgehen. Der wahre Beginn oder das Ende der Bahn ist also nur selten bekannt, aber ibrigens sind die RAwITzschen Angaben so bestimmt und können sie nach meiner Meinung späteren Forschern soviel nützen, daß ich sie trotzdem hier alle referieren will. In meinen Figuren 51, 52 und 53, welche nach den RAwitzschen angefertigt worden sind, habe ich die verschiedenen Ganglienzellgruppen durch Strichellinien begrenzt. Von innerhalb dieser Arealen sich begebenden Bahnen meldet RAwITz nicht, ob sie dort enden oder aus Ganglienzéllen entspringen.

Fir ol.

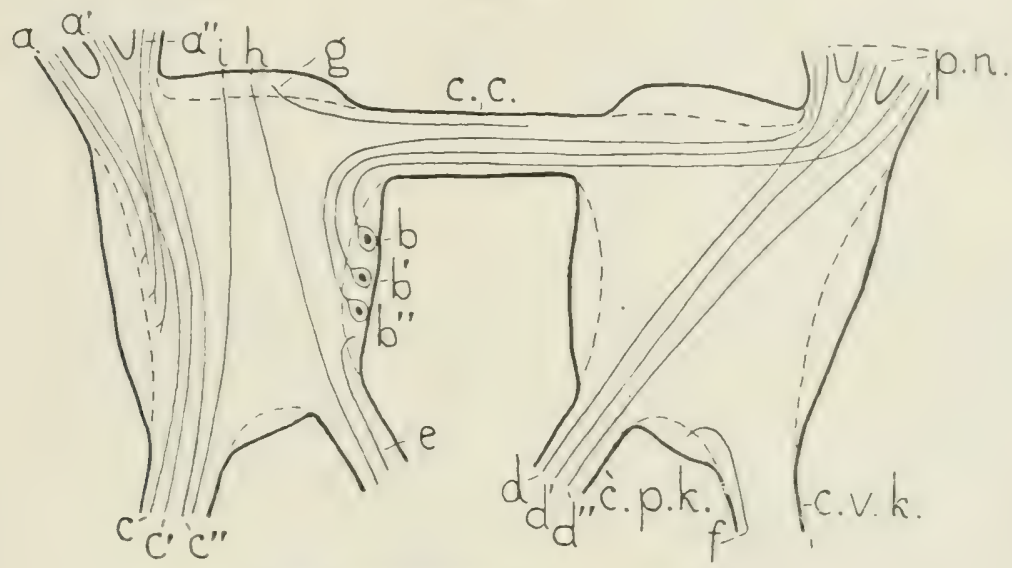

Die Cerebralganglien von Mytilus.

Abgeändert nach RAwitz (1887), Fig. 91, Taf. 28.

$a, a^{\prime}, a^{\prime}, c, c, c^{\prime \prime}, d^{\prime}, d^{\prime}, d^{\prime \prime}$, und $e$ bis $i=$ Nervenfasern

$b, b^{\prime}, b^{\prime \prime}=$ Ganglienzellen

c. $c$. $=$ commissura cerebralis

c. p. $k$ : = Cerebropedalkonnektiv

c. $v \cdot k$. = Cerebrovisceralkonnektiv

p. n. $=$ peripherer Nerv

Die Strichellinien begrenzen die Ganglienzellgruppen vom Neuropilemab.

Die beiden Cerebralganglien von Mytilus werden durch eine Cerebralkommissur vereinigt (Fig. 5̃ l, c.c.). Wit den Pedal- und Visceralganglien sind sie durch die Cerebropedal- und Cerebrovisceralkonnektive verbunden (Fig. 51 , c.p. $k$. und $c . v . k$.). Außerdem entsenden sie drei periphere Nerven (Fig. $51, p . n$.$) .$

Die Ganglienzellen sind in vier periphere Gruppen gestellt: eine vordere, eine laterale, eine mediale und eine Gruppe zwischen den beiden Konnektiven. Das Neuropilem nimmt die Mitte des Ganglions ein und wird nach Rawitz im allgemeinen aus Nervenfasern, welche Fortsätze der Ganglienzellen in der Peripherie des Ganglions sind, zusammengesetzt.

Die drei peripheren Nerven führen alle sensibele Nervenfasern, welche lateral im Ganglion enden (Fig. $\left.51, a, a^{\prime}, a^{\prime \prime}\right)$. (RAwitz sagt anfangen, aber 
wenn es wirklich sensibele Nervenfasern sind, befinden sich ihre Ganglienzellen und also ihr Anfang außerhalb des Ganglions.)

Daneben enthalten die drei Nerven motorische Nervenfasern, welche aus lateralen Ganglienzellen hervorgehen, nicht aber aus Zellen desselben Ganglions, sondern aus Zellen des Ganglions der anderen Seite. Diese Nervenfasern kreuzen also in der Cerebralkommissur (Fig. 51, b, b', b").

Motorische Nervenfasern werden auch von den drei Nerven aus dem Cerebrovisceralkonnektiv (Fig. 51 ,

Fig. 5.2.

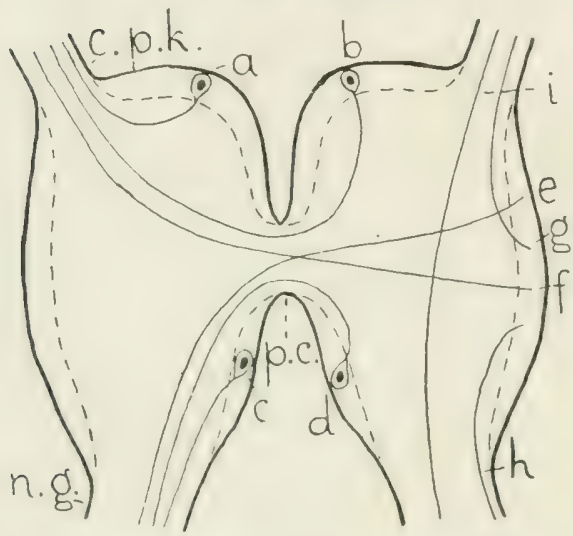

Die Pedalganglien von Mytilus.

Abgeändert nach Rawitz (1887), Fig. 92, Taf. 28.

$a$ bis $d=$ Ganglienzellen

$e$ bis $i=$ Nervenfasern

c. $p . k_{0}=$ Cerebropedalkonnektiv

n. g. $=$ Nervengruppe

p.c. $=$ commissura pedalis

Die Strichellinien grenzen die Ganglienzellgruppen vom Neuropilem ab. $\left.c, c^{\prime}, c^{\prime \prime}\right)$ und aus dem Cerebropedalkonnektiv (Fig. 5l, $d, d$,,$d^{\prime \prime}$ ) empfangen.

Die Cerebropedalkonnektive enthalten weiter Nervenfasern, welche sich zur medianen Ganglienzellgruppe begeben (Fig. 51, e) und die Cerebrovisceralkonnektive solche zur Ganglienzellgruppe zwischen den beiden Konnektiven (Fig. $51, f$ ).

Die vordere Ganglienzellgruppe -sendet Nervenfasern in die Cerebralkommissur (Fig. 51, g) und auch in die beiden Konnektive (Fig. 51, $h, i) . \mathrm{Ob}$ es wirklich die dortigen Ganglienzellen sind, woraus diese Fasern hervorgehen, ist nicht bekannt, ebensowenig kennen wir ihre weiteren Wege.

Die beiden Pedalganglien sind durch die kurze Pedalkommissur (Fig. 52, p.c.) verbunden. Sie senden eine ganze Gruppe peripherer Nerven aus (Fig. 52, n.g.), welche aber

in der Fig. 52 von mir nicht unterschieden werden, weil auch RAwitz sie hinsichtlich ihrer Hodologie zusammenfaßt. Wie bekannt bilden die Cerebropedalkonnektive (Fig. 52, c.p.k). eine Faserbrücke zwischen den Cerebral- und den Pedalganglien.

Im Ganglion unterscheidet RAwiт\% eine vordere, eine hintere und eine laterale Ganglienzellgruppe. Ganglienzellen der vorderen Gruppe besitzen Fortsätze, welche in das Cerebropedalkonnektiv derselben oder der anderen Seite ziehen (Fig. 52, a und b). Die letztgenannten Nervenfasern durchsetzen dabei die Kommissur.

Ganglienzellen der hinteren Gruppe senden mit oder ohne Kreuzung der Medianlinie ihre Nervenfasern in die peripheren Nerven (Fig. 52, $c$ und d).

Die Ursprungszellen der anderen Leitungsbahnen sind nicht genau bekannt. Viele beginnen oder enden in der lateralen Ganglienzellgruppe. Wenn diese Fasersysteme in die Pedalkommissur ziehen, laufen sie weiter in die 
peripheren Nerven (Fig. 52, e) oder das Cerebropedalkonnektiv (Fig. 52, f) und das gleiche können sie tun, ohne vorher zu kreuzen (Fig. 52, $g$ und $h$.).

Ueberdies wird das Pedalganglion ganz durchzogen von Nervenfasern, welche einerseits durch die Cerebropedalkonnektive in dem Cerebralganglion, andrerseits in den peripheren Nerven verschwinden (Fig. 52, i).

Die beiden Visceralganglien sind bei Mytilus zu einer einheitlichen Masse verwachsen, aber bei anderen Lamellibranchiern sind sie das nicht. Das Visceralganglion (Fig. 53) hat vorn, hinten und an beiden Seiten periphere Ganglienzellgruppen. Nach vorn ist es durch das Cerebrovisceralkonnektiv (Fig. 53 , c.v.k.) mit dem Cerebralganglion verbunden. Daneben geht der Kiemennerv (Fig. こ3, k.n.) ab. Nach hinten treten der Mantelnerr (nervus pallialis Fig. 53, n.p.) und die Nerven zu den Muskeln des Körpers, in der Figur 53 wie ein einziger Nervenstamm (m.n.) dargestellt, aus.

RAwтTz erwähnt sehr viele Fasersysteme, leider alle ohne die zugehörigen Ganglienzellen genau nachzuweisen.

Es gibt Nervenfasern, welche von der lateralen Ganglienzellgruppe in den Mantelnerven (Fig. 53, $a$ ) oder den Muskelnerven (b) oder den Kiemennerven $(c)$ gehen.

Andere Nervenfasern verbinden die hintere Zellgruppe mit dem Muskelnerven

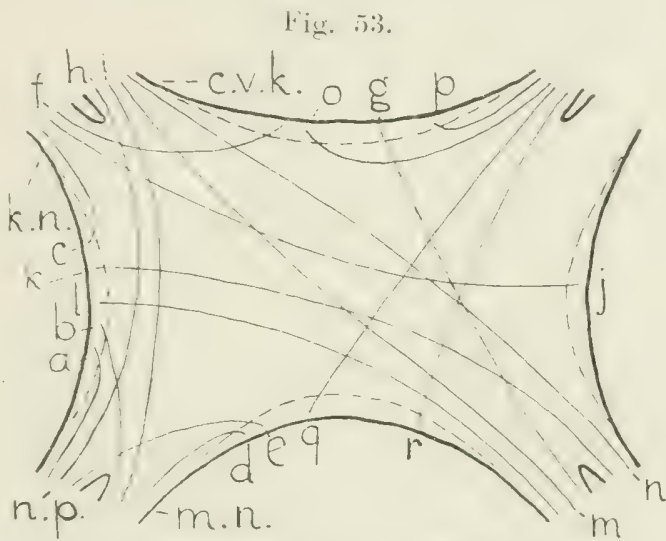

Yisceralgang'ion von Mytilus.

Abgeändert nach RAwitz (1887), Fig. 93, Taf. 28 .

$a$ bis $r=$ Nervenfasern

c. $v \cdot k$. Cerebrovisceralkonnektiv

k. n. = Kiemennerv

m. $n$. = Muskelnerven

n. $p . \quad=$ nervus pallialis

Die Strichellinien grenzen die Ganglienzell gruppen vom Neuropilem ab. (Fig. 53, $d$ ) oder dem Mantelnerven (e).

Die vordere Ganglienzellgruppe ist Ursprungsstelle für Fasem des Kiemennerven (Fig. 53, f) und des Muskelnerven $(g)$.

Noch andere Nervenfasern kommen aus dem Cerebrovisceralkonnektiv und schreiten teils in den Mantelnerven (Fig. $53, h$ ), teils in den Muskelnerven hinein $(i)$.

Keines dieser Systeme kreuzt die Medianebene, andere aber wohl. Die laterale Ganglienzellgruppe sendet Nervenfasern zum Kiemennerven aus (Fig. 53, j) oder vielleicht zum Konnektiv; das ist mir aus der Beschreibung PAWITz' nicht ganz klar geworden. Ebenso verlassen andere Nervenfasern diese Ganglienzellgruppe um in den entgegengesetzten Mantelnerven (Fig. 53, k) oder Muskelnerven $(l)$ auszutreten.

Die Cerebrovisceralkonnektive führen Nervenfasern mit sich, welche die 
Medianlinie des Ganglions ïbersehreiten und in den Muskelnerven (Fig. 53, $m$ ) oder den Mantelnerven $(n)$ austreten.

Ebenso erhalten sie Nervenfasern aus der vorderen Ganglienzellgruppe und zwar derselben (Fig. 53, $p$ ) oder der gekreuzten Seite $(o)$.

Schließlich ist anch die hintere Ganglienzellgruppe mit dem korrespondierenden und dem gekreuzten Cerebrovisceralkonnektiv verbunden (Fig. $53, q$ und $r$ ).

Bei anderen Lamellibranchiern waren die Fasersysteme nicht so bequem zu eruieren. Pecten iacobaeus ist sehr abweichend gebaut, wenigstens in Visceralganglion. Was RAwitz über die Leitungsbahnen mitteilt, ist aber zu unvollständig um hier wiedergegeben zu werden.

Unio, also eine Heteroconche, entbehrt in seinem Pedalganglion die Ganglienzellen $b$ und $d$ und die Kommissurfasern laufen in Bïndeln beisammen. Das ist alles, was RAwITz als Lnterschiedsmerkmale mit Mytilus anführt.

Es bleiben jetzt noch die heteroconchen Lamellibranchier zur Besprechung übrig.

Anch hier wurden ziemlich früh Sinnesnervenzellen, oft in der (iestalt der FemmixGschen Pinselzellen, entdeckt. So von Drost (1887) bei Cardium edule im Mantelrande und in den Siphopapillen, aber ich finde seine Darstellung der Verbindung der Nervenfaser mit der Pinselzelle nicht besonders deutlich.

Auch Rawitz (1890 und 1892) hat manche Heteroconchen untersucht. Er sah (1890) bei Unio pictorum und Anodonta anatina Pinselzellen im Mantelrande.

Bei Cardium edule (RAwTz 1892) waren für ihn drei Arten Simnesnervenzellen zu unterscheiden, welche auch Drost schon als Sinneszellen erkannt hatte. Zwei sind über den ganzen Körper verbreitet; die dritte ist nur in den Siphopapillen anzutreffen und es sind multipolare Ganglienzellen darunter gelagert, welche mit ihren fortsätzen nicht nur unter einander, sondern anch mit den Yervenfortsätzen der Simesnervenzellen unmittelbar zusammenhängen. Sie bilden also einen wahren Ganglienzellplexus.

Andere Cardium-Arten und Cyprina islandiea haben nur eine Sinnesnervenzellart.

Venus gallina hat in den Siphopapillen Sinnesnervenzellen, deren basale Yervenfortsätze zu Nervenfasem des Papillemerven werden.

Bei Psammobia vespertina sind rerschedene Simesorgane mit Sinnesnervenzellen ausgestattet. So entdeckte Rawiтz in den siphopapillen oder den Papillen des Mantelrandes Sinnesnervenzellen, welehe dureh stïtzzellen umingt wurden. In den siphorippen waren andere Sinnesorgane. Die Nervenfortsitze ihrer sinnesnervenzellen waren in multipolare (ianglienzellen \%u verfolgen, welche auch fortsätze in den siphonerven hineinsandten.

Tellina nitida und planati, chenso wie Donax trunculus, haben nur einzelstehende simesnervenzellen in den siphonen und dem Mantedrande.

Unter den Myacea weist soldecurtus strigillatus in Sipho einzelstehende sinnesnervenzellen neben solchen, welche in sinnesorgane angehäuft sind, anf. Letztere liegen äber eines (iruppe multipolares (ianglienzellen und we so oft sind diese (ianglienzellen

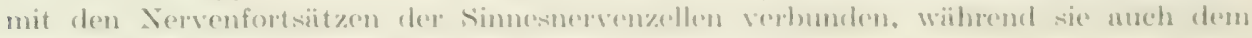
Nerven des sinnesorgans fortsiatze ïbermitteln.

solen siligua und ensis haben in den Siphopapillen und den P'apillen des Mantel-

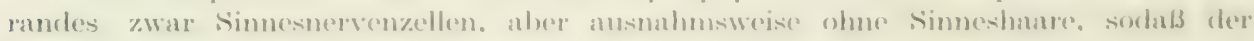
Nime Pinselzelle nicht dimanf angewande werden kïmute.

Bei feredo navalis meldet R.IWT\% wiedermu simnesnervenzellen im sipho, deren Nervenfortsatz entweder aus der Zolle oder aus dem kern hervorgehen wiarde.

Encllich hat Pholus dactylus noch sinnesnervenzellen in den siphopapillen, deren

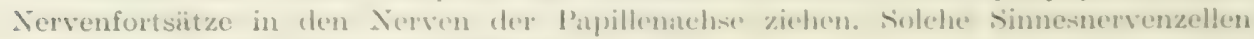
stehen auch in der sipho-Aulsenfliiche. 
Man bekommt also aus den RAwitzschen Untersuchungen bestimmt den Eindruck, daß die Sinnesnervenzellen bei Lamellibranchia eine veitverbreitete Erscheinung sind.

Freidenfelt (1896) hat auch mit Hilfe der vitalen Nethylenblau-Methode bei einer Heteroconche und zwar Mactra elliptica Sinnesnervenzellen entdeckt. Sie liegen auch hier in den Papillen des Mantelrandes. Ihr bipolarer Zellkörper ist tief unter dem Epithel gelegen, aber ihr Sinnesfortsatz dringt darin bis zur Cuticula durch. FreidenfELT beobachtete weiter die interessante Tatsache, daß ihr Nervenfortsatz sich meistens gabelte, aber die Aeste endeten, nachdem sie eine gewisse Strecke zurückgelegt hatten, olne daß ihr Zusammenhang mit dem übrigen Nervensystem sichtbar war.

Später hat Freidenfelt (1897) diese Angaben insofern widerrufen, als er behauptete damals nur Bindegewebszellen zu Gesicht bekommen zu haben, während wahre Sinnesnervenzellen mit ebenfalls subepithelialem Zellkörper doch an gleicher Stelle vorkommen. Diese Zellen werden durch ihre Sinneshaare als Sinneszellen gekennzeichnet. Ich glaube, es ließe sich fragen, ob am Ende nicht zwei Arten Sinnesnervenzellen im Mantelrande von Mactra vorhanden wären.

Die Nerven des Mantelrandes ließen nach Freidenfelt (1896) auch Nervenfasern aus sich hervorgehen, welche sich in den Papillen des Mantelrandes verästelten. Er blieb in Unsicherheit, ob sie zu den Sinneszellen in Verhältnis ständen. Seiner Abbildung nach wïrde man das verneinen und da wären es also frei endende, sensibele Nervenfasern.

Freidenfelt (1897) ist auch, wenn ich mich nicht irre, neben Rawitz der einzige Forscher gewesen, welcher sich bemüht hat, die Wege im Zentralnervensystem einer Heteroconche zu entwirren. Er hat das Visceralganglion von Anodonta mit modernen Färbungsmethoden untersucht, aber die GoLGische Methode wollte ihm nicht gelingen.

Aus dem Visceralganglion gehen drei nervi palliales posteriores hervor, ein mittlerer, großer und zwei seitliche, kleine. In der Nähe ihrer Wurzeln liegen manche unipolare, einige wenige bipolare und auch multipolare Ganglienzellen, welche Freidenfelt als Anhänger der Neuronenlehre Neuronen nennt. Einige senden ihren Neuriten in den Nerven himein. Es gibt aber auch Ganglienzellen mit nur kurzen, gleich verästelten Fortsätzen, welche FREIDENfELt als zur Assoziation dienende Neuronen betrachtet. Ich stimme ihm darin gerne bei. Sie liegen angehäuft zwischen den Wurzeln des nervus pallialis posterior und des nervus branchialis, wo sie nach FreIdexfelt sogar ein laterales Assoziationszentrum bilden.

Der nervus branchialis oder Kiemennerv enthält selber Ganglienzellen und ist nach Freidenfelt ein selbständiges sensomotorisches Zentrum. Seine Fasern gehen zu den Kiemenmuskeln und andere umschlingen Epithelzellen der Kiemen, sind also frei von Sinneszellen endende sensibele Nervenfasern. Noch andere aber sind die zentralwärts ziehenden Nervenfortsätze der Sinnesnervenzellen des Osphradiums, unter welchem Sinnesorgan der nervus branchialis läuft.

Ich kann jetzt zur dritten Klasse der Mollusken übergehen, zur Klasse der Gastropoden: Auch hier besteht das Zentralnervensystem meistens aus gut gesonderten Ganglien durch Kommissuren und Konnektive verbunden, aber die Zahl der Ganglien ist größer als bei den Lamellibranchiern, hauptsächlich durch die Entwicklung der Pleural- und Parietalganglien im Cerebrovisceralkonnektiv. Aus den Ganglien gehen wiederum die peripheren 
Nerven hervor. Als Beispiel des Nervensystems einer Gastropode gebe ich hier dasjenige eines Prosobranchiers (Buccinum, Fig. 54).

Man ordnet die Gastropoda in fuinf Ordnungen. Darunter sind die Pulmonaten besonders gut in ihren Leitungsbahnen bekannt, aber bei den Pteropoden fehlen, soviel ich weiß, alle diesbezïglichen Angaben.

Fig. 54 .

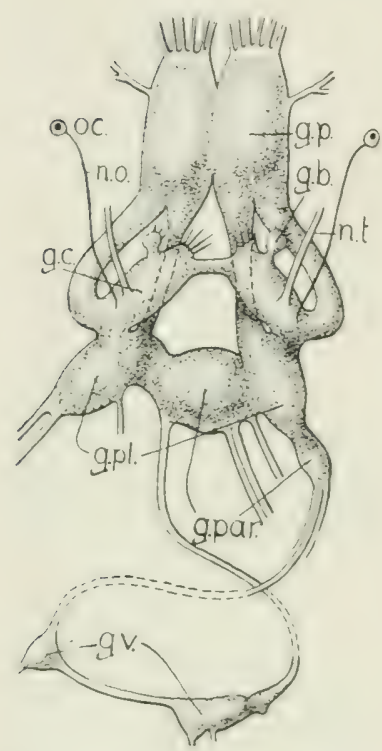

Nervensystem einer Ciastro. pode (Buceinum).

Nach Bitsschli (1912), Fig. 371.

y. $b .=$ ganglion buceale

y. c. = ganglion cerebrale

\%.p. = ganglion perlale

\%. par. = ganglion parictale

\%. $p l$. = ganglion pleurale

$\% \cdot v=$ ganglion viscerale

n.o. = nervus optieus

n.t. = nervus tentaroularis

$$
o c .=\text { Auge }
$$

Dic gestrichelten 'T'eile der lionnektive stellen eine $\mathrm{Cn}_{n}$ terbrechung dersolben dar.

Ich will aber mit der Ordnung der Opisthobranchier anfangen. Die frühesten Angaben beziehen sich wiederum auf das periphere Nervensystem.

LACAZE-DuthlERs (1865) entrleckte bei 'Tethys leporina einen Nervenplexus mit Ganglien im velum buccale. Damit ist noch nicht gesagt, wie die Nervenfasern sich verhalten, aber man wird keine große Aussicht haben darin bestimmte Leitungshahnen $z, 1$ erkennen. Viel wahrschemlicher ist es, claß, wie so oft im peripheren Nervensistem der Mollusken, die Ganglienzellen selhst durch ihre Fortsätze zu einem Ganglienzellplexus verbunden sind, denn solche Verhältnisse fand $H$. ScHuLTzE (1879) im allgemeinen bei den (iastropoden im Magen-Darmnerven.

Nachdem Dietl (1878) im allgemeinen behauptet hatte, daß bei Tethys fimbria die Ganglienzellen der Ganglien ihre Fortsätze ins Neuropilem senden, konnte DE Nabias (1594) uns einige mehr bestimmte Mitteilungen über Aplysia punctata iiberliefern.

Das linke, hintere Visceralganglion bringt den Genitalnerven hervor und darin begeben sich Fortsätze von Ganglienzellen des Ganglions. Ebenso den Rectalnerven, dessen Fasern aber größtenteils aus dem vorderen Visceralganglion herstammen.

Das rechte, hintere Visceralganglion sendet zwei Pericardnerven aus, welche Nervenfasem enthalten, die aus Ganglienzellen des rorderen Visceralganglions hervorgehen. Neben den Wurzeln dieser beiden Nerven liegen hingegen kleine Ganglienzellen, welche ihre fortsätze in umgekehrter lichtung zur Seite des ('erebralganglions senden.

Ein anderer Nerv verläßt dieses Ganglion um zur Umgebung der Genitalöfnumg zu gehen. Er wird gebildet durch Fortsätze von Ganglienzellen aus diesem und dem korrespondierenden Ganglion der anderen Seite.

Endlich geht auch der Kiemennerv, eigentlich ein Doppehnerv, aus diesem Ganglion hervor und fïhrt Nervenfasern. Welche fortsätze der Ganglienzellen dieses Ganglions sind. 
Aplysia ist abermals von GiLcurist (1897) hodologisch untersucht worden und zwar mit Hilfe der BeTHEschen Methylenblau-Methode. Er hat seine Aufmerksamkeit sowohl dem zentralen, wie dem peripheren Nervensystem zugewandt.

Gruchrist entdeckte in den Buccalganglien, zwei Ganglien, welche zwei Konnektive mit den C'erebralganglien verbinden, motorische Ganglienzellen mit Dendriten, welche sich im Ganglion selbst verzweigten und mit einem Neuriten, welcher in einem peripheren Nerven das Ganglion verließ. Daneben sah er Kommissurzellen, deren Dendriten sich im einen Ganglion verästelten, während der Neurit durch die Buccalkommissur ins andere Ganglion schritt. Drittens waren auch Nervenfasern der peripheren Nerven da, welche sich im Ganglion verzweigten und deshalb wohl außerhalb desselben Ursprung nahmen.

Nervenfasem wie die letztgenamnten traten mit den peripheren Nerven auch in die Pleural-, C'erebral- und Pedalganglien ein.

Im Pleuralganglion beobachtete Gilchrist neben Assoziationszellen, deren Fortsätze und Verästelungen nicht das Ganglion verließen auch Ganglienzellen mit Dendriten im Ganglion und einem Neuriten im peripheren Nerven.

Gilchrist weicht in seiner Beschreibung der Visceralganglien von DE Nabias ab. Nach ihm hat Aplysia zwei Visceralganglien und umschließt das eine ein degeneriertes Abdominalganglion. In den Visceralganglien waren wiederum Ganglienzellen nachweisbar, welche ihre Neuriten in einen peripheren Nerven aussandten, ihre Dendriten aber im Ganglion behielten. Das stimmt also mit dem, was DE NABIAs uns lehrt und solche Ganglienzellen waren auch wohl a priori zu erwarten. Andere Nervenfasern drängen mit den peripheren Nerven ins Ganglion hinein und verästelten sich dort. Noch andere passierten nur das Ganglion, indem sie vom einen Nerven oder Konnektiv in den anderen ïbergingen.

Auch im peripheren Nervensystem hat Gilurrist einige Leitungsbahnen aufgeklärt. Er begegnete in der Epidermis Sinnesnervenzellen mit tief unter dem Epithel gelegenem Zelliörper. Viclleicht waren auch subepitheliale Ganglienzellen da. Eine besondere trt der Sinnesnervenzellen fand er im Osphradium. Der Zellkörper steht hier im Epithel, der Sinnesfortsatz ragt aber daraus hervor. Die basalen Nervenfortsätze ziehen in ein Ganglion, welches, unter dem Epithel gelegen, einem Nerven, welcher aus dem rechten Visceralganglion herstammt, aufsitzt.

HaLler (1913) hat, wie wir noch besser bei anderen Mollusken kennen lernen werden, auch bei den Opisthobranchiern Oncinella und Siphonaria ,globuli" entdeckt, das heißt, kleinzellige Abteilungen der Cerebralganglien, woraus keine Nerven oder lange Leitungsbahnen hervorgehen und welche er deshalb als hervorragende Assoziationsgebiete oder als ,Intelligenzsphären" betrachtet, wie die corpora pedunculata (Pilzkörper) der tracheaten Arthropoden und höheren Wïrmer. Bei Oncinella und Siphonaria beobachtete HALLER, wie die globuli oder corpora pedunculata, wie sie genannt werden sollten, falls sie mit den corpora pedunculata der Würmer und Inseliten ho- 
molog sind, durch eine Kommissur verbunden sind, welche sich der Cerebralkommissur anschließt.

Auch in der Ordnung der Prosobranchier sind bestimmte Leitungsbahnen eher im peripheren Nervensystem als in den großen Ganglien bekannt geworden.

Simrotн (1876) gebührt die Ehre hier als erster Sinnesnervenzellen nachgewiesen zu haben. Er sah bei Paludina im Epithel der 'Taster Haarzellen durch Nervenfortsätze mit Ganglienzellen in ihrer Nähe verbunden.

Später hat Fleming (1884) bei Trochus, Haliotis und anderen Mollusken in den Tastern Sinnesnervenzellen entdeckt, welche dort gruppiert in den Papillen lagen und im selben Jahre lernte HaLcer (1884) sie bei Rhipidoglossen kennen. Hier sind sie Bausteine der Seitenorgane und HALLER vermutet, daß ihre Nervenfortsätze mit Ausläufern der unter dem Epithel gelagerten Ganglienzellen zusammenhängen. Er beweist aber diesen Zusammenhang eben so wenig, wie im Seitentaster, welcher neben das Seitenorgan gestellt ist.

In der Mundhöhle der Rhipidoglossen kommen Geschmacksknospen vor. Darin befinden sich nach HALLER neben Stützzellen Sinnesnervenzellen mit einem Stiftchen an ihrer Oberfläche und einem basalen Nervenfortsatz, welcher mit einem Fortsatz einer Ganglienzelle unter der Geschmacksknospe zusammenhängt. Diese Ganglienzellen bilden zusammen einen subepithelialen Ganglienzellplexus.

HALLER hat bei den Rhipidoglossen auch einige motorische Leitungsbahnen beschrieben. So sah er im Seitentaster einen Nervenplexus, worin u.a. Ganglienzellen, welche Muskelfasern innervierten. In der Herzwand beobachtete er keine apolaren Ganglienzellen, wie Dogrel bei Pecten zu erkennen meinte, sondern kleine, multipolare neben großen, bipolaren Ganglienzellen. Letztere innervierten mit einem Fortsatz die Muskelfasern und mit dem anderen waren sie mit den multipolaren Ganglienzellen verbunden, welche mit ihren übrigen Fortsätzen unter einander vereinigt waren. HALLer sah also einen typischen Ganglienzellplexus ohne bestimmte, sichtbare Leitungsbahnen und keinen Nervenplexus.

Einen besonders schönen, regelmäßigen, mit Ganglien ausgestatteten Nervenplexus sah Brock (1889) im Fuß der Prosobranchier. Hier lösen sich die vorderen Fußnerven, welche aus dem Pedalganglion hervorgehen in einen engmaschigen Nervenplexus mit Ganglien darin auf. Jedes Ganglion strahlt Nerven aus und ist sternförmig durch Nerven mit den benachbarten Ganglien verbunden. Pei einigen Arten, wo die Ganglien nahe beisammen liegen, sind auch die Nerven dazwischen mit Ganglienzellen besetzt.

Ich will hier nochmals den Untersehied eines solchen Nervenplexus mit einem Ganglienzellplexus, wie wir soeben bei HALLER begegneten, betonen: im Nervenplexus Ganglien, welche durch Nerven, also Nervenfaserbiundel, verbunden sind, im Ganglienzellplexus durch ihre Fortsaitze, also durch Nervenfasern, verbundene Ganglienzellen.

Bevor ich mit der Beschreibung der Leitungsbahnen im Zentralnervensystem der Prosobranchier anfange, will ich erst noch das Auge behandeln.

Ich bin der Heinung, daß Pattex (ISs6) hier als erster die Weise der 
Innervation beschrieben hat. Wie bei Lamellibranchiern, wo ich seine Ansichten in extenso mitgeteilt habe, erkennt PATTEx auch bei Haliotis seine Retinophoren als Sinneselemente der Retina. Obgleich die Retinophoren zwei mit einander verwachsene Zellen sind, welche eine zwischenliegende Nervenfaser in sich aufgenommen haben, schildert PATTEx den Endzustand so. daß die Retinophoren basal ganz allmählich in eine Nervenfaser übergeht. Andere Nervenfasern sollen aber die Retinophore umspinnen.

Da aber BAECkER (1903) in seiner Arbeit iiber die Augen einiger Gastropoden, worüber eine vorläufige Mitteilung schon 1902 erschienen war (BAECKER 1902), bei Haliotis tuberculata und Aporrhais pespelecani die umspinnenden Nervenfasern Pattexs verneinte und beobachtete, wie die Sehzellen der Retina (die PatTexschen Retinophoren) sich basal in Nervenfasern des nervus opticus fortsetzen und also Sinnesnervenzellen sind, so glaube ich, daß auch hier, wie bei den Lamellibranchiern, PatTEx nicht Recht behalten kann und die Sinneszellen im Auge der Prosobranchier, wie freilich bei allen Mollusken, nach dem Typus der Sinnesnervenzellen gebaut sind. Die Pattexsche Beschreibung der Retinophoren selbst läßt sich eigentlich, wie man oben lesen kann, ganz gut damit in Einklang bringen.

Die Bahnen im Zentralnervensystem der Prosobranchier sind meines Wissens nur Fig. 55.

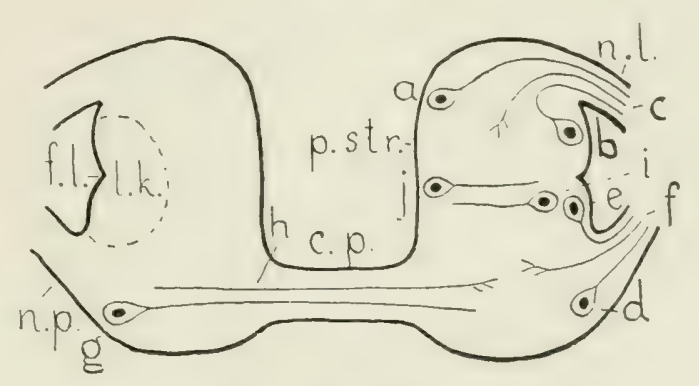

Querschnitt der Peclalstränge von Fissurella. Nach HaLler (1886). $a b, d, e, g, i, j=$ Ganglienzellen

$c, l, h=$ Nervenfasern

c. $p .=$ commissura pedalis

f.l. = fissura lateralis

$l_{0} l_{0}=$ Lateralkern

$n . l .=$ nervus lateralis

n. $p .=$ nervus pedalis

p. st $r_{0}=$ Pedalstrang

von HALLER studiert worden.

Erst hat el über die Rhipidoglossen eine Arbeit veröffentlicht (HaLler 1886), welche leider durch falsche Verweisungen nach den Figuren und sinnstörende Druckfehler an manchen Stellen schwer zu faßen und deshalb auch schwer zu referieren ist.

HALLER hat vornehmlich Fissurella als Gegenstand seiner Untersuchungen gewählt. Da er damals noch nicht die modernen, spezifischen Untersuchungsmethoden des Nervensystems anwenden komnte, meinte er noch, dal3 auch aus dem Kerne und nucleolus der Ganglienzelle Fortsätze dieser Zellen hervorgehen könnten. Das ist aber für meinen Zweck ohne Belang.

Die Rhipidoglossen weisen noch manche primitiven Merkmale in ihrem Nervensystem auf. So haben sie noch kein Paar Pedalganglien, sondern an ihrer Stelle zwei lang ausgezogene Pedalstränge, welche viele Kommissuren vereinigen. Figur 55 ist das Schema eines Querdurchschnitts durch die beiden Pedalstränge (p.str.) von Fissurella, wobei nicht nur eine der Pedalkommissu- 
ren (c.p.), sondern auch zu beiden Seiten die Wurzel eines Lateralnerven $(n . l$.$) und eines Pedalnerven (n.p.) angeschnitten gedacht worden ist. Die$ Lateralnerven gehen aus dem oberen Teil des Pedalstranges hervor und ziehen zur Seitenwand des Körpers. Die Pedalnerven entspringen mehr basal und sie innervieren den Fuß der Schnecke. Zwischen beiden Nerven ist der Pedalstrang mit einer longitudinalen Rinne, der fissura lateralis (Fig. 55, f.l.), ausgestattet.

Die Nervenfasern nehmen im Pedalstrang eine zentrale Stellung ein, die Ganglienzellen eine periphere, aber sie sind besonders in der Nähe der Lateralrinne angehäuft, was HALLER Anlaß gibt diese Ganglienzellgruppe als Lateralkern (Fig. 55, l.k.) zu bezeichnen.

Die Fasern des Lateralnerven gehen zum Teil aus Ganglienzellen der oberen Hälfte des Pedalstranges hervor und zwar liegen diese Zellen medial (Fig. 55, a) oder lateral im Lateralkerne (Fig. 55, b).

Andere Nervenfasern des Pedalstranges laufen erst der Länge nach nach hinten und biegen dann in einen Lateralnerven ab. Einige Fasern dieser Art sind Fortsätze von Ganglienzellen, welche zwischen diesem Lateralnerven und dem vorigen liegen.

Noch andere Nervenfasern (Fig. 55, c) entspringen nach HALLER aus dem Neuropilem des Pedalstranges. Wie immer glaube ich, daß man besser sagt, daß diese Nervenfasern im Neuropilem enden, weil ihre Ganglienzellen wohl irgendwo im peripheren Nervensystem zu suchen sind.

Ventral im Pedalstrang sah HALLer Ganglienzellen (Fig. 5), (l), welche ihren Fortsatz in den Pedalnerven schickten und derartige Zellen lagen anch im Lateralkerne (Fig. 55, e). Andere Nervenfasern des Pedalnerven enden im Neuropilem (Fig. 55, f). Sie sind zahlreich vorhanden.

Zum Lateralkerne gehören weiter noch Ganglienzellen, deren lortsätze erst nach vorn ziehen und damn im nächsten Pedalnerven austreten.

In den Kommissuren kreuzen Nervenfasem die Nerlianlinie, welche $z u$ beiden Seiten teils aus Ganglienzellen herrorgehen (Fig. „̌ g), teils im Neuropilem enden (Fig. 5.), h). Auch gibt es longitudinale Nervenfasern, welehe in die Kommissur abbiegen.

In den Pedalsträngen beobachtete HALLER auch Ganglienzellen (Fig. 55 , $i$ und $j$ ) mit Fortsätzen, welehe sich innerhally des Stranges von der einen Seite zur anderen begaben. HALLER hat dieses Fisersystem eine innere Kommissur genannt, aber, wo ich nur jene Fasem Kommissurfasern nemne, welche die Medianebene des Körper's überschreiten, kann ich diesen Namen nicht beibehalten.

Nicht immer gehen bei den Rhipidoglossen die beiden Pedalnerven eines Paares lateral aus dem l'edalstrang hervor. Bisweilen sind ihre Wurzeln so weit nach der Mitte und nach unten verlegt, daß sie gemeinsam aus der Pedalkommissur entspringen. Da gibt es denn scheinbar cinen ungepaarten Pedalnerven. In diesen Nerven treten longitudinale Nervenfasern hinein, aber auch l'ortsätze von Ganglienzellen des Pedalstranges in der Nahe der Nervenwurzel. Daneben enthält der Nerv Fasern, welche im Neuropilem enden.

Bei den Rhipidoglosien hat sich das Pleuralganglion noch nicht vom 
Pedalstrang getrennt und so ist vorn am Pedalstrang eine Stelle, wo dieser Strang nicht nur mit dem Cerebropedalkonnektiv, sondern auch mit dem Cerebropleuralkonnektiv zusammenkommt.

Diese Stelle, welche Haller den pleurocerebralen Teil des Nervensystems nennt, hat er besonders durchforscht und ich habe versucht einige der darin entdeckten Bahnen in der sehr schematischen Figur 56 , welche einen Längsschnitt darstellt, einzutragen.

Jeder Pedalstrang endet vorn in einer pars pleurocerebralis (Fig. 56, p.pl.c.) und die beiden Pleurocerebralteile werden durch eine Kommissur verbunden. Thre Fasern sah HaLler aus dorsalen Ganglienzellen hervorgehen oder im Neuropilem enden.

Hinten im Pleurocerebralteil ist eine mediane Ganglienzellgruppe und mehr nach vorn sind zwei laterale. Diese Zellgruppen verlassen drei Faserbündel, welche sich einander anschließen. Sie ziehen erst ventral und biegen sich dann nach vorn $u$. Ein Teil der Nervenfasern dieser Bïndel sind Fortsätze der Ganglienzellen der drei Gruppen, welche entweder zur Peripherie des Pleurocerebralteils ziehen (Fig. $56, a)$ oder in das Cerebropleuralkonnektiv eintreten (Fig. 56, b). Andere Fasern gehen aber gerade aus Ganglienzellen (Fig. $56, c$ ) hervor, welche dort im Pleurocere-

liig. 5 ti.

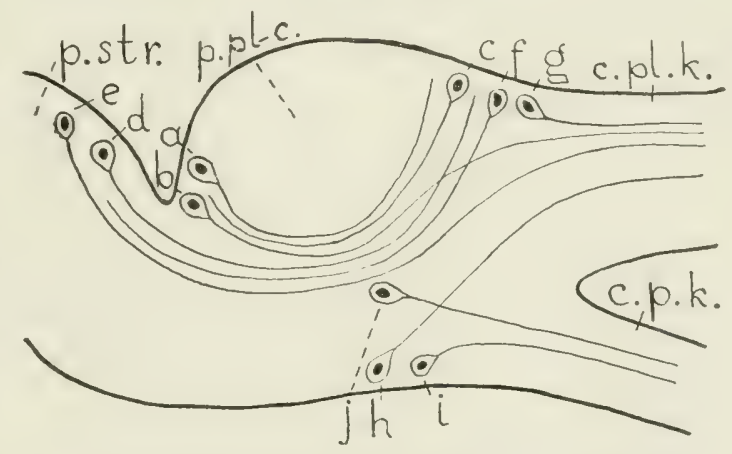

Längsschnitt des pleurocerebralen Teils des Nervensystems von Fissurella.

Nach Haller (1886).

$a$ bis $j=$ Ganglienzellen

c. p.k. = Cerebropedalkommektiv

c. $p l . l .=$ Cerebropleuralkonnektiv

$p . p l . c .=$ pars pleurocerebralis

p.sir. = Pedalstrang bralteil liegen, wo die erstgenannten enden. Das glaube ich wenigstens aus der HaLLerschen Beschreibung zu verstehen, muß aber gestehen, daß vieles mir zweifelhaft erscheint.

An die lateralen Faserbündel schließen sich auch Fortsätze von Ganglienzellen der Pedalstränge an (Fig. $56, d$ und $e$ ) und auch unter diese Bündel sind Fortsätze von Ganglienzellen des Pleurocerebralteils gemischt (Fig. 56,f), welche HALLER zusammen als die Vorstufe eines Pleuropedalkonnektivs betrachtet.

$\mathrm{Zu}$ Fasern des Cerebropleuralkomektivs gesellen sich ebenfalls Ausläufer gewisser Ganglienzellen des Pleurocerebralteils (Fig. 56,g).

Auch ventral im Pleurocerebralteil sind Ganglienzellen (Fig. 56, h) gelegen, welche ihre Fortsätze in das Cerebropleuralkonnektiv senden. Andere dortige Ganglienzellen (Fig. 56, i) tragen mit ihren Fortsätzen zur Bildung des Cerebropedalkonnektivs bei, ebenso wie Ganglienzellen, welche eine Fortsetzung des Lateralkernes des Pedalstranges sind (Fig. $\tilde{j}(j, j)$. 
In Anfang der Cerebropleural- und Cerebropedalkonnektive beobachtete Haller ,innere Kommissuren", wie wir sie im Pedalstrang (Fig. $56, i$ und $j$ ) kennen lernten. Er meint, daß ihre Fasern eine Ganglienzelle der lateralen Seite des Konnektivs unmittelbar mit einer Ganglienzelle der medialen Seite verbänden, aber diese Angabe bedarf der Bestätigung.

Aus dem Pleurocerebralteil geht der Subradularnerv hervor. Er enthält nach HALLER Fasern, welche im Pleurocerebralteil enden und solche, welche aus dessen Ganglienzellen entspringen, aber H ALLER bleibt den Beweis schuldig.

Auch der Mantelnerv verläßst den Pleurocerebralteil und führt Nervenfasern, welche dort im Neuropilem enden oder dort aus Ganglienzellen hervorgehen.

So weit über Fissurella. Tubo und Haliotis stimmen in manchen Hinsichten mit Fissurella überein, aber es gibt doch Linterschiede. So überliefern bei Turbo keine Ganglienzellen des Lateralkernes des Pedalstranges ihre Nervenfasern dem lateralen Nerven. (Also fehlen die Zellen des Typus $b$ der Fig. 55). Dagegen senden bei Turbo Ganglienzellen im Anfang des Cerebropleuralkonnektivs Fortsätze in das Buccalkonnektiv.

Bei einigen Rhipidoglossen durchsetzen die Fasem des Bucealkonnektivs zwar das Cerebralganglion, aber sie haben damit nichts zu schaffen und treten wieder aus.

Im Cerebralganglion liegen Ganglienzellen mit Fortsätzen, welche sich in das Cerebropleuralkonnektiv begeben, während andere Nervenfasern dieses Kommektirs im Neu. ropilem des Ganglions enden. Das gleiche gilt für das Cerebropedalkonnektiv, den Sehnerven, den Tentakelnerven und die drei Buccahnerven. Im Rïsselnerven konnte HaLLER dagegen nur Nervenfasern beobachten, welche im Neuropilem des Cerebralganglions endeten.

HALLER (1913) hat viele Jahre nach dieser Arbeit nochmals das Studium der Prosobranchier zur Hand genommen und dabei besonders die globuli oder ,Intelligenzsphären” beachtet.

Fissurella hat keine globuli. Nacella, Cypraea, Paludina, Hurex und Oliva haben globuli, welche insofern primitiv sind, als sie Ganglienzellen enthalten, deren Fortsätze nicht nux kurze, sondern auch lange Bahmen bilden.

Im Cerebralganglion sah HALLER jetzt eine Gruppe Ganglienzellen mit Fortsätzen in den fünf vorderen Kopfnerven und eine Zellgruppe, mit dem mittleren Hirnteil der Pulmonaten übereinstimmend, in der die Ganglienzellen Fortsätze in die Cerebropedal- und Cerebropleuralkonnektive und in die Nerven aussandten. Uebrigens bekommen die Kopfnerven Nervenfasern aus sehr weit aus einander gelegenen Ganglienzellen des C'erebralganglions.

Wie man sieht, iibertreffen diese Angaben die vorigen an Genauigkeit.

Der nervus staticus (von HALLer acusticus genamnt) führt Fasem, welche zum sogenannten "Vereinsgebiete" gehen, welches HALLER im C'erebralganglion vieler Mollusken erkannte und das wir bei den Pulmonaten näher kemnen lemen werden, aber auch solche, welche durch die C'erebralkommissuir zum anderen Cerebralganglion ïbergehen.

Es kommen jetzt die Heteropoden an die Reihe. Die Ausbildung ihres Nervensystems gleicht im allgemeinen derjenigen der Prosobranchier.

Wie man erfahrungsmäßig erwarten könnte, sind die ersten genau bekamnten Reizleitungsbahnen auch hier wieder die Nervenfortsätze einiger 
Sinnesnervenzellen. Merkwürdigerweise sind diese bei Heteropoden zuerst im statischen Organe oder wie man frïher sagte, im Gehörorgane entdeckt worden und zwar von Bolt (1869). Sagt doch Bolu bestimmt, daß im Gehörorgan der Heteropoden die borstentragenden Zellen unmittelbar mit Nervenfasern zusammenhängen.

BoLL hat in der Statocyste nicht die verschiedenen Arten von Sinnesnervenzellen zu unterscheiden gewußt, welche tatsächlich darin vorhanden sind und das hat ohne Zweifel dazu beigetragen, daß die ihm folgenden Untersucher seine Angaben verneint haben, obgleich er am Ende doch Recht bekommen hat.

RANKE (1875), welcher unter den Heteropoden Pterotrachea untersuchte, behauptete, daß BoLL nicht den wahren Beginn (RAxke sagt Ende) der Fasern des nervus staticus beobachtet habe. Er sah der Stelle, wo der nervus staticus die Statocyste verläßt gegenüber, am distalen Pole des Bläschens also, fünf Sinneszellen kreuzweise gestellt, welche er als die eigentlichen Sinneszellen betrachtete und beobachtete, wie Fasern des nervus staticus in diese Zellen eintraten, aus welchem Umstand ich mir erlaube zu schließen, daß es Sinnesnervenzellen sind, welche ihre Nervenfortsätze in den statischen Nerven senden.

RAхKЕ beschrieb daneben ein ringförmiges Ganglion mit abgerundeten Ganglienzellen, welche mit Nervenfasern des staticus zusammenhingen, aber da hat er wohl nicht das Rechte gesehen, eben so wenig, als wenn er meinte, daß Nervenfasern dieses Ringganglions zur mittleren der fünf Sinneszellen zögen.

Claus (1876) hat ebenfalls die Statocyste bei Pterotrachea und Carinaria erforscht und das ist ihm besser als seinen Vorgängern gelungen, sodaß er einige Angaben RAxkEs, worunter die letztgenannten, mit Erfolg bestreiten konnte.

Nach CLats besteht das Epithel der Statocyste im allgemeinen aus Flimmerepithelzellen zwischen indifferenten Plattenepithelzellen, aber am distalen Pole befindet sich eine große Zentralzelle umgeben von Haarzellen mit starren Borsten. Die Flimmerepithelzellen sind die borstentragenden Zellen, welche Boll beobachtete, aber Cuals konnte nicht wahrnehmen, daß sie sich in Nervenfasern fortsetzten, was doch, wie wix sehen werden, nach 'Tschachotrs (1908) gewiß der Fall ist.

Die Zentralzelle und die sie umgebenden Haarzellen sind die Raxkeschen Sinneszellen und CLAUs bestätigte, daß sie sich in Nervenfasern fortsetzen. Ein Ringganglion fand er aber nicht.

CLaus teilt uns außerdem mit, daß der nervus staticus ein gemischter Nerv ist, welcher njcht nur die Statocyste, sondern auch gewisse Muskeln innerviert.

So weit waren die Untersuchungen der Imnervation der Statocyste gediehen, als Tschaснотіх (1908) eine vorzügliche Arbeit über die Statocyste der Heteropoden lieferte, wobei er spezifische Nervenfärbungsmethoden angewandt hat. Er hat den distalen Pol der Statocyste mit den besonderen Sinneszellen die macula genannt und hat beobachtet, wie die fiasern des nervus staticus sich in 12 bis 16 Meridianbündeln zur macula begeben. 
In der macula sah er Stützzellen ohne Haare und behaarte Sinnesnervenzellen, unter denen noch die Zentralzelle und kleine Sinnesnervenzellen ringsumher zu unterscheiden waren. Sowohl die Zentralzelle, wie die anderen Haarzellen sind nach ihm wahre Flimmerzellen. In Uebereinstimmung mit RANke und CLAus sah er, daß sie sich basal in Nervenfasern der Meridianbiindel des nervus staticus fortsetzten.

Außerhalb der macula sah er flache, indifferente Zellen und sternförmige Borstenzellen das Epithel der Statocyste zusammenstellen. Die Borstenzellen, nach Tsснаснотіх ebenfalls Flimmerzellen, haben manche fortsätze, welche sie gegenseitig verbinden und außerdem, wie BoL. schon behauptete, einen Nervenfortsatz und alle diese Nervenfortsätze ziehen ebenfalls in die Meridianbündel des statischen Nerven.

Tschachотіx faßt die Borstenzellen als motorische Kellen auf und glaubt, ihre Nervenfasern leiteten den Reiz zentrifugal. In diesem Falle wären also nur die Zellen der macula Simnesnervenzellen, aber dann wïrde ich vermuten, daß die Borstenzellen auch nicht nach dem 'Typus der Sinnesnervenzellen gebaut sind, mit anderen Worten, daß die herantretende Nervenfaser kein. Fortsatz der Borstenzelle ist, wie 'Tsснаснотіх behauptet, sondern ein Fortsatz einer noch unbekannten Ganglienzelle, welche die Zelle wie eine Muskelfaser oder Drüsenzelle innerviert. Eher glaube ich aber, daß T'Tschacnotis sich in dieser Ansicht irrt und anch die Borstenzellen Sinnesnervenzellen sind.

Wie nach 'Tsснаснотіх die Nervenfasern des nervus staticus sich im Cerebralganglion verhalten, werde ich weiter unten im Anschluß an andere Mitteilungen über das Zentralnervensystem dartun. Erst will ich noch etwas ïber das periphere Nervensystem erzählen.

EDragr (1877) hat die Hautnerven bei Pterotrachea mit Osmiumsëune untersucht. Er fand unter der Haut einen Nervenplexus mit (ianglienzellen in den Knotenpunkten des Netzes und in den Nerven selbst. Ein zweiter Nervenplexus, welcher mit dem ersten verbunden ist, liegt neben der Muskulatur und seine multipolaren (ianglienzellen innervieren die Muskelfasern. Den ersten Nervenplexus verlassen Nervenfasern, welche sich zu indifferenten Epithelzellen begeben und darin eindringen. Das sind also sehr wahrscheinlich sensibele Nervenfasern, welehe, wenn nieht frei von allen hellen, so doch frei von spezialisierten simneszellen in Epithel enden und da gebiihrt EDivier die Ehre als erster diese Fasem bei einer Molluske aufgefunden zu haben, lange bevor sinnsow sie bei einem Wum entreckte.

EDINGer blieben aber atch die simnesnervenzellen in Epithel nicht verborgen. Er sah sie in Gruppen neben einumler gestellt und die Vervenfortsätze, welehe sie alle aussandten, vereingten sich zu einem Nervenfaserbindel des nervösen Plexus. Èr fund diese Simnesnervenzellgruppen auf kleinen Papillen gesessen oder dureh Berherzellen zu abgerundeten Zellgruppen vereinigt, welehe seitenscheiben heißen, weil sic in den Seitenwänden cler Schnecke liegen.

Ueber das Auge sei Lolgendes bemerkt. (in Exachen (1892) hat beobachtet, wie bei Pterotrachea coronata die sehzellen der Retima sich basal in manche P'rotoplasma. fortsätze, sogenante racliculac. fortsetzen, welehe von friiheren Autoren bisweilen als Nervenfasern betrabtet wurlen. aber dic wahe Dervenfaser sah er oberlull, der Wiir. zelchen, also nicht basal. aus der Retinzelle hervorgehen. Aus seiner Beschreibung

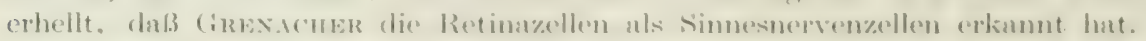

Hesse (1900) hat auch bei einigen Heferoputen serine Aufmerksamkeit auf der 
Innervation der Augen hingelenkt. Bei Carinaria konnte er den GRexacherschen Befund bestätigen, daß die Nervenfasern nicht ganz basal, sondern in gewisser Höhe aus den Sehzellen der Retina hervorgehen. Die Sehzellen sind also auch nach HEssE Sinnesnervenzellen und das gleiche gilt für die Nebensehzellen außerhalb der eigentlichen Retina, nur daß ihre Nervenfortsätze gewiß basal abgehen.

Alle Nervenfortsätze der Sehzellen laufen zum Hinterende des Auges und hier fand Hesse zwischen den Pigmentzellen, welche bedeutend zur Bildung der Augenwand beitragen, unipolare und multipolare Ganglienzellen, deren Neuriten er in den Sehnerven ziehen sah, welcher vom Hinterrande des Auges zum Cerebralganglion geht. Die Hessfschen Mitteilungen und Abbildungen machen mich glauben, daß cliese Ganglienzellen nicht das zweite Neuron der optischen Bahn sind, sondern daß die Nervenfortsätze der Sehzellen sie auf ihrem Wege zum Sehnerven passieren. Da wäre also ihre wahre Natur noch nicht aufgeklärt.

Pterotrachea gleicht Carinaria in manchen Hinsichten ; Oxygyrus ebenfalls, insofern es den Verlauf der Nervenfasern betrifft.

Ich kehre jetzt wieder zu TscHAcHoTIN (1908) zurück um seine Angaben über die Hodologie des Cerebralganglions der Heteropoden wiederzugeben. Man wird sich erinnern, daß er mit

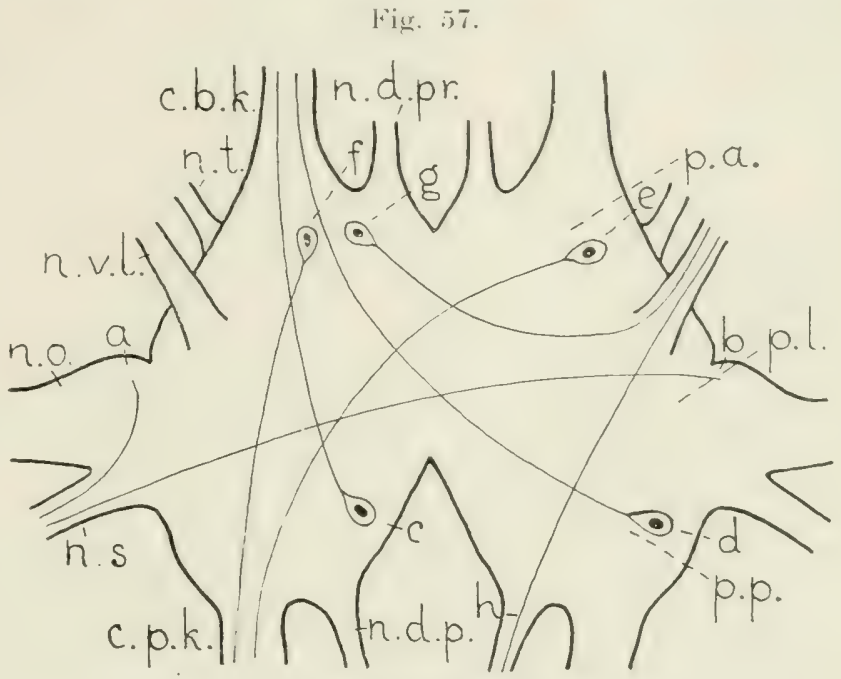

Cerebralganglion einer Heteropode. Abgeändert nach TschaснотіN (1908),

$$
\begin{aligned}
& \text { Fig. 1, Taf. } 24 . \\
& a, b, h=\text { Nervenfasern } \\
& \text { c bis } g=\text { Ganglienzellen } \\
& \text { c. b. k. = Cerebrobuccalkonnektiv. } \\
& \text { c. } p . k_{0}=\text { Cerebropedalkonnektiv } \\
& n . d . p .=\text { nervus dorsalis posterior } \\
& \text { n.d.pr. = nervus dorsalis proboscidis } \\
& \text { n. o. }=\text { nervus opticus } \\
& \text { u. } s_{0}=\text { nervus staticus } \\
& n . t .=\text { nervus tentacularis } \\
& \text { n. v.l. }=\text { nervus ventrolateralis } \\
& \text { p. } a \text {. = pars anterior } \\
& p . l .=\text { pars lateralis } \\
& p \cdot p_{0}=\text { pars posterior }
\end{aligned}
$$
spezifischen Nervenfärbungsmethoden gearbeitet hat.

Man kann im Cerebralganglion, das wahrscheinlich das Pleuralganglion in sich aufgenommen hat, vier Gebiete unterscheiden: eine pars anterior (Fig. $57, p . a$.$) , eine pars lateralis (p . l$.$) , eine pars posterior ( p . p$.$) und eine pars$ dorsalis. Das Ganglion ist durch die Cerebrobuccalkonnektive (Fig. 57, c.b.k.) mit den Puccalganglien und durch die Cerebropedalkonnektive (c.p.k.) mit den Pedalganglien verbunden. Es sendet manche Nerven aus, welche nicht alle in der schematischen Figur 57 gezeichnet sind.

Der nervus staticus (Fig. 57, n.s.), dessen Fasern wir schon bei der Be- 
sprechung des statischen Organs kennen lernten, geht aus dem lateralen 'Teile hervor. Seine Fasern trennen sich im Cerebralganglion angelangt, in zwei Systeme. Das kleinere der beiden geht zwischen den Opticusfasern hindurch zu einer dorsalen Ganglienzellgruppe derselben Seite (Fig. 57, a). Das größere kreuzt die Medianlinie und tritt dann in die dorsale Gruppe ein (Fig. 57, b). Es ist Tsснаснотім nicht gelungen zu entscheiden, ob die Nervenfasern des statischen Nerven aus diesen Ganglienzellen hervorgehen, oder ob sie dieselben mit ihren Endverästelungen umspinnen. Wenn sie wirklich alle Fortsätze der Sinnesnervenzellen der Statocyste sind, wïrde man das letztere erwarten.

Der nervus staticus kreuzt den nervus basalis oculi, welcher aus der pars posterior hervorgeht und an dieser Stelle wechseln beide Nerven einige Fasern aus; wenigstens bei Pterotrachea coronata, aber nicht bei Pterotrachea scutata. Dieser nervus basalis oculi ist motorisch und innerviert einige Augenmuskeln und so meint 'Tsснаснотіs, daß vielleicht wie bei Vertebraten und decapoden Crustaceen mittels dieser nervösen Verbindung der genannten Nerven eine Beziehung zwischen der Funktion der Statocyste und der Stellung der Augen auftritt.

Tschachotix meldet auch die Wege einiger anderen Nervenfaserbündel im Cerebralganglion. Im hinteren Teile des Ganglions befinden sich Ganglienzellen, welche ihre Fortsätze mit oder ohne Kreuzung der Mittellinie ventralwärts und in das Cerebrobuccalkonnektiv senden (Fig. 57, $c$ und $d$ ). Diesem Systeme schließen sich Nervenfasern des nervus dorsalis proboscidis (Fig. 57, n.d.pr.) an.

Fasern des Cerebropedalkonnektivs gehen aus Ganglienzellen des Vorderteils des Cerebralganglions hervor. Meistens sind diese Zellen in der anderen Ganglienhälfte gelegen (Fig. 57, e) und dann sind ihre Fortsätze Fasern der Cerebralkommissur, welche darin mehr nach vorn gelagert sind als die Kommissurfasern des Cerebrobuccalkonnektivs, aber bisweilen findet man sie anch in derselben Seite des Ganglions (Fig. 57, f).

Die meisten peripheren Nerven haben einen doppelten Ursprung, weil die Nervenfasern teils mit, teils ohne Kreuzung der Medianlinie in sie eintreten. Aber der nervus tentacularis, welcher aus dem Dorsalteile hervorgeht (Fig. 57, n.t.), sowie der hintere Dorsalnerv (Fig. 57, n.d.p.) haben keine Fasern, welche die Medianlinie überschreiten.

Der Ventrolateralnerv (Fig. 57, n.v.l.) nimmt Fortsätze von Ganglienzellen der anderen Ganglionhälfte auf (1ig. 57, g) und, wie ich bei Tschacнoтr im Schema sehe, sein 'l'ext sehweigt aber dariiber, auch Nervenfasern aus dem hinteren Dorsalnerven derselben Seite (Fig. $57, h)$.

Manche von 'T'schachots entdeckten 'Tatsachen sind später von REupsci (1912) bestätigt worden, andere aber nicht und, da REupsci auch mehr gibt als T'schachotr, will ich seine Resultate, insofern sie sich auf die Wege der Leitungsbahnen bezichen, hier ausfïhrlich referieren.

REUPSCI hat unter den Heteropoden unter Anwendung von Gold- und Silbermethoden besonders Pterotrachea untersucht und nicht nur das Cerebralganglion, sondern auch das Buccal- und Pedalganglion, sowie einige peri- 
phere Leitungsbahnen. Es ist nur schade, daß REUPSCH fast niemals unzweideutig angibt, ob Nervenfasern, welche aus einer Ganglienzellgruppe hervorgehen, auch Fortsätze dieser Ganglienzellen sind oder ob sie sich zwischen diesen Ganglienzellen verästeln, m.a.W. ob die Bahn in der Ganglienzellgruppe endet oder anfängt. Man muß dies bei Beurteilung der Reupschschen Resultate beachten.

Die beiden Buccalganglien sind durch eine Kommissur verbunden und Reupsch teilt uns mit, daß die Nervenfasern dieser Kommissuraus Ganglienzellen hervorgehen, welche so weit wie möglich lateral im Buccalganglion liegen. Ich muß gestehen, daß die Abbildung solches nicht überzengend darstellt.

Das Buccalganglion wird von dem Oesophagusnerven und den Radulanerven verlassen. Dabei sind die Ursprungszellen der Nervenfasem des ersteren mediocaudal gestellt, die des letzteren laterocaudal.

Nach Reupsch wïrde ein Cerebro-

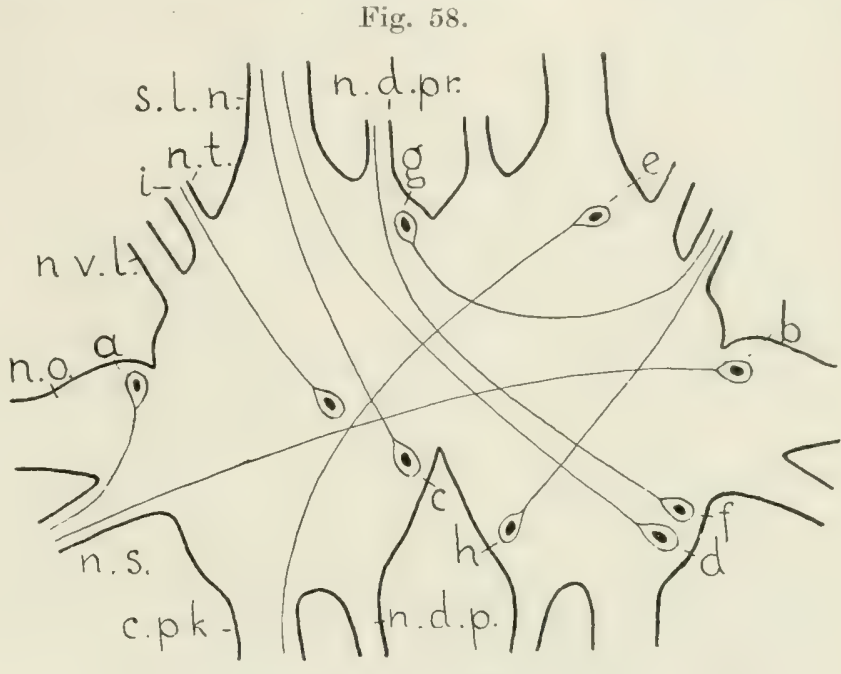

Cerebralganglion von Pterotrachea. Abgeändert nach REUPSCH (1912).
$a$ bis $i=$ Ganglienzellen
c. p. k. = Cerebropedalkonnektiv
n. d. $p_{0}=$ nervus dorsalis posterior
$n . l_{0} p r_{0}=$ nervus dorsalis proboseidis
n. o. $=$ nervus opticus
n. $s .=$ nervus staticus
u. $t$. $=$ nervus tentacularis
$n . v . l .=$ nervus ventrolateralis
s. $l . n .=$ Speicheldrüsenlippennerv.

buccalkonnektiv, wie z.B. auch 'Tschachотік erkennt (Fig. 57, c.b.k.), den Heteropoden abgehen. Es soll aber vorgetäuscht werden, weil sich Tasern der Buccal- und Cerebralnerven mischen.

Obgleich Reupsch mich nicht zu seiner Ansicht bekehrt hat, will ich seiner Terminologie folgen und das Cerebrobuccalkonnektiv den Speicheldrüsenlippennerven nennen (Fig. 5s, s.l.n.). Glücklicherweise stimmt er betreffs des Ursprungs der Fasern dieses Nerven mit 'Tschachotis überein. Ich kann also in der Fig. 58, welche die Leitungsbahnen des Cerebralganglions nach Reupsci darstellt, dieselben Zelltypen $c$ und $d$ zeichnen, wie in der Fig. 57 nach T'schachotis.

Die Nervenfasern des nervus dorsalis proboseidis (Fig. 58, n.d.pr.) begleiten jene Fasern des Speicheldrüsenlippennerven, welche die Median- 
linie kreuzen und gehen aus Zellen (Fig. 58, f) derselben Ganglienzellgruppe hervor.

Die Fasern des Cerebropedalkonnektivs (Fig. 5s, c.p.l.) sah Reupsch in Uebereinstimmung mit Tsснаснотгх als Fortsätze der Ganglienzellen des Typus $e$ (Fig. 58).

Der nervus ventrolateralis (Fig. $58, n . v . l$.) wird von Reupsch der ventrale Kopfnerv genannt. Ein 'Teil seiner Fasem sind Ausläufer von medialen Ganglienzellen der anderen Ganglionhälfte (Fig. 58, g). Das stimmt also mit Tschachotrx. Ein zweiter Teil krenzt nicht die Nedianlinie, sondern stammt

liig. 59.

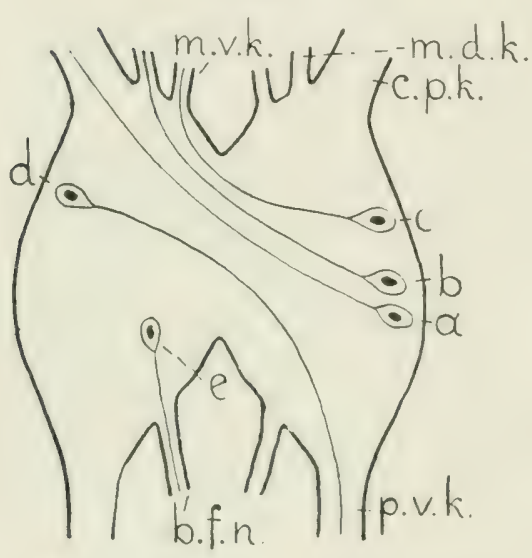

Pedalganglion von Pterotrachea.

Abgeändert nach REupsch (1912).

« bis $e=$ Ganglienzellen

b. 1. n. = Bauchflossennerv

c. $p \cdot k \cdot=$ Cerebropedalkonnektiv

m. d. $k$. = mittlerer dorsaler Kopfnerv

m. $v . k$. $=$ mittlerer ventraler Kopfnerv

p. v. $k=$ Perlovisceralkonnektiv aus einer caudodorsalen Ganglienzellgruppe her (Fig. $58, h$ ). Tch glaube, daß Reupsch den Ursprung dieser Nervenfasern besser beobachtet hat als 'I'schAснотт, welcher sie in den nervus dorsalis posterior iibergehen läBt (Nig. $57, h$ ).

Reupsch konnte die Fasern des nervus tentacularis aus einer caudodorsalen Ganglienzellgruppe derselben Seite hervorgehen sehen (Fig. $58, i$ ).

In der Darstellung der Weise, wie sich die Fasern des nervus staticus im Cerebralganglion verhalten, stimmt Reupsch wiederum mit Tschachotin überein (Fig. 5s, a und b). Nur drückt er sich im 'Texte so aus, daß er sagt, die Nervenfasern strahlen in eine Ganglienzellgruppe ein, während man aus seiner Abbildung schließen wiirde, daß die Nervenfasern Fortsätze der Ganglienzellen dieser Gruppe wären. Man wird sich erinnern, daß auch 'L'schaснотіх nicht nachweisen konnte, ob die Fasern hier anfingen oder endeten. REupscix scheint ersteres zu meinen, aber in diesem Falle sind diese Nervenfasern wahrscheinlich nicht die Nervenfortsätze der Sinnesnervenzellen der Statocyste und wahrscheinlich andere als 'I'scuAchots beobachtete.

Das Pedalganglion wurde ebenfalls von REupscur studiert. Es ist, wie gesagt, mit dem Cerebralganglion durch das Cerebralpectalkonnektiv (Fig. 59, c.p.k.) verbunden und durch das Pedorisceralkonnektiv (Fig. 59, p.v.l.) mit dem Visceralganglion. Neben anderen Nerven gehen daraus nach vorn der mittlere dorsale und der mittlere ventrale Kopfnerv (Fig. 59, m.d.l. und m.x.k.) hervor, sowie nach hinten der Bauchflossennerv (Fig. 59, b.f.n.).

Im Cerebropedalkonnelitiv gibt es Nervenfasern, welche in eine laterodorsale Ganglienzellgruppe eintreten (Fig. 59, a). Ob sie als Fortsätze dieser Ganglienzellen zu betrachten sind, ist nicht gewil3. 
Die Fasern des mittleren dorsalen und ventralen Kopfnerven überschreiten die Medianlinie. Die ersteren entspringen aus dorsalen Ganglienzellen (Fig. 59, b), die letzteren aus ventrorostralen (Fig. 59, c).

Reupsch sah, daß Fasern des Pedovisceralkonnektivs kreuzten und sich mit einer dorsorostralen Ganglienzellgruppe verbanden (Fig. 59, $d$ ), aber ob die Fasern wirklich Fortsätze dieser Ganglienzellen waren, wie ich in meinem Schema vorausgesetzt habe, sagt er nicht.

Die Fasern des Schwanznerven (von mir nicht gezeichnet) gehen aus einer mediodorsalen Zellgruppe hervor, überschreiten die Medianlinie und treten caudal aus dem Ganglion.

Die Fasern der Bauchflossennerven bleiben in 'derselben Ganglionhälfte, wo sie eingetreten sind; ihre Ursprungszellen liegen fast ïberall ventral im Pedalganglion (Fig. 59, e).

Endlich durchsetzen die Fasern der Nerven des Visceral- und des Saugnapfganglions das ganze Ganglion und gehen aus Ganglienzellen, welche ihren Abgangsstellen diametral gegenüber liegen, hervor.

Mit dieser ziemlich allgemeinen Bemerkung habe ich die Reupschschen Angaben über das Zentralnervensystem referiert. Nur wenige Mitteilungen über das periphere Nervensystem bleiben übrig.

Im Hautepithel von Pterotrachea fand Reupsch Sinnesknospen, deren Sinneszellen sich wahrscheinlich kontinuirlich in Nervenfasern fortsetzten. aber vielleicht auch durch Nervenfasern umsponnen wurden. Bei diesem Zweifel verdient es meines Erachtens den Vorzug sie als Sinnesnervenzellen zu betrachten. In der Haut befindet sich ein feiner Nervenplexus und überhaupt anastomosieren die peripheren Nerven oft und wechseln dabei Fasern aus.

Als letzte Ordnung der Gastropoden sollen jetzt noch die relativ sehr gut erforschten Pulmonaten Erwähnung finden. Ich brauche keine besonderen, allgemeinen Bemerkungen über das Nervensystem zu machen. Es ist auch hier wieder ein System von Ganglien durch Konnektive und Kommissuren verbunden, welches die peripheren Nerven aussendet.

Der erste, welcher bei den Pulmonaten das Problem der Hodologie des Nervensystems stellte, war BuchHoLz (1863) im Jahre 1863. Man braucht sich nicht zu wundern, daß er damals nicht fähig war es zu lösen, wo wir jetzt noch so weit davon entfernt sind, aber BuchHolz hat doch bei Limnaeus stagnalis und Planorbis corneus in den Ganglien die peripheren Ganglienzellen und das zentrale Neuropilem untersehieden und auch eingesehen, daß das Neuropilem aus Fortsätzen der Ganglienzellen zusammengestellt ist. Im allgemeinen sah er auch, daß Ganglienzellfortsätze in die peripheren Nerven eintreten.

Im Jahre 1870 deutet Fleming (1870) in nicht sehr klarer Weise auf sinnesnervenzeilen hin. Er beschreibt in dem Tentakel der Landschnecken einen Nerven, welcher, nachdem er den nervus opticus abgespalten hat, im Tentakelganglion endet. Dieses Ganglion verlassen zahlreiche kleine Nerven, welche nach Fummist Ganglienzellen enthalten und zum Epithel gehen. Hier angelangt, enden die Nervenfasem bisweilen in spindelförmigen Verdickungen, welche zwischen den Epithelzellen liegen. RETzIUS (1892) hat später erwiesen, daß Flemmst hier wirklich die Simesnervenzellen gesehen hat, welche von ihm und nachher auch von SArAssd (1894) an dieser Stelle mit aller wïnschenswerten Deutlichkeit gefunden wurden. Nur hat FLEmmíg den Zellkörper' der Sinnesnervenzelle, welcher hier besonders tief unter das lippithel geriickt ist, als DROOGLEVER FORTUXX. 
eine in die Nervenfaser eingeschaltete Ganglienzelle betrachtet und somit seinen wahren Charakter verkannt.

Erst nach zehn Jahren folgen den Flemungschen Untersuchungen einige Angaben iiber das sympathische Nervensystem von Helix pomatia. Damals beschrieb Ravvier (1880) in der Darmwand einen plexus myentericus, das heißt, einen Nervenplexus, wobei bipolare Ganglienzellen in den Nerven eingelagert sind oder unipolare, auf kurzen oder langen Stielen gesessen, daraus hervorragen.

VigraL (1883) konnte alles bestätigen, nur fand er im Nervenplexus auch multipolare Ganglienzellen. Es ist nicht bekannt, ob vielleicht in diesem Plexus bestimmte Reizleitungsbahnen ausgebildet sincl. So lange man nicht genau den Zusammenhang der verschiedenen Ganglienzellen kennt, ist es möglich, aber wahrscheinlich ist es nicht.

Anno 1883 hat auch Bовнuп (1883) die Hodologie des Nervensystems von Helix pomatia studiert und zwar dés zentralen Nervensystems. Neben Helix studierte er auch Limnaeus stagnalis. Boенмic hat ohne Zweifel bisweilen über die Wege der Nervenfasern richtige Bemerkungen gemacht, aber oft hat er nur kleine Bruchteile daron angegeben und manche Bahnen mehr erraten als erwiesen, sodaß seine Angaben alle einer Bestä. tigung bedï̈ren, welche sie nicht immer in den Arbeiten späterer Autoren haben finden können. Statt also seine Mitteilungen genau zu referieren, will ich mich beschränken auf die allgemeine Bemerkung, daß diesem Forseher, die in der Cerebralkommissur kreuzenden Nervenfasern nicht entgangen sind und daß er in fast alle peripheren Nerven Fortsätze der Ganglienzellen des zugehörigen Ganglions ziehen sah.

Als Beispiel einer besonderen von ihm gemeldeten Bahn kamn ich sagen, daß er bei Helix pomatia im nervus tentacularis, oder nervus ommatophorus, wie er ihn nennt, das heißt also im Nerven des großen Tentakels, welcher aus dem Cerebralganglion hervorgeht, ein Bündel ganz feiner Fortsätze unipolarer Cianglienzellen des Cerebralganglions beobachtete, aber seine Abbildung daron scheint mir nicht beweisend zu sein.

Fräulein Hexchunx (1890) hat, was immer bei Wvertebraten eine Seltenheit ist, der Ontogenie des Zentralnervensystems gewisse Data iiber die Wege der Nervenfasern entlehnt. Sie wählte Limax maximus als Objekt. Die verschiedenen Ganglien werden in der Ontogenie getrennt angelegt und ihre paarweise Verbindung ist folge eines sekun. dären Yorgangs: des Answachsens der Nervenfasem. So werden zwei Cerebralganglien angelegt, welche später cine Cerebralkommissur erlangen, weil aus jedem Ganglion Nervenfasern auswachsen. In gleicher Weise bilden sich die Bucealkommissur und die vordere und hintere Pedalkommissur.

In den Kommissuren liegen nach Hexcumax später außerhalb der Nervenfasern auch spindelförnige Zellen und ich glaube, das können sehr gut Gliazellen sein, wie SuIDT (1900) sie bei Helix in den Kommissuren und (ianglien und Nerven beobaehtete.

Ich will noch sagen, daß die Konnektive zum ersten Male als Zellreihen sichtbar werden, aber einige andere Einzelheiten, welehe Hexcumas, da sie keine spezifischen Nervenfärbungsmethoden anwendet, nicht in klarer Weise zeigt, lasse ich fort.

Die originelle Huxcmussehe Arbeit giht mir die leberzeugung, da 3 in dieser Weise noch viele Leitungsbahmen bei Mollusken entdeckt werden können oder ihr Dasein in selbständiger Weise aufs neue bestätigt Werden kamn. Man hat sich zur Ausdehnung unseres Wissens bis jetzt noch viel zu wenig der Ontogenie der Leitungsbahnen bedient.

Das Zentralnervensystem der Pulmonaten hat abermals Berïcksichfigung gefunden in der sehr wichtigen. Ibhandlumg, welche DE NABAs (1894) dariiber veröftentlicht hat. Seine Ingaben sind sehr glaubwiirdig; nichtsdestoweniger bleibt der Wunseh bestehen, sie mit Hilfe der Golsischen oder Methylenblau-Methode bestätigt zu finden.

De NABIAs hat manche Pulmonaten untersucht und im allgemeinen weitgehende Uebereinstimmung unter ihnen gefunden. Er hat den Löwenanteil seiner Aufmerkamkeit dem Genus II clix gewidmet, von dem er drei Arten : Helix pomatia, aspersa und pisena durehforscht hat. 
Ich will also mit Helix anfangen. Die beiden durch eine Kommissur verbundenen Cerebralganglien werden von DE NABras zusammen als das Gehirn bezeichnet und er erkennt darin ein proto-, meso- und postcerebrum.

Das protocerebrum ist ein Agglomerat kleiner Ganglienzellen, worin drei Abschnitte des Neuropilems gelegen sind, welche DE NABIAs die medulla terminalis, medulla interna und medulla externa nennt. Er betrachtet das protocerebrum der Gastropoden als analog mit den Pilzkörpern (corpora pedunculata) der Arthropoden und, wo später Haller (1913) einen Teil des protocerebrum, den globulus, mit den corpora pedunculata nicht nur analogisiert, sondern sogar homologisiert hat, ist er darin von der Wahrheit wohl nicht weit entfernt gewesen.

Die Fortsätze der kleinen Ganglienzellen des protocerebrum ziehen ins Neuropilem und teilweise bilden sie ein Nervenfaserbïndel zum mesocerebrum. Die medulla interna empfängt Fasern aus laterobasalen Ganglienzellen des protocerebrum und manche Kommissurfasern der anderen Gehirnhälfte. Sie ist ein wichtiges Assoziationszentrum. Die medulla externa empfängt hinten zahlreiche Endverästelungen von Fasern der Cerebrovisceral- (oder Cerebropleural-) und Cerebropedalkonnektive.

Das mesocerebrum enthält einige Ganglienzellanhäufungen (masses ganglionnaires), welche DE NABIAs nicht mit dem Namen Ganglion bezeichnet haben will, weil sie kein zentrales Neuropilem besitzen. Ich glaube, darin hat DE NABias völlig Recht, schlage dann aber vor, nicht nur hier, sondern bei allen Evertebraten Ganglienzellanhäufungen im Zentralnervensystem, welche keinen besonderen Abschnitt des Neuropilems umfassen, insofern sie nicht schon einen anderen lateinischen Namen tragen, mit dem Namen nucleus zu belegen. Solches ist in Uebereinstimmung mit der Terminologie der Vertebraten und nucleus ist ein ganz bequemes Wort, viel bequemer als Ganglienzellanhäufung oder masse ganglionnaire.

Das mesocerebrum enthält erstens den nucleus connectivalis (nicht commissuralis, wie DE NabIas, welcher die Konnektive Kommissuren nennt, sagen würde). Seine großen Zellen senden die direkte oder ungekreuzte Pyramidenbahn in das Cerebropedalkonnektiv aus. Dieser so geläufige, weil bei Vertebraten so bekannte Name ward dieser Bahn gegeben, weil sich ihre Fasern einander pyramidenförmig nähern.

Zwischen diesen großen Ganglienzellen liegen kleinere, deren Fortsätze mit der Pyramidenbahn mitlaufen oder zur medulla externa des protocerebrum gehen oder zur Ursprungsstelle des medianen Labialnerven.

Zweitens ist der nucleus corticalis im mesocerebrum gelegen. Seine Ganglienzellen senden ihre Fortsätze durch die Cerebralkommissur zur anderen Hirnhälfte. Diese Nervenfasern bilden die gekreuzte Pyramidenbahn. Da DE NABIAS nicht meldet, daß diese Bahn auch in das Cerebropedalkonnektiv weiter zieht, ist es nicht gewiß, daß die gekreuzten und ungekreuzten Pyramidenbahnen mit Beiseitesetzung der Kreuzung einander so ähnlich sind wie die Namen vermuten lassen.

Neben diesen beiden nuclei umfaßt das mesocerebrum noch eine Gruppe lateraler Ganglienzellen mit geraden Fortsätzen in die Kommissur. 
Das postcerebrum ist in zwei Lappen geteilt, welche mit dem. Cerebrovisceral- und Cerebropedalkonnektiv zusammenhängen und lobus visceralis und lobus pedalis genannt werden.

Die Fortsätze der Ganglienzellen des lobus visceralis bilden ein Bündel, welches den lobus pedalis durchsetzt und im Cerebropedalkonnektiv deszendiert. Andere Ganglienzellfortsätze treten in den nervus tentacularis, den nervus peritentacularis internus und externus und in den nervus labialis medianus und externus ein. Endlich gibt es noch Ganglienzellen im lobus visceralis mit Fortsätzen in der Cerebralkommissur.

Die Ganglienzellen des lobus pedalis versorgen den nervus labialis internus und die vordere Wurzel des nervus stomatogastricus I) mit Nervenfasern und, insofern sie dies nicht tun, senden sie ihre Fortsätze in die Cerebralkommissur oder das Cerebropedalkonnektiv. Die Fasern des Penisnerven, welcher ungepaart und nur rechts ausgebildet ist, durchsetzen den lobus pedalis, bevor sie aus demselben austreten, aber ihre Ursprungszellen sucht DE NABIAs das Cerebropedalkonnektiv entlang oder sogar im Pedalganglion. Später hat Pelsexeer (1906) ihm darin Recht gegeben und gesagt, daß bei den meisten Pulmonaten der Penisnerv aus dem Cerebralganglion hervorgeht, aber seine Nervenfasem im Pedalganglion entspringen.

Torn im lobus pedalis hat DE NABIAs Riesenganglienzellen entdeckt, welche ihren Forsatz zum Zentrum des Ganglions senden. Dort angelangt. teilt er sich in einen Ast, welcher sich im lobus pedalis verästelt und einen Ast, welcher sich in die Cerebralkommissur zur anderen Seite begibt.

Das Cerebrovisceralkonnektiv fuihrt aszendierende und deszendierende Nervenfasern. Die aszendierenden Fasern gehen aus Ganglienzellen der beiden Visceralganglien, der beiden Pleuralganglien (nach DE NABIA Kommissuralganglien, aber da wäre doch, ,Konnektivalganglien " besser) und des Genitalganglions hervor, welche alle nahe beisammenliegen. Im Cerebralganglion angelangt, bilden diese Fasern zwei Bündel. Das innere geht durch die Cerebralkommissur zur anderen Seite des Ganglions, das äußere geht in die medulla externa des protocerebrum.

Die deszendierenden Nervenfasern sind Fortsätze von Ganglienzellen des Cerebralganglions, worunter Zellen des nueleus connectivalis.

Auch das ('erebropedalkonnektiv besteht aus aszendierenden und deszendierenden Nervenfasern. Die ersteren gehen aus Ganglienzellen des Pedalganglions hervor. Sie werden begleitet von zahlreichen Nervenfasern, deren Zellen sich im lobus perlalis oder in großen Mengen im Konnektir selbst befinden. Im (erebralganglion bilden auch diese Nervenfasern zwei Bündel, ein inneres, in die Kommissur vichendes und ein äuberes. in der medulla externa endendes Biindel.

Die deszendierenden Nervenfasern haben wir schon größsenteils als ungekreuzte Pyramirlenbahn kemen gelemt.

1) Besser gesagt Cerebrobuecallinnnektiv und nicht Buecalkomisur, wie Simnoru (1909-1911), wemn er DE N.IBIAs zitiert den nervas stomatogastriens nennt. 
Ich hatte schon Gelegenheit einige Bemerkungen iiber die Nervenfasem der peripheren Nerven zu äußeren. Es folgen jetzt noch andere.

Der nervus tentacularis umfaßt nicht ein, sondern zwei Faserbündel. Beider zugehörige Ganglienzellen liegen, wie gesagt, im lobus visceralis des Cerebralganglions. Außerdem treten Fasern dieses Nerven in die medulla terminalis ein.

Der nervus opticus endet im mesocerebrum neben der Stelle, wo der nervus staticus endet.

Die Fasern des nervus peritentacularis internus gehen, wie gesagt, aus Zellen des lobus visceralis hervor. Wo dieser Nerv austritt, liegt eine einsame, große Ganglienzelle, welche ihren Fortsatz in das Cerebrovisceralkonnektiv sendet und einen Seitenast in die Cerebralkommissur.

Der nervus staticus wird gebildet durch die basalen Nervenfortsätze der Sinnesnervenzellen der Statocyste und, wenn seine Fasern in den Hinterteil des Cerebralganglions eingetreten sind, gabeln sie sich und enden dort.

Ganglienzellen des lobus pedalis bilden mittels ihrer Fortsätze den nervus labialis internus, welcher demnoch aus dem mesocerebrum hervorgeht. Wahrscheinlich ist es ein gemischter Nerv, welcher also auch im Cerebralganglion endende Fasern führt.

Ein Ast des nervus labialis medianus durchsetzt ein peripheres Ganglion im Ende des kleinen Tentakels gelegen. Das Ganglion enthält unipolare Ganglienzellen, welche ihren Fortsatz ins Neuropilem senden und daneben,bipolare Ganglienzellen.

Ein derartiges peripheres Ganglion hat auch der nervus labialis externus, dessen Ursprungszellen im lobus visceralis gelagert sind.

Zuletzt noch ein Wort ïber den nervus stomatogastricus. Ich habe schon bemerkt, daß Ganglienzellfortsätze des lobus pedalis die vordere W Wuzel bilden. Die hintere. Wurzel besteht aus Nervenfasern, welche die Neuriten der Ganglienzellen der stomatogastrischen Ganglien oder Buccalganglien sind und welche bis in die medulla externa zu verfolgen waren.

DE NABIAS fand keine Differenzen zwischen Helix aspersa, pomatia und pisena in den obengenannten Leitungsbahnen. Auch das Gehirn von Arion rufus und empiricorum ist demjenigen von Helix täuschend ähnlich. Zonites algirus weicht von Helix ab hinsichtlich der Abgangsstellen der Nerven des protocerebrum und hinsichtlich der Wege der in die Nerven austretenden Nervenfasern, aber diese Unterschiede haben kein prinzipielles Interesse, da der Ursprung der Nervenfasern immer derselbe ist, wie bei Helix. Auch Limax maximus gleicht dem Zonites.

Kehren wir jetzt wieder zum peripheren Nervensystem zurïck, weil es ziemlich lange gedauert hat, ehe nach DE NABLs cin anderer Leitungsbahnen im Zentralnervensystem der Pulmonaten aufgefunden hat.

Retzius (1892) hat die Golgische Methode angewandt auf alis sensibele Nen'ven. system der Limaciden und infolgedessen hat er Sinnesnervenzellen im bithel der Haut gefunden. Er sah im Epithel fadenförmige Sinnesnervenzellen, deren Zellkörper tief unter dem eigentlichen Epithel gelegen war und eine bipolare Gestalt hatte, weil er sich 
basal in eine Nervenfaser fortsetzte. Diese Zellen sind iiberall in der Haut verbreitet und ihre Nervenfortsätze bilden Bündel.

Auch im Epithel der Tentakeln fand ReTzrus derartige Sinnesnervenzellen, aber ihr Sinnesfortsatz ist unmittelbar unter der Oberfläche ein wenig angeschwollen. Ihr Nervenfortsatz dringt ins Tentakelganglion. Diese Zellen waren schon von FiLMMING entdeckt, aber nicht genau beschrieben worden.

Bipolare Sinnesnervenzellen konnte RETzIUS auch in der Mundhöhle beobachten.

Fig. 60 .

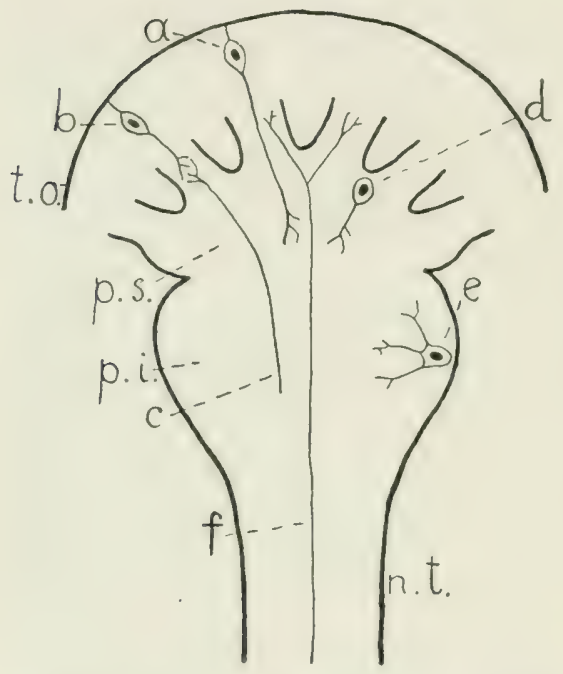

Schema der Tentakelspitze von Helix pomatia. Nach SAMASSA (1894).

$a, b, d, e=$ Ganglienzellen.
$c, f=$ Nervenfasern
$n . t$. = nervus tentacularis
p. $i .=$ pars inferior
p. s. $=$ pars superior
t. o. $=$ Tentakeloberfläche

Retzius meint, daß man diese Zellen richtiger sensibele Nervenzellen als Sinnesepithelzellen nennt, weil ihr Zellkörper so tief unter die Oberfläche gerückt ist. Ich kann ihm darin nicht folgen, weil ich erst dann von sensibeler Ganglienzellen spreche, wenn ihr Sinnesfortsatz nicht mehr die Oberfläche erreicht und somit nieht mehr selber unmittelbar durch die Außenwelt erregt werden kann. Das ist aber hier nicht der Fall.

Später hat Retzius (1900) noch einmal im allgemeinen in der Haut der Mollusken Sinnesnervenzellen beschrieben mit Nerven. fortsätzen bis in die Ganglien.

Die Sinnesnervenzellen im Epithel der' Tentakeh, welche Retzius bei den Limaciden fand, hat SAMASSA (1894) ebenfalls mit Hilfe der Golgischen Methode bei Helix pomatia ans Licht gebracht. Aber er tat mehr. Er hat auch die Leitungsbahnen im 'I'entakelganglion erfor'scht.

Der Fiihlernerv oder nervus tentacularis (Fig. 60, n.t.) geht in der Spitze des augentragenden 'T'entakels in ein Ganglion iiber, wetches durch eine Furche in einen oberen und einen unteren Abschnitt (pars superior und inferior, Fig. 60, p.s. und p.i.) geteilt wird. Vom Oberteil ziehen sechs Ausstrahlungen zur 'Tentakeloberfläche (Fig. 60, t. o.) Es sind dies keine eigentlichen Nerven, denn sie enthalten ebensogut Neuropilem und Ganglienzellen, wie das Ganglion selbst.

Im Epithel des 'Tentakels liegen die Simnesnervenzellen (Fig. 60, $a$ und $b$ ), und es interessiert uns sehr, daß SAMASSA sagt, daß diese Zellen neben anderen Variationen ihrer Gestalt auch bisweilen einen Sinnesfortsatz aufweisen. welcher mit einigen kurzen, frei endenden Seitenästchen versehen ist. Solche Zellen, welche wir später auch bei VERATTr $(1900)$ kiennen lernen werden, veranschaulichen in treffender Weise den Uebergang einer Sinnesnervenzelle in eine sensibele Ganglienzelle, wie er nach meiner Hypothese phylogenetisch stattgefunden hat.

Die Nervenfortsätze der Sinnesnervenzellen verhalten sich in zwei Weisen. Entweder treten sie durch eine Ausstrahlung des Tentakelganglions in 
dessen oberen Teil ein und verästeln sich dort (Fig. 60, a), oder sie enden schon, ebenfalls verästelt, in einer Ausstrahlung (Fig. 60, b). Niemals setzen sich die Nervenfasern der Sinnesnervenzellen bis in den 'Tentakelnerven fort.

Die terminalen Verästelungen der Nervenfortsätze der Sinnesnervenzellen werden umschlungen durch Endverästelungen vou Nervenfaserin, welche aus dem unteren Teil des Tentakelganglions herstammen, aber uibrigens unbekannter Herkunft sind (Fig. 60, c).

In der Peripherie des Ganglions befinden sich unipolare oder multipolare Ganglienzellen (Fig. 60, $(l$ und $e$ ), mit Fortsätzen, welche sich im Neuropilem verzweigen.

Im Tentakelnerven befinden sich weiter noch Nervenfasern unbekannter Herkunft (Fig. 60, f), welche sich im oberen 'Teil des Ganglions gabeln. Jeder Ast zieht in eine Ausstrahlung des Ganglions und verzweigt sich dort wahrscheinlich noch mehr.

Im Ganglion fand SAmassa noch andere Nervenfasern, ohne ihren Anfang oder ihr Ende entdecken zu können. Ich will diese hier nicht weiter beschreiben.

Samassa meldet auch im vorderen 'Tentakel, welcher kein Auge trägt, Sinnesnervenzellen mit Nervenfortsätzen, welche ins 'Tentakelganglion sehreiten und auch die eigentiimlich gegabelten Nervenfasern ( $f$ der Fig. 60) wurden dort beobachtet.

Eine ganz besondere Innervation soll nach Sumassa der Tentakelmuskel haben. Am peripheren Ende dieses Muskels entdeckte er multipolare Zellen, welche wohl nervöser Art sein müssen, denn sie senden einen starken, unverzweigten Fortsatz zur Körperoberfläche und manche andere verzweigte zwischen die Muskelfasern. Sanassa zieht den Schluß, daß, weil eine andere Innervation des Tentakelmuskels unbekannt ist, diese Zellen ,,motorische Sinneszellen" sind (ich würde sagen Simnesnervenzellen, siehe S. 154), welche den Reiz durch ihre zentralen Fortsütze ummittelbar zum Muskel leiten. Da hätte man also eine Leitungsbahn, welche nur aus einer einzigen Zelle bestände, wie auch Alexandrowicz bei Astacus und Palinums gefunden zu haben moint (Vergl. S. 235). Diese Zellen bilden nach SAmASSA die primitivste Form eines Nervensystems, völlig unabhängig vom übrigen Nervensystem der Schnecke. Ich bin damit einverstanden, glaube aber, daß jedem eine Bestätigung eines so außerordentlich merkwürdigen Verhältnisses willkommen sein wird.

Samassa kritisiert in seinemi Artikel die Von LenHosseksche Hypothese über die Umbildung der Sinnesnervenzelle im Lpithel von Lumbricus in eine Spinalganglionzelle der Vertebraten und gibt eine Verbesserung derselben. Ich brauche seine Ansichten nicht zu referieren, weil ich meine die ganze Vox LexHosseksche Hypothese bis auf einen kleinen Teil als unzutreffend dargestellt zu haben. (Vergl. S. 94).

Im Jahre 1896 hat Brsogñ (1896) bei Limax subfuseus und agrestis im l'harynx, im Darm und in den Speicheldrisen einen Nervenplexus beobachtet, weleher zun 'I'eil iibereinstimmt mit dem plexus myentericus, welcher von RANvin bei Helix gefunden wurde. Bisogni sah ebenso wie Ranvme, daß Ganglienzellen mit kurzen Stielen den Nerven dieses Plexus aufsaßen oder darin eingebettet waren, aber er sah außerdem, 
daß Nervenfasern dieses Plexus die glatten Muskeln des Darmkanals innervierten. Der ganze Plexus hängt mit den beiden Bucealganglien zusammen.

Die Golgische Methode hat auch in anderen Händen als jenen Retzius' und Samassas Resultate gegeben. So hat Smidt (1899) damit in den Lippen und dem Oberkiefer von Helix Sinnesnervenzellen sichtbar gemacht und HAveT (1899 a) damit unsere Kenntnis der Leitungsbahnen von Limax gefördert.

HAvet bestätigte im Epithel der großen Tentakeln die Gegenwart der bipolaren Sinnesnervenzellen, welche Retzius darin meldete und auch die Tatsache, daß ihr Nervenfortsatz ins Tentakelganglion eindringt. Unter der Epidermis wies er einen Nervenplexus nach, welcher durch Nerven mit den Ganglien, z.B. dem Pedal- und Pleuralganglion verbunden war. Bipolare, offenbar sensibele Ganglienzellen sandten einen Fortsatz in diesen Plexus hinein, während der andere sich in der Haut verästelte. Hier waren auch uniund multipolare Ganglienzellen gelagert.

Auch innerhalb der Pharynxwand sind multipolare und bipolare Ganglienzellen. Die bipolaren haben einen verästelten oder unverästelten peripheren Fortsatz im Epithel und ihre zentralen Ausläufer ziehen in Bündeln nach kleinen Ganglien, welche um den Pharynx gelegen sind. Ich betrachte auch diese Zellen als sensibele Ganglienzellen mit frei im Epithel endendem Fortsatz, also als andere Zellen als die von Brsogxi wahrgenommenen.

HAvET hat die Struktur der Ganglien nicht unerwähnt gelassen. Er beobachtete auch darin unipolare, bipolare und multipolare Ganglienzellen und sah, wie die unipolaren oft einen Zweig (den Dendriten) ins Neuropilem und einen anderen (den Neuriten) in einen peripheren Nerven oder in eine Kommissur russandten.

Im Cerebralganglion meldet er Ganglienzellen mit ihrem einzigen Fortsatz in der C'erebralkommissur, wie auch DE NABIAs sie beschrieb. Der Neurit spaltet vor seinem Uebergang in die Kommissur nur kleine Kollateralen im Neuropilem ab. Daneben gibt es im Cerebralganglion multipolare Ganglienzellen mit vielen ins Neuropilem ziehenden Fortsätzen (Dendriten) und mit cinem einzigen Ausläufer (dem Neuriten) in der Cerebralkommissur.

Im Pedalganglion entdeckte er multipolare Ganglienzellen mit einem Fortsatz im Pedalnerven und anderen im Neuropilem.

In einer anderen Arbeit aus demselben Jahre hat Havir (Is?g b) noch hinzugefügt, daß bei Limax Fortsätze von Ganglienzellen des Pedalganglions durch das C'erebropedalkonnektiv derselben Seite ins C'erebralganglion treten und weiter durch die ('erehralkommissur zur anderen Seite zichen.

Gleich nach den HAVETschen Mitteilungen erseheint die wunderschöne Arbeit Veraters (1900), in der abermals das Nervensystem von Limax einer Untersuchung mit Hilfe der GoLgischen Methode, und anch bisweilen der Methylenblau-Methode unterworfen wird.

VERATti hat sowohl das Zentralnervensystem, wie das periphere Nervensystem bearbeitet.

Hinsichtlich des ersteren sei bemerkt, daß er im .,unteren Schlundganglion" (Pedalganglion) Kommissurellen entrleckte, also Ganglienzellen, welche 
ihren Neuriten von der einen Ganglionhälfte durch die Kommissur zur anderen sandten und beiden Hälften Kollateralen überließen. Ebensolche Zellen fand er in den ganglia stomatogastrica.

Ein anderer Zelltypus, der in manchen Ganglien zu finden ist, hat nur kurze Fortsätze im Neuropilem desselben Ganglions. Havet hat solche Zellen nicht zu Gesicht bekommen. Hingegen blieben V ERATti lange Fortsätze der Ganglienzellen, welche in die Nerven gehen, wie Havet sie beschrieb, verborgen. Zweifelsohne beides infolge der Launenhaftigkeit der GoLgIschen Methode.

Konnte Veratti also in den peripheren Nerven der Ganglien keine zentrifugalen Nervenfasern beobachten, so sah er doch darin, u.a. in den Nerven des Pedalganglions, zentripetale Nervenfasern, welche sich im Neuropilem verzweigten.

Lateral neben dem ,oberen Schlundganglion" (C'erebralganglion) unterschied VERATTI ein Ganglion, welches nach ihm vielleicht ganglion opticum heißen sollte. In sein Neuropilem treten Nervenfasern des Tentakelnerven und des Cerebralganglions und in seiner Peripherie sind eine unipolare und eine multipolare Ganglienzellart, deren Fortsätze sich im Neuropilem verzweigen. Ob die letztgenannten Fortsätze sich in den Tentakelnerven begeben, oder in das Konnektiv zum C'erebralganglion, konnte nicht nachgewiesen werden.

Veratti macht die Bemerkung, daß die Fasern des Neuropilems auch die Zellkörper der Ganglienzellen in der Peripherie des Ganglions umspinnen. Das ist sehr wichtig, weil daraus erhellt, daß es nicht genügt zu wissen, daß, wie man so oft lesen kann, ein Nervenfaserbündel in eine Ganglienzellgruppe tritt. Man weiß dann noch nicht, ob die Nervenfasern aus diesen Ganglienzellen hervorgehen oder nicht, m.a.W. ob sie in dieser Ganglienzellgruppe enden oder anfangen. Ich habe deshalb im allgemeinen niemals bei den Evertebraten Angaben iiber das Enden oder Anfangen von Nervenfasern in einer Zellgruppe als der Erwähnung wert betrachtet, wenn nicht außerdem mitgeteilt wurde, ob die Nervenfasern wirklich Fortsätze dieser Ganglienzellen seien oder diese Ganglienzellen mit ihren Endverästelungen umschlängen.

Dem peripheren Nervensystem hat Verattr in der Haut, in den T'entakeln und in der Darmwand seine Aufmerksámkeit gewidmet.

Seine Beobachtungen über die Simnesnervenzellen und Ganglienzellen der Haut sind für mich besonder's wichtig, weil es VERATTI gegeben war, manche Zwischenstufen zwischen einer Sinnesnervenzelle und einer sensibelen Ganglienzelle mit freien Nervenendungen nachzuweisen, womit er die denkbar köstlichste Illustration meiner Hypothese iiber die phylogenetische Entwicklung der sensibelen Ganglienzelle aus einer Sinnesnervenzelle (vergl. S. 12) geliefert hat.

Was hat VERATT denn gesehen? Er sah erstens in der Haut von Limax bipolare Sinnesnervenzellen mit der bekannten Gestalt. Ihr Zellkörper lag unter dem Epithel; ihr peripherer Fortsatz drang zwischen den Epithelzellen bis an die Oberfläche hervor ; ihr zentraler Nervenfortsatz trat in einen unter der Haut gelegenen Nerven eir. 
Eine Besonderheit, welche kein anderer Forscher noch meldete, war diese, daß die Nervenfaser sich nicht immer ganz einfach in den Hautnerven umbog, sondern, daß sie bisweilen sich T-förmig spaltete und einen Ast in beide Richtungen sandte. Bisweilen hat auch die Simnesnervenzelle zwei Nervenfortsätze, welche jeder eine Richtung im Nerven einschlagen. Dann ist also das $T$ so niedrig geworden, daß der vertikale Ast ganz in den Zellkörper aufgenommen ist. Ich erkläre so auch die multipolaren Sinnesnervenzellen Samassas (S. 151).

Uns interessiert es mehr, daß auch der Sinnesfortsatz nicht immer unverzweigt his zur Körperoberfläche emporsteigt. Der Zellkörper kann mehrere Sinnesfortsätze tragen, welche alle die Oberfläche des Epithels erreichen oder der Sinnesfortsatz kann verzweigt sein und damn können die Zweige sich auf verschiedene Weisen verhalten. Sie können die Oberfläche erreichen oder wie ein Nervenfortsatz in den Hautnerven eintreten oder aber freie intraepitheliale Verästelungen bilden.

Im letzten Falle ist die Zelle eine schöne Zwischenstufe zwischen einer Sinnesnervenzelle mit unverzweigt bis zur Körperoberfläche emporsteigendem Simnesfortsatz und einer sensibelen Ganglienzelle mit frei im Epithel verästelten Fortsätzen. VERATTI hat freie, sensibele Nervenendungen überall in der Haut von Limax beobachtet, aber besonders schön in einer Flimmergrube, welche am Seitenrande des Fußes entlang zu finden ist, wo die Nervenendungen bis zur Basis der Flimmer emporsteigen. Diese freien Nervenendungen gehören zu Nervenfasern der Hautnerven. Ihre Ganglienzellen liegen in diesen peripheren Nerven verbreitet, oder, wie im 'T'entakel, subepithelial.

Das sind die Tatsachen. Wir können nicht anders als Verattr Recht geben, wenn er sagt, daß er keine scharfen Grenzen wahmimmt zwischen Sinnesnervenzellen mit frei im Epithel endenden Seitenästchen des Sinnesfortsatzes (wie in der Haut), subepithelialen Ganglienzellen mit freien, sensibelen Nervenendungen im Epithel (wie im Tentakel) und derartigen sensibelen Ganglienzellen in den peripheren Nerven. Nur ob ein Fortsatz die Körperoberfläche erreicht, bestimmt für mich den Charakter der Zelle.

Dem-ufolge betone ich nochmals, daß ich mir durch. Versenkung die sensibele Ganglienzelle phylogenetisch aus der Sinnesnervenzelle entstanden denke, nicht bei Mollusken, sondern bei den niedrigsten Wïmern, wo wir ebenfalls sensibele Ganglienzellen neben Sinnesnervenzellen kennen, aber keine so stattliche Reihe von Uebergangsformen.

Unipolare Ganglienzellen im Nervenplexus der Haut hat Veratrim Gegensatz zu Havet nicht auffinden kömnen.

Veratti gelang es in den Muskeln des bulbus pharyngeus einen Nervenplexus sichtbar zu machen mit vielen Ganglienzellen darin. Er erzählt uns, daß zuvor Paravicixi, dessen Arbeit mir leider nicht zugänglich war, diesen Plexus gesehen und gemeint hatte, daß3 seine Nervenfasern die Muskeln innervierten. VERATTI beschreibt die Ganglienzellen teils als unipolare Zellen, deren Fortsatz nach T'förmiger 'Teilung in ein Nervenfaserbündel übergeht, teils als multipolare Zellen mit allen ihren Fortsätzen im Plexus.

Im Epithel der Mundhöhle und des Pharynx sah V'ERATT Sinnesnerven- 
zellen, deren Fortsätze einen intraepithelialen und subepithelialen Nervenplexus bildeten. Er betont, wie auch Paravicixi, Retzios und Smidt solche Zellen schon bei Limax und anderen Pulmonaten beobachtet hatten. Er erkenut nur eine einzige Art dieser Sinnesnervenzellen an mit einem Sinnesfortsatz. welcher bis in die Cuticula fortschreitet und dort einen Faserbüschel bildet. Als SiInt (1899) Stachelzellen mit einem einzigen Fortsatz in der Cuticula und Polypenzellen mit manchen Seitenästchen darunter unterschied, hat er nach VERATTI in beiden Fällen dieselben Zellen, wie er, aber unvollständig imprägniert gesehen.

In den Tentakeln gibt es einen ebensolchen Nervenplexus mit ebensolchen Sinnesnervenzellen wie im Pharynx. Auch hier ist eine Cuticula entwickelt. Ueberdies sind unter dem Epithel bipolare Zellen, deren einer Fortsatz in den Plexus geht, während der andere sich frei im Epithel verästelt. Das sind also wahre, sensibele Ganglienzellen. Tief im Tentakel tritt ein Ganglion auf, aus kleinen, unipolaren Ganglienzellen zusammengesetzt, deren Fortsätze in ein einem Neuropilem ähnliches Gewebe tauchen.

Wenn ich zuletzt noch gemeldet habe, daß die Fasern des nervus opticus das Auge mit einem Plexus umgeben, wobei, wie aus der Abbildung VERATTIS erhellt, die Fasern selbst kontinuirlich in einander übergehen und daßalle peripheren Nerven der Ganglien und besonders jene der Geschlechtsorgane und des Darmsystems Ganglienzellen allein oder in Gruppen führen, sodaß vielleicht diese Nerven den Reiz nicht bloß ihrer Länge nach leiten, habe ich dem Aufsatz VERATTIs -wohl das wichtigste entnommen.

Simd (1901) hat das Studium des Nervensystems des Vorderdarms der Pulmonaten nach seiner ersten Arbeit darïber (1899) nicht ruhen lassen. Er fand jetzt die Muskulatur um den Oesophagus herum innerviert durch motorische Fasern der Nerven des Buccalganglions. Diese motorischen Nervenfasern waren in den Nerven mit sensibelen Fasern, welche hauptsächlich aus einem Nervenplexus in der Basalmembran der Radula herstammten, gemischt.

Im Epithel der Mundhöhle erkannte er neben den bekannten Sinnesnervenzellen intraepitheliale Nervenfasern. Diese bilden mit den Nervenfortsätzen der Sinnesnervenzellen starke Bündel, welche lateral ins Buecalganglion eintreten und mit Gruppen unipolarer, bipolarer oder multipolarer Ganglienzellen, wahrscheinlich jener ebenfalls von VERATti beobachteten Ganglienzellen, umgeben sind.

Im nächsten Jahre hat SmIDT (1902) abermals die freien intraepithelialen Nervenendungen mit Hilfe einer modifizierten GoLGIschen Methode studiert. Er arbeitete jetzt mit Helix und wies sie nach in der Vagina, im Epithel der Fußdrüse und in der Haut. In den beiden letzten Fällen sah er die Nervenfasem aus einem subepithelialen Nervenplexus mit Ganglienzellen hervorgehen.

Im Pharynx meldet er den Uebergang des Nervenfortsatzes einer Sinnesnervenzelle in eine Nervenfaser des Bucealganglions. Neben den Simesnervenzellen freie intraepitheliale Nexvenendungen, welche mit einem Nervenplexus zusammenhingen. Merkwürdigerweise weist auch SuId, ebenso wie VEritTr, darauf hin, daß bisweilen Aestchen dieses Plexus besonder's die Zellkörper der Simesnervenzellen umspannen. Wenn diese Zellen nicht selbst einen Nervenfortsatz hätten, wäre das Verhältnis ganz begreiflich, jetzt aber nicht. Hat man vielleicht darin eine Zwischenstufe zwischen einer Sinnesnervenzelle. und einer dureh die Nervenendungen einer sensibelen Ganglienzelle umspommenen wahren Sinneszelle zu erblicken, oder beruht das angebliche Verhältnis der Simnesnervenzelle mit der sensibelen Nervenfaser auf 'Iäusehung ?

lch werde jetzt noch einige Angaben über die Innervation des Pulmonaten-Auges hier machen. 
Der wahre Sachverhalt ist hier schon außerordentlich frïh von BABUchiN (1865) eingesehen worden. Er beschrieb in der Retina bei manchen Pulmonaten pigmentierte und pigmentfreie Stäbchenzellen, welche basal ummittelbar in Nervenfasern übergehen. BABUCHIN bildet diese Zellen ab und man kann darin ohne Mühe Simnesnervenzellen erkennen. Der BABUChinsche Befund ist übrigens später bestätigt worden. BABUCHIN ist mit Hensen (1865) der erste, weleher bei Mollusken Zellen des Typus der Sinnes. nervenzelle beobachtet hat.

BaEcker (1903) hat bei Helix, Arion und Limax in der Retina Pigmentzellen neben pigmentlosen Zellen mit Stiftchensaum gefunden. Beide Zellarten setzten sich basal in eine Faser fort, aber die derbe Faser der Pigmentzelle geht nur zur Basalmembran der Retina, ist also eine Haftfaser, wähend die Faser der pigmentlosen Zelle sich in den Sehnerven begibt, eine Nervenfaser ist und somit die Zelle als Sehzelle charakterisiert. Die Sehzellen der Retina sind deshalb Sinnesnervenzellen.

GRANT SimTh (1906) hat die BAEckERschen Mitteilumgen für Limax völlig bestätigt. U'eberdies entdeckte er, daß auch die Sehzellen der akzessorischen Retina von Limax sich in Nervenfasem fortsetzen, welche sich dem Hauptnerven anschließen. Auch die Sehzellen von Planorbis verjingen sich in Nervenfortsätze.

Nachher hat noch Stantschinsky (1908) die Rïckenaugen von Oncidium vericulatum und anderen Oncidium-Arten untersucht, wobei er entcleckte, daß auch hier die Sehzellen Simesnervenzellen sind. Ihre Nervenfortsätze vereinigen sich mit anderen Nervenfasern, worunter motorische, zum nervus opticus, welcher selber Ganglienzellen enthält. Im Rückenepithel sah er außerdem Sinnesnervenzellen. Ihr Zellkörper war, wie so oft, unter das Epithel geriickt.

In letzter Zeit hat noch HaLLer (1913) in seinem schon zitierten Aufsatz uiber die Intelligenzsphären der Mollusken den Leitungsbahnen der Pulmonaten große Aufmerksamkeit gewidmet. Er hat die Nethylenblauund GoLgische Methode angewandt und damit die folgenden uns hier interessierenden Resultate erreicht.

HALLER komnte im Cerebralganglion von Helix pomatia drei Abschnitte unterscheiden, einen vorderen, mittleren und hinteren Teil. Den S. 146 besprochenen, sehr wichtigen Artikel, welchen DE NABrAs (1894) ïber das Nervensystem der Pulmonaten veröffentlicht hat, kennt HALLER nicht und so geht er leider für Helix auf die viel weniger bedeutende Arbeit Bömmas (1883) zuriick. Die drei Abteilungen des Cerebralganglions werden deshalb mit den drei 'leilen verglichen, welche Böнuı darin unterschied, nicht aber mit dem proto-, meso- und postcerebrum DE NABLAs'. So geht es auch in anderen Hinsichten und, weil ich es nicht wage ohne eigene Beobachtungen die Himabschnitte HaLlers mit den DE NABLasschen zu vergleiehen, will ich die HALLERschen Untersuchungen an und für sich referieren.

Die vordere Abteilung des C'erebralganglions trägt dorsal eine Erhabenheit, worin kleine Ganglienzellen liegen. Es ist der globulus oder die Intelligenzsphäre, nach HALLER mit den corpora pedunculata der Wiirmer und Arthropoden homolog. Die Ganglienzellen nehmen nur eine laterale Stellung ein, sodaß median das Neuropilem die Oberfläche des Gehins erreicht. Sie sind nach HALLER durch vicle anastomosierende Fortsätze gegenseitig verbunden und senden auch Fortsätze ins Neuropilem. Diese treten aber niemals in die peripheren Nerven und das gibt dem globulus den Charakter einezentralen Assoziationsgebietes. Wohl gehen Fasern des Neuropilems des globulus durch die Cerebralkommissur zum Neuropilem der vorderen Hirn- 
abteilung der anderen Seite und ebenso zum "Vereinsgebiete", das heißt zur Stelle, wo die drei Hirnabteilungen zusammenstoßen und welche nach HALLER mit allen Zentren des Zentralnervensystems Verbindungen hat.

Andere Ganglienzellen als jene des globulus sind im vorderen Hirnabschnitt nur noch neben der Wurzel des zweiten Nerven, des nervus tentacularis oder ommatophorus gelegen. Sie gehören diesem Nerven an.

Es scheint mir, daß die Angaben HALLERs über die vordere Abteilung des Cerebralganglions im allgemeinen gut übereinstimmen mit einigen Bemerkungen, welche DE NABIAs über das protocerebrum macht. Nur erzählt uns De Nabias mehr dariuber.

Die mittlere Abteilung des Cerebralganglions sendet nach HALLER keine Nerven aus, sondern daraus geht die Cerebralkommissur hervor. Haller betrachtet sie als motorisch. Er fand darin multipolare Ganglienzellen, welche kurze Fortsätze ins Neuropilem sandten oder unmittelbar mittels dieser Fortsätze zusammenhingen und auch einen langen Neuriten besaßen. Betreffs dieser Neuriten bemerkt er, daß auch sie durch Seitenäste anastomosieren, aber man wird sich erinnern, daß HALLER an manchen Stellen Zusammenhang der Ganglienzellen sieht, wo solches anderen Autoren nicht gelingt. Vorn in dieser Abteilung gelegene Ganglienzellen senden ihre Neuriten ins Pleuralganglion derselben Seite; hinten gelagerte Zellen haben Fortsätze, welche in der Cerebralkommissur kreuzen und im Pleuralganglion der anderen Seite enden.

Die hintere Abteilung des Gehims umfaßt einen vorderen und einen hinteren Teil. Der Hinterteil ist das dem Gehirn angeschlossene Pleuralganglion; der Vorderteil gehört zum Cerebralganglion. Die mittelgroße Ganglienzellen einer Gruppe des Vorderteils senden ihre Fortsätze in das Cerebropedalkonnektiv (HALLER sagt irrtülich Cerebropleuralkommissur). Das Neuropilem der hinteren Gehirnabteilung ist nach HALLER ein sensibeles Assoziationsgebiet.

Arion empiricorum zeigt keine wichtigen Differenzen Helix gegenüber. Der globulus ist besser entwickelt. Ein zartes Nervenfaserbündel verbindet sein Neuropilem mit dem ,Vereinsgebicte". Andere Nervenfasern bilden eine Globularkommissur.

Ganglienzellen der mittleren Hirnabteilung senden Fortsätze in den zweiten Hirnnerven, den nervus tentacularis (nervus ommatophorus) und diese Nervenfasern ziehen teils oberhalb, teils unterhalb des Neuropilems des globulus.

Auch Limax cinereoniger weicht nicht erheblich ab. Die Ganglienzellrinde des globulus hat größere Ausdehnung als bei Arion und erreicht die mediane Seite. Die Globularkommissur ist besser entwickelt. Auch hier rieht ein Nervenfaserbündel ins ,Vereinsgebiet”.

Das Pleuralganglion ist bei dieser Schnecke durch ein Konnektiv mit dem Cerebralganglion verbunden. Es enthält Ganglienzellen, welche ihren Fortsatz ins Cerebralganglion oder in das Konnektiv zu den Buccalganglien (vorderen Eingeweideganglien) senden, während Seitenäste ins Neuropilem des Ganglions ziehen. Im Pleurobuccalkonnektiv, welches von anderen 
Autoren, welche das Pleuralganglion zum Cerebralganglion rechnen Cere-, brobuccalkonnektiv genannt wird, beobachtete HALLER auch Nervenfasern, welche im Pleuralganglion endeten.

Ganglienzellen der hinteren Abteilung des Cerebralganglions senden Fortsätze durch das Cerebropleuralkonnektiv ins Pleuralganglion.

HALLER entdeckte im Cerebralganglion der Pulmonaten einige Riesenzellen, wie auch DE NABIAs getan hat. Diese Ganglienzellen sind bei den verschiedenen Tierarten jedoch nicht mit einander homolog. Das geht ohne weiteres hervor aus der 'Tatsache, daß3 z.B. die hintere Riesenzelle von Arion seinen Fortsatz in den nervis tentacularis (sive ommatophorus) sendet, während die hintere Riesenzelle von Limax mit dem siebenten Nerven in Verbindung steht. Die vordere Riesenzelle von Limax sendet Fortsätze ins Pleuralganglion durch das Cerebropleuralkonnektiv und in den vierten Hirnnerven.

Auch über die peripheren Nerven des Cerebralganglions hat HALLER einige hodologische Bemerkungen gemacht. Er bezeichnet die Nerven nicht mit den üblichen Namen, sondern mit Ziffern, was wiederum die Vergleichung der Beobachtungen, welche DE NABLAS uns mitteilt, mit den seinigen sehr erschwert.

Die sechs vorderen Hirnnerven, unter denen der zweite, der nervus tentacularis oder ommatophorus, der wichtigste ist, gehen aus der vorderen Hirnabteilung hervor, der siebente und achte, sowie der nervus staticus, welchen HALLER noch im Jahre 1913 nervus acusticus nennt, aus der hinteren Abteilung des Cerebralganglions.

Die Fasern des nervus tentacularis gehen nach HALLER aus Ganglienzellen der mittleren und hinteren Abteilung des Cerebralganglions hervor. Andere Nervenfasern suchen das ,Vereinsgebiet" oder kreuzen die Medianlinie in der Cerebrallkommissur. Nur ein Teil dieser Angaben kann vielleicht ïbereinstimmen mit demjenigen, was DE NABIAs uns über die Fasern dieses Nerven lehrt.

Ebenso wie der zweite Nerv aus manchen 'Teilen des Cerebralganglions Fasern empfängt, stammen die Nervenfasern der fünf anderen vorderen Hirnnerven nach HALLER aus vielen Regionen. Bestimmte Kerne, worin die Nerven wurzeln gibt es nicht. Die Ursprungszellen der Nerven liegen regellos gemischt.

Der siebente Nerv empfängt hauptsächlich Fasern aus der mittleren Hirnabteilung. Hier sah Hatcer erstens Ganglienzellen mit ihrem Fortsatz im siebenten Nerven, zweitens Ganglienzellen, deren Fortsatz sich spaltete in einen Ast im siebenten Nerven und einen Ast, welcher in der Cerebralkommissur lireutzte. Drittens sah er Ganglienzellen, deren Fortsatz in der Cerebralkommissur kreutze und damn in den siebenten Nerven der anderen Seite zog oder im Vereinsgebiete endete.

Neben diesen Nervenfasern ziehen solehe aus der hinteren Hirnabteilung in den siebenten Nerven. Einige Ganglienzellen dort haben einen Fortsatz mit sogar drei Lesten : einem in dem siebenten Nerven, einem im Vereins- 
gebiete und einem kreuzenden in der Cerebralkommissur. Bisweilen geht noch ein vierter Ast in das Cerebropedalkonnektiv.

Der achte Nerv hat drei Wurzeln. Seine Fasern gehen alle aus dem Neuropilem hervor, das will sagen enden dort.

Auch die Fasern des nervus staticus enden im Neuropilem, gerade so wie DE NABIAS gemeldet hat, aber nach HALLER überschreitet ein Teil die Medianlinie in der Cerebralkommissur, was DE Nabias seinerseits nicht gesehen hat.

In den Konnektiven begegnet man nach HALLER Fortsätzen von Ganglienzellen anderer Ganglien, welche im Cerebralganglion mit oder ohne Kreuzung enden und Fortsätze cerebraler Ganglienzellen, welche mit oder ohne Kreuzung in einem anderen Ganglion enden.

Die Verbindung des Cerebralganglions mit dem Pleuralganglion schließlich könnte man ein inneres Konnektiv nennen. Sie wird, wie gesagt, gebildet durch Fortsätze von Ganglienzellen der mittleren Hirnabteilung, welche zum Teil nach Kreuzung in der Cerebrallkommissur im Pleuralganglion enden.

Nachdem wir also

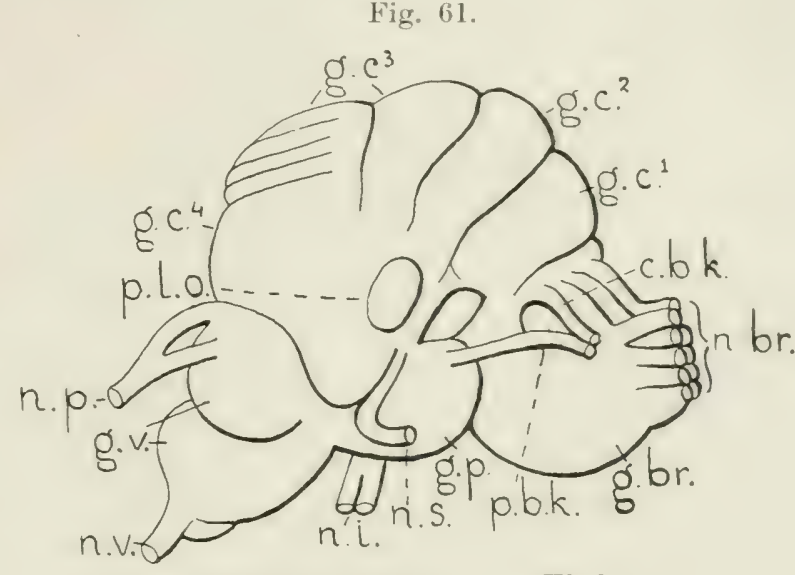

Zentralnervensystem von Eledone. Rechte Seite. Nach Haller (1913), Textfigur 10.

c. b. $k$. $=$ Cerebrobuccalkonnektiv

g. $b r$. = ganglion brachiale

g. c. $l=$ vorderes Cerebralganglion

g. c. $2=$ mittleres Cerebralganglion

g. c. $3=$ hinteres Cerebralganglion

g. c. $4=$ posterobasales Ganglion

g. p. = ganglion pedale

g. $v .=$ ganglion viscerale

$n$. br. $=$ nervi brachiales

n. $i$. = nervus infundibuli

$n . p_{0}=$ nervus pallialis

n. $s_{0}=$ nervus staticus

n. $v$. $=$ nervus visceralis

p. b. l. = Pedobuccalkonnektiv

p. l. $c_{0}=$ pedunculus lobi optici

(abgeschnitten)

die Leitungsbahnen der Gastropoden besprochen haben, bleibt uns noch die Klasse der Cephalopoden oder Tintenfische übrig. Ihr Nervensystem ist besonders gut entwickelt. Die wichtigsten Ganglien bilden einen einzigen Komplex, welcher den Oesophagus umringt.. Ich glaube zum richtigen Verständnis der Sache die gegenseitige Lage der wichtigsten Ganglien mit einem Beispiel erklären zu müssen.

Ich wähle dazu eine Seitenansicht des Zentralnervensystems von Eledone (Fig. 61), welche ich dem HaLLERschen Aufsatz (1913) entnehme und wonach ich oft verweisen werde. 
Die Leitungsbahnen des Nervensystems der Cephalopoden sind relativ gut bekannt und ihre Beschreibung bildet eins der schwersten Kapitel der Hodologie der Evertebraten. Weitaus die meisten Autoren befassen sich mit den Dibranchiaten, nur MIERTOx (1905) hat auch den tetrabranchiaten Nautilus hinzugezogen.

Es ist ganz merkwürdig und wahrscheinlich auf Rechnung der relativen Größe des Zentralnervensystems zu stellen, daß bei den Cephalopoden nicht, wie so manchmal, einige Leitungsbahnen im peripheren Nervensystem lange bekannt sind, ehe die ersten Leitungsbahnen im Zentralnervensystem entdeckt werden.

Schon im Jahre 1868 haben OwsJAxyikow und Kowalewsky (1868) sich mit den Leitungsbahnen der Dibranchiaten beschäftigt und manches richtig beobachtet, obgleich die damalige Technik nur selten erlaubte, Ursprung und Wege der Nervenfasern exakt nachzuweisen. Es sind besonders Sepia officinalis unter den Decapoden und Octopus unter den Octoporten, welche untersucht wurden.

OWSJANAKOW und KowALEWSKY unterscheiden bei Sepia ein oberes Schlundganglion, welches aus vier durch Furchen begrenzten Teilen besteht. Es ist dies das Cerebralganglion (Fig. 61, g.c. 1-4), in der 'Tat oberhalb des Oesophagus gelegen, welchen man sich in der Figur 61 etwa horizontal auf der Höhe des durchschnittenen pedunculus lobi optici (p.l.o.) denken muß3. Das untere Schlundganglion OwsJarikows und Kowalewskys umfaßt nach ihnen drei Ganglien, welche man jetzt ganglion brachiale, pedale und viscerale (Fig. 61, g. br., q.p. und g.v.) nennt. Ich werde zur bequemeren Verglejchung der Resultate der verschiedenen Autoren hier die moderneren Namen gebrauchen.

Wenn ich die Beschreibung gut fasse, sahen OWsJAxIKOW und KowaLEWSKY die folgenden Leitungsbahnen.

Ganglienzellen des vorderen Cerebralganglions (Fig. 61, g.c. 1) sind verbunden mit Nervenfasern zum mittleren Cerebralganglion (Fig. 61, g. c. 2) und zum Buccalganglion. (In Fig. 61 ist das Cerebrobuccalkonnektiv als $c . b . k$. bezeichnet worden.)

Basal im hinteren Cerebralganglion (Fig. 61, g.c. 3. Es ist bei Eledone abermals durch eine Furche geteilt.) liegen Ganglienzellen, deren Fortsätze zum mittleren Ganglion (g.c. 2) ziehen.

Neben diesen Fasersystemen beschreiben die Autoren noch andere Bündel ohne ihre Ursprungszellen anzugeben. So gibt es Fasern, welche das mittlere Ganglion ( $\%, c, 2)$ mit dem unteren Schlundganglion verbinden. Das sind also Fasem aus dem kurzen Konnektiv. Andere Nervenfasern vereinigen das vordere und das hintere Cerebralganglion.

Eine Cerebralkommissur kommt vor.

Der pedunculus lobi optici (oder nervus opticus) (Fig. 61, p.l.o.) verbindet das Cerebralganglion mit dem lobus opticus (oder dem ganglion opticum) welcher in der Fig. 61 abgeschnitten gedacht ist. OWSJAxikow und KowArawsky sahen im letzteren schon ein Mark und eine Rinde mit zwei Ganglienzellschichten und drei Nervenfaserschichten, nämlich zwei \%wischen 
den Ganglienzellen und eine außerhalb derselben. Wir werden nachher die Struktur des Sehlappens viel genauer kennen lernen. Die beiden Autoren beobachteten auch die commissura optica oberhalb des Oesophagus und die Nervenfasern, welche aus dem posterobasalen Ganglion oder dem vierten Teil des Cerebralganglions (Fig. 61, g.c.4) in den lobus opticus ziehen. Die commissura optica verbindet nach ihnen die beiden lobi optici, aber die Untersuchungen HaLLERS (1913) machen es zweifelhaft, ob wirklich Fasern des einen lobus in den anderen übergehen. Wohl ziehen Fasern des einen lobus opticus ins Cerebralganglion der anderen Seite.

Auch im sogenannten unteren Schlundganglion wurden einige Leitungsbahnen erforscht. Ganglienzellen des Pedalganglions (Fig. 61, g.p.) senden Fasern zum unteren Buccalganglion, welches man bei Cephalopoden neben dem oberen Buccalganglion unterscheiden kann. (Fig. 61 zeigt nur das Pedobuccallkonnektiv $p . b . k$.$) . Zu diesem Systeme fügen sich Nervenfasern des$ Brachialganglions (Fig. 61, g. br. ).

Ganglienzellen des Brachialganglions senden ihre Fortsätze zum Pedalganglion. Die Ganglienzellen, welche mit ihren Nervenfasern die Brachialkommissur bilden, sowie die Ganglienzellen, deren Fortsätze das Brachialganglion mit dem vorderen Cerebralganglion ( g.c. 1 ) in Verbindung stellen, blieben OWsJanxikow und KowaLEwsky verborgen.

Einige Ganglienzellen des Pedalganglions haben Fortsätze, welche zum Trichter gehen und also Nervenfasern des nervus infundibuli ( Fig. 61, n. $i$.) sind. Andere senden Nervenfasern aus zum Visceralganglion (Fig. 61, g.v.).

Auch die beiden Pedalganglien stehen durch eine Kommissur, die Pedalkommissur, in Verbindung und das gleiche gilt für die beiden Visceralganglien.

Aus multipolaren Ganglienzellen des Visceralganglions gehen Nervenfasern zum Mantelganglion hervor. Diese laufen also im Mantelnerven (nervus pallialis, Fig. 61,n.p.) und treten ins Mantelganglion ein. Andere Fasern des Mantelnerven entspringen aus Ganglienzellen des Mantelganglions und schreiten hirnwärts oder zu den Mantelmuskeln, noch andere gehen dicht an dem Mantelganglion vorüber. Das Visceralganglion enthält auch Ganglienzellen, welche ihre Nervenfasern in den sympathischen Nerven zum Eingeweide, den Visceralnerven (Fig. 61, n.v.) senden.

OWSJANNIKow und KowalEwsky haben auch das statische Organ von Sepia, das sie als ein Gehörorgan betrachten, untersucht. Sie entdeckten in der lamina acustica und crista acustica (richtiger 1. statica und er. statica) Sinnesnervenzellen, deren Fortsätze in den nervus staticus (Fig. 61, n.s.) zogen.

Octopus stimmt nach OwsJanNikow und KowALEwsky in manchen Hinsichten mit Sepia überein. Das hintere Cerebralganglion (Fig. 61, g. c. 3) wird durch vier longitudinale Furchen (wie sie auch in Fig. 61 sichtbar sind) in fünf Abschnitte geteilt, welche nach manchen Autoren einigermaßen den Windungen des Vertebratenhirns gleichen. Jede dieser Windungen verläßt ein Nervenfaserbündel zum ungefurchten Teil des dritten Cerebralganglions und ebenso zum posterobasalen Ganglion (Fig. 61, (\%.c.4). 
Ganglienzellen des ungefurchten Teils des dritten Cerebralganglions senden auch ihre Nervenfasern zum vierten Cerebralganglion. Auch stehen das vordere Cerebralganglion (g.c. 1) und das vierte durch ein Nervenfaserbündel in Verbindung. Das sind also alle wieder andere Leitungsbahnen als die bei Sepia beobachteten.

Eine commissura optica hat anch Octopus.

Sowohl das Brachialganglion wie das Visceralganglion sind durch Konnektivalfasern mit dem Cerebralganglion verbunden.

Der nervus staticus geht aus dem Pedalganglion hervor, aber OwsJANxIKow und Kowalewsk Y halten es für möglich, daß seine Fasern bis ins Cerebralganglion ziehen und also dort und nicht im Pedalganglion enden. Später erklärte DreTu (1878) sich ebenfalls davon überzeugt, aber erst HALLER (1913) hat den Beweis dafür geliefert. Im statischen Organ sahen sie die Sinnesnervenzellen der crista sich in Nervenfasern fortsetzen, aber, ob auch die Ausläufer der Sinneszellen der lamina Nervenfasern sind, konnten sie nicht entscheiden.

Später hat auch RAxke (1875) in der Statocyste von Octopus und ebenso von Eledone Sinnesnervenzellen beobachtet, denn, wie er sagt, gehen Nervenfasern in die ,Hörzellen” über. Die Fasern des statischen Nerven hängen nach ihm aber mit den Zellen eines Ringganglions zusammen.

Die Leitungsbahnen von Sepia oflicinalis wurden, nachdem OwsJAxwirow und KowALEWSKY sie studiert hatten, abermals von STIEDA (1874) erforscht. Weil er jedoch nie die Ursprungszellen der Nervenfasern, noch ihr Ende nachweist, haben seine Angaben nur geringen Wert und sind sie schwer mit den Resultaten anderer Autoren zu ver. gleichen. Was soll man heutzutage anfangen mit der allgemeinen Bemerkung, daß der pedunculus lobi optici und das Brachialganglion mit den Cerebralganglion, das Visceralganglion mit dem Pedalganglion, das Pedalganglion mit dem Cerebral- und dem Brachialganglion durch Nervenfasern verbunden sind, oder daß Nervenfasern der Ganglien in ihre peripheren Nerven austreten? Man glaubt so etwas gern, will aber weit mehr davon wissen und das gibt STIEDA uns nicht.

STIEDA hat auch die commissura optica, die Pedalkommissur und die Brachialkornmissur gesehen, welchen wir schon oben begegnet sind.

Er hat auch Nervenfasern beobachtet, welche aus dem Pedalganglion in den pedun. culus lobi optici zogen und andere, welche, das Brachialganglion durehsetzend, das Pedalganglion mit den Brachialnerven (Fig. $61, n . b r$.) verbanden. Diese Angaben inte. ressicren uns mehr, weil der Lauf dieser Nervenfasern nicht selbstrerständlieh ist.

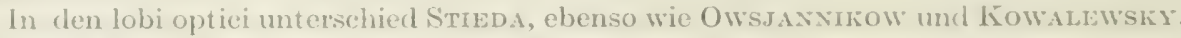
Rinde und Mark. Das Mark fand er aus Nervenfasern und (innglienzellgruppen zusammengesetzt; in der Rinde beschrieb er zwci Ganglienzellschichten und eine zwischenliegende Fasersehicht, worin bei näherer Betrachtung noch fïnf schmalere selnichten. zu unterseheiden waren, aber der wahe Verhuf der Nervenfasern. we diesen uns die Arbeiten Vox Leviosstes (1896i) und liopsciss (1896) kennbar machen, blieb ihm verborgen. Die lasern des peclunculus lobi optici sah er in Bïndeln in den lobus opticus (eint reten.

Ditet (1878) hat elenso wie STIEnA rine Arbeit äber das Zentmulnervensystem einiger C'ephalopoden veröfentlicht, in der man wahrscheinlich manchen Mitteilungen hegegnet, welche dem Anfinger, welcher sich auf diesem (iebjete orientieren will, von Nutzen sind. Worin aber dic Leitungshahnen levineswegs exalst machgewiesen werden.

Dasjenige, was er dariber behouptet, ist meistens zu unbestimmt und nit zu primitiven Hilfsmitteln berbuchtet worden, um hier mit Recht wiectergegeben zu werden. Xiu cinige fiaserststenc, wie z. B. (lie Cerebralkommisur in , lobus supraoesophagalis 
(Cerebralganglion) von Eledone moschata und die commissura optica von Eledone und Sepiola bilden eine Ausnahme.

Im allgemeinen braucht alles was Dietu hinsichtlich der Hodologie der Cephalopoden bemerkt hat, der Bestätigung, was nicht sagen will, daß es diese nicht teilweise tatsächlich bekommen hätte.

Sowohl der StIEDAsche Aufsatz, wie die DiETLschen Abhandlungen stehen hinsichtlich genauerer Angaben über die Wege der Nervenfasern hinter der Arbeit OwsJANNIKOWS und KowALEWSKYS zurïck.

Wir sind bis jetzt bei den Cephalopoden nur in der Statocyste Sinnesnervenzellen begegnet. Wie sich erwarten ließ, sind sie auch an anderen Stellen entdeckt worden.

Vox Lenhossek (1894) hat u.a. mit Hilfe der Golgrschen Methode bei Sepia und Eledone in der Epidermis der Tentakeln typische Sinnesnervenzellen gefunden. Er hat überdies beobachtet, daß die Sehzellen der Retina Sinnesnervenzellen sind.

Darin hat er übrigens nicht die Priorität. Schon Hexsex (1865) glaubte, daß, ebenso wie bei Pecten, die Retinazellen oder Stäbchenzellen der Cephalopoden sich kontinuirlich in Nervenfasern fortsetzten. Er ist jedoch dessen nicht gewiß und wünscht das Dasein anderer Nervenfasern, welche die Sehzellen umspinnen, nicht auszuschließen. Auch GrexAcHer (1886) hat noch früher als Vor LexнosseK ganz besonders bei Sepia, aber auch bei Eledone und Octopus den Uebergang des spitzen, basalen Endes der Petinazelle in eine Nervenfaser beobachtet und seine Abbildungen zeigen ganz klar, daß es Sinnesnervenzellen sind.

Vox Lexhossex nun sah in der Retina (Fig. 62) die Sehzellen (Fig. 62, s. z.), welche ein Stäbchen tragen (Fig. 62, st.) in einer einzigen Schicht geordnet und jede Sehzelle die ganze Dicke der Retina durchsetzen. Gerade so wie Grexacher fand er das basale Ende in eine Nervenfaser verjüngt (Fig. 62). Neu war seine Unterscheidung der Sehzellen in zwei Typen, den ,Riechzelltypus", eine dünne Zelle ohne Nebenfortsätze und mit oberhalb der Zellmitte gelegenem Kern und den ,Lumbricustypus”, eine dicke Zelle mit kleinen Nebenfortsätzen neben dem Nervenfortsatz und unterhalb der Zellmitte gelegenem Kern.

Nachher hat auch Hesse (1900) die Ueberzeugung geäußert, daß die Retinazellen der Cephalopoden in Nervenfásern übergehen.

Nachdem also alle Autoren ïbereinstimmend den Sinnesnervenzellcharakter der Sehzellen der Cephalopoden anerkannt hatten, tritt zuletzt MERTox (1905) hervor mit der Meinung, daß der wahre Sachverhalt immer verkannt worden sei und die Sehzellen der Cephalopoden wahre Sinneszellen seien, welche nicht selbst basal in eine Nervenfaser übergingen, sondern durch darin eindringende Nervenfasern innerviert würden. Man bedenke, daß man solchen wahren Sinneszellen bei den Mollusken übrigens nicht begegnet, wenn man absieht von den offenbar falschen Angaben PATtexs, welche oben lang und breit besprochen wurden und daß ein besonders schlagender Beweis deshalb erwünscht wäre. Den nun kann Mertox nicht geben. Er hat neben den Dibranchiaten Sepia, Eledone und Ilex auch den Tetrabranchiaten Nautilus untersucht, aber jedenfalls hat Nautilus ihm schlecht fixiertes 
Material geliefert. Dabei hat er keine spezifischen Nervenfärbungsmethoden angewandt. Wenn er also sagt, daß Von LenHossek, durch die Golgische Methode irregeführt, die an die Sehzelle herantretende Nervenfaser mit dem sie umgebenden Bindegewebe für den Nervenfortsatz der Sehzelle angesehen hat, so kann ich ihm schlechthin nicht glauben. Man könnte meinen, daß die Neurofibrille in der Sehzelle, welche schon GrExacher beobachtet hatte, von Merton für eine in die Zelle eingedrungene Nervenfaser angesehen worden war, aber darin steckt nicht der Fehler Mentors, denn er sieht die Neurofibrille ebenfalls und kann sogar ihren Zusammenhang mit (len angeblichen Nervenfasern in der Sehzelle nicht entdecken. Es bleibt somit verborgen, was MerTon beobachtet haben mag.

Von LENHossek begnügte sich nicht damit die Sinnesnervenzellnatur der Retinazellen gezeigt zu haben, er hat (VON LENHOSSEK 1896) auch ihre Nervenfasern im lobus opticus bis zu ihrem Ende verfolgt und außerdem die Leitungsbahnen des lobus opticus oder Sehlappens mustergiultig dargestellt.

Es ist wiederum die Golgische Methode, welche Von Lenmosser seine glänzenden Resultate gegeben hat und Eledone wurde hauptsächlich untersucht.

Die Figur 62 soll mir helfen, die von Von LENHOSSEK entdeckten Leitungsbahnen zu erklären. Sie wurde mit einigen Abänderungen nach einer VoN LENHossEKschen Figur kopiert und stellt schematisch einen Schnitt durch die Retina und den lobus opticus dar. Links sieht man die Retina mit den Sehzellen $\left(s_{.} z_{\text {. }}\right.$, welche ein Stäbchen (st.) tragen. Die Stützzellen, welche zwischen den Sehzellen stehen, sind in der Figur fortgelassen worden. Die Nervenfasern der Sehzellen oder Retinalfasern $(r . f$.$) , wie Vox LExhossek$ sie nennt, sammeln sich in Bündel, Retinalfaserbündel $\left(r_{\circ} f . b.\right)$, welche die Knorpelkapsel des Auges $(k n$.) durchbohren und in den lobus opticus eintreten.

Der lobus opticus hat eine Rinde (cortex lob. opt.) und ein Mark (medulla lob. opt.). Die Rinde ist konzentrisch gebaut und weist zwei Körnerschichten auf, die äußere Körnerschicht oder lamina granularis externa $(l . g r . e$.$) und die innere Körnerschicht oder lamina granularis interna (l . g r$. i.). Unnötig zu sagen, daß die Kömer dieser Schichten kemhaltige Ganglienzellkörper sind. Die beiden Körnerschichten waren, wie gesagt, auch schon von älteren Autoren beobachtet worden. Sie werden getrennt durch eine Faserschicht oder lamina plexiformis $(l . p l$.), worin noch eine Fünfteilung gesehen wurde. In der Mitte findet man die breite Hittelschicht (m.s.) mit hauptsächlich vertikal zur Oberfläche des Sehlappens gestellten Nervenfasern. Daneben sind der ïußere und immere Horizontalplexus (ä.h.p. und $i . h . p$.$) , ziemlich breit und mit überwiegend horizontal, das heißt der Ober-$ fläche des lobus opticus parallel gestellten Nervenfasem. Zwischen diesem Horizontalplexus und den Kömerschichten befinden sich damn noch zwei ganz schmale, helle Schichten. Die lamina plexiformis ist nicht zellfrei, denn es sind darin typische Gliazellen gelagert, aber Ganglienzellen sind nicht darin. Vor LENHossek betont, daß die lamina plexiformis sich nur durch die bestimmte Anordnung der Fasern einem Neuropilem gegenüber unter scheidet. 
CEPHALOPODA.

Fig. 62 .

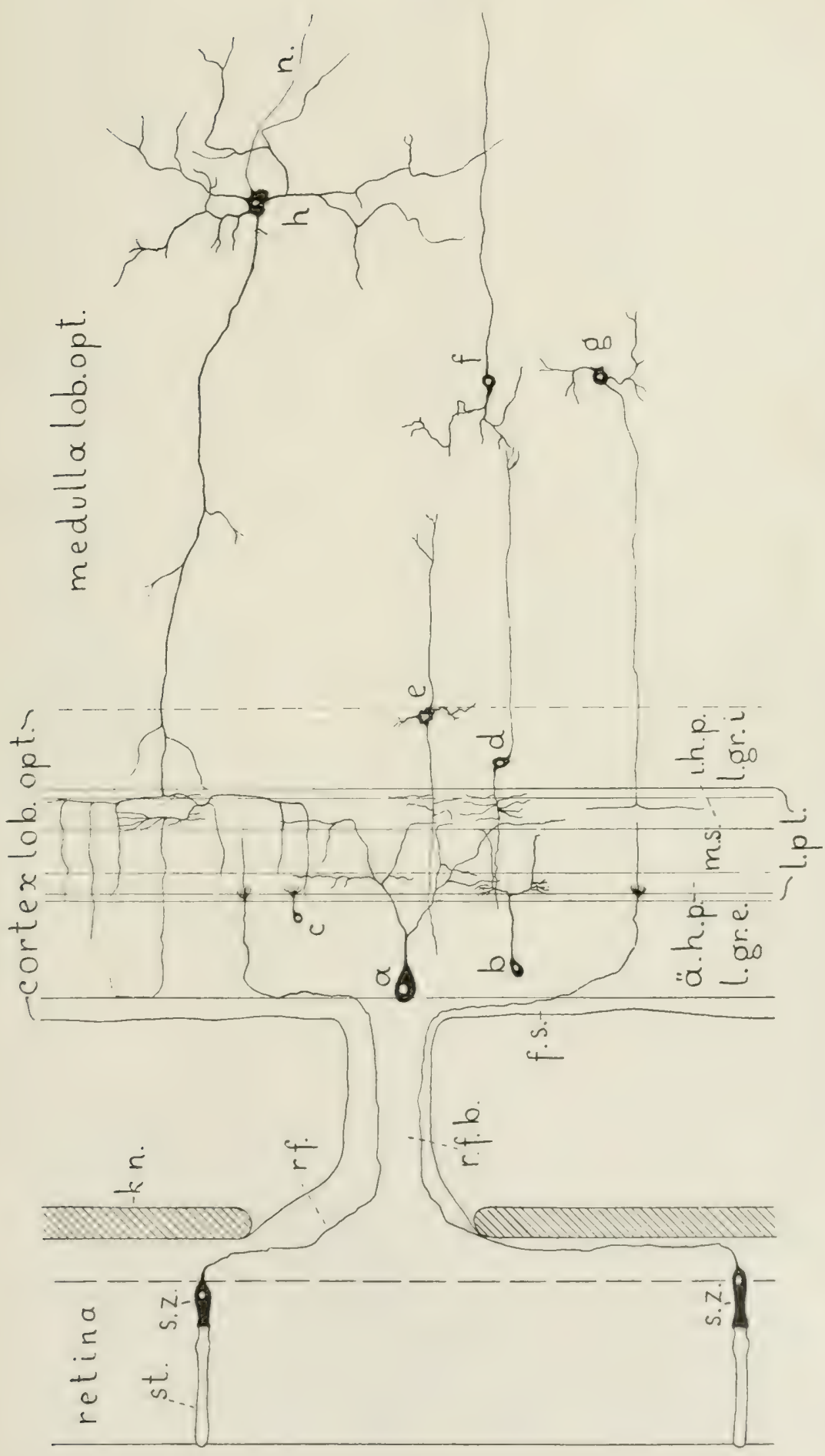

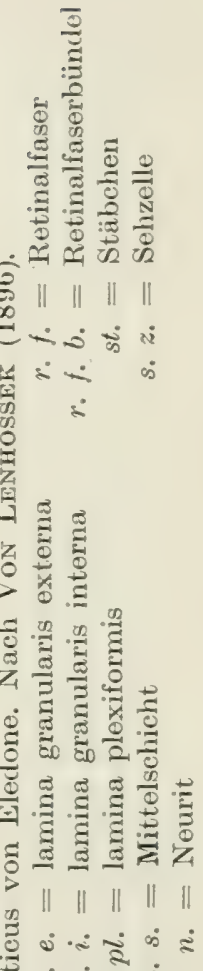
ดิ่ง ह 资心

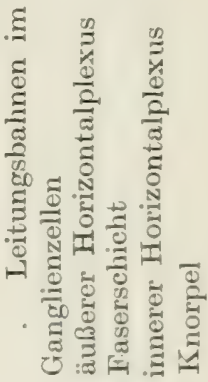
|| || || || $\|$ $\approx \dot{R} \dot{8} \dot{8}$ $\frac{\pi}{2}=-2$ $0: 8$. 
Verfolgen wir jetzt die Leitungsbahnen. Ich habe schon gesagt, daß3 die Retinalfasern in Bündeln zum lobus opticus schreiten. In diesen Retinalfaserbündeln laufen die Fasern mehr peripher, je nachdem ihre Sehzellen weiter vom Bündel entfernt sind. Wenn das Retinalfaserbündel den Sehlappen erreicht hat, dringen die zentralen Fasern sofort darin ein, aber die peripheren legen erst eine größere Strecke an der Oberfläche des Sehlappens zurück, je nachdem sie mehr in der Peripherie des Bündels gelegen sind. Diese Verhältnisse veranschaulichen die obere und untere Sehzelle der Fig.62. Die peripheren Nervenfasern der Retinalfaserbündel bilden also eine Faserschicht. $\left(f . s_{.}\right)$an der Oberfäche des lobus opticus, außerhalb der lamina granularis externa.

Wenn die Retinalfasern in den Sehlappen eindringen, durchsetzen sie die äußere Körnerschicht und enden im inneren Horizontalplexus, nachdem sie dem äußeren Horizontalplexus Kollateralen übermittelt haben.

Den Retinalfasern parallel laufen spärliche zentrifugale Nervenfasern, welche aus dem Cerebralganglion herstammen und somit die ganze medulla und cortex des Sehlappens durchziehen. Weil weder die Ursprungszellen, noch das Ende dieser Fasern bekannt ist, habe ich sie in der Fig. 62 fortgegelassen.

In der äußeren Körnerschicht entdeckte Vox LExhossek drei Arten unipolarer Ganglienzellen, welche ihre Fortsätze zur lamina plexiformis wenden. Am meisten nach außen, aber bisweilen auch mehr nach innen liegen spärliche Riesenzellen (Fig. 62, a). Diese sehr großen Ganglienzellen sind unregelmäßig gestellt. Ihr Fortsatz schreitet quer durch die Körnerschicht und verbreitet sich in der lamina plexiformis, jedoch in so verschiedener Weise, daß man unter diesen Zellen noch drei Arten unterscheiden kann.

Neben diesen Riesenzellen begegnet man in der äußeren Körnerschicht zwei Ganglienzelltypen : großen Körnerzellen von außen und kleinen Körnerzellen von innen. Die großen Körnerzellen (Fig. 62,b) senden ihren Fortsatz zur plexiformen Schicht, wo er sich im äußeren. Horizontalplexus verästelt, bisweilen auch in der Mittelschicht. Die kleinen Körnerzellen (Fig. 62, c) haben einen Fortsatz, welcher sich nur im äußeren Horizontalplexus verästelt.

Die innere Körnerschicht und das Mark enthalten beide Ganglienzellen. Diese stehen in der Körnerschicht in Längsreihen, in der medulla aber sind sie in netzförmig zusammenhängende Reihen gestellt.

Die lamina granularis interna ist insofern das Spiegelbild der äußeren Körnerschicht als hier die kleinsten Ganglienzellen nach außen gekehrt liegen, damn folgen größere und am tiefsten befinden sich sporadische Riesenzellen. Die Riesenzellen (Fig. 62,e) sind multipolar, die anderen Ganglienzellen bipolar (Fig. 62, d) oder bisweilen multipolar. In der Weise, wie sich ihre Fortsätze verhalten, weichen alle diese Zellen prinzipiell nicht von einander ab. Die bipolaren Zellen senden ihren Dendriten in die plexiforme Schicht hinein. Hier gibt er dem inneren Horizontalplexus seine meisten Seitenäste, aber selber geht er bis in die äußere Körnerschicht (Fig. 62, $d$ und $e$ ). Der Neurit der bipolaren Ganglienzelle zicht ins Mark des lobus opticus 
wahrscheinlich so weit, bis er die Fortsätze einer Narkzelle erreicht hat (Fig. 62, d), vielleicht auch bis ins Cerebralganglion. Die Neuriten der Körner. zellen bilden Faserbündel in der inneren Körnerschicht, welche zwischen den Ganglienzellen liegen.

Die Ganglienzellen des Markes sind in Stränge angehäuft, welche dicker sind, je nachdem sie mehr nach außen liegen. Vox LExHosser erkannte große und kleine Markzellen. Die kleinen Markzellen gehören zu zwei Typen. Der erste Typus (Fig. 62, f) ist multipolar oder meistens unipolar, aber dam spaltet sich der Stammfortsatz sofort. Die Dendriten verästeln sich im Neuropilem der medulla, der Neurit zieht ins Cerrebralganglion.

Der zweite Typus der kleinen Markzellen (Fig. 62, g) gleicht dem vorigen, aber der Neurit geht zur Rinde des Sehlappens und verzweigt sich dort in der Mittelschicht oder im inneren oder äußeren Horizontalplexus.

Die großen Markzellen sind immer deutlich multipolar. Thr Neurit sucht nach Vox Lexhossek das Cerebralganglion.

Schließlich erwähnte Vox LExHossek in der medulla lobi optici auch multipolare Riesenganglienzellen (Fig. 62, h). Ihr Neurit $(n$.$) zieht in dem$ pedunculus lobi optici zum Cerebralganglion; die meisten Dendriten ver-. ästeln sich in der medulla, aber einer dringt in die Rinde ein und verzweigt sich dort ïberall.

VOx LExHossek hat sich sehr bemüht die verschiedenen Schichten und Ganglienzellen der Retina und des lobus opticus der Cephalopoden mit jenen der Retina der Vertebraten zu homologisieren. Ich glaube, das ist nicht der glücklichste Teil seiner übrigens so schönen Arbeit, schon gleich deshalb, weil man doch immer nur von Analogien und nicht von Homologien zwischen dem Cephalopoden-Auge und dem Auge der Vertebraten reden kann.

Vox LExHOSSEK nun betrachtet die Retina der Vertebraten als homolog mit der Retina nebst der Rinde des lobus opticus der Cephalopoden. Die Sehzellen der Cephalopoden sind nach ihm eher homolog mit den Zapfenzellen der Vertebraten als mit den Stäbchenzellen. Die äußeren Körnerzellen sind nach ihm homolog mit den Bipolaren der Vertebraten, aber ich begreife nicht warum diese unipolaren Ganglienzellen nicht mit den unipolaren Amakrinen der Vertebraten-Retina übereinstimmen, statt mit bipolaren Ganglienzellen. Nur die Riesenzellen der äußeren Körnerschicht sollen nach Vox Lexhossek mit den Amakrinen homolog sein. Die inneren Körnerzellen sollen nach ihm mit den großen multipolaren Ganglienzellen der Vertebraten-Retina übereinstimmen. Ich frage mich, warum denn nicht mit den Bipolaren der Vertebraten?

In der lamina plexiformis der Cephalopoden findet man nach. Vox LExHOSSEK die beiden plexiformen Schichten der Retina der Vertebraten zurück und ihre Gliazellen sind die Stiitzzellen der Vertebraten-Retina.

Das Mark des lobus opticus kehrt nach Vox Lexirossek in der Retina der Vertebraten nicht wieder. Man könnte das bezweifeln und fragen, ob denn nicht die Ganglienzellen darin, deren Neurit sich zentralwärts wendet (Fig. 62, f), eben so gut, wie die inneren Körnerzellen, mit den großen Ganglienzellen der Vertebraten-Retina homolog sein können. Wenn aber Vox 
Lenhossek das Mark des lobus opticus ein primäres Sehzentrum, wie die corpora quadrigemina anteriores der Säugetiere nennt, werden nur wenige sich berufen fühlen, ihm darin zu folgen. Wohl gebe ich ihm Recht, wenn er darauf hinweist, wie überraschend ähnlich in manchen Hinsichten der Bauplan nicht nur des ganzen Auges, sondern auch der nervösen Teile desselben bei den Cephalopoden und Vertebraten ist, aber seinen Homologisationen kann ich durchaus nicht beistimmen.

Im selben Jahre als Vox Lexhossek den Bau des lobus opticus der

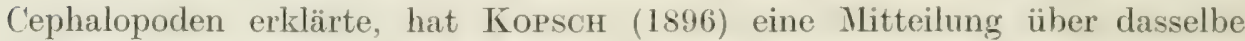
Thema veröfffentlicht und später hat er (1899) noch weitere Angaben hinzugefügt.

Корьсн arbeitete mit Loligo und wandte seine Modifikation der Gor.Gr-

Fig. 63 .

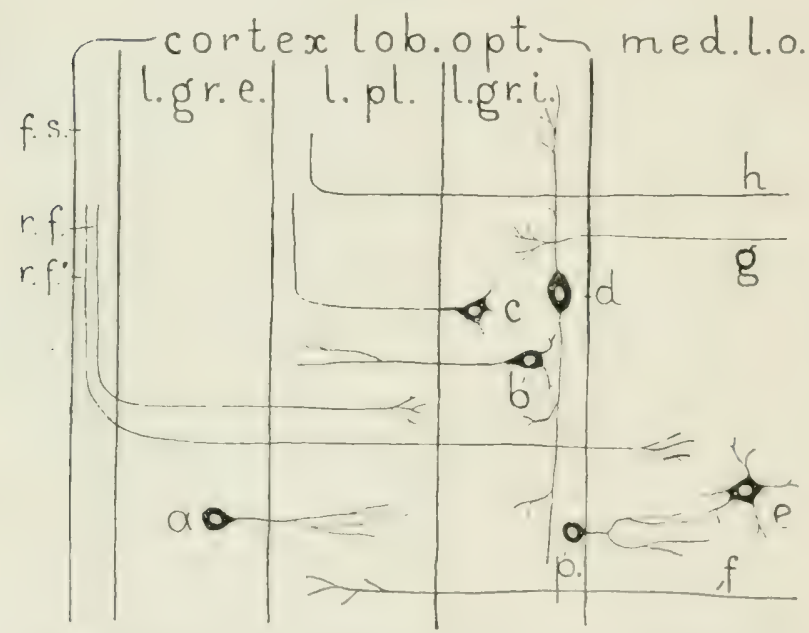

Leitungsbahnen im lobus opticus von Loligo. Abgeändert nach Корsch (1896).

$a$ bis $e=$ Ganglienzellen

$f, g, h=$ Nervenfasern

f. $s_{0}=$ Faserschicht

l. gr. $e_{0}=$ lamina granularis externa

l. gr. $i .=$ lamina granularis interna

l. $p l_{0}=$ lamina plexiformis

med. $l . o .=$ medulla lobi optici

$p_{0}=$ Palisadenzelle

$r . f ., r . f^{\prime}=$ Retinalfaser schen Methode an. Er sah ebenso wie Vox Lenhossex im lobus opticus ein Mark (Fig. 63 , med.l.o.) und eine Rinde (Fig. 63, cortex lob. opt.) und in der letzteren zwei Körnerschichten, eine äuBere (Fig. 63, l.gr.e.) und eine innere (Fig. $63, \quad l . g r . i$.$) , welche$ durch eine Faserschicht getrennt waren. Korsch nemnt diese Schicht die reticuläre Schicht; ich aber will fortfahren sie lamina plexiformis (Fig. 63, l.pl.) zu nennen. Die äußere Kömerschicht wird bekleidet mit einer Faserschicht (Fig. 63, f.s.), deren Nervenfasern die Fortsätze der Sehzellen sind.

Kopsch nennt diese Fasern die Stäbchenfasern, aber ich will sie mit Vox LExHOssek auch hier als Retinalfasern bezeichnen.

Wenn ich Korsch richtig fasse, so treten nur zwei Retinalfaserbündel. welche ein Chiasma bilden, an den lobus opticus heran. Anders also als bei Eledone, wo manche Retinalfaserbindel waren. Die Retinalfasem selbst. enden entweder, wie bei Eledone, in der lamina plexiformis (Fig. 63, r. f.), oder sie enden im Mark (Fig. 63, $r . f^{\prime}$.). 
In der äußeren Körnerschicht gibt es große und kleine Körnerzellen. Das Schicksal der Fortsätze der großen Körnerzellen ist unbekannt. Die kleinen Körnerzellen (Fig. 63, $a$ ) sind unipolar und senden ihren Stammfortsatz in die plexiforme Schicht, wo er sich verästelt. Sie stimmen darin, sei es auch nicht in der Weise der Verästelung, mit den äußeren Körnerzellen von Eledone iiberein.

In der inneren Körnerschicht sind zwei kleine multipolare Ganglienzellarten gelagert (Fig. 63, b und $c$ ). Beider Dendriten verlassen die Körnerschicht nicht, aber die Neuriten begeben sich zur lamina plexiformis. Hier verhalten sie sich nicht in gleicher IVeise. Der Neurit der einen Ganglienzellart verzweigt sich und endet (Fig. 63, b) ; der Neurit des anderen Zelltypus krümmt sich und läuft parallel mit der Oberfläche des lobus opticus weiter (Fig. 63,c).

Außerhalb der kleinen Ganglienzellen gibt es in der inneren Körnerschicht auch eine Art großer Ganglienzellen (Fig. 63, d) mit weit ausgedehnten Verästelungen, hauptsächlich in einer mit der Schicht parallelen Ebene.

Unmittelbar an die medulla grenzend sind weiter noch die Zellkörper der Palisadenzellen, wie Kopsch sie nennt, in einer Schicht geordnet. Sie sind unipolar und ihr Fortsatz verzweigt sich im Mark (Fig. 63, p.).

In der medulla lobi optici fand Kорsch nur multipolare Ganglienzellen (Fig. 63, e), welche ihre kurzen Fortsätze nach allen Seiten wandten. Sie sind gruppiert oder liegen vereinzelt.

Neben diesen Ganglienzellen entdeckte Kopsch Nervenfasern unbekannter Herkunft in der medulla. In seiner ersten Mitteilung (1896) erwähnt er nur eine Art, welche, aus dem Mark kommend, bis in die plexiforme Schicht emporsteigt und dort verästelt endet (Fig. 63, f). Später (1899) hat er noch zwei andere Typen hinzugefügt, nämlich Nervenfasern der medulla, welche sich in der inneren Körnerschicht verzweigen (Fig. 63, g) und Nervenfasern der medulla, welche zur lamina plexiformis emporsteigen und sich dann parallel mit der Oberfläche umbiegen. (Fig. 63, $h$ ).

Man sieht, die Rinde des lobus opticus enthält ebenso wie das Mark bei Loligo im allgemeinen ganz andere Elemente als bei Eledone, was wiederum die obengenannten Vox Lexhosserschen Homologisationen sehr schwächt.

Neuerdings hat CAJAL (1917) Beiträge zur Kenntnis der Retina der Cephalopoden veröffentlicht, welche ich, da sie in spanischer sprache geschrieben sind, hier nicht referieren, nur nennen, kann.

Hofmary (1907) hat sich bemüht die Innervierung der glatten Muskelfasern der Cephalopoden zu erforschen. Er sah in Methylenblau-Präparaten die Muskelfasern, welche an den Chromatophoren von Loligo haften, ebenso wie die Fasern der Flossenmuskulatur von Sepiola Rondeleti und Sepia elegans innerviert durch einen Nervenfaserplexus, dessen Fasern alle kontinuirlich in einander übergingen, ohne je frei $\mathrm{zu}$ enden. Ganglienzellen werden nicht von ihm erwähnt. Hofmaxx, welcher auch im Herzmuskel des Frosches die nämlichen Verhältnisse fand, verneint aus diesem Grunde überall das Bestehen eines Ganglienzellplexus und richtet sich namentlich gegen BETHE und seine Figur, welche ich als Fig. 4,S. 13 reproduziert habe. HoFmaxis irt sich dabei im allgemeinen durchats. Wie die Lage bei den genannten 
Muskelfasern der Cephalopoden ist, soll dahingestellt bleiben; meiner Meinung nach hat Hownavs seine Behauptungen nicht genügend bewiesen.

Im Jahre 1908 hat GuÉRIN (1908) ganz merkwürdige Besonderheiten ïber die Leitungsbahnen der Tentakeln der Cephalopoden veröffentlicht. Er hat die Tentakeln mancher Octopoden mit der GoLgischen Methode untersucht und dabei einen 'Teil der Leitungsbahnen aufgefunden. Er beschreibt

Fig. 64.

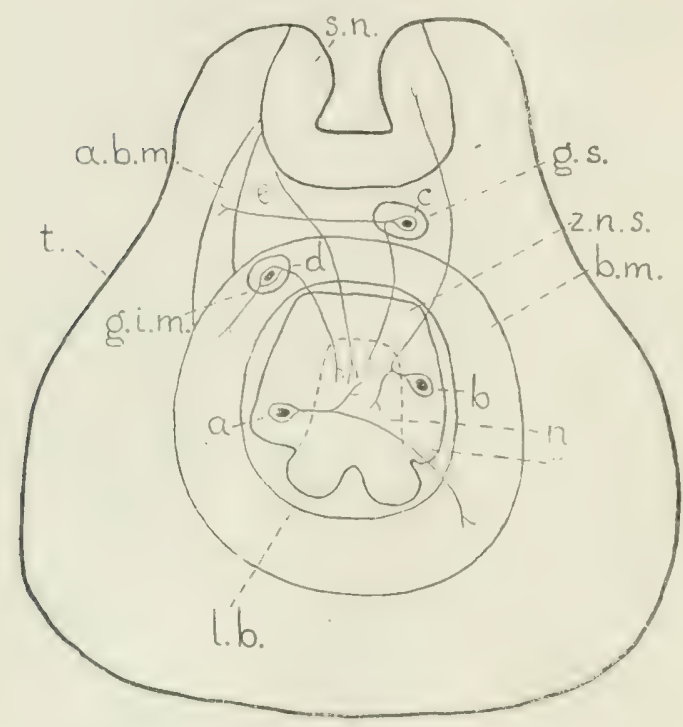

Querschnitt eines Armes von Octopus.

Abgeändert nach GUéRIN (1908). Textfigur 29. $a$ bis $d=$ Ganglienzellen

$$
e=\text { Nervenfaser }
$$

a. $b . m$. = Acetabulobrachialmuskel

b. $m$. = Brachialmuskeln

g. $i . m .=$ ganglion intermusculare

g. s. = ganglion subacetabulare

l.. . $=$ Längsbündel von Nervenfasern

n. $=$ Neuropilem

$r_{.}=$Rinde

$s . n$. = Saugnapf

1. = T'entakel

z. $n . \kappa .=$ zentraler Nörvenstrang diese als von einander getrennte Neuronen, wie die Methode sie ihm vor die Augen führt, will aber deswegen noch nicht als ein Anhänger der Neuronentheorie betrachtet werden.

Was (ivérix beobarhtet hat, habe ich in der schematischen Figur 64, welche abgeändert nach seiner Figur 29 angefertigt worden ist, eingetragen. Die Figur stellt einen Querschnitt durch einen Tentakel dar. Oben ist ein Saugnapf $(s . n$.) getroffen worden. In der Achse des Armes findet man einen zentralen Nervenstrang $(z . n . s$.$) . Drei der vier$ Seiten desselben sind mit einer Rinde von Ganglienzellen $(r$.) bekleidet. An der vierten Seite liegen zwei Längsnervenfaserbiindel (l.b.). In der Mitte des Stranges begegnet man einem Neuropilem (n.).

Der zentrale Nervenstrang wird umringt von den Muskeln des Tentakels oder den Brachialmuskeln (b.m.) Innerhalb dieser Muskelschicht wurden vier intermuskulare Ganglien wahrgenommen. Die Figur 64 zeigt nur ein einziges dieser Ganglien (g.i.m.). Sie sind durch Nerven mit dem Nervenstrang verbunden, ebenso wie die subacetabulare Nerrenmasse oder das ganglion subacetabulare (g.s.), welches zwischen dem Saugnapf und den Brachialmuskeln gelegen ist. Vom Saugnapf, weleher selber natiirlich Muskeln enthält, zu den Brachialmuskeln strecken sich endlich noch die Acetabulobrachialmuskeln $(a, b, m)$ aus.

Gú́RIN beobachtete nun zwischen allen diesen Organen die nachstehenden Leitungsbahnen. 
In der Rinde des axialen Nervenstranges sind unipolare Ganglienzellen, welche ihren Stammfortsatz ins Neuropilem senden. Hier angelangt, spaltet er sich in Dendriten, welche sich im Neuropilem wiederholt verzweigen und einen Neuriten, welcher die Brachialmuskeln innerviert (Fig. 64, a) oder zur Muskulatur des Saugnapfes geht (Fig. 64, b).

Im ganglion subacetabulare sah GuÉRIN unipolare Ganglienzellen mit Fortsätzen zum Neuropilem des zentralen Nervenstranges, zu den Muskeln des Saugnapfes und zu den Acetabulobrachialmuskeln. GUÉRIN vermutet, daß zwei Ganglienzelltypen da sind. Einer, wie die Zelle $c$ der Fig 64, mit Fortsätzen zu den Acetabulobrachialmuskeln und zum zentralen Neuropilem, ein anderer mit Fortsätzen zur Muskulatur des Saugnapfes und zum zentralen Neuropilem.

In den ganglia intermusculares erwähnt GuÉRIN Ganglienzellen, welche mir bipolar scheinen (Fig. 64, d). Sie senden einen Fortsatz in die Muskulatur des Tentakels und den anderen ins Neuropilem des Nervenstranges.

Neben diesen motorischen Ganglienzellen sah GUÉRIx auch Fasern, welche er als sensibele Nervenfasern betrachtet. Sie gehen aus dem Rand des Saugnapfes hervor und schreiten zum Neuropilem des Nervenstranges, wo sie sich verästeln (Fig. 64,e). Thre Ursprungszellen blieben leider unbekannt.

GUÉRIN behauptet, daß diese Nervenfasern im Neuropilem mit den Dendriten der motorischen Ganglienzellen funktionell zusammenhängen und daß sehr gut eine Reflexbahn zwischen den sensibelen Nervenfasern und einem jeden der beschriebenen motorischen Ganglienzelltypen bestehen könne.

Die longitudinalen Nervenfasern der Längsbündel biegen ab zum zentralen Neuropilem und verzweigen sich dort. Die Ganglienzellen, aus denen sie hervorgehen, fand GUÉRIN im unteren Schlundganglion, das heißt also im Brachialganglion, oder im Pedalganglion (vergl. Fig. 6l, S, 174 wo n. br . die Brachialnerven oder Nerven der 'Tentakeln darstellen). Er meint, daß einige dieser Nervenfasern den Reiz der genannten sensibelen Nervenfasern zum Zentralnervensystem leiten, andere motorische Reize aus dem Zentralnervensystem zu cinem jeden der motorischen Ganglienzellen des 'Tentakels führen. Weil er aber diese beiden Fasertypen nicht unterscheiden konnte, scheint mir diese Behauptung mehr wahrscheinlich als bewiesen.

Die GUÉRINschen Resultate kann man in extenso referiert finden in der Einführung in die Physiologie der Cephalopoden BAUERs (1909). Diese Arbeit erstrebt u. m. dasselbe Ziel bei den Cephalopoden, welchem ich in diesem Buche bei allen Evertebraten nachstrebe, nämlich eine übersichtliche Darstellung der Leitungsbahnen zu geben, nur mit diesem erheblichen Unterschiede, daß BAUER an die Anerkennung einer Bahn gar nicht so strenge histologische Forderungen stellt, wie ich, wahrscheinlich, weil er schließlich doch hauptsächlich eine Darstellung der Physiologie der Cephalopoden beabsichtigt.

BAUER stützt sich bei seinen hodologischen Auseinandersetzungen auf die Forschungen anderer Autoren, welche er sehr gut wiedergibt. Manche dieser Forschungen habe ich schon oben besprochen und es wäre überflüssig zu wie- 
derholen, was BAUER darüber sagt. Nur die Untersuchungen JATTAS, worauf BAUER die Aufmerksamkeit hinlenkt, fehlen hier, weil ich sehr zu meinem Bedauern diese Angaben nicht selber zu Gesicht bekommen konnte. Ich glaube übrigens, daß BATER Leitungsbahnen, welche gar nicht histologisch, sondern nur physiologisch nachgewiesen sind, ebenfalls referiert und eine

Fig. 65.

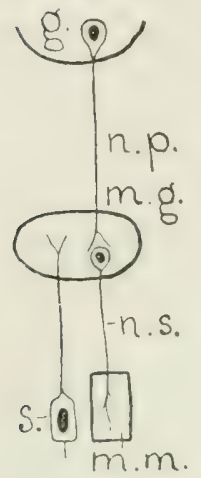

Schema der Leitungsbahnen des Mantels der Cephalopoden nach FröHLich (1910).

$$
\text { g. }=\text { Gehirn }
$$

$m \cdot g \cdot=$ Mantelganglion

m. $m$. = Mantelmuskeln

n. p. $=$ nervus pallialis

n. $s .=$ nervus stellaris

s. = Sinnesnervenzelle des Mantels

Beschreibung dieser Bahnen wäre in diesem Werke nicht am Platze.

Während BAUER in seinem Aufsatz einer anderen Einteilung und Nomenklatur der Cerebralganglien folgt, als die oben angewandte (vergl. Fig. 61, S. 174), bringt uns GariaEF F (1909) eine ganz andere Benennung der suboesophagalen Ganglien. Aber hinsichtlich der Leitungsbahnen sagt er nur, daß fast alle Ganglienzellen dieser Ganglien unipolar sind und daß ihre Fortsätze die peripheren Nerven zusammenstellen.

Weil die Cephalopoden so überaus günstig sind zur Anstellung physiologischer Experimenten, hat sich bei diesen Tieren oft und mehr als bei anderen Evertehraten der Mangel an Bekanntheit mit den histologischen Leit ungshahnen fühlen lassen an Stellen, wo die Physiologie der Reizleitung schon große Fortschritte gemacht hatte.

Fig. 66.

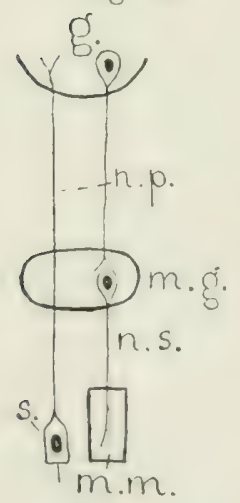

Ein interessantes Beispiel davon ist das folgende. FröHLich (1910) hat die Reflexe des Mantelganglions

Schema der Leitungs. bahnen des Mantels der Cephalopoden nach VoN UExTïirs und BAGLIONI. Nach Frörtlich (1910). Bezeichnungen wie in Fig. 65 .

worden sind. In der Figur 65 stellt $g$. das Gehirn dar. FröHLicir setzt darin Ganglienzellen voraus, deren Fortsätze den nervus pallialis bilden und im Mantelganglion (m.g.) enden. In diesem Ganglion liegen nach ihm andere Ganglienzellen, welche die Mantelmuskeln (Fig. 65, m.m.) innervieren und deren Fortsätze also in die Stellarnerven (n.s.) ziehen. Ueberdies enden nach Frönucin im Mantelganglion die Nervenfortsitze von Simmenervenzellen (s.).

Die FröHLICHschen Ansichten streiten mit jenen, welche Vox UExkuLL und BAGLioni ebenfalls aus physiologischen Gründen zu den ihrigen machten. Thre Jeinung griht das sichema Fig. b6 wieder. Wie Fröntch erkennen 
sie im Gehirn Ganglienzellen an, welche ihre Fortsätze zum Mantelganglion senden und im Mantelganglion Ganglienzellen, welche die Muskeln des Mantels innervieren. Aber die Nervenfortsätze der Sinnesnervenzellen enden nach diesen Autoren nicht im Mantelganglion, sondern sie durchsetzen dasselbe um im Gehirn zu enden (Fig. 66, s.).

Was ist uns nun bistologisch über diese Neuronen bekannt? Ich meine, nur dasjenige was OwsJANNIKow und KowalEwsky (1868) uns darüber lehrten. Sie beobachteten, wie schon S. 161 bemerkt wurde, in der Tat im Visceralganglion, also im ,Gehirn”, Ganglienzellen mit Fortsätzen in dem Mantelnerven zum Mantelganglion und im Mantelganglion Ganglienzellen mit Fortsätzen zur Muskulatur des Mantels, beide Ganglienzelltypen, welche sowohl Fröhlich wie VoN UexküLL und BAGLIoni voraussetzten. Daneben sahen sie auch Nervenfasern, welche an dem Mantelganglion vorüberginger. Wären diese vielleicht die Nervenfortsätze der Sinnesnervenzellen, welche Vox U'ExküLL und BAGLioni das Mantelganglion passieren lassen, so würden diese Autoren Recht bekommen und FröHLICH, welcher solche Fasern nicht anerkennt, Unrecht, aber ganz gewiß kann man dessen nicht sein.

Daß Owsjannikow und Kowalewsky überdies Nervenfasern des nervus pallialis, welche aus Ganglienzellen des Mantelganglions hervorgehen, erwähnen, von denen weder Fröhlich, noch Vox Uexkült und BAgLtoni die Wirkung beobachtet haben, erregt den Wunsch in mir, daß die Uebereinstimmung der Histologie und der Physiologie in diesem Gebiete künftighin noch größer werden möge.

Histologisch und in vorzüglicher Weise wurden die Leitungsbahnen des Zentralnervensystems der Cephalopoden in letzter Zeit von HALLer (1913) bearbeitet. Es ist derselbe Artikel, welchen ich schon oft zitiert habe und worin die Intelligenzsphären der Mollusken behandelt werden. Die Cephalopoden haben jedoch keine globuli.

Haller hat hauptsächlich die Bahnen von Eledone studiert und ich verweise nochmals auf Fig. 61, welche dem HALLERschen Artikel entnommen wurde und das ,Gehirn” von Eledone von der rechten Seite gesehen, darstellt. Erst HALLER hat manche Fasersysteme, welche von anderen Autoren nur undeutlich gesehen worden waren, überzeugend nachgewiesen, weil er Beginn und Ende der Fasern entdeckt hat.

Betrachten wir zuerst das Brachialganglion (Fig. 61, g.br.). HALLER sieht die beiden Brachialganglien verbunden durch eine Kommissur, welche er die commissura anterior nennt und welche auch früheren Autoren, so wie Owsjanyikow und Kowalewsky und STIEDA, nicht mbekannt war.

Eine zweite Kommissur dieser Ganglien läuft bogenförmig über den Oesophagus hin und legt sich unten an das Cerebralgangliori an. Diese Kommissur hat DietL commissura anterior genannt, aber HALLER täuft sie commissura superior.

Das Brachialganglion hat peripher gelagerte Ganglienzellen. Die Fortsätze vieler dieser Ganglienzellen ziehen in die Brachialnerven (Fig. 61, n. br.) und zwar bilden sie dabei vier Bündel, die vier Wurzelı der Brachialnerven. Wenn diese Wurzeln sich noch im Neuropilem des Brachialganglions befin- 
den, durchsetzt jede eine kleine Ganglienzellgruppe (einen nucleus oder Kern), isoliert im Neuropilem gelegen. Die Zellen dieser Kerne senden ihre Fortsätze teils in die Wurzeln der Brachialnerven, teils wenden sich ihre Fortsätze durch die commissura superior zum Brachialganglion der anderen Seite, wo sie dann immer im entsprechenden Kerne enden.

Die commissura anterior setzt sich hauptsächlich zusammen aus Fortsätzen von Ganglienzellen der Rinde des Brachialganglions, welche nachher in

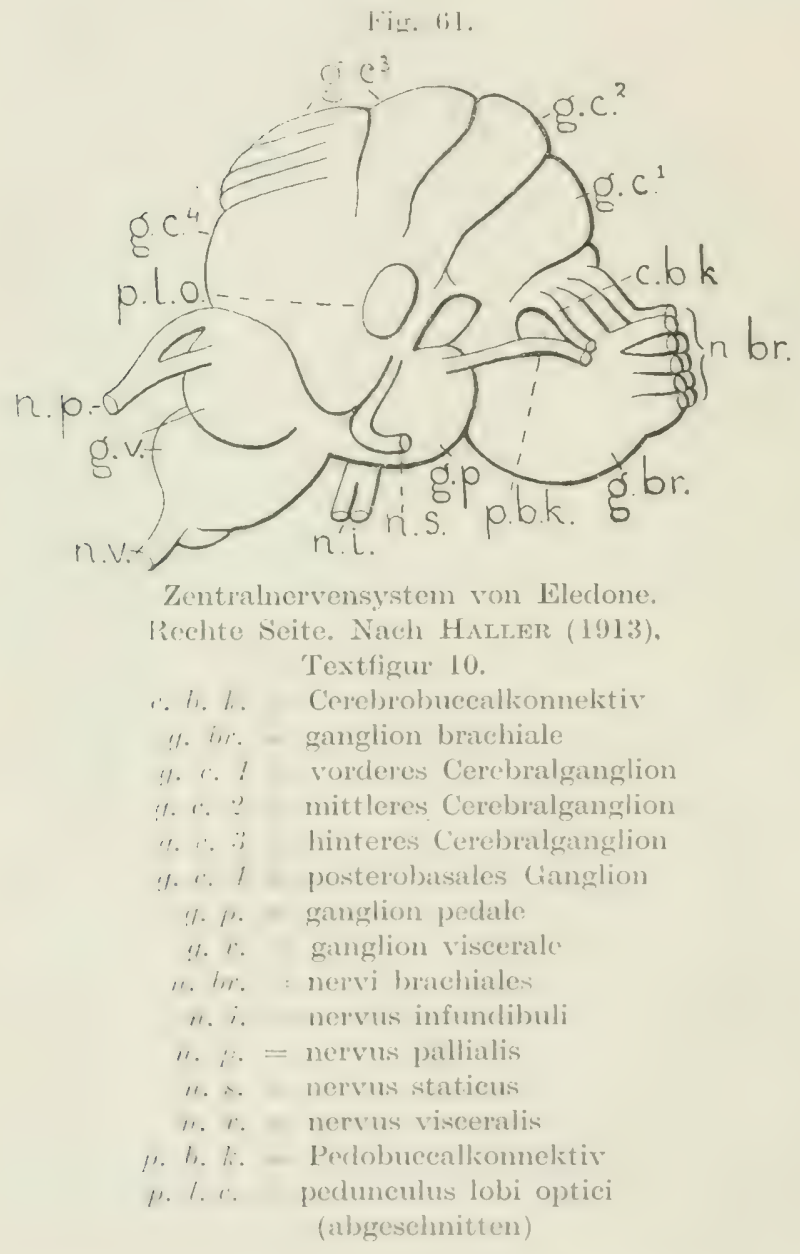
die Wurzeln der Brachialnerven der anderen Seite iibergehen.

Die Ganglienzellausläufer, welche selbst in die Brachiaherven treten, senden oft Aeste aus zum Neuropilem des Brachialganglions. Einige dieser Aeste kreuzen ebenfalls in der commissura anterior die Medianlinie und treten ins Neuropilem der anderen Seite.

Das Brachialganglion ist mit dem Cerebralganglion durch das Cerebrobrachialkonnektiv verbunden. Seine Fasern stammen aus allen Teilen des C'crebralganglions und gehen ohne zu kreuzen ins Brachialganglion. Fest steht, daß ein 'Teil dieser Fasern aus Ganglienzellen des vorderen C'erebralganglions (Fig. 61, g. c. 1) hervorgeht und auch, daß Ganglienzellendes Brachialganglions ihre Fortsätze durch das Cerebrobra-

chialkonnektiv ins C'erebralganglion senden.

Die beiden Pedalganglien werden durch die commissura media vereinigt. Ich habe diese bis jetzt Pedalkommissur genannt. Die Fasern dieser Kom. missur gehen teils aus dem Pedalganglion, teils aus dem Pleurovisceralganglion, das heißt der unteren Abteilung des Visceralganglions (Fig. 61, g. v.) hervor. Die ersteren sind teilweise Fortsätze von Ganglienzellen des P'edalganglions, teilweise sind es Seitenäste von liortsätzen, welche Ganglienzellen des Pedalganglions in den Trichternerven (Fig. 61, n. i.) oder den Mantelnerven (Fig. 
61, n.p.) senden. Man wird sich erinneren, daß3 die Nervenfasern des Trichternerven, welche aus Ganglienzellen des Pedalganglions hervorgehen auch schon von OwsJaxisow und KowaLEwsky bei Sepia beobachtet worden waren.

Große Ganglienzellen des Pleuro- oder Palliovisceralganglions (des unteren oder oberen Teils des Visceralganglions, Fig. 61, g.v.) senden ihre Fortsätze ins Pedalganglion. Dieselben durchschreiten dabei die , commissura longitudinalis ventralis" nach HALLER eine ,Kommissur", welche kein anderer Forscher noch erwähnt hatte, welche aber nach meiner Meinung nichts anders als das Pedovisceralkonnelitir ist, oder vielleicht ein besonderer Abschnitt desselben. Wenn die Fortsätze im Pedalganglion angelangt sind, senden sie einen Ast in die commissura media, wie oben gesagt wurde, andere Aeste verzweigen sich im Pedalganglion selbst, aber der Fortsatz selber geht weiter ins Brachialganglion.

Zuletzt kommt das Visceralganglion (Fig. 61,g. v.) an die Reihe. HALLER ist hier miederum sehr nachlässig in der Anwendung derselben Namen für dieselben Hirnteile im Text und in seiner Figurerklärung, weshalb ich nicht immer gewiß bin, daß ich ihn richtig verstehe. Ich schließe das folgende aus seiner Beschreibung.

Das Visceralganglion hat einen gepaarten dorsalen Teil, das Palliovisceralganglion und einen ungepaarten ventralen Teil das Pleurovisceralganglion. Das letztere ist mit einer diffusen Kommissur, Hallers commissura posterior, oben von mir Visceralkommissur genannt, ausgestattet.

Die Rinde des Palliovisceralganglions zeigt einen besonderen Bau, weil hier Gruppen großer und kleiner Ganglienzellen mit einander abwechseln. Die großen Ganglienzellen sind multipolar und senden manche kleinen Fortsätze zu den benachbarten Zellgruppen. Diese Fortsätze laufen ganz an der Oberfläche des Ganglions. Es sind hier also nicht, wie gewöhnlich in den Ganglien der Evertebraten, die Ganglienzellen ganz peripherisch gestellt, sondern eine Nervenfaserschicht, welche nach HALLER z.B. an die lamina zonalis der Großhirnrinde der Vertebraten erinnert. Die großen Ganglienzellen besitzen aber auch lange Fortsätze, welche sich an die Wurzel des nervus pallialis (Fig. 61, n. p.) anschließen, welche aus dem Pedalganglion stammt. Einige dieser langen Fortsätze kreuzen dabei die Nedianlinie in der commissura posterior, andere nicht. Offenbar haben OwsJAxsikow und Kowalewsixy diese Ganglienzellen bei Sepia gekannt.

Nicht alle langen Fortsätze der großen Ganglienzellen des Palliovisceralganglions treten in die Mantelnerven. Auch der Visceralnerv (Fig. 61, n.v.) empfängt einen Teil davon, aber er nimmt auch Fasern aus dem Pleurovisceralganglion auf.

Die kleinen Ganglienzellen des Palliovisceralganglions sind multipolar. Einige ihrer Fortsätze verbinden die Zellkörper gegenseitig, anastomosieren also, andere wenden sich zum Neuropilem des Ganglions.

Das Pleurovisceralganglion zeigt verschiedene Gebiete in seiner Rinde. Ganz ventral befinden sich sehr kleine Ganglienzellen an der Oberfläche des Ganglions mit Fortsätzen in dem Visceralnerven. Mehr nach innen liegen 
große Ganglienzellen ebenfalls mit Fortsätzen im Visceralnerven. Wahrscheinlich haben Owsjannikow und Kowalmwsky diese Zellen bei Sepia beobachtet.

Das Cerebrovisceralkonnektiv, welches HALJER weniger treffend die cerebropleurale Visceralkommissur nennt, vereinigt das Cerebralganglion mit dem Palliovisceralganglion. Seine Fasern kreuzen teilweise in der commissura posterior. Sie gehen entweder aus Ganglienzellen des Cerebralganglions oder aus solchen des Pleurovisceralganglions hervor.

Haller hat es nicht unterlassen über die Nervenfasern des nervus staticus (Fig. 61, n. s.) und des pedunculus lobi optici (Fig. 61, p. l.o.) Mitteilungen zu machen.

Die Fasern des nervus staticus, welche wir schon als Nervenfortsätze der Sinnesnervenzellen der Statocyste kennen gelernt haben, sind nach HALLER kontinuirlich verbunden mit Ganglienzellen des Cerebralganglions, welche drei Gruppen oder Kerne in der Nähe der commissura optica bilden. Diese Ganglienzellen wïrlen nach ihm mit manchen anderen einen wahren Ganglienzellplexus ausmachen, worin also keine bestimmten Leitungsbahnen sichtbar wären.

Die eben erwähnte commissura optica besteht nach Haller aus Nervenfasern der pedunculi loborum opticorum welche im vierten Cerebralganglion (Fig. 61, g.c.4) kreuzen und zu allen Teilen des Cerebralganglions ziehen mit Ausnahme des vorderen (Fig. 61, g.c. 1).

Dem pedunculus lobi optici sitzt endlich noch ein Ganglion auf, das HALLER als ein Stück abgetrennter Gehirnrinde betrachtet: das ganglion pedunculi. Zellen dieses Ganglions senden Fortsätze aus, welche mit oder ohne Kreuzung in der commissura optica ins Cerebralganglion ziehen. Umgekehrt gehen Fortsätze von Ganglienzellen des vierten Cerebralganglions ins ganglion pedunculi. Das Ganglion ist überdies durch ein Nervenfaserbündel mit dem lobus opticus verbunden, aber die Ursprungszellen dieser Fasern sind unbekannt.

So viel lehrt uns Halter ïber die Hodologie der Cephalopoden. Seinem Artikel folgte noch die Arbeit ScHKafrs (1914).

Scrikaff hat die Myopsidae unter den Cephalopoden studiert und zwar Loligo und Sepiola. Er nennt manche Fasersysteme, ist aber in der Angabe der Ursprungszellen der Nervenfasern sehr unbestimmt.

Folgendes kann uns hier interessieren. Auch Loligo und Sepiola haben im vierten 'Teil des Cerebralganglions eine commissura optica zwischen den beiden pedunculi, aber doch, wie ich meine, wahrscheinlich nicht so, daß die beiden pedunculi selbst Fasern auswechseln.

Der pedunculus lobi optici (nervus opticus) empfängt Fasern aus manchen 'Teilen des Cerebralganglions, aber auch durch das Cerebropedalkonnektiv hin aus dem Pedalganglion. ScHKaFr bestätigt damit die Mitteilung STIEDAs, welche für Sepia galt.

W'eder Sepiola noch Loligo besitzen nach ScukAfF eine commissura media (Pedalkommissur) im Pedalganglion, noch eine commissura anterior im Brachialganglion. Das lautet sehr sonderbar. 
Das ganglion brachiale sendet $u$. a. fünf Paar Brachialnerven aus. Ihre Fasern stammen aus dem Brachialganglion und daneben aus dem Pedalganglion. SchKAfF bestätigt damit, wie er selber bemerkt, die JATTAschen Angaben aus dem Jahre 1889, welche mir leider unbekannt blieben und auch eine noch viel ältere Mitteilung Stiedas über Sepia.

Die Fasern des nervus staticus sah Schkaff, ebenso wie Harler bei Eledone, aus dem Cerebralganglion hervorgehen. Sie laufen weiter durch das Cerebropedalkonnektiv und bilden im Neuropilem des Pedalganglions ein Chiasma, wonach das Faserbündel eine Dreiteilung erleidet und aus dem Ganglion austritt.

Endlich sagt ScHKAFF auch noch etwas über die Fasern einiger peripheren Nerven, welche von anderen Autoren vernachlässigt wurden und auch in der Figur 61 nicht zu finden sind. Der nervus nuchalis oder postorbitalis geht hinten aus dem Cerebralganglion hervor, aber seine Nervenfasein entspringen nicht, wie man meinte, in diesem Ganglion, sondern sie durchschreiten das Cerebralganglion und entspringen im dorsalen Teil des Palliovisceralganglions. $\mathrm{Ob}$ sie hier wirklich aus Ganglienzellen hervorgehen, sagt SchKaFF nicht. Die Fasern des nervus ophthalmicus et oculomotorius superior entspringen kurz vor den Fasern des nervus nuchalis im Palliovisceralganglion und durchsetzen ebenfalls das Cerebralganglion, ehe sie daraus als peripherer Nerv hervortreten.

Man sieht, wie mangelhaft, trotz aller Mühe, welche sich die Forscher gegeben háben, unsere Kenntnis der Leitungsbahnen der Cephalopoden noch ist, wie überall noch kleinere und größere Lücken bestehen, aber auch, wie unser Wissen und damit unser Verständnis ständig wächst. Wo dasselbe mit noch mehr Recht von den anderen Mollusken gesagt werden kann, glaube ich, daß solches nur eine Anregung sein kann, mit verdoppelter Anstrengung neue Untersuchungen anzustellen.

\section{I I E R A T U R.}

1. BaвUchin (1865), Ueber den Bä der Netzhaut einiger Lungenschnecken, Sitzungsberichte der Mathem. Naturwiss. Classe der Akademie der Wissenschaften, Wien 13d. 52, 1ste Abtheil., 1886.

2. BAECKER (1902), Zur Kenntnis der Gastropodenaugen, Zoologischer Anzeiger, Bd. 25,1902 .

3. BAkCher (1903), Die Augen einiger Gastropoden, Arbeiten aus den zoologischen Instituten der Universität Wien, Bd. 14, 1903.

4. BAUEr (1909), Einfuihrung in die Physiologie der Cephalopoden, Mittheilungen aus der zoologischen Station zu Neapel, Bd. 19, 1908 - 1909.

5. Brsogiri (1896), Le terminazioni nervose nelle fibre lisce delle tuniche muscolari del tubo digerente del Limax subfuscus e del Limax agrestis, Anatomischer Anzeiger, 13d. $12,1896$.

6. Blumrici (1891), Das Integument der Chitonon, Zeitschrift für wissenschaftliche Zoologie, Bd. 52, 1891.

i. Bozhuig (1883), Beiträge zur Kenntnis des Centralnervensystems einiger PulmoDROOGLEEVER FORTUYN. 
naten Gasteropoden : Helix pomatia und Limnaea stagnalis, Inaugural Dissertation, Leipzig, 1883.

8. BoLt (1869), Beiträge zur vergleichenden Histiologie des Molluskentypus, Archiv für mikroskopische Anatomie, Supplement, 1869.

9. Brock (1889), Zur Neurologie der Prosobranchier, Zeits. f. wiss. Zoologie, Bd. 48, 1889 .

10. BuCHHolz (1863), Bemerkungen über den histologischen Bau des Centralnervensystems der Süßwassermollusken, Archiv für Anatomie, Physiologie und wissenschaftliche Medicin, 1863.

11. Buetschli (1912), Vorlesungen über vergleichende Anatomie, 2te Lieferung, 1912.

12. CAJAL (1917), Contribucion al conocimiento de la retina y centros opticos de los Cefalopodos, Trabajos del Laborat. de Invest. biolog., Tomo 15, 1917.

13. Carrière (1889), Ueber Molluskenaugen, Archiv f. mikr. Anatomie, Bd. 33, 1889.

14. Claus (1876), Das Gehörorgan der Heteropoden, Arehiv f. mikr. Anatomie, Bd. $12,1876$.

1\%. Dietl (1878), Untersuchungen über die Organisation des Gehirns wirbelloser Thiere, Iste Abtheilung (Cephalopoden, Tethys), Sitzungsberichte der Mathem.

Naturwiss. Classe der Kais. Akademie der Wissenschaften, Wien, Bd. 77, 1ste Abt, 1878.

16. Dogiel (1877), Die Muskeln und Nerven des Herzens bei einigen Mollusken, Arehiv f. mikr. Anatomie, Bd. 14, 1877.

17. Drost (1887), Ueber das Nervensystem und die Sinnesepithelien der Herzmuschel (Cardium edule L.) u. s. w., Morphologisches Jahrbuch, Bd. 12, 1887.

18. Edrnger (1877), Die Endigung der Hautnerven bei Pterotrachea, Archiv f. mikr. Anatomie, Bd. 14, 1877.

19. Fleming (1870), Untersuchungen über Sinnesepithelien der Mollusken, Archiv f. mikr. Anatomie, Bd. 6, 1870 .

20. Fleming (1884), Ueber Organe vom Bau der Geschmacksknospen an den Tastern verschiedener Mollusken, Archiv f. mikr. Anatomie, Bd. 23, 1884.

21. Fol (1889), Sur l'anatomie microscopique du dentale, Archives de Zoologie Expérimentale, 2me série, tome 7, 1889.

2.2. Freidenfelt (1896), Ueber das Nervensystem des Mantels von Mactra elliptica, Zoologische Jahrbücher (A bt. Anat.), Bd. 9, 1896.

23. FreIdENFELT (1897), Das centrale Nervensystem von Anodonta, Biologisches Centralblatt, Bd. 17, 1897.

24. Fromulch (1910), Das Mantelganglion der Cephalopoden als Reflexorgan, Zeitschrift für allgemeine Physiologie, Bd. 10, 1910.

2.). GARIAEF (1909), Zur Histologie des centralen Nervensystems der Ceplalopoden, I, Suboesophagealganglionmasse von Octopus vulgaris, Zeits. f. wiss. Zoologie, Bd. $92,1909$.

21;. Gilchrist (1897), Notes on the Minute Structure of the Nervous System of the Mollusca, The Journal of the Linnean Society ; Zoology, Vol. 24, 1898.

27. Grant Sumit (1906), The Eyes of Certain Pulmonate Gasteropods, with Special Reference to the Neurofibrillae in Limax maximus, Bulletin of the Museum of Comparative Zoology at Harvard College in Cambridge, Vol. 48, $1905-1907$.

$2:$ Grenachei (1886), Abhandlungen zur vergleichenden Anatomie des Auges, I. Die Retina der Cephalopoden, Abhandlungen der naturforschenden (ieselischaft zu Halle, Bd. 16, 1886.

23. Grevicher (1892), Abhandl. zur vergl. Anatomie des Auges, II, Das Auge der Heteropoden, Abhandl, der naturf. Gesells. zu Halle, Bd. 17, 1892.

30. CiUérix (1908), Contribution à l'étude des systèmes cutané, museulaire et nerveux de l'appareil tentaculaire des C'éphalopodes, Arehives de Zoologie Lixpérimentale, tme série, tome 8, 1908.

31. Haller (1881), Vorläulige Mittheilung über das Nervensystem und Mundepithe] niederer Gastropoden, Zoologiseher Anzeiger, Bd. 4, 1881.

3:. Haller (1882-185t), Die Organisation der Chitonen der Adria, Arbeiten aus 
dem zoologischen Institute der Universität Wien, Bd. 4, 1882 und Bd. 5, Iss4.

33. HALLER (1884), Untersuchungen über marine Rhipidoglossen, I, Morphologisches Jahrbuch, Bd. 9, 1884.

34. Haller (1886), Unters. uiber marine Rhipidoglossen, II, Morphol. Jahrbutch, Bd. 11,1886 .

35. Hatler (1913), Die Intelligenzsphären des Molluskengehirns, Archir f. mikr. Anatomie, Bd. 81, 1913.

36. Havet (1899 a), Note préliminaire sur le système nerveux des Limax (méthode de Golgr), Anatomischer Anzeiger, Bd. 16, 1899.

37. Havet (1899 b), L'état moniliforme des neurones chez les invertébrés, La Cellule, Tome 16, 1899 .

38. Hexchuax (1S90), The Origin and Development of the Central Nerrous Srstem in Limax maximus, Bulletin of the Museum of Comp. Zoology at Harvard College in Cambridge, Vol. 20, 1890 - 1891.

39. Hensex (1865), Ueber das Auge einiger Cephalopoden, Zeits. f. wiss. Zoologie, Bd. 15, 1865 .

40. Hesse (1900), Die Augen einiger Mollusken, Zeits, f. wiss. Zoologie, Bd. 68, 1900.

41. HofmanN (1907), Histologische Untersuchungen über die Innervation der glatten und der ihr verwandten Muskulatur der Wirbeltiere und Mollusken, Archiv f. mikr. Anatomie, Bd. 70, 1907.

42. Корsch (1896), Das Augenganglion der Cephalopoden, Anatomischer Anzeiger, Bd. 11, 1896.

43. Kорsch (1899), Mitteilungen über das Ganglion opticum der Cephalopoden, Internationale Monatschrift für Anatomie und Physiologie, Bd. 16, 1899.

44. LACAZE-Duthiers (1865), Multiplicité et terminaison des nerfs dans les Mollusques, Comptes rendus de l'académie des sciences, Paris, Tome 61, 1865.

45. Von Lenhossek (1894), Zur Kenntnis der Netzhaut der Cephalopoden, Zeits. f. wiss. Zoologie, Bd. 58, 1894.

46. VoN LENHOSSEK (1S96), Histologische Untersuchungen am Sehlappen der Cephalo. poden, Archiv f. mikr. Anatomie, Bd. 47, 1896.

47. Mertox (1905), Ueber die Retina von Nautilus und einigen dibranchiaten Cephalo. poden, Zeits. f. wiss. Zoologie, Bd. 79, 1905.

48. DE NABras (1894), Recherches histologiques et organologiques sur les centres nerveux des Gastéropodes, Actes de la Société Linnéenne de Bordeaux, Tone $47,1894$.

49. OwsJANxiKow und Kowalewsky (1868), Ueber das Centralnervensystem und das Gehörorgan der Cephalopoden, Mémoires de l'Académie impériale des sciences de Saint-Pétersbourg, Tme série, Tome 11, 1868.

;il. Pattex (1886), Eyes of Molluses and Arthropods, Mitteil. a. d. zoolog. Station zu Neapel, Bd. 6, 1886.

51. Pelseneer (1906), Mollusca, RAY LAnkester, A Treatise on Zoology, Part V, 1906.

i.). Plate (1892), Ueber den Bau und die Verwandtschaftsbeziehungen der Solenoconchen, Zoologische Jahrbücher (Anat. Abt.), Bd. 5, 1892.

ii) RANKE (1875), Der Gehörvorgang und das Gehörorgan bei Pterotrachea, Zeits. f. wiss. Zoologie, Supplement zum 25sten Band, 1875.

it. Raxvier (1850), Leçons d'Anatomie générale, Appareils nerveux terminaux, 1880.

i.j. Rawitz (1887), Das zentrale Nervensystem der Acephalen, Jenaische Zeitsehrift für Naturwissenschaft, Bd. 20, N. F. 13, 1887.

jfi. Rawitz (1888), Der Mantelrand der Acephalen, I, Ostracea, Jenaische Zeits. f. Naturwiss., Bd. 22, N. F. 15, 1888.

57. RAwrz (1890), Der Mantelrand der Acephalen, II, Jenaische Zeits. f. Naturwiss., Bd. 24, 1890.

5). Rawitz (1892), Der Mantelrand der Acephalen III, Siphoniata, Jenaische Zeits. f. Naturwiss., Bd. 27, 1892 .

59. Retzius (1892), Das sensibele Nervensystem der Mollusken, Biologische Untersuchungen, N. F. Bd. 4, 1892. 
60. Retzivs (1900), Zur Kenntnis des sensibelen und des sensorischen Nervensystems der Würmer und Mollusken, Biol. Untersuch. ,N. F. Bd. 9, 1900.

61. Reupsch (1912), Beiträge zur Anatomie und Histologie der Heteropoden, Zeits. f. wiss. Zoologie, Bd, 102, 1912.

6i:. Samassa (1894), Ueber die Nerven des augentragenden Fühlers von Helix pomatia, Zoologische Jahrbücher, (Abt. Anat.), Bd. 7, 1894.

6i:. Schkaff (1914), Zur Kenntnis des Nervensystems der Myopsiden, Zeits. f. wiss. Zoologie, Bd. 109, 1914.

(it. K. C. SchNeIDER (1902), Lehrbuch der vergleichenden Histologie der Tiere, 1902,

(i). H. Schultze (1879), Die fibrilläre Structur der Nervenelemente bei Wirbellosen. Arehiv f. milkr. Anatomie, Bd. 16, 1879.

tit: Sinroth (1876), Ueber die Sinneswerkzeuge unserer einheimischen Weichthiere, Zeits. f. wiss. Zoologie, Bd. 26, 1876.

(i). Sniroth (1892 - 1894), Amphineura und Scaphopoda in Browss Kilassen und Ordnungen des Thierreichs, Bd. III, Abt. 1, 1892-1894.

(is. Sinroth (1909-1911), Pulmonata in Bronxs Klassen und Ordnungen des T'ierreichs, $\mathrm{Bd}$. $\mathrm{HI}, 1908-19$ ??.

(i؛. Sindt (1899), Die Sinneszellen der Mundhöhle von Helix, Anatomischer Anzeiger, Bd. 16,1899 .

71. Sumpt (1900), Ueber die Darstellung der Begleit- und Gliazellen im Nervensystem von Helix mit der Golgimethode, Archiv f. mikr. Anatomie, Bd. $55,1900$.

i1. Sиmт (1901), Ganglienzellen in der Schlundmusculatur von Pulmonaten, Archiv f. mikr. Anatomie, Bd. 57, 1901.

7-. SuId (1902), Die intraepithelialen freien Nervenendigungen bei Helix und ihre Beziehungen zu Sinneszellen und Drüsen, Anatomischer Anzeiger, 13d. 20, 1902.

7:3. STantschinskx (1908), Ueber den Bau der Rückenaugen und die Histologie der Rückenregion der Oncidien, Zeits. f. wiss. Zoologie, Bd. 90, 1908.

it. Stieda (1S7t), Studien über den Bau der Cephalopoden, Zeits. f. wiss. Zoologie, Bd. 24, 1874 .

7... Thiele (1889), Die abdominalen Sinnesorgane der Lamellibranchier, Zeits. f. wiss. Zoologie, Bd. 48, 1889.

ii. Tschachotin (1908), Die Statocyste der Heteropoden, Zeits. f. wiss. Zoolngie, Bd. 90, 1908.

7-. Veratti (1900), Richereho sul sistema nervoso dei Limax, Alemorie del R. Istituto Lombardo di Seienze e Lettere, Vol. 18, Fase. 9, 1900.

in. Vigana (1883), Recherches histologiques sur les centres nerveux de quelques inver. tébrés, Archives de Zoologie Expérimentale, 2me série, tome 1, 1883.

i!. WIREN (1892), Studien über Solenogastres, I, Monografie des Chaetoderma nitidulum, Kongliga S'venska Vetenskaps-Akademiens Handlingar, Bd. 24, 1890-1891. 


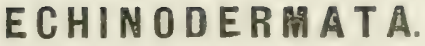

Im Augenblicke, worin ich im Begriff stehe die Hodologie der Fchinodermen zu beschreiben, exschrecke jch fast, so wenig ist über die Wege der Leitungsbahrien bekannt. Kein anderer Stamm des Tierreichs ist in dieser Hinsicht noch so unaufgelzlärt gebiieben und es ist dies um so mehr zu bedauern, als gerade die Asteriden oder Seesterne zu manchen physiologischen Experimenten Anlaß gegeben haben.

Der Mangel an hodologischen Ergenbnissen läßt sich wohl einigermaßen erklären. Erstens sind die Echinodermen, lauter Meerestiere, nicht so allgemein erreichbar, wie die Würmer oder Mollusken. Zweitens ist die Technik der histologischen Untersuchungen des Nervensystems außerordentlich schwer, weil die Tiere so große Mengen Kalk enthalten. Und drittens weicht der Bau des Nervensystems erheblich ab, verglichen mit den anderen Evertebraten. Es gibt nämlich nicht ein, sonderu drei Nervensysteme, welche, es ist kaum zu glauben, fast immer ohue gegenseitigen Zusammenhang sein sollen. Ueberdies sind die wichtigsten Abschnitte des Nervensystems, den anderen Geweben gegenüber nicht selbständig, weil die größeren Nerven oft basal in einem Epithe! liegen, das heißt, durch die fadenförmigen Bases der Epithelzellen durchsetzt werden. Diese Tatsache hat zweifelsohne die U'nterscheidung der nervösen und nicht-nervösen Gewebselemente sehr erschwert und man findet in der Literatur viel Streit über die Natur gewisser Zellen und Fasern.

Dennoch glaube ich, daß man hierdurch nicht den Mut verlieren darf und daß gerade die Echinodermen denjenigen Forschern, die die Technik volliommen beherrschen; reiche Ausbeute an neuen Tatsachen versprechen.

Die Echinodermen werden allgemein zu fünf Klassen gerechnet: die Asteroidea, Ophiuroidea, Crinoidea, Echinoidea und Holothuria.

Mit den Asteroideen will ich anfangen. Zur Einleitung sei es mir gestattet eirige allgemeine Bemerkungen ïber das Nervensystem zu machen, welche ich hauptsächlich dem Sammelwerke „Brovas Kilassen und Ordnungen des Tierreichs" entnehme, worin Ludwig und Hamans (1899) die Seesterne bearbeitet haben.

Die Asteriden besitzen drei völlig unabhängige Nervensysteme. Am längsten bekannt ist das Ektoneuralsystem. Es setzt sich zusammen aus einem. 
Ringnerven um den . Mund und fünf Radialnerven in den ventralen Mittellinien der Arme, welche aus dem Ringnerven hervorgehen. Der Ring sendet periphere Nerven zur Mundhaut und zum Darm, die Radialnerven zu den Füßchen, Pedicellarien, Augeri und anderen Organen des Armes. Nervenring und Radialnerven liegen im ektodermalen Epithel basal zwischen den Zellen.

Das zweite Nervensystem ist das Hyponeuralsystem in der Wand der Hyponeuralkanäle (Pseudohämalkanäle) gelegen und zwar im Epithel. Es bildet in jedem Arm zwei Epithelverdickungen und fünf solche Verdickungen um den Mund herum. Es wurde von LaxaE entdeckt. Ludwig verneint die nervöse Natur dieses Systems, aber Hamann, Cuḱvot, Jickeli, u.a. schließen sich in ihrer Meinung der Einsicht LANGEs an. Das Hyponeuralsystem innerviert mit seinen Seitennerven einen Teil der Muskeh.

Letzteres kann man auch sagen vom dritten Nervensystem, dem Entoneuralsystem, welches Cú́NoT entdeckte. Es liegt im Peritonealepithel unter den dorsalen Muskeln des Armes und der Körperscheibe.

HAECKEL (1860) scheint als erster sich mit der Histologie der Nerven der Seesterne beschäftigt zu haben. Er fand im Ringnerven ebenso wie in den Radialnerven, also im Ektoneuralsystem, zentral gestellte Ganglienzellen und Nervenfasern ringsherum.

HoFmann (1873) beschrieb die Ganglienzellen als bipolare Zellen und betonte den übereinstimmenden Bau des Nervenringes und der Radialnerven.

Teuscher (1876) rechnete zu den Radialnerven drei Gewebsschichten, nämlich eine Bindegewebsschicht, welche jetzt nicht mehr als zum Nerven gehörig betrachtet wird, eine Nervenfaserschicht und eine Hautschicht. Die Nervenfaserschicht ist der eigentliche Nerv. Es sind darin longitudinale Nervenfasern und Zellen, bisweilen regellos verbreitet, bisweilen eine Schicht gegen die Hautschicht bildend, welche nach Teuscher Ganglienzellen sind, obgleich ihr Zusammenhang mit den Nervenfasern ihm verborgen blieb. In der Nervenfaserschicht sah TEuscher auch Querfasern, welche er mit Recht als Stiutzfasern betrachtet, denn, wie aus späteren Untersuchungen hervorgegangen ist, sind es dic basalen Teile der ektodermalen Epithelzellen, welche iibrigens die Zellen der Teuscherschen Hautschicht darstellen. Ich glaube nicht fehl zu gehen, wenn ich diese Stitzfasern der Echinodermen den Gliafasern anderer Tiere gleichstelle. Auch Teuscrer entdeckte keinen Unterschied im Bau des Nervenringes und der Radialnerven.

Im selben Jahre als Teuscher seine Untersuchungen veröffentlichte hat LANGE (1876) in einer sehr schönen. Arbeit die Existenz des Hyponeuralsystems dargetan. Es ist schade, daß er dabei die nervöse Art des Ektoneuralsystems geleugnet hat, aber man kam sich denken, daß er noch nicht wie spätere Forscher darauf gefa $3 t$ war, bei den Echinodermen mehr als ein Nervensystem zu erkennen.

Bei den Asteroideen sah er in den Radialnerven des Hyponeuralsystems Ganglienzellgruppen. Dic Fortsätze dieser Ganglienzellen bilden eine Nervenfaserschicht, welche durch eine bindegewebige Lamelle vom Ekitoneuralsystem getrennt wird. Unter den am Ende des Armes gestellten Augen bildet das Hyponeuralsystem ein Ganglion. 
Sehr wichtig. weil er damit wenigstens den Anfang einer Leitungsbahn angibt, ist die Bemerkung LANGEs, daß die pigmentierten Zellen des Auges, das heißt die Sehzellen, sich in Fasern fortsetzen. Es hat sich später erwiesen, da $B$ diese Fasern wirklich Nervenfasern und die Sehzellen somit Sinnesnervenzellen sind, aber LANGE selbst scheint nur den Sehzellfortsatz, nicht seine nervöse Natur erkannt zu haben.

LUDWIG (1878) hat seine Aufmerksamkeit wieder dem Ektoneuralsystem der Asteriden gewidmet und in den Radialnerven beobachtet, was Teuscher noch entgangen war, daß die Querfasern, welche den Nerven durchsetzen mit den peripheren Zellen, also den Epithelzellen, rerbunrlen sind. Uebrigens bestätigt er nur bekannte Sachen.

Hamann (1883a) ist der erste Forscher, welcher sich bewußt war, daß die Seesterne mit Sinneszellen vom Typus der Sinnesnervenzelle ausgestattet sind; er nennt sie jedoch Epithelsinneszellen. Im ektodermalen Epithel des Tasters am Ende der Arme entdeckte er Sinnesnervenzellen mit einem Fortsatz in der dortigen intraepithelialen Nervenfaserschicht und daneben Stützzellen, deren basale Fortsätze die Nervenfaserschicht quer durchsetzen bis zur Basalmembran des Epithels. Letztere sind also die Epithelzellen, welche z.B. auch Ludwig schon sah.

Auch in den Tastfüßchen der Arme traf Hamann solche Sinnesnervenzellen im Epithel mit Fortsätzen in der daruntergelegenen Nervenfaserschicht.

In Uebereinstimmung mit diesem Befund betrachtet HAMANN die basalen Fortsätze der pigmentierten Zellen des Auges als Nervenfortsätze und er meint sogar, daß sie mit Fortsätzen bipolarer Ganglienzellen zusammenhängen.

Obgleich spätere Untersuchungen Hamans Recht gegeben haben, hat anfänglich CuÉNot (1887) sich ihm entgegengestellt. Er meinte damals, daß niemals und in keiner Weise Epithelzellen des Asteriden mit Fasern der Nervenfaserschicht verbunden seien und folglich, daß HAMANn sich geirrt habe. Zwar sah auch Cú́not die basalen Fortsätze der Sehzellen des Auges und der Sinneszellen des Tasters, aber diese hefteten sich nach ihm ans Bindegewebe unter dem Epithel und seien deshalb keine Nervenfasern. Später hat Cú́not (1891) seine vorigen Angaben zum Teil widerrufen und erkannt, daß wirklich einige Epithelzellen des Endtasters ihre Fortsätze in die Nervenfaserschicht des Epithels senden und somit als nervöse Zellen (ich sage Simnesnervenzellen) zu betrachten sind. Er meint nur noch, daß solche Zellen nicht so allgemein verbreitet sind, wie HAMANN es will.

In seiner erstgenannten Arbeit (1887) bemerkt Cú́Noт noch, daß die Nerven des Ektoneuralsystems nicht scharf begrenzt sind gegen das umgebende Epithel, weil iiberall basal zwischen den Epithelzellen der Haut eine mehr oder weniger dicke Nervenfaserschicht verbreitet ist. Auch basal im Epithel des Darmkanals läßt sich eine Nervenfaserschicht beobachten.

Ebensowenig wie andere Forscher konnte Cú́NoT bestimmte Leitungsbahnen im Ektoneuralsystem beobachten, ja, er sah sogar nicht den Zusammenhang der Nervenfasern mit den bipolaren Ganglienzellen, welche in den Nerven zerstreut liegen.

Auch JickeLI (1888) sah im Ektoneuralsystem der Asteriden zirkulare 
Nervenfasern im Ringnerven und longitudinale in den Radialnerven, aber keine Andeutung mehr spezieller Leitungsbahnen. Er fand im Ektoneural system, ebenso wie im Hyponeuralsystem, Ganglienzellen in der Peripherie der Nerven und im Zentrum derselben.

In der Arbeit Ludwigs und Hamaxws (1899), welche eine Uebersicht der damaligen Literatur der Asteroidea darbietet, werden auch keine Leitungsbahnen erwähnt. Uns interessiert hier noch ihre Bemerkung, daß auch das Entoneuralsystem der Seesterne in den Armen aus longitudinalen Nervenfasern und Ganglienzellen zusammengesetzt wird, welche eine Schicht bilden zwischen den dorsalen Armmuskeln und dem Coelom. Letzteres ist bekleidet mit dem Peritoneum und die basalen Abschnitte der Peritonealzellen bilden ebensolche querlaufenden Stützfasern in diesem Nervensystem, wie die Ektodermzellen im Ektoneuralsystem.

Die Sehorgane der Seesterne sind abermals von W.Pfeffer (1901) untersucht worden und zwar bei sehr vielen Arten. Er sah den Radialnerven in der Spitze des Armes anschwellen zu einem Augenpolster, welches dieselben Elemente wie der Radialnerv enthielt, nur daß sie größer waren. So beobachtete er darin bei einigen Seesternen viele, bei anderen nur wenige Sinnesnervenzellen, wie sie auch in den Nerven vorkommen, wo HAMAYs sie entdeckte. Aber die wichtigsten Elemente des Augenpolsters sind die rot pigmentierten Sehzellen. Meistens sind sie zu Augen gruppiert, bisweilen aber auch diffus verteilt. Die Sehzellen tragen ein Stäbchen und verjüngen sich in eine Faser, welche in der Nervenfaserschicht des Augenpolsters verschwindet. Es sind deshalb, ebenso wie die anderen Simneszellen, Sinnesnervenzellen.

In letzter Zeit hat R. Meyer (1906) den feineren Bau des Nervensystems des Seesternes Asterias rubens einer Untersuchung unterworfen. Er betont mit Nachdruck, daß wenigstens bei dieser Art kein Entoneuralsystem vorhanden ist, denn das Peritonealepithel enthält nach ihm keine nervösen Elemente.

Tatsächlich erkennt MeYER nur ein einziges Nervensystem und zwar das Ektoneuralsystem. Er bestätigt darüber viele uns schon bekannte Tat. sachen, macht aber auch einige Bemerkungen, welche uns hier besonders interessieren. Er erwähnt in den Nerven neben bipolaren Ganglienzellen auch multipolare, wclche vordem oft gefunden, aber eben so oft als Bindegewebszellen betrachtet worden waren. Auch sah er mehr Ganglienzellen im Ringnerven als in den Radialnerven. MEYER konnte auch mit aller wiinschenswerten Deutlichkeit die Sinnesnervenzellen in Ektoderm wahmehmen. Er beschreibt sie und bildet sie ab als bipolare Zellen mit einem Simesfortsatz bis zur Cuticula und einem Nervenfortsatz, welcher sich (oft 'I' förmig) zwischen den Fasern des Nerven verzweigt. Niemals sah er diese Nervenfortsütze kontinuirlich in Fortsätze der Ganglienzellen des Nerven ïbergehen und er glaubt ja auch nicht daran. Aber auch das sich aneinanderlegen dieser Fortsätze, woran er wohl glaubt, hat er nicht beobachtet.

Wie aus dem oben Mitgeteilten erhellt, sind uns bei den Asteriden gar keine Leitungsbahnen des Nervensystems bekannt. Nur die Nervenfortsätze der verschiedenen Simmesnervenzellen, welche deren ersten Anfang bilden. 
Die Ophiuren oder Schlangensterne haben ebenso wie die Asteriden ein Ekto-, Hypo- und Entoneuralsystem. Das Ekto- und Hyponeuralsystem bilden zusammen den Ringnerven um den Mund und die Radialnerven in den Armen. Diese beiden Nervensysteme liegen nicht mehr im Epithel selbst, sondern subepithelial.

Teuscher und Lavge, deren Arbeiten wir schon oben kennen lernten, haben auch die Ophiuren untersucht. 'TEUSCHER (1876) erkannte schon die Doppelnatur der Radialnerven, welche durch Verwachsung des Ekto- und Hyponeuralsystems entsteht.

LANGE (1876) hat nur die Radialnerven des Hyponeuralsystems studiert. Er entdeckte darin gepaarte Ganglien durch Längsverbindungen (,,Konnektive”) und durch eine oder zwei Querverbindungen „(Kommissuren”) vereinigt. Aus den Ganglien gehen Nerven hervor; welche oft gewisse Miskeln innervieren. Auch hier wird über die Wege der Nervenfasern geschwiegen. Das Hyponeuralsystem ist durch eine bindegewebige Membran vom Ektoneuralsystem getrennt. LANGE betrachtet das Ektoneuralsystem als ein nicht-nervöses Band und er hebt besonders hervor, daß es keine Fasern mit dem hyponeuralen Radialnerven auswechselt.

Einen ganz kleinen Beitrag zur Hodologie der Ophiuren liefert LuDwIG (1880), wenn er sagt, daß die longitudinalen Nervenfasern der Radialnerven kontinuirlich in Nervenfasern des. Ringnerven übergehen.

HaMarn (1889) teilt uns manche Einzelheiten des Nervensystems der Ophiuren mit, welche, so weit sie nicht selbst den Lauf der Leitungsbahnen berïcksichtigen, späteren diesbezüglichen Untersuchungen behilflich sein können.

Auch Hanaxy beobachtete, daß die Radialnerven durch eine Membran in einen ventralen oder oralen 'Teil (das Ektoneüralsystem) und einen dorsalen Teil (das Hyponeuralsystem) zerlegt werden. Die Radialnerven des Hyponeuralsystems setzen sich zusammen aus einer dünnen Schicht longitudinaler Nervenfasern, welche an der einon Seite durch die bindegewebige Membran. an der anderen Seite durch eine einzige Schicht von Ganglienzellen begrenzt wird. Die Nervenfasern sind Fortsätze der Ganglienzellen. An manchen Stellen ist die Gangiienzellschicht verdickt und diese Ganglienzellanhäufungen bilden gepaarte Ganglien. Die Radialnerven des Hyponeuralsystems senden Nerven zu den Muskeln.

Die Radialnerven des Ektoneuralsystems bestehen ebenfalls aus einer Nervenfaserschicht, welche einerseits durch die Membran, andrerseits durch eine Zellschicht bekleidet wird. Die Nervenfaserschicht ist aber viel mächtiger entwickelt als im Hyponeuralsystem und enthält hier und dort eine Ganglienzelle. Die Zellschicht ist an den Stellen, welche mit den Ganglien des Hyponeuralsystems übereinstimmen zu einem Ganglion verdickt und enthält hier meistens bloß multipolare Ganglienzellen, bei Ophiothrix aber auch Stützzellen. Zwischen diesen Stellen stehen die Zellen nur in einer Schicht und hier wechseln Stützzellen, welche Stützfasern quer durch die Nervenfaserschicht zur Bindegewebsmenbran senden, nit Ganglienzellen ab.

Die Seitemerven dieser ektoneuralen Radialnerven gehen zu den Füßchen 
Sie sind ventral mit Ganglienzellen belegt und bilden um das Füßchen ein kreisförmiges ganglion pedale mit zirkularen Nervenfasern. Auch dieses ganglion pedale sendet viele Nerven aus. Man begreift, daß in dieser Lage die Wege der Nervenfasem hier nicht ohne weiteres gegeben sind, eben so wenig, wie an gar manchen anderen Stellen, wo Hamans Ganglien und ganglienzellführende Nerve! beschreibt.

Interessant ist es, daß einige Scitennerven des Radialnerven sowohl Nervenfasern des Ektoneuralsystems wie des Hyponeuralsystems erhalten.

Im Ringnerven laufen die Nervenfasern im Kreise. Es gibt hier zwei Ganglienzellarten, aber keine Stützzellen und auch hier sind die ventralen Ganglienzellen in (ranglien angehäuft. Den Ringnerven verlassen periphere'Nerven. welche Ganglienzellen enthalten und oft $\mathrm{zu}$ peripheren Ganglien gehen. Alle diese Angaben erregen nur Fragen nach dem Lauf der Nervenfasern, aber beantworten sie durchaus nicht.

Sinnesnervenzellen wurden von HAMANN auch bei den Ophiuren beobachtet und zwar im Epithel der Mundfüßchen und der Keulenstacheln, welche einge Ophiuren besitzen und hei Ophioglypha in allen Fiikchen. Immer senden sie ihren Nervenfortsatz in die darunterliegende Nervenfaserschicht.

In der zusammenfassenden Arbeit, welche Ludwig und HAMAxx (1901) zusammen schrieben, kann man obige Bemerkungen über das Nervensystem der Ophiuren neben vielen anderen wiederfinden, aber hinsichtlich der Hodologie fiihrt sie uns num wenig weiter. Es werden widerum im Epithel der Füßchen Sinnesnervenzellen beschrieben; jetzt wird aber darüber bemerkt, daß ihre Nervenfortsätze ins oben erwähnte ganglion pedale ziehen. Falls sie dort enden, ist hier also cine Leitungsbahn genugsam bekannt. In don Fülbchen ron Ophiothrix bilden die Simesnervenzellen simnesknospen und ihre Nerrenfortsätze besondere Nerven, welche Seitennerven des Füßchennerven sind.

Die dritte Klasse der Echinodermen bilden die Crinoideen. Auch sie besitzen drei Nervensysteme, hier Ektoneuralsystem, dorsal oder apical Nerrensystem und ventral Nervensystem genannt. Das Ektoneuralsystem ist nur wenig entwickelt. Nerven im Epithel der ventralen Seite der zehn Arme und der 'Tentakelrinnen der Mundscheibe bilden es, aber ein Ringnerv fehlt.

Das apicale Nervensystem ist eine Hohlkugel, welche das „Dorsalorgan” umgibt und aus diesem Zentralorgan gehen periphere Nerven zu den Muskeln der Arme, den Cirrhen und dem Stiel des Crinoidenkörpers hervor.

Das ventrale Nervensystem, welches sich aus dem Mesoderm entwickelt und somit von der Mehrzahl der Nervensysteme der Tiere abweicht, bildet einen Ring um den Mund mit Seitenästen zu den Armen, dem Wassergefäßssystem und der ventralen Haut. In den Armen werden das apicale und das ventrale Nervensystem durch Seitennerven verbunden, wenigstens nach LUDWIG und HAMANN (1907).

Das Elitoneuralsystem besteht nach Hamaxx (1889) aus Nervenfasern mit zwischenliegenden Gamglienzellen. Man hexernet demedhen, wie gesagt. im ventralen Epithel der Arme und hier stehen nach HAMAxy auch Sinnesnerrenzellen. welehe ihre Nervenfort-itze in die Nervenfaserschicht hineinsenden. 
Das ventrale Nervensystem enthält, wie z.B. Ludwig und HAMAnx (1907) uns belehren, überall Ganglienzellen neben den Nervenfasern und im Nervenringe sind die Ganglienzellen bipolar oder multipolar und laufen die Nervenfasern zirkular, aber Bemerkungen iber den Verlauf der Leitungsbahnen habe ich nirgends finden können.

Das apicale Nervensystem ist in dieser Hinsicht noch am besten studiert worden. Ludwig und HAMAN (1907) beschreiben in der zentralen Hohlkugel dieses Nervensystems neben Ganglienzellen dorsal gestellte, zirkulare Nervenfasern und andere, welche aus dem Ringe in die Nerven ausstrahlen, wie sie auch schon von HAMANi (1889) im Jahre 1889 beobachtet worden waren. Die Nerven enthalten neben longitudinalen Nervenfasern bi- und multipolare Ganglienzellen.

Die fünf Radialnerven des apicalen Nervensystems (Fig. 67, n. r.) gehen $\mathrm{zu}$ den fünf Armpaaren und, wenn sie an der Basis der Arme (Fig. 67, A.) angelangt sind, spaltet ein jeder sich in zwei Brachialnerven (Fig. $67, n$. br.). An der Spaltungsstelle werden die beiden Brachialnerven durch eine Querverbindung, „Kommissur" genannt (Fig. 67, c.), verbunden und außerdem durch zwei einander kreuzende Faserbündel, welche das Chiasma (Fig. 67, ch.) bilden (Man beachte, daß die Wörter Kommissur, kreuzen und Chiasma hier nicht in demselben Sinne wie bei den bilateral symmetrischen Nervensystemen anderer Tiergruppen gebraucht werden.) Diese Stelle ist allerdings sehr geeignet unsere Neugier nach dem Lauf der Nervenfasern zu

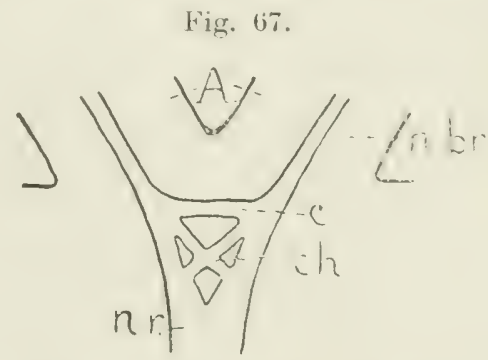

Schema der Verzweigung des Radialnerven der Crinoideen.

Nach Ludwig und Hamann (1907). A. $=$ Arm

$c .=$ Kommissur

$c h$. = Chiasma

$n . b r .=$ nervus brachialis

n. $r .=$ nervus radialis erregen.

HaMANx (1889) hat uns erst mitgeteilt, daß wirklich Fasern des einen Armnerven durch die Kommissur in den anderen übergehen und daß ebenso im Chiasma die Armnerven Fasern tauschen. Später aber [Ludwig und HaMANe (1907)] hat er gesagt, daß die Bündel des Chiasma zwar als solche einander kreuzen, daß aber ihre Fasern sich nicht mischen, in welchem Falle das Wort also eigentlich gar nicht angewandt werden darf, weil so oft zwei Nerven über Kreuz liegen, ohne daß man von einem Chiasma spricht.

Neuerdings hat auch Reichexsperger (1912) das apicale Nervensystem der Crinoiden erforscht. Er beschreibt in den Nerven der Arme Nervenfasern und mancherlei Ganglienzellen, bisweilen in Ganglien vereint. Einige dieser Ganglienzellen senden Fortsätze in die Dorsalfasern, das heißt, in die Muskelfasern, welche die Syzygien oder Armglieder verbinden. Es sind also motorische Ganglienzellen.

Das Nervensystem der Echinoidea bildet wiederum einen Ring um den 
Mund und fünf Radialnerven. Bei den Regulares sind sie aus dem Ekto- und Hyponeuralsystem aufgebaut, bei den Irregulares fehlt aber das Hyponeuralsystem. Es gibt auch ein Entoneuralsystem. Das Nervensystem liegt zum größeren Teil subepithelial.

Die Leitungsbahnen der Seeigel sind uns durchaus nicht besser bekannt als diejenigen der anderen Echinodermen. Daß die Nerven Ganglienzellen und daneben Nervenfasern enthalten, weiß man für die Echiniclen und Spatangen seit HofFMaxi (1871) und Teuscher (1876) hat dies allgemein bestätigt gefunden, ebenso wie Frédérice (1876), aber LUDwig und HaMANx (1904) meinen, da/3 wenigstens die peripherisch gestellten Ganglienzellen HofFManxs Stuitzzellen sind.

Hamaxn (1887) ist anch bei diesen Stachelhäutern in der Hodologie am weitesten fortgeschritten. Die Regulares haben nach ihm zirkulare Nervenfasern im Ringnerven und longitudinale in den Radialnerven. Zwischen den Nervenfasern liegen bipolare oder multipolare Ganglienzellen ganz regellos zerstreut. Oberhalb und unterhalb der Nerven sind Stuitzzellen in einer oder mehreren Schichten zu beobachten, welche Querfasern in die Nerven aussenden. Aus den Nerven gehen Seitennerven hervor, welche ebenfalls Ganglienzellen führen und außerdem trifft man einen Nervenplexus mit Ganglienzellen unter dem Ektoderm:

In der Basis der Stacheln fand Humaxs einen Nervenring mit Ganglienzellen und in der Basis der Sphaeridien einen Nervenring mit zirkularen Nervenfasern. Sinnesnervenzellen wurden beobachtet in den Tastfüß3chen. in den Saugfüßchen und in den 'Tastpapillen der Pedicellarien. Sie alle senden ihre Nervenfortsätze in den subepithelialen Nervenplexus.

Die Irregulares stimmen in manchen Hinsichten mit den Regulares iiberein.

Ludwig und Hamans (1904) melden noch, daß die Ganglienzellen des Hyponeuralsystems im Mundring fünf Ganglien bilden, sodaß die Echinoiden nicht aller Ganglien entbehren. Weitere hodologische Angaben machen sie nicht.

Die letzte Klasse der Echinodermen, die Holothuria, folgt in der Ausbildung ihres Nervensystems dem allgemeinen Grundriß. Es umgibt ein Ringnerv den Mund und fünf Radialnerven gehen daraus hervor. Der Ringnerv sendet periphere Nerven zu den 'T'entakeln, dem Oesophagus, u. s. W: ; die Radialnerven z.B. zu den Fïßchen, der Haut, den Muskeln und zum Mesenterium.

In den Radialnerven kennt man schon sehr lange Nervenfasern und Ganglienzellen, aber über die Natur ihrer äußeren Zellschicht ist viel gestritten worden. Heute kann man woh! mit Recht sagen, daß ihre Zellen keine Ganglienzellen sind, sondern Stiitzzellen, welehe Querfasem in die Nerven senden. Eine bindegewebige Membran teilt die Radialnerven in eine obere und untere Hälfte.

HAMAXX (1883b) hat wiedermm bei den Holothurien Sinnesnervenzellen entdeckt. Sie stehen im Epithel der Füßschen und 'Tentakeln und senden ihre 
Nervenfortsätze in die darunterliegende Nervenfaserschicht, welche Ganglienzellen umfaßt. SExrox (1883) hat übrigens zu gleicher Zeit ganz ähnliche Mitteilungen gemacht.

Bei den Synaptiden beobachtete Havaxx (18836) Sinnesnervenzellen in den vier Tastern der Tentakeln und in den Tastpapillen der Haut. Die Nervenfortsätze der letzteren traten in den Nerven der Papille ein, welcher auch Ganglienzellen führte. Handaxx beschrieb auch Sinnesknospen in den Tentakeln und behauptete, daß ihre Kellen sich in Nervenfasem fortsetzten aber das scheint mir nicht zureichend erwiesen.

Im Ringnerven der Synaptiden sah HAMAxN zirkulare Nervenfaserı mit Ganglienzellen dazwischen.

Hamaxxs Buch ,Beiträge zur Histologie der Echinodermen”, 1884, habe ich leider nicht zu Gesicht bekommen kömmen. Es enthält wahrscheinlich noch andere Angaben als die oben erwähnten, welche uns in Verbindung mit der Hodologie der Holothurien interessieren können.

LuDWIG (1889-1892) erwähnt in seiner zusammenfassenden Arbeit neben manchen oben beschriebenen Tatsachen in der Haut der Holothuria einen subepithelialen Nervenplexus mit Ganglienzellen neben einem ebensolchen tiefer gelegenen Plexus. Es ist, wie so oft in derartigen Nervenplexus, nicht wahrscheinlich, daß hier bestimmte Leitungsbahnen bestehen. Jedenfalls sind sie nicht beobachtet worden, auch nicht von SchNeIDER (1902), welcher bei Synapta diesen Nervenplexus mit eingelagerten Ganglien unter der Haut aufs neue nennt.

Der Leser kann sich jetzt selber ein Urteil bilden, wie äußerst spärliche Resultate die Erforschung der Leitungsbahnen der Echinodermen gehabt hat. Es wird ihm aufgefallen sein, daß selbst die vitale Methylenblau- und die GoLGIsche Methode offenbar keine Erfolge gehabt haben. Tatsächlich ist dies ein wichtiger Grund für den Mangel an genau bekannten Leitungsbahnen, aber zugleich geht daraus die Hoffnung hervor, daß, wenn es einmal den Forschern gelungen ist, die richtigen Modifikationen dieser Methoden auch für die Echinodermen zu entdecken, auch die Hodologie der Echinoder men nicht mehr eine terra incognita sein wird.

\section{ITERATUR.}

1. Cú́xotot (1887), Contribution à l'étude anatomique des Astérides, Archives de Zoologie Expérimentale, 2me série, tome 5 bis (suppl.), 1887.

2. Сயахот (1891), Etudes morphologiques sur les Echinodermes, Archives de Biologic, 'T. $11,1891$.

3. F'RÉdériç (1876), Contributions à l'anatomie et l'histologie des Echinides, Comptes rendus des Séances de l'Aeadémie des Seiences, 'T. 83, 1876.

4. Haterel (1860), Ueber die Augen und Nerven der Seesterne, Zeitschrift für wissenschaftliche Zoologie, $13 \mathrm{~d} .10,1860$.

5. Hanano (1883 a), Die Holothurien und das Nervensystem der Asteriden, Zeits. f. wiss. Zoologie, Bd. 39, 1883.

6. Hamand $(1883 \mathrm{~b})$, Beiträge zur Histologie der Echinodermen, 2te Mitteilung. Zeits. f. wiss. Zoologie, Bd. 39), 1883. 
7. Hamann (1887), Beiträge zur Histologie der Echinodermen, Jenaische Zeitschrift für Naturwissenschaft, Bd. 21, 1887.

s. Harann (1889), Anatomie der Ophiuren und Crinoiden, Jenaische Zeits. f. Naturwiss., Bd. 23, N. F. 16, 1889.

9. Hoffirann (1871), Zur Anatomie der Echiniden und Spatangen, Niederländisches Archiv für Zoologie, Bd. 1, $1871-1873$.

11). Hofminan (1873), Zur Anatomie der Asteriden, Niederl. Archiv f. Zoologie, Bd. $2,1874-1875$.

11. JiCkeli (1888), Vorläufige Mitteilungen iiber das Nervensystem der Echinodermen, Zoologischer Anzeiger, Bd. 11, 1888.

12. LAvge (1876), Beitrag zur Anatomie und Histiologie der Asteriden und Ophiuren, Morphologisches Jahrbuch, Bd. 2, 1876.

13. Ludwig (1878), Beiträge zur Anatomie der Asteriden, Zeits. f. wiss. Zoologie, Bd. $30,1878$.

14. Ludwig (1880), Neue Beiträge zur Anatomie der Ophiuren, Zeits. f. wiss. Zoologie, Bd. 34, 1880 .

15. LUDwrg (1889-1892), Echinodermata, Bronns Klassen und Ordnungen des Thierreichs, Bd. II, Abt. 3, Buch 1, Holothuria, $1889-1892$.

16. Ludwig und Hamann (1899), Asteroidea, Browns Ḱlassen und Ordnungen des Thierreichs, Bd. II, Abt. 3, Buch 2, 1899.

17. Ludvig und Hamany (1901), Ophiuridae, Bronns Klassen und Ordnungen des Thierreichs, Bd. II, Abt. 3, Buch 3, 1901.

18. Lodwig und Hamann (1904), Ehinoidea, Bronss Krlassen und Ordnungen des Thierreichs, Bd. II, Abt. 3, Buch 4, 1904.

19. Ludvig und Hayann (1907), Crinoidea, Bronss Klassen und Ordnungen des Thierreichs, Bd. II, Abt. 3, Buch 5, 1907.

2). R. Mryer (1906), Untersuchungen über den feineren Bau des Nervensystems der Asteriden (Asterias rubens), Zeits. f. wiss. Zoologie, Bd. 81, 1906.

21. W. Pfeffer (1901), Die Sehorgane der Seesterne, Zoologische Jahrbiicher, (Abt. Anat.), Bd. 14, 1901.

2.2. Reicmessperger (1912), Beiträge zur Histologie und zum Verlauf der Regeneration bei Crinoiden, Zeits. f. wiš. Zoologie, Bd. 101, 1912.

23. K. C. ScHNeIder (1902), Lehrbuch der vergleichenden Histologie der 'Tiere, 1902.

21. Seron (1853), Das Nervensystem der Holothurien, Jenaische Zeits. f. Naturwiss, Bd. 16, N. F. 9, 1883.

2.). Teuscher (1876), Beiträge zur Anatomie der Echinodermen, Jenaische Zeitschrift fïr Naturwissensehaft, Bil. 10, N. 1: :3, 187 (i. 


\section{ARTHROPODA.}

Das Nervensystem der Arthropoden hat gewisse Eigentümlichkeiten mit demjenigen der Würmer gemein. Nan begegnet auch bei den Gliedertieren einem Hirnganglion, einem unteren Schlundganglion und einem Bauchstrang, welcher mehrere Ganglien enthält. In diesem letzteren sind die Ganglien, welche die peripheren Nerven entsenden, wiederum durch Querverbindungen oder Kommissuren und Längsverbindungen oder Konnektive verknüpft. Obgleich die Konnektive sehr oft von den Autoren ebenfalls Kommissuren genannt werden, so werde ich dies um Verwechselung vorzubeugen, dennoch niemals tun, sondern immer der Nomenklatur MrLwe Edwards folgen, welcher nach VIALLANes (1887) und KüHxLe (1913) schon im Anfang des neunzehnten Jahrhunderts die Konnektive den Kommissuren gegenübergestellt hat.

Die Kommissuren und Konnektive des Bauchstranges sind bei manchen Tieren so stark verkürzt, daß sie von außen unsichtbar sind und nur innere Fasersssteme der Ganglienkomplexe bilden. Hirnganglion und unteres schlundganglion sind immer durch die Schlundkonnektive verbunden, weshalb auch die Arthropoden einen Schlundring besitzen.

Weil es auch hier nur meine Absicht ist, die uns bekannten Reizleitungsbahnen des Nervensystems zu beschreiben, will ich es unterlassen eine allgemeine Beschreibung der mikroskopischen Anatomie des Nervensystems zu liefern. Meistens sind die Bahnen der verschiedenen Ganglienzellgruppen und Fasergebiete (Neuropileme), welche man in den Ganglien unterschieden hat, doch nicht bekannt und eine solche Erörterung würde nicht nur großen Raum einnehmen und manche Figuren fordern, sondern auch würden die hodologischen Angaben sich ganz zwischen den anderen verstecken, während sie hier gerade in den Vordergrund gestellt werden sollen. Wer sich für die Anatomie des Nervensystems interessiert, wird vorzüglichen Einzeldarstellungen in manchen der von mir in Betracht gezogenen Arbeiten begegnen. Ich werde hier nur soviel darüber sagen als mich zum richtigen Verständnisse der Wege der Nervenfasern unumgänglich dünkt.

An dieser Stelle sei schon erwähnt, daß das Hirnganglion der meisten Arthropoden sich in drei Abschnitte teilen läßt: das protocerebrum, welches die beiden lobi optici trägt, das deuterocerebrum, welches die Antennalganglien oder lobi olfactorii enthalt und das tritocerebrum. Die mikroskopi- 
sche Anatomie des protocerebrum und der lobi optici wird später an geeigneter Stelle beschrieben werden. Hier sei nur bemerkt, daß bei allen Tracheaten corpora pedunculata (globuli, Pilzkörper) im protocerebrum aufgefunden werden, welche allen Crustaceen abgehen, während hier im lobus opticus die medulla terminalis immer vorhanden ist, welche ihrerseits den Tracheaten fehlt. BeLloxar hat als erster diese beiden Hirnteile wenigstens teilweise homologisiert. Die Antennalganglien des deuterocerebrum sind bei allen Arthropoden mit eigentümlichen Nervenfaserknäueln (kleinen Neuropilemen) ausgestattet, welche glomeruli olfactorii genannt werden, nicht nur weil sie äußerlich mit den glomeruli olfactorii der Vertebraten große Uebereinstimmung zeigen, sondern auch weil sie aller Wahrscheinlichkeit nach zum System der Riechbahnen gehören. So lehren uns z.B. Belloncr (1883) und Rads (1902). Das tritocerebrum ist bei den Crustaceen das Gebiet des zweiten Antennalnerven, bei den 'I'racheaten jedoch, wo die zweite Antenne fehlt, das Zentrum des Tritocerebralnerven.

Bevor ich die Besprechung der einzelnen Gruppen der Arthropoden anfange, möchte ich zwei Fragen behandeln, welche allem Anschein nach bei sämtlichen Gliedertieren die gleiche Beantwortung erhalten sollen. Es sind die Fragen nach der Innervierungsweise der Augen und der Simneshaare des Körpers.

Meines Wissens ist LEYDrG (1855) der erste Forscher gewesen, welcher sich eine bestimmte Meinung betreffs der Innervierungsweise des Gliedertierauges gebildet hat und zwar sagt er, daß in den zusammengesetzten Augen der Crustaceen die Opticusfasem kontinuirlich in ,Nervenstäbe” übergehen. Wir werden bald erfahren, raß in der Retina aller Arthropodenaugen Sehzellen vorhanden sind, welche den 'lypus der Sinnesnervenzelle haben und man könnte meinen, daß3 LEYDIG mit ,Nervenstäben" diese Sehzellen bezeichnet und ganz das Richtige getroften hätte. Dem ist aber nicht so. Wahrscheinlich hat LEYDIG, wie M.ScIULT\%E (1867) bemerkt, den Kristalliegel des Ommatidium als das Nervenende betrachtet und sich diesen in kontinuirlichem Zusammenhang mit den Rhabdomeren gedacht, welche, wic bekannt, jede für sich ein 'Teil (das Stäbchen) der Retinulazelle oder Sehzelle sind.

Es war also ein Schritt vorwärts als M.Schultze (1867) den Kristallkegel als selbständiges Gebilde erkannte und, das Richtige der LEYDiGschen Beobachtungen, den kontinuirlichen Zusammenhang der Sehnervenfasem mit den Retinaelementen, beibehaltend, den Zusammenhang der Nervenfasem mit den Rhabdomeren proklamierte. SchULTZE hat iiherdies dasselbe fuir die zusammengesetzten Augen aller Arthronoden, nicht blols der C'rustacren behauptet.

Aber erst Grexacher $(1879)$, 1850) hat infolge seiner glänzenden und vielgelobten (Intersuchungen eingesehen, dals das Retinatement aller Arthropodenaugen, der zusammengesetzten, sowie der rinfachen (()zellen) eine Zelle ist, welche ein Stäbchen trägt und sich basal in eine optische Nervenfaser fortsetzt. Er hat also die Sehzelle ïberall als Sinnesnervenzelle erkannt.

lch werde die einzelnen Beobachtungen, worauf Grexicher seine Mei- 
nung grïndet, bei den betreffenden Ordnungen der Arthropoden ezörtern, hier Iu noch darauf hinweisen, daß GRENACHer (1879) zu einer Zeit, wo der Beweis fast völlig fehlte, mit seltenem Scharfsinn eingesehen hat, daß die Sehzelle im ganzen Tierreich von ektodermaler Herkunft und überall nach demselben Typus und zwar demjenigen der Sinnesnervenzelle gebaut ist. Grenacher nennt neben den Arthropoden die Coelenteraten, Würmer, Mollusken und Vertebraten. Betreffs der Echinodermen war er noch im Ungewissen, aber, wie wir oben gesehen haben, schließen sie sich ganz den anderen Tieren an. Grenacher zieht daraus den berechtigten Schluß, daß das Retinaelement (oder die lichtempfindliche Sinnesnervenzelle, wie ich sagen würde) phylogenetisch sehr alt ist.

Die Grenacherschen Anschauungen fanden sofort Bekämpfung von der Seite Grabers (1880). Graber konnte in den ocelli der Arachnoideen und Myriapoden keine Sehzellen, wie Grenacher sie entdeckte, wiederfinden und behauptete, daß die Retinazellen Grexachers mehrere Zellen, worunter eine bipolare Ganglienzelle enthielten. Grenacher hat auf diesen Angriff geantwortet mit seiner Arbeit über die Augen der Myriapoden (1880) und seine Behauptungen aufrecht erhalten und weil GRABER auch später nicht Recht bekommen hat, soll diese kurze Erwähnung seiner Arbeit genügen.

Auch PatTen (1886) hat sich hinsichtlich des Arthropodenauges GrenaCHER gegenübergestellt. Er sieht auch im Komplexauge der Arthropoden Retinophoren, wie sie uns schon bei den Mollusken begegnet sind. Dort habe ich die PatTenschen Anschauungen ausführlich besprochen und bin nach dem Beispiel so vieler anderer Autoren zu ihrer Unhaltharkeit gelangt. Hier enthalten sie prinzipiell dasselbe und ich kann mich deshalb kurz fassen, zumal, auch hei den Arthropoden PatTex in den Beobachtungen anderer Forscher keine Stiitze findet.

Patten ist der Meinung, daß im Ommatidium die Kristallkegelzellen der anderen Autoren, welche er Retinophoren nennt, die eigentlichen Sehzellen sind und daß dieselben sich auf der einen Seite in die Rhabdomeren fortsetzen. Die Rhabdomeren sind also nach ihm nicht Teile der sieben Retinulazellen, wie man jetzt im Ommatidium die Grenacherschen Sehzellen nennt, und die Retinulazellen betrachtet er als Pigmentzellen. Jedes Ommatidium enthält zwei oder vier Retinophoren, welche (und das interessiert uns hier besonders) durch Nervenfasern umsponnen und durchsetzt werden und, wo sie verschmelzen, einige Nervenfasern als axiale Nervenfasern in sich aufnehmen. Es würden also keine Sinnesnervenzellen, sondern wahre Sinneszellen sein, aber, wie gesagt, ich glaube, daß PATTEN sich irrt und keinen Glauben verdient.

Später hat PATTEN (1890) seinen älteren Angaben hinzugefügt, daß bei einigen Insekten die Kristallkegelzellen sich zwar in Fasern, wahrscheinlich Nervenfasern, fortsetzen, aber nicht kontinuirlich in die Rhabdomeren übergehen und in diesen Fällen setzen sich auch die Retinulazellen, welche sich jetzt den Rhabdomeren anschließen nach innen in Nervenfasern fort. So wenigstens verstehe ich die jetzt sehr verwirrten Einsichten Pattens. Ueber die Weise der Innervation des Ommatidium kommt man eigentlich gar nicht ins Reine. 
Nicht nur in den zusammengesetzten Augen der Arthropoden, auch in den ocelli meint PATTEN Retinophoren zu sehen. Wenigstens hat er solche: für die Larven von Acilius, einen Wasserkäfer, behauptet (PAtTen 1888). Ich hege hier denselben Zweifel.

Wie Patten (1890) meinen kann, das Ommatidium der Arthropoden sei einer haartragenden Sinnesknospe vergleichbar, kann ich nur mitteilen, wenn ich die Sinneshaare der Gliedertiere besprochen habe (S. 206).

VIALLANes (1892a) hat sich im allgemeinen gegen die Retinophoren Pattens ausgesprochen und ihr Dasein bei den Arthropoden verneint. Seine Mitteilungen lassen sich wohl mit dem GrExACHERschen Befund in Uebereinstimmung bringen, aber, daß die Retinulazellen des Ommatidium Sinnesnervenzellen sind, hat er nicht ganz klar gesehen. Sagt or doch, daß bei Palinurus vulgaris, und auch bei anderen Crustaceen und Inseliten, in jede der sieben Retinulazellen ein Neurit eindringt und sich mit der Rhabdomere verbindet, statt zu sagen, daß jede Retinulazelle sich in einen Nervenfortsatz verjüngt. Viallanes hat jedenfalls in dieser Arbeit seine fruhere Ansicht, daß jedes Ommatidium nur eine Nerveufaser verläßt, aufgegeben.

Die Untersuchungen GrExACHERs wurden, außer vielen Einzelangaben, welche später Erwähnung finden werden, durch zwei vielumfassende Arbeiten völlig bestätigt. REDIKORzew (1900) sah in den Ozellen der Inseliten jede Retinazelle basal in eine Nervenfaser übergehen. Seine vorzüglichen Figuren erweisen, daß er Sinnesnervenzellen beobachtet hat. Außerdem belehrt uns Redikor\%.Ew, daß die Nervenfasern der Retinazellen den nervus ocellaris bilden, welcher zum Hirnganglion geht. Er beschreibt uns also wenigstens teilweise eine Leitungsbahn.

Hesse (190l) hat ebenso wie Grenacher Ozellen und zusammengesetzte Augen vieler Arthropoden untersucht und dabei wahrgenommen, daßs sie alle nach demselben Plan gebaut sind und die Sehzellen selbst in Nervenfasern iibergehen, also Sinnesnervenzellen sind.

Ich schließe mich in meinen weiteren Betrachtungen völlig den Ansichten Grexarhers und Hesses an.

Wer sich ïber die Innervierungsweise der über den Körper zerstreuten sinneshare dex Arthropoden eine klare Vorstellung zu bilden wïnscht, findet große Sehwierigkeiten. Die Angaben darïber gehen sehr auseinander. Man könnte meinen, daß dies seine Ursache hätte in der Verwirklichung verschiedener Innervierungsweisen bei verschiedenen Tierarten oder bei verschiedenen Arten ron Simneshaaren. Die Sache liegt aber anders. Von den vielen Autoren, welche iiber diesen P'unkt berichtet haben, meldet nur Lowse (1890-1892) (S. 3-9) versehiedenartige Innervierungsweisen (iiber BETH: (1S!)(i) siehe S. 205) und mancher generalisiert seinen Befund und behauptet; die von ihm beobachtete fnnervierungsweise sei die einzige. Wenn dies der Fall ist und die Meinungen der Forscher gehen dennoch auseinander, so mul3 man daraus schließen, daß einige Autoren sich irren und versuchen die Üntersuchungen gegeneinander abzuwägen, um so zur Wahrheit zu gelangen.

Bevor ich das tue, will ich die drei Ansichten, zwischen welchen wir zu wählen haben nebeneinander setzen. 
Die Sinneshaare der Arthropoden, welche sich an den mannigfaltigsten Körperteilen befinden können, von denen ich aber hier nachdriicklich die Sinneshaare der Statocysten, Halteren und Gehörorgane ausschließe und welche oft, aber nicht immer, Riech- oder Tastorgane sind, bestehen aus einem chitinösen und einem protoplasmatischen Teil. Der chitinöse Teil (Fig. 68,c.) schließt sich der Cuticula der Haut an. Er hat gar nicht immer die Gestalt eines langen, dünnen Haares, aber kann kegel-, keulen-, flaschen- oder blasenförmig sein oder noch fremdartigere Gestalt besitzen, was sich gewöhnlich im Namen des Haares abspiegelt. Für unseren Zweck ist solches gleichgültig.

Der chitinöse Teil des Sinneshaares ist meistens an seiner Basis ein wenig eingeschniirt und immer hohl. Die soliden Haare scheinen niemals Sinneshaare zu sein. In der Höhlung liegt ein protoplasmatischer Fortsatz der Zelle, welche das chitinöse Haar gebildet hat, der Haarzelle, Haarmutterzelle, Matrixzelle oder trichogenen Zelle also (Fig. 68, h. z.). Der Zellkörper mit dem Kerne dieser Haarzelle ist unter dem Haare $\mathrm{zu}$ finden. Oft ist es der Fall, daß mehrere Haarzellen das chitinöse Haar gebildet haben und alle einen Fortsatz in das Haar schicken, aber, weil solches die Sache nur kompliziert und mit dem Prinzip der Innervierung des Haares nichts zu schaffen hat. habe ich in meinem Schema Fig. 68 den eiufacheren Fall gewählt.

A priori kann man betreffs der Innervierung des Haares w'enigstens drei Möglichkeiten

Fig. 68 .

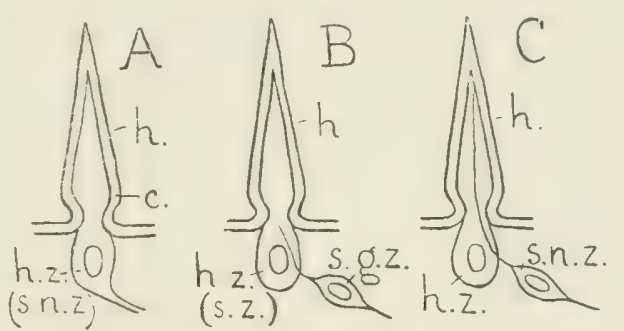

Schema der drei Ansichten der Innervierung des Sinneshaares.

A; die Haarzelle ist eine Sinnesnervenzelle

$B$; die Haarzelle ist eine wahre Sinneszelle

C; neben der Haarzelle enthält das Haar eine Sinnesnervenzelle

c. = chitinöses Haar oder Cuticula

$h_{.}=$Haar

h.z. = Haarzelle

s. g. $z .=$ sensibele Ganglienzelle

s. n. $z$. = Sinnesnervenzelle

s. $z$. = Sinneszelle

erwarten und wir werden bald sehen, daß alle drei ihre iiberzeugten Verteidiger gefunden haben. Die Haarzelle selbst könnte nicht bloß die Mutterzelle des Haares, sondern auch die sensibele Zelle sein, welche den Reiz empfinge. Dabei wäre aber noch zweierlei möglich. Erstens könnte die Haarzelle selbst eine Sinnesnervenzelle sein, das heißt, selbst basal einen Nervenfortsatz tragen, wie dies Fig. 68, A ausdrückt. Dann wäre die Haarzelle die einzige Zelle, welche auf das Haar Beziehung hätte. Zweitens könnte die Haarzelle eine wahre Sinneszelle sein, inuerviert durch den peripheren Fortsatz einer sensibelen Ganglienzelle. Die Forscher, welche dies behaupten, sehen die sensibele Ganglienzelle in der Nähe der Haarzelle und deren peripheren Fortsatz sehen sie sich dem Körper der Haarzelle anlegen oder darin eindringen, aber niemals sich in die Spitze des Haares selbst begeben (Fig. $68, \mathrm{~B})$.

Drittens (Fig. 68, C) wäre es möglich, daß dic Haarzelle licine nervöse 
Funktion hätte und der Reiz unmittelbar durch den peripheren Fortsatz einer oder mehrerer nervöser Zellen (Fig. $68, \varepsilon_{n} n . z$.) aufgenommen würde. Die Autoren, welche dies behaupten, sind dariiber einig, daß in diesem Falle der periphere Fortsatz der nervösen Zelle unverzweigt ist und in das Haar selbst bis zur Cuticula eindringt. Die nervöse Zelle wäre also eine Sinnesnervenzelle mit einem ein wenig gesenkten Körper und ebenso wie die Haarzelle eine Hypodermiszelle, aber keine sensibele Ganglienzelle mit freier Nervenendi. gung, deren peripherer Fortsatz nicht unverzweigt bis zur Cuticula schreiten würde. In diesem Falle dränge die Sinnesnervenzelle also ebenso in die Höhlung des chitinösen Haares hinein, wie eine zweite Haarzelle es tun würde, welche, wie gesagt, oft vorhanden ist.

Man wird schon von vornherein einsehen, daß nur ganz vorzügliche histologische Bilder uns zu urteilen gestatten, ob wir in einem konkretem Falle mit einer sensibelen Ganglienzelle zu tun haben, deren Fortsatz mit der Haarzelle verbunden ist und nicht bis zum Chitin vordringt (B) oder mit einer Sinnesnervenzelle, deren Fortsatz von der Haarzelle unabhängig ist und wohl bis zum chitinösen Haare vordringt (C). Daher die weit auseinander gehenden Meinungen und die große Schwierigkeit zu bestimmen, wer Recht hat. Doch ist die Sache sehr wichtig, weil, falls das Schema Fig. 68, B richtig ist, wir hier zum ersten Male bei den Evertebraten einer wahren Sinneszelle, innervicrt durch eine sensibele Ganglienzelle, begegnen würden.

Ich werde jetzt die Meinungen der verschiedenen Autoren kurz auseinandersetzen. Speziellere Angaben werden, wo nötig, später folgen. Man könnte vielleicht meinen, es wäre ganz bequem zu entscheiden, ob ein gewißer Forscher in den Sinneshaaren nur Haarzellen (ihrer Art nach Sinnesnervenzellen Fig. 68, A) unterscheide, oder daneben eine zweite Kategorie nervöser Zellen (B und C). Dem ist aber nicht so, und zwar aus zwei Gründen. Die älteren Autoren rechnen noch nicht mit dem möglichen Dasein zweier Zellarten bei einem Sinneshaare, die neueren scheinen bisweilen das Dasein der Haarzellen neben den Sinnesnervenzellen so sehr als selbstverständlich zu betrachten, dal3 sie die ersteren gar nicht erwähnen. Sehr viel trägt dazu bei, daß die Golgische oder die Methylenblau-Methode, welche gerade die nervösen Zellen am deutlichsten sichtbar machen, sehr oft nur eine einzige Zelle zu jedem Haare färben, auch wenn mehrere nervöse Zellen oder Haarzellen da sind. Da bleibt es unaufgeklärt, ob der ungefärbte 'Teil der Lichtung des Haares durch Fortsätze von Sinnesnervenzellen oder von Haarzellen ausgefiullt wird.

lch glaube daher besser zu tun alle Autoren, welche in deniSinneshaaren Simnesnervenzellen erkennen (besonders die älteren Autoren nennen diese Zellen oft Ganglienzellen oder Sinneszellen, weil ihnen der Begrifi der Sinnesnervenzelle noch abgeht) nebeneinanderzustellen - sei es, daß sie daneben nicht-nervöse Haarzellen erwähnen oder nicht - und sie den Forschern, welche Haarzellen und diese immervierende sensibele Ganglienzellen (Fig. 68, B) anerkennen, gegenuiberzustellen.

Vom Ratu ist ohne Zweifel derjenige gewesen, welcher sich am meisten bestrebt hat, darzutun, dal3 Simnesnervenzellen allen Simeshaaren der Arthropoden zuzurechnen sind. Seine Beschreibungen und Mbbildungen sind 
sehr überzeugend und wirklich haben sich manche Forscher Vor RATH angeschlossen; ob mit Recht werden wir später sehen.

In seiner ersten größeren Arbeit hat Voм RATH (1888) besonders die Innervierung der Hautsinnesorgane der Insekten untersucht. Er entdeckte bei verschiedenen Insekten der Ordnungen der Thysanuren, Orthopteren, Neuropteren, Trichopteren, Hemipteren, Dipteren, Lepidopteren, Coleopteren und Hymenopteren, also ganz allgemein, unter jedem Sinneshaar eine oder mehrere Zellen, welche früher Ganglienzellen genannt wurden, aber nach VoM RATH Sinneszellen heißen sollen, weil sie selbst den Reiz empfangen. Die Zellen senden einen Fortsatz in das Haar und ihr zweiter, zentraler Fortsatz ist eine Nervenfaser. Jetzt würden wir sie also Sinnesnervenzellen nennen.

Vom RATH erzählt uns, wie die Sinnesnervenzellen durch Neurilemmazellen umgeben sind, welche sich bis zur Haarbasis fortsetzen, aber nicht in das Haar eindringen. Es werden also keine Haarzellen neben den Sinnesnervenzellen erwähnt und das Schema Fig. 68, A würde passend sein, aber, weil Vou RATH in seinen späteren Werken allerdings Haarzellen neben Sinnesnervenzellen beschreibt und er immer betont, daß die Verhältnisse bei allen Arthropoden die gleichen seien, glaube ich, daß Vом RAтн vielleicht auch hier Haarzellen neben Sinnesnervenzellen anerkannt sehen möchte.

Bei Crustaceen begegnete Vom Rath (1891) denselben Verhältnissen. Unter jedem Sinneshaare ist eine Gruppe Sinnesnervenzellen. Die zentralen Fortsätze dieser Zellen bilden den Nerven, die peripheren dringen in das Haar ein und bilden zusammen den "Terminalstrang" darin. Außerdem begeben sich die Fortsätze einiger Matrixzellen (Haarzellen) ins Innere des Haares. Die Lage würde also durch das Schema Fig. 68, C wiedergegeben werden können. Nach Vom RATH weichen die sogenannten freien Hörhaare Hensexs darin nicht $a b$ von den anderen Sinneshaaren. Weil ich später auch die Innervierung der Haare der Gehörorgane der Arthropoden besprechen möchte, will ich hier bemerken, daß die sogenannten freien Hörhaare nichts mit Gehörorganen gemein haben.

VoM RATH (1895 und 1896) hat durch Anwendung der Methylenblauund der GoLgI-Methode die Bestätigung seiner früheren Anschauungen erhalten und dieselben nicht nur für Crustaceen und Insekten, sondern auch für Myriapoden und Arachniden gültig befunden. Voм RATH (1895) wendet jetzt selber das Wort Sinnesnervenzelle statt Sinneszelle an, und betont nachdrücklich, daß diese Zellen keine sensibelen Ganglienzellen sind, welche mit ihrem peripheren Fortsat\% Simeszellen innervieren (ako Fig. (ss. (' und nicht B).

Von RAтH hat Vorgänger gehabt, welche mehr oder weniger dentlich dasselbe behaupteten, wie er. Oft wird in der Literatur.LEYDIG als der erste genannt, welcher eine richtige Vorstellung von der Innervierung der Sinneshaare hatte und zwar soll er dieselbe bei der Larve von Corethra plumicornis im Jahre 1851 erworben haben. Nachschlagen seiner Arbeit hat mich überzeugt, daß solches nicht der Fall sein kann. Im selben Jahre hat LEYDiG (1851) einen Aufsatz über die branchiopoden Crustaceen Artemia salina und Branchipus stagnalis publiziert. Er sagt darin, daß jede Nervenfaser der Nerven, welche die Borsten der Kopfhörner des Branchipus-Weibchens und 
die Borsten des Thorax und des Abdomen innervieren in eine bipclare Ganglienzelle ïbergeht, deren peripherer Fortsatz zwischen einer an der Basis der Borsten gelegenen Zellgruppe verschwindet.

Ob die Zellen dieser Zellgruppe, womit LeYDIG nur die Haarzellen gemeint haben kann, selbst durch die peripheren Fortsätze der bipolaren Ganglienzellen innerviert werden (Schema B) oder nur die Fortsätze der bipolaren Zellen zwischen sich fassen (Schema C), wird damit nicht entschieden und freilich würden die Untersuchungsmethoden LEYDigs eine solche Entscheidung auch nicht gestatten. Obgleich also LEYDIG hier dasjenige, was er beschrieb, richtig beobachtet hat, hat er nicht genug beobachtet um die Innervationsweise der Sinneshaare genau erkannt zu haben.

Viele Jahre später hat LEYDIG (1886) abermals die Innervation der Sinneshaare der Arthropoden besprochen, ohne zu einer genaueren Angabe zu gelangen.

Während LEXDIG nur mit einer fantastischen Ergänzung seiner Angaben als älterer Geistesverwandter VOM RATrs betrachtet werden kann, hat jedenfalls Claus (1875) schon vor ihm das gleiche gesehen. Claus schildert uns bei verschiedenen Crustaceen aus manchen Gruppen Sinneshaare, welche von mehreren Haarzellen gebildet werden. Neben diesen Haarzellen befindet sich eine bipolare „Ganglienzelle" (richtiger Sinnesnervenzelle) mit einem zentralen Fortsatz, welcher in den Nerven eintritt und einem peripheren Fortsatz, welcher als ,Achsenfaden" das Haar durchzieht. Das ist also genau die Lage, welche das Schema Fig. 68, C wiedergibt. Auch später ist CuAUs der gleichen Lage bei den Tastborsten der Daphniden (1576) und der Copepoden (1891) begegnet.

Die Meinung Hausfirs (1880) scheint ebenfalls mit den Vou RATuschen Ansichten in Einklang gebracht werden zu können. Sagt er doch, daß die Riechzellen der Geruchsorgane (Riechhaare) in den Antennen der Insekten (Orthoptera, Diptera, Lepidoptera und Hymenoptera) sich in Nervenfasem fortsetzen. Während HAUSER uns zu belehren versucht, daß die Riechhaare der Insekten nach dem Schema Fig. 68, A gebaut sind und eine Sinnesnervenzelle enthalten, welche nach ihm eine große Zahl Nukleolen aufweist, haben spätere Forscher dargetan, wie sehr HAuser sich irrte. Schon Bütscrul (1885) hat sich gegen HAUSER gewandt und überzeugend gezeigt, daß HAUSER mit seiner Sinnesnervenzelle mit den vielen Nukleolen eine Gruppe von Ganglienzellen, jede mit ihrem Kern, gemeint hat, wovon ihm die Zellgrenzen verborgen blieben. Auch wirft er ihm vor, daß ihm das Dasein zweier Zellarten bei den Simneshaaren entgangen ist und auch darin hat BüTscini Recht, denn er konnte die beiden Zellarten (wie sie auch Fig. 68, B und C zeigen) unterscheiden in den Riechhaaren der Antennen von Vespa crabro und der Chilognathen oder Diplopoden.

Nach BüтscmLI gehörte zu jedem Sinneshaare eine Gruppe bipolarer Sinnesnervenzellen. Ihre peripheren Fortsïtze wiirden das Haar bilden und ihre zentralen Fortsätze kontinuirlich übergehen in die Zellen eines naheliegenden Ganglions, woraus auch der Nerv hervorginge. Es wïrde also das Schema Fig. 68, A verwirklicht sein mit dem Unterschiede, daß3 sich der Sinnes- 
nervenzelle noch eine periphere Ganglienzelle anschlösse. Auf Grund gar mancher späteren Untersuchungen kann ich BïTschur darin nicht Recht geben. Seine Sinnesnervenzellen sind die Haarzellen anderer Autoren, welche aber keinen zentralen Fortsatz besitzen. Daß sie leicht einen solchen vortäuschen können, geht aus der Fig. 68, B oder C hervor, wo die Bütschlischen Ganglienzellen durch die sensibele Ganglienzelle oder die Sinnesnervenzelle repräsentiert sind, welche ihren peripheren Fortsatz neben die Haarzelle legen. Also hat auch BüTscHuI nicht die wahre Innervationsweise der Sinneshaare erkannt und wollen wir dieser Sache weiter nachforschen.

KüNCKEL und GAZAGNAIRE (1881) beschrieben im allgemeinen bei den Insekten unter den Sinneshaaren bipolare Sinnesnervenzellen (,,cellules nerveuses" sagen sie) mit zentralem Nervenfortsatz und peripherem Fortsatz im Haare. Das Schema Fig. 68, A kann also auf ihre Anschaumgen angewandt werden und, weil sie keine Fchler gemacht haben, wie HAUsER und BüTSCHLI, liegt kein Grund vor, sie nicht als übereinstimmend mit VoM RATH und dann auch als dessen Vorgänger zu betrachten.

Auch Ruland (1888) hat zu gleicher Zeit, als Vom Rath anfing seine Ansichten zu publizieren, gewissermaßen übereinstimmende Gedanken geäußert. Er studierte verschiedene antennale Sinnesorgane der Insekten. Die Innervierung der Tasthaare blieb im Ungewissen. Unter jedem Riechhaare hingegen fand er ein ,Ganglion” mit bis ins Haar gehenden Nervenfasern. Es ist dies wohl eine Sinnesnervenzellgruppe mit ihren peripheren Fortsätzen (wie im Schema Fig. 68, A oder C). Eine ähnliche Innervation besaßen einige stark abgeänderte Haare, welche als Riechhaare betrachtet werden, aber nach RuLAND nur Gehörorgane sein können. Die Angaben Rulaxds stehen jedenfalls sehr hinten denjenigen Voм RatHs zurück.

So weit über die Autoren, welche schon in besonderen Fällen eine Innervierung zu sehen glaubten, welche später Vow RATH als bei allen Arthropoden zutreffend dargestellt hat. VOM RATH haben sich aber nachher noch andere Forscher angeschlossen. So schon bald R fizius (1895). Retzius (1890) hatte zuvor bei Palaemon squilla, einer decapoden Crustacee, in der Haut sensibele Nervenfasern beschrieben, welche verzweigt die Chromatophoren umschlungen oder bis in und unter die Sinneshaare vordrangen. Er konnte damals, obgleich er die Methylenblau-Methode anwandte in diesen Nervenfasern keine peripheren Zellkörper entdecken. Als nun Vом RATH seine Beobachtungen publizierte, hat Rerzius (1895) abermals mit Hilfe der GoLGischen und Methylenblau-Methode die Innervation der Sinneshaare erforscht, seine früheren Angaben als fußend auf mangelhaft gefärbten Präparaten widerrufen und sich mit Vow RATH einverstanden erklärt. Er erkannte jetzt bei Palaemon und anderen Crustaceen unter den Sinneshaaren bipolare Sinnesnervenzellen mit unverzweigten peripheren Fortsätzen, welche oft, aber nicht immer, in das Haar eindrangen. Letztere Bemerkung ist sehr wichtig, weil- Retzius, obgleich er sich der Vox Ratischen Meinung anschließt, welche im Schema Fig. 68, C Ausdruck findet, sich doch vielleicht auch nicht gégen das Schema B sträuben wiirde. Ich lromme hierauf noch zurück. Viele Jahre später hat Retzrus (1906) abermals Simesnervenzellen in Sinneshaaren 
beschrieben, jetzt in den Tastborsten der ersten Antenne der Daphniden. Auch Bethe (1895b) gesellt sich Vom Rath bei, als er in den Antennen und Schwanzanhängen von Mysis, Pagurus und Crangon, Crustaceen also, Simnesnervenzellen beschreibt mit Fortsitzen, welche in Sinneshaare eindringen.

E. Holmaren (1896) hat der Innervierung der Sinneshaare der Raupe von Sphinx ligustri die gleiche Deutung, wie Vom RATH gegeben, denn er bildet in diesen Haaren Sinnesnervenzellen $a b$ und in seiner Beschreibung wendet er dafür auch des Wort Sinnesnervenzelle an. Wir brauchen also nicht zu zweifeln.

Schenr (1903) hat bei vielen Lepidoptera und Hymenoptera verschiedenartige Sinneshaare der Antennen untersucht und immer darin Sinnesnervenzellen gefunden. Darüber lassen Text und Figuren keinen Zweifel übrig. Weil er niemals neben diesen Sinnesnervenzellen nicht-nervöse Haarzellen erwähnt, bekommt man den Eindruck, daß er nur eine Zellart erkennt, also wie im Schema Fig. 68, A.

Schröpfr (1908) hat die Innervation der Sinneskegel und Sinnesborsten der Skorpionskämme nicht genau ermitteln können, aber die dort ebenfalls vorhandenen, einzelligen Sinnesorgane bestehen nach ihm aus einer Sinnesnervenzelle, welche sich unmittelbar in eine Nervenfaser fortsetzt.

ScHöx (1911) hat ebenfalls bei cinigen Ameisenarten Sinnesnervenzellen in manchen Typen von Sinneshaaren (Sinneshaaren, Membrankanälen und Sinneskegeln) beobachtet. Immer drang ihr peripherer Fortsatz ins Haar hinein und ihr zentraler war eine Nervenfaser des sensibelen Nerven. Auch Sснӧx erwähnt keine Haarzellen neben den Sinnesnervenzellen, vielleicht, weil er es für überflüssig hält, vielleicht, weil er sie nicht gesehen hat. Ich will deshalb nicht entscheiden, ob seine Ansichten durch das Schema Fig. 68, A oder $\mathrm{C}$ wiedergegeben werden können.

Alle bis jetzt genannten Autoren stimmen jedenfalls darin überein, daß sie in den Sinneshaaren der Arthropoden Sinnesnervenzellen erkennen. Eine Gruppe anderer Forscher erkennt keine Sinnesnervenzellen, sondern immer Haarzellen, welche durch die peripheren Fortsätze sensibeler Ganglienzellen innerviert werden (Fig. 68, B), wobei als Kriterium gelten liann, daß dieser periphere Fortsatz zwar zur Haarbasis, aber nimmer durch das ganze Haar

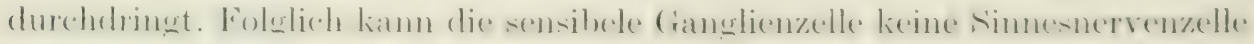
genannt werden und ist die innervierte Haarzelle als eine wahre Sinneszelle zu betrachten.

LAxDoIS (1868) meldet schon im Jahre 1868, daß Tasthaare und andere Sinneshaare der Antemen einiger Kafer innerviert werden durch darunter gelegene bipolare Ganglienzellen, deren peripherer Fortsatz bis zur Haarbasis vordringt. Da wenigstens die größeren dieser Haare, hohl" sind, kann man vermuten, daß LAx̃oIs die Harzellen, welche diese Hare mit ihren Fort sätzen ausfüllen, übersehen hat. In diesem Falle hätte LAxnors die sensibelen Ganglienzellen, welche die Haare innervieren, beobachtet, aber die innervierten Sinneszellen wären ihm entgangen. Andrerseits ist es nicht ausgeschlossen, daß Laxinors, zumal bei den scheinbar soliden kleinen Haaren Sinnes- 
nervenzellen als bipolare Ganglienzellen betrachtet hat, weil damals die Sinnesnervenzellen noch sehr wenig bekannt waren. Es läßt sich nicht ganz bestimmt sagen, welche Ansichten LAxDois selbst gehabt hat (vergl. S. 300).

Vielleicht ist auch MAX WEBER (1881) ein Forscher gewesen, welcher uber die Innervierung der Sinneshaare eine andere Meinung hatte, als die bis jetzt besprochene. LEYDIG (1886) jedenfalls nennt seine Ansichten abweichend. Die WEBERschen Angaben beziehen sich nur auf die Trichonisciden, auf Crustaceen also, aber hier zeigten ihm Goldchlorid-Präparate, daß jedes Tasthaar durch eine Nervenfaser innerviert wird, welche Fortsatz einer multipolaren Ganglienzelle zu sein sich ergibt. Nichts läßt uns vermuten, daß WEBER Sinnesnervenzellen erkannt hat; im Gegenteil, das Haar (die Haarzelle) scheint eine wahre Sinneszelle zu sein und folglich kann nur das Schema Fig. 68, B (nicht A oder C) die Webersche Ansicht erläutern.

Sehr bestimmt hat sich VIALLANES (1882) geäußert, welcher auch die oben erwähnten, klaren Anschauungen KüxCKEIs und GAZAGxaIREs zu widerlegen sucht. Er hat die Larve von Stratiomys chamaeleon, einem Dipter, als Objekt gewählt und bei diesem Tiere gefunden, daß das chitinöse Haar durch eine nicht immer leicht darstellbare Haarzelle ausgefüllt wird. Diese Haarzelle ist keine Sinnesnervenzelle, sondern sie wird innerviert durch den peripheren Fortsatz einer bipolaren Ganglienzelle, welche (und das ist sehr wichtig) zwar in die Haarzelle bis zur Haarbasis, aber nicht in das Haar selbst eindringt (Fig. 68, B). Wenn schon KüxckeL und GaZAGNatre (1881) behaupten, daß die Nervenfaser in das Haar selbst eintritt, so verneint solches dennoch Viallanes.

VIALlanes erweist meines Erachtens als erster unzweideutig, daß die Sinneshaare, wenigstens dieser Insektenlarve, keine Sinnesnervenzellen, sondern wahre durch den Fortsatz einer sensibelen Ganglienzelle innervierte Sinneszellen sind. Ich hoffe bald zu zeigen, daß solches bei allen Arthropoden zutrifft, daß die Sinneshaare niemals mit Sinnesnervenzellen, sondern immer mit Sinneszellen verbunden sind, ungeachtet dessen, was VoM $\mathrm{R}_{\mathrm{ATH}}$ und seine Geistesverwandten behauptet haben und es ist deshalb um so mehr zu bedauern, daß VOM RATH, welcher in seiner sehr vollständigen Literaturübersicht (Vom RATH 1888) VIALLANEs nicht nennt, diese Arbeit übersehen und folglich auch seinerseits keine Kritik dazu veröffentlicht hat.

Zu der gleichen Ueberzeugung wie VIALLANES geriet auch Lowne (18901892) als er die Fliege Calliphora erythrocephala studierte und dabei Haarzellen fand, welche durch den Fortsatz einer Ganglienzelle innerviert wurden, sei es, daß derselbe in die Haarzelle eintrat, sei es, daß er diese umspann. Neben diesen wahren Sinneszellen erkennt Lowxe aber auch das Vorkommen von Sinnesnervenzellen in Sinneshaaren.

Die entgegengesetzten Ansichten VIALLANES' und Vom RATHS wurden von DuboscQ einer Kritik unterworfen mit dem Lirfolge daß DuBoscQ die Fehler, welche Vom RATH und manche anderen gemacht hatten, zeigen konnte und er sich ganz auf die Seite VIALLANES' stellte.

DuBosce (1897) hat Methylenblau-Präparate der Sinneshaare von l'or- 
ficula auricularia, einem Insekt, studiert und daneben GoLGI-Präparate einiger chilopoden Myriapoden. Alle zeigten ihm dasselbe, nämlich, daß die chitinösen Sinneshaare des ganzen Körpers durch die Fortsätze einer oder mehrerer Haarzellen ausgefüllt werden. DuboscQ betont, daß diese Haarzellen wahre Sinneszellen sind und keine Sinnesnervenzellen. Sie werden innerviert durch den peripheren Fortsatz einer bipolaren Ganglienzelle, welche zwar in die Haarzelle bis zur Haarbasis, aber niemals in das Haar selbst vordringt. Also wie in Fig. 68, B.

DuBoscQ weiß uns glïcklicherweise auch mitzuteilen, warum dennoch Vom RATH und andere Forscher, welche die GoLGI-Mlethode anwandten, den peripheren Fortsatz der bipolaren Ganglienzelle bis zur Spitze des Haares fortschreiten sahen, sodaß dieselbe einer Sinnesnervenzelle glich. Es beruht dies auf einer Eigentümlichkeit der GoLGI-Methode, welche oft außerhalb der bipolaren Ganglienzelle und im Anschluß an ihren peripheren Fortsatz auch den Inhalt des Haares, also den Fortsatz der Haarzelle (oder einen Fortsatz der Haarzellen) mitfärbt. Anscheinend läuft dann der Ganglienzellfortsatz bis zur Spitze des Haares, aber wer genau beobachtet, sieht, wie der Fortsatz in der Haarbasis plötzlich sehr viel dicker wird. Diese für eine Nervenfaser ganz ungewöhnliche Erscheinung wird dadurch erklärt, daß hier die Stelle ist, wo die dïnne Nervenfaser sich dem dicken Fortsatz der Haarzelle anschließt.

Der besonders große Wert der DuBoscQsehen Arbeit liegt also nicht nur in den darin niedergelegten genauen Beobachtungen, sondern auch in der überzengenden Weise, worauf er die Fehler der ihm gegeniibergestellten Beobachtungen nachweist. Nicht weniger ist es ihm zur Ehre, daß er auch die prinzipielle Bedeutung seiner Beobachtungen eingesehen hat, denn er weist darauf hin, daß die Arthropoden mit den Vertebraten übereinstimmen in dem Besitz sensibeler Ganglienzellen, welche zu Sinneszellen umgebildete Epithelzellen innervieren. - In der 'Tat sind es, wie ich in diesem Buche zu beweisen glaube, nur die Arthropoden unter den Evertebraten, welche darin mit den Vertebraten übereinstimmen. - Und dabei ist DüBOsCQ nicht der Unterschied zwischen den Vertebraten und Arthropoden verborgen geblieben, nämlich die 'Tatsache, daß3 der periphere Fortsatz der sensibelen Ganglienzelle bei den Vertebraten verzweigt, bei den Arthroporlen unverzweigt ist.

Als Dubosce (1898) im nächsten fahre eine Arbeit besonders den Chilopoden widmete, konnte er darin seine vorigen Angaben bestätigen und vervollständigen. Er neunt jetzt VTALLAXEs den ersten, weleher die lnnervierung der Haarzelle dureh eine bipolare, sensibele Ganglicnzelle beschrieb und will es auf Grund der Lowxeschen Untersuchungen aus Vorsicht dahingestellt lassen. ob wirklich Sinneshare mit nur einer zugehörigen Zelle, wclche folglich eine Sinnesnervenzelle ist, rorkommen oder ob die diesbezïgliehen Angahen auf fehlerhafte Beobachtungen zuriickzuführen sind.

Durosce nennt in diesem Aufsatz die bipolare Zclle, welche die Haarzelle innerviert nicht Ganglienzelle, sondern simneszelle. Wie er dazu gelangt, ist mir nicht recht begreiflich, aher grliicklicherweise gribt er uns selber einen indirekten Beweis, daß er sich irrt. Sagt er doch, daß er mit Verwunde- 
rung gesehen habe, dåß die bipolaren, ,Sinneszellen" NISSL-Körper enthalten, welche niemals in Sinnoszellen beobachtet worden seien. Ich glaube, gerade die Nisst-Körper helfen die bipolare Zelle als Ganglienzelle zu kennzeichnen, wozu auch alle anderen Merkmale mitwirken. Ich möchte sogar in dieser Richtung weiter gehen und künftigen Forschern empfehlen, den NissL-Körpern der bipolaren Zellen in der Nähe der Sinneshaare ihre Aufmerksamkeit zu widmen. Werden sie gefunden, so bilden sie ein weiteres Argument gegen die Auffassung, daß die bipolaren Zellen Sinnesnervenzellen sind, weil sie nur in Ganglienzellen gefunden werden.

Die Angaben Viallanes', Lownes und DuboscQs beziehen sich nur auf die Insekten und Myriapeden. Daß auch die Crustaceen damit übereinstimmen, teilen uns Nusbaur und Schreiber (1897) mit. Diese Forscher entdeckten mit Hilfe der Methylenblau-Nethode in einiger Entfernung von der Basis der Sinneshaare bipolare Ganglienzellen, welche ihren peripheren Fortsatz zur Haarbasis sandten. Aehnliches taten Ganglienzellen, welche überall in der Haut einen subepithelialen Ganglienzellplexus bilden. Wenn die beiden Gelehrten melden, daß die Ganglienzellfortsätze bisweilen in die Spitze des Haares eindrängen, glaube ich solches nach den Auseinandersetzungen DUBoscs einer mangelhaften Färbung zuschreiben $\mathrm{z}^{\mathrm{n}} \mathrm{\lambda}$ müssen.

Auch Gïnther (1901) gehört ohne Zwejfel zu jenen Forschern, welche sich Viallanes anschließen. Er hat die Sinnesschuppen der Flügel einiger Schmetterlinge studiert, welche doch auch woll den Sinneshaaren unterzuordnen sind. Die Sinnesschuppen stehen hauptsächlich die Adern entlang, in denen die Nerven laufen. In jungen Flügeln von Puppen liegen bei jeder Schuppe zwei Zellen : die Schuppenbildungszelie, welche man meiner Meinung nach mit der Haarzelle der einfachen Sinneshaare zu homologisieren hat und eine ,Sinneszelle", welche offenbar eine bipolare, sensibele Ganglienzelle ist, weil ihr zentraler Fortsatz in den Flügelnerven eintritt und ihr peripherer Fortsatz in den Porenkanal der Schuppe bis zur Schuprenbasis eindringt, aber niemals in die Schuppe selbst. Ich glaube, diese Verhöltnisse stimmen'ganz gut überein mit jenen, welche von VIALLAxes u. a. wahrgenommen sind und lassen sich ebenfalls durch das Schema Fig. 68, B illustrieren. Sonderbar ist nur, daß nach Güsther die Schuppenbildungszelle später zu Grunde greht und also bei der Imago die Schuppe dem Fortsatz der sensibelen Ganglienzelle aufzusitzen scheint. Die sensibele Ganglienzelle täuscht dann eine Sinnessı̨:venzelle vor. Auch dieser Fall mahnt zur Vorsicht bei der Anerkennung von Sinnesnervenzellen bei den Sinneshaaren der Arthropoden.

Hiltow (1902) ist wiederum ein Forscher, welcher die Angaben Vuil RATHs geradewegs bestreitet. Mancherlei Raupen, worunter besonders die Larve von Bombyx mori, und auch die Larve von Corydalis, einem Hymenopteron, und Maikäferlarven bildeten sein Material. Er sah immer die Sinneshaare durch Haarzellen ausgefüllt und die Haarzellen innerviert durch die peripheren Fortsätze bipolarer, sensibeler Ganglienzellen, welche mit ihren zentralen Fortsätzen die peripheren, sensibelen Nerven bildeten. Der periphere Fortsatz der Ganglienzelle konnte meistens nur bis zur Haarbasis verfolgt werden (also wie in der Fig. 68, B). Nur bei Bombyx mori entdeckte er einige 
Haare, wo der Ganglienzellfortsatz bis in den unteren Teil des Haares eingedrungen war. Hпton betont, daß Vom RAth sich irrt, wenn er sagt, daß die Nervenfaser sich bis zur Spitze des Haares fortsetzt.

Ich finde deshalb gar keinen Anlaß zu vermuten, daß bei Bombyx mori ausnahmsweise dennoch Sinnesnervenzellen in den Sinneshaaren sich vorfinden, betrachte eher diesen Fall besonders geeignet, den Ursprung des Fehlers Vom Raths und gar mancher anderer Gelehrter zu beleuchten.

HILTON erzählt uns, daß BLANC insofern von ihm abweicht, als er Verzweigungen des Ganglienzellfortsatzes in der Haarzelle von Bombyx mori beobachtet haben will, aber ich bin leider nicht im Stande dies zu kontrollieren.

In den Arbeiten Kоттеs (1903) und Fischels (1908) finde ich Andeutungen der Anwesenheit wahrer Sinneszellen in den Sinneshaaren, obgleich ich nicht gern behaupten möchte, daß dieselben darin genau nachgewiesen worden waren. Котте hat Plesionika cottei, eine Tiefsee-Decapode, untersucht und dabei merkwürdige Fiederborsten entdeckt, Borsten, welche selbst ihrerseits zwei Reihen Haare tragen. Es macht ganz den Eindruck, wie wenn die Fiederborste kein Haar, sondern eine haartragende Hautausstülpung wäre, denn die Schicht der Hypodermiszellen setzt sich ununterbrochen in ihrer Basis fort. In diesem Falle ist es auch nicht verwunderlich, daß Nervenfasern, welche aus einem Ganglion an der Basis der Fiederborste hervorgehen, in der Achse der Fiederborste emporsteigen und darin einen "Terminalstrang" bilden. Ueber die Innervierungsweise der eigentlichen Haare wird damit noch nichts gesagt und diese bleibt im Dunkeln. Ich habe denn auch nur deshalb diese Fiederborsten hier erwähnt, weil sie scheinbar und bei oberflächlicher Betrachtung die Vou RatHschen Ansichten stïtzen.

Neben diesen Fiederborsten beschreibt nun KoтTE an dem Außenast der inneren Antenne zahlreiche Riech- oder Geschmacksborsten. Unter jedem dieser Haare liegt eine Gruppe von Sinneszellen, welche mit ihren Fortsätzen das Haar ausfüllen. Daß diese Zellen Sinnesnervenzellen sein könnten, geht aus nichts hervor, aber: wohl sagt KоттЕ, daß unter den Sinneszellen eine Ganglienzellgruppe sichtbar ist, welche durch Nervenfasern einerseits mit den Sinneszellen, andrerseits mit dem peripheren Nerven des Organs verbunden ist. Ich glaube, diese Beschreibung stimmt am besten überein mit der Meinung, daß die Ganglienzellen sensibele Ganglienzellen sind, welche die Haar- oder Sinneszellen innervieren.

Fischer (1908) hat die Crustacee Daphnia mit einer von ihm entdeckten, vitalen Nervenfärbung mittels Alizarin untersucht. Er beobachtete unter den Schwanzborsten ein Ganglion. Aus den Zellen dieses Ganglions treten Fortsütze in die Schwanzborsten. Sollte man vielleicht geneigt sein in diesen Zellen Simnesnervenzellen zu sehen, so zeugt die Tatsache, daß3 das Ganglion durch ein Konnektiv mit dem Bauchstrang verbunden ist, dafür, daß wir hier mit einem wahren, sensibelen Ganglion zu tun haben und nicht mit einer Sinnesnervenzellgruppe, welche sich doch niemals als ein Ganglion des Bauchmarks vortut. Ich gestehe, daß ein solches Argument nicht anzuführen ist bei den Riechborsten der ersten Antenne, wo Fiscuel ebenfalls eine Gruppe 
von Ganglienzellen beschreibt, welche ihre peripheren Fortsätze in die Haare senden. Da könnte man die Ganglienzellen als Sinnesnervenzellen betrachten, wenn nicht andere, oben beschriebene Erscheinungen damit in Widerspruch wären.

Es bleibt mir jetzt noch übrig zu melden, daß BETHE (1896) bei Astacus fluviatilis zweierlei Sinneshaare auf den Mundteilen beschreibt. Zur einen Art gehören hohle Haare, worunter nur eine bipolare Zelle liegt, welche ihren peripheren Fortsatz zur Haarbasis, aber nicht in das Haar selbst sendet. BEтнE nennt hier keine Haarmutterzelle, aber es ist selbstverständlich, daß diese neben der bipolaren Zelle bestehen muß, denn was anders würde das hohle Haar ausfüllen? Es ist dann aber auch die bipolare Zelle eine sensibele Ganglienzelle, welche die nicht beobachtete Haarzelle innerviert und das Schema Fig. 68, B kann auf diese Haare angewandt werden.

Die zweite Art Sinneshaare haben jedes eine ganze Gruppe bipolarer Zellen unter sich und diese schicken ihre peripheren Fortsätze wenigstens eine kurze Strecke in das Haar hinein. Ob neben diesen Zellen auch Haarzellen auftreten, ist unbekannt. Das Haar könnte vielleicht nur durch die Fortsätze der bipolaren Zellen ausgefüllt werden und diese wären dann Sinnesnervenzellen. Müssen die bipolaren Zellen Sinnesnervenzellen sein ? Ich glaube, das ist nicht der Fall. Wo sie offenbar nicht zur Spitze des Haares gehen, können es auch sensibele Ganglienzellen sein, welche die von BETHE übersehenen Haarzellen innervieren und welche nur ein wenig weiter als gewöhnlich in das Haar vordringen. So lange spätere Untersuchungen die Entscheidung nicht gebracht haben, glaube ich nicht gezwungen zu sein in den Angaben Bethes eine Widerlegung des Satzes zu sehen, daß alle Sinneshaare der Arthropoden mit wahren Sinneszellen und nicht mit Sinnesnervenzellen ausgestattet sind. BETHE selbst (1895̌b) schließt sich jedoch Vour Rath an.

In Verbindung mit den BeTHEschen Forschungen, will ich darauf hinweisen, daß Retzius (1895) in seiner schon von mir genannten Arbeit über die Sinneshaare der Crustaceen (u. a. Astacus) ebenfalls erkennt, daß die Fortsätze der Sinnesnervenzcllen, wie er sie nennt, oft, aber nicht immer in das Haar eindringen. Wir können darin einen Fingerzeig sehen, daß auch er tatsächlich sensibele Ganglienzellen beobachtet hat.

Schließlich möchte ich noch betonen, daß auch Von RatH (1895) bei Astacus fluviatilis zwar Sinnesnervenzellen in den Sinneshaaren beschreibt, daß aber in seinen Figuren die peripheren Fortsätze dieser Zellen nicht in das Haar vordringen, also ganz wie Bethe und Retzius uns lehren. Ich schließe daraus, daß Astacus ein besonders günstiges Objekt ist, sich vom Dasein sensibeler Ganglienzellen (nicht Sinnesnervenzellen) bei den Sinneshaaren zu überzeugen.

Wenn ich alle Untersuchungen und Argumente überblicke, glaube ich zu dem Schluß berechtigt zu sein, daß ganz allgemein die Sinneshaare der Arthropoden durch die Fortsätze von Haarzellen ausgefüllt werden, welche wahre Sinneszellen sind, weil sie nicht selbst einen Nervenfortsaty entsenden, sondern durch den peripheren Fortsatz einer sensibelen Ganglienzelle, welcher selbst nicht oder nur wenig in das Haar vordringt, innerviert werden. 
Wir haben gesehen, daß manche Forscher statt Sinneszellen und sensibeler Ganglienzellen Sinnesnervenzellen anerkennen, aber, so viel ich weiß, antworten sie niemals auf die Angriffe seitens ihrer Gegnor, welche behaupten, daß sie durch die bekannte Launenhaftigkeit der GolgI- und Methylenblau-Methode irregeführt seien oder in anderer Weise bestrebt sind ihre Fehler nachzuweisen. Deshalb und auch, weil ihre Arbeiten bisweilen Angaben enthalten, welche sich nicht recht mit der Anwesenheit von Sinnesnervenzellen vereinigen lassen, glaube ich ihren Anschauungen nicht beitreten zu müssen. Die Möglichkeit, daß hier und dort bei den Arthropoden wirklich Sinneshare mit Simesnervenzellen ausgestattet sind, ist damit nicht ganz ausgeschlossen, aber das muß in jedem Einzelfalle auss neue nachgewiesen werden und alle diesbezüglichon Angaben bedürfen der Bestätigıng.

Weil also die Arthropoden wahre Sinneszellen in den Sinneshaaren aufweisen, während dieser Zelltypus allen übrigen Evertebraten ganz abgeht und nur noch den V'ertebraten zukommt, schließe ich, daß die wahre Sinneszelle mit der sie innervierenden, sensibelen Ganglienzelle eine phylogenetisch junge Errungenschaft ist, welche erst mit den Arthropoden auftritt, wie ich schon in meiner Besprechung der HerTwisschen Hypothese (S. 12) geäußert habe.

Es ist hier die geeignete Stelle nochmals einen Augenblick zu verweilen bei jenem Aufsatz, worin PATTEx (1890) das Ommatidium des zusammengesetzten Iuges der Arthropoden mit einer haartragenden Sinnesknospe vergleicht. Er vergleicht die Retinophoren des Auges, welche nach ihm Doppelzellen sind mit den Simneshaaren, wozu er ebenfalls wenigstens zwei Kellen. die Haarzelle und die sensibele Ganglienzelle, rechnet. Weil er jedoch einerseits im Auge Rotinophoren erkennt, welche, wie ich oben (S. 193) dargetan habe, gar nicht existieren, andrerseits die Innervierung der Sinneshaare nicht genau erforscht hat, ist der Wert seines Vergleichs sehr problematisch.

Hit Rücksicht auf meine Behauptung, daß die sensibele Ganglienzelle: welche eine Sinneszelle innerviert, phylogenetisch aus einer sensibelen Ganglienzelle mit freien Nervenendungen und diese aus einer Sinnesnervenzelle hervorgegangen ist und daß die Sinneszelle bei den Arthropoden phylogenetisch neu entstanden ist, verdient es Beachtung, was PATTEN über die Phylogenese dieser Zellen sagt. PATTEx ist der Mcinung, daß phylogenetisch im Auge der Arthropoden Retinulazellen sich gesenkt und sich damit in sensibele Ganglienzellen verwandelt haben, welche ihrerseits wiederum eine neuc Generation von Retinulazellen innervieren. Die Retinulazellen sind dabei für ihn weder typische Simnesnervenzellen, noch typische Simeszellen, sondern man könnte sagen Simesnervenzellen, welche durch den jeripheren Fortsat\% einer sensibelen Ganglienzelle immerviert werden. Ein soleher Zelltypus ist nur angeblich von V EraTTI (190(0) und Swent (1902) bei Pulmonaten (Mollusken) (siehe S. 15is) beobachtet worden, ohne daßB die Bedeutung einer solchen Innervation klar wurde. Ich hezweifle: somit scine Existenz.

PATTEx beschäftigt sich hier also mit der Herkunft der sensibelen Ganglienzelle und der dadureh innervierten '/olle. Richtig ist dabei der Gedanke, daß die sensibele Ganglienzelle eine Simnesnervenzelle, die sich gesenkt hat ist, abcr. wie ich nachgewiesen z.11 haben glaube, entsteht dieselbe nicht im 
Auge und nicht bei den Arthropoden, sondern bei den Würmern und hat sie anfänglich freie Nervenendungen. Richtig ist ebenfalls der Gedanke, daß die Zelle, welche die sensibele Ganglienzelle bei den Arthropoden innerviert, phylogenetisch zuerst bei diesen Tieren aufgetreten ist, aber eine solche Zelle ist eine Sinneszelle ohne Nervenfortsatz und keine Sinnesnervenzelle und dieselbe ist nicht im Auge entstanden - denn dort fehlt sie ganz sondern wahrscheinlich in den Sinneshaaren des Körpers oder vielleicht in einem der spärlichem anderen Organe, wo wir bei Arthropoden noch wahren Sinneszellen begegnen (Dccapoden-Statocyste und Nackenorgan von Daphnia).

Zwei Jahre, ehe PAtTex diese Meinung äußerte, hat er (Pattex 1888), wenn ich ihn gut verstehe (vergl. S. 301), in der Retina der Ozellen der Acilius-Larve (eincr Käferlarve) frei endende Nervenfasern zu sehen gemeint und daran die Bemerkung geknüpft, daß es Fortsätze von Ganglienzellen seien, welche man als unter das Epithel gesunkene Sinnesnervenzellen aufzufassen habe. Hiergegen fülire ich abermals an, daß zwar die sensibele Ganglienzelle mit freien Nerrenendungen auch meiner Meinung nach eine Sinnesnervenzelle ist, die sich unter das Epithel gesenkt hat, daß aber dieser Prozeß sich nicht in Auge der Käfer, sondern schon lange vorher bei den niedrigsten Würmern abgespielt hat.

Ich glaube mit diesen Bemerkungen diese etwas umständliche Einleitung über den Anfang einiger Leitungsbahnen der Arthropoden beenden und zur Beschreibung der Leitungs'jahnen der einzelnen Gruppen schreiten zu können.

Es kommen da zuerst die Crustaceen an die Reihe, welche sich in zwei Unterklassen, die Entomostraca und die Malacostraca unterbringen lassen. Wie bekannt, zeigen die Malakostraken eine höhere Ausbildung, auch ihres Nervensystems, und ich will deshall mit den Entomostraken anfangen.

Zur Unterklasse der Entomostraca rechnet man einige Ordnungen. Für nur zwei dieser Ordnungen, die Copepoden und Branchiopoden hat man, so weit mir bekannt, zurzeit Angaben über die Leitungsbahnen gemacht.

Mit den Copepoden hat CLaús sich zuerst beschäftigt. Ich entlehne dem Sammelwerke Cierstaeckers $(1866$ - 1879), daß er z.B. bei Cetochilus drei Paar Ganglien. zellgruppen im Hirnganglion begegnete und die beiden unteren Zellgruppen durch Kommissurfasern verbunden fand, während andere Nervenfasern aus dem Hirnganglion in das Schlundkonnektiv der gleichen oder der gelłreuzten Seite übertraten. Lebrigens sei daran erinnert, daß LEYDiG (1864) auch schon in dieser Zeit Kommissuren in den Ganglien der Arthropoden beobachtet hat.

Diese spärlichen Mlitteilungen sind später fast nicht vermehrt worden. CLAUS selbst (1891) hat noch behauptet (wie ich schon S. 195 beschrieb), daß bei Copeporten eine Nervenfaser ins Innere der 'Tastborsten ziehe und Retzius (1895) (vergl. S. 199) meinte. daß3 die Copepoden bipolare Sinnesnervenzellen unter den Sinnesharen besüfjen, aber, wie oben dargetan wurde, haben wohl beide sich geirrt.

Eine richtige Bemerkung machte GreNAcher (1879), als er sagte, dal. Calanella mediterranea im ocellus Sehzellen aufweist, welche sich lisontinuirlich in Nervenfasern fortsetzen (vergl. S. 192), aber damit ist auch alles über die Leitungsbahnen gesagt worden.

Die Branchiopoden sind mehr als die Copepoden berücksichtigt worden. Auch für diese Ordnung ist C'LAUs (1876) der Pionier. Er hat Daphnia unter- 
sucht und davon Zupfpräparate hergestellt. Diese lehrten ihn, daß Fasern des Sehnerven des Frontalauges aus der peripheren Ganglienzellschicht des Hirnganglions hervorgingen. Weil wip jetzt wissen, daß bei allen Arthropoden die Nervenfortsätze der Sehzellen im Auge ebenso Fasern des Sehnerven bilden, eine Tatsache, welche Nowıкoff (1905) für die Augen der Branchiopoden besonders bestätigt hat, fragt es sich, ob CLAUs richtig beobachtet hat und ob nicht vielleicht die von ihm beobachteten Sehnervenfasern in der Peripherie des Hirnganglions enden, statt dort anzufangen. Reтzius (1906) hat, wie wir bald sehen werden, wirklich solche Nervenfasern bei Daphniden entdeckt (Fig. 69, a), aber man darf andrerseits nicht vergessen, daß sowohl BERGER (1878) bei Artemia salina, wie Samassa (1891) bei Sida crystallina Ganglienzellen in der Peripherie des ganglion opticum, eines 'Teils des Hirnganglions, beschreiben, welche Fortsätze in den nervus opticus des zusammengesetzten Auges senden. Diese Beobachtungen und die CLAusschen stiutzen sich gegenseitig und der Sehnerv der Branchiopoden scheint also doppelläufig zu sein.

Claus hat weiter im Kopfe von Daphniden frontal und im Nacken unter der Haut Ganglienzellen gefunden, welche durch Nervenfasern mit dem Gehirn verbunden waren. Auch Retzius (1906) scheint die gleichen Ganglienzellen wahrgenommen zu haben (Fig. 69, $j$ ).

In der Nähe der Tastborsten traf Claus meistens unterhalb der Haarzellen eine Gruppe bipolarer ,Ganglienzellen”, welche einen Fortsatz zwischen die Haarzellen und einen anderen in den Nerven schickten. An günstigen Objekten konnte ClaUs den peripheren Fortsatz bis in das Haar verfolgen und er hat deshalb Sinnesnervenzellen zu sehen gemeint. Wahrscheinlich sind es aber wirklich sensibele Ganglienzellen.

Daß Claus im Hirnganglion Kommissuren gesehen hat, ist eine Bemerkung über die Leitungsbahnen, welche wir natürlich gerne glauben.

Ich habe schon erwähnt, daß Berger (1878) bei Artemia salina Ganglienzellen in der Rinde des ganglion opticum erkannt hat, welche Fortsätze in den Sehnerven des Frontalauges senden. Hier will ich noch hinzufügen, daß diese Nervenfasern bis in die Retina fortschreiten und daß ebensolche Nervenfasern aus Zellen im Innern des ganglion opticum hervorgehen.

Auch SAmassa (1891) habe ich oben schon genannt, weil er entdeckt hat, daß Sima crystallina Ganglienzellen im ganglion opticum besitzt, welche Nervenfasem des Sehnerven aussenden. Seitenäste dieser Nervenfasern gehen zum Neuropilem des ganglion opticum selbst. Neben diesen Nervenfasern beschreibt SAMASSA teilweise auch die Wege anderer Leitungsbahmen, aber, weil er keine spezifischen Nervenfärbungen angewandt hat, sind seine Angaben schr unvollständig. Hier will ich noch mitteilen, daß $\mathrm{er}^{\mathrm{im}}$ Hirnganglion von Sima zwei Kommissuren sah, eine obere und eine untere, während er auch die Ganglien des Bauchstranges durch Kommissuren verbunden fand.

Die Konnektive des Bauchmarks von Sima sind nach SAMASSA mit Ganglienzellen belegt und dasselbe ist der Fall mit den Konnektiven und Kommissuren des Bauchstranges von Daphnia sima. Selbstverstandlich wird dadureh die Kenntnis der Leitungsbahnen dieser Konnektive und Kommissuren sehr ersehwert. 
SAMASSA teilt uns denn auch darüber nichts mit. Wohl erwähnt er bei Daphnia sima eine Kommissur im Hirnganglion, eine retrooesophageale Kommissur und eine Kommissur zwischen den beiden Mandibelganglien. Kommissuren beschreibt er auch bei Bythotrephes longimanus und Leptodora hyalina. Letztere Tierart hat wiederum zwei Kommissuren im Hirnganglion, je eine über und unter dem Zentralkörper.

Cunnmgtox (1903) hat ebenfalls das Nervensystem einer Daphnide und zwar Simocephalus sima untersucht, aber, da ihm spezifische Nervenfärbungen mißlangen, bringt er uns nur wenig weiter als SAvASSA. Wohl behauptet er, daß dieser oder jener Nerv aus diesem oder jenem Neuropilem entspringe, áber ich kann diese Angaben nur als Vermutungen betrachten und unterlasse es, sie hier wiederzugeben. Cunntigtox hat im Hirnganglion mehr Kommissuren beobachtet als SAMASSA, denn er sah neben anderen Kommissuren eine Kommissur des ersten Antennalnerven (nervus antennarius primus) und zwei Kommissuren im ganglion opticum, eine vordere dorsale und eine hintere ventrale. Darauf beschränken sich die zuverlässigen Mitteilungen CUNxixgtoxs.

Ueber den Anfang einiger sensibelen Leitungsbahnen hat NowıокF (1905) uns belehrt. Er zeigte, dal3 die Sehzellen der zusammengesetzten und einfachen Augen einiger Branchiopoden Sinnesnervenzellen sind und entdeckte ebenfalls Sinnesnervenzellen in dem dorsalen und ventralen Frontalorgan von Branchipus und Limnadia.

Retzius (1906) ist wiederum derjenige, welcher unsere Kenntnis der Leitungsbahnen der Branchiopoden sehr erweitert hat. Er arbeitete mit Daphniden und ich will seine Resultate mit Hilfe der Figur 69 darstellen. Man sieht darin den Kopf einer Daphnide von der rechten Seite. Rechts unten ist die kurze,

Fig. 69 .

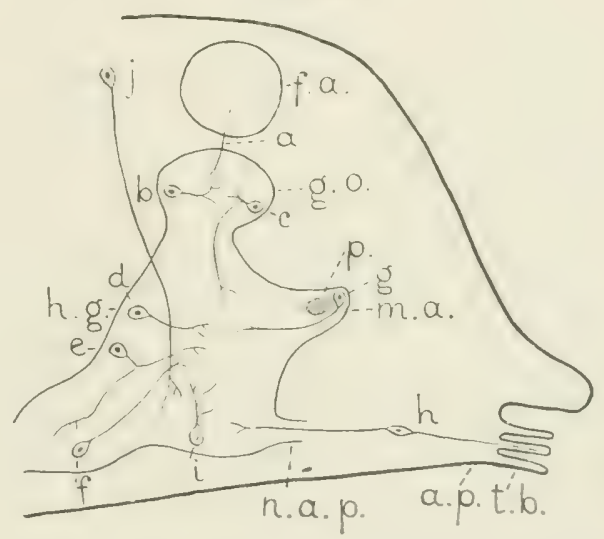

Kopf einer Daphnide von der rechten Seite. Abgeändert nach Retzius (1906).

$a=$ Nervenfaser

$b$ bis $g$ und $i$ und $j=$ Ganglienzellen

$h=$ Simnesnervenzelle (sensibele Ganglienzelle?)

a. $p_{0}=$ antemna prima

f. $a .=$ Frontalauge

g. . = ganglion opticum

h. $g$. $=$ Hirnganglion

$m . a .=$ Medianauge

n. $a . p .=$ nervus antennarius primus

p. = Pigment

t. $b$. $=$ Tastborste erste Antenne $(a . p$.$) mit den Tastborsten (t . b$.$) ; oben ist das zusammenge-$ setzte Frontalauge (f.a.); in der Mitte das Hirnganglion (h.g.) mit dem ganglion opticum (g.o.) und dem einfachen Medianauge (m.a.), worin sich Pigment $(p$.$) befindet als Anhang. Aus dem Hirnganglion geht der nervus$ antennarius primus $(n \cdot a \cdot p \cdot)$ hervor, welcher die erste Intenne innerviert. Retzius hat nun die nachfolgenden Reizleitungsbahnen entdeckt und 
zwar in Golgi-Präparaten. Aus dem Frontalauge treten durch den nervus opticus Nervenfasern (Fig. 69, $a$ ) ins ganglion opticum, welche sich im vorderen Abschnitt desselben verzweigen. Die Fasern enden also dort und RetziUs ist durchaus berechtigt zu der Annahme, daß diese Fasern Fortsätze der Sehzellen des Auges sind, obgleich er solches der starken Pigmentierung des Auges wegen nicht entscheiden konnte.

In der Rinde des Sehganglions befinden sich Ganglienzellen, welche ihre Fortsätze in das Neuropilem des Ganglions und also auch zwischen die Aeste der Augennervenfasern aussenden. Einige dieser Ganglienzellen (Fig. 69, b) verzweigen sich nur in einem der drei Abschnitte des ganglion opticum, andere durchziehen mit ihren Ausläufern das ganze Ganglion, noch andere (Fig. 69, c) senden neben den Fortsätzen zum ganglion opticum auch solche zum Hirnganglion.

Auch das Hirnganglion ist mit peripher gestellten Ganglienzellen aus gestattet. Manche darunter breiten ihre Fortsätze nur ins Neuropilem des Ganglions aus (Fig. 69, d). Andere aber (Fig. 69, e) senden einen Fortsatz zu dem gepaarten, hinteren Teil des Hirnganglions, wo wiederum andere Ganglienzellen gelagert sind (Fig. 69, f) mit Fortsätzen, welche zum unpaaren Hirnganglion zurücklaufen.

Das Medianauge (Naupliusauge) ist cine vordere Ausstülpung des Hirnganglions. Es enthält Pigment und ringsherum eine Reihe ,Ganglienzellen" mit Fortsätzen im Hirnganglion (Fig. 69, g). Rerzius ist nicht besonders klar in seiner Beschreibung des Medianauges und es läßt es sich fragen, ob die Ganglienzellen keine Sinnesnervenzellen scin können.

Sinnesnervenzellen glaubte RETrius zu sehen im Ganglion der ersten Antenne (Fig. 69, $h$ ). Es sind bipolare Zellen mit einem peripheren und einem zentralen Fortsatz. Der periphere Fortsatz endet nach RexzIUs in einer Tastborste und da wäre die Zelle wirklich eine Sinnesnervenzelle. Wenn dieser Fortsatz aber in der Tat, was mich wahrscheinlich dünkt, nur die Haarzelle der Tastborste innerviert, ist die Zelle eine sensibele Ganglienzelle. Wie dem auch sei, jedenfalls endet der zentrale Fortsatz der 'Lelle ventral im Hirnganglion, das er durch den ersten Antennalnerven erreicht. An dieser Stelle ist eine Gruppe unipolarer Ganglienzellen (Fig. 69, i) gelegen, deren kurze Fortsätze im Hirnganglion emporsteigen.

Mit dem Hirnganglion stehen noch zwei Ganglienzellgruppen in Verbindung, welche selbst außerhalb des Ganglions gelegen sind. Die eine Gruppe trifft man hinter dem Frontalauge und ihre Ganglienzellen senden lange Fortsätze zum Neuropilem des Hirnganglions (Fig. $69, j$ ). REtzius meint, daß3 sie vielleicht zum Nackenorgan gehören. Aus den Ganglienzellen der anderen Gruppe geht ein Ast zur Darmwand und ein Ast zum Hirnganglion hervor.

Schließlich meldet REizius uns noch, daß der Nerv der zweiten Antenne die zentralen Fortsätze einiger bipolaren Simesnervenzellen enthält.

Kurz nach ReTzius hat zuletzt noch lisciel (1908) das Nervensystem von Daphnia untersucht und zwar mit Alizarin, einem Farbstoff, welcher, wie Fiscnes entdeckte, eine gute, vitale Nervenfärbung liefert. Die damit errungenen Resultate sind derart, daß ich nur dic Lrwartung aussprechen kann, daß 
diese Methode künftighin noch viele Leitungsbahnen der Evertebraten (bei Vertebraten hat er keinen Erfolg) aufklären wird. Ich habe schon S. 204 zwei von Fischel aufgefundene Leitungsbahnen erwähnt und verweise den Leser auf diese Seite. Man wird bemerken, daß er betreffs der Natur der ,Sinnesnervenzellen" zu den Sinneshaaren der ersten Antenne völlig mit REtzIUs einverstanden ist und ebenso, wie jener hat er beobachtet, daß ihre zentralen Fortsätze ins Gehirn eintreten. Interessant ist weiter der Befund, daß der nervus tegumentarius, welcher das Gehirn mit dem Nackensinnesorgan verbindet aus einigen Fasern besteht, welche verzweigt im Inneren becherförmiger Sinneszellen enden. Ein zweites Beispiel wahrer Sinneszellen neben den verschiedenartigen Sinneshaaren.

Obgleich kurz vorher erschienen, bietet die Arbeit NiLs HoLmGrens (1916) ïber das Gehirn von Apus glacialis nur wenig Auskunft über die Wege der Leitungsbahnen, aber destomehr vergleichend-anatomische Betrachtungen. Ich bezweifele in manchen Fällen ihre Richtigkeit. Hier möchte ich nur erwähnen, daß Holmgrex in den Zentra der ersten Antennalnerven an den Wurzeln der Schlundkonnektive glomeruli sieht, welche durch eine Antennalkommissur verbunden sind.Z wischen den ganglia optica laufen zwei Kommissuren und noch eine andere, breite Kommissur verbindet zwei laterale Teile des Gehirns in denen sich glomeruli befinden, welche nicht zum Gebiete der ersten Antenne gehören. Letztgenannte Kommissur läuft unter dem Zentralkörper, einer Ganglienzell-und Norvenfasergruppe im Zentrum des Gehirns, welche Houmgrex mit dem Zentralkörper der Insekten homologisiert.

Fig. 70.

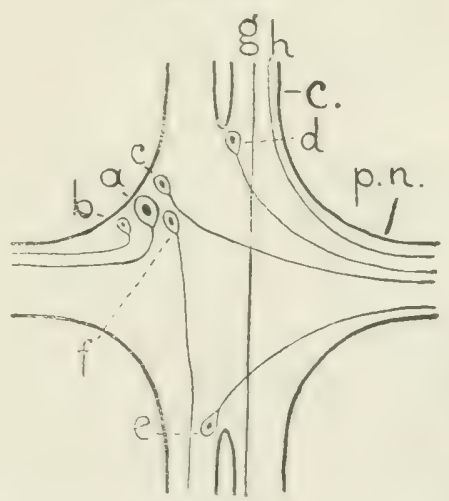

Thorakalganglion von Phronima. Nach Claus (1879).

$a$ bis $f=$ Ganglienzellen

$g, h=$ Nervenfasern

$c$. $=$ Konnektiv

p. n. $=$ peripherer Nerv

In der zweiten Unterklasse der Crus-

taceen, den Malacostraca, sind Tiere aus allen Ordnungen hie und da hinsichtlich der Reizleitungsbahnen untersucht worden. Im allgemeinen ist es bemerkenswert, daß in den Urdnungen der Stomatopoden und Decapoden das Hirnganglion und die damit verbundenen lobi optici sich eines besonderen Interesses erfreuen, wie solches auch bei den Insekten der Fall ist.

Die Malacostraca spalten sich in fünf Ordnungen : die Amphipoda, Isopoda, Schizopoda, Stomatopoda und Decapoda, welche hier der Reihe nach besprochen werden sollen.

Claus (1879) ist auch jetzt wieder der erste Forscher, welcher sich mit den Wegen der Nervenfasern im Zentralnervensystem der Amphipoden beschäftigt hat und zwar hat er in Phronima ein durchaus günstiges Objekt gefunden. Schöne Angaben hat er über die Thorakalganglien des Bauchstran- 
ges gemacht. Diese Ganglien, welche alle übereinstimmend gebaut sind; werden durch zwei Konnektive (Fig. 70, c.) verbunden und zu jeder Seite geht aus ihnen ein peripherer Nerv (Fig. 70, p.n.) hervor. Jedes Ganglion enthält eine vordere und eine hintere mediane Zellgruppe, dort wo die Konnektive anfangen und zu jeder Seite eine vordere und hintere laterale Ganglienzellgruppe, wovon in der Figur 70 nur die linke, vordere gezeichnet worden ist.

In jeder der vier lateralen Zellgruppen sind eine oder-zwei besonders große Ganglienzellen (Fig. 70,a), welche ihren Neuriten in den peripheren Nerven der gleichen Seite senden. Die kleineren Zellen dieser Gruppen tun das gleiche $(b)$, oder aber ihr Neurit kreuzt die Medianlinie des Ganglions und tritt in den peripheren Nerven der anderen Seite aus (c). Es gibt nach CLAUS auch Kommissurfasern, welche nicht in den Nerven schreiten, sondern nur die beiden Hälften des Ganglions verknüpfen. Wo sie entspringen oder enden, ist mir nicht bekannt.

Ganglienzellen der medianen Zellgruppen senden ebenfalls ihren Fortsatz in den peripheren Nerven und zwar so, daß die vorderen Ganglienzellen (d) den Nerven der gleichen Seite, die hinteren $(e)$ den gekreuzten Nerven begünstigen.

Auch unter den Konnektivalfasern wurden solche entdeckt, welche aus Ganglienzellen des Thorakalganglions hervorgingen. Gewiß lagen diese 'Zellen in der vorderen lateralen Gruppe $(f)$, vielleicht auch in der hinteren.

Neben diesen Fasern beobachtete Cuaus in den Konnektiven Nervenfasern umbekannter Herkunft $(g)$, welche das ganze Ganglion durchzogen und andere, welche in den peripheren Nerven abbogen. Es wird nicht gesagt, ob diese Nervenfasern von vorn oder von hinten kommen; vielleicht stammen sie aus dem Hirnganglion und kommen sie von vorn, wie die Faser $h$ der Figur 70.

Nach Claus zeigt das untere Schlundganglion von Phronima, welches aus sechs oder sieben Ganglien verschmolzen ist, ähnliche Leitungsbahnen wie das Thorakalganglion.

Claus hat auch das Hirnganglion mit den lateral daraufsitzenden lobi optici (Augenganglien) in seine Untersuchungen bezogen, aber nur wenige zuverlässige Mitteilungen darïber gemacht. Hat er doch manche Fasersysteme ohne Anfang oder Ende beschrieben, wie er sie ummittelbar im aufgehellten Gehirn beobachtet hat, allerdings mit nachfolgender Kontrolle an Gehirnschnitten. Auf Grund seiner Wahmehmungen beschreibt CLAus im Hirnganglion vier oder fünf Kommissuren mit Fasern, welche wenigstens teilweise zu den lobi optici ziehen und worin sich auch Fasern der Schlundkonnektive befinden, welche jedoch nicht alle im Himganglion kreuzen. Auch gelangen Nervenfasem des Scheitelauges, das aus zwei Hälften besteht, welche jede fuir sich ein Nervenfaserbündel zum Gehirn senden, ins Gehirn und iiberschreiten dort die Medianlinie in einer Kommissur, welche C'LAUs den, inneren Balken" nemnt. Schließlich teilt C'LAUs uns mit, daß sich in den lateralen Augen (ebenso wie im Scheitelauge) eine Schicht bipolarer Ganglienzellen befindet. welehe ihren zentralen fortsatz zum lobus opticus, ihren peripheren zur Retina senden. Wie der letztere dort endet, ist unbekannt. 
Ebenso wie Claus hat Vom RATH (1895) einige Leitungsbahnen der Amphipoden aufgeklärt. Nicht nur, daß er bei Niphargus putaneus und ebenso bei Gammarus pulex und G. fluviatilis Sinneshaare mit Sinnesnervenzellen beschrieb - man weiß schon, daß und warum ich diese Angaben für verfehlt halte und besonders Niphargus, wo sich mit Hilfe der GoLgischen Methode auch in allen anderen Haaren als Sinneshaaren Fasern mit zellkörperähnlichen Anschwellungen darstellen ließen, stimmt mich zweifelmütig über die Richtigkeit der Vou RATHschen Beobachtungen - aber Vou RATH hat auch bei Niphargus gesehen, daß die Ganglien des Bauchstranges Ganglienzellen enthalten, woraus Fortsätze zur Körperperipherie hervorgehen, während die peripheren Nerven daneben Fasern führen, welche frei innerhalb des Ganglions enden.

Daß Vox RATH (1896) uns später mitteilt, daß bei Gammarus und ebenso bei der Isopode Asellus die Zellkörper der ,Sinnesnervenzellen” nicht unter den Sinneshaaren, sondern unmittelbar neben dem Zentralnervensystem liegen, scheint mir abermals darauf hinzuweisen, daß man hier mit sensibelen Ganglienzellen zu tun hat, wobei diese Lage durchaus nicht merkwiurdig wäre.

Nemec (1896) weist bei der Amphipode Orchestria auf einem unter der Haut gelegenen Ganglienplexus hin. Wir werden dasselbe Gebilde später bei den Isopoden (S. 214) besprechen. Es scheint mir ein Ganglienzellplexus zu sein, woraus Nervenfaserbündel hervorgehen.

GERSTAECKER und Ortalann (1901) behandeln in ihrem Sammelwerke auch die Amphipoden. Sie wiederholen manche Angaben, welche CLAUs über Phronima niedergeschrieben hat und welche ich oben gleichfalls wiedergegeben habe, fügen aber andere hinzu, so z.B. daß im Hinterteil des Hirnganglions Ganglienzellen liegen, welche Fortsätze in die Schlundkonnektive senden.

Neuerdings hat noch Schracz (1914) sich bemüht die Leitungsbahnen einiger Amphipoden zu verfolgen. Leider war die Konservierung der Tiere zu mangelhaft um solches in befriedigendem Maße zu gestatten. Schuldz sah bei Vibilia und Lanceola drei große Kommissuren im Gehirn und Rhabdosoma und Oxycephalus besitzen dort gleichfalls Kommissuren. Interessanter ist es, daß Lanceola und Vibilia im statischen Organ Sinnesnervenzellen haben, deren Nervenfortsätze bis ins Gehirn verfolgt werden konnten. Bei Rhabdosoma und Oxycephalus war die Verbindung der Nervenfasern mit den Sinnesnervenzellen unklar, die Fasern jedoch konnte ScHMalz das Gehirn durchschreiten und in das Schlundkonnektiv eintreten sehen.

Damit habe ich leider schon alles über die Reizleitungsbahnen der Amphipoden erzählt.

Die erste Leitungsbahn einer Isopode hat Gresacher (1879) gesehen, als er kon. statierte, daß die Retinazellen von Porcellio seaber sich unmittelbar in eine Nervenfaser fortsetzen und also Sinnesnervenzellen sind.

Ihm folgt MAX WEBER (1881), dem Goldchlorid-Präparate zeigten, daß die Tast haare und Tastkegel der Trichoniscidae alle durch eine Nervenfaser innerviert werden, welche ein Fortsatz einer multipolaren Ganglienzelle war. Ich schliebe daraus (S. 201), daß die Sinneszellen dieser Tastorgane wahre Sinneszellen sind.

WEBER sagt weiter, daß die multipolaren Ganglienzellen mit ihren Fortsätzen zusammenhängen und so einen Plexus bilden. Es ist dies also ein Ganglienzellplexus, wie man weiß die primitivste Gestalt, welche das Nervensystem zeigen kann und wel. chem wir auch bei anderen Evertebraten, namentlich aber bei Coelenteraten begegnet sind. Daß die sensibelen Ganglienzellen selbst Zellen dieses primitiven Ganglienzellplexus seien, kann ich freilich schwer glauben, weil sie selbst gar nicht primitiv sind. $\checkmark$ ielleicht liegen sie nur dazwischen.

Ein Ganglienzellplexus, wie der obengenamnte, ist später auch von NEmEC (1896) bei den Isopoden und nachher von anderen Forschern bei Crustaceen aus anderen Gruppen entdeckt worden. Ob BeтнE (1896) gleichfalls diesen Plexus bei Astaeus zu Gesicht bekommen hat, ist nach der HoLıGRENschen Kritik wenigstens zweifelhaft (vergleiche Astacus). 
NEMEC fand bei einigen Vertretern der Oniscideen unter der Hypodermis des Körpers und der Extremitäten was er ,plexusartige" Ganglien nennt. Diese Ganglien, welche gepaart und regelmäßig gestellt sind und durch Nerven mit dem Bauchstrang verbunden werden, strahlen nach allen Seiten aus und setzen sich in einzelliegende Ganglienzellen fort. Weil NEıEC über einzelliegende Ganglienzellen spricht und diesen 'Teil des Plexus für vielleicht besonders vergleichbar hält mit dem Ganglienzellplexus, welchen BETHE kurz vorher bei Astacus zu sehen glaubte, schließe ich, daß NEMEc in der Tat einen Ganglienzellplexus (ohne anatomisch nachweisbare Leitungsbahnen) beobachtet hat, welcher jedoch in einen Nervenplexus mit eingelagerten Ganglien übergeht. Nach Nemec enden einige Fortsätze dieser Ganglienzellen ohne spezifisehe Endigung zwischen den Hypodermiszellen. Dessenungeachtet bin ich nicht überzeugt, daß man hier mit frei endenden Ausläufern sensibeler Ganglienzellen zu tun hat. Bei 'Titanethes, einer Isopode, kehrten diese peripheren Ganglien zurück.

Was Nusbaur und Schreiber (1897) mit der Methylenblau-Methode bei verschiedenen Crustaceen entdeckten, stimmt noch mehr als der NEMEcsche Befund mit den WeBErschen Angaben iberein. Sie beschreiben im ganzen Körper einen subepithelialen Ganglienzellplexus. Die feinsten Aestchen des Plexus anastomosieren und die Plexuszellen senden bisweilen Fortsätze zur Basis der Haare. Andere Fortsätze hingegen bilden zusammen typische Nerven und es schließen sich hier also, ebenso wie NEMEc erzählt, dem Ganglienzellplexus wahre Nerven an. ScHreiber (1898) hat später gleiche Resultate mit der GioLGI-Methode erhalten. Auch hier frage ich mich, ob die sensibelen Ganglienzellen, welche die Haare innervieren, wirklich selbst zum Ganglienzellplexus gehören und nicht nur dazrischen liegen .

Die Hodologie des Zentralnervensystems der Isopoden hat PAckARD (1884) als erster bekanntzumachen versucht und er hat sich in dieser Absicht mit dem Hirngan. glion von Asellus communis beschäftigt. Er sah darin dorsolaterale, unipolare Ganglienzellen mit Fortsätzen, welche entweder eine Kommissur bildeten oder in die Schlundkonnektive zogen. In die Schlundkonnektive traten auch Fortsïtze dorsofrontaler Ganglienzellen und die Ausläufer anderer unipolarer Ganglienzellen spalteten sich wiederholt und bildeten so das Neuropilem des Gehirns.

Caecidotaea stygia ist eine blinde Verwandte von Asellus. Das Tier hat noch ein Rudiment des zusammengesetzten Auges, aber die nervi und lobi optici fehlen und dennoch weicht das Hirnganglion nach PACKARD in seinem Bau nur wenig ab von dem. jenigen sehender Arten. Es bilden hier die Fortsätze dorsofrontaler Ganglienzellen ebenfalls eine Kommissur im protocerebrum.

Auch Bellonci (1886) hat unsere Kenntnis der zentralen Leitungsbahnen der Isopoden bereichert, aber einige Angaben sind bei der von ihm angewandten Jethode zu unzuverläßig um hier wiedergegeben zu werden. Bei Porcellio maculicornis und Sphaeroma liegen dorsal und median im Gehirn drei Gruppen von Ganglienzellen, welehe ihre Fortsätze in drei Bïndeln vereint zum Neuropilem des Hirnganglions senden. Die Fasern des lateralen Bïndels ziehen in die laterale, vordere ,masse reticolate", das heißt, in die medulla terminalis, wie ich diesen Teil des protocerebrum immer nennen werde (vergl. die Beschreibung des lobus opticus S. 216). Idotea hat nur zwei solcher Ganglienzellgruppen im Gehirn. Bei diesem Tiere und bei Porcellio wiirde nach Bfelonci ein Fasersystem vorhanden sein, welches das ganglion olfactorium (oder Antennalganglion, wie es oft genannt wird) mit dem lobus opticus derselben und der gekreuzten Seite verbände, aber diese Angabe bedarf genauerer Bestätigung.

HALLER (1905) hat in seiner Arbeit über das Hirnganglion der Trachenten, welehe auch vergleichend-anatomische und phylogenetische Betrachtungen enthilt, einige Bahnen der Isopoden besonders erwihnt. Seitclem aher NiLs HoLxGrex (1916) z. B. aus der HALLerschen textfigur \& $A$, welche cin Augo darstelit, abgeleitet hat, daß HaLLER statt Porcellio eine diplopode Myriapode untersucht hat, is es nicht erwiunscht seino Angaben über die Bahnen der Isopoden hier zu wiederholen.

Howgrex (1916) selbst hat bei Porcellio seaber zwnrimnnche Besonderheiten der. Hirnstruktur entdeckt _ so fand er im protocerebrum allein nicht weniger als 
17 Kommissuren - aber die Leitungsbahnen wurden dennoch nicht genau erforscht.

Damit ist auch die Behandlung der Isopoden zu Ende geführt und kann ich zu den Schizopoden übergehen. So viel ich $\pi$ eiß, entlält nur die Arbeit Bethes (18956), hodologische Mitteilungen iiber ein Tier aus dieser Ordnung und zwar über Mysis. BEтнE hat die Statocyste von Mysis, welche im mittleren Schranzanhang gelegen ist, u.a. in GolGIPräparaten untersucht. Er sah die Wand des Bläschen mit Sinneshaaren besetzt. Diese Haare sind ein Produkt! der Matrixzellen (Haarzellen) und neben diesen Matrixzellen liegen langgestreckte Sinnesnervenzellen, deren Sinnesfortsätze bis weit in die Haare zu verfolgen waren. Nun werden nach Bethe auch in den Sinneshaaren des Schwanzes und der Antennen von Mysis und anderen Crustaceen Sinnesnervenzellen aufgefunden, aber, während ich dort (vergl. S. 200) geneigt bin an der Wahrheit dieser Bemerkung zu zweifeln, finde ich hier dazu keine Veranlassung, weil es hier nicht eine Art Sinneshaare der allgemeinen Körperoberfläche, sondern die Sinneshaare eines ganz besonderen Sinnesorgans anbelangt und man nicht aus Tatsachen des einen Falls zu Schlußfolgerungen im anderen Fall berechtigt ist.

Fig. 71 .

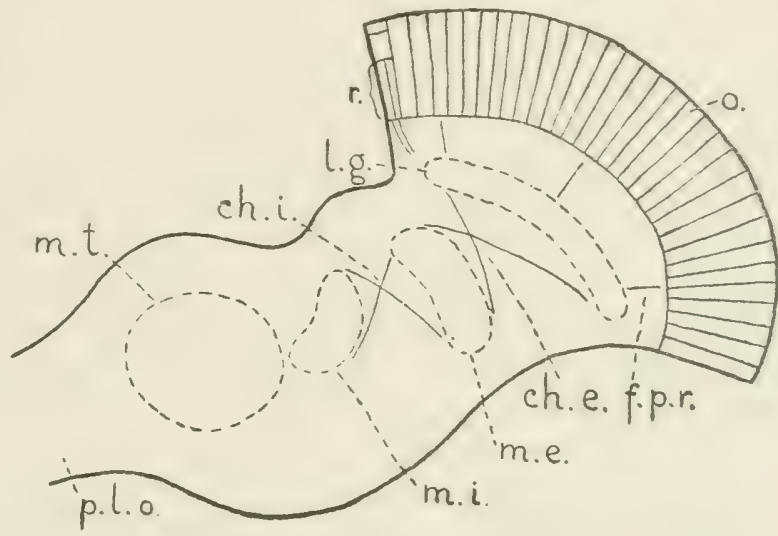

Schematischer Längsschnitt des lobus opticus und des zusammengesetzten Auges der Stomatopoden und Decapoden.

$c h . e .=$ chiasma externa

ch. $i$. = chiasma interna

f. p. $r$. = fibrae postretinales

l. g. = lamina ganglionaris

m. e. = medulla externa

m. $i_{\text {. }}=$ medulla interna

$m . t_{0}=$ medulla terminalis

o. = ommatidium

p. $l . o .=$ pedunculus lobi optici

$r$. $=$ retinula

Man wird bemerkt haben, daß bis jetzt die meisten Mitteilungen über die Hodologie der Crustaceen nebeneinander st nden, sodaß man ohne eigene Untersuchungen keine Kontrolle ihrer Zuverlässigkeit hat. Bei den beiden letzten Ordnungen der Crustaceen, den Stomatopoden und den Decapoden, ändert sich das, was ein günstiges Ereignis heißen darf.

Die Untersuchungen der Stomatopoden beschränken sich alle auf Squilla mantis. Weil dabei vornehmlich die optischen Leitungsbahnen studiert. worden sind, will ich hier eine kurze Beschreibung und eine schematische Abbildung des mikroskopischen Baues der lobi optici beifügen, welche nicht nur für die Stomatopoden, sondern auch für die Decapoden gilt (Fig. 71).

Die Figur 71 stellt einen Längsschnitt des lobus opticus und des zusammengesetzten Auges schematisch dar. Das Auge selbst bildet einen Teil einer 
Hohlkugel und wird aus mannigfachen Ommatidien (o.) zusammengesetzt. Jedes Ommatidium besteht basal aus der retinula $\left(r_{0}\right)$, welche, wie wir seit Grenacher wissen, eine Gruppe von Sinnesnervenzellen ist. Die Nervenfortsätze dieser Zellen dringen in den lobus opticus ein. Dieser läßt verschiedene Ganglienzellgruppen und auch verschiedene Faserschichten und Neuropileme unterscheiden. Letztere sind bei den Crustaceen sehr konstant und erteilen dem lobus opticus einen typischen Bau, welcher schon lange bekannt und viel studiert worden ist.

Unmittelbar unter der Retina, der Gesamtheit aller retinulae ist die Schicht der postretinalei Nervenfasern (Fig. 71, f.p.r.). Dann folgt eine gebogene Platte, welche aus einigen Schichten von Zellen und Nervenfasern besteht und lamina ganglionaris $\left(l . g_{0}\right)$ genannt wird, weil sie einem Ganglion gleicht. Dahinter durchkreuzen die Nervenfasern, und zwar iibrigens ganz gleichwertige Nervenfasern, einander in ganz eigentiimlicher Weise und bilden das chiasma externum (ch.e.). Dieser Name ist so eingebürgert, daß er sich nicht mehr ändern läßt, aber man muß dabei bedenken, daß man unter diesem Chiasma von optisehen Fasem ganz etwas andres als bei den Vertebraten versteht. Dort bilden die Fasern, welche die Medianlinie des Gehirns überschreiten und deshalb eine Kommissur bilden, das Kreuz. Hier sind die sich kreuzenden Fasern durchaus keine Kommissurfasern. Optische Kommissuren findet man zwar auch bei den Crustaceen; diese befinden sich jedoch begreiflicherweise im Hirnganglion, nicht in einem lobus opticus. Wenn die Fasern einer commissura optica der Crustaceen nicht alle einander parallel fortschreiten, sondern, wie bei den Vertebraten ein Kreuz bilden, nennen einige Forscher solches wiederum ein Chiasma. In Vergleichung mit den Vertebraten ist dies ganz korrekt, aber ich meine, zur Vermeidung von Hißverständnissen ist es besser diese Benennung bei den Crustaceen zu unterlassen.

Dem chiasma externum folgt ein Neuropilem : die medulla externa (m.e.) und diesem eine zweite Kreuzung ïbereinstimmender Nervenfasern: das chiasma internum (ch.i.). (Wenn ungleichwertige Nervenfasern einander kreuzen, darf men nicht über ein Chiasma reden). Es folgen dann noch zwei Neuropileme, von denen das äußere medulla interna $(m$. $i$ ), das innere medulla terminalis $(m . t$.$) genannt wird. Dann kommt endlich der Stiel (p.l.o.), womit$ der lobus opticus dem Gehirn, das heißt dem protocerebrum, aufsitzt.

Man wird in manchen der unten zu erwähnenden Werken sehr genaue Angaben iiber die mikroskopische Anatomie des lobus nachschlagen können. leh werde sie nur berücksichtigen, insoweit sie die Hodologie beriihren. Nur das möchte ich betonen, daß manche Autoren mit sehr verschiedenen Namen dasselbe Gebilde deuten. Meistens wendet jeder seine eigene Muttersprache an, statt alle dieselben lateinischen Namen zu gebrauchen, aber ich werle mir erlauben, immer die obigen anzuwenden, welche internationale Anerkennung finden können.

Kehren wir jetzt zu den Reizleitungsbahmen von Squilla mantis zurück. DiEti (1878) hat schon im Jahre 1878 versucht die Leitungsbahnen des (iehirns von Squilla mantis kennen zu lemen, aber, weil er die Bahnen bisweilen nur nach makroskopischer Betrachtung beschreibt, sind seine Angaben zu 
unzuverlässig um hier wiedergegeben zu werden. Natürlich hat er bisweilen richtig beobachtet, so, wenn er im Hirnganglion cin Chiasma und zwar eine semidecussatio von Nervenfasern des lobus opticus beschrieb, welches vielleicht besser eine commissura optica genannt wiirde, ohgleich daneben noch eine andere optische Kommissur vorhanden ist.

BERGER (1878) brachte es schon sehr weit in der Kenntnis der mikroskopischen Anatomie des Gehims von Squilla, aber, obgleich er manche Fasersysteme beobachtete, blieben ihm deren Ursprung und Ende meistens unbekannt und kömnen seine Mitteilungen der Hodologie des Nervensystems nur wenig nützen. So erkannte er im lobus opticus (,Augenganglion”) schon das chiasma externum und internum, die lamina ganglionaris, die medulla externa, interna und terminalis (vergl. Fig. 71) und manche Ganglienzellgruppen daneben, aber, wie die Nervenfasern und Ganglienzellen zusammenhängen, blieb ihm völlig unbekannt. Beachtenswert ist seine Beobachtung, daß Ganglienzellen vorn im Gehirn Fortsätze zum lobus opticus senden. Andere Nervenfasern des lobus opticus bilden im Hirnganglion das Chiasma mit Semidekussation, welches auch DietL wahrgenommen hat. Berger vermutet, daß diese Fasern in den Stiel der , pilzhutförmigen Körper" übergehen, womit er aller Wahrscheinlichkeit nach das Antennalganglion im deuterocerebrum gemeint hat. Die von ihm entdeckte Kommissur zwischen den pilzhutförmigen Körpern von links und rechts wäre dann die Antennalkommissur. Nicht alle Fasern des lobus opticus überschreiten die Medianlinie im Chiasma; andere tun solches in der commissura optica, welche sich zwischen den beiden lobi optici erstreckt. Eine vierte Kommissur im Gehirn bilden zuletzt noch Fasern der Schlundkonnektive.

Wichtige Leitungsbahmen im lobus opticus von Squilla mantis hat BELLONCI (1882) entdeckt. Er arbeitete mit Osmiumsäure-Präparaten und seine Resultate bedürfen also gewiß noch der Bestätigung, obgleich sie sehr zuverlässig scheinen. BeLLorcr hat eine eigene, sehr abweichende und leider italienische Nomenklatur für die Zellgruppen und Neuropileme des lobus opticus eingeführt. Ich erlaube mir die oben angeführten Namen anzuwenden.

BeLLoncr beschreibt neben der medulla externa (vergl. hier und nachher Fig. 71) von ihm corpus stratificatum anterius genannt, einige Ganglienzellgruppen. Einige dieser Ganglienzellen sind bipolar und senden einen Fortsatz in die medulla externa. Dieser Fortzatz verästelt sich und anastomosiert mit den Nervenfasern des nervus opticus, worunter Belloxcr die Fasern des chiasma externum versteht. Diese Fasern des chiasma externum enden verzweigt in der medulla externa, woselbst auch Nervenfasern enden, welche durch das chiasma internum aus mehr zentral gelegenen 'T'eilen kommen. (Dieses Verhältnis findet man bei Astacus und Palinurus wieder; siehe dort.)

Neben der medulla interna (corpus stratificatum posterius) fand BELLONCr eine Gruppe sehr großer Ganglienzellen, welche ihre Fortsätze zentralwärts aussenden in den, ,nervus peduncularis”. Damit hat BELLover den Stiel gemeint, welcher den lobus opticus mit dem Hirnganglion vereinigt und welcher von vielen anderen gerade nervus opticus genannt wird. lch glaube, man 
hat keine Veranlassung hier über einen „Nerven” zu sprechen und möchteihn Stiel oder pedunculus lobi optici nennen.

In der medulla terminalis unterscheidet BELLONCI einige Neuropileme, das corpus hemiellipsoideale, das corpus prolongatum (wie ich BeLLoncis „,corpo allungato" nennen möchte) und das corpus reniforme, welche ein zentrales Neruropilem umgeben. Das corpus hemiellipsoideale und prolongatum bilden zusammen ein System, welches BeLLover ganz den corpora pedunculata der Insekten vergleichbar achtet.

Neben dem corpus hemiellipsoideale liegen Ganglienzellen, deren Ausläufer darin einziehen; neben dem corpus prolongatum solche, welche dieses mit ihren Fortsätzen suchen. In der Umgebung des corpus reniforme beobachtete BeLloxcr Ganglienzellen mit Fortsätzen im zentralen Neuropilem der medulla terminalis oder im pedunculus lobi optici. Dabei hat BeLlorcr bemerkt, daß die Fortsätze der Ganglienzellen des lobus opticus zum Gehirn alle dicke Nervenfasern des pedunculus sind, während feine Nervenfasern daraus, welche ein besonderes Bündel bilden, sich zum Teil im corpus hemiellipsoideale verästeln und somit mehr zentral ihren Ursprung haben. Dieses besondere Bündel bildet im Hirnganglion das Chiasma, welches auch DretL und BERGER schon zeigten.

BeLlonci hat auch Nervenfasern des pedunculus bis in die medulla interna fortschreiten sehen und er beschreibt noch andere Bahnen, aber diese zu unvollständig um genau wiedererkennbar zu sein.

Im nächsten Jahre hat BeLLoxcr (1883) abermals Squilla mantis studiert, sich jetzt aber mit dem Antennalganglion (lobus olfactorius) beschäftigt. Er sah die ,olfactorischen" Nervenfasern des nervus antennarius primus im Antennalganglion enden und natülich hat er auch die dortigen glomeruli beobachtet. Interessant ist seine Mitteilung, daß ein Faserbiindel, welches aus dem. Inneren des Antennalganglions hervortritt, sich auflöst in einem Neuropilem, vorn in der Mitte des Gehims gelagert, das die optischen Fasern des Chiasma durchziehen, weil damit der. Vermutung BERGERs, daß die Chiasmafasern selbst ins Antennalganglion übergehen (vergl. S. 217) keine Stütze gegeben wird.

Einen 'Teil des peripheren Nervensystems von Squilla hat Nusbaum (1899) beobachtet, als er in der Wand des Herzens multipolare Ganglienzellen entdeckte, welche mit ihren Fortsätzen einen Plexus bildeten und einen Fortsatz in den zutretenden Nerven sandten.

Die letzte mir bekannte Arbeit, worin wir horlologisehe Angaben über Squilla mantis erwarten konnten, ist die RADLsche (1900). RADL hat besonders den lobus opticus studiert und darin manche anatomischen Besonderheiten wahrgenommen, aber die Wege der Leitungsbahnen sind ihm wohl ganz verborgen geblieben, was nicht befremdend ist, weil er gegenüber der GoLGIMethode eine Hämatoxylin-Mlethode bevorzugt. Ich will diesem Aufsatz nicht viele Worte widmen, num mit cinem Beispiel die Resultate RaDLs beleuchten. Er erkennt in den Retinulazellen des zusammengesetzten Auges keine Sinnesnervenzellen wieder, wie GREXACHER und andere Forscher. Es tritt nach ihm in jede Retinulazelle eine Nervenfaser, welche bis zum Kern fortschreitet und 
dann endet ohne Verbindung mit dem Rhabdom. Der letzte Teil dieser Nervenfaser ist selbstverständlich eine Neurofibrille im Inneren der Retinulazelle ; der erste Teil ist der Nervenfortsatz der Zelle. Nicht also nach RADL. Nach ihm ist die Nervenfaser kein Fortsatz der Retinulazelle, noch diese selbst eine Sinneszelle, welche durch einen Ausläufer einer mehr zentral gestellten Ganglienzelle innerviert wiirde. Was denn ? RADL kann es uns nicht sagen; er konnte nicht entdecken, ob die Nervenfaser der Retinulazelle zentripetal oder zentrifugal ausgewachsen sei. Die Nervenfasern der Retinulazellen ziehen in Bündeln zum ganglion retinae, wie er die lamina ganglionaris nennt und sie verzweigen sich dort, aber enden dennoch nicht, sondern scheinen bloß dieses Ganglion zu durchlaufen. Wie man sieht, wird mit solchen Angaben die Hodologie nicht weiter geführt. Wahrscheinlich hat RADL Retinulazellen beobachtet, deren Nervenfortsätze verzweigt in der lamina ganglionaris enden, wie auch bei anderen Arthropodengeschieht, aber ganz sicher kann man davon nicht sein.

Auch Squilla mantis und die Stomatopoden bedürfen also noch sehr vieler Untersuchungen, ehe ihre Leitungsbahnen ganz aufgeklärt sind.

Ueber die Hodologie der Decapoden haben erfreulich viele Abhandlungen das Licht gesehen und weil die meisten sich mit nur vier Tieren: Astacus, Palinurus. Homarus und Carcinus beschäftigen, ist es hier möglich ihre Ergebnisse synthetisch zu bearbeiten und kritisch einander gegenüberzustellen. Ich fange also an, die vier genannten Tierarten jede für sich zu beschreiben und lasse die Arbeiten, welche sich mit anderen Decapoden oder mit den Decapoden im allgemeinen befassen, folgen.

Fig. 72

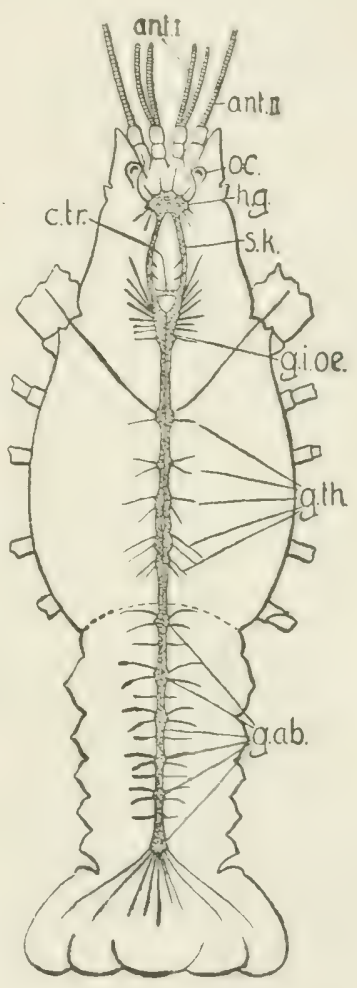

Nervensystem von Astacus fuviatilis. Abgeändert nach Büтschli (1912), Fig. 357.

ant. $\mathbf{I}=$ erste Antenne

ant. Il $=$ zweite Antenne

c. $t r$. - commissura tritocerebralis

g. ab. - ganglion abdominale (1. i. oe. - ganglion infraoesophageum

g. th. ganglion thoracale

h. g. Hirnganglion

oc. Auge

s. k. Schlundkonnektiv

Es gehe Astacus voran, weil mit diesem Tiere am meisten gearbeitet worden ist. Obgleich hier und dort andere Astacus-Arten studiert worden sind, hat Astacus fluviatilis (Potamobius astacus), der Flußkrebs, die größte Aufmerksamkeit erlangt und, wenn nicht ander's gemeldet wird, beziehen sich die 
Angaben auf diese Spezies. Die Differenzen mit anderen Arten scheinen iibrigens nicht erheblich zu sein.

Fig. 72 gibt eine Uebersicht ïber das ganze Zentralnervensystem des Flußkrebses. Vorn im Kopfe liegt das Hirnganglion (h.g.) durch die Schlundkonnektive $\left(s . k_{.}\right)$verbunden mit dem Unterschlundganglion $\left(g . i . o e_{\text {. }}\right)$ Hinter dem Oesophagus sind die Schlundkonnektive verbunden durch die Tritocerebralkommissur (c.tr.)

Dem Unterschlundganglion folgen erst fünf 'Thorakalganglien $(g . t h$.$) und$ dann sechs Abdominalganglien ( $g . a b$.$) , welche den eigentlichen Bauchstrang$ zusammensetzen.

Ich werde nicht das ganze Nervensystem von Astacus fluviatilis zu gleicher Zeit betrachten, sondern erst das Gehirn oder das obere Schlundganglion, dann die Ganglien des Bauchstranges und zuletzt das periphere Nervensystem behandeln.

Es sei zuvor bemerkt, daß neben den Schlundkonnektiven, welche das Hirn mit dem unteren Schlundganglion und den pedunculi lobi optici (oder nervi optici), welche dasselbe mit den lobi optici verbinden, vier Nervenpaare das Hirn verlassen. Es sind die nervi oculomotorii zu den Augenmuskeln, die nervi antennarii primi und secundi und schließlich noch die nervi tegumentarii zum Cephalothorax. Ueberdies tritt vorn zwischen den pedunculi lobi optici und hinten zwischen den Schlundkonnektiven in der Medianebene ein Nerv aus dem Gehirn hervor. Diese beiden treten nach KRIEGER mit dem Geflecht der Magennerven in Verbindung und wir werden den hinteren bald in der Altensschen Arbeit (vergl. Fig. 81, S. 237) als nervus anterior medianus näher kennen lernen, , anterior", obgleich der hintere Mediannerv des Gehirns, weil er der vordere Mediannerv des ganglion oesophageum ist. Weil der Name nervus anterior medianus also schon angewandt worden ist, will ich den vorderen Mediannerven des Gehirns schlechthin nervus medianus nennen (vergl. für die Hirnnerven Fig. 73, S. 222).

OwsJannikow (1861) ist der erste, welcher über die Leitungsbahnen des Gehirns zuverlässige Nitteilungen macht, obgleich er der Meinung ist, daß3 die zentralen Nervenfasern zwei Ganglienzellkörper ummittelbar verbinden und ihm also die wahre Endigungsweise der Nervenfasern im Zentralnervensystem entgangen ist. OWSJANNIKOW entdeckte im Himganglion Kommissuren und daneben Fasern, welche das Gehirn mit dem Bauchstrang vereinigten. Einige dieser Fasem stehen nach ihm sowohl im Gehim, wie im Bauchstrang mit Ganglienzellen in direkter Verbindung, andere enden im Gehirn und darunter befinden sich Fortsätze von kleinen, multipolaren Ganglienzellen, welche in den Bauchstrangganglien liegen und welchen wir dort abermals begegnen werden. Diese Ganglienzellen haben oft vier oder mehr Ausläufer, aber nur einer zieht zum Hirn.

Einige Jahre später hat Ows Jxxikow (1563) besonders die Wege der Nervenfasern der Gehirnnerven untersucht und er stellte dabei fest, dal3 alle Himnerven Nervenfasern führen, welche aus Ganglienzellen des Gehirns hervortreten. Zwar hat Ows axviow seine Beschreibungen für Palinurus locusta aufgestellt, aber, weil er betont, dal3 Astacus fluviatilis und marinus (Homarus) 
die gleichen Verhältnisse darbieten, will ich seine Angaben auch an dieser Stelle wiedergeben.

Das Gehirn umfaßt eine mediane dorsale Gruppe ziemlich großer Ganglienzellen, deren Fortsätze in den ,nervus opticus”, (das heißt in den Stiel des lobus opticus), in den nervus oculomotorius oder in den sechsten Hirnnerven, den nervus tegumentarius ziehen. Diese Gruppe ist neben eine andere gestellt und deren kleine Ganglienzellen senden Fortsätze in den nervus antennarius secundus (Nerven der zweiten Antenne) und in den Bauchstrang; vielleicht überdies in den nervus anterior medianus. Die Ganglienzellen, welche ihre Ausläufer dem nervus antennarius primus beimischen, liegen lateral. Ventral zwischen den beiden Antennalnerven sind Ganglienzellen angehäuft mit Fortsätzen im pedunculus lobi optici. Der zweite Antennalnerv empfängt auch Fortsätze von Ganglienzellen einer ziemlich zentral gestellten Gruppe. Andere Zellen dieser Gruppe bilden nach OwsJAxnikow die Antennalkommissur in deren Nähe sie liegen, aber die Resultate anderer Forscher lassen mich zweifeln, ob er darin Piecht hat.

Nachdem OwsJannikow das Gehirn von Astacus studiert hatte, hat Lemorne (1868) demselben seine Aufmerksamkeit gewidmet. Er fand es in mancher Hinsicht den Ganglien des Bauchstranges gleich gebaut, deutet aber nur sehr unbestimmt und unzureichend einige Bahnen an.

DietL (1876) beobachtete im Gehirn von Astacus neben anderen Kommissurfasern ein Chiasma von Fasern des lobus opticus. Andere Leitungsbahnen wurden so mangelhaft gesehen, daß sie für andere Forscher wohl nicht mit voller Gewißheit wiedererkennbar sind und das gilt nicht nur für Astacus, sondern auch für andere von DiETL studierte Arthropoden.

Später hat DieTL (1878) abermals bei Astacus das Chiasma von Nervenfasern des lobus opticus erwähnt. Andere Bahnen sind wiederum sehr ungenau, oft sogar makroskopisch beobachtet worden.

BERGER (1878) zeigte im Astacus-Gehirn eine commissura optica neben dem Chiasma von Dietu und eine Kommissur von Nervenfasern aus den Stielen der pilzhutförmigen Körper. Weil er mit diesen Körpern wahrscheinlich die Antennalganglien gemeint hat, ist die Kommissur wahrscheinlich die Antennalkommissur, welche auch von OwsJANNIKow beobachtet wurde.

Im Jahre 1880 erschien die Arbeit KrIEgERs (1880) über das Zentralnervensystem des Flußkrebses. Obgleich darin noch keine modernen Färbungen des Nervensystems angewandt werden konnten und auch falsche Begrifte, so die Meinung, daß alle Fasern der peripheren Nerven aus dem Neuropilem entsprängen und nicht unmittelbar aus Ganglienzellen hervorgehen kömnten, KRIEGER daran hinderten alle Leitungsbahnen vom Anfang bis zum Ende zu verfolgen, hat KRIEGER durch seine sehr sorgfältigen Rekonstruktionen der Fasersysteme und Neuropileme eine Arbeit geschaffen, welche nicht nur so weit führt wie man ohne spezielle Nervenfürbungsmethoden überhaupt kommen kann, sondern auch viele spätere Mitteilungen überragt und immer eine gute Kontrolle für die Untersuchungen anderer darbieten wird.

Ich will die von KrIEGER beobachteten Neuropileme und Fasersysteme als Erläuterung zu der Figur 73 beschreiben. Man findet darin das Hirngan- 
glion von Astacus von oben gesehen schematisch dargestellt. Vorn geht der nervus medianus $(n . m$.) daraus hervor. Ihm folgt der pedunculus lobi optici (p.l.o.) oder nervus opticus, wie er oft genannt wird. Dann kommt der nervus oculomotorius $(n . o c$.) und der ventral austretende nervus antennarius primus $(n . a . p$.$) . Es treten jetzt der nervus tegumentarius (n.t.) und der$ nervus antennarius secundus (n.a.s.) hervor und nach hinten gehen endlich die Schlundkonnektive ( $s . k_{*}$ ) ab: Zwischen beiden Konnektiven noch der ner-

Fig. 73.

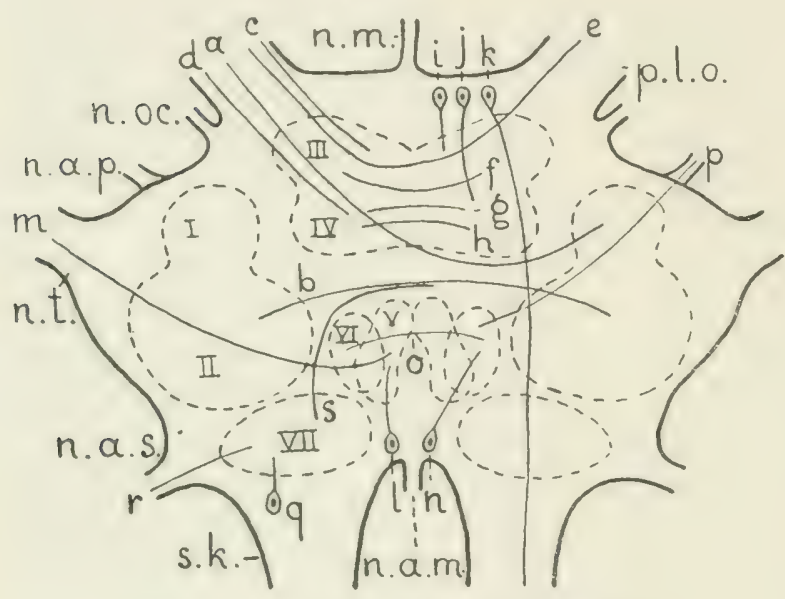

Gehirn (ganglion supraoesophageum)

von Astacus fluviatilis.

Abgeändert nach KRIEGER (1880), Hig. 1.

a bis $h, m, o, p, r, s=$ Nervenfasern

$i$ bis $l, n, q=$ Ganglienzellen

$I$ bis $V I I=$ Neuropilome

$n . a . m .=$ nervus anterior medianus

n. $a . p .=$ nervus antennarius primus

n. $a . s .=$ nervus antemnarius secundus

n. $m$. $=$ nervus medianus

$n$.oc. $=$ nervus oculomotorius

$n . t$. $=$ nervus tegumentarius

p. l. o. $=$ peduneulus lobi optici

s. $k$. = Schlundkonnektiv vus anterior medianus (n. a.m.).

KRIEGER erkannte im Innern des Gehirns sieben Neuropileme (Punktsubstanzballen) (Fig. 73, I bis VII). Die zwei ersten homologisierte er nach dem Vorbilde von Dietr, und Berger mit den corpora pedunculata (pilzhutförmigen Körpern) der Insekten. Abermals geht aber aus der Figur und den angefuihr ten Verbindungen dieser Neuropileme hervor, wie falsch eine solche Homologisation ist. Denn die corpora pedunculata der Insckten liegen im protocerebrum, hier dem Gebiet der Neuropileme 111 und IV, während die Neuropileme I und II zum deuterocerebrum und also zum Antennalganglion gehören. Die Neuropileme $V$ und VI sind ebenfalls

dem denterocerebrum zuzurechnen, während VII, das Gebiet des zweiten Antennalnerven. das tritocerebrum darstellt.

Auch Krieger hat, wie Dietu und Berger, im Gehirn das Chiasma von Fasern des lobus opticus beobachtet und er läßt sie in das erste Neuropilem eintreten (Fig. 73, a). Das erste Neuropilem empfängt ebenso Nervenfasem aus lateral und medial neben demselben gestellten Ganglienzellgruppen, aber KRIEGER sagt nicht, ob diese Ganglienzellen auch die Ursprungszellen dieser Fasern sind. Dergleichen Fasern, wie die letatgenamnten, empfängt auch das zweite Neuropilem. Außerdem ist es durch eine Kommissur mit dem zweiten Neuropilem der anderen Seite verbunden (Fig. 73, b) und ich glaube nicht 
fehlzugehen, wenn ich diese Kommissur die Antennalkommissur nenne und sie der von OwsJANnikow und BERGER beobachteten Kommissur gleichstelle. Nervenfasern des lobus opticus ziehen in die Neuropileme III $(c)$ und IV (d) und zwar größtenteils in das Neuropilem der gleichen Seite, bisweilen aber überschreiten sie die Medianlinie. Andere optische Nervenfasern bilden eine direkte Kommissur zwischen den beiden lobi optici (Fig. 73, e), während daneben zwischen den beiden Neuropilemen III eine Kommissur $(f)$ und zwischen den beiden vierten Neuropilemen zwei Kommissuren ( $g$ und $h$ ) entdeckt wurden.

Die Ganglienzellen, woraus alle diese Nervenfasern hervorgehen, sind leider unbekannt. Gliicklicherweise ist solches nicht der Fall mit drei Arten von Nervenfasern, welche KRIEGER mit vorn im Gehirn gelagerten Ganglienzellen in Verbindung sah und welche zum dritten oder vierten Neuropilem $(i$ und $j$ ) oder zum Schlundkonnektiv zogen $(k)$.

Hinten im Gehirn ist eine mediane Ganglienzellgruppe gestellt, deren Zellen (l) Fortsätze in das füfte Neuropilem senden, dasselbe Neuropilem, woraus gleichfalls Fasern des nervus tegumentarius $(m)$ hervorgehen.

Andere Zellen der ebengenannten Zellgruppe $(n)$ senden ihre Fortsätze in das sechste Neuropilem, das einen Teil seiner Fasern dem Nerven der ersten Antenne abgibt $(p)$. Beide Neuropileme VI werden durch eine Kommissur (o) verbunden.

Das siebente Neuropilem nimmt die Ausläufer der daneben gelagerten Ganglienzellen $(q)$ auf und ebenso Nervenfasern des zweiten Antennalnerven $(r)$. Andere Nervenfasern $(s)$ verbinden das siebente Neuropilem mit der Antennalkommissur, welche also diesen Namen mit Recht trägt, weil sie nicht nur die Gebiete der ersten Antenne (Neuropileme II), sondern auch die Gebiete der zweiten Antenne (Neuropileme VII) verknüpft.

KRIEGER meldet zwar noch weitere Fasersysteme im Hirn, aber ich will diese als zu unbestimmt, nicht erwähnen.'Man wird bemerken, daß die KRIEGERschen Angaben sich relativ selten decken mit jenen OwsJArrixows. Namentlich werden bei KRIEGER die Ganglienzellen, welche Fortsätze in die peripheren Nerven senden, vermisst; das hat aber, wie gesagt, seinen Grund in den theoretischen Anschauungen KRIEGERs, welche sich als irrig erwiesen haben.

Man hat durch KRIEGER mehr Kommissuren im Nervensystem von Astacus kennen gelernt als zuvor. PeICHeNBACH (18S8) hat darüber bemerkt, da $B$ diese Kommissuren auch beim Embryo in erster Linie sichtbar werden, aber nicht ehe das Embryo das Ei verlassen hat.

Retzius (1890) hat das Gehirn von Astacus fluviatilis mit modemen Hilfsmitteln bearbeitet, jedoch darin nur wenige Leitungsbahnen festgestellt. Vorn im Hirnganglion liegen Ganglienzellen, welche ihren Neuriten in den lobus opticus senden und Seitenäste ins Neuropilem. Wahrscheinlich sind es die Ganglienzellen $i$ oder $j$ der Figur 73, wobei KRIEGER dann den Fortsatz zum lobus opticus vernachlässigt haben wïrde. Jedenfalls bekommt OWSJANAiKow gegenüber KRIEGER Recht in seiner Behauptung, daß es im Hirn Ganglienzellen gibt, welche einen Fortsatz in den Stiel des lobus opticus senden.

Den gleichen Schluß muß man ziehen bezïglich des zweiten Antennalner- 
ven. Retzius beobachtete darin Fortsätze von Ganglienzellen in der Nähe der

Fig. 74 .

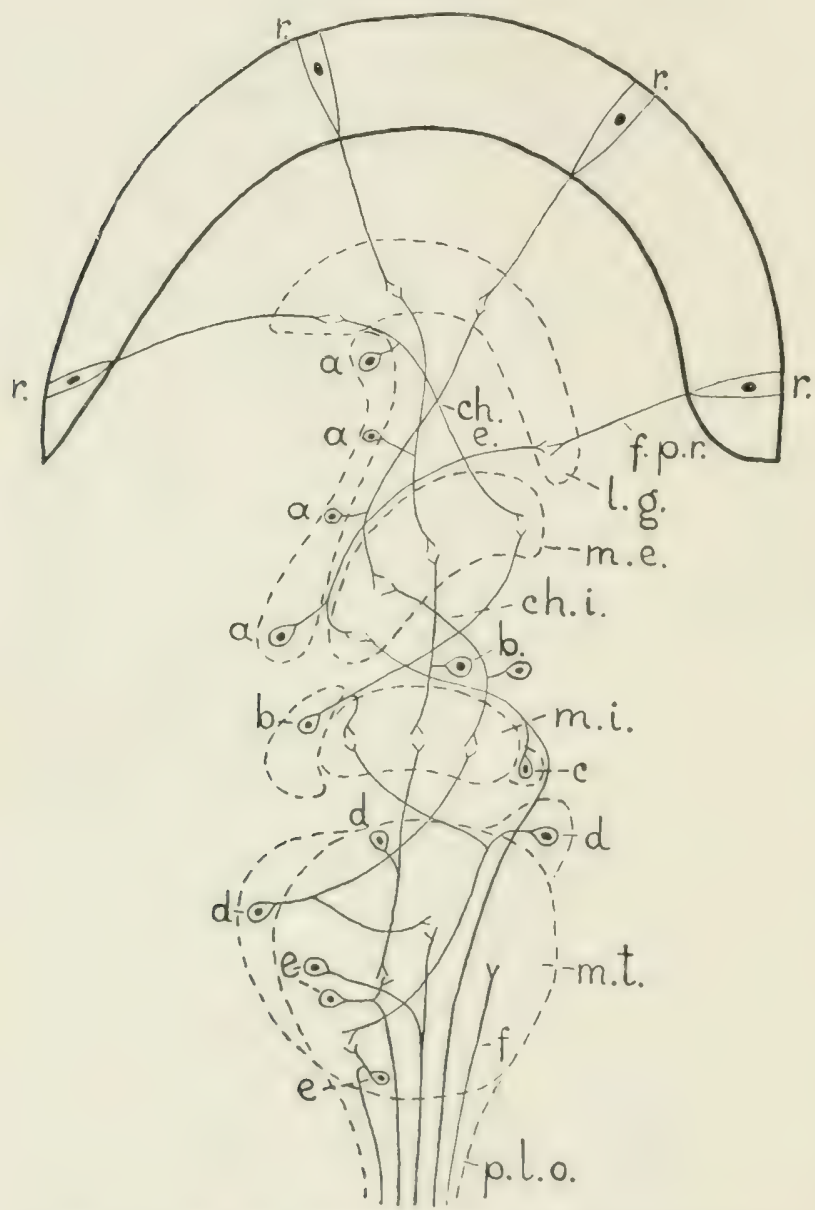

Schema der Reizleitungsbahner im lobus opticus von Astacus.

Abgeändert nach Parker (1895), Fig. 59.

$$
\begin{aligned}
& a \text { bis } e \text { Cianglienzellen } \\
& f=\text { Nervenfaser } \\
& \text { ch. e. chiasma oxternum } \\
& \text { ch. } i \text { chinsma intermum } \\
& \text { i. } r \text { fibrae post retinales } \\
& l \quad g \text {. lamina ganglionaris } \\
& \text { in. e. medulla externa } \\
& \text { ii. i. medulla interna } \\
& \text { m. } t \text {. medulla terminalis } \\
& \text { 1. 1. ". pedunculus lobi optici } \\
& r \text { Retinulazelle }
\end{aligned}
$$

Wurzel dieses Nerven gelegen. WWahrscheinlich ist dies der Zelltypus $q$ der Figur 73 nach KRIEGER - und auch der Zelltypus $p$ (Fig. 84, S. 247) von Homarus.| Eine dritte Ganglienzellart, neben der vorigen gelegen, sah Retzius die Fortsätze in das Schlundkonnektiv schicken.

- Die lobi optici von Astacus sind in sehr schöner Weise von PARKer(1895) studiert worden. Die GoLgIund MethylenblauMethoden lieferten ihm seine Resultate und er hat nicht nur Astacus fluviatilis, sondern auch Astacus leptodactylus untersucht und beide iabereinstimmend gefunden. Ich bin so frei einige der von ihm gegebenen Namen durch die in diesem Buche immer angewandten zu ersetzen. Im lobus opticus, dessen Leitungsbahnen Fig. 74 zeigt, sieht Parker vier, optische Ganglien". Das erste ist die lamina gangliomaris (Fig. $74, l . g$ ), das zweite die medulla externa (m. e.), das dritte die medulla interna (m.i.) und das vierte die medulla ter-

minalis (m.l.). Von hier führt nach PARker der, ,nervus opticus" zum ,lobus 
opticus", einem hervorragenden Hirnabschnitt; ich würde sagen : von hier führt der pedunculus lobi optici (Fig. 74, p.l.o.) zum protocerebrum, aber es wird nicht nach Namen, sondern nach Leitungsbahnen gefragt, und diese hat PARKer in großer Menge beobachtet.

In jedem Ommatidium des zusammengesetzten Auges sah PARKer sieben funktionierende Retinulazellen. Vier dieser Retinulazellen $(r$. $)$ sind schematisch in die Figur 74 eingezeichnet worden. PARKER betrachtet diese Zellen in Uebereinstimmung mit Grexacher als Sinnesnervenzellen, denn sie setzen sich alle in eine Nervenfaser fort. In ihrem Inneren sieht man Neurofibrillen, welche sich mit dem Phabdom in Verbindung setzen.

Die Nervenfortsätze der Retinulazellen bilden erst die Schicht der postretinalen Nervenfasern und treten dann in die lamina ganglionaris ein, wo sie verzweigt enden. In der lamina ganglionaris konnte PARKER vier Schichten unterscheiden: zwei Körnerschichten, welche Kerne enthalten und zwei Faserschichten. Weil die Kerne der Körnerschichten nach PARKER zu Stützzellen gehören und nicht zu Ganglienzellen, haben diese Schichten für die Hodologie kein weiteres Interesse, weshalb ich sie auch in der Fig. 74 fortgelassen habe. Es sei jedoch bemerkt, daß Palinurus nach VIALLANes und auch die Insekten wohl Ganglienzellen in der lamina ganglionaris aufweisen.

Die Neuropileme, welche medulla interna, externa und terminalis genannt werden, werden durch Ganglienzellen umringt, welche entweder unipolar oder apolar sind. Apolare Ganglienzellen kommen hier ohne Zweifel vor, aber nur dort, wo sich im späteren Leben des Tieres noch neue Abschnitte des Ganglions ausbilden. Es sind also Neuroblasten und das Fehlen der Fortsätze findet darin seine Erklärung. Der Stammfortsatz der unipolaren Ganglienzellen spaltet sich wiederum, wie so oft, in einen Neuriten und ein Dendritensystem.

Die Ganglienzellen, welche neben der medulla externa stehen (Fig. 74, a), senden einen Stammfortsatz aus, welcher sich spaltet in einen Ast zur lamina ganglionaris und einen anderen zur medulla externa. Die Aeste sind die Fasern des bekannten chiasma externum ( $\left.h . e_{0}\right)$. Sie laufen in einer sehr bestimmten Weise, welche die Figur 74 näher beleuchtet.

Bei der medulla interna und dem chiasma internum wiederholt sich die Lage der medulla externa und des chiasma externum. In der Umgebung der medulla interna befinden sich Ganglienzellen-(b), deren Fortsätze teils zur medulla externa, teils zur medulla interna ziehen und das chiasma internum (ch. i.) bilden. Es gibt hier aber auch Ganglienzellen (c), deren zentraler Fortsatz nicht in die medulla interna geht um dort verzweigt zu enden, sondern die medulla terminalis durchbohrt und in den pedunculus lobi optici zieht. Wahrscheinlich haben auch BeLloxer bei Squilla (S. 217) und Viatlanes bei Palinurus (S. 240) diese Zellen gesehen, aber weniger genau beschrieben.

In der Nähe der medulla terminalis sind Ganglienzellen (d) gelagert, welche einen Fortsatz in die medulla interna und einen anderen in die medulla terminalis aussenden. Diese Fasern bilden tatsächlich ein ebensolches Chiasma, wie das chiasma externum und internum. Nur ist es nicht so regelmäßig und wurde es nicht von älteren Autoren erkannt, weshalb es auch keinen besonderen Namen trägt. 
In der medulla terminalis hat PARKer außerdem eine größere Ganglienzellart $(e)$ beschrieben, welche einen Fortsatz in die medulla terminalis selbst. und einen anderen in den Stiel des lobus opticus aussendet, welcher bis ins Gehirn zu verfolgen war. Aehnliche Zellen hat auch wohl BeLLoxcr bei Squilla beobachtet (S. 218).

Bei diesem Sachverhalt gelangt PARKer zu dem Schluß, daß die optischen Reize, bevor sie das Gehirn erreichen, eine Kette von fünf oder wenigstens drei Neuronen zu durchlaufen haben. Diese fünf Neuronen sind die Retinulazelle $(r$.$) und die Ganglienzellen a, b, d$ und $e$, während die Zelle $c$ die Zellen $b, d$ und $e$ ersetzen kamn. Die Leitungsbahnen sind also nicht für alle Ommatidien dieselben.

Dorsal im pedunculus lobi optici war ein besonderes Faserbündel unterscheidbar, welches aus einer dorsalen Anschwellung der medulla terminalis hervortrat, aber die Ganglienzellen dieser Fasern lagen ebenso wie die anderen in der medulla terminalis. Wichtiger war es, daß PARKER im Stiel des lobus opticus Nervenfasern (Fig. 74, f) entdeckte, welche in der medulla terminalis endeten ohne dort mit Ganglienzellen in Verbindung zu treten. (Auch diesen Fasertypus hatte BeLLOxcI schon bei Squilla beschrieben.) Sie stammen also wohl aus dem Gehirn, ebenso, wie einige motorische Nervenfasern zu den Muskeln des Augenstieles, welche den pedunculus lobi optici begleiten.

Endlich wird noch von PARKER eine sehr eigentümliche Nervenfaserart des pedunculus beschrieben, welche aus bipolaren Ganglienzellen in der Nähe der lamina ganglionaris hervogehen, jedoch nicht die Chiasmata durchlaufen. Der zweite Fortsatz dieser Ganglienzellen breitet sich über die lamina ganglionaris aus. PARKER spricht diesen Zellen eine optische Funktion ab und betrachtet die Fasern als nervi nervorum, mit wahrscheinlich sensibelem Charakter. Ich glaube, diese Zellen sind einer erneuten Untersuchung wert. Auch bei Insekten (z. B. Aeschna) kennt man Nervenfasern der lamina ganglionaris, welche außer den Chiasmata laufen.

Eine commissura optica im Gehirn wurde von PARKER vermilit.

Die ersten Mitteilungen über die Bahmen der Ganglien des Bauchstranges sind sehr allgemein gehalten. Ows zwei oder drei Kommissuren beobachtet und außerdem Ganglienzellen, welehe ihren Fortsatz in einen peripheren Nerven senden. Bemerkenswert ist das Vorkommen kleiner Ganglienzellen im Bauchstrang, welche wenigstens vier Fortsätze besitzen. Einer geht, wie ich schon oben meldete, zum Hirn, ein anderer ist eine Kommissurfaser und die iibrigen treten in die peripheren Nerven des Ganglions.

LEMorve (1868) ist ebenso wie OWSJAxirow im Stande in den Batuchgan. glien zwei oder drei Kommissuren nachzuweisen, deren fasern aus Ganglienzellen des Ganglions hervorgehen. Ebenso sah er Ganglienzellen mit Fortsätzen in den peripheren Nerven. Daneben hat er seine Aufmerksamkeit den Nervenfasern der Konnelitive gewidmet und festgestellt, dal3 sie oft aus Ganglienzellen dèr Bauchganglien hervortgehen. Lis sind dies nur die aszendierenden Nervenfasern.

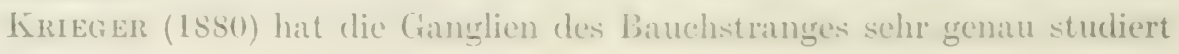


und darin manche Leitungsbahnen wenigstens teilweise angedeutet. Es gelten hier dieselben Bemerkungen, welche ich oben (S. 221) über seine Arbeit äußerte.

Das Gehirn ist durch die Schlundkonnektive mit dem unteren Schlundganglion verbunden. In jedem Schlundkonnektiv entdeckte KRIEGER schon zwei kolossale Nervenfasern (Neurochorde), welchen wir nachher noch manchmal begegnen werden und welche sich nach KRIEGER im Gehirn verzweigen. Wo sie entspringen sagt er nicht.

Halbwegs des Schlundkonnektivs ist ein Ganglion darin eingeschaltet. Es ist dies das Konnektivalganglion (Kommissuralganglion nach KRIEGER, welcher die Konnektive Kommissuren nennt), das auch in der Allexschen Arbeit (siehe Fig. 81, S. 237) angeführt wird. Die Ganglienzellen des Konnektivalganglions senden ihre Fortsätze ins Neuropilem, aber, ob sie dort enden, ist nicht bekannt, wohl, daß ein Teil der Fasern dieses Ganglions dem Konnektiv folgt, was uns nicht wundern kann.

Das untere Schlundganglion ist nach KRIEGER aus sechs hinter einander gelegenen Ganglien zusammengesetzt (man vergleiche S. 243) und Fig. 75, welche mit einigen Abänderungen der KRIEGERschen Arbeit entnommen wurde, soll uns darüber belehren. Man sieht das Ganglion von der ventralen Seite. Vorn gehen die Schlundkonnektive (s. k.) ab, hinten die Konnektive $(k$.), welche das Ganglion mit dem ersten Thorakalganglion verbinden. An der ventralen Seite gehen zu jeder Seite sechs periphere Nerven ( 1 bis 6) ab und an der dorsalen Seite vier Paare, wovon nur ein $\operatorname{Paar}(n . d$.) in die Figur eingetragen wurde. Rechts und links liegen ventral im Ganglion sechs Neuropileme ( $\mathrm{I}$ bis VI) und dorsal noch zwei weitere (VII und VIII), welche gegenseitig verbunden sind.

Die zwölf ventralen Neuropileme sind

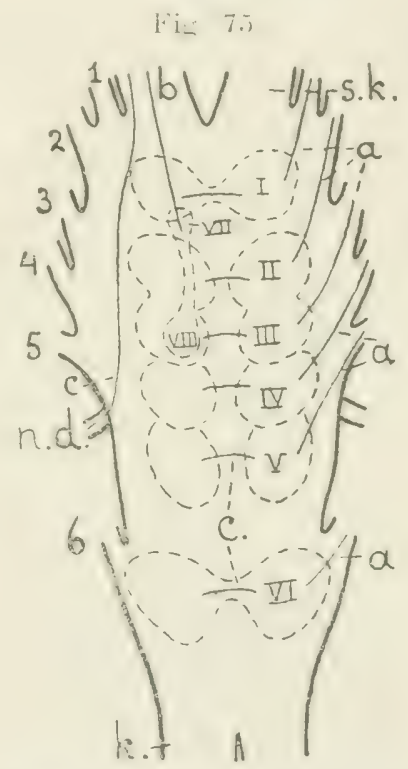

Unteres Schlundganglion von Astacus.

Abgeändert nach KRIEGER (1880), Fig. 3a.

$a, b, c=$ Nervenfasern

1 bis $6=$ ventrale Nerven

I bis VIII = Nouropileme

$$
\text { c. }=\text { Kommissur }
$$

k. $=$ Konnektiv

n. d. = nervus dorsalis

s. $k$ : = Schlundkonnektiv paarweise durch Kommissuren (c.) verbunden und aus einem jeden entspringen Nervenfasern für einen der zwölf ventralen Nerven $(a)$. Im vorderen dorsalen Neuropilem (VII) enden Fasern aus dem Schlundkonnektiv, während nach KrIEger aus dem hinteren (VIII) Nervenfasern zu den Muskeln der Flagella hervorgehen.

Im unteren Schlundganglion liegen manche Ganglienzellgruppen. Ihre Zellen senden meistens ihre Fortsätze zum nächsten Neuropilem, aber große Ganglienzellen, welche lateral vorn im Ganglion gelagert sind, senden ihre Fortsätze in die Konnektive und manche Ganglienzellausläufer kreuzen die 
Medianlinie. Wir werden bald im ersten Thorakalganglion Nervenfasern kennen lernen, welche aus dem vorderen Konnektiv kommend in die peripheren Nerven des Ganglions austreten. Das Bündel dieser Nervenfasern spaltet sich im unteren Schlundganglion und die Aeste sind nach KrIEgER teilweise durch ein Chiasma verbunden. Ich muß dabei bemerken, daß es keineswegs möglich war, die einzelnen Nervenfasern zu verfolgen und daß diese Angaben also sehr der Bestätigung bedürfen. Die Fasern der drei hinteren dorsalen Nerven sah KrIEger aus den Schlundkonnektiven herstammen (Fig. 75, c).

Dem unteren Schlundganglion von Astacus folgen füf 'Thorakalganglien, welche nach KrIEGER übereinstimmend gebaut sind. Fig. 76 ist eine schema-

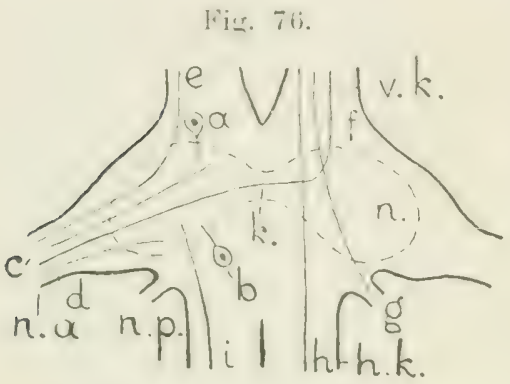

Thorakalganglion von Astacus. Abgeändert nach KRIEGer (18S0), Fig. 7.

$a, b=$ Ganglienzellen

$c$ bis $i=$ Nervenfasern

h. l. = hinteres Konnelitiv

k. $=$ Kommissur

n. = Neuropilem

n. $a$. $=$ nervus anterior

n. p. = nervus posterior

$r . l$. = vorderes lionnektiv

tische Abbildung eines derselben. Die Ganglien werden durch die vorderen und hinteren Konnektive ( $v . k$. und $h . k$.) gegenseitig verbunden und ein jedes Ganglion läßt zwei Nervenpaare aus sich hervorgehen. Der vordere Nerv $\left(n . a_{0}\right)$ ist der größere. Er geht zu den Schreitfüßen und den Kiemen. Der kleinere, hintere Nerv $(n, p$.$) geht zu den Muskeln des$ Thorax.

Rechts und links im Ganglion ist ein Neuropilem (n.), welche beide durch eine Neuropilembrücke verbunden sind. Die Nervenfasern der Konnektive laufen dorsal über dieses Neuropilem hinweg und sie werden dabei in einige Bündel auseinandergedrängt durch eine dreifache Kommissur ( $k$.), welche über der Neuropilembrïcke sich befindet.

Lateral vorn $(a)$ und medial hinten $(b)$ ist eine Gruppe von Ganglienzellen sicht-

bar, deren Fortsätze ins Neuropilem tauchen, wo KrREgER sie nicht weiter verfolgen konnte. In dieser Hinsicht war später RETziUs glücklicher (vergl. S. 229).

Im vorderen peripheren Nerven hat KrIEger Fasem beobachtet, welche entweder aus dem Neuropilem des Ganglions oder aus dem vorderen lionnektiv dorthin gelangten. Die l'asern der ersten Art liamen aus versehiedenen Teilen des Neuropilems (Fig. $76, c$ und $d$ ) ; die letztgenannten entweder aus dem Konnektiv der gleichen (e) oder der gekreuzten Seite (f), wobei KRıEER die wichtigo 'Tatsache entdeckte, dal3 jene liasern, welehe den weitesten II eg zurückgelegt hatton, im Konnelitiv am meisten lateral liefen.

Ebenso wie der nervus anterior, empfängt der nervus posterior lasern (g) aus dem vorderen Konnektiv der greichen seite und daneben durchlaufen riederum andere Nervenfasern $(h)$ das ganze Ganglion $u m$ im hinteren Konnelitiv zu versehwinden. Das hintere Konnelitiv steht durch Nervenfasern (i) mit dem Neuropilem des 'Thorakalganglions in Verbindung, aber, ob es 
auch Fasern für den vorderen Nerven enthält, komnte KRLEGER nicht feststellen.

Das ist, was KrIEgER uns über die Hodologie des Thorakalganglions erzählt. Retzius (1890) hat eben dasselbe Objekt mit Hilfe der MethylenblauMethode studiert. Die Bahnen, welche er besonders in den zwei hinteren Ganglien entdeckte, sind in Fig. 77 schematisch dargestellt. Vorn lateral im Ganglion liegen Ganglienzellen (a), welche ihren Neuriten nach Abgabe von Seitenästen im Neuropilem in den vorderen Nerven senden. Die MethylenblauMethode läßt Retzıus, wie begreiflich den von Nervenfasern der peripheren Nerven mit Ganglienzellen des Ganglions erkennen. Weil KrIEgER einen solchen Zusammenhang prinzipiell verneint, bin ich geneigt, die Ganglienzelle (a) von Retzius (Fig. 77) mit der Ganglienzelle $(a)$ von Kírieger (Fig. 76) zu identifizieren und dieser Zelle auch die Faser $c$ (Fig. 76) zuzurechnen. Dann ist die erwünschte Uebereinstimmung erreicht. Ganglienzellen des Typus $a$ sind auch von Altex bei Homarus beschrieben worden ( $\mathrm{S}$. $246)$.

Retzius konnte auch die Fortsätze anderer Ganglienzellen verfolgen. Eine Art ist hinten im Ganglion gelagert $(b)$. Ihr Fortsatz überschreitet die Medianlinie, gibt dem Neuropilem Seitenäste ab und läuft im Konnektiv nach vorn. Ein anderer Typus ist eine wahre Kommissurzelle (c). Ihr Stammfortsatz verzweigt sich im Neuropilem der gleichen und der gekreuzten Seite. Eine letzte Ganglienzellart $(d)$ ist median gestellt. Der Neurit zieht nach hinten in das Konnektiv, aber Seitenäste dringen ins Neuropilem.

In den peripheren Nerven beobachtete

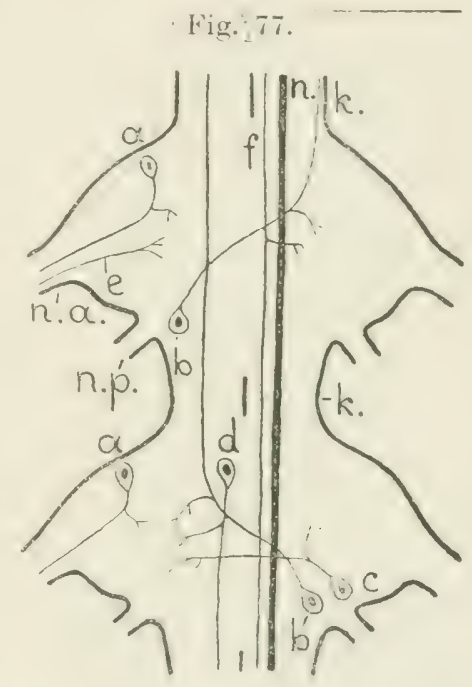

Die zwei hinteren Thorakalganglien von Astacus.

Abgeändert nach Retzros (1890). $a$ bis $d=$ Ganglienzellen

$$
\begin{aligned}
e, f & =\text { Nervenfasern } \\
k . & =\text { Konnektiv } \\
n . & =\text { Neurochord } \\
n . a . & =\text { nervus anterior } \\
n . p_{0} & =\text { nervus posterior }
\end{aligned}
$$

Retzius Fasern (e), welche scheinbar verzweigt im Neuropilem endeten. Warum Retzius meint, daß auch diese Fasern wohl mit Ganglienzellen des Ganglions in Verbindung stehen würden, ist mir nicht klar. Sie stimmen so gut mit den Fasern $d$ der Figur 76 nach KRIEger überein und können sensibele Nervenfasern sein.

Retzius beschreibt in den Konnektiven Nervenfasern, welche die beiden letztên Thorakalganglien durchziehen, ohne mehr zu tun als darin einige Seitenäste abzuspalten. Einige dieser Fasern (Fig. 77,f) stimmen mit von KrIEgER aufgefundenen überein (Fig. 76, h), andere sind kolosisale Nervenfasern oder Neurochorde (Fig. 77, n.), wie KrIEGER sie auch in den Schlundkonnektiven beschrieb. 
Den Thorakalganglien von Astacus folgen fünf Abdominalganglien.

KrIEGER (1880) sagt, daß sie alle übereinstimmend und so, wie die schematische Figur 78 darstellt, gebaut sind. Die Ganglien werden durch die Konnektive $(k$.) verbunden und jedes Ganglion hat zwei Paar peripherer Nerven. Der erste Nerv, welchen ich nervus anterior ( . a.) nennen möchte, geht zu den Afterfüßen, der zweite, der nervus posterior (Fig. 78, n.p.) zu den Abdominalmuskeln. Hinter jedem Abdominalganglion entspringt ein drittes Nervenpaar, diesmal aus dem Konnektiv. Ich schlage vor, diesen Ner-

Fig. 78.

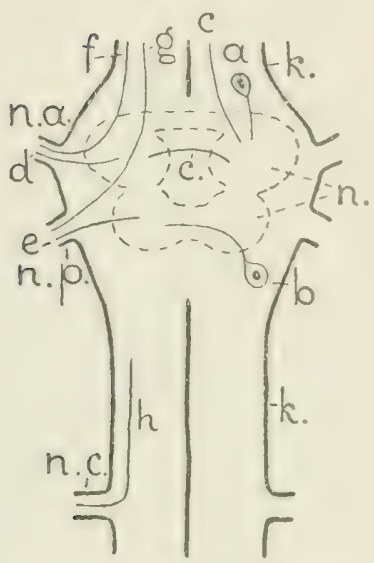

Abdominalganglion vonAstreus.

Abgeändert nach KRIEGER (1880), lig. 9 .

$a, b=$ Ganglienzellen

$c$ bis $h=$ Nervenfasern

$c$. $=$ Kommissur

$k$. = Konnektiv

$n$. $=$ Neuropilem

n. $a .=$ nervus anterior

n. $c$. $=$ nervus connectivalis

n. $p$. $=$ nervus posterior ven Konnektivalnerven (nervus connectivalis, Fig. 78, n.c.) zu nennen. In jedem Ganglion liegen vier Neuropileme (Fig. 78, $n$.) alle gegenseitig zusammenhängend. Die beiden vorderen werden außerdem durch eine Kommissur (c.) verbunden.

Die Ganglienzellen liegen alle ventral. Thre Fortsätze ziehen ins Neuropilem (Fig. 78,a). Daß sie dort bisweilen die Medianlinie iiberschreiten (Fig. 78,b) wurde von KRIEGER beobachtet, nicht aber, daß andere Nervenfasern der peripheren Nerven oder der Konnektive ihre unmittelbare Fortsetzung sind (vergl. unten Retzius). Wohl teilt Krieger uns mit, daß aus dem Neuropilem Nervenfasern des vorderen Konnektivs, (c) und des vorderen und hinteren Nerven $(d, e)$ hervorgehen, ebenso wie die beiden genannten Nerven auch Fasern aus dem rorderen Konnelitiv empfangen $(f, g)$. Der nervus connectivalis erhält nach KrIEgER Fasem, welche im Konnektiv deszendieren und dam darin abbiegen (Fig. $78, h$ ).

ReTzrus (1S90) hat dic W'ege der Leitungsbahnen im Abdominalganglion weit besser als Krieger gesehen, wozu ihm die MethylenblauMethode den Weg bereitete. Seine Beschreibung des allgemeinen Baues dieser Abdominalganglien stimmt ganz gut mit der KrIEGERschen iiberein, weshalb ich die von ihm entdecliten Bahnen in einen ebensolchen Umriß wie der Figur 78 cintragen kann (siehe Fig. 79).

RETziUs hat dem ersten Abdominalganglion von Astacus besondere Aufmerksamkeit gewidmet und die Figur 79 stellt dieses dar. Seine Angaben über die ähnlich gebauten vier ïbrigen Abdominalganglien werde ich unten wiedergeben.

Erstens liegen im ersten Abdominalganglion einige Ganglienzelltypen. Der erste (Fig. 79, a) sendet seinen Neuriten in das Konnektiv nach rorn, aber die Dendriten ziehen ins Neuropilem. Ein zweiter 'Typus (b) gleicht dem ersten mit dem Untersehiede, daß der Neurit kreuzt und in das Konnelitir der anderen Seite tritt. Der Zelltypus $c$ (Fig. 79) kann die vordere mediane Ganglienzelle genannt werden. Sein Fortsatz zieht nach hinten in das lionnek- 
tiv, Seitenäste aber ins Neuropilem der beiden Seiten. In den anderen Abdominalganglien ist dieser Zelltypus meistens multipolar. Lateral im Ganglion entdeckte ReTzIUs Ganglienzellen mit Fortsätzen, welche in das Konnektiv nach hinten ziehen, entweder ungelireuzt $(d)$ oder nach Ueberschreitung der Medianlinie (e). Immer suchen Seitenäste das Neuropilem. Es wäre denkbar, daß der Zelltypus $e$ auch von KRIEGER beobachtet worden wäre (vergl. Fig. 78, b). Neben der Abgangsstelle des vorderen Nerven sind nach Retzius Ganglienzellen $(f)$ gestellt, welche ihren Neuriten diesem Nerven beimischen, während Seitenäste sich im Neuropilem verzweigen. Andere Nervenfasern des vorderen und auch des hinteren Nerven waren nicht mit Zellen des Ganglions verbunden, was Retzius einer mangelhaften Färbung zuschreibt, weil in anderen Abdominalganglien diese Fasern unzweifelbare Ausläufer von Ganglienzellen waren. Ich habe diese Fasern deshalb in der Figur 79 fortgelassen; -wir werden aber später sehen, daß OwsJAxNIKow(1900)wirklich im hinteren Nerven Fasern zu Gesicht bekommen hat, welche verzweigt im Ganglion enden. Das könnte also auch hier der Fall gewesen sein.

Neben diesen Ganglienzellen und ihren Fortsätzen beschrieb Retzios manche Nervenfasern, deren Zellen außerhalb des Ganglions zu suchen sind. Zuerst wiederum die kolossalen Nervenfasern oder Neurochorde $(n$.$) , welche$ hier ebenso wie im thorakalen Teil des Bauchstranges die Ganglien und Konnektive der Länge nach durchziehen. Besonders dick sind auch Nervenfasern (Fig. 79, g), welche mit dem Konnektivalnerven (n.c.) in den Bauchstrang eintreten, nach vorn umbiegen und im ersten Abdominalganglion enden. Die Fasern

Fig. 79.

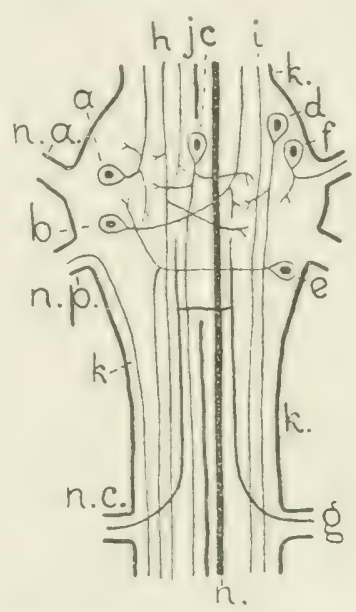

Erstes Abdominalganglion von Astacus.

Abgeändert nach RETzrus (1890).

$a$ bis $f=$ Ganglienzellen $g$ bis $k=$ Nervenfasern

$k$. $=$ Konnektiv

$n$. $=$ Neurochord

几. $u$. $=$ nervus anterior

n. $c$. = nervus connectivalis

n. $p .=$ nervus posterior von links und rechts werden dabei durch Querverbindungen, kommissurale Seitenäste, verbunden. Wahrscheinlich sind diese Fasern dieselben, welche auch KRIEGER (Fig. 78, $h$ ) wahrgenommen hat (vergl. S. 230).

Auch andere Fasern neben den Neurochorden durchlaufen das ganze Ganglion und das vordere und hintere Konnektiv. Einige spalten dabei Aeste ab, welche ins Neuropilem derselben oder der gekreuzten Seite ziehen $(h)$, andere jedoch unterlassen dieses $(i)$.

PuEtzius hat ebenso wie KrIEger Nervenfasern beobachtet, welche aus dem vorderen Konnektiv herstammend in das erste Abdominalganglion endeten (vergl. Fig. 79, $j$ mit Fig. $78, c$ ). Ueber die Fasern des hinteren peripheren Nerven meldet Retzios endlich noch, daß sie ihren Lauf im hinteren Konnektiv fortsetzen (Fig. 79, k). 
Die übrigen Abdominalganglien stimmen, wie gesagt, mit dem ersten überein. Das zweite zeigte Rerzius Ganglienzellen der Typen $a, c, f$ und $b$ der Figur 79 und einen Typus, der der Zelle $b$ sehr ähnlich war, aber der Zellkörper war vorn lateral im Ganglion gelagert. Der nervus posterior enthielt Fasern wie $k$ der Figur 79, daneben jedoch andere, welche Fortsätze von kleinen Ganglienzellen in der Nähe der Nervenwurzel waren und wiederum wurden in diesem Nerven Fasern beobachtet, welche sich im Neuropilem des Ganglions verzweigen ohne mit Ganglienzellen in Verbindung zu stehen. Der nervus connectivalis bekam hier Fortsätze von hinten im Ganglion gelagerten Ganglienzellen mit Seitenästen im Neuropilem. Die Neurochorde und Fasern der Typen $h, i$ und $j$ (Fig. 79) traten aufs neue zu Tage. Neu hingegen war eine Art Kommissurzelle ohne langen Fortsatz, aber mit Verästelungen im Neuropilem der beiden Seiten. Könnten ihre kreuzenden Fortsätze vielleicht die von KrIEGER (Fig. 78, c) beschriebene Kommissur bilden ?

Das dritte Abdominalganglion weist ebenfalls die vordere, mediane Ganglienzelle $(c)$ und manche Ganglienzellen und Fasern auf, welche wir in den beiden ersten Ganglien kennen lernten. Der nervus connectivalis empfängt nicht nur Fasern, welche vorn aus dem Konnektiv kommen, sondern auch solche, welche von hinten aus dem Konnektiv herkommen.

Das vierte Abdominalganglion bot viele bekannte Zell- und Fasertypen dar. Daneben Fasern, welche aus dem vorderen Konnektiv herstammend in den vorderen, peripheren Nerven abbogen und also mit Fasern des Typus $f$ der Figur 78 nach KRIEGER übereinstimmten.

Das fünte Abdominalganglion war besonders dem vierten gleich.

OwsJañikow (1900) hat den obengenannten Retzrusschen Angaben kritisch nachgearbeitet und manches bestätigt, einiges verneint. Auch er untersuchte die Abdominalganglien von Astacus fluviatilis mit Hilfe der Methylenblau-Nethode. Daneben standen ihm GoLGI-Präparate zur V'erfügung. OwsJannikow bestätigte das Vorkommen von Ganglienzellen des Typus $f$ (Fig. 79) und von Ganglienzellen mit Fortsätzen, welche die Medianlinie iiberschreiten. Im hinteren Nerven überwiegen nach ihm Nervenfasern, welche verzweigt im Ganglion enden. Man wird sich erinnern, daß RETzius derartige Nervenfasern im ersten und zweiten Abdominalganglion tatsächlich sah, aber nicht recht an ihr. Dasein glauben konnte. Einige Aeste dieser Nervenfasern ziehen nach hinten in das Konnektiv. Eine Minderheit der Nervenfasern des hinteren peripheren Nerven sprossen aus Ganglienzellen des Ganglions hervor.

Der nervus connectivalis enthält nach Ows.dxxikow ebenfalls Nervenfasern, welche sich im Ganglion verästeln. Es sind dies aber nicht die dicken Nervenfasern (Fig. 79, g), welche RETzus darin zu sehen meinte, denn diese sind nach OwsJAxхmow überhaupt keine Nervenfasern, sondern Blutgefäße. Ich gestehe, daß die sonderbaren Querverbindungen der rechten und linken „Nervenfasern”, welche für Blutgefïße gar nicht fremd sein wïrden, mich an ihrer Natur zweifeln machen. Sind es wirklich Blutgefäße, was ich gerne bestätigt sähe, so hat KRIEGER vielleicht nicht diese, sondern die von UwsJANxikow entdeckten Nervenfasern beobachtet. Es soll jedoch hier nicht verschwiegen werden, daß OWs. Axinow der Meinung ist, daß auch die von 
Retzics beschriebenen Neurochorde Blutgefäße sind. Nun hat OwsJanvikow wirklich Blutgefäße ins Auge gefaßt, denn er beschreibt die Muskelfasern, das Endothel und die Blutkörperchen, aber ich glaube, daß RETzIUs in diesem Falle etwas andres gesehen hat: wahre Neurochorde.

In gutem Einklang mit Retzius meldet OwsJanxikow Fasern im Konnektiv, welche Fortsätze von Ganglienzellen derselben oder der gekreuzten Seite sind und besonder's große multipolare Ganglienzellen, welche nach ihm auch Retzius gesehen hat (die vordere, mediane Ganglienzelle, Fig. 79, $c$ ?) senden Fortsätze ins Neuropilem, in die Konnektive und außerdem in die rechten und linken peripheren Nerven.

Das letzte Ganglion des Bauchstranges von Astacus fluviatilis ist das Schwanzganglion. Es weicht in seinem Bau erheblich von den anderen Ganglien $a b$.

KrIEGER (1880) erzählt uns, daß ein medianer Nerv (Fig. $80, n . m$.) und fünf. Nervenpaare das Ganglion verlassen. Davon treten vier Paare ventral aus (Fig. so, 1, 2, 3, 4) und ein Paar dorsal ( $n$. d.). Selbstverständlich ist das Schwanzganglion durch das Konnektiv (k.) mit den Abdominalganglien verbunden.

Witten im Ganglion befindet sich das Neuropilem, an dem man einen Vorderteil (neuropilema anterius, Fig. 80, n.a.) und einen Hinterteil (n. p.) unterscheiden kann. Der Vorderteil besitzt nicht weniger als drei Kommissuren (Fig. 80, c.) und weil aus diesem Neuropilem Nervenfasern für drei ventrale Nerven hervortreten ( $a, b$ und $c$ ), achtet KRIEGER diesen Teil drei Ganglien gleichwertig. Fig. 80 .

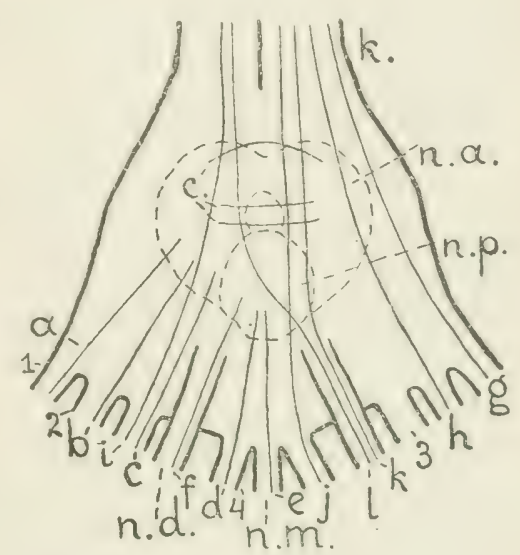

Seliwanzganglion (oder sechstes Abdominalganglion) von Astacus.

Abgeändert nach KRIEGER (1880), Fig. 10.

$a$ bis $l=$ Nervenfasern

1 bis $4=$ ventrale Nerven

c. $=$ Kommissur

$k_{\mathrm{i}}=$ Konnektiv

n. $a$. = neuropilema anterius

n. $d .=$ nervus dorsalis

$n . m$. $=$ nervus medianus

n. $p$. = neuropilema posterius Das hintere Neuropilem verschafft dem vierten ventralen $(d)$, dem medianen $(e)$ und dem dorsalen Nerven $(f)$ Fasern. Wie immer, so glaubt KRIEGER auch hier, daß die Ausläufer der Ganglienzellen des Schwanzganglions sich ins Neuropilem begeben, aber nicht unmittelbar in die peripheren Nerven austreten. Die vier ventralen Nerven empfangen Fasern aus dem Konnektiv $(g, h, i, j)$ und wahrscheinlich stimmt der mediane Nerv darin mit ihnen überein. Den dorsalen Nerven sind Fasern beigemischt, welche aus dem Konnektiv derselben oder der gekreuzten Seite herstammen ( $k$ und $l$ ) und welche nach KRIEGER durch Spaltung der Neurochorde der Konnektive entstanden sind.

Auch Retzius (1890) hat gesehen, daß die Neurochorde der Konnektive unmittelbar in die peripheren Nerven des Schwanzganglions übergehen. Sie 
scheinen also den ganzen Bauchstrang von Astacus vom Gehirn bis zu den peripheren Nerven des Schwanzganglions zu durchlaufen, aber die zugehörigen Neurochordzellen wurden weder von KRIEGER noch von RETzIUs entdeckt. (Allex hat bei Homarus die Neurochordzelle im Hirn vorgefunden. Siehe S. 243).

Retzrus hat im Schwanzganglion einige Ganglienzelltypen der Abdominalganglien wiedergefunden. So die multipolare ,vordere mediane Ganglienzelle" (Fig. 79, c), deren Fortsatz jetzt in einen der hinteren Nerven eintritt. Ganglienzellen des Typus $b$ der Fig. 79 sind zahlreich, nicht nur vorn im Ganglion, sondern auch zwischen den Nervenwurzeln. Die peripheren Nerven, jedenfalls die vorderen oder lateralen, enthalten Fasern, welche aus Ganglienzellen des Ganglions hervorgehen. Daß sie auch Fasern führen, welche verzweigt im Neuropilem enden (vielleicht die Fasern $a, b, c, d, e, f$, der Fig. 80) hat Retzius $\mathrm{zu}$ sehen gemeint, aber er kann es wiederum nicht glauben. Warum ist mir auch hier nicht klar geworden. Hat doch später auch Vour RATH (1896) bei Astacus unzweifelhaft sensibele Nervenfasern ins letzte Abdominalganglion eintreten und sich dort verästeln sehen. Wohl ist RETzIUs davon überzeugt, daß Nervenfasern aus dem Konnektiv verzweigt im Neuropilem enden.

Was SchyeIder (1902) über das Zentralnervensystem von Astacus sagt, kann man alles schon bei KrIEger und Retzius finden und ich brauche deshalb hier nicht darauf einzugehen. Bemerkenswert ist nur, daß er einer derjenigen Autoren ist, denen ich selbst mich anschließe, welche das Neuropilem der Ganglien nicht als ein diffuses Netz betrachten, sondern als ein Gewebe, worin die Fortsätze einer Ganglienzelle nur mit jenen bestimmter anderer Ganglienzellen zusammenhängen.

Ich verlasse das. Zentralnervensystem von Astacus um dem peripheren Nervensystem noch einige Worte zu widmen.

Ueber die Innervation der Sinneshaare des Körpers habe ich in der Einleitung zu den Arthropoden schon das Wichtigste gesagt. Retzius (IS95) beschrieb in GoLgI- oder Methylenblau-Präparaten bipolare ,Sinnesnervenzellen" unter den Sinneshaaren mit peripheren Fortsätzen, welche oft, aber nicht immer in das Haar eindrangen. Die Körper dieser Zellen konnten einzeln oder in Gruppen, unmittelbar unter dem Haare oder in großer Entfernung liegen. Auch konnten mehrere dieser Zellen ein und dasselbe Haar innervieren. Vou RATH (1895̃) entdeckte im selben Jahre dieselben Zellen mit Hilfe der GoLGischen Methode. Er betrachtet sie als Sinnesnervenzellen, aber in seinen Abbildungen dringen ihre Fortsätze nicht in die Haare ein und dies trägt dazu bei, daß ich sie als sensibele Ganglienzellen auffasse, wie oben auseinandergesetzt wurde. Wie BeтnE (1896) zwei in verschiedenen Weisen innervierte Arten von Sinnesharen auf den Mundteilen von Astacus fluviatilis erkennt, habe ich oben (S. 205) schon mitgeteilt.

Dogiec (1894) hat in der Herzwand von Astacus fluviatilis einen Nervenplexus mit Ganglienzellen entdeckt, also eine Stelle des Nervensystems, wo wir fast keine anatomisch bestimmten Leitungsbahnen erwarten können.

BETHE (1896) beschrieb in den Mundteilen einen Ganglienzellplexus, welcher demjenigen der Coelenteraten sehr älunlich war und dessen multipolare 
Ganglienzellen unmittelbar durch Fortsätze verbunden waren. Hier folgt also der Reiz gewiß keinen anatomisch bestimmten Leitungsbahnen. E. HoLxGREN (1898) behauptet jedoch, daß der von BETHE aufgefundene Plexus aus Bindegewebszellen bestände, was nicht sagen will, daß ein solcher Plexus nicht besteht, denn er selbst fand ihn, ebenso wie NUSBAUM und ScHreIBER, bei manchen Crustaceen.

Schyeider (1902) trägt zur Kenntnis des peripheren Nervensystems von Astacus bei, daß peripher gelegene Ganglienzellen einen Fortsatz durch den vorderen Nerven der Bauchganglien (vergl. Fig. 76, 77, 78 oder 79) in den Bauchstrang senden. Hier angelangt, teilen die Fortsätze sich dichotomisch und die zwei Aeste laufen nach vorn und nach hinten um im selben oder im nächsten Ganglion zu enden. Dieses Verhältnis erinnert also an dasjenige der Chaetopoden und einiger Insekten, z B. Carabiden (S. 303). Offenbar hat ALLEx ähnliche Zellen bei Homarus beobachtet, nur beschreibt er sie als Sinnesnervenzellen (vergl. S. 2こ3).

AlexArdrowicz (1909) hat das sympathische Nervensystem des Darmes einiger Decapoden, worunter auch Astacus, untersucht. Er wandte mancherlei Methoden an, so auch die Methylenblau-Nethode. Die Muskulatur des Darmes hinter dem MIagen wird durch einen Nerven des Schwanzganglions (sechsten Abdominalganglions) innerviert, welcher sich verästelt und einen Nervenplexus bildet. In diesen Plexus ziehen ebenfalls die zentralen Fortsätze bipolarer oder ausnahmsweise tripolarer Ganglienzellen, deren anderer Fortsatz zwischen die Epithelzellen des Darmes in der Richtung der Lichtung geht. AlexANDrowicz ist überzeugt, daß diese Zellen Ganglienzellen sind, denn er sah ihre Neurofibrillen. Es würden dann sensibele Ganglienzellen sein mit freien Nervenendungen im Epithel, ein Ganglienzelltypus, welcher bei den Arthropoden äußerst spärlich vorhanden ist. So viel ich weiß, haben nur VIALlaxes (1882), Lowre (1892) und vielleicht Nemec (1896) auf solche Zellen bei Arthropoden hingedeutet. Noch wumderbarer ist es, was ALExAxDRowICZ wahrscheinlich achtet, daß die zentralen Fortsätze dieser Zellen, welche in Bündeln in den Nervenplexus ziehen, geradewegs zu den Muskeln des Darmes gehen. Die Zellen wären also zu gleicher Zeit sensibel und motorisch oder mit anderen Worten, es gäbe hier eine Reizleitungsbahn, welche nur ein einziges Neuron umfaßte. Solch eine Bahn haben wir schon vorher durch die Bemühungen SAMASSAs im Tentakel von Helix kennen gelernt (S. 151). Dort bildete eine Sinnesnervenzelle, nicht eine sensibele Ganglienzelle mit freien Nervenendungen die Bahn und, weil solches eher einer primitiven Sinnesnervenzelle als einer sensibelen Ganglienzelle zuzutrauen ist (vergl. S. 12) fragt es sich, ob nicht auch die ALEXAxDrowiczschen Zellen am Ende Sinnesnervenzellen sein können. Ich halte dies nach seiner Beschreibung für sehr gut möglich.

Es bleibt mir jetzt noch ïbrig die wichtige Arbeit, welche ALLEx (1894b) iiber das stomatogastrische Nervensystem von Astacus publiziert hat, zu besprechen. Ich verweise dafür auf die Figur S1, welche ich mit einigen Abänderungen nach der Allexschen Figur 1 angefertigt habe. Man sieht darin die beiden Schlundkonnektive $\left(s . l_{i}\right)$, welche das Hirnganglion (h.g.) mit dem 
unteren Schlundganglion $(g . i$. oe.) vereinigen. Halbwegs des Tonnektivs (ALLEN spricht immer über Kommissuren statt Konnektive) befindet sich das Konnektivalganglion (g.c.) Dahinter vereinigt eine Kommissur, welche ich für die Tritocerebralkommissur (tr.c.) halte (vergl. Fig. 72 und S. 241), die beiden Konnektive. Aus jedem ganglion connectivale gehen zwei Nerven hervor, welche das Ganglion mit dem Oesophagalganglion $(g . o e$.$) verbinden.$ Es sind der nervus dorsalis $\left(n . d_{\text {. }}\right)$ und der nervus ventralis $(n . v$.$) , wobei ich$ bemerke, daß ich den Ventralnerven deutlichkeitshalber viel zu dick gezeichnet habe. Das ganglion oesophageum läßt einen dorsalen und einen ventralen Teil unterscheiden. Der dorsale Teil, wo die Dorsalnerven einander begegnen, enthält im Gegensatz zum ventralen Teil nur Neuropilem und keine Ganglienzellen. Das ganglion oesophageum ist durch den nervus azygos (n.az.) mit dem Gastralganglion, welches man nicht mehr in der Zeichnung antrifte, verbunden. Der nervus anterior medianus $(n . a, m$.), in der Figur nach links verlegt, vereinigt das Oesophagalganglion mit dem Hirnganglion. Der nervus ventralis hat zwei Seitennerven A und B. B erreicht einen Nervenplexus, das Gebiet, welches in Fig. 81 mit pl. bezcichnet wurde. Dieser Plexus steht auch mit dem Oesophagalganglion in Verbindung und zwar mittels des Nerven C, welchen man sehr gut nervus posterior medianus nennen könnte. Auch der Dorsalnerv spaltet zwei Aeste ab, welche mit D und E bezeichnet wurden.

Was erzählt uns nun ALLEN ïber die Leitungsbahnen dieses ganzen Systems? Erstens, daß die Kommissur zwischen den beiden Schlundkonnektiven Fasern enthält, welche aus dem Gehirn (Fig. 81, a) oder aus dem Konnektivalganglion (b) stammen. Wo ihre Ganglienzellen sind, blieb leider unbekannt. ' $Z u$ den Fasern der Schlundkonnektive gehören weiter noch solche, welche geradewegs vom Hirnganglion zum Unterschlundganglion laufen (c). Ich sehe diese Fasern in der AllExschen Abbildung, nicht in dem Text, aber wir wissen schon, daß auch andere Autoren solche Fasern für Astacus beschrieben haben.

Im nervus ventralis begegnete ALLEN Nervenfasern, welche zum Nervenplexus ziehen. Einige $(d)$ benutzen dafür den Nerven B, andere hingegen $(e)$ machen einen großen Umweg ïber das Oesophagalganglion und erreichen durch den Nerven C den Plexus.

Die Ganglienzellen der Fasern des Typus $d$ und $e$ sind unbekannt. Vielleicht liegen sie im Konnektivalganglion, wo ALLEx Ganglienzellen fand, ohne ihre Fortsätze verfolgen zu können. Es gibt aber gewiß auch Nervenfasern im Ventralnerven, welche im Konnektivalganglion enden, weil sie dort sich verzweigen (Fig. 81, f).

Im Oesophagalganglion hat ALLex wohl den Lanf der Fortsätze einiger Ganglienzellarten entdeckt. Erstens beschreibt er darin einen bipolaren Ganglienzelltypus $(g)$, welcher einen Fortsatz in den Ventralnerven und den anderen in den nervus azygos schickt. Zweitens wurde ein unipolarer Zelltypus (h) aufgefunden mit einem Stammfortsatz, weleher sich bald teilt in einen Ast zum nervus azygos und zwei Aeste, welche jeder in einem Ventralnerven zu einem Konnektivalganglion laufen. Die dritte Ganerlienzellart war ebenfalls unipolar, aber ihr Fortsatz trat in den Dorsalnerven ein (i). 
Fị. SI.

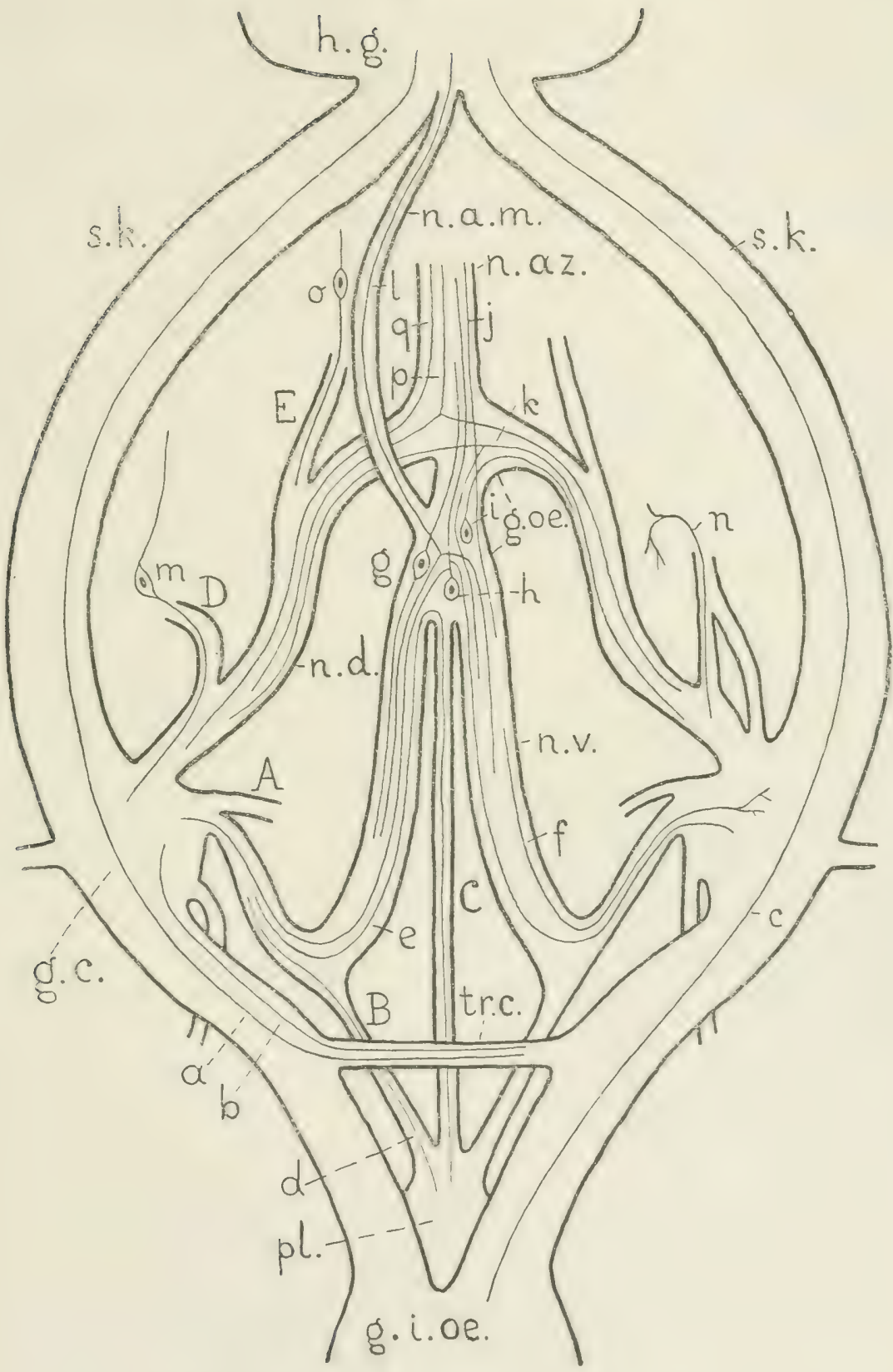

Das stomatogastrische Nervensystem von Astacus. Abgeïndert nach Allen (1894b), Fig. 1. $a$ bis $t, j, k, l, n, p, q=$ Nervenfasern $g, h, i, m, o=$ Ganglienzellen $A$ bis $E=$ Nerven $g . c .=$ ganglion connectivale $g . i . o e .=$ ganglion infraoesophageum $\% . o e,=$ ganglion oesophageum $h . g .=$ Hiruganglion $n . a \cdot m .=$ nervus anterior medianus $n, a z$. = nervus azygos $n . d$. = nervus dorsalis $n_{0}, v_{0}=$ nervus ventralis $r l_{0}=$ plexus $s . k_{0}=$ Schlundkonnelitiv $t r . c_{0}=$ commissura tritocerebralis 
Fasern ohne bekannten Anfang oder bekanntes Ende gingen vom nervus azygos in einen Ventralnerven über (Fig. 81, j), oder vom einen Dorsalnerven in den anderen, wobei sie einem nervus ventralis einen Seitenzweig überlieferten $(k)$. Diese letzten Fasern sind also Kommissurfasern des Oesophagalganglions. Fasern im nervus anterior medianus kamen aus dem Gehirn und spalteten sich im Oesophagalganglion in zwei Aeste, jeder für einen Ventralnerven bestimmt.

Der Seitennerv D des Dorsalnerven ist der. Weg zum Konnektivalganglion für Nervenfasern, welche die zentripetalen Fortsätze bipolarer '/cellen ( $m$ ) sind. Die peripheren Fortsätze dieser Zellen treten ïberall in die Wand des Oesophagus ein. Nach Altex sind diese Zellen Simesnervenzellen sehr gleich, wie es mir aber vorkommt, ist dieser Charakter durchaus nicht erwiesen und würden es auch sehr gut sensibele Ganglienzellen mit frei in der Oesophaguswand endigenden Fortsätzen sein kömnen. Vielleicht gibt man später noch einmal darauf acht. Im Nerven D sind auch Faserm, welche im Oesophagus als motorische Nervenfasern enden $(n)$.

Im Seitennerven E des Dorsalnerven sind Fasern, welche Fortsätze bipolarer Zellen $(o)$ sind, deren periphere Fortsätze zu scharf begrenzten Gebieten des Oesophagus gehen, wo sie an der Oberfläche enden. AlLEN betrachtet diese Areale wohl mit Recht als Sinnesorgane und danu sind die Zellen des Typus o Sinnesnervenzellen der Oesophaguswand.

Der nervus azygos führt Nervenfasern, welche entweder sich im Oesophagalganglion spalten und einen Ast in einen jeden Dorsalnerven senden (rig. $81, p)$ oder sich unmittelbar in einen Dorsalnerven fortsetzen $(q)$. Bei Astacus, ebensogut wie bei Homarus (vergl. Fig. 87, S. 253), gibt es Azygos-Fasern, welche sich im Gastralganglion verzweigen, während hier unipolare Ganglienzellen gelegen sind, welche anderen. Nerven dieses Ganglions ihre Neuriten ïbermitteln.

Ich bin jetzt fertig mit der Beschreibung von Astacus und fange an mit. jener der Languste, Palinurus, welehe uns gar nicht so gut bekannt ist, wic der Elußkrebs.

OwsJAxykow (1861 und 1863) hat iiber dieses Tier (Palinurus locusta) die ersten hodologischen Mitteilungen gemacht. Weil sie genau dieselben sind: welche ïber Astacus und Homarus gemacht wurden, geniigt es hier den Leser auf $\mathrm{S} .220 \mathrm{zu}$ verweisen.

Berger (1878) hat ebenso wie bei anderen Crustacen im Gehirn von Palinurus ein Chiasma von Nervenfasern des lobus opticus besehrieben. Diese Fasern gehen zum Antennalganglion, von ihm der pilzhutförmige Körper genannt. Weil sie nicht alle im Chiasma die Medianlinie lireuzen, ist das Chiasma semidekussat. BERGEr erkamnte bei der Languste eine Kommissur von Fasern der ersten Antenne, die Antennalliommilbur also, und lehrte, daß einige fasern dieser Kommissur aus Ganglienzellen hervorgehen, welehe in einer (iruppe zwischen den beiden, ,Sehnerven" (peduneuli loborum opticorum) liegen.

Vialdaxes hat nicht weniger als viermal studien iiber den lobus optieus (nach ihm ganglion opticum) von Palinurus vulgaris publiziert. Diese Aufsaitze enthalten sehr viel (iutes, besonders hinsichtlich der miliroskopischen Ana- 
tomie dieses Hirnteiles, aber betreffs der Hodologie sind sie weniger glïcklich. Ich drücke neben der Beschreibung seiner Angaben die Figur 71 abermals ab.

Die Schwierigkeiten fangen schon an in der Retina. VIALLANES gelangt nicht zur klaren Erkenntnis, daß die Retinulazellen Sinnesnervenzellen sind. Zuerst ist er (VIALLAXES, $1854 a$ ) der Meinung, daß nur eine einzige Nervenfaser jedes Ommatidium (Fig. 71, o.) oder jedes Rhabdom verläßt. Später $(1892 a)$ zählt er jedem Ommatidium sieben Nervenfortsätze zu, jeder Retinulazelle einen. Auch jetzt betrachtet er den Nervenfortsatz nicht als einen Ausläufer der Retinulazelle, sondern läßt er ihn mit der Rhabdomere der Retinulazelle verschmelzen, was für die Neurofibrillen der Zelle richtig sein mag, nicht aber für den ganzen Fortsatz.

Die Nervenfortsätze der Retinulazellen durchbrechen die Basalmembran der Retina und bilden dann die Schicht der postretinalen Nervenfasern (Fig.? 71, f. p.r.), worin sie gruppiert sind. Sie treten ein in die lamina ganglionaris (Fig. 71, l.g.). In seiner ersten Arbeit weckt VIALLAyES (1884a) die Vorstellung, $\mathrm{da} ß$ die postretinalen Fasern zum 'Teil dort énden, zum Teil weiter Fig. 71 .

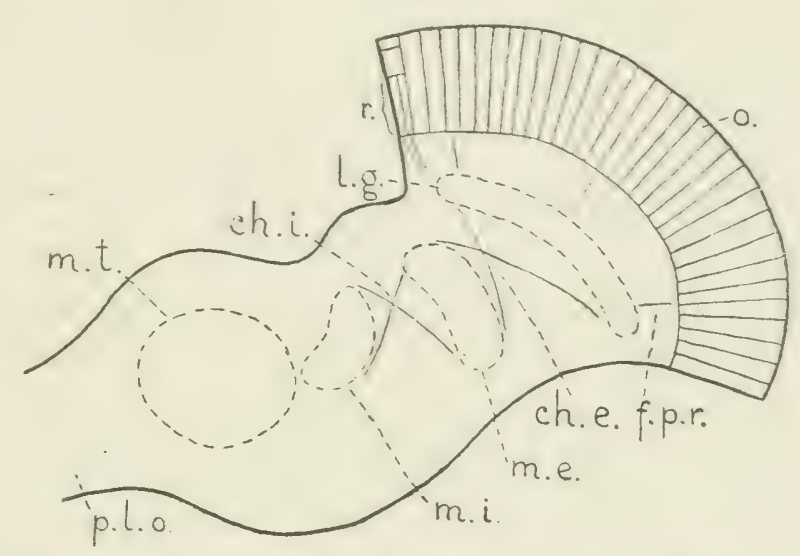

Schematischer Längsschnitt des lobus opticus und des zusammengesetzten Auges der Stomatopoden und Decapoden.

ch. e. = chiasma externa

ch. $i_{\text {. }}=$ chiasma interna

t. $p . r .=$ fibrae postretinales

l. g. = lamina ganglionaris

m. c. = medulla externa

m. $i .=$ medulla interna

m. $t$. = medulla terminalis

o. = ommatidium

p. l. o. $=$ pedunculus lobi optici

$r_{.}=$retinula

ziehen und das chiasma externum (Fig. 71, ch.e.) durchlaufen, um in der medulla externa (Fig. 71, m.e.) verzweigt zu enden. Später hat er besonders die lamina ganglionaris von Palinurus studiert (VIALLANES, 1892b) und jetzt sprichter nur über postretinale Nervenfasern, welche die lamina ganglionaris passieren und in der medulla externa enden. Ich bezweifele die Richtigkeit dieser Angaben. PARKER wenigstens läßt bei Astacus alle postretinalen Nervenfasern in der lamina ganglionaris enden (vergl. Fig. 74, S. 224) und der gleichen Lage werden wir bei den Insekten, freilich mit Ausnahme der Dipteren, begegnen.

VIALlares (1884a und 1892b) hat der Struktur der lamina ganglionaris große Aufmerksamkeit gewidmet. Er sieht darin, wie andere Forscher, einige Zell- und Faserschichten. Wenn sich postretinale Fasern in der lamina gan 
glionaris verästeln, tun sie solches in der mittleren Faserschicht (1884a). VIALlanes (1892b) hat in der lamina ganglionaris die Neurommatidien entdeckt. Es sind dies kleine Fasergebiete, jedes mit einem Ommatidium korrespondierend, welche von den sieben Nervenfortsätzen eines Ommatidiums durchzogen werden. Derartige, sei es auch nicht identische Fasersysteme sind von anderen Autoren auch bei Insekten beschrieben worden (vergl. S. 330). VIallanes blieb ihre wahre Struktur wahrscheinlich verhüllt.

Die lamina ganglionaris wird nach VIALLANES von innen und außen durch eine Schicht unipolarer Ganglienzellen bekleidet. Die Zellen senden ihren Fortsatz in die lamina, wo sie nicht weiter verfolgbar waren. Es sind diese Zellen wahrscheinlich dieselben, welche PARKer bei Astacus als Stützzellen betrachtet (S. 225) und ihre Natur wäre also genauer festzustellen. Wenn es erlaubt ist, die Insekten zur Stütze anzuführen, so ist dort gewiß die lamina ganglionaris mit Ganglienzellen ausgestattet.

$\mathrm{Zu}$ den Fasern des chiasma externum gehören nach VIALLANes (1884a) neben den genannten noch Nervenfasern, welche die lamina ganglionaris mit der medulla externa verbinden und sich in beiden verästeln. Fis sind die Fasern, welche auch PARKer bei Astacus beobachtet hat (Fig. 74), deren Zusammenhang mit Ganglienzellen (Fig. 74,a) VIALLAxEs jedoch verborgen blieb. Wohl hat er vielleicht die Ursprungszellen dieser Nervenfasern selbst wahrgenommen, denn er beschreibt neben der medulla externa eine Ganglienzellgruppe (die corona ganglionaris). Die Fortsätze dieser Zellen verschwinden jedoch nach ihm in der medulla externa und das wiirde dann nicht ohne weiteres der Fall sein können. Besonders große Ganglienzellen in der Nähe der medulla externa senden ihre Fortsätze zur lamina ganglionaris. Auch das stimmt teilweise mit den Ganglienzellen $a$ von Astacus (Fig. 74). Aus allem schließe ich, daß VIALLANES hier die Leitungsbahnen nicht genau beobachtet hat, aber doch der Wahrheit ziemlich nahe kam.

Die Mehrzahl der Fasern des chiasma internum geht nach VraLlaxes (1884a) von der medulla externa zur medulla interna. Nan begreift aus der Figur 74 von Astacus, daß er Fasern, wie diejenigen der Ganglienzellen $b$ damit meint. Er hat überdies richtig gesehen, daß einige Nervenfasern ummittelbar von der medulla externa zur medulla terminalis oder zum peduneulus lobi optici ziehen (wie die Fasern der Ganglienzellen $c$ der Figur 74 von Astacus). Unwahrscheinlich dagegen ist seine Angabe, daß die medulla interna an manchen Seiten von unipolaren Ganglienzellen umgeben ist, welche ihren Fortsatz darin senden. Da hat er wohl die Ganglienzellen (wie $b$ und c der Fig. 74) beobachtet, deren Fortsatz sich spaltet und eine der obengenannten Fasern des chiasma internum bildet.

Der medulla terminalis schreibt Vratuaxes eine Rinde von unipolaren Ganglienzellen zu, welche ihre Fortsitze nach inmen senden. Die medulla terminalis selbst teilt er in einen unteren und oberen Abschnitt ein, welche ich neuropilema inferius und superius nennen möchte. (BELLoxc unterschied bei Squilla weit mehr Gebiete der medulla terminalis; vergl. S. 2ls). Beide neuropilemata erhalten Nervenfasem aus den Ganglienzellen der Rinde und beide Nervenfasern aus dem pedunculus lobi optici, welche in der medulla 
terminalis enden (also, wie bei Astacus die Fasern $f$ der Fig. 74). Ueberdies werden neuropilema inferius und superius durch Nervenfaserbündel verbunden und dann bekommt das neuropilema superius noch Nervenfasern aus dem chiasma internum und aus dem „pedunculus medullae internae”, einem hervorragenden Teil der medulla interna, welcher sich neben dem chiasma internum der medulla terminalis unmittelbar anlegt.

Vtallanes (1893) hat das oben Angeführte verwertet in einer vergleichenden Studie des Nervensystems von Palinurus und einer Grille. Weil der Aufsatz keine neuen Leitungsbahnen von Palinurus kennbar macht und manches enthält, was man jetzt nicht mehr aufrecht erhalten kann, will ich ihn mit Stillschweigen übergehen.

Schon habe ich bei Astacus (S. 235) erwähnt, was ALExAndrowicz (1909) über das sympathische Nervensystem dieses Tieres entdeckt hat. Ueber Palinurus teilt er uns das nämliche mit. Auch hier also wird die Darmwand hinter dem Magen durch einen Nervenplexus innerviert, worin bipolare „Ganglienzellen“ (entweder Sinnesnervenzcllen oder sensibele Ganglienzellen mit freien Nervenendungen im Epithel) ihren zentralen Fortsatz senden und auch jetzt vermutet Alexandrowicz, daß diese Fortsätze direkt die Muskeln des Darmes innervieren, in welchem Falle ein einziges Neuron eine ganze Leitungsbahn darstellen wiurde.

Die dritte Decapode, wie die beiden vorigen eine Makrure, welche mehrfach das Interesse der Histologen fesselte, ist Homarus vulgaris, der Hummer. OwsJANNIKow (1861 und 1863) hat dieselben Leitungsbahnen, welche ich oben (S. 220) für Astacus beschrieb, auch besonders bei Homarus festgestellt.

Newton (1873) hat gesehen, daß ein Nervenfaserbündel aus dem lobus opticus herstammend die Basalmembran der Retina durchbohrte und sich mit dem Rhabdom des Ommatidiums vereinigte. Das ist eine für damals sehr richtige Beobachtung, aber die Anerkennung der Retinulazellen als Sinnesnervenzellen blieb doch GRExACHER überlassen.

Allex hat sich in drei Arbeiten $(1894 a, 1894 b$ und 1896) als der beste Kenner der Leitungsbahnen von Homarus vulgaris erwiesen. Seine erstklassigen Untersuchungen wurden mit Hilfe der GoLGI- und Methylenblau-Methoden ausgeführt und nicht mit dem erwachsenen Tiere, sondern mit Embryonen vorgenommen. Dies geschah aus dem Grunde, daß Embryonen auch bei den Vertebraten so gute Resultate liefern.

In erster Linie wurden die Leitungsbahnen des Zentralnervensystems studiert. Im Stadium, welches Altex (1894a) zur Verfügung stand, erkennt man schon recht deutlich das Gehirn (Fig. 82, h.g.) und den Bauchstrang (Fig. 82, b. str.), welche beide durch noch sehr kurze Schlundkonnektive (Fig. 82, s. k.) verbunden sind. Die beiden Schlundkonnektive werden durch eine Kommissur, welche ich Tritocerebralkommissur (tr.c.) nennen möchte, vereinigt und zeigen eine Anschwellung, das Konnektivalganglion (Fig. 82, g. c.). Die Tritocerebralkommissur begrenzt das Loch im Schlundringe (Fig. 82, oe :), wo der Oesophagus hindurchtritt. Wie die Verhältnisse beim erwachsenen Tiere sind, kann Fig. 72, S. 219, welche die Lage bei Astacus andeutet, beleuchten. Wichtig ist weiter, daß sich im Hirnganglion auch schon der letzte 
Fig. 82.

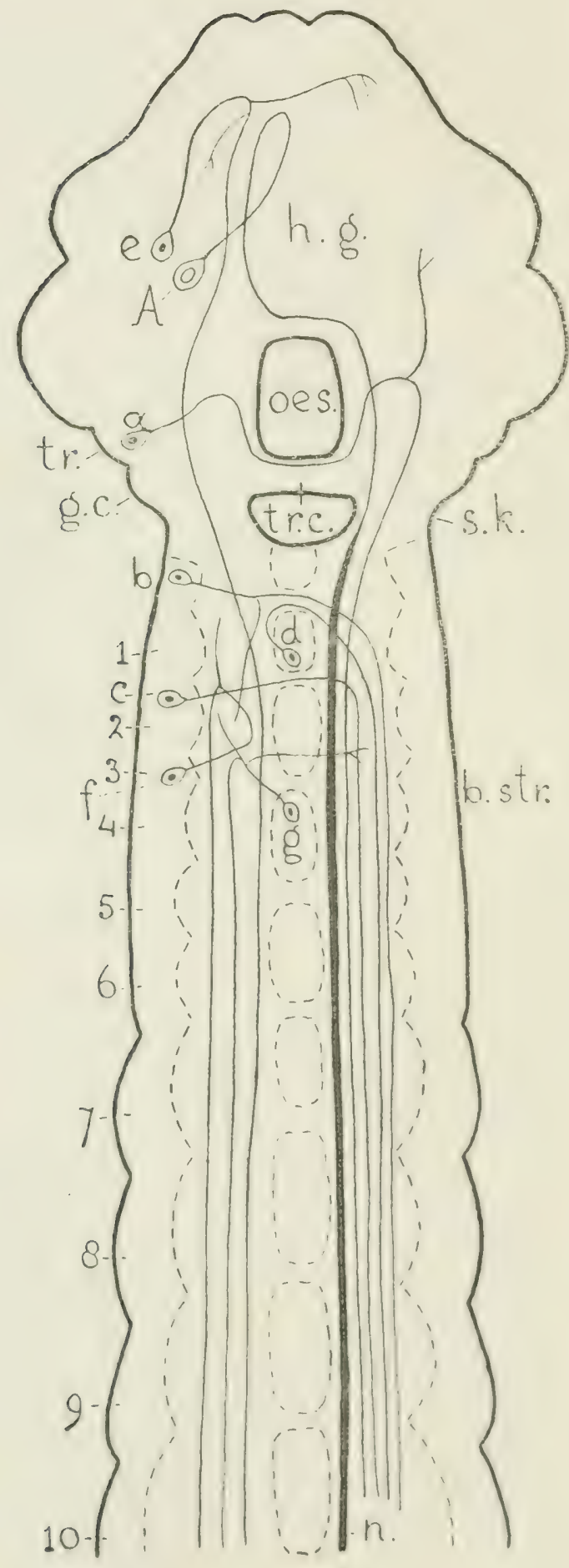

Schema einiger Leitungsbahnen des Zentralnervensystems des jüngeren Embryos von Homarus vulgaris.

Abgeändert nach ALlen (1894a). $a$ bis $g=$ assoziative Ganglien-

$$
A=\text { Neurochordzelle }
$$
zellen.

1 bis $10=$ Bauchganglien

1 bis $6=$ Anlage $\cdot$ des unteren Schlundganglions

7 bis $10=$ vier Thorakalganglien

b. str. = Bauchstrang

g. c. = ganglion connectivale

g. $\iota_{0}=$ Hirnganglion

n. = Neurochord

oes. = Loch wodurch der Oesophagus tritt

s. $k_{\text {. }}=$ Schlundkonnektiv

tr. $=$ tritocerebrum

tr. $c$. = commissura tritocerebralis

Die Strichellinien begrenzen die Cianglienzellgruppen.

Abschnitt, das tritocerebrum (Fig. 82, $t r$.) erkennen läßt. Das tritocerebrum umfalit das Ganglion der zweiten Antenne. Im Bauchstrang des Embryos sind die Ganglien (Fig. \$2, 1 bis 10) noch alle gegenseitig verwachsen. Es sind deshalb keine Konnektive unterscheidbar (nur sanfte Rinnen dort. wo sie kommen werden) und die Kommissuren sind ebensowenig äußerlich sichthar. Innerlich sind sie schon angelegt und tremen sie mediane Ganglienzellgruppen. (Man sehe die Fig. S2, wo alle Ganglienzellgruppen mit Strichellinien umgeben sind.)

Nach Aldus zähit der Bauchstrang elf 'Thorakalganglien (deren man zehn in Fig. $\$ 2$ sieht), wovon die sechs ersten 
das ,vordere Thorakalganglion" des erwachsenen Tieres bilden. Man wird begreifen, daß damit das untere Schlundganglion gemeint wird, denn die übrigen fünf Thorakalganglien des Embryos bilden dann die fünf Thorakalganglien des erwachsenen Tieres. Daß das Unterschlundganglion von Homarus aus sechs Ganglien entsteht, stimmt sehr gut zu der Meinung KrIEgers über dieses Ganglion bei Astacus (vergl. Fig. 75, S. 227). Ich möchte die elf ,'Thorakalganglien" des Embryos, um Irrtümern vorzubeugen, fortan lieber Bauchganglien nennen. Die Ganglienzellen in jedem der elf vordersten Bauchganglien bilden vier Gruppen, zwei laterale, eine mediodorsale und eine medioventrale. Dazwischen befindet sich das Neuropilem. Wenn im erwachsenen Tiere die Ganglien auseinandergegangen sind, haben sich die medianen Zellgruppen alle in einen Vorder- und einen Hinterteil gespalten. Um dies gut zu verstehen, hat man sich in der Figur 82 die Trennung zur Höhe der Rinnen zwischen den Ganglien 7 bis 10 zu denken.

ALLEN unterscheidet assoziative Ganglienzellen, deren Fortsätze das Zentralnervensystem nicht verlassen, motorische Ganglienzellen mit ihrem Zellkörper im Zentralnervensystem und ihrem Neuriten in einem peripheren Nerven und sensibele Ganglienzellen, außerhalb des Bauchstranges gelegen und einen Fortsatz in ein Bauchganglion sendend.

Es seien hier zuerst die Assoziationszellen besprochen. AlLEN teilt sie in vier Kategorien ein. Zur ersten Kategorie gehören unipolare, symmetrisch links und recht. im Hirnganglion oder in einem Bauchganglion gelegene Ganglienzellen mit deszendierendem Neuriten, welcher meistens jedem passierten Neuropilem Kollateralen abgibt.

Die erste Ganglienzelle dieser Kategorie ist eine Neurochordzelle (Fig. 82, A) ventral im Hirnganglion. Ihr Fortsatz beschreibt einen Bogen, überschreitet die Medianlinie vor dem Oesophagus, geht zum Bauchstrang und verdickt sich dort zu einer Kolossalfaser oder einem Neurochord (Fig. 82,n.), welcher nach hinten läuft und sich im Schwanzganglion (sechsten Abdominalganglion) verzweigt, nachdem er zuvor nur dem Neuropilem des Hirnganglions einige Kollateralen überliefert hat. Man wird sich erinnern, daß KRIEGER und Retzius den Neurochord bei Astacus entdeckt hatten ohne seinen Zusammenhang mit einer Ganglienzelle zeigen zu können.

Die zweite Ganglienzelle (Fig. 82, a) liegt im Ganglion der zweiten Antenne, also im tritocerebrum. Thr Fortsatz kreuzt in der Tritocerebralkommissur und spaltet sich dann in zwei Aeste, einen zum Hirnganglion und einen anderen, welcher im Bauchstrang deszendiert, wahrscheinlich bis ins Schwanzganglion. Jetzt wird es klar, weshalb ich die Kommissur zwischen den beiden Konnektiven, so hier wie bei Astacus, Tritocerebralkommissur genannt habe. Es geschah weil ihre Fasern aus dem tritocerebrum herstammen. Auch die 'l'ritocerebralkommissur der Insekten läuft hinter dem Oesophagus herum.

Lateral vorn im ersten Bauchganglion (also später im Unterschlundganglion) befindet sich eire Ganglienzelle b, deren Fortsatz einen Ast zum Neuropilem des zweiten Bauchganglions abspaltet, dann kieuzt und nach hinten zicht bis ins Schwanzganglion.

Lateral im zweiten Bauchganglion fand ALLEN eine Ganglienzelle $c$ mit 
einem kreuzenden Fortsatz, welcher bis ins sechste Abdominalganglion (Schwanzganglion) deszendiert. Die Seitenäste des Stammfortsatzes verlassen das zweite Bauchganglion nicht. Aehnliche Zellen gibt es im dritten und fünften Thorakalganglion. Sie werden später wohl alle ins untere Schlundganglion aufgenommen.

Ein anderer Zelltypus (Fig. 82, d) ist ventromedial im zweiten Bauchganglion gelagert. Sein Fortsatz zieht erst nach vorn ins erste Bauchganglion, geht dann zur anderen Seite des Bauchstranges iiber und deszendiert dort.

Die bis jetzt genannten Zelltypen hatten alle kreuzende Neuriten. Dies ist nicht mehr der Fall mit drei weiteren Zellarten, welche zur ersten Kategorie der Assoziationszellen gehören. Die Zelle $e$, ventral im Hirnganglion und unmittelbar vor der Neurochordzelle $A$ gelegen, sendet ihren Neuriten erst mit einem Bogen nach vorn und dann nach hinten bis ins Schwanzganglion. Seitenäste gehen zum Neuropilem der beiden Gehirnhälften.

Mit $f$ ist in der Figur 82 eine laterale Ganglienzelle des dritten Bauchganglions bezeichnet worden. Der Fortsatz beschreibt einen Bogen nach vorn bis ins zweite Bauchganglion, wo ein Ast zum ersten Bauchganglion abgegeben wird und zieht dann im Bauchstrange nach hinten.

Die Ganglienzelle $g$ ist in einer ventromedialen Zellgruppe zu suchen und gehört vielleicht zum dritten, vielleicht zum vierten Bauchganglion. Der Fortsatz läuft erst nach vorn ins dritte Bauchganglion, wo er zwei Aeste abspaltet, einen zum Neuropilem des dritten Bauchganglions der anderen Seite und einen zum zweiten Bauchganglion derselben Seite. Nachher zieht er nach hinten.

Die zweite Kategorie der Assoziationszellen umfaßt unipolare Ganglienzellen (immer wie die vorigen gepaart), welche in einem Bauchganglion liegen und einen Fortsatz zum Hirnganglion senden. Ihr Fortsatz aszendiert also. Deutlichkeitshalber sind diese Zellen nicht in die Figur 82, sondern in eine ähnliche, schematische Figur 83 eingezeichnet worden.

Der erste Zelltypus (Fig. $83, h$ ) ist ventromedial im ersten Bauchganglion gelegen. Sein Fortsatz überschreitet mit einem Bogen die Medianlinie und tritt ins Hirnganglion ein, wo er nicht weiter zu verfolgen war.

Der zweite 'Iypus (Fig. 83, i) ist eine laterale Ganglienzelle des zweiten Bauchganglions. Sein Stammfortsatz sendet Aeste aus ins Neuropilem des zweiten und dritten Bauchganglions und der Neurit geht zur anderen Seite des Bauchmarks und rieht dam nach vorn ins Gehirn. Sein Ende ist unbekannt.

Die Zellen $j$ und $k$ (Fig. S3) zeigen enge Verwandtschaft. Beide sind lateral gestellt, $j$ im fünften Bauchganglion, also im späteren Unterschlundganglion, k im achten Bauchganglion, also im zweiten 'Thorakalganglion des erwachsenen 'Tieres. Beide senden ihren fortsatz durch eine Kommissur zur anderen Bauchmarkshälfte, aber vorher schicken sie Seitenäste ins Nenropilem des vorigen und des nächsten Ganglions. Die beiden Neuriten aszendieren und im Gehirn angelangt, verästeln sie sich in der Nähe des medianen Naupliusauges und enden dort. Es ist bemerkenswert, dal. die beiden Zellen sich oft gleichzeitig färben. Später ist ALLEx (1896) einer ahnlichen Zelle (K', Fig. S5) auch 
Schema einiger Leitungsbahnen des Zentralnervensystems des jüngeren Embryos von Homarus vulgaris.

Abgeändert nach ALLEN (1894a). Man vergleiche Fig. 82.

$h$ bis $n$ und $n^{\prime}=$ assoziative Ganglienzellen.

1 bis $10=$ Bauchganglien

1 bis $6=$ Anlage des unteren Schlundganglions

7 bis $10=$ vier Thorakalganglien h. $g .=$ Hirnganglion

Die Strichellinien begrenzen die Ganglienzellgruppen.

im elften'Bauchganglion begegnet. Man lese darüber und iiber die Verwandtschaft mit dem Zelltypus $i$ Seite 250 .

Eine andere Ganglienzelle dieser Kategorie (Fig. 83, l) liegt ventromedial im sechsten Bauchganglion. Der Fortsatz gibt dem Neuropilem des Ganglions einen Zweig, kreuzt, aszendiert und endet verästelt in Hirnganglion.

Die dritte Kategorie der Assoziationszellen umfaßt nur einen einzigen Zelltypus. In jedem der Bauchganglien 6 bis 10 , also in dem unteren Schlundganglion und den vier vorderen Thorakalganglien, fand ALLEN zu jeder Seite lateral eine Ganglienzelle ( $m$ in Fig. 83 wird als Beispiel gegeben), deren Fortsatz mit einigen Wellen nach hinten und medianwärts läuft und im nächsten Ganglion endet. Seitenäste gehen zum Neuropilem des Ganglions, wo der Zellkörper gelegen ist.

Die Ganglienzellen $m$ stehen offenbar in funktioneller

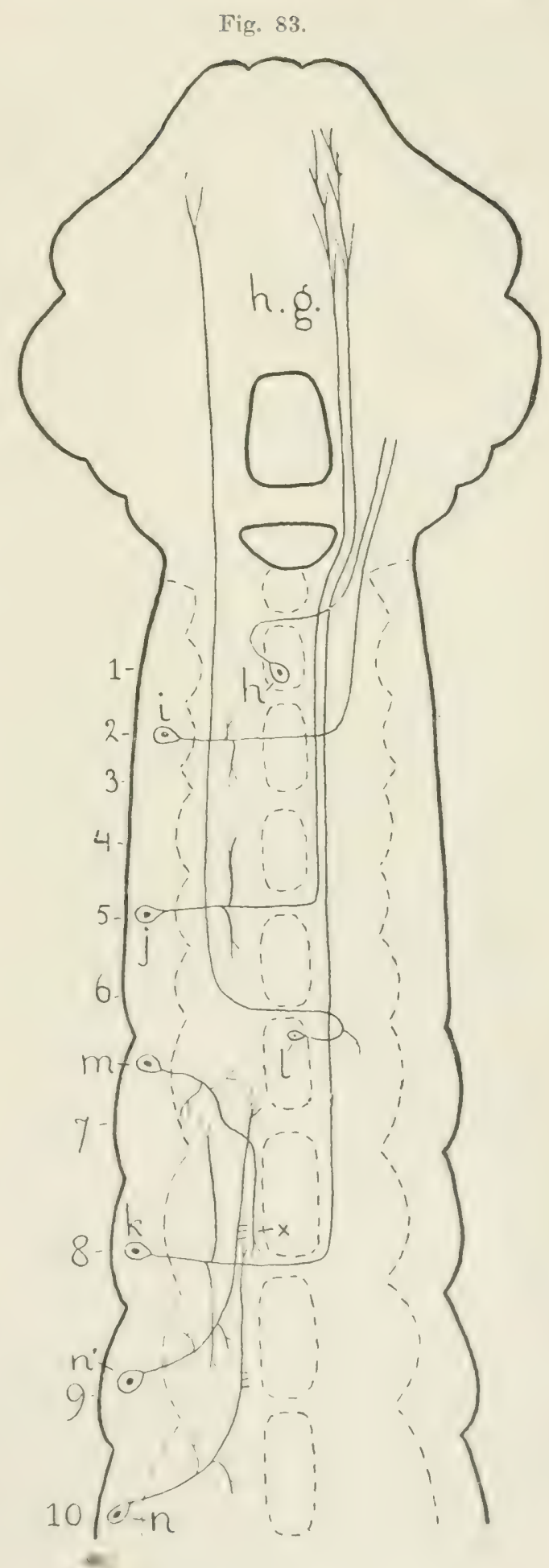


Beziehung zu den Assoziationszellen der vierten Kategoric (Fig. 83, n, n'). Die Bauchganglien 6 bis 11 enthalten alle ein laterales Paar Ganglienzellen, welche übereinstimmend gebaut sind. Der Fortsatz geht nach innen und nach vorn. Er endet im vorvorigen Ganglion dort, wo auch der Fortsatz einer Zelle des Typus $m$ endet. Zuvor hat er dem Neuropilem des Ganglions, wo der Zellkörper gelagert ist, Seitenäste überliefert und auch spaltet er kleine Zweige ab, dort, wo er die Endigungsstelle der nächsten Zelle desselben Typus und einer Zelle des Typus $m$ passiert. Es haben also, wie ALLEN entdeckte, zwei Zellen des Typus $n$ und eine Zelle des Typus $m$ Verästelungen an ein und derselben Stelle (Fig. 83 bei $x$ ) und wohl läßt sich daraus ihre physiologische Zusammenwirkung ableiten. Ich möchte daran erinnern, daß wir auch bei einem Wurme (Nereis, S. 75 und Fig. 31) drei mit einander in Wechselwirkung stehende Neuronen im Bauchstrange kemnen. BEтHe (1895a) hat Ganglienzellen des Typus $n$ auch bei Carcinus maenas gefunden (Fig. $89, i)$.

Die verschiedenen Assoziationszellen, welche ALLEx zu entdecken vermochte, sind jetzt beschrieben worden und es werden die motorischen Ganglienzellen folgen. Wie begreiflich hat man dann den peripheren Nerren Rechnung zu tragen. Ich füge darum diesen Beschreibungen eine schematische Figur (Figur 84) bei, welche den vorigen gleicht, nur daß darin auf der einen Seite auch die peripheren Nerven angedeutet worden sind. Die verschiedenen Bauchganglien besitzen alle zwei Paar Nerven, ein vorderes und ein hinteres Paar. Der Vordernerv (nervus anterior, Fig. $84, n$. a.) geht zu den Gliedmaßen. In dem zweiten und dritten Bauchganglion ist er tatsächlich doppelt (vergleiche Fig. 84, wo alle nervi anteriores länger als die nervi posteriores gezeichnet sind, damit man sie bequemer unterscheiden kann), aber auch in den anderen Ganglien ist er nahezu ein Doppelnerv. Der hintere Nerv (Fig. $84, n . p$.) geht zur Körperwand. In der Figur $S 4$ sind mit n. a. und n. p. die Nerven des ersten und neunten Bauchganglions angegeben worden.

Die Bauchganglien sechs bis neun sind mit eben denselben motorischen Ganglienzellen ausgestattet. Der erste Typus (Fig. 84,o) liegt lateral vorn im Ganglion. Sein Fortsatz beschreibt einen Bogen nach hinten und tritt in den vorderen Nerven aus. Zu beiden Seiten liegen mehrere solcher Zellen im Ganglion. Dieser Zelltypus beschränkt șich nicht auf die Ganglien 6 bis 9, sondern ist auch im dritten, fünften, zehnten und elften Bauchganglion (also später im unteren Schlundganglion und allen Thoralialganglien) aufzufinden. Es ist nicht schwer in diesem 'Typus eine von Rerzius bei Astacus entdeclite Zellart (Fig. 77, a) wiederzuerkennen.

Eine mit den Ganglienzellen des Typus o iibereinstimmende Zelle (Fig. $84, p)$ liegt im zweiten Antennalganglion, also im tritocerebrum und sein Fortsatz im nervus antennarius secundus $(n . a . s$.$) . Wahrscheinlich ist diese Zelle$ denjenigen homolog, welche RETzus bei Astacus neben der Wurzel des zweiten Antennalnerven fand und welche ihren Fortsatz in diesen Nerven schickten (vergl. S. 224).

Die motorischen Ganglienzellen des Typus q (Fig. 8t) weichen nur wenig ab von den Zellen $o$. Sie liegen lateral, eine Zelle in beiden Hälften der Bauch- 
Schema einiger Leitungsbalınen des Zentralnervensystems des jüngeren Embryos von Homarus vulgaris.

Abgeändert nach ALLEN(1894a .

Jan vergleiche Fig. 82.

$o$ bis $v$ und $q$ ' motorische Ganglienzellen

ae, $a f=$ sensibele Nervenfasern 1 bis $10=$ Bauchganglien

1 bis $6=$ Anlage des unteren Schlundganglions

7 bis $10=$ vier Thorakalgang-

$$
\begin{aligned}
& \text { g. c. }=\text { ganglion } \quad \begin{array}{c}
\text { lien } \\
\text { connec }
\end{array} \\
& \text { tivale } \\
& \text { h. g. = Hirnganglion } \\
& \text { n. } a \text {. }=\text { nervus anterior } \\
& \text { n. a. } s \text {. = nervus antenna- } \\
& \text { rius secundus. } \\
& \text { n. } p \text {. nervus posterior } \\
& \text { tr. }=\text { tritocerebrum }
\end{aligned}
$$

Alle vordere Nerven der Batchganglien "sind länger gezeichnet als die hinteren. Die Strichellinien begrenzen die Ganglienzellgruppen.

ganglien fünf bis neun und ihr Fortsatz verläßt nach einer typischen Schlinge clas Ganglion im vorderen Nerven. Allew meldet auch im ersten Bauchganglion eine solche Zelle (Fig. 84, q'), aber, wenn ich es gut einsehe, tritt er in den hinteren Nerven aus. Später hat ALLEx (1896) ähnliche Zellen wie $q$ auch im zehnten und elften Bauchganglion entdeckt.

Median in den Bauchganglien 2, 3, 7, 8 und 9 und später (ALLEx 1896) auch in 10 und 11 wurde eine Ganglienzelle (Fig. 84, r) entdeckt, welche ebenfalls ihren Fortsatz nach Abgabe von Seitenästen
Fig. 84 .

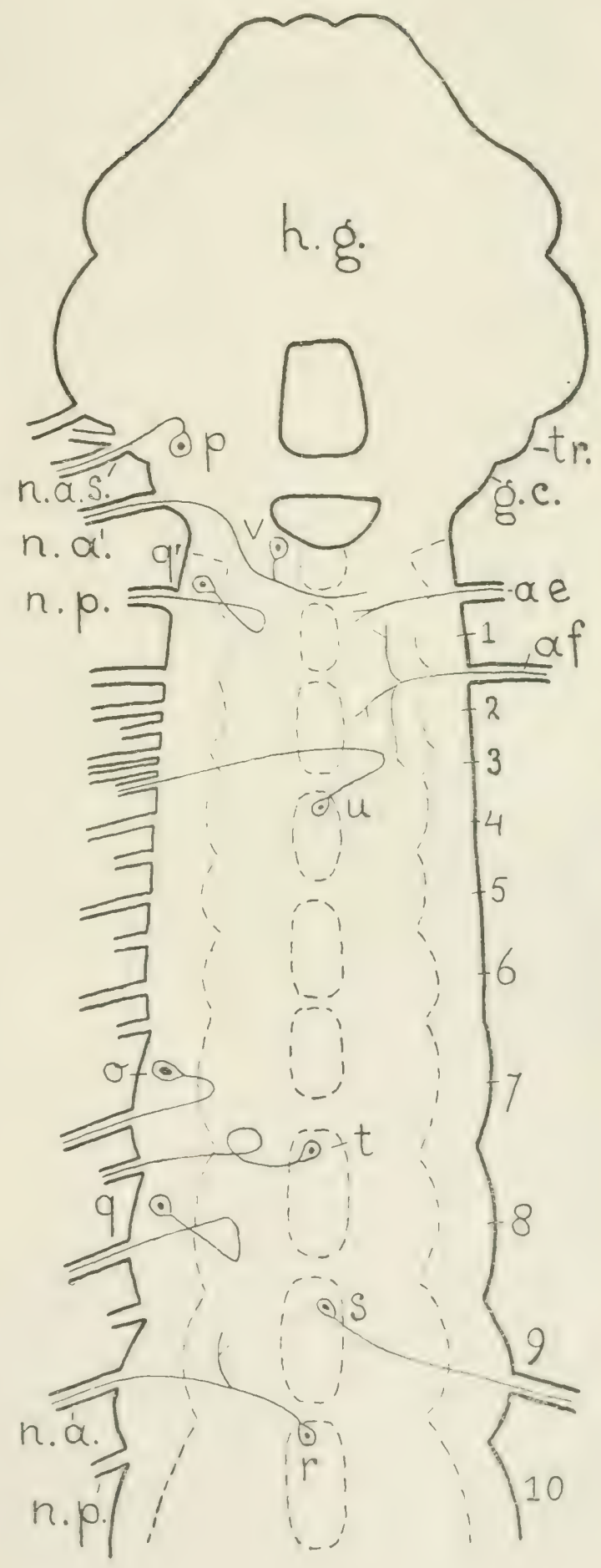


ans Neuropilem des Ganglions dem vorderen Nerven beimischt. Dem vorigen Typus sehr ähnlich ist die mediane Ganglienzelle $s$, ebenfalls mit einem Fortsatz im vorderen peripheren Nerven. Beim Embryo ist sie in der medianen Zellgruppe kurz hinter der Zelle $r$ gestellt. Wenn aber im Laufe der Entwicklung jede mediane Zellgruppe geteilt und vie oben beschrieben wurde, zwei Ganglien zugeteilt wird, geht die Trennungslinie zwischen den Zellen $r$ und $s$ hindurch, was zur Folge hat, daß $s$ ganz vorn, $r$ ganz hinten im ausgebildeten Ganglion zu liegen kommt. Die Zellen $r$ und $s$ der Figur 84 gehören also später beide dem dritten Thorakalganglion (jetzt dem neunten Bauchganglion) an. Der Zelltypus $s$ wurde in den Bauchganglien 5 bis 10, später (ALLEN 1896) auch in 11 entdeckt.

Zum hinteren Nerven der Bauchganglien 7 bis 9 geht der Fortsatz einer median im Ganglion gelegenen Zelle (Fig. St, $t$ ), welcher eine Spirallinie beschreibt.

Im dritten Bauchganglion beobachtete ALLEN eine mediane Ganglienzelle (Fig. 84, $u$ ) mit einem Fortsatz, welcher die Medianlinie kreuzte und in dem nervus posterior der anderen Seite verschwand. Später (Allex 1896 ) wurde diese Zelle auch im achten Bauchganglion gesehen.

Als letzter motorischer Ganglienzelltypus sei hier eine Ganglienzelle des ersten Bauchganglions erwähnt (Fig. 84, v). Sie befindet sich nicht in, sondern neben der medianen Zellgruppe und ihr Stammfortsatz spaltet sich in zwei Aeste, einen in den vorderen Nerven und einen zur anderen Seite des Bauchstranges schreitenden.

Sensibele Nervenfasern wurden von Alten nur selten im vorderen Teile des Bauchstranges entdeckt, aber regelmäßig im Abdomen, wie wir später sehen werden. Im hinteren Nerven des ersten Bauchganglions dringt eine Nervenfaser unbekannter Herkunft (Fig. 84, ae) in den Bauchstrang ein und verästelt sich im ersten Ganglion. Ebenso führt der vordere Nerv des zweiten Bauchganglions Nervenfasern (Fig. 84, af), welche sich nicht nur in diesem Ganglion, sondern auch in den beiden benachbarten verzweigen. Es sind wahrscheinlich sensibele Nervenfasern.

In seiner späteren Arbeit hat ALLeN (1896) diesen Nervenfasern noch einen dritten Typus heigefügt. Die Faser (Fig. si, all) tritt mit dem hinteren Nerven des zehnten Bauchganglions (vierten Thorakalganglions) ein und spaltet sich in einen deszendierenden und einen aszendierenden Ast, welcher bis ins erste Bauchganglion zu verfolgen war, ohne daß sein Ende erreicht wäre. Aehnliche Nervenfasern werden wir in den Abdominalganglien von Homarus besser und in größerer Zahl kennen lernen.

Am Schluße seiner glänzenden Arbeit versucht ALLEx die gegenseitigen funktionellen Beziehungen der verschiedenen Ganglienzelltypen zu prifen. Weil es mich sehr unwahrscheinlich dïnkt, daß er schon alle Typen aufgefunden hätte, auch wenn man seine späteren Nachträge (ALLEN 1896) berücksichtigt - hat doch Retzius beim naheverwandten Astacus fast nur andere Typen beobachtet - und weil, wie It.LEx selher sagt, solehe Fragen schlieblich nicht ohne physiolegische Intersuchungen gelöst werden kïnnen, werde ich diese Aluenschen Spekulationen beiseite lassen. 
Fig. 85 .
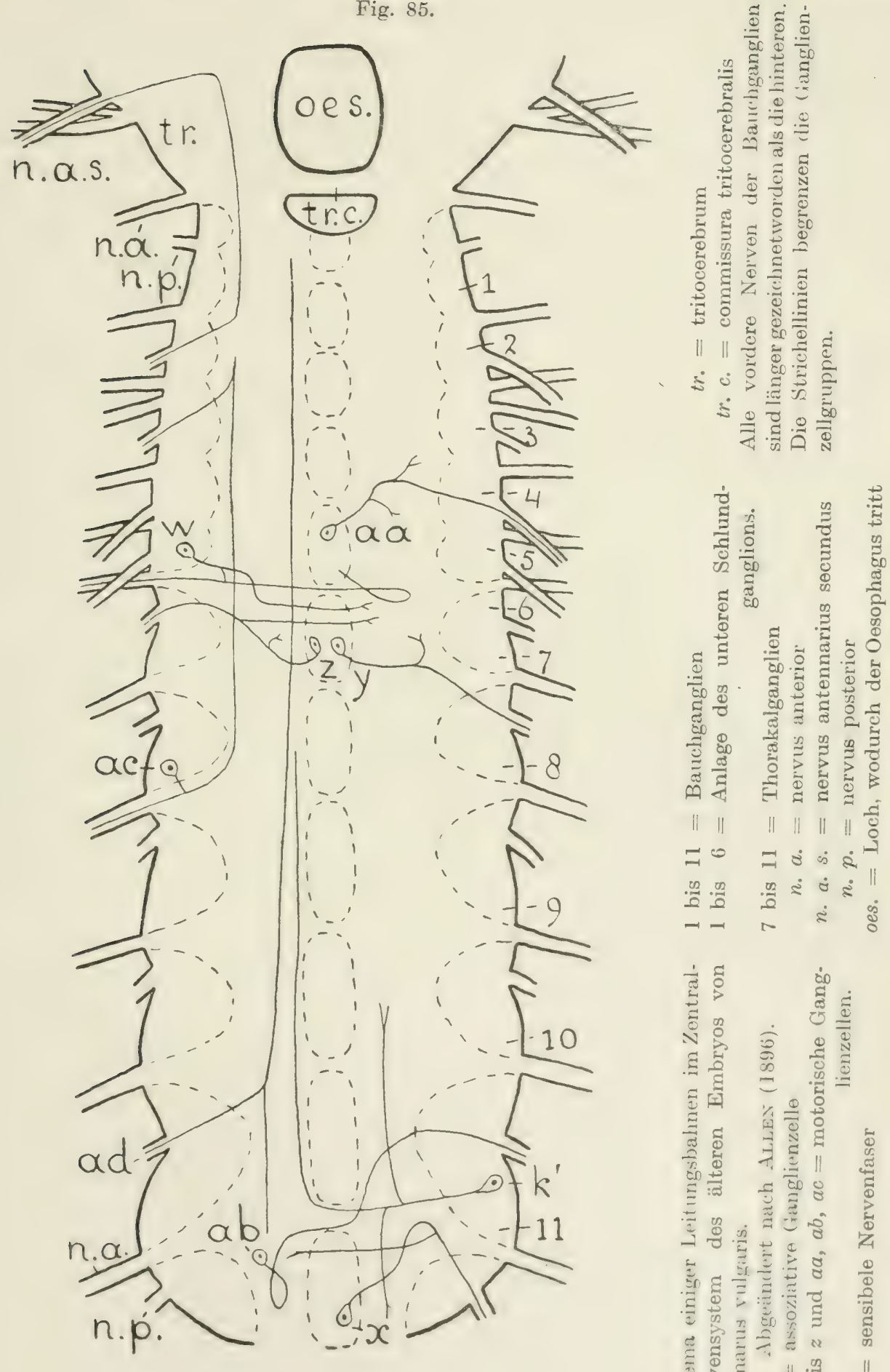

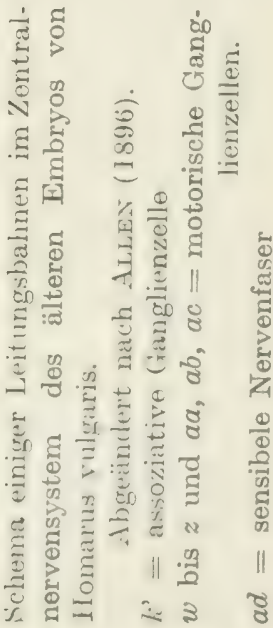


Die Anlagen des unteren Schlundganglions und der Thorakalganglien von Homarus vulgaris wurden abermals von ALLEx (1896) mit Methylenblau erforscht bei Embryonen, welche im Begriffe waren auszuschlüpfen und also älter waren als die Embryonen der vorigen Arbeit. Im Schema, welchesich von diesem Stadium gebe (Fig. 85) sieht man vom Hirnganglion nur das tritocerebrum (tr.). Vom Bauchstrang sieht man die elf vorderen Ganglien, welche das Unterschlundganglion ( 1 bis (j) und die fünf Thorakalganglien ( 7 bis 11 ) bilden werden. AlLEN nennt sie alle Thorakalganglien; ich werde sie wiederum Bauchganglien nemnen. Die Abdominalganglien sind fortgelassen ; sie werden nachher besprochen werden. Ich habe auch jetzt zur bequemeren Unterscheidung die nervi anteriores $(n, a$.) der Ganglien länger gezeichnet als die nervi posteriores (n. p.), ausgenommeń dort, wo es erwünscht war zu zeigen, daß der nervus posterior sich über den nächsten nervus anterior legt. Man wird bemerken, daß der Vordernerv des dritten Bauchganglions noch doppelt vorhanden ist, daß aber das zweite Bauchganglion, ebenso wie die anderen einen einzigen Vordernerven hat. Die Fasern der Vordernerven teilen jetzt die lateralen ( Aanglienzellgruplen eines jeden (ranglions in zwei. Die (ianglienzelleruppen sind in der Figur 85 wiederum durch Strichellinien begrenzt.

Verschiedene früher beobachtete Ganglienzellen wurden auch jetzt wieder gesehen. Ich komme darauf nicht zurück.

Lateral im elften Bauchganglion kam die Ganglienzelle l', (Fig. 85) ans Licht. Ihr Fortsatz kreuzt und aszendiert, nachdem er zuvor einen Seitenast nach vorn und einen nach hinten abgespalten hat. Obgleich ALLEx dem aszendierenden Neuriten nicht bis ins Gehirn folgen konnte, ist er überzeugt, daß er dort endet, denn der Endteil des Neuriten wurde noch ein anderes Mal gesehen, jetzt aber ohne Zusammenhang mit dem Zellkörper. Wenn Altex Recht hat, stimmt, wie er selbst bemerkt, die Zelle $l_{i}$ sehr mit $l_{i}$ und $j$ (Fig. 83) überein und, wenn auch die Zelle $i$ (Fig. 83) dazu gerechnet werden darf, haben wir eine Reihe von vier gleichartigen Ganglienzellen $\left(i, j, k\right.$ und $\left.k^{*}\right)$ im Bauchstrange, welche in den Bauchganglien 2, 5, 8 und 11 gelegen sind, also regelmäßig mit zwei Ganglien Zwischenraum.

Ganz neu waren die Ganglienzellen der nachstehenden Typen. Zuerst eine motorische Ganglienzelle (Fig. 85, w) lateral, vorn im sechsten Bauchganglion. Der Fortsatz spaltet erst einen Ast ab, welcher zum Neuropilem der anderen Seite geht und teilt sich dann in zwei Aeste. Einer derselben tritt aus in den vorderen Nerven des Ganglions, der andere kreuzt und beschreibt einen Bogen, aber sein Ende blieb unbekannt.

Der motorische Ganglienzelltypus $x$ (Fig. 85) gleicht dem Typus $t$ (Fig. 84) in manchen Hinsichten. Mehr noch ist er nach Aluex einem Zelltypus der Abdominalganglien (Fig. S6, $x^{\prime}$ ) gleich. Ich werde den Untersehied S. 252 betonen. Die Zelle wurde nur im elften Bauchganglion gefunden, hinten in der medianen Ganglienzellgrippe. Ihr Fortsatz tritt in den hinteren Nerven aus, nachdem er dem Neuropilem der anderen Seite des Ganglions einen Seitenast gegeben hat.

Nur im siebenten Bauchganglion ist der motorische Ganglienzelltypus y (Fig. 85). Der Zellkörper ist median gelagert, der Fortsatz geht in den hin- 
teren Nerven des Ganglions und Seitenäste gehen zum Neuropilem. Bis jetzt sind wir nur motorischen Ganglienzellen begegnet, welche ihren Neuriten in einen Nerven ihres eigenen Ganglions senden. Es gibt aber auch andere. So befindet sich median im siebenten Bauchganglion, und nur dort, eine motorische Ganglienzelle (Fig. 85, z), deren Fortsatz eine Nervenfaser des hinteren Nerven des sechsten Bauchganglions ist. Seitenäste gehen zum Neuropilem derselben Seite des siebenten und der anderen Seite des sechsten Ganglions.

Im vierten, fünften und sechsten Ganglion entdeckte ALLEx eine mediane Ganglienzelle (Fig. 85, aa), welche ihren Neuriten dem hinteren Nerven des vorhergehenden Ganglions beimischt. Die Zelle hat keine Fortsätze zur anderen Seite.

Im hinteren Thorakalganglion liegt, außerhalb der bekannten Zellgruppen ein Ganglienzelltypus (Fig. 85, $a b$ ), wie er sonst nicht in den Thorakalganglien oder dem Lnterschlundganglion, wohl aber in den Abdominalganglien (Fig. 86, $a b$ ) vorkommt. Sein Neurit überschreitet die Medianlinie und verläßt im hinteren Nerven des vorhergehenden Ganglions das Bauchmark.

Es gibt auch, wie bei Carcinus maenas, Ganglienzellen mit mehreren in die peripheren Nerven austretenden Fortsätzen. Nan wird sich erinneren, daß z.B. auch Hirudo (Fig. 47, S. .102) solche Zellen aufweist. Bei Homarus fällt unter diesen Begriff eine laterale Ganglienzelle des siebten und achten Bauchganglions (ersten und zweiten Thorakalganglions) (Fig. 85, ac). Der Stammfortsatz dieser Zelle teilt sich sofort dichotomisch. Ein Ast geht in den vorderen Nerven des Ganglions; der andere zieht nach vorn und sendet Seitenåste zu zwei oder drei nervi posteriores. Der hintere Nerv des dritten Bauchganglions empfängt jedenfalls einen Zweig. Die anderen mit Seitenzweigen beschenkten Nerven sind mir nicht klar, weil der ALlexsche Text nicht mit seiner Abbildung übereinstimmt und die Zelle des siebenten Bauchganglions sich anders verhält als die Zelle des achten. Vielleicht gehört auch eine Nervenfaser, welche in den hinteren Nerven des zweiten Bauchganglions und in einen kleinen Nerven unmittelbar vor dem zweiten Antennalnerven (Fig. 85, n.a.s.) austrat (siehe Fig. 85 links) zu diesem Typus, aber die Ganglienzelle wurde leider nicht beobachtet.

Ich unterlasse die Beschreibung einiger Ganglienzellen des vierten Bauchganglions, welche nicht genau beobachtet werden konnten.

ALLEx hat im Jahre 1896 auch die Abdominalganglien von HomarusEmbryonen untersucht. Er fand die Struktur der fünf vorderen Abdominalganglien äberein-timmend, das sechste aber. dat sehwanzanglion, abweichend gebaut. Nach allem, was wir über Astacus wissen, kann uns das nicht wundern. Ich werde das Schwanzganglion an und für sich besprechen.

Die fünf Abdominalganglien (zwei derselben stellt Fig. 86 schematisch dar) haben alle ein vorderes und ein hinteres Nervenpaar (Fig. 86, n. a. und n.p.) und ein drittes Nervenpaar, das ich in Uebereinstimmung mit Astacus (Fig. 78) die nervi connectivales (Fig. 86, n.c.) nennen will. Natürlich sind die Ganglien alle durch Konnektive $(k$.) verbunden.

ALLEx hat in den Abdominalganglien dssoziationszellen sichtbar gemacht, 
alle vom selben Typus (Fig. 86, $a$ ). Die Zelle liegt vorn lateral im zweiten bis fünften Abdominalganglion. Ihr Fortsatz kreuzt und aszendiert zum Hirnganglion, während ein Seitenast sich im Neuropilem des Ganglions verzweigt. Nach Allex hat Retzius diese Zellart bei Astacus beobachtet. Es wird dies dann wohl die Zelle $b$ der Fig. 79 sein.

Fig. 86.

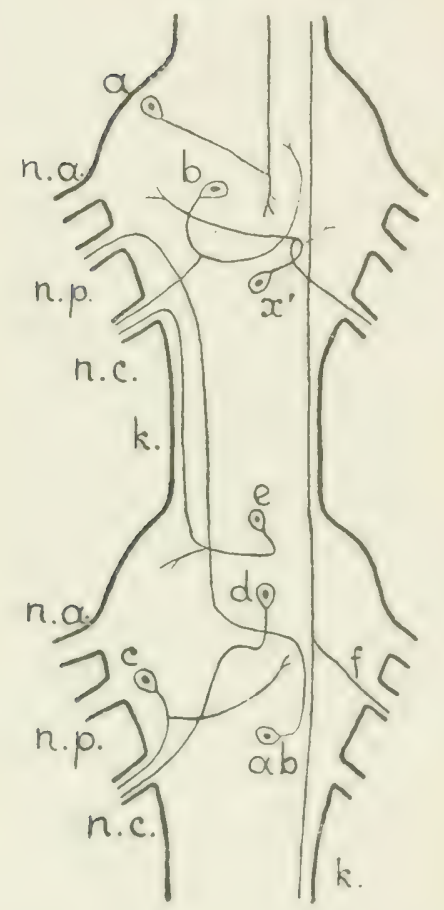

Einige Leitungsbahnen in zwei Abdomin 1 ; anglien des älteren Embryos von Homarus vulgaris Abgeändert nach ALLEN (1896), Fig. 3.

$a$ bis $e, a b, x^{\prime}=$ Ganglienzellen $f=$ Norvenfaser

k. $=$ Konnektiv

11. a. - nervus anterior

n. $c=$ nervus connectivalis n. $p .=$ nervus posterior

Motorische Ganglienzellen sind in mancherlei Arten vorhanden. Erst eine Ganglienzelle (Fig. 86, b) in allen Abdominalganglien ventral in der Mitte gelagert, welche ihren Neuriten in den nervus connectivalis sendet, aber nicht bevor er einen Ast zum Neuropilem der anderen Seite abgegeben hat. Eine ähnliche Zelle der fïnf Abdominalganglien ist die Zelle $c$, aber sie ist lateral gestellt.

Der motorische Ganglienzelltypus $x^{\prime}$ (Fig. 86) ist uns nach ALLEN schon aus dem fünften Thorakalganglion (Fig. 85, $x$ ) bekannt. Die Zelle hat eine mediane Stellung und ihr Fortsatz iiberliefert dem Neuropilem der anderen Seite einen Seitenast. Während jedoch die Zelle $x$ des letzten 'Thorakalganglions ihren Neuriten in den hinteren Nerven sandte, tritt hicr der Neurit in den Konnektivalnerven aus. Es ist dies ein Unterschied, welcher nicht übersehen werden darf.

Der Zelltypus $x$ ' wurde in den fünf Abdominalganglien aufgefunden, ebenso wie der Zelltypus $d$ (Fig. 86), welcher vorn median im Ganglion liegt und seinen Neuriten in den Konnektivalnerven der anderen Seite sendet.

Zwei motorische Ganglienzelltypen sind nicht auf ein Ganglion beschränkt, sondern ihr Neurit tritt in einen Nerven des vorhergehenden Ganglions aus. Beide wurden in den fünf Abdominalganglien entdeckt. Die Zelle $e$ (Fig. 86) liegt neben der Medianlinie vorn im Ganglion. Der Fortsatz ïhersehreitet die Medianlinie, spaltet einen Ast ab zum Neuropilem des Ganglions, aszendiert im Konnektiv und verläl3t durch den Konnektivalnerven des näch-

sten Ganglions den Bauchstrang.

Dem anderen Typus (Fig. $8(6, a b)$ sind wir schon im fünften Thorakalganglion (Fig. S5, $a b$ ) begegnet. Der Fortsatz dieser Zelle lïuft nach vorn, kreuzt, aszendiert weiter und tritt aus in den hinteren Nerven des vorhergehenden Ganglions.

Ueber die sensibelen Nervenfasern der Abdominalganglien hatte ALLEN 
(1894a) schon vorher wichtige Angaben gemacht. Er entdeckte damals dorsal im Abdomen bipolare Sinnesnervenzellen. Thre zentralen Fortsätze gelangen mit den peripheren Nerven ins Abdominalganglion und spalten sich dann in einen aszendierenden und einen deszendierenden Zweig, welche Längsfasern des Bauchstranges sind und, in Bündeln vereint, einige Ganglien durchziehen. Wo sie eben enden, blieb unbekannt. Offenbar hat Schxeider (siehe S. 235̃) dieselben Zellen bei Astacus beobachtet, nur nennt er sie Ganglienzellen und geht ihre Natur als Sinnesnervenzellen aus seiner Beschreibung nicht hervor.

Im Jahre 1896 hat Altex noch mitgeteilt, daß solche sensibelen Nervenfasern besonders durch den hinteren Nerven ins Abdominalganglion eintreten (Fig. $86, f)$. Eine Nervenfaser, welche ins erste Abdominalganglion eintrat, konnte bis ins zweite Bauchganglion verfolgt werden, ohne daß das Ende erreicht war.

Im sechsten Abdominalganglion oder Schwanzganglion beschreibt ALLEx (1896) Ganglienzellen, wie $a$ der Abdominalganglien neben anderen Ganglienzellen, deren Fortsatz kreuzt und zum Hirnganglion zieht. Auch entdeckte er im Telson spindelförmige Zellen (Sinnesnervenzellen oder Ganglienzellen ?) mit zentralen Fortsätzen, welche ins Schwanzganglion eintraten und hierauf nach vorn liefen. Es ist erwähnenswert, daß auch RetziUs bei Astacus Ganglienzellen des Typus a im Schwanzganglion besonders

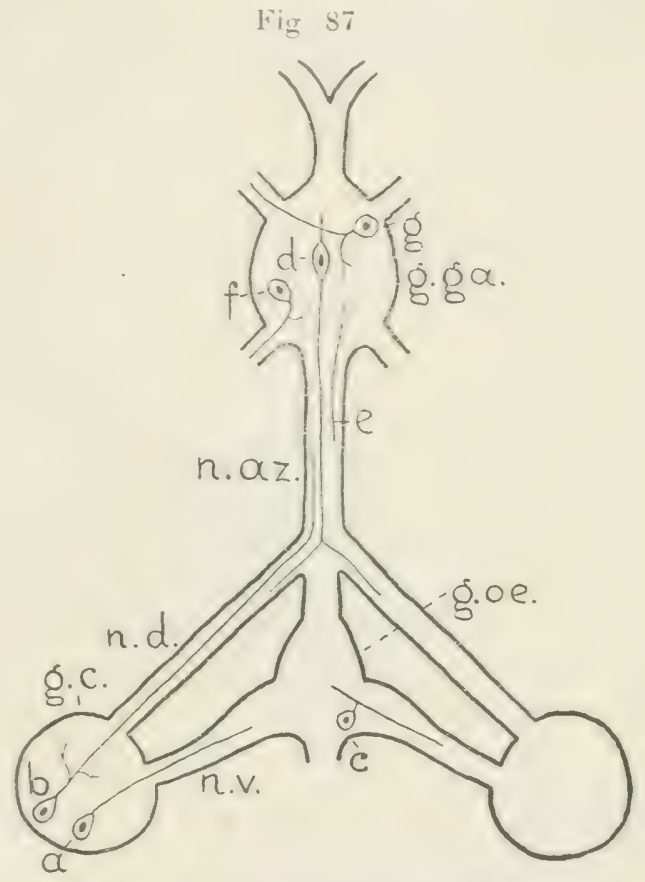

Schema des stomatogastrischen Nervensystems des jüngeren Embryos von Homarus vulgaris.

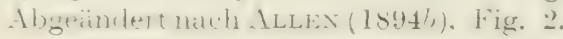
$a, b, c, d, f, g=$ Ganglienzellen

$e=$ Nervenfaser

g. c. $=$ ganglion connectivale

g. $g \alpha_{0}=$ ganglion gastrale

3. ne. = ganglion oesophageum

n. $a z$. = nervus azygos

n. $d$. = nervus dorsalis

n. $v$. $=$ nervus ventralis zahlreich gefunden hat.

ALLEN hat nicht nur die Leitungsbahnen des Zentralnervensystems erforscht - und man hat gesehen mit wie gutem Erfolg — sondern auch einen wichtigen Teil des peripheren Nervensystems und zwar das stomatogastrische Nervensystem von Homarus-Embryonen (AlLEx 18946).

Ich gebe seine Beschreibungen wieder mit Hilfe der Figur 87, welche ich zu besserem Verständnis mit der Fig. 81 nach Astacus zu vergleichen bitte. Man sieht das ganglion oesophageum (Fig. 87, g. oe.) durch den Dorsalnerven $(n . d)$ und den Ventralnerven $\left(n . v_{0}\right)$ mit dem ganglion connectivale $\left(g . c_{*}\right)$ und 
durch den nervus azygos $(n$. az.) mit den Gastralganglion (ganglion gastrale, Fig. 87, g.ga.) verbunden. Das Gastralganglion verlassen mehrere Nerven.

ALLEN hat nun die folgenden Ganglienzelltypen entdeckt. Im Konnektivalganglion sind einige Ganglienzellen, welche ihren Fortsatz in den Ventralnerven senden (Fig. 87, a), während andere $(b)$ ihren Neuriten durch den Dorsalnerven in den nervus azygos schicken und dem Neuropilem des Ganglions kleinere Aeste übermitteln. Im Oesophagalganglion waren Ganglienzellen (Fig. 87, c), deren Stammfortsatz sich sofort teilte in einen Ast in dem Ventralnerven und einen im Ganglion selbst. Im Gastralganglion fand ALLEN

Fig. 88

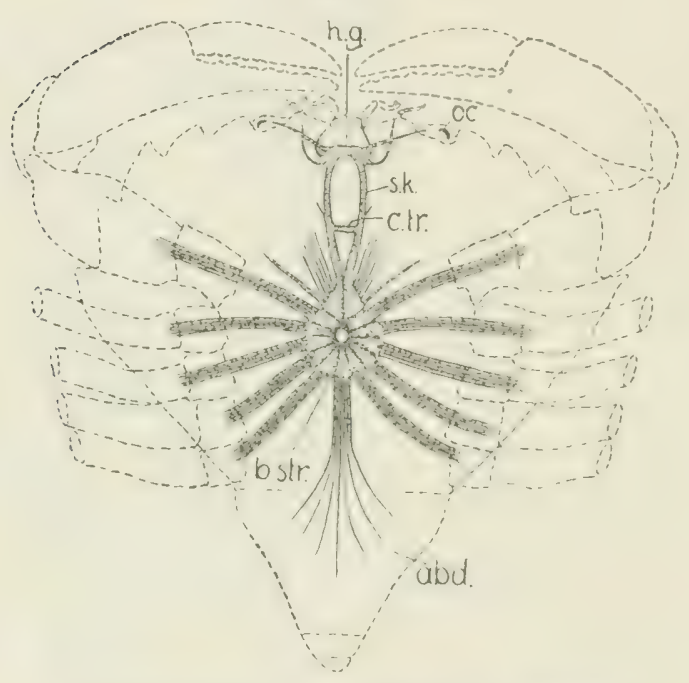

Nervensystem von Carcinus maenas.

Nach Bütschli (1912), Fig. 358.

$$
\begin{aligned}
a b d . & =\text { abdomen } \\
\text { b. str. } & =\text { Bauchstrang } \\
c . t r . & =\text { commissura tritocerebralis } \\
\text { h. } g . & =\text { Hirnganglion } \\
o c . & =\text { Auge } \\
\text { s. } k . & =\text { Schlundkonneltiv }
\end{aligned}
$$
bipolare Ganglienzellen (Fig. 87, d) mit einem Fortsatz, welcher den nervus azygos durchzog und einen Ast in jeden der beiden Dorsalnerven sandte, gleichwie die Fasern des 'Typus $p$ (Fig. 81) von Astacus.

Homarus hat mit Astacus auch Fasern gemein, welche wie die Faser e der Fig. 87 aus dem nervus azygos herstammend, sich im Gastralganglion verzweigen und iiberdies Ganglienzellen, welche im Gastral-. ganglion gelagert, ihre Neuriten den peripheren Nerven, ihre Dendriten dem Neuropilem dieses Ganglions beimischen. Die Abbildung, welche ALLEx von diesen Zellen gibt, hat mich gelehrt, daß einige Neuriten dabei kreuzen (Fig. 87, g), andere nicht (Fig. 87, f).

Die drei bis jetzt behandelten Decapoden waren Makruren. Es gibt auch eine

Brachyure, welche hinsichtlich ihrer Leitungsbahnen so vollständig untersucht wurde, daß eine gesonderte Beschreibung nötig ist. C'arcinus maenas, der kleine 'Taschenkrebs, ist die Brachyure und BETHE (1895a, 1897, 1898) ihr Untersucher.

BETHE hat zweimal (1895a und 1897) mit Hilfe seiner MethylenblauMethode sowohl das Hirnganglion, wie den Bauchstrang studiert. Weil seine späteren Angaben die vollständigeren sind, werde ich diese hier wieder geben, wenn nötig ergänzt mit Mitteilungen aus dem , Jahre $189 \%$.

Fangen wir an mit dem Bauchstrang. Derselbe ist sehr kurz und gedrïngt gebaut und hat die Gestalt einer ovalen, in der Mitte durchlöcherten Platte (Fig. s8, b. slr. und Fig. 89). Lange Schlundkonnektive (Fig. 8s und 89, s. k.) 
verbinden den Bauchstrang mit dem Hirnganglion (Fig. 88, h. g.). Das Loch in demselben (Fig. 89, l.) verleiht einem Blutgefäße Durchgang. Man begegnet im Bauchstrange denselben Ganglien wie bei den Makruren. Vorn ist das Unterschlundganglion (Fig: 89, g. i.oe.), deutlicher als bei den Makruxen aus sechs Ganglien (Fig. 89, 1 bis 6) zusammengesetzt, welche ich nach dem Beispiele BEtHes Mundganglien nennen werde. Es folgen fünf Thorakalganglien (Fig. 89, g.th. I bis $T$.) Das erste derselben wird von BETHE das Scherenganglion genannt, weil es zum ersten, mit einer großen Schere ausgestatteten Schreitfuß gehört (Fig. 88). Die vier übrigen Thorakalganglien gehören zu den übrigen Schreitfüßen. Die Abdominalganglien, welche den Bauchstrang abschließen, sind sehr klein. Beтнe zählt deren sieben (Fig. 89, g.ab. ! bis 7 ) ; bei den MIakruren sind es bekanntlich sechs.

In den Ganglien des Bauchstranges kann man ein laterales und ein medianes Neuropilem unterscheiden und daneben Ganglienzellen, motorische, assoziative und sensibele, welche manchen Typen unterzuordnen sind.

BETHE hat die nachstehenden motorischen Ganglienzellen im Bauchstrang von Carcinus maenas beobachtet. Sie liegen alle lateral oder dorsal.

Erstens befindet sich (BEтнe, 1895̃a, 1897) in den Ganglien des Bauchstranges, z. B. im dritten Thorakalganglion (Fig. 89, a) eine unipolare Ganglienzelle, deren Stammfortsatz Aeste sendet zum medianen und lateralen Neuropilem desselben Ganglions der gleichen und der anderen Seite, Aeste zum medianen und lateralen Neuropilem des vorigen und des nächsten Ganglions dersélben Seite und überdies einen Ast in den peripheren Nerven des Ganglions. Dieser Ganglienzelltypus ist der einzige, welchen die Abdominalganglien aufweisen.

Der zweite Typus (BeтHe 1897) (Fig. 89, b) ist median im ersten Thorakalganglion gestellt. Seine Fortsätze stimmen in manchen Hinsichten mit jenen des ersten Typus überein, nur geht ihm der Ast nach vorn ab.

Der dritte Typus (Bетнғ 1895̃ , 1897) (Fig. 89, c) ist ganz einfach. Der Neurit tritt aus in den peripheren Nerven, während die Dendriten nur zum medianen und lateralen Neuropilem desselben Ganglions gehen. Solche motorischen Ganglienzellen liegen z. B. im zweiten Thorakalganglion.

Sehr merkwürdig ist eine vierte motorische Zellart (Fig. 89, d) (BЕтнE 1897), welche aller Wahrscheinlichkeit nach lateral im Scherenganglion (ersten Thorakalganglion) - gelagert ist. Der Stammfortsatz sendet Aeste in die peripheren Nerven der vier' vorderen 'Thorakalganglien und ein fünfter Zweig kreuzt die Medianlinie und verästelt sich im medianen Neuropilem des zweiten 'Thorakalganglions.

Die Assoziationszellen umfassen mehr als vier Ganglienzellarten, deren Fortsätze das Zentralnervensystem nicht rerlassen.

Der erste 'Typus (Fig. 89, e) (BЕTHE 1895a, 1897) wurde lateral im zweiten bis vierten Thorakalganglion entdeckt. Seine Fortsätze tragen nur zur Bildung des lateralen Neuropilems des Ganglions bei.

Ein anderer Typus (Fig. 89, f) (BEтHE 1897) liegt im fünften und sechsten Nundganglion (also im unteren Schlundganglion) und sendet Aeste zum medianen und lateralen Neuropilem des Ganglions. 
ARTHROPODA, CRUSTACEA.

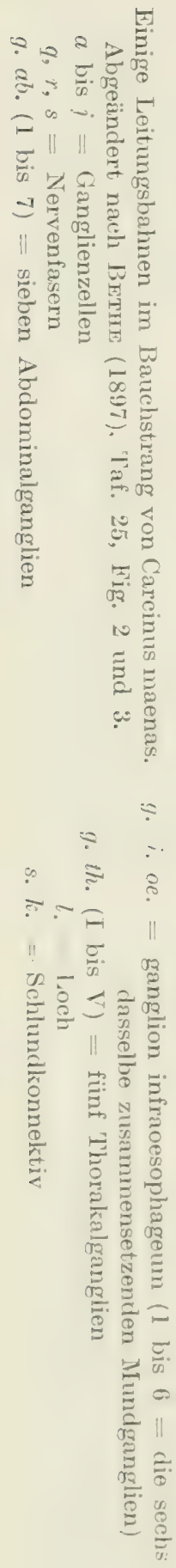

Fig. 89 .

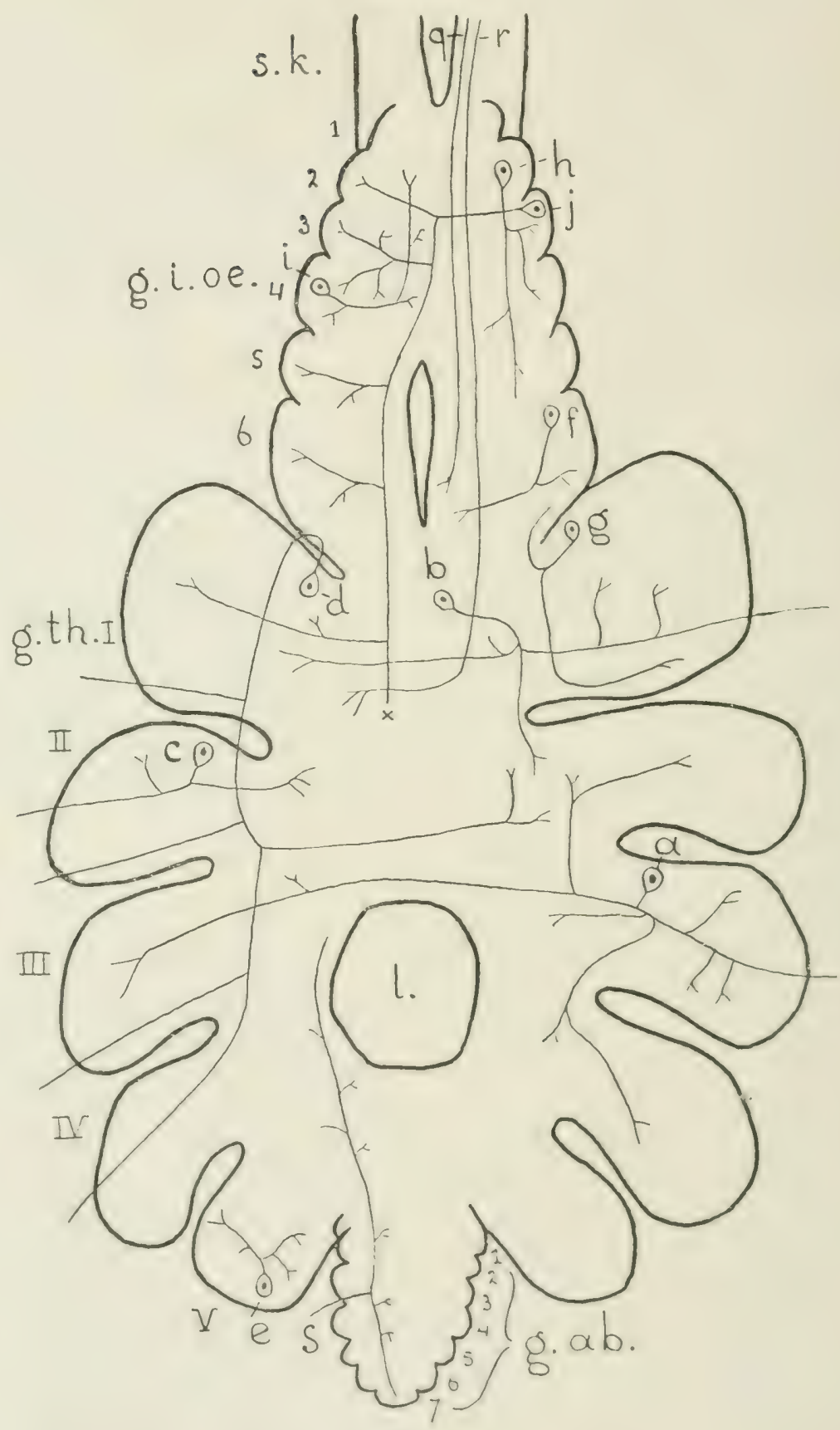


Im ersten Thorakalganglion entdeckte BЕтне (1895a, 1897) eine Gan glienzelle (Fig. 89, g), welche Fortsätze zum lateralen Neuropilem desselben und des vorigen Ganglions (sechsten Mundganglions) sendet.

Im zweiten Mundganglion (BEтнe 1895a, 1897) liegt eine Ganglienzelle (Fig. 89, h), deren Fortsätze zum lateralen Neuropilem des dritten und vierten Mundganglions ziehen und zum medianen Neuropilem des vierten und fünften.

In allen Thorakalganglien und in den Mundganglien 3 bis 6 beschreibt Bethe (1895a, 1897) einen Zelltypus (Fig. 89, i), dessen Neurit aszendiert und sich im medianen Neuropilem der beiden vorhergehenden Ganglien verästelt, nachdem er erst dem lateralen und medianen Veuropilem des eigenen Ganglions: Aeste überliefert hat. BETHE (1895̃a) homologisiert diesen Ganglienzelltypus wohl mit Recht mit dem Allexschen Typus $n$ (Fig. 83) von Homarus. Die Homologisierung von Zelltypus $h$ von Carcinus mit $m$ (Fig. 83) von Homarus ist, wie BETHE selber einsieht, weniger sicher.

Lateral im dritten Mundganglion befindet sich der Zelltypus $j$ (Fig. 89) (Bетне 1895a, 1897). Der Fortsatz kreuzt und deszendiert bis zu den Abdominalganglien, dabei zum medianen und lateralen Neuropilem eines jeden passierten Ganglions einen Ast abspaltend. Um die Figur 89 nicht zu verwirren habe ich den Ausläufer im ersten Thorakalganglion bei $\times$ abgebrochen. Aus der Betheschen Abbildung erhellt, daß auch das zweite Mundganglion von einem Ast besucht wird (wie in Fig. 89), aber aus dem Text geht solches nicht hervor. Vielleicht ist auch das zweite Mundganglion mit diesem Zelltypus ausgestattet (BETHE 1895̃a).

Es wurden auch median gestellte Assoziationszellen enteleckt. So in allen Mundganglien der Typus $k$ (Bетне 1895a, 1897). Deutlichkeitshalber habe ich diesen Typus nicht mehr in die Figur 89 eingetragen, sondern in die gleichförmige Figur 90. Der Stammfortsatz der Zelle $k$ teilt sich dichotomisch. Der eine Ast geht zum lateralen Neuropilem desselben Ganglions; der andere kreuzt und teilt sich in einen auf- und einen absteigenden Ast, welche den ganzen Bauchstrang durchziehen und ins laterale Neuropilem aller Ganglien (Mund-, Thorakal- und Abdominalganglien) derselben und der anderen Seite Aeste senden. In der Figur 90 wurde der Zweig nach vorn bei $\times$ abgebrochen

In allen Thorakalganglien fand Bethe (1895a, 1897) den Zelltypus $l$ (Fig. 90). Der Zellkörper liegt median. Der Stammfortsatz teilt sich in zwei Aeste, von denen der eine kreuzt. Beide teilen sich bald abermals in zwei Aeste, welche im ganzen Bauchstrang auf- und absteigen und dem medianen Neuropilem aller Ganglien Seitenäste übermitteln. In der Figur 90 sind diese vier Aeste bei $\mathrm{O}$ abgebrochen um die Figur nicht $\mathrm{zu}$ ïberfüllen.

Nervenfasern, welche den ganzen Bauchstrang durchziehen sind nicht nur Fortsätze von Ganglienzellen des Bauchstranges, sondern bisweilen auch von Ganglienzellen des Hirnganglions. So treten mit den Schlundkonnektiven zwei Fasertypen in den Bauchstrang ein. Ihr Ursprung ist unbekannt, aber wohl im Hirnganglion zu suchen. Der eine Typus (Fig. 90, m) (BEтHE 1895a, 1897) läuft zwischen dem lateralen und medianen Neuropilem der Ganglien des Bauchstranges und gibt zu jedem Ganglion kurze Aeste ab. Der andere Typus n (Bетне 1895) 1897 ) sendet Zweige zum lateralen Neuropilem aller 


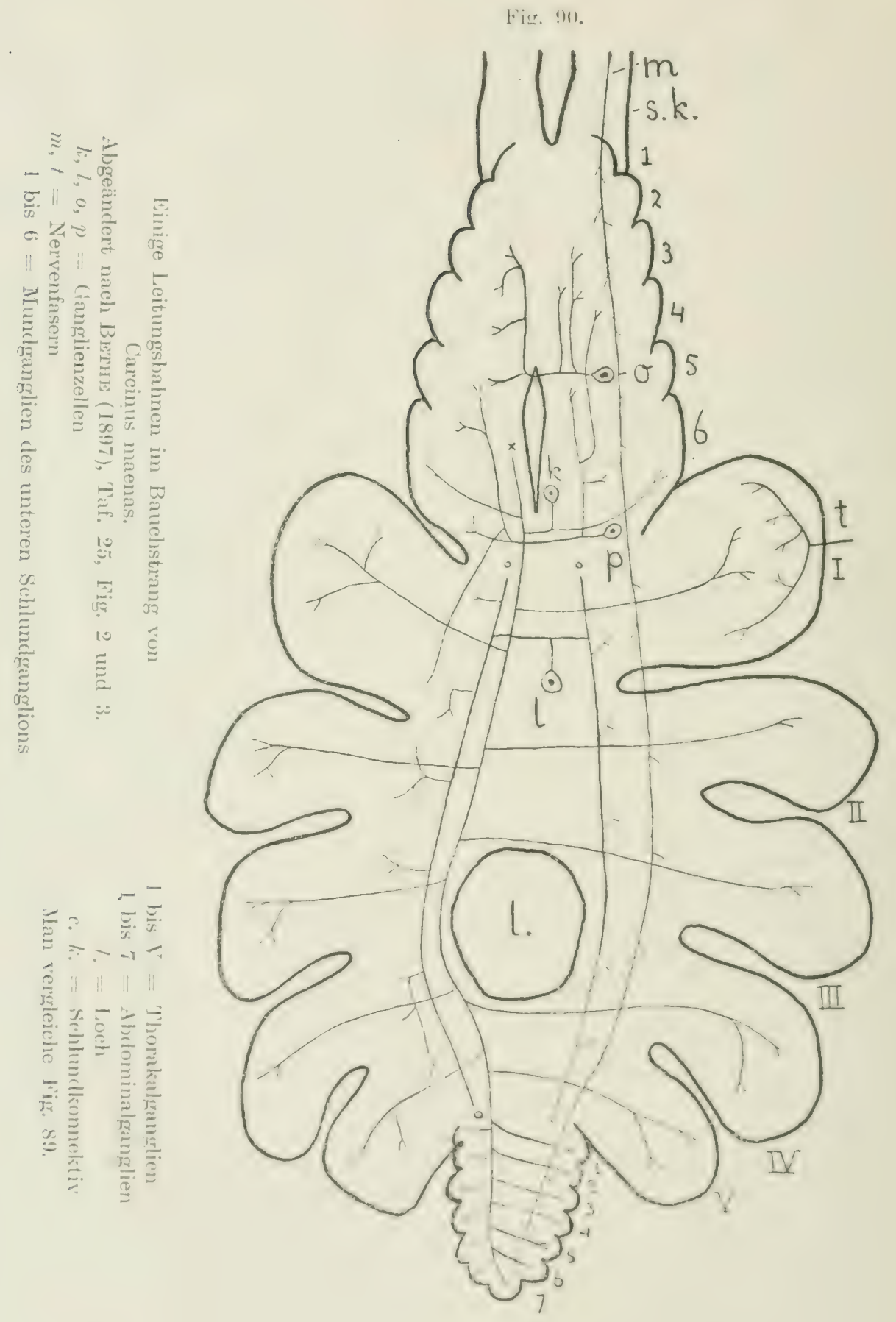


Ganglien. Er gleicht also sehr dem vorigen Typus und ich habe es nicht nötig geurteilt ihn in der Fig. 90 abzubilden.

Der Zelltypus o befindet sich lateral im fünften MLundganglion (Fig. 90) (Bethe 1895a, 1897). Seine Aeste gehen zum medianen Neuropilem des dritten, vierten und fünften Nundganglions derselben und der anderen Seite.

Zum sechsten Mundganglion gehört die Zelle p) (Fig. 90) (Ветне 1897). Es gehen aus ihr Aeste hervor zum medianen Neuropilem des vierten, fünften und sechsten Mundganglions derselben und der gekreuzten Seite und überrlies sendet der gekreuzte Zweig einen Ast nach hinten ins Scherenganglion.

Die Schlundkonnektive führen neben den Fasern $m$ und $n$ noch zwei andere Fasertypen mit unbekannter Herkunft. Der erste Typus (Fig. 89, q) (BЕтне 1897) endet im medianen Neuropilem des sechsten Nundganglions: der zweite (Fig. 89, r) (BЕTHE 1897) zieht ins erste Thorakalganglion, überschreitet dort die Medianlinie und endet verzweigt im medianen Neuropilem dieses Ganglions.

Damit sind die wichtigsten Assoziationszellen besprochen worden. Einige untollständig bekannte Nervenfasern, welche ВетнЕ beschreibt, sind hier fortgelassen.

Die sensibelen Nervenfasern des Bauchstranges gehören zu Zellen (sensibelen Ganglienzellen oder Sinnesnervenzellen), welche in der Peripherie des Körpers liegen. Die meisten dieser Fasern, wie Faser $s$ der Fig. 89, teilen sich im Bauchstrang angelangt ' $\mathrm{T}$-förmig in einen aszendierenden und einen deszendierenden Ast, welche den medianen Neuropilemen der Ganglien Kollateralen zuführen (Ветне 1895a, 1897). Nach Ветне (1895 $\alpha$ ) bilden die sensibelen Fasern im Bauchmark ein oberes und ein unteres Längsbündel. Dem oberen Längsbündel fügen sich auch sensibele Nervenfasern bei, welche nur aszendieren, nicht deszendieren. Noch andere sensibele Nervenfasern (Fig. 90, $t$ ) verzweigen sich nur im Ganglion, in das sie eintreten und enden dort (BЕтнE 1895a, 1897). Sie treten ein an der ventralen Seite der Ganglien.

Bethe (1895a und 1897) hat nicht nur die Leitungsbahnen des Bauchstranges, sondern auch die Hodologie des Hirnganglions von Carcinus maenas studiert. Er fand das Gehirn in seinem allgemeinen Bau, demjenigen von Astacus, wie KRIEGER es beschreibt (vergl. Fig. 73, S. 222), sehr ähnlich. Das Hirnganglion hat eine mehr oder weniger rechteckige Gestalt und ist in der Nitte durchlöchert. In den Figuren 91 und 92 stellt $l$. das Loch dar.

Es gehen sechs Nervenpare aus dem Gehirn hervor.

Median am Vorderrande verläßt der nervus medianus (Fig. 91, n.m.) das Gehirn und geht zu einem sympathischen Plexus. Ihm folgt der nervus opticus oder pedunculus lobi optici (Fig. 91 und 92, p.l.o.), wie ich ihn auch hier nennen werde, Dann kommt der nervus oculomotorius (Fig. 91, n. oc.), von BETHE im Jahre 1895 irrtümlich nervus tegumentarius genannt, wie er später (1897) selbst festgestellt hat. Er tritt, wie der pedunculus lobi optici, in den Augenstiel ein. Es folgt jetzt der Nerv der ersten Antenne, nervus antennarius primus (Fig. 92, n.a.p.), welchel aus zwei Biindeln zusammengesetzt ist, eins zur Statocyste und eins zur Antenne selbst. Hinter dem ersten Antennalnerven tritt der wahre nervus tegumentarius (Fig. 91 und 92, $n . t$.) 
Fig. 91 .

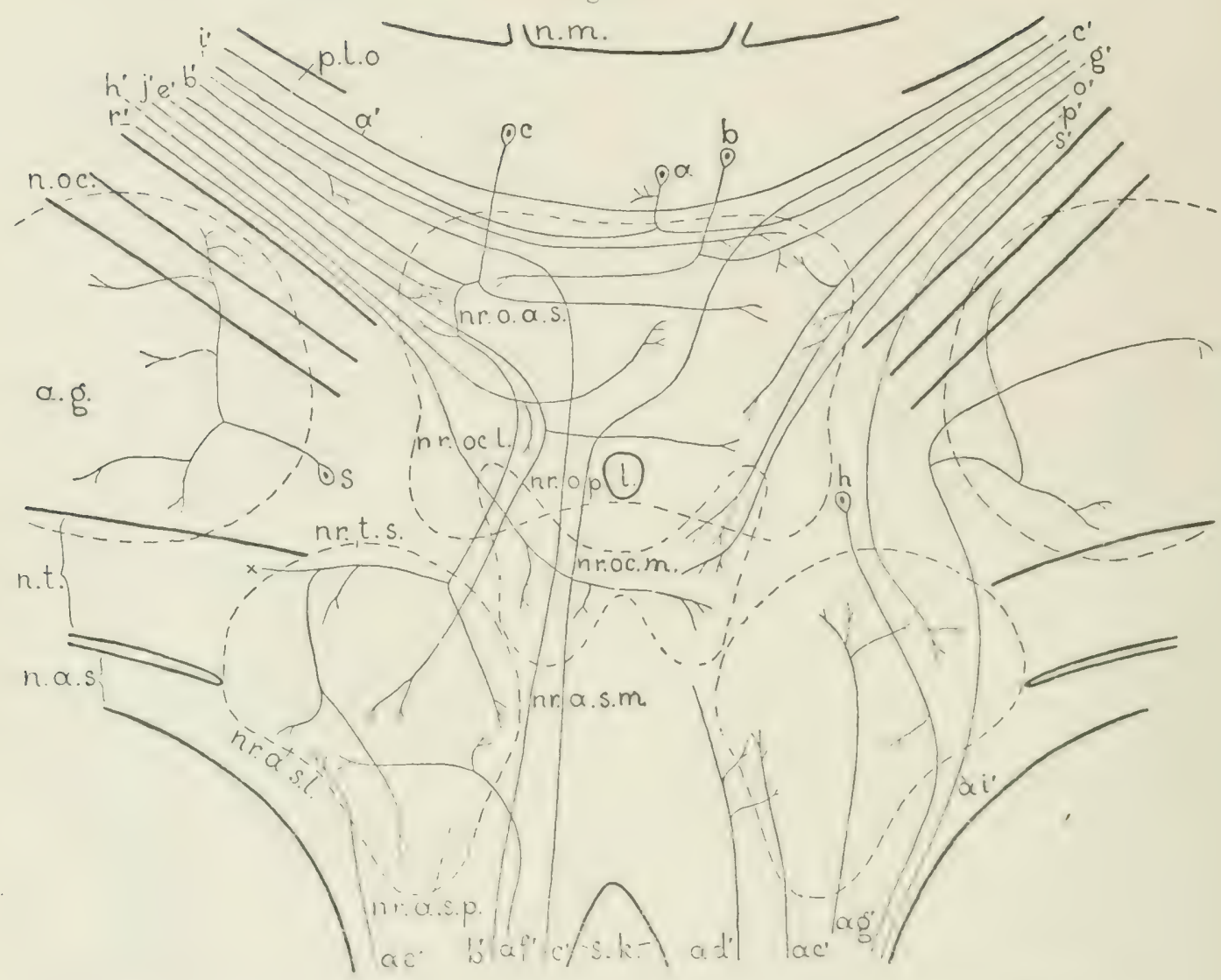

Schema einiger Leitungsbahnen im Hirnganglion von Carcinus maenas. Das Hirn-

ganglion von oben gesehen. Abgeändert nach BETHE (1897).

$a, b, c, h, s=$ Ganglienzellen

$i^{\prime}, l^{\prime}, r^{\prime}, \therefore g^{\prime}$ bis $i^{\prime}, o^{\prime}, p^{\prime}, r^{\prime}, s^{\prime}, a c^{\prime}$ bis $a g^{\prime}, a i^{\prime}=$ Nervenfasern

a. $y .=$ Antennalganglion

l. $=$ Loch

11. a. s. = nervus antennarius secundus

n. $m$. = nervus medianus

n. $n c=$ nervus oculomotorius

.1. $\% . . \%=$ neuropilema antennarii secundi laterale

11. $"$... $m .=$ neuropilema antennarii secundi mediale

ir. a. . ". neuropilema antennarii secundi posterius

rr. ". ". . . = neuropilema optici anterosuperius

.r. $\cdots . .=$ neuropilema optici posterius

in. $\ldots .1$. = neuropilema oculomotorii laterale

"1...... $\ldots .=$ neuropilema oculomotorii mediale

.... . . = neuropilema tegumenturii superius

1.. 1. nervus tegumentarius

p. l.o. = peduneulus lobi optici

s. li. sichlundkonnektiv

Die Strichellinien begrenzen die Neuropileme. 
hervor und als sechster Nerv der nervus antemmarius secundus (Fig. 91 und $92, n$. a.s.) zur zweiten Antenne. Nach hinten verbinden die beiden Schlundkonnektive (Fig. 91 und 92, s.l.) das Gehim mit dem Bauchstrang.

Im Inneren des Hirnganglions konnte BEтHE (1897) verschiedene Ganglienzellgruppen und neuropilemata unterscheiden. Zwischen den beiden pedunculi loborum opticorum befinclet sich ein viereckiges Neuropilem, worin optische Leitungsbahnen enden und in dem vier Gebiete zu unterscheiden sind, nämlich das neuropilema optici anterosuperius (Fig. 91, nr.o.a.s.), das neuropilema optici posterius (Fig. 91, nr. o. p.), das neuropilema optici mediale (Fig. 92, nr. o.m.) und das neuropilema optici inferius (Fig. 92, $n$. o. $i$.$) . Zwischen dem neuropilema optici inferius und mediale beobachtete$ Bethe ein in die Länge gezogenes Neuropilem, den „Balken”.

Die Nervenfasern des Oculomotorius enden, wie wir sehen werden im neuropilema oculomotorii laterale und mediale (Fig. $91, n r . o c . l$. und $n r . o c . m$.).

Auf beiden Seiten des Gehirns liegt ein großes kugelförmiges Gebilde (Fig. 91 und 92, a.g.), ein Neuropilem mit umgebenden Ganglienzellen, welches BETHE den globulus nennt, weil er es mit den pilzhutförmigen Körpern (corpora pendunculata) der Insekten homologisiert. Er unterscheidet darin einen hemiglobulus anterior und posterior. Wenn wir in der BetHeschen Arbeit selbst nachschlagen, welche Leitungsbahnen im sogenaninten globulus anfangen oder enden, so sehen wir, daß er keineswegs ein Assoziationszentrum für Bahnen aus dem ganzen Gehirn ist, wie die pilzhutförmigen Körper der Insekten, sondern, daß darin Nervenfasern des ersten Antennalnerven enden. Der ,globulus" gehört also zum Gebiete des nervus antennarius primus und er ist in der Tat demselben Gebiete der Insekten, also dem Antennalganglion oder lobus olfactorius zu vergleichen. Ich werde ihn, um Verwirrung mit den corpora pedunculata der Insekten, welche allen Crustaceen abgehen, vorzubeugen, immer Antennalganglion nennen. Auch Nils HoLigrex (1916) ist überzeugt, daß die BEтHEschen globuli die Antennalganglien sind und nicht die homologa der corpora pedunculata der Insekten. Belloxci (1880) nennt bei Nephrops norwegicus die Endstätte mancher Fasern des nervus antennularis (nervus antennarius primus) lobus olfactorius und weil er darin glomeruli olfactorii entdeckt hat, hat er die Uebereinstimmung mit dem lobus olfactorius der Insekten wohl sehr überzeugend dargetan.

Während die corpora pedunculata immer zum protocerebrum zu rechnen sind, gehört das Antennalganglion dem deuterocerebrum an. Hier bei Carcinus maenas liegen also im protocerebrum die neuropilemata optici und oculomotorii. Im deuterocerebrum befinden sich die Antennalganglien, aber auch zwei ventral gestellte Neuropileme, welche mit dem nervus antennarius primus zusammenhängen: das neuropilema antennarii primi laterale und mediale (Fig. 92, nr. a. p.l. und nr.a.p.m.).

Hinten im Hirnganglion, im tritocerebrum, liegen fünf Neuropileme beisammen. Es sind das neuropilema antennarii secundi laterale, posterius und mediale (Fig. 91, nr.a.s.l., nr.a.s.p. und $n$ r.a. s.m. $_{\text {. }}$ und das neuropilema tegumentarii superius (Fig. 91, nr.t.s.) und inferius (Fig. 92, nr.t. i.). Die Namen deuten die Nerven an, welche damit verbunden sind. 
Auch die verschiedenen Ganglienzellgruppen haben von BETHE (1897)。 Namen erhalten. Vorn oben im Hirn liegen die cellulae superiores mediales, zwischen den Antennalganglien und dem neuropilema optici die cellulae superiones laterales. im. Intemalganglion. das Neuropilem deselben umingend, die cellulae (globuli) anteriores und posteriores. Ventral im Hirnganglion sind die cellulae inferiores laterales und mediales gelagert und im Winkel zwischen dem nervus antennarius secundus und dem Schlundkonnektiv die cellulae angulares. Die Ganglienzellen sind sämtlich unipolar.

Fangen wir jetzt an mit der Beschreibung der von BETHE beobachteten Leitungsbahnen.

Im pedunculus lobi optici allein hat er nicht weniger als 23 verschiedene Typen von Nervenfasern entdeckt. Diese überraschend große Zahl soll uns davor warnen nicht nur hier, sondern bei allen Evertebraten, zu glauben. daß3 die bis jetzt bekannten Leitungsbahnen wirklich alle existierende seien und soll uns ebenso davon abhalten zwei von versehiedenen Autoren aufgrefundene Leitungsbahnen zu identifizieren oder zu homologisieren, falls sie nicht genau denselben Wegen folgen. Es sei dies namentlich dem Leser gesagt, welcher dieses Buch zu wenig synthetisierend findet.

Drei Nervenfasertypen des pedunculus lobi optici gehen aus Ganglienzellen des Hirnganglions hervor und zwar aus cellulae superiores mediales. Der erste Typus (Fig. 91, a) hat einen Stammfortsatz, welcher bald einen kleinen Ast nach unten ins Neuropilem sendet, sich dann aber teilt in zwei deste, welche die gerade Fortsetzung von einander bilden und jeder in einen pedunculus lobi optici ziehen. Diese Aeste bilden so die commissura optica superior.

Der Neurit des zweiten 'Typus (Fig. 91, b) zieht in den peduneulus der gleichen Seite, aber Seitenäste gehen zum neuropilema optici anterosuperius der beiden Hirnhälften.

Die dritte Zellart (Fig. 91, c) ist sehr kompliziert. Der Neurit verläßt das Hirnganglion in dem pedunculus derselben Seite, nachdem zuvor der Stammfortsatz einen kreuzenden Ast zum neuropilema optici anterosuperius der anderen Seite gesandt hat. Die übrigen Dendriten überschreiten nicht die Medianlinie. Sie suchen das neuropilema optici anterosuperius derselben Seite, das neuropilema antennarii secundi mediale, das neuropilema tegumentarii superius, das neuropilema antennarii secundi laterale und posterius und schließlich noch das neuropilema antennarii primi laterale auf. Der letztgenannte $Z$ weig ist in der Figur $\$ 1$ bei $\times$ abgebrochen.

Betne hat diese drei Ganglienzelltypen sowohl 1895 wie 1897 beschrieben.

Nicht weniger als zwanzig Fasertypen des pedunculus lobi optici sind unbekannter Herkunft, aber ihre Ganglienzellen liegren gewil3 aul3erhalb des Ilirnganglions. Ich werde alle l'asern ohne bekannten Ursprung mit dem Akrent bezeichnen zum Untersehied von den Fortsiitzen bekamnter Ganglienzellen.

Erstens gibt es Fasern (Fig. 91, $a^{*}$ ), welche vom einen pedunculus zum anderen ziehen ohne'dem Gehirn Seitenäste zu ïbermitteh.

Zweitens Fasern (Fig. (1), l'), welche mit dem pedunculus ins Cehirn 
eintreten, einen Ast zum neuropilema optici inferius senden, neben der Medianlinie nach hinten umbiegen und im ungekreuzten Schlundkonnektiv das Gehirn wieder verlassen.

Die Fasern des Typus c' (Fig. 91) sind im Hirnganglion unverzweigt. Sie treten mit dem pedunculus ein, überschreiten vor dem Loch (Fig. 91, l.) die Medianlinie und treten aus in das Schlundkonnektiv der anderen Seite.

Die Fasertypen $a^{\prime}, b^{\prime}$ und $c^{\prime}$ wurden zweimal von BETHE (1895a und 1897 ) beschrieben.

Die Fasern d' des pedunculus lobi optici (BETHE 1897) enden verzweigt im neuropilema optici inferius (Fig. 92); die Fasern e' (BETHE 1895̃ $\alpha, 1897$ ) im neuropilema optici anterosuperius (Fig. 91) ; die Fasern des 'Typus !' (Fig. 92) (BEthe 1897) im neuropilema optici mediale und die Fasern des Typus $g^{\prime}$ (Fig. 91) (BETHE 1897) im neuropilema optici anterosuperius und posterius.

Daneben gibt es Fasern (Fig. 91, h') (BETHE 1897), welche sich verzweigen im neuropilema optici posterius derselben Seite und im gekreuzten neuropilema optici mediale und Fasern (Fig. 91, $i$ ) (BEтнE 1897), 'welche die Medianlinie überschreiten und dann im neuropilema optici anterosuperius enden. Letztere stimmen also ungeachtet der Kreuzung der Medianlinie mit den Fasern $e$ überein.

Die Fasern des 'Typus j' (Fig. 91) (BETHE 1895a, 1897) senden einen Zweig zur Endverästelung der Fasern $e$ '. Dann geht aus ihnen ein Ast zum neuropilema optici posterius der anderen Seite hervor und schließlich enden sie verzweigt im neuropilema antennarii secundi derselben Seite.

Ich bin gezwungen den nächsten Fasertypus in einer neuen Figur, Fig. 93, abzubilden, welche jedoch in ihrem Umriß der Figur 91 gleich ist. Die Fasern $l '$ ' des peduneulus lobi optici (Fig. 93) (BEтне 1895a, 1897) spalten Zweige ab zum neuropilema optici anterosuperius und posterius ; dann kreuzen sie und senden ebenfalls Aeste zu den beiden genannten Neuropilemen der anderen Seite und wahrscheinlich auch einen Ast zum neuropilema antennarii secundi.

Die Fasern l' (Fig. 92) (BETHE 1897) enden verzweigt im neuropilema optici inferius der beiden Gehirnhälften; die Fasern m' (Fig. 92) (BEтнE 1897) ebenfalls, aber sie verästeln sich nur dort, wo die Fasern d' enden.

Bethe ( 1897 ) konnte die Fasern des Typus $u^{\prime}$ (Fig. 92) nicht ganz verfolgen. Die Faser ist deshalb auch in der Figur 92 zweimal bei $\times$ abgebrochen worden Wahrscheinlich geht ein Ast zum neuropilema optici mediale und zieht dic Faser selbst in das Schlundkonnektiv; gewiß sucht ein Ast das neuropilema antennarii primi laterale und das neuropilema antennarii secundi laterale auf.

Endlich gibt es noch Nervenfasern im perluneulus lobi optici (BE'HE 1897), welche im neuropilema optici anterosuperius und im neuropilema oculomotorii mediale ihre Endverästelungen haben (1'ig. 91, o').

Die iibrigen Fasern des pedunculus stehen nicht mehr mit dem neuropilema optici, sondern nur mit anderen Neuropilemen in Verbindung. So verzweigen sich die Fasern p' (Fig. 91) nur im neuropilema oculomotorii mediale (Bethe 1897). Die Fasern q' (Fig. 93) bilden nach Beтнe (1897) den 
Fig. 92.

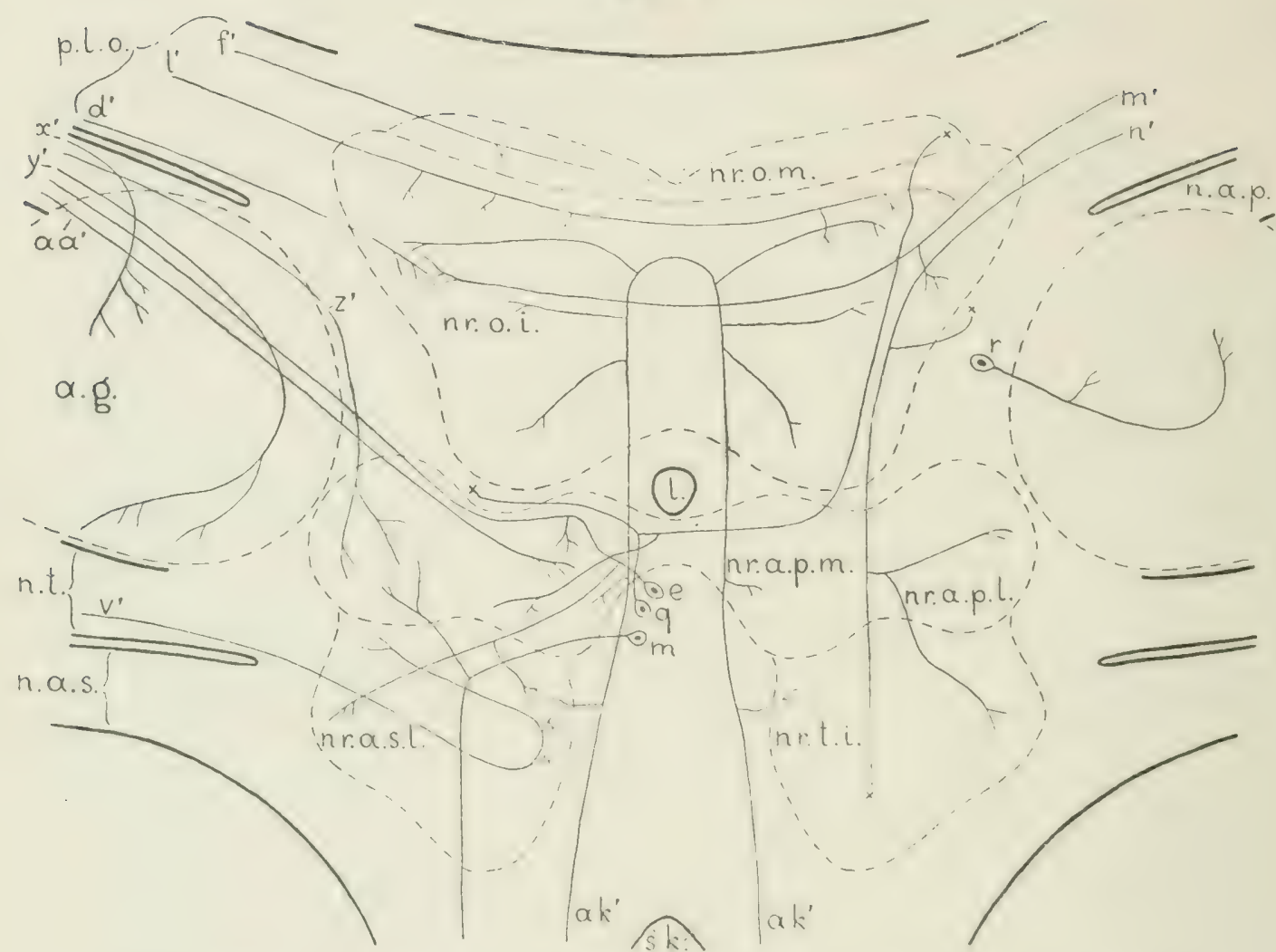

Schema einiger Leitungsbahnen im Hirnganglion von Carcinus maenas. Das Hirnganglion von unten gesehen. Abgeändert nach BeTHE (1897), Taf. 28.

$e, m, q, r=$ Ganglienzellen

$l^{\prime}, f^{\prime}, l^{\prime}, m^{\prime}, n,^{\prime} v^{\prime} x^{\prime}, y^{\prime}, z,^{\prime} a a^{\prime}, a l^{\prime}=$ Nervenfasern

a. $g .=$ Antennalganglion

l. $=$ Loch

n. $a . p .=$ nervus antennarius primus

n. a. $s$. = nervus antennarius secundus

$n r . a . p . l .=$ neuropilema antennarii primi laterale

$n r . a . p . m .=$ neuropilema antennarii primi mediale

$n$ r. a. s. $l .=$ neuropilema antennarii secundi laterale

$n r$. o. $i .=$ neuropilema optici inferius

nr. o. $m .=$ neuropilema optici mediale

$n r . \iota_{0} i_{0}=$ neuropilema tegumentarii inferius

n. $t$. $=$ nervus tegumentarius

p.l. o. $=$ pedunculus lobi optici

s. $k$. = Schlundkonnektiv

Die Strichellinien begrenzen dic Neuropileme 
tractus opticoglobularis, welcher den pedunculus lobi optici mit dem Antennalganglion (,globulus") der beiden Hirnhälften verbindet. ВЕтнЕ scheint diese Bahn als besonders wichtig zu betrachten, weil er nur dieser einen eigenen Namen gibt, aber sie ist eigentlich sehr mangelhaft bekannt, da BETHE im Antennalganglion keine Verästelungen der Nervenfasern zeichnet und somit weder der Anfang noch das Ende der Bahn bekannt ist. Auch geht die Verbindung dieser Fasern mit dem Antennalganglion der gleichen Seite nicht aus den Betheschen Abbildungen hervor. Weil außerdem der Name tractus opticoglobularis nach meinen Ansichten nicht beibehalten werden kann, sehe ich in den Fasern $q$ ' nur Fasern, welche aufs neue studiert werden müssen und gewiß bis jetzt nicht verdienen einen besonderen Namen zu tragen.

Die drei letzten Fasertypen des pedunculus lobi optici haben einen relativ einfachen Lauf. Der 'Typus $r$ ' (Fig. 91) (BEтнe 1895a, 1897) verzweigt sich im neuropilema oculomotorii der beiden Seiten, die Fasern s' (Fig. 91) im neuropilema tegumentarii superius (BETHE 1897) und die Fasern $t^{\prime}$ (Fig. 93) im neuropilema antennarii secundi mediale (BETHE 1897).

Es sind damit die von BETHE entdeckten Nervenfasern des pedunculus lobi optici beschrieben, aber BEтHE ist-der Meinung, daß noch andere Fasertypen da sind.

Im nervus oculomotorius hat BETHE (1895a, 1897) zwei Fasertypen aufgefunden. Der erste ist dex Neurit einer Ganglienzelle der cellulae superiores laterales (Fig. 93, d). Dendriten dieser Zelle gehen zum neuropilema oculomotorii laterale. Ein sehr wichtiger Dendrit zieht ins neuropilema optici anterosuperius, spaltet Aeste ab in der Nähe der Endverästelungen der Faser e', läuft selber weiter, kreuzt die Medianlinie und endet wahrscheinlich auch in der anderen Hälfte des Hirnganglions in der Nähe der Faser $e^{\prime}$. In der Figur 93 habe ich jedoch diesen Ast bei $\times$ abgebrochen, weil sein Weg nicht ganz sicher festgestellt worden ist. Ein anderer wichtiger Dendrit der Zelle $d$ läuft nach hinten und verzweigt sich im neuropilema tegumentarii superius und im neuropilema antennarii secundi mediale und posterius. Noch andere Dendriten, welche ich in meiner Figur nicht abbilden konnte, gehen zum neuropilema optici mediale und zum neuropilema antennarii primi mediale und laterale.

Die zweite Nervenfaserart des nervus oculomotorius ist meiner Meinung nach nicht genügend bekannt und ich bilde sie deshalb nicht ab. BETHE meint, daß diese Fasern Neuriten der cellulae inferiores mediales sind. Seitenäste gehen ins neuropilema oculomotorii mediale, neuropilema optici mediale, neuropilema tegumentarii superius und in die neuropilemata antennarii secundi laterale und posterius.

Der nervus tegumentarius enthält drei Nervenfasertypen (BETHE 1897), welche alle im Hirnganglion enden. Die erste Art (Fig. 93, $u^{\prime}$ ) (BETre 1895a, 1897) verzweigt sich im neuropilema tegumentarii superius, die zweite (Fig. $\left.92, v^{\prime}\right)$ läuft erst zum neuropilema tegumentarii inferius und spaltet dort Aeste ab, geht dann aber zuriick zum neuropilema tegumentarii superius um dort zu enden. Die dritte Art (Fig. $93, w^{\prime}$ ) endlich verästelt sich im neuropilema oculomotorii mediale.

Im nervus antennarius primus konnte BETHE (1897) fünf verschiedene 
Fiig. 93.

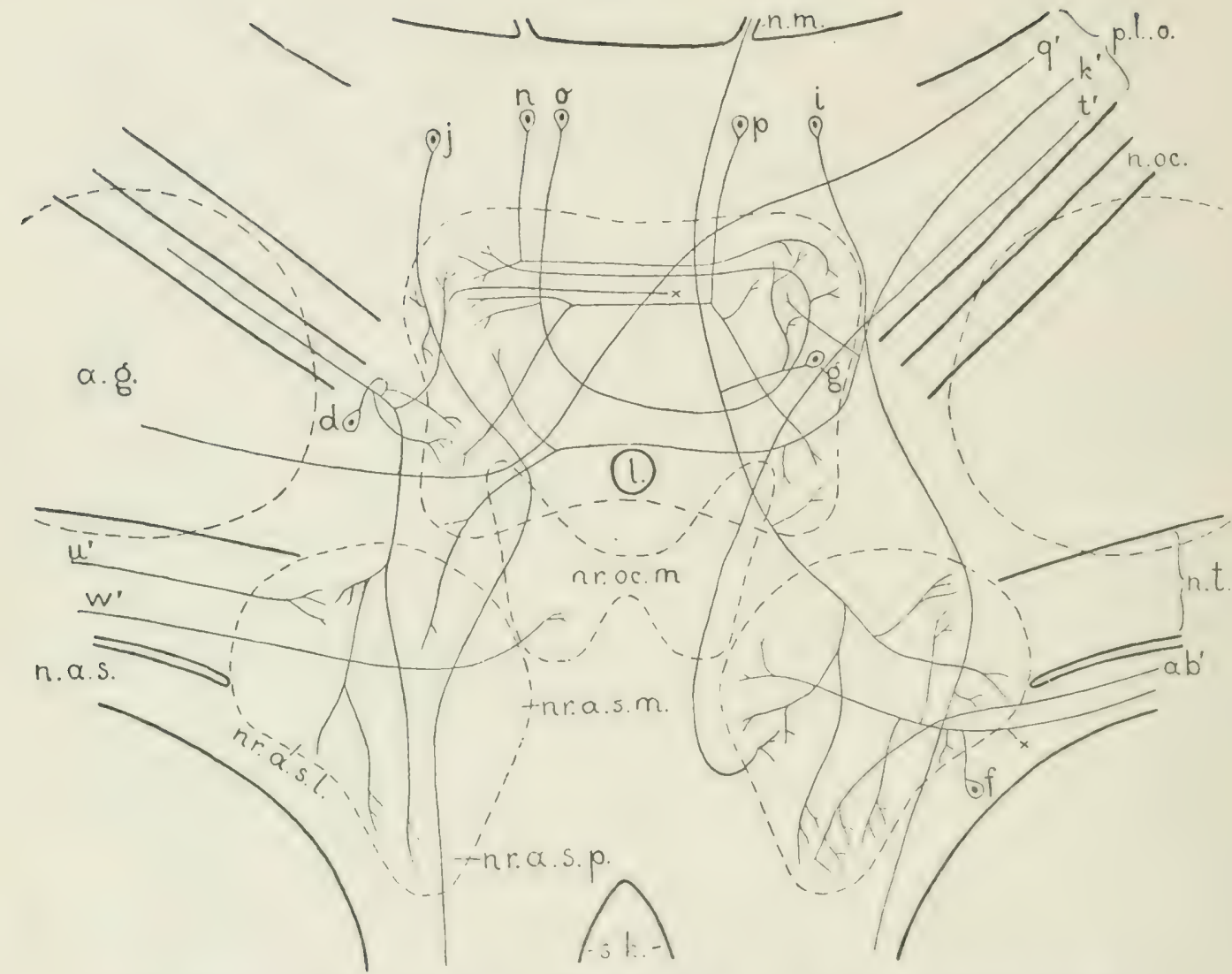

Schema einiger Loitungsbahnen im Hirnganglion von Carcinus maenas. Das Hirn-

ganglion von oben gesehen. Abgeändert nach BЕтне (1897).

$d, f, g, i, i, n, o, p-$ Ganglienzellen

$k^{\prime}, q^{\prime}, t^{\prime}, u^{\prime}, w^{\prime}, a b^{\prime} \quad$ Nervenfasern

1. \%. Antennalganglion

1. - Loch

11. u. . - nervus antennarius secundus

11. $m$. nervus medianus

11. $\cdots$. - nervus oculomotorius

II. 4. .. I. neuropilema antennarii secundi laterale

Ir. . . s. m. neuropilema antennarii secundi mediale

11\%. и. .. \%. - neuropilema antennarii secundi posterius

iir. "w. m. - neuropilema oculomotorii mediale

11. t. nervus tegumentarius

I. I. o. - pedunculus lobi optici

s. li. - Sehlundkonnektiv.

Die strichellinien begrenzen die Neuropileme. 
Nervenfasertypen unterscheiden. Tier derselben endeten im Hirnganglion, einer aber ging aus Ganglienzellen des Gehirns hervor. Einige cellulae inferiores mediales (Fig. 92, e) senden nämlich ihren Neuriten in den ersten Antennalnerven, während Dendriten ins neuropilema antennarii secundi laterale, neuropilema tegumentarii inferius und ins neuropilema antennarii primi mediale ziehen.

Die übrigen Fasern des nervus antennarius primus enden vorn im Antennalganglion (nach BETHE im hemiglobulus anterior) (Fig. 92, $x^{\prime}$ ), hinten im Antennalganglion (nach BETHE im hemiglobulus posterior) (Fig. 92, $y^{\prime}$ ) im neuropilema antennarii primi laterale (Fig. 92, $z^{\prime}$ ) oder im neuropilema añtennarii primi mediale (Fig. 92, $a a^{\prime}$ ). Nach Bethe stammen die Fasern, welche im Antennalganglion oder im neuropilema antennarii primi laterale enden (also $x^{\prime}$, y' und $z^{\prime}$ ) von der Statocyste her, während im neuropilema antennarii primi mediale die übrigen Fasern der ersten Antenne enden.

Der nervus antennarius secundus führt wenigstens drei verschiedene Nervenfaserarten (BEтie 1895̆, 1897), aber nur zwei derselben sind hinreichend bekannt. Der zweite Antennalnerv hat zwei IVurzeln, eine obere und eine untere, welche sich anfangs vereinigen, sich aber später wieder trennen, wonach die untere zu den Antennalmuskeln geht. Dieser motorische Zweig enthält, wie zu erwarten war, zentrifugale Nervenfasern, Fortsätze von Ganglienzellen der cellulae angulares (Fig. 93, f). Der Stammfortsatz dieser Zellen spaltet erst einen Ast ab zum neuropilema antennarii secundi laterale, mediale und posterius und zum neuropilema tegumentarii superius. Bevor der Neurit austritt, geht aus ihm ein anderer Zweig hervor, welcher von BETHE nicht genau beschrieben wird und von mir in Figur 93 bei $\times$ abgebrochen wurde. BEтHE (1897) sagt, daß dieser Ast das neuropilema tegumentarii inferius und das neuropilema antennarii laterale und mediale aufsucht. Ob hier das neuropilema antennarii primi oder secundi gemeint wird, sagt BETHE nicht, aber aus seinen Abbildungen scheint mir hervorzugehen, daß das neuropilema antennarii secundi gedacht worden ist.

Die Neuriten der Ganglienzellen $f$ bilden in der unteren Wurzel ein dickes Bündel. Ein dünneres Bündel derselben Wurzel besteht aus Nervenfasern (Fig. 93, $a^{h}$ '), welche im neuropilema antennarii secundi posterius verzweigt enden.

Die obere Wurzel des zweiten Antennalnerven enthält nach Bethe (1895a) ebenfalls Nervenfasern, welche an verschiedenen Stellen des Neuropilems verzweigt enden.

In den Mlediannerven sind 10 bis 15 Nervenfasern, welche aus Ganglienzellen der cellulae superiores laterales (Fig. 93, g) hervorgehen. Seitenäste dieser Nervenfasern dringen in alle Neuropileme der Oberseite des Hirnganglions ein, nur nicht ins neuropilema oculomotorii mediale. Auch diese Fasern wurden zweimal von BETHE (1895a, 1897) erwähnt.

Ich habe jetzt die Fasern der Hirnnerven von Carcinus maenas beschrieben, also die motorischen und sensibelen Leitungsbahnen und es bleiben mir jetzt noch Assoziationselemente übrig.

Viele Nervenfasern verbinden das Hirnganglion mit dem Bauchstrang. 
Einige entspringen im Gehirn aus Ganglienzelle, aber wo irgend sie im Bauchstrang enden, blieb leider verborgen. Welche Ganglienzellen also die Fasern $m, n$, $q$ und $r$ des Bauchstranges aussenden (vergl. S. 257 und 259 und Fig. 89 und 90 ) ist noch zu entdecken.

Fiis. 9.1.
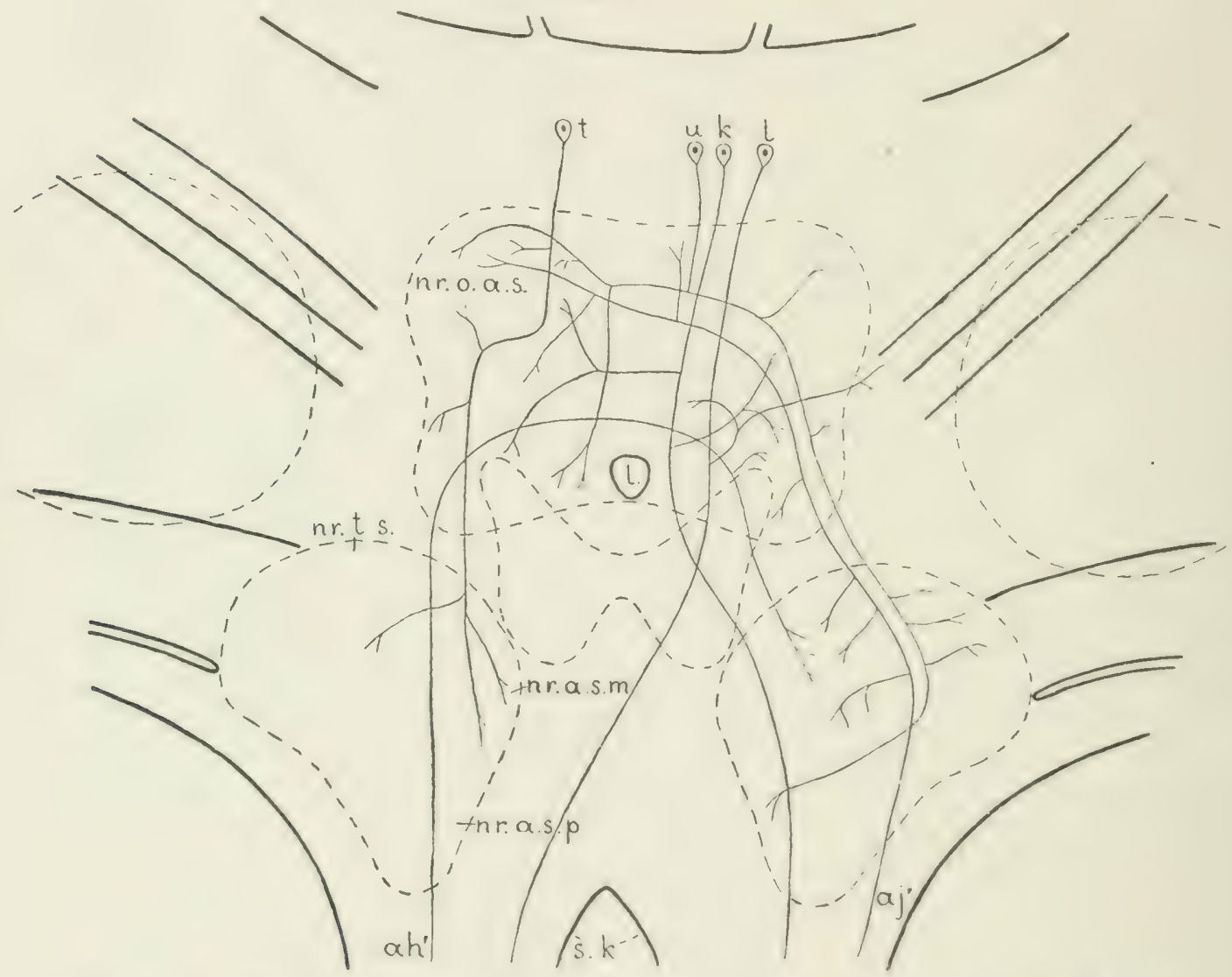

Schema einiger Leitungsbahnen im Hirnganglion von Carcinus maenas. Das Hirnganglion von oben gesehen. Abgeändert nach BetuE (1897). Man vergleiche Fig. 91.

$k, l, u, t=$ Ganglienzellen

$a h^{\prime}, a j^{\prime}=$ Nervenfasern

l. $=$ Loch

$n r . a . s . m .=$ neuropilema antennarii secundi mediale

$n r . a . s \cdot p .=$ neuropilema antennarii secundi posterius

$n r$. o. a. $s .=$ neuropilema optici anterosuperius

$n r . t$. s. $=$ neuropilema tegumentarii superius

s. k. $=$ Sehlundkonnektiv

Die Strichellinien begrenzen die Neuropileme.

$\mathrm{Zu}$ den cellulae superiores laterales gehört der Ganglienzelltypus h (Fig. 9]). Der Neurit sendet einen Ast aus zum neuropilema antennarii secundi laterale und zicht in das Schlundkonnektiv. 
Unter den cellulae superiores mediales beobachtete Bethe Ganglienzellen (Fig. 93, i), deren Neurit, nachdem er dem neuropilema antennarii secundi laterale einen Ast abgegeben hat, im Schlundkonnektiv verschwindet.

Andere cellulae superiores mediales (Fig. 93, j) senden unter Abspaltung von Seitenästen zum neuropilema optici anterosuperius ihren Neuriten in das Schlundkonnektiv.

Diese drei Ganglienzellen wurden auch im .Tahre 1895 beschrieben, die nachstehenden, welche ihren Neuriten in das Schlundkonnektiv senden, nur 1897 von BEтHE erwähnt.

Mit der Bezeichnung cz4 deutet Beтнe eine Nervenfaser an, welche örtlich außerordentlich breit ist und nicht genau mit einer Ganglienzelle in Verbindung gesehen wurde. Ich bin durchaus nicht überzeugt, daß es eine Nervenfaser ist und bilde sie deshalb hier nicht ab.

Unter den cellulae superiores mediales befindet sich auch der Ganglienzelltypus $k$, welchen ich aus Mangel an Raum in den Figuren 91 und 93 in einer ähnlichen Figur 94 abgebildet habe. Der Neurit geht in das Schlundkonnektiv derselben Seite, aber Seitenäste gehen zu den neuropilemata optici anterosuperius und posterius derselben und der gekreuzten Seite.

Schließlich sind noch die Ganglienzellen des Typus $l$ (Fig. 94) zu den cellulae superiores mediales zu rechnen. Ihr Neurit überschreitet hinter dem Loch im Hirn die Medianlinie und mischt sich dem Schlundkonnektiv der anderen Seite bei. Seitenäste ziehen ins neuropilema optici mediale.

Zwischen den cellulae inferiores mediales liegen Ganglienzellen (Fig. 92, $m$ ), welche dem neuropilema antennarii primi laterale einen Ast übermitteln und ihren Neuriten in das Schlundkonnektiv schicken.

Nicht ganz verfolgbar war der Neurit einiger Ganglienzellen aus der Gruppe der cellulae anteriores des Antennalganglions, welche BerHe mit $c z 7$ bezeichnet. Ich bilde sie deshalb nicht ab.

Es enden im Gehirn noch mehr Nervenfasern, welche aus den Schlundkonnektiven darin eintreten, als solche, welche aus Hirnganglionzellen hervorgehen. Sie sind unbekannter Herkunft.

Erstens hat man darunter Fasern, welche sich im neuropilema antennarii secundi mediale verzweigen (Fig. 91, ac') (BЕтнЕ 1895a, 1897); andere tun dasselbe, senden aber überdies einen Ast gegen das neuropilema oculomotorii mediale (Fig. 91, ad'). Weiter gibt es Fasern (Fig. 91, ae'), welche sich im neuropilema antennarii secundi laterale verästeln, oder darin und zugleich im neuropilema antennarii secundi mediale (Fig. 91, af'). Auch enden einige Fasern (Fig. 91, $a g^{\prime}$ ) im neuropilema tegumentarii superius. Ungenügend erforscht sind Fasern, welche ins neuropilema oculomotorii mediale eintreten, deren Verästelungen aber nicht beobachtet wurden.

Die Fasern des Typus ah' (Fig. 94) (Ветне 1895a, 1897) kreuzen in derselben Kommissur wie die optischen Nervenfasern des 'Typus h' (Fig. 91) die Medianlinie und verzweigen sich dann im neuropilema optici mediale und vielleicht im neuropilema antennarii secundi.

Es gibt auch Fasern der Schlundkonnektive, welche sich wie die Faser $a i$ ' der Figur $91 \mathrm{im}$ Antennalganglion verzweigen und Fasern (Fig. 94, $a j^{\prime}$ ) 
(BETHE 1895a, 1897), welche erst dem neuropilema antennarii secundi der gleichen Seite und nachher dem neuropilema optici posterius und anterosuperius der beiden Gehirnhälften 'Lweige zuführen.

Ganz merkwürdig ist noch eine letzte Nervenfaserart (Fig. 92, ak'). Sie tritt mit dem einen Schlundkonnektiv ins Gehirn, läuft median nach vorn bis zum Vorderrande des neuropilema optici inferius, kreuzt und legt denselben Weg zurück zum Schlundkonnektiv der anderen Seite. Dabei werden ganz symmetrisch Kollateralen abgespalten und zwar zum neuropilema antennarii secundi mediale und primi mediale und zu manchen Teilen des neuropilema optici inferius.

Manche Assoziationseleniente beschränken sich auf das Gehirn. Nach BEтHF (1897) gibt es darunter 22 Arten, aber viele dieser Nervenfasern, worunter Kommissurfasern, sind unbekannter Herkunft und man kann also nur vermuten, daß sie das Hirnganglion nicht verlassen. Ich unterlasse es, alle diese nicht genau bekannten Nervenfasern zu beschreiben und will nur acht verschiedene Typen von Assoziationszellen mit ihren Nervenfasern wiedergeben.

$\mathrm{Zu}$ den cellulae superiores mediales gehören Ganglienzellen (Fig. 93, $и$ ) (BETHE 1895a, 1897), deren Stammfortsatz sich teilt in zwei Aeste zum neuropilema optici anterosuperius der beiden Hirnhälften. Der kreuzende Zweig läuft durch die commissura magna.

In der gleichen Ganglienzellgruppe liegen Ganglienzellen (Fig. 93, o) (BETIE 1895a, 1897), welche ebenfalls, Aeste aussenden zum neuropilema optici anterosuperius der beiden Seiten, aber durchläuft der kreuzende Zweig die Kommissur, welche die beiden neuropilemata optici posteria verbindet und merkwürdigerweise kann der kreuzende Ast bisweilen durch die commissura magna zurückkehren zur anderen Seite, wo der Zellkörper gelegen ist.

Wiederum andere cellulae superiores mediales (Fig. 93, p) (BЕтне 1895a, 1897) suchen mit ihren Fortsätzen das neuropilema optici anterosuperius und posterius der beiden Seiten auf und auch hier zieht der kreuzende Zweig durch die commissura magna.

BETHE fand unter den cellulae inferiores mediales den Ganglienzelltypus $q$ (Fig. 92). Die Zelle gibt dem neuropilema antennarii primi mediale einen Fortsatz. Zwei anderen Ausläufern war nicht bis zum Ende zu folgen. Der eine zieht seitwärts nach unten, vielleicht zum Antennalganglion, der andere kreuzt und läuft nach vorn. Beide sind in der Figur 92 bei $\times$ abgebrochen.

Einige cellulae anteriores des Antennalganglions senden ihren Fortsatz ins Neuropilem desselben (Fig. $92, r$ ), während auch die Fortsätze einiger cellulae posteriores (Fig. 91, s) sich im vorderen und hinteren Teil des Antennalganglions verästeln.

Endlich sind hier noch zwei Zelltypen der cellulae superiores mediales zu nemmen. Die Ganglienzellen $t$ (Fig. 94) (BETHE 1895a, 1897) senden ihre Fortsätze ins neuropilema optici anterosuperius und posterius und ins neuropilema antennarii secundi mediale derselben seite. Die Ganglienzellen u. (Fig. 94) besitzen einen Fortsatz, welcher mach hinten geht und allen Neuropilemen der Himoberseite 'Zweige abgibt. Zuror hat er aber einen Ast abgespalten welcher durch die commissura magna kreuzt und im neuropilema optici anterosuperius und posterius der anderen Seite endet. 
Bethe hat zweimal versucht die Entdeckung so mancher Leitungsbahnen physiologisch zu verwerten. Im Jahre 1895 stellt er sich auf den Standpunkt der Neuronenlehre. In einigen Fällen gelingt es ihm die Bahn eines bestimmten Reizes zu zeigen. So kann ich ihm heistimmen, wenn er sagt, daß, wenn die zweite Antenne sich nach Reizung reflektnrisch bewegt, der Reiz dabei der Nervenfaser $a b^{\prime}$ und den Fortsätzen der Ganglienzelle $f$ (vergleiche Fig. 93) folgt. Aber meistens sind wir zurzeit, wo durchaus nicht alle Leitungsbahnen uns bekannt sind, außer Stande zu entscheiden, ob ein zum Zentralnervensystem von Carcinus maenas gelangter Reiz einem uns bekannten Wege folgen muß oder vielleicht ebensogut anderen bekannten oder unbekannten Wegen folgen kann und so lange wir in dieser Lage sind, kommen wir mit unserer hodologischen Kenntnis nicht weiter in der Erklärung der physiologischen Tatsachen. Ein Beispiel. Wir wissen (BEтнe 1895a), daß das Auge sich bewegt nach Reizung des Auges selbst oder der zweiten Antenne. Vielleicht sind die Wege dazu gegeben in der optischen Nervenfaser $e^{\prime}$ und der Ganglienzelle $d$, welche nähere Beziehungen aufweisen (vergl. S. 265) und in der Nervenfaser $a b^{\prime}$ des nervus antennarius secundus und der Ganglienzelle $d$ (vergl. Fig. 93). Aber warum kann nicht die Faser j' statt e' benutzt werden, da ihre Verästelungen an gleicher Stelle liegen und warum nicht statt $a b^{\prime}$ und $d$, $a b^{\prime}$ und die zweite, unvollständig bekannte Nervenfaserart des nervus oculomotorius (vergl. S. 265), welche sich doch auch im neuropilema antennarii secundi posterius verzweigt?

Man darf nicht vergessen, daß wenn auch die Weise, worauf BETHE die Physiologie mit Hilfe der Hodologie zu fördern sucht - ein Ziel, welches schließlich auch mit diesem Buche beabsichtigt wird - ganz richtig ist, die Versuche dazu sehr wohl zu früh unternommen sein können. Ich glaube, daß das der Fall ist, denn wie viel Schönes die BerHeschen Untersuchungen auch enthalten, manches harrt noch näherer Erforschung und am Ende bedarf alles noch der Bestätigung seitens anderer Autoren, denn so viel ich weiß, hat nur BEтHE sich mit der Hodologie von Carcinus maenas beschäftigt. Wer dessenungeachtet wissen will, in welcher Weise BETHE seine hodologischen Entdeckungen mit seinen physiologischen Versuchen verbindet, sei auf das Original verwiesen.

In seiner dritten Arbeit über Carcinus maenas (BETHE 1898) zeigt sich Betнe als Gegner der Neuronenlehre und erkennt er im Nervensystem ein einziges Neurofibrillennetz an, welches aus physiologischen Gründen nicht diffus sein kann. Obgleich er bei Carcinus maenas niemals zwei Neuronen durch Neurofibrillen kontinuirlich verbunden sah, glaubt er doch daran auf Grund seiner Erfahrungen bei anderen Evertebraten. Auch jetzt gibt er für gar manche reflektorischen Bewegungen die Bahnen an (ohne größere Gewißheit als zuvor) und er verweist dabei auf die früher entdeckten Neuronen. Ein gruter Beweis datiur, dali, auch wenn die Neurotibrillen die eigentlichen Leitungsbahnen in den Nervenfasern und Ganglienzellen sind, die Ganglienzellen mit ihren Fortsätzen zur Bahnbeschreibung völlig hinreichend sind. Dazu kommt, daß, während es Betne so vorzüglich gelang, die Neuronen mit Methylenblau 
darzustellen, er nach seinen eigenen Worten den Lauf der Neurofibrillen nur in einigen Neuronen und hier nur teilweise kennt.

Das oben Gesagte soll nur beweisen, daß man auch mit anderen Anschauungen als denjenigen, welche BETHE hatte, als er die Bahnen von Carcinus maenas histologisch studierte $(1895 a, 1897)$, seine Resultate sehr gut verwenden kann, aber doch ist das nur möglich, wenn man kein diffuses Netz der Neurofibrillen erkennt. Bedenken sind nur dort zu erheben, wo Berre behauptet, daß gewisse Neurofibrillen mit dem einen Nerven ins Zentralnervensystem eintreten, das Neuropilem passieren ohne in einen Ganglienzellkörper einzutreten und mit einem anderen Nerven das Zentralnervensystem wieder verlassen. Eine solche Bahn ohne jeglichen Zellkörper wird, falls sie bestände (die Betheschen Versuche das Dasein solcher Bahnen zu beweisen, bedïrfen meiner. Meinung nach sehr der Bestätigung) nicht durch die oben nach Bетне dargestellten Schemata wiedergegeben und ist auch mit der Neuronenlehre im Widerspruch.

Neue histologisch aufgeklärte Leitungsbahmen gibt BETHE in seiner dritten Carcinus-Arbeit nicht.

Die Aufsätze, welche über andere Decapoden handeln als Astacus, Palinurus, Homarus und Carcinus sind nicht außerordentlich bedeutungsvoll.

HENSEN (1863) hat die Statocyste der Decapoden untersucht, welche er als Gehörorgan betrachtet. Der Nerv des Organes trägt ein terminales Ganglion. Darin befinden sich nach HENsEn bipolare Ganglienzellen, welche ihre zentralen Fortsätze in den Nerven senden, während ihre peripheren Ausläufer in die Bases der chitinösen Haare der Statoeyste eindringen und sich dort an die lingula haften. Man würde daraus schließen, daß Hensen hier tatsächlich, und also noch vor Vialdanes (1882), sensibele Ganglienzellen entdeckt hat, welche wahre Sinneszellen, die Haarzellen, die freilich von ihm nicht erwähnt wurden, innervieren. Weil aber BEThe (1895b) und Schmalz (1914) beide in der Statocyste von anderen Crustaceen Sinnesnervenzellen aufgefunden haben und die Untersuchungen Hensens jedenfalls in'einer Zoit vollbracht sind, da man den Unterschied zwischen Sinnesnervenzellen und sensibelen Ganglienzellen noch gar nicht kannte, ist ihre Bestätigung sehr erwünscht.

Hensen (1863) hat am Sehwanze der Decapoden Sinneshaare entdeckt, welche er freie Hörhaare nennt und welche nach ihm die gleiche Innervierungsweise wie die statocystenhaare haben, aber BETHE (1985b) glaubt sich berechtigt zu vermuten, dal3 HENsEn hier jedenfalls Sinnesnervenzellen für Ganglienzellen angesehen hat und Vou RАтн (1891) behauptet, die Sinnesnervenzellen beobachtet zu haben (vergl. S. 197). Ebensowenig wie ich glaube, daß die Funktion der "Hörhaare" mit der f'unktion der statocystenhaare übereinstimmt, ebensowenig glaube ich, dal3 sie unbedingt in gleicher Weise innerviert zu sein brauchen. Auch hier tun also nühere Forschungen zur Lintscheidung not.

YUNG $(1878,1879)$ hat sich mit dem Zentralnervensystem der Decapoden beschüftigt. In Hirnganglion (YUNG 1878) sah er drei Kommissuren. In den Thorakalganglien ebenfalls Kommissuren und Fasern der peripheren Nerven, welehe sich bis in die Sehlundkonnektive fortsetzten. Am Hinterende des schlundkonnektivs sah er Ganglienzellen, welche ihre fortsätze darin einsenkten. Bei. Brachyuren wie Cuncer sah er, wie uns von Carcinus maenas bekannt ist, alle Thorakalganglien in einem Klumpen, welehen dic arteria sternalis durehbohrt, vereinigt und er beobachtete darin Nervenfusern, welehe alle tanglien von dem Sehlundkonnektiv bis zu den Abdominalganglien durchzichen.

In den Abclominalganglien fand liva (1878) drei fiommissuren, welche nach ihm Ganglienzellen der rechten und linken seite unmittelbar verbinden. Wir können das jetzt nieht mehr gluben. Einige Fisern der Konnektive enden in einem Abdominal 
ganglion, andere passieren es nur und ziehen weiter. Die Fasern der peripheren Nerven entspringen in einem Abdominalganglion oder sie kommen aus dem vorderen Konnektiv.

Diese Angaben hat YUNG (1879) noch vermehrt mit der Mitteilung, daß auch Nervenfasern des Gehirns manche Ganglien des Bauchstranges durchziehen können und mit der Mitteilung, daß die Nervenfasern der Sinnesorgane aus Ganglienzellen des Hirnganglions hervorgehen. Letzteres ist schwer zu glauben.

BeLlonci (1880) hat bei Nephrops norwegicus erwiesen, daß manche Fasern des nervus antennarius primus (nervus antennularis) in den glomeruli olfactorii, kleinen Faserknäueln des lobus olfactorius, enden. Der lobus olfactorius nun ist derselbe Hirnteil, welchen ich bei Carcinus maenas Antennalganglion und BETHE mit Unrecht glo. bulus genannt hat. Im Antennalganglion fand BELLONCI weiter zwei Ganglienzellgrup. pen (BETHE's hemiglobulus anterior und posterior?), deren Zellen ebenfalls ihre Fort sätze in die glomeruli sandten. Die Uebereinstimmung mit Carcinus ist also groß (vergl. die Fasern $x$ ' und $y^{\prime}$ (Fig. 92) und die Zellen $r$ und $s$ (Fig. 92 und 91).

Im Jahre 1886 beschrieb BELlonci (1886) bei Nephrops dorsal, median im Hirnganglion zwei Gruppen von Ganglienzellen, welehe ihre Fortsätze ins Neuropilem schickten. Es werden dies wohl cellulae superiores mediales nach Beтнe (1897) sein.

Vollständigkeitshalber will ich hier melden, daß PATTEN (1886) besonders im Auge der Decapoden Penaeus und Galathea Retinophoren, von anderen Krystallkörperzellen genannt, beschreibt, welche sich nach ihm in die Rhabdomeren fortsetzen und durch Nervenfasern umsponnen werden. Wie ich darüber urteile, habe ich schon S. 193 auseinandergesetzt.

Palaemon hat mehrmals zu Untersuchungen des peripheren Nervensystems gedient. Voir RAth (1895) und Retzius (1895) (vergl. S. 199) sehen bei diesem Tiere Sinnesnervenzellen unter den Sinneshaaren; Nusbaum (1899) studierte die Wand des Herzens und fand darin multipolare Ganglienzellen, welehe offenbar mit ihren Fortsätzen einen Plexus bilden, einen primitiven (ianglienzellplexus also.

Die Arbeit KotтE's (1903), welche sich mit Tiefsee-Decapoden beschäftigt, habe ich schon S. 204 erwähnt.

Die Leitungsbahnen der Decapoden und damit die Behandlung aller Crustacen ist jetzt zu Ende geführt worden. Es gibt aber einige 'liere, welche am besten in Anschluß an die Crustaceen besprochen werden. Es sind dies die Pycnogoniden und Limulus.

Hoek (1881) hat gezeigt, daß die Pycnogoniden Colossendeis und Nymphon unter dem Integument des ganzen Körpers einen Nervenplexus mit Ganglienzellen und hier also keine bestimmten Leitungsbahnen besitzen.

Grenacher (1879) hat im zusammengesetzten Auge von Limulus deutlich gesehen. daß die Retinulazellen in Nervenfasern übergehen und damit die erste Leitumgsbahm dieses Tieres zu Tage gefördert. PATTEN (1894) fand in den Geschmacksporien der Mandibeln Zellen, welche offenbar Sinnesnervenzellen sind, welche aber PATTEN mit seinen Retinophoren der Mollusken- und Arthropodenaugen vergleichen will. Unter der Epidermis verschiedener Körperteile, Fïße, Kiemen, u. s. w. liegt ein Plexus von Nervenfasern und Ganglienzellen.

Die Tracheaten bilden die zweite Unterabteilung der Arthropoden. HALLER (1905) hat über das Gehirn der Tracheaten eine schöne Arbeit verfaßt, welche manche phylogenetischen und vergleichend-anatomischen Betrachtungen enthält. Ich werde noch oft darauf zurückiominen. Dic anderen Autoren befassen sich nur mit dieser oder jener Klasse oder Ordnung der Tracheaten und ich glaube wieder am besten zu tun, wenn ich dic Ordinungeis nach einander behandele. 
Ueber die Leitungsbahnen der Protracheaten (Perijatus) ist mir leider nichts bekannt. Auch in der Arbeit Nils HoLMGRENs (1916) sind sie nicht genau genug beschrieben um hier wiedergegeben werden zu können.

Die erste Klasse der eigentlichen Tracheaten bilden die Myriapoden. Grenacuer (1880) hat bei diesen Tieren die erste Leitungsbahn entdeckt, als er fand, daß die Retinazellen der Augen sich basal in Nervenfasern fortsetzen und also Sinnesnervenzellen sind. Grenacher hat dies klar gesehen bei der Diplopode Iulus und bei den Chilopoden Lithobius und sicutigera, also in beiden Ordnungen der Myriapoden.

BuftSchli (1S85) meinte an einer anderen Stelle Sinnesnervenzellen zu beobachten und zwar in den Riechorganen der Antennen der Diplopoden (vergl. S. 198). Er beschreibt darin Sinnesnervenzellen mit peripherem und zentralem fortsatz, welche mit einem tiefer gelegenen Ganglion in Verbindung stehen.

Auch Vom RATH (1895) behauptet in Sinneshaaren der Myriapoden Sinnesnervenzellen aufgefunden zu haben, so in den ,Kegeln" der Iulidae, Polydesmiclae und Glomeridae, alle Diplopoden und in den Simneshaaren der Beine von Lithobius und Geophilus, beide Chilopoden. Er wird jedoch darin widerlegt (vergl. S. 202) von DUBoscQ.

DuBosce (1897) hat erst Geophilus longicornis und Scutigera coleoptrata mit der GoLGi-Methode studiert. Er beobachtete unter den Sinneshaaren Haarzellgruppen und sensibele Gianglienzellen, welche diese Haarzellen innervierten. Die peripheren Auslïufer der Ganglienzellen, stiegen doch nie ins Haar selbst empor, sondern endeten immer an der Haarbasis, also zwischen den Haarzellen, welche als wahre Simneszellen zu betrachten sind.

Später hat Dubosce (1898) seine Untersuchungen über die ganze Ordnung der Chilopoden ausgedehnt und mit der Methylenblau-Methode die gleichen Resultate wie mit der GoLgischen Methode erreicht. Mit Methylenblau behandelte er Lithobius piceus. Er fand die Haare der Beine innerviert durch eine oder mehrere bipolare Zellen in einiger Entfernung des Haares gelegen, welche einen peripheren Fortsatz bis zur Haarbasis senden und deren zentrale fortsätze, in Bündel vereint, sensibele Nerven bilden. DUBoscQ nennt die bipolaren Zellen jetzt unglïcklicherweise Sinneszellen; es geht aber aus der Beschreibung ohne Zweifel hervor, daß es sensibele Ganglienzellen sind, welche die Haarzellen, welche die Haare ausfüllen, innervieren. DuBosce fand ebensolche Haare bei Lithobius Martini und ebenso sind bei Lithobius piceus Haare von anderen Körperteilen, z.B. von der forceps innerviert. Lithobius piceus zeigte auf den Mandibeln und der forceps stumpfe Papillen, „Zähne", welche ebenso wie die Sinneshare innerviert werden und welche mir modifizierte Haare zu sein scheinen. Merkwürdigerweise sind die allergrößten Haare der Beine von Lithobius und Scutigera so groß, daß einige bipolare sensibele Ganglienzellen mit ihren Zellkörpern in Haare selbst liegen. Solche Ausnahmefälle ändern jedoch nicht den Charakter dieser Zellen.

Die Golar-Methode färbte bei scutigera coleoptrata oft nicht nur die sensibele Ganglienzelle, sondern auch die Haarzelle und es sah dann aus, als ob Vom Ratu Recht hätte und die Haarzelle eine Sinnesnervenzelle wäre, wie ich schon oben (S. 202) besprochen habe. Geophilus linearis und longicornis lieferten ebenfalls Präpurate, welche DUBosce in seiner Auffassung der Innervation der Sinneshare unterstützten.

Wie man auch die Zellen, welche die Simmeshane der Myriapoden imervieren, auffaß $3 t$, jedenfalls ist es interessant was Vou RATn (1896) uns lehrt, nämlich, daß die zentralen Fortsätze der nervösen Zellen der Simneskegel der Unterlippe von Iulus und an. deren Myriapoden bis ins untere Schlundganglion zu verfolgen sind, wo sie verzweigt enden.

HALLER (1905) hat die Leitungsbahnen des Zentralnervensystems einiger Myriapoden untersucht und sie bei Lithobius und Iulus iibereinstimmend gefunden, obgleich später N. HoLMGREx (1916) erhebliche Unterschiede gezeigt hat. Er erkennt bei diesen Tieren im Gehirn ein proto- und deuterocere- 
brum in der Bedeutung, welche VIALLANEs denselben gegeben hat, aber das Gebiet der Mandibular- und Maxillarnerven rechnet er mit Recht nicht zum tritocerebrum, sondern zum unteren Schlundganglion. Das tritocerebrum wird somit das Gebiet des Nerven des Nackenorgans oder des TömösrarYschen Organs. Obgleich die beiden Labralnerven (Fig. 95, n.l.l. und n.l.m.) ebenfalls daraus hervorgehen, teilt HaLLER ihr Gebiet dem Unterschlundganglion zu. Da irrt er sich aber VIALLANES gegenüber, welcher sie zum tritocerebrum rechnete. Das protocerebrum enthält die corpora pedunculata (oder globuli nach HALLER), das deuterocerebrum die Antennalganglien. Dem Gehirn schließt sich der Bauchstrang an.

In den Ganglien des Bauchstranges, im unteren Schlundganglion oder das Schlundkonnektiv entlang hat HALLER Ganglienzellen entdeckt, welche ihren Fortsatz durch das Schlundkonnektiv in den dorsalen Teil des Hirnganglions oder ins Antennalganglion senden, wo er sich im Neuropilem verzweigt. Einige dieser Nervenfasern, welche aus einem Ganglion des Bauchmarks hervorgehen, kreuzen in diesem Ganglion die Medianlinie.

Im Schlundkonnektiv befinden sich auch Nervenfasern, welche gerade in entgegengesetzter Richtung laufen und also aus Ganglienzellen des Gehirns entspringen und in den Bauchganglien enden (vergl. Fig. 96).

Dem corpus pedunculatum verläßt ein Faserbündel, welches sich nach HaLler in einer. Schraubenlinie fortbewegt, was eine sehr seltene Erscheinung ist. Nur die Biene und Somomya zeigen etwas ähnliches (vergl. S. 306 und S. 328) N. Holmarex (1916) hat aber die Spiralwindungen nicht wiedergefunden. Ganglienzellen des corpus pedunculatum senden Fortsätze ins Neuropilem desselben und hier enden auch Nervenfasem der Schlundkonnektive, ebenso wie auch außerhalb des corpus pedunculatum gelegene Ganglienzellen des Gehirns mit ihren Fortsätzen dieses Neuropilem suchen. Die corpora pedunculata der beiden Seiten sind durch eine Kommissur zwischen ihren Neturopilemen verbunden.

Ueber die optischen Bahnen teilt Haller uns Nachstehendes mit. Unter den Retinazellen befindet sich eine Ganglienzellschicht und damn passi eren die optischen Bahnen zwei Ganglien (Fig. 96, l. s. und m. s.), welche nebeneinander liegen. Diese beiden Ganglien sind aus unipolaren Ganglienzellen aufgebaut, welche ihre Dendriten ins Neuropilem der Ganglien senden. Ihre Neuriten ziehen in den nervus opticus und setzen sich nach HALLER kontinuirlich fort in die Fortsätze der Ganglienzellen unter der Retina. Im medianen Sehganglion befinden sich außerdem bipolare Ganglienzellen mit Dendriten im Neuropilem und mit einem Neuriten, welcher kreuzt und sich im Neuropilem der anderen Hirnhälfte verzweigt. Diese Fasern bilden also eine commissura optica.

Halter beschreibt neben dieser optischen Kommissur noch eine Antennalkommissur und eine Kommissur zwischen dorsalen Hirnteilen. Nach $\mathrm{N}$. Holigrex (1916) hat er aber bald die Tritocerebralkommissur (lig. 9.) c. (r.), bald die stomatogastrische Brücke (Fig. 95, p. st.) mit der Antennalkommissur verwechselt. Mediodorsal im Antennalganglion sah or Ganglienzellen, welche ihre Fortsäize in die glomeruli olfactorii (Fig. 96, gl. o.) sandten, kleine, runde 
Faserknäuel, wie man sie auch bei Crustaceen und Insekten im Antennalganglion kennt.

Die besten Angaben iiber die Leitungsbahnen der Myriapoden verdanken wir Nils Holmarex (1916). In erster Linie hat er Iulus studiert. Das Gehirn besteht bei diesen 'Tiere aus einem protocerebrum, welches die lobi optici (Fig. 95 und 96, 7. o.) trägt, aus einem deuterocerebrum oder Antennalganglion, aus dem der motorische und der sensibele Antennalnerv (Fig. 95, n. \%.m.

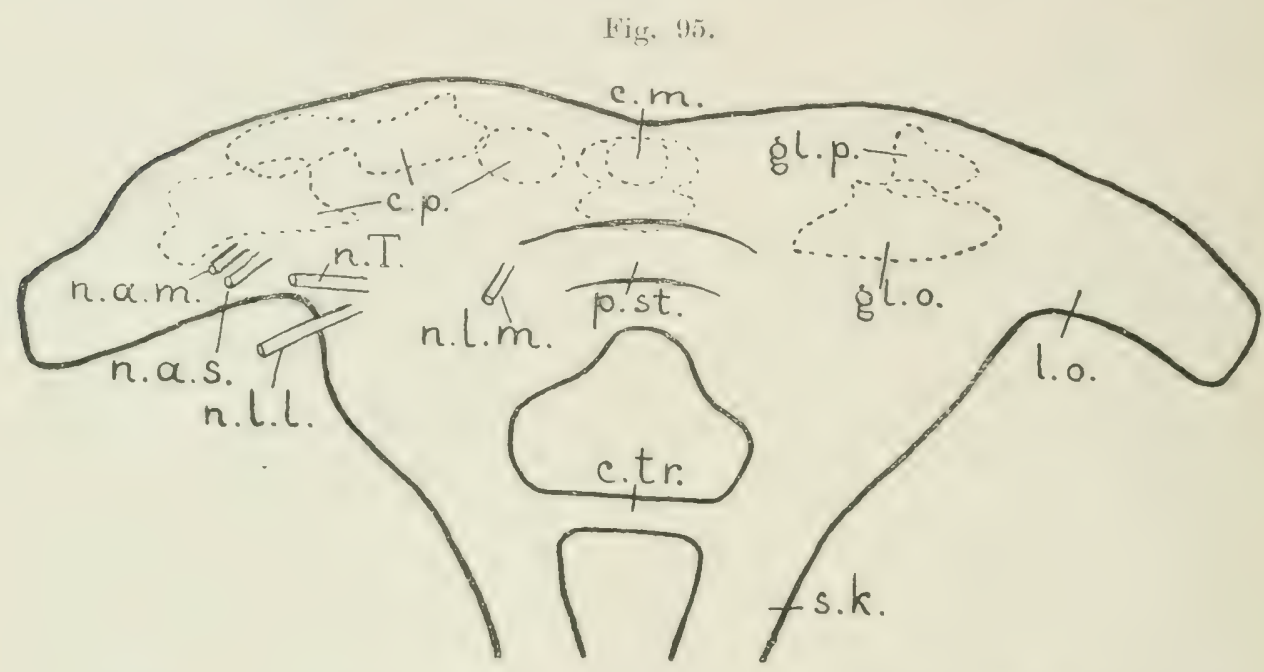

Gehim von Iulus von vorn und etwas von unten geschrn. Abgeändert nach Holmeren (1916), 'Textfigur 25 .

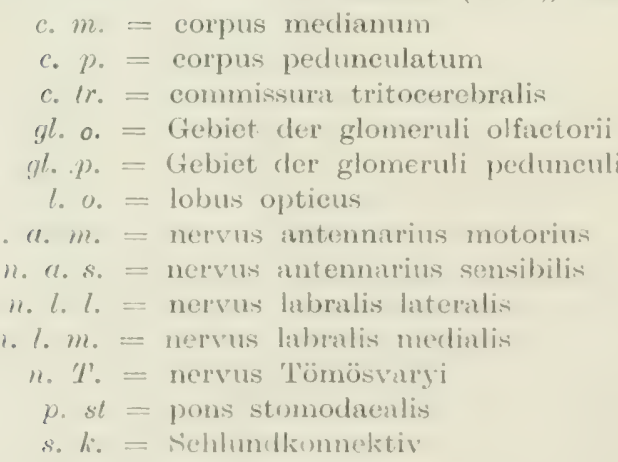

und $n . a . s$.$) hervorgehen und einem tritocerebrum, dem der Nerv des T'örös-$ varYschen Organes (Fig. 95, n. 'T'.) und der laterale und mediale Labralners (Hig. 95, n.l.l. und $2.1 . \mathrm{m}$.) entspringen. Das linke und rechte tritocerebrum ist, wie bei allen Arthropoden, durch die commissura tritocerebralis (Fig. 95 und $96, c .(r$.$) verbunden und hier iiberdies durch die stomatogastrisehe$ Bricke oder Stomodealbribcke (Fig. 95 und 96, p. st.) womit das sympathisehe Nervensystem zusammenhängt. Nicht alle Lulus-irten besitzen einen motorischen und einen sensibelen Antemnaherven. Bisweilen ist nur ein einziger \& :...! chter Antennalnery da (Fig. $96, n . a$.$) .$ 
Im Inneren des protocerebrum findet man ein dreiteiliges corpus pedunculatum (Fig. 95, c. p.). Die Fortsätze der Ganglienzellen desselben bilden die Stiele, welche auf einer gewissen Strecke von kleinen Faserknäueln umringt werden. HoLMGrex nennt sie glomeruli und zwar Stielglomeruli zur Unterscheidung der Antennalglomeruli oder glomeruli olfactorii, welche sich im deuterocerebrum befinden. Figur 95. zeigt die getrennten Gebiete der glomeruli pedunculi $(g l . p$.$) und glomeruli olfactorii (g l . o$.$) ; Fig. 96$ läßt einen Stielglomerulus ( $g l . p$.$) und drei Antennalglomeruli \left(g l . o_{\circ}\right.$ ) erkennen. Im lobus opticus ist ein laterales und ein mediales Sehganglion (Fig. 96, l.s. und m.s.) und in der Mitte des protocerebrum liegt ein Neuropilem, das von Hourgrex den Namen Mediankörper (Fig. 95, c.m.) empfangen hat und in dem die Stiele der corpora pedunculata zusammenkommen.

HoLigRex hat nicht weniger als 500 Gehirne mit Methylenblau gefärbt und darin die nachstehenden Leitungsbahnen gefunden. Median hinten im Gehirn befindet sich im protocerebrum eine unipolare Ganglienzelle (Fig. $96, a)$, welche ihren Nervenfortsatz geradewegs in das Schlundkonnektiv der gleichen Seite sendet. Neuron $b$ (Fig. 96) liegt neben $a$, sendet aber seinen Fortsatz ins Schlundkonnektiv der anderen Seite. Eine dritte Ganglienzelle (Fig. $96, c)$ its in der Nackengegend. Ihr Stammfortsatz spaltet sich in zwei Aest: von denen je einer in ein Schlundkonnektiv zieht. Ganglienzellen wie $a, b$ und $c$ befinden sich auch vorn im protocerebrum. Die Zelle d (Fig. 96) wurde in der Nackengegend beobachtet. Ihre Fortsätze verzweigen sich vorn im protocerebrum. Der Zelltypus e der Figur 96 ist nicht unipolar, sondern multipolar. Der Neurit schreitet in einem weiten Bogen zum Schlundkonnektiv der gleichen Seite. Vorn im protocerebrum liegt die Zelle $f$ (Fig. 96). Ihr Stammfortsatz spaltet sich in einen Ast zum lobus opticus und einen anderen zum Schlundkonnektiv. Vorn lateral im protocerebrum ist die Ganglienzelle $g$ (Fig. 96) mit einem Fortsatz zur Medianlinie, welche sich aber dem Gesicht entzog, bevor das Ende erreicht war. Die Zelle $h$.(Fig. 96) ist der Zelle $g$ sehx änhlich, aber ihr Fortsatz sendet einen Zweig zum medianen Sehganglion. Der Zelltypus $i$ (Fig. 96) befindet sich mehr median vorn im protocerebrum. Der kurze Stammfortsatz verzweigt sich in drei Aeste. Der erste geht zum medianen Sehganglion; der zweite fasert sich auf in protocerebrum und der dritte zieht wahrscheinlich zum Mediankörper. In der Figur 96 wird mit j eine laterale Ganglienzelle bezeichnet mit einem Fortsatz, welcher einen Ast ins mediane Sehganglion sendet und einen anderen in der Richtung des Schlundkonnektivs. Die Zelle $l_{i}$ (Fig. 96) ist ganz merkwürdig. Ihr Stammfortsatz sendet vier parallele Seitenäste zum medianen Sehganglion und spaltet sich dann in einen Zweig zum corpus medianum und einen Zweig, welcher im Neuropilem des protocerebrum endet. Der Typus $l$ (Fig. 96) hat dieselben vier Seitenäste zum medianen Sehganglion wie $/ ;$, aber der Neurit geht weiter in die Stomodealbriicke. Ganglienzelle m. (Fig. 96) befindet sich unten lateral im protocerebrum. Ihr Stammfortsatz spaltet sich in einen Ast zum medianen Sehganglion und einen anderen zum Mediankörper. Die Zelle $n$ (Fig. 96) schließlich liegt unter dem medianen Sehganglion. Ihre Dendriten veräisteln sich darin, aber ihr Neurit geht zum medianen Sehganglion der anderer Seite. 
Zum deuterocerebrum oder Antennalganglion gehören in erster Linie Nervenfasern (Fig. 96, o), welche mit dem Antennalnerven ins Gehirn eintreten und sich in einem glomerulus verästeln. Daneben liegen im Antennalganglion, Ganglienzellen, deren Stammfortsatz sich sofort in einem glomerulus olfactorius verzweigt (Fig. 96, p) neben anderen, welche vorher vier parallele Aeste zu den glomeruli pedunculi senden (Fig. 96, q). Wiederum andere deuterocerebrale Zellen senden ihren Fortsatz nur zu einem Stielglomerulus (Fig. 96,r). Motorisch sind die Ganglienzellen des Antennalganglions, welche ihren Neurit im Antennalnerven den Muskeln der Antenne zuführen.

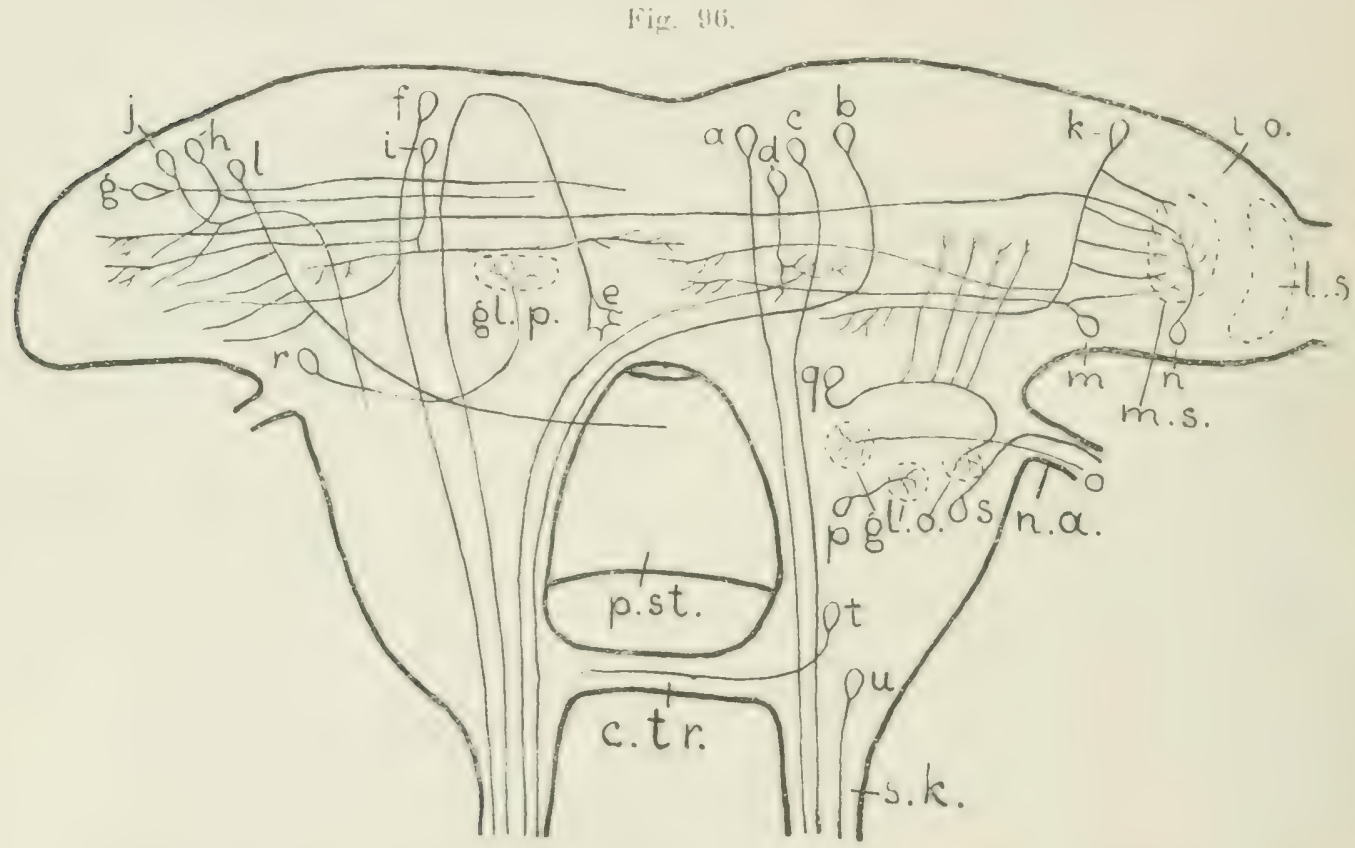

Gehirn von Iulus von hinten. Abgeändert nach HoLMGREN (1916). Textfigur 27.

c. $t r .=$ commissura tritocerebralis gl. $o_{0}=$ glomeruli olfactorii gl. $p .=$ glomerulus pedunculi l. o. $=$ lobus opticus l. $s .=$ Iaterales Sohganglion

m. $s$. = medianes Sehganglion

n. $a .=$ nervus antenuarius

p. st. = pons stomodrealis

s. ki $=$ Schlundkonnektiv

" bis $n$ und $p$ bis $n=$ Ganglienzellen $o=$ Nervenfaser

Holmarex (1916) beschreibt die Neuronen des tritocerebrum nicht. Aus seiner Abbildung geht jedoch hervor, dal3 darin unipolare Ganglienzellen sind, deren Fortsatz entweder in der 'Lritocerebralkommissur lireuzt (Fig. 96, $t$ ) oder in das Schlundkonnektiv der gleichen Seite zieht (Fig. 96, u).

Holmarex konnte das Methylenblaubild der Kommissuren des Gehirns nicht mit demjenigen der Schnittserien in Lebereinstimmung bringen. Ich will eine Beschreibung derselben deshalb hier unterlassen.

Neben lulus ist anch Lithobius von Honmakex (1916) untersucht worden. 
Fig. 97 stellt das Gehirn dar. Das protocerebrum trägt die beiden lobi optici (Fig. 97, $l$. o.) und enthält links und rechts ein dreieckiges corpus pedunculatum (c. p.). Der Stiel desselben trägt wiederum Stielglomeruli (gl.p.) Mitten im protocerebrum befindet sich wiederum ein Mediankörper $(c . m$.$) und überdies$ ein anderes medianes Neuropilem, die Protocerebralbrïcke oder pons (Fig. 97, p.), wie wir später auch bei Insekten begegnen werden (vergl. S. 306). Im protocerebrum beschreibt HoLıGREx drei Kommissuren, welche in der linken Hälfte der Figur 97 sichtbar sind.

$\mathrm{Zu}$ den Ganglienzellen des corpus pedunculatum gehören sehr kleine, unipolare Zellen (Fig. 97, a) mit einem Stammfortsatz, welcher im Stiele zu den glomeruli pedunculi läuft, vordem aber dem vorderen lateralen Teile des Gehirns einen Ast zusendet. Jedem Stielglomerulus wird ein reichverzweigtes Fasersystem übermittelt, aber der Fortsatz endet im Mediankörper. Andere Zellen des corpus pedunculatum stimmen met den vorigen überein, ent-

Fig. 97 .

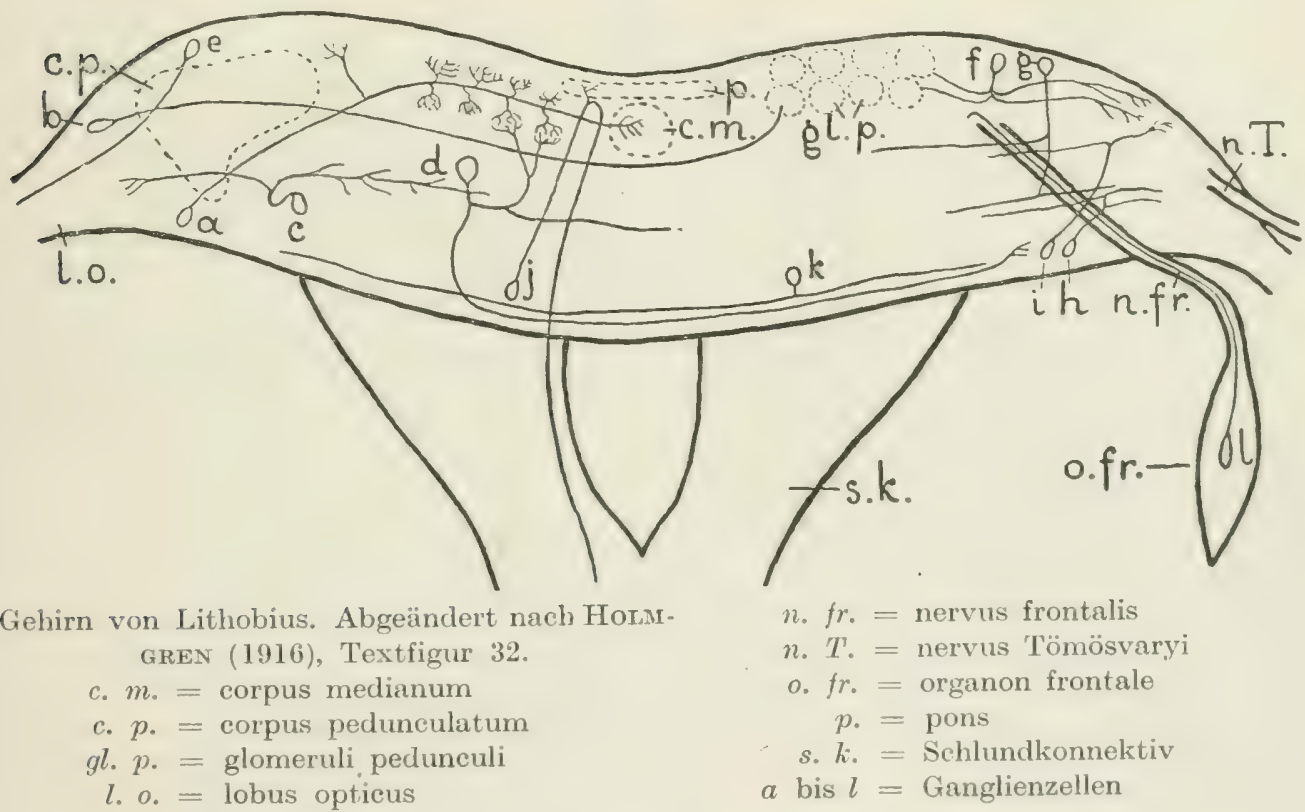

behren jedoch den ersten Ast zum Vorderteile des protocerebrum. Ventrolateral im protocerebrum liegt eine Ganglienzelle (Fig. 97, b), deren Fortsatz die Medianlinie überschreitet und in den medialsten Stielglomerulus der entgegengesetzten Seite eindringt. Mit $c$ (Fig. 97) wird eine dorsale Zelle bezeichnet mit einem Fortsatz, welcher sich spaltet in einen lateralen Ast und einen medialen, welcher sich der zweiten Kommissur anschließt. Die Zelle d (Fig. 97) ist eine Riesenzelle, welche Zweige in dic zweite und dritte Kommisisur und $\mathrm{zu}$ den Stielglomeruli sendet. Frontal im Gehirn entdeckte HowigreN eine Ganglienzelle (Fig. 97, e), welche ihren Fortsatz in den lobus opticus schickt. Frontal gestellt ist auch der Zelitypus $f$ (Fig. 97) mit zwei medianen 
Aesten zu den Stielglomeruli und zwei lateralen zum Neuropilem des protocerebrum. Die Zelle g (Fig. 97)) ist ebenfalls frontal, aber sie sendet Aeste in die erste und zweite Kommissur. Lateral hinten im Gehirn befindet sich die Zelle $h$ (Fig. 97). Sie trägt mit ihren Fortsätzen zur zweiten Kommissur bei. Neben ihr liegt die Zelle $i$ (Fig. 97) mit einem Ausläufer, welcher sich spaltet in einen Ast in die ersten Kommissur und einen anderen zum lateralen Teile des protocerebrum. In der Nackenregion des protocerebrum ist die Zelle $j$ (Fig. 97) entdeckt worden. Ihr Fortsatz geht zu der pons, überliefert derselben einen Seitenzweig und läuft weiter ins Schlundkonnektiv. Die Zelle $k$ (Fig. $79)$ ist eine Kommissurzelle der dritten Kommissur. Endlich hat HoLugrex noch im Frontalorgan von Lithobius, welches neben dem Tömösvaryschen Organ existiert Ganglienzellen (Fig. 79, $l$ ) aufgefunden, welche ihren Fortsatz im Frontalnerven zum Gehirn senden.

HoLvGrex hat die oben beschriebenen Neuronen aus etwa 400 mit Methylenblau gefärbten Präparaten gesammelt.

Ich kann jetzt zur Klasse der Insekten übergehen, worüber, wie man crwarten wird, wenigstens eben so wichtige Angaben gemacht worden sind wie über die Myriapoden. Auch hier besteht das Hirnganglion aus drei Abschnitten dem protocerebrum, welches die lobi optici trägt und die corpora pedunculata enthält, dem deuterocerebrum, welches die Antennalganglien umfaßt und dem tritocerebrum, dem Gebiet der Tritocerebralnerven. Andere wichtige Teile des Hirnganglions werden an geeigneter Stelle besprochen werden I) Schlundkonnektive verbinden auch bei den Insekten das Gehirn mit dem Bauchstrang, einer Reihe von Ganglien, welche eine überaus wechselnde (iestalt aufweist.

Die ersten hodologischen Angaben über Insekten danken wir, wie ich glaube, LEYDr: (18(i.4), welcher uns damals auch schon mit den Eigenschaften des Neuropilens, von ihm und nachher von manchen anderen Punktsubstanz genannt, bekannt muchte. LAYDic erzählt, wie im Bauchstrang der Insekten manche Fasern der Konnektive ein (ianglion passieren ohne dazu in nähere Beziehung zu treten. Andere Nervenfasern, aus dem vorderen oder hinteren Komnektiv stammend, treten in eimen peripheren Nerven ein. Wiederum andere Konnektivalfasern verzweigen sich im Ganglion und enden dort. Die Fasern der peripheren Nerven stammen, wie gesagt, oft aus den Konnektiven, manchmal jedoch aus dem Neuropilem des Ganglions, oder sie kamen durch eine Kiommissur aus der anderen Hälfte des Ganglions.

CAJAL hat in zwei Arbeiten Mitteilungen gemacht, welehe alle Insekten beriicksich. tigen und welche ich also der Besprechung der einzelnen Insekten-Ordnungen vorangehen lassen will. Im Jahre 1890 hat CA.J.L (1890) um die Muskelfuserbiindel der Fliigelmuskeln der Insekten einen Plexus multipolarer (ianglienzellen beschrieben. Weil die Ganglienzellen unmittelbar mittels ihrer fortsiitze zusammenhaingen, hat man da zur Stelle mit der primitivsten (iestalt des Nervensystems, welehe auch die Coelenteraten uns zeigen, zu tun. Anutomisch bestiumte Leitungsbahnen gibt es darin nicht.

Die zweite Arbeit ist eine sehr unfangreiche studie über das Zentralnervensystem der Insekten, welehe CAJAL zusammen mit Siscuez gesehrieben hat (CAJAL y SAxchez. 1915). Der spanische Text dieses wiehtigen Aufsatzes zwingt mich es bei dieser Ankündigung bewenden zu lassen.

Mit einigen Worten möchte ich hier auch einer Arbeit BaUERs (1904) gedenken, weil daraus hervorgeht, wie sehr das Nervenșstem und danit wohl auch die Leitung8. 
bahnen desselben sich ändern bei der Metamorphose, welchésich bei manchen Insekten vollzieht. Neue Leitungsbahnen hat, BAUER selbst jedoch nicht entdeckt, sondern er schließt sich den Untersuchungen KENyoNs an, welche später zur Sprache kommen werden.

Ich räume jetzt der Behandlung der verschiedenen Insekten-Ordnungen einen Platz ein.

Bei den Apterygoten kommen nur drei Aufsätze in Betracht. Erstens hat Vom RATH (1895) behauptet, daß er bei Machilis Sinnesnervenzellen in Sinneshaaren beobachtet hat, aber seine Angaben bedürfen immer der Bestätigung.

Zweitens hat BoETTGer (1910) das Gehirn von Lepisma saccharina untersucht. In dieser Arbeit treten die abweichenden Verhältnisse, welche das Gehirn dem Hirnganglion anderer Insekten gegenüber aufweist, klar zu Tage, so die Endungsweise der Stiele der corpora pedunculata in Trauben (uvae), welche später N. HoLıGRex (1916) mit den glomeruli pedunculi der Myriapoden homologisiert hat, und das Fehlen der ocelli und ihrer Nerven und zentralen Bahnen. Obgleich BoETTGER mit Silbermethoden arbeitete um die Wege der Leitungsbahnen zu studieren, hat er es darin nicht weit gebracht. Er stellt hypothetisch den Lauf der Leitungsbahnen der corpora pedunculata und der Antennalganglien auf, welchen ich hier nicht wiedergeben möchte. Wichtiger scheinen mir die tatsächlichen Beobachtungen, daß das Gehirn von Lepisma mit einer vorderen Kommissur oberhalb des Antennalganglions, einer commissura optica zwischen den beiden lobi optici, einer commissura subcentralis unter dem corpus centrale und einer Antennalkommissur zwischen den beiden Antennalganglien ausgestattet ist. Der hier genannte Zentralkörper oder das fächerförmige Organ ist eine Sammlung von Ganglienzellen und Nervenfasern in der Mitte des Gehirns, welche wir oft bei anderen Insekten zurückfinden werden. Nach Boettger gehen Nervenfasern des nervus antennarius in das Schlundkonnektiv und ins protocerebrum, aber damit sind ja seine hodologischen Angaben erschöpft. Vielleicht wird es dem Leser nützen, wenn ich sage, daß BOETTGER eine Literaturübersicht liefert über alle Insekten, deren Gehirn bis damals Bearbeitung fand.

Drittens hat auf die Apterygoten die Mitteilung Kiihnles (1913) Beziehung, daß bei der Collembole Tomocerus flavescens Ganglienzellen der corpora pedunculata ihre Fortsätze in die Stiele derselben senden.

Die zweite Ordnung der Insekten ist diejenige der Archiptera oder Pseudoneuroptera. Es gehören dazu die Libellen und gerade die Leitungsbahnen der lobi optici dieser Tiere sind eingehend untersucht worden.

Die allgemeinen Bauverhältnisse des lobus opticus nicht nur der Libellen, sondern aller Insekten werden aus der Figur 99, S. 287 ersichtlich. Sie stimmen in mancher Hinsicht mit denjenigen der Crustaceen überein (man vergl. Fig. 74, S. 224). Die Nervenfortsätze der Retinulazellen des zusammengesetzten Auges verlassen die Retina und bilden, indem sie dem lobus opticus zustreben, die Schicht der postretinalen Nervenfasern (Fig. 99, f.p.r.). Im lobus opticus selbst sind drei Neuropileme mit zugehörigen Ganglienzellen zu unterscheiden : die lamina ganglionaris (Fig. 99, l.g.), die medulla externa 
(Fig. 99, m.e.) und die medulla interna (Fig. 99, $m_{\text {. }}$.). Eine medulla terminalis, wie bei den Crustaceen, fehlt. Zwischen der lamina ganglionaris und der medulla externa befindet sich das chiasma externum (Fig. 99, ch.e.), zwischen den beiden medullae das chiasma internum $(c h . i$.), beide Stellen, wo optische Nervenfasern, welche aus gleichwertigen Ganglienzellen hervorgehen, sich kreuzen, wie uns solches von den Crustaceen bekannt ist. Der pedunculus lobi optici (Fig. 99, p.l.o.) verbindet den lobus opticus mit dem Gehirn. Er kann sehr kurz sein, oder sogar fehlen.

Die beiden chiasmata der Libellen wurden schon von BERGER (1878) beschrieben, ohne daß es ihm gelang Herkunft und Ziel der Nervenfasern darin nachzuweisen. Manche anderen Teile des lobus opticus blieben ihm ebensowenig wie die chiasmata verborgen; uns interessiert es jedoch nur, daß er Nervenfasern der rechten und linken medulla interna im Gehirn eine commissura optica bilden sah, während andere Nervenfasern der medulla interna zur Rinde des Hirnganglions zogen. Beide Angaben haben später Bestätigung gefunden.

Nach Berger hat sich Viallanes (1884b) mit den Leitungsbahnen des lobus opticus (oder ganglion opticum) einer Libelle beschäftigt und zwar hat Aeschna maculatissima als Versuchstier gedient. VIALLANES untersuchte die Imago und die Larve in manchen Entwicklungsstadien. So vorzüglich seine mikroskopisch-anatomische Beschreibung des lobus opticus ist, das heißt die Beschreibung der Neuropileme und Ganglienzellgruppen, so verfehlt ist leider seine Darstellung der Leitungsbahnen, nicht nur. weil seine Angaben später keine Bestätigung gefunden haben, sondern auch, weil sie einander widersprechen. Offenbar hat VIaldaxes den Wegen der Nervenfasern nicht gut folgen können und ich werde hier nur die wichtigsten seiner Mitteilungen wiederholen.

Nach Viallanes verläßt nur eine Nervenfaser ein jedes Ommatidium. Diese Faser wird eine postretinale Nervenfaser, passiert nach VIaLlanes die lamina ganglionaris und läuft nach ihm unabgebrochen durch das chiasma externum, die medulla externa, das chiasma internum, die medulla interna und den pedunculus lobi optici zum Hirn. Wir werden bald sehen, wie sehr VIALlanes sich darin irrt.

In der lamina ganglionaris sah er eine äußere Ganglienzellschicht, ein mittleres Neuropilem und eine innere Zellschicht, wie später auch ZAWARzIN (vergl. Fig. 99). Die unipolaren Ganglienzellen der lamina ganglionaris senden nach ihm ihren Fortsatz ins Neuropilem derselben, was nicht mit den Angaben ZAWARZINS im Widerstreit ist.

Neben der medulla externa liegen vier Ganglienzellgruppen. Die corona ganglionaris ist eine gebogene /ellplatte außerhalb der medulla externa. Ihre unipolaren Ganglienzellen senden ihre Fortsätze in die medulla externa. Dasselbe tun die unipolaren Ganglienzellen des, ganglion en coin", welches sich der corona ganglionaris anschließt. VIALLAxes selber hat später (1S87a) bei Vespa dieses Ganglion mit dem , keilförmigen" Ganglion anderer Autoren identifiziert und behauptet, daß dieses Ganglion bei der Libelle ebenso, nur kleiner, vorhanden sei. Ich würde es nicht gewagt haben selber, mich auf 
seine Darstellung verlassend, diesen Schluß zu ziehen, weil Viallaxes (1884b) das Ganglion en coin von Aeschna neben der corona ganglionaris und nicht unmittelbar hinter dem chiasma externum, wie bei Vespa (1887a) zeichnet, wo auch andere Autoren es hinstellen (vergl. Fig. 98); ich schließe mich aber jetzt am liebsten VIALLAxES an. Ich werde dieses Ganglion von jetzt an das ganglion cuneatum nemnen um die gewünschte Einheit der Nomenklatur zu veranlassen. Es hat sich übrigens erwiesen, daß die Ganglienzellen des ganglion cuneatum in nichts von den Ganglienzellen der corona ganglionaris abweichen. sodaß es fast keinen Zweck hat beide zu unterscheiden.

Die beiden anderen Ganglienzellgruppen neben der medulla externa werden von VIALLANES , masse ganglionaire antérieure” und ,masse ganglionaire inter-

Fig. 98.

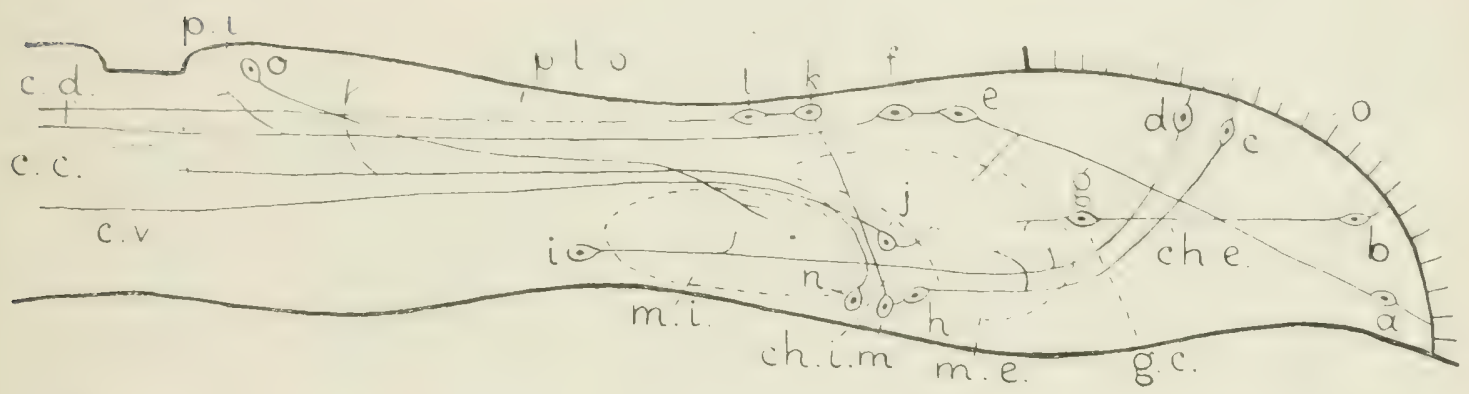

Schematischer Querschnitt durch die rechte

Hirnhälfte und den rechten lobus opticus ron Gomphus. Abgeändert nach HALLER (1905),

Fig. 27.

$a$ bis $o=$ Ganglienzellen

c. $c .=$ corpus centrale

c. d. = commissura dorsalis

ch. e. = chiasma externum ch. $i .=$ chiasma internum

c. $i==$ commissura ventralis

g. c. = ganglion cuneatum

$m . e_{0}=$ medulla externa

m. $i$. = medulla interna

o. $=$ ommatidium

p. $i$. = pars intercerebralis

p. l. o. $=$ pedunculus lobi optici

ne" genannt. Die unipolaren Ganglienzellen der ersteren haben Fortsätze, welche sich in drei Bündel vereinigen und sich in der medulla externa auflösen.

Neben der medulla interna sind Ganglienzellgruppen gestellt, deren Zellen ihre Fortsätzo darin eintauchen.

Wenn ich noch mitgeteilt habe, wie VIALlanes beachtet hat, daß die medulla interna und externa nicht nur durch die Fasern des chiasma internum verbunden werden, sondern daneben durch zwei Faserbündel außerhalb des chiasma internum und daß die Fasern des pedunculus lobi optici zwei Bündel bilden, eins zum Neuropilem des Vorderteils und eins zum mittleren und unteren Abschnitt des Gehirns, glaube ich das wichtigste seiner Arbeit erzählt zu haben.

Nach Viallaxes hat Haller (1905) das Studium der Leitungsbahnen des lobus opticus der Libellen wieder aufgenommen. HALLER sieht hier wie so oft die Ganglienzellen unmittelbar durch breite Fortsätze verbunden und keine Neuronen wie andere Autoren. Solches wird ausgedrückt in der Wig. 
98, welche mir helfen soll die Leitungsbahnen des lobus opticus von Gomphus, einer Libelle, zu beschreiben. Die Figur stellt einen Schnitt nicht nur des lobus opticus, sondern auch der anschließenden Hirnhälfte dar. In der Mitte des Gehirns sieht man das corpus centrale (Fig. 98, c. c.) ; auf beiden Seiten daneben die pars intercerebralis $\left(p . i_{\text {. }}\right)$, womit HALLER den Hirnabschnitt zwischen den corpora pedunculata andeutet. Dann folgt der pedunculus lobi optici $(p . l . o)$, welcher den lobus opticus (HALlers Sehganglion) trägt. Im lobus opticus findet man die medulla interna und externa (m.i. und m.e.) mit dem chiasma internum $(c h, i$.) dazwischen. Lateral der medulla externa liegen die Ganglienzellen des ganglion cuneatum (g.c.) und dann das chiasma externum (ch.e.). Die lamina ganglionaris wird als solche nicht von HALLER erkannt, obgleich die Ganglienzellen, welche er unter der Retina beobachtete, zweifelsohne dazu gehören. Vom zusammengesetzten Auge sind in die Figur 98 nur die basalen Teile der Ommatidien (o.) schematisch eingetragen.

Wenn ich jetzt dazu übergehe die Leitungsbahnen nach HALLER zu beschreiben, will ich betonen, daß ZAWARZIN, wie wir sehen werden, später ganz andere Verhältnisse fand. ZAWARZIX kennt nur unipolare Ganglienzellen, deren Zellkörper nicht mit Fortsätzen anderer Ganglienzellen zusammenhängen; HaLLER kennt fast keine unipolaren Ganglienzellen und sieht die Zellkörper sonst iiberall in direkter Verbindung. An manchen Stellen ist eine ganz andere Vorstellung der Leitungsbahnen davon die Folge und nur selten stimmen die Ansichten Hallers und Zawarzins über die Wege, denen der Reiz folgt, im Grunde überein. Immer aber glaube ich persönlich, daß die Beobachtungen ZAWARzrss die richtigen sind.

Nach Hatier also setzen sich die basalen Fortsätze der Retinulazellen fort in Ganglienzellen (Fig. 98, $a, b, c, d$ ), welche unter der Retina liegen (und offenbar zur lamina ganglionaris gehören) und andrerseits in Fasern des chiasma externum übergehen. Noch andere Fortsätze verbinden die Zellen gegenseitig. Die Fasern des chiasma externum folgen verschiedenen Wegen. Die Fortsätze der Ganglienzellen $a$ vereinigen sich mit Ausläufern von Ganglienzellen $c$ (Fig. 98), welche neben der medulla externa liegen, aber ein Seitenast geht nach Haller in die medulla externa. Die Zellen, wie $e$ der Figur 98, stehen ihrerseits unmittelbar mit benachbarten Ganglienzellen $f$ in Verbindung. Die Fortsätze der Zellen des Typus $b$ gehen über in die Fortsätze von Ganglienzellen $g$ des ganglion cuneatum, welche andere Ausläufer in die medulla externa senden. Der Zelltypus $c$ hat einen Fortsatz, welcher nach HALLER kontinuirlich übergeht in den Fortsatz einer hinter der medulla externa gelegenen Ganglienzelle (Fig. 98, h). Ein Seitenast tritt in die medulla externa. Endlich verbindet sich der Fortsatz des Zelltypus d mit einer hinter der medulla interna gelagerten Ganglienzelle (Fig. 98, i). Diese Faser durchläuft also auch das chiasma internum und sie spaltet teste ab zur medulla externa und interna

Im Gehim entdeckte HALAR zwei optische Kommissuren, eine dorsale (Fig. 9s, c. l.) iiber dem corpus centrale (oder ganglion centrale) und eine ventrale (Fig. 98, c. r.) darunter. Die Fasern der commissura ventralis sind Fortsätze von Ganglienzellen j, welche zwischen der medulla externa und interna gelegen sind. Sie ziehen zur medulla interna oder externa der anderen 
Seite. Aus diesen Ganglienzellen gehen auch Fortsätze zur medulla externa oder interna derselben Seite hervor. Die Fasern der commissura dorsalis suchen ebenfalls die medulla interna oder externa der anderen Seite auf, aber sie gehen aus neben der medulla externa gelagerten Ganglienzellen (Fig. 9s, $f$ oder l) hervor. Dabei senden diese Fasern Aeste ins Neuropilem des Gehirns.

Obige Darstellung erregt den Eindruck, als wenn HALLER im lobus opticus von Gomphus bestimmte Leitungsbahnen erkennen konnte. Dem ist aber nicht so, wie er selber zugibt, denn nicht nur hängen nach ihm alle Ganglienzellen durch Fortsätze mit ihren Nachbarn zusammen (wie $e$ und $f, h$ und $m$, $k$ und $l$ der Fig. 98), sondern auch weit entfernte Ganglienzellen wie $k$ und $m$ sind unmittelbar verbunden und es fehlen deshalb in den HALLERschen Angaben die anatomischen Grundlagen für die Erkennung bestimmter Leitungsbahnen, wozu die Seitenäste der Zellfortsätze zum Neuropilem das ihrige beitragen.

Im chiasma internum entdeckte HALLER neben den schon genannten Nervenfasern soIche, welche aus Ganglienzellen (Fig. 98, n) neben der medulla interna entsprangen und im Gehirn teilweise im Zentralkörper, teilweise im corpus pedunculatum (globulus) endeten. HALLER nennt das Bündel fasciculus globulocentralis, welcher Name nicht der Regel folgt, daß damit Beginnund Endpunkt der Bahn angedeutet werden und daher zu verwerfen ist.

In der pars intercerebralis wurden Ganglienzellen (Fig. 98, o) aufgefunden, welche Fortsätze zur medulla interna aussenden. Mit funiculus opticoantennalis deutet HaLLer Nervenfasern an, welche aus Ganglienzellen des lobus opticus hervorgehend zum Antennalganglion gehen und dort im Neuropilem zwischen den glomeruli enden und schließlich beschreibt er auch Ganglienzellen des Iobus opticus, welche ihre Fortsätze in die Schlundkonnektive sender. Einige dieser Fasern kreuzen im Unterschlundganglion die Medianlinie. Wenn ich noch im corpus centrale Ganglienzellen gemeldet habe, deren Fortsätze sich nur im Neuropilem desselben verästeln, habe ich alle hodologischen Angaben HALLERs wiedergegeben, welche sich besonders auf die Libellen beziehen.

Elst vor wenigen Jahren hat ZAWARzIx (1914) abermals die Leitungsbahnen des lobus opticus der Libellen studiert und an Resultaten alle seine Vorgänger übertroffen. ZAWARZIx arbeitete mit Larven von Aeschna grandis, Aeschna juncea und Aeschna cyanea, fand aber keine histologischen Differenzen zwischen den drei Arten. Er färbte seine Präparate mit der Methylenblau- und GoLgI-Methode und daneben mit nicht spezifischen Nervenfärbungsmethoden.

ZAWARZIY konnte hinsichtlich des Baues des lobus opticus die älteren Autoren im allgemeinen bestätigen. Ich will seine Ansichten mit Hilfe der Figur 99 erläutern. Der lobus opticus ist durch die Bündel der postretinalen Nervenfasern (Fig. 99, $t . p . r$.) mit der Retina des zusammengesetzten Auges verbunden. Im lobus opticus erkannte ZAWARZIx drei Abschnitte, welche er erstes, zweites und drittes ganglion opticum nannte, welche ich aber wie immer lamina ganglionaris $(l . g$.$) , medulla externa \left(m . e_{.}\right)$und medulla interna $(m . i$. nennen werde. Die lamina ganglionaris hat eine äußere , Kömerschicht" 
oder Ganglienzellschicht, ein mittleres Neuropilem und eine innere Zellschicht. ebenso, wie VIALLANes es uns schon lehrte. Hinter der lamina ganglionaris folgt das chiasma externum (ch.e.). Die medulla externa wird vorn und hinten durch eine Ganglienzellschicht bekleidet. Das sogenamnte keilförmige Ganglion (ganglion cuneatum) ist ein Teil der vorderen Ganglienzellschicht, welcher durchaus nicht von anderen Teilen abweicht und keinen eigenen Namen braucht. Das Neuropilem der medulla externa ist geschichtet. ZAWARzIN unterschied darin (vergl. Fig. 99) eine breite äußere und eine breite innere Schicht mit einer schmalen Schicht dazwischen. Die drei Schichten selbst können abermals in Schichten zerlegt werden. Zwischen der medulla externa und interna befindet sich das chiasma internum (ch.i.). Das Neuropilem der medulla interna zerfällt nach ZAWARzIN in vier Teile (siehe Fig. 99). Davor und dahinter liegen wiederum Ganglienzellen. Neben der medulla interna und externa befindet sich ein Fasersystem, welches vom chiasma internum unabhängig ist. VIALLAxes (S. 283) hatte diese Fasern schon erwähnt. ZAWARzr nennt das Bündel die ,Kommissur" , aber weil ich darunter nur Fasern verstehe, welche die Medianebene des'Körpers durchqueren und solches für diese Fasern nicht erwiesen wird. kann ich diesen Namen nicht beibehalten.

Nach dieser allgemeinen Beschreibung des lobus opticus, will ich die von ZAWARzIN entdeckten Leitungsbahnen der Reihe nach nennen. Jedes Ommatidium des Auges enthält vier Retinulazellen, welche Nervenfortsätze tragen und deshalb Simnesnervenzellen sind. Die Fortsätze.der Retinulazellen verlassen in Bündeln als postretinale Nervenfasern (Fig. 99, a) die Retina und dringen in den lobus opticus ein. Sie enden im Neuropilem der lamina ganglionaris. In der äußeren Zellschicht der lamina ganglionaris liegen zwei unipolare Ganglienzellarten. Die erste und größere (Fig. 99, $b$ ) sendet ihren Fortsatz ins Neuropilem der lamina, wo er Kollateralen abspaltet und weiter durch das chiasma externum zur äußeren Faserschicht der medulla externa, wo er endet. Die Kollateralen der Neuriten der Ganglienzellen b umspinnen das Ende der Postretinalfasern a und zwarsteht nach ZAWARZIX jeder Fortsatz einer Ganglienzelle $b$ mit vier P'ostretinalfasern, also mit einem Ommatidium, in Verbindung, das heißt, es wird ein Neurommatidium gebildet, wie Vigier und CAsal es bei Dipteren entdeckt haben (vergl. S. 330). ZAWARZIX gegenüber bekommt also weder V'IALAANEs, welcher die postretinalen Nervenfasern bis zum Hirn weiterziehen ließ, noch HALLER, welcher sie kontinuirlich in die Zellkörper der Ganglienzellen $b$ ïbergehen ließ, Recht.

Die zweite, kleinere Zellart der lamina ganglionaris (Fig. (39, c) sendet ihren Fortsatz ins Neuropilem der lamina, aber nicht weiter. ZAW solche Zellen Lokalzellen, ebenso wie die unipolaren Gianglienzellen der inneren Zellschicht der lamina ganglionaris (Fig. (9!), (l), deren Fortsatz ebenfalls: nur das benachbarte Neuropilem sucht.

Im Neuropilem der lamina ganglionaris enden zwei Nervenfasertypen, welche aus Ganglienzellen der äußeren Zellschicht der medulla externa (Firs. 99, e) oder der inneren (Fig. 99, f) hervorgehen und welche somit zum chiasma externum beitragen. Nach ZaWArza, blieb der Ursprung dieser Nervenfasern CAJAL (1:USi) bei Musca unbekamnt. Zuletzt endet noch im Neurojilem der 
Fig. 99.

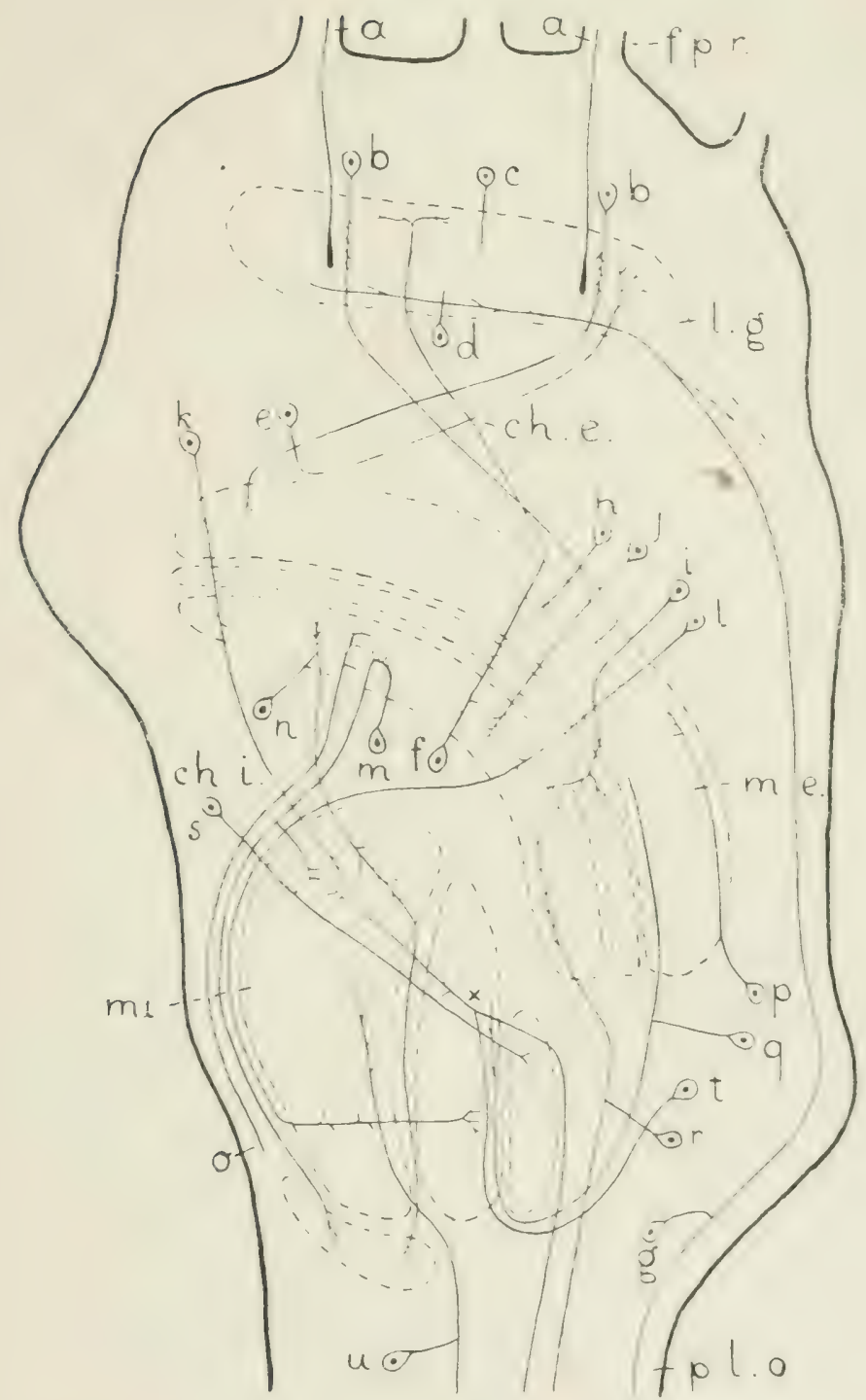

Sehema der Leitungsbahnen im lobus opticus der Larve von Aeschna. Abgeändert nach ZawarzrN (1914), Taf. I.

$a$ und $o=$ Nervenfasern

b bis $n, p$ bis $u=$ Ganglienzellen

ch. e. $=$ chiasma externum

ch. $i$. = chiasma internum

f. p. $r$. = fibrae postretinales

l. g. = lamina ganglionaris

m. $c$. = medulla externa

$m . i .=$ medulla interna

p. $l$. $o_{0}=$ pedunculus lobi optici

Die Strıchellinien begrenzen die Neuropileme. 
lamina ganglionaris ein Nervenfasertypus, welcher nicht im chiasma externum, sondern seitwärts neben der medulla externa und interna zum Hirn läuft. ZawARziN glaubt, daß die Ursprungszellen dieser Fasern (Fig. 99, g) neben der medulla interna liegen, welche also einen T-förmig geteilten Fortsat\% haben würden mit einem Ast zur lamina ganglionaris und einem Ast zum Hirn, aber er ist dessen nicht ganz sicher.

Betreffs der medulla externa beginnt ZAWARZIX mit der Bemerkung, daß er die langen in die medulla externa endenden Fortsätze der Retinulazellen, welche CAJAL (1909) bei Musca entdeckt hat, nicht finden konnte. Ei leitet daraus ab, daß CAJAL sich irrte, was aber durchaus nicht so zu sein braucht, denn eine Libelle und eine Fliege brauchen doch keineswegs immer die gleichen Leitungsbahnen zu besitzen.

Zur äußeren Rinde der medulla externa gehören manche Ganglienzelltypen. Erstens der Zelltypus $e$, welcher schon beschrieben wurde. Dain drei verschiedene Arten von Lokalzellen mit Fortsätzen, welche sich nur in der medulla externa verästeln und zwar in der äu(3eren Faserschicht (Fig. 99, h). in der mittleren und inneren Faserschicht (Fig. 99, $i$ ) oder nur in der inneren Faserschicht (Fig. 99, j). Auch liegen noch in der äußeren Rinde der medulla externa Ganglienzellen, deren Fortsätze die medulla externa durchsetzen, obgleich sie derselben Kollateralen abgehen, ins chiasma internum laufest und in einer Abteilung der medulla interna enden (Fig. 99, $k_{i}$ und $l$ ).

In der inneren Rinde der medulla externa befinden sich keine Lokalzellen. sondern drei andere Ganglienzellarten. Erstens die Zellen wie $f$ der Fig. (9), welche schon beschrieben wurden. Ihr Neurit überliefert dem Neuropilem der medulla externa Kollateralen. Zwweitens Ganglienzellen (Fig. 99, m) mit rückläufigem Fortsatz, welcher erst in die innere Faserschicht der medulla externa eindringt, dort in sehr charakteristischer Weise Kollateralen abspaltet, dann umkehrt und nach Passierung des chiasma externum im Neuropilem der medulla interna endet. Drittens gibt es Ganglienzellen (Fig. 99, $n$ ), deren Ausläufer sich in der inneren Fasersehicht der medulla externa ' $\mathrm{T}$-förmig teilt. Der eine Ast verzweigt sich dort, der andere schreitet durch das chiasma internum ins Neuropilem der medulla interna und endet dort.

An verschiedenen Stellen der medulla externa enden Nervenfasern unbekannter Herkunft (Fig. 99, o). CAJAL sah bei einer Fliege solche Fasern dem Gehirn entspringen.

Die medulla externa hat nicht nur eine äußere und innere Ganglienzellrinde, sondern es liegen auch manche Ganglienzellen an jenem Ende der medullit externa, welches dem Hirn zugewandt ist. Sie bilden eine gesonderte Gruppe, welche ZAWARzIx, wenn nötig, das Eckganglion nennen möchte. (Ist es vielleicht das VIALLaxessche, ganglion en coin"?) Er komnte diese Zellen nicht genïgend klar erforschen, aber wohl sah er, dal3, während die Fortsätze der Zellen der äußeren und inneren linde immer vertikal in der medulla externa liefen, die Fortsätze der ebenerwähnten Zellen alle horizontal liefen (vorgl. Fig. 99). Wemn ZAWARZIN richtig beobachtet hat, gibt es unter diesen Zellen drei Arten, zwei kleine und eine große. Ein kleiner Ganglienzelltypus (Fig. $99, p)$ sendet seinen Fortsatz nur in das Neuropilem der medulla externa 
ein anderer kleiner Zelltypus (Fig. 99, q) hat einen Stammfortsatz, welcher sich T-förmig teilt in einen Ast zum Neuropilem der medulla externa und einen Ast zum Neuropilem der medulla interna. Der große Ganglienzelltypus (Fig. $99, r)$ hat einen T-förmig geteilten Fortsatz, mit einem Ast ins Neuropilem der medulla externa und dem anderen in den pedunculus lobi optici zum Hirn.

Die medulla interna hat im Inneren vier Neuropileme und daneben einen äußeren und inneren Ganglienzellbelag. Die unipolaren Zellen der äußeren Rinde sind alle Lokalzellen (Fig. 99,.s.), welche ihren Fortsatz durch das chiasma internum in das Neuropilem der medulla interna senden, wo er endet. Man kann unter diesen Lokalzellen noch verschiedene Typen unterscheiden, wofür ich auf das Original verweise. Die unipolaren Ganglienzellen der inneren Rinde liegen zwischen den Zellen des Eckganglions (Fig. 99, t). Thr Fortsatz begibt sich ins Neuropilem der medulla interna und teilt sich dort (bei $\times$ ) T-förmig. Der eine Ast läuft zum Hỉn, der andere verzweigt sich im Neuropilem der medulla interna und je nach der Weise, worauf er dieses tut, kann man unter diesen Fasern vier Typen unterscheiden.

Hinter der medulla interna um die Fasern des pedunculus lobi optici herum hat ZAWARZIx schließlich noch große, unipolare Ganglienzellen (Fig. y9 u) entdeckt, wolche ebenfalls einen Ast des Stammfortsatzes zum Him und einen anderen zu einer der vier Abteilungen des Neuropilems der medulla interna senden.

ZAWARZIX hat sich gefragt, welchen Wegen der optische Reiz im lobus opticus von Aeschna folgen kann. Es kommen verschiedenen Bahnen in Betracht, unter anderen die Bahn, welche über die Elemente $a, b$, $l$ und $t$ (Fig. 99) läuft und die Bahn der Elemente $a, b, l i$ und $u$.

Die Homologisationen, welche ZAWARzIx über die optischen Bahnen der Vertebraten, Cephalopoden und Insekten aufstellt, finde ich viel zu unglaubwürdig um sie hier zu wiederholen (rergl. S. 327). Wer sich dafür interessiert, weiß, wo er sié finden kamn.

Ich glaube damit die schönen ZAWARZixschen Resultate der Hauptsache nach referiert zu haben und kann zur dritten Ordnung der Insekten, zu den Orthopteren, übergehen.

Unter allen Orthopteren haben die Leitungsbahnen von Blatta oder Periplaneta, der Küchenschabe, am meisten Beobachtung gefunden und ich will also dieses Tier an und fïr sich heschreiben.

Floegel (1878) hat, so viel ich weiß, die ersten hodologischen Mitteilungen gemacht. Er hat sich namentlich mit der mikroskopischen Anatomie dex Ciehirns nicht nur von Periplaneta orientalis, sondern auch anderer Insekten beschäftigt und darüber wertvolle Angaben gemacht, welche ich dem Leser, welcher sich orientieren will nachzuschlagen empfehle, aber nur einmal war er im Stancle cine Leitungsloahn bis zum Anfang zu verfolgen. Das war als er sah, daß in clen corpora perlunculata (abgebildet in Fig. 102, c.p.) (Ganglienzellen lagen, welehe ihre Fortsätze in das Neuropilem derselben, die Becher und die Stiele, sandten.

Im nächsten Jahre publiziert Newtox (1S79) eine Arbeit iilur das (ichirn derselben Periplaneta orientalis. Er bringt neben manchen mikroskopisch-anatomischen Eimzelheiten auch einige Leitungsbahnen zu unserer Kenntris, aber nicht so, dal sie nicht 
der Bestätigung bedürfen. Nach NEwToN (und ich zitiere hier nur seine genauen Angaben) enden einige Fasern des lobus opticus im corpus centrale, während andere zur anderen HirnhäIfte ziehen. Im corpus centrale enden ebenfalls Fasern des Antennalganglions, während andere Nervenfasem dieses (ianglions die Medianlinie kreuzen. Vielleicht hat Newtos hier schoi Nervenfasern beobachtet; welche Bretschneider (1914) in Verbindung mit ihren Ganglienzellen gesehen und deshalb richtiger beschrieben hat (Fig. 101, $a$ und $b$ ). NEwToN hat überdies beobachtet, daß median gestellte (ianglienzellen des Gehirns durch ihre Fortsätze mit dem Zentralkörper verbunden sind.

Im Jahre 1905 hat HaLler (1905) dem Gehirn von Periplaneta (Blatta) große Aufmerksamkeit gewidmet, aber bevor ich seine Nitteilungen wiederhole, will ich bemerken, daß BRETschNemer (1914) sie einer scharfen Kritik unterzogen hat und manches ganz anders sieht. Weil HALLER Periplaneta nicht monografisch bearbeitet hat, sondern eine allgemeine Darstellung der Leitungsbahnen des Tracheaten-Gehirns zu liefern sucht, welche jedoch nur auf einige Tierarten fußt (Gomphus, Periplaneta, Apis, Lithobius u. s. w.) ist es mir schwer, genau zu bestimmen, welche Angaben gerade fïr Periplaneta gelten und wird man manche Bahnen, welche ich erst bei der Beschreibung von Apis nenne, auch Periplaneta zuerkennen müssen, wie auch umgekehrt.

Auf Periplaneta bezicht sich jedenfalls das Folgende. An beiden Seiten im protocerebrum befinden sich die zwei Becher (calyces) der corpora pedunculata (vergl. Fig. 102). HaLLER nennt sie zusammen den globulus. Jedes corpus pedunculatum enthält zwei mehr oder weniger pilzhutförmige Ganglienzellgruppen, welche ein becherförmiges Neuropilem, den Becher oder calyx, umgeben. Die beiden Becher sitzen auf einem Stiel (pedunculus), ebenfalls zum Neuropilem gehörig. Die Ganglienzellen dieser corpora pedunculata sind nach HALLER durch kurze Fortsätze verbunden, einen langen Fortsatz aber schicken sie ins Neuropilem. Bei einigen Ganglienzellen des lateralen leils des corpus pedunculatum geht dieser zum medianen Becher, bei einigen Ganglienzellen des medianen 'Teils des corpus pedunculatum umgekehrt zum lateralen Becher. Fortsätze noch anderer Ganglienzellen ziehen in den Stiel (pedunculus) der Becher und weiter in das cornu internum, mit welchem Namen ich den Querfortsatz oder das Innenhorn des peduneulus belegen möchte (vergl. Fig. 102). Die Querfortsätze von links und rechts bilden nach einigen Autoren den ,Balken”, ein sehr irreführender Name, denn die Querfortsütze berühren einander in der Medianebene des Gehirns, aber sie bilden gerade keine liommissur, wie es der Name Balken erwarten ließe. Ich glaube, dieser Name soll aus der Literatur verschwinden und man spreche über das cornu internum des pedunculus. Wemn die Fortsätze der ebengenamnten Ganglienzellen der corpora pedunculata im cornu internum angelangt sind, verästeln sie sich und bilden nach HALLER ein Netz mit den Ausläufern gewisser Ganglienzellen der pars intercerebralis des protocerebrum. Andere Ganglienzellen der pars intercerebralis, vor und zwischen den corpora pedunculata der beiden seiten gelegen, senden einen Fortsatz aus, welcher sich spaltet in einen Ast zum Stiel des lateralen und einen Ast zum Stiel des medianen Bechers.

Die Antennalkommissur, welche Newrox vielleicht schon wahrgenommen hat, ist von HALLER gut beobachtet worden. Er sah im Antennalganglion 
Ganglienzellen, deren Fortsätze zum Antennalganglion der anderen Seite zogen, wie auch Bretschneider (1914) später fand (siehe Fig. 101, g).

Im Zentrum des Gehirns sah HaLLer das corpus centrale (oder fächerförmiges Ganglion) (siehe Fig. 101 und 102),das nach NEwTox allen Insekten eigen ist. Darüber liegt die commissura dorsalis, darunter erst die beiden cornua interna, dann die ventrale Kommissur und dann die schon erwähnte commissura antennalis. Ueber die Herkunft der dorsalen und ventralen Kommissurfasern äußert HALLER sich nicht. Man vergleiche dafür BrEtschneIDER.

HaLler beschreibt uns, wie das Gehirn von Periplaneta mit einen ungepaarten Darmnerven (nervus intestinalis Fig. $100, n . i$.) zusammenhängt. Dieser geht mit zwei Wurzeln aus der pars intercerebralis (Fig. 100, p.i.) des protocerebrum hervor. In den Verlauf dieses Nerven sind zwei Ganglien eingeschaltet (Fig. $100, g . p$. und g.s.); aus dem zweiten geht neben dem Darmnerven ein anderer peripherer Nerv (Fig. 100, p.n.) hervor.

Ganglienzellen der pars intercerebralis senden Fortsätze in die Wurzeln des Darmnerven hinein. Diese enden jedoch immer schon im ersten Ganglion (Fig. 100, $a$ und $b$ ). Die hier gelegenen Ganglienzellen suchen mit ihrem Neuriten das Neuropilem des Gehirns (Fig. $100, c)$, oder sie senden ihren Neuriten in den Darmnerven hinein (Fig. 100, d). Kurze Fortsätze verbinden diese Zellen gegenseitig nach HALLER, aber das soll näher bestätigt werden. Das zweite Ganglion besitzt ebenfalls Ganglienzellen (e) mit ihrem Neuriten im Darmnerven, andere senden ihren Neuriten in den peripheren Nerven $(f)$. Endlich führt der Darmnerv noch Fasern, welche entweder im ersten oder im zweiten Ganglion enden (Fig. 100, g Fig. 100 .

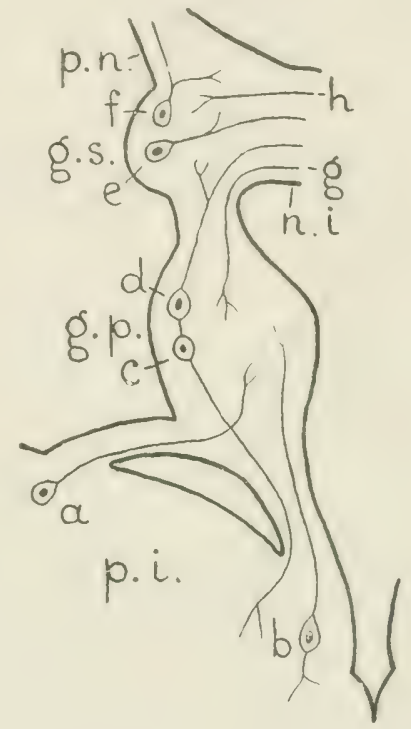

Schema der Leitungsbahnen im Ursprung des Darmnerven von Periplaneta. Abgeändert nach Hat.ter (1905), Fig. 25.

a bis $f=$ Ganglienzellen

$g, h=$ Nervenfasern

$g \cdot p .=$ ganglion primum

g. $s .=$ ganglion secundum

n. $i_{0}=$ nervus intestinalis

p. $i_{\text {. }}=$ pars intercerebralis

p. n. $=$ peripherer Nerv und $h$ ).

In einem späteren Aufsatz hat HALLer (1907) uns noch etwas über die Leitungsbahnen der Ozellen von Periplaneta orientalis mitgeteilt. Er rektifiziert darin seine frühere Meinung, daß der Tritocerebralnerv die Ozellen inner:viere. Das tut der Ozellarnerv, weleher aus der pars intercerabralis des protocerebrum hervorgeht. Die zum Epithel gehörigen Sehzellen der Ozellen setzen sich in einer basalen Nervenfaser fort; es sind also Sinnesnervenzellen. Unter den Sehzellen liegen einige Schichten multipolarer Ganglienzellen. Diese Zellen senden nach HALler alle einen Fortsatz in den Ozellarnerven, während die anderen kontinuirlich üborgehen in die Nervonfortsïtze ciniger Solizellen. 
Die letzte hodologische Arbeit über das Gehirn von Periplaneta orientalis ist wohl von BrETSCHAIEIDER (1914) veröftentlicht worden. Leider hat er dabei keine spezifischen Nervenfärbungsmethoden angewandt, sodaß manche Bahnen unsicher blieben, oder er sich stützen mußte auf die Mitteilungen anderer Autoren über andere Insekten. BRETSCHX EIDER hat die mikroskopische Anatomie des Gehirns sehr gut beobachtet und er schließt sich in seinen Auffassungen Viallaxes an. Die beiden Figuren 101 und 102, womit ich seine Ergebnisse erläutere, geben wenigstens ïber den Bau einiger Hirnteile Aufsehluß. Der Schnitt der Figur 102 ist hinter demjenigen der Figur 101.

Das Gehirn zer-

Fig. 101.

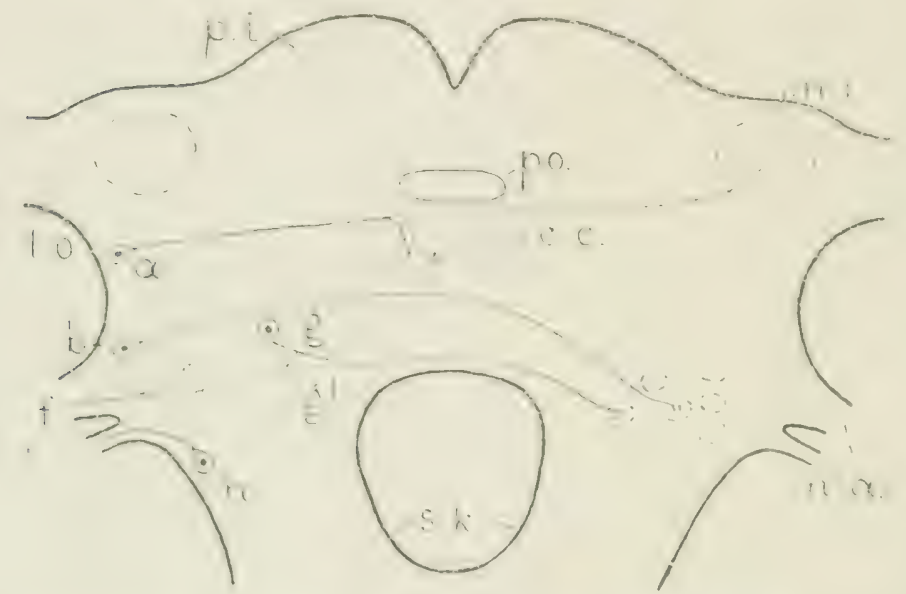

Schematischer Querschnitt durch das Hirnganglion von Periplaneta oriontalis. Abgeändert nach I3rETschisenter. (1914), Textfigur 11 . $u, i, \iota, h=$ (ianglienzellen

$f=$ Nervenfaser

$c=$ corpus centrale

!l. = glomerulus

l. $o .=$ lobus opticus

m. $i_{0}=$ medulla interna

11. $\%$. = nervus antemnarius

p.i. = parts intereerebrali

po. $=$ pons

s. $l_{\text {. }}=$ Schlundkonnolitiv fällt in drei Abschnitte : das proto-, deutero- und tritocerebrum. Das protocerebrum enthält das corpus centrale (Fig. 101 und 102, c. c.), worüber das Fasersystem der Brücke (pons, Fig. 101 , po.), und die corpora pedunculata (Fig. 102, c. p.). Das Neuropilem der corporapedunculata bildet einen Stiel. den pedunculus (lig. 102, p.), welcher zwei Becher, den calyx medianus (c. m.) und den calyx lateralis (c. l.) trägt. Die Becher sind iiberfüllt mit Ganglienzellen, welche also auch an der Aubenseite der

Becher gelegen :ind. Den l'eches mit seinen Ganglienzellen hat einigermaßen die Ciestalt cines P'ilzhutes; daher der Name pilzhutfömmiger Körper statt corpus pedunculatum. Die beiden pedunenli von rechts und linkis haben am unteren Ende cinen nach der Nedianehene gerichteten Fortsatz, das Innenhorn (cornu internum. Fig. 102., c. i.). Die beiden cornua interna berihnen (inander in der Medianchene, aher sie vereinigen sich nicht. Vor und zwischen den corpora pedunculata von links und rechts befindet sich die pars intercerchralis (Figr. 101, p. i.) des protocerebrum. Das protocerebrum trägt link unt rechts einen lobus opticus (Fig. 101 und 102, l.o.). Während bei 
anderen Insekten der lobus opticus oft mit einem Stiel, dem pedunculus lobi optici, dem protocerebrum aufsitzt, fehlt hier dieser Stiel und ist die medulla interna des lobus opticus (Fig. 101 und 102, m. i.) fast innerhalb des Gehirns aufgenommen. Aus dem protocerebrum geht, wie auch HALLER (1907) erwähnt, der Ozellårnerv hervor.

Das deuterocerebrum enthält die Antennalganglien, worin die glomeruli (Fig. 101 und 102, gl.) als merkwürdige, kleine neuropilemata. Der nervus anteninarius' geht aus dem Antennalganglion hervor. (Fig. 101 und $102, n . a$. und zwar hat er nach BRETSCHNEIDER eine dickesensihele Turzel (rie:l) „,nervus olfactorius") und eine dünne motorische.

Dem deuterocerebrum folgt das tritocerebrum mit einer Tritocerebralkommissur unter dem Oesophagus.

BRETSCHNEIDER beschreibt gar mañche Fasersysteme, ohne daß deren Anfang und Ende bekannt wären, welche ich hier also fortlassen will. Genügend bekannt

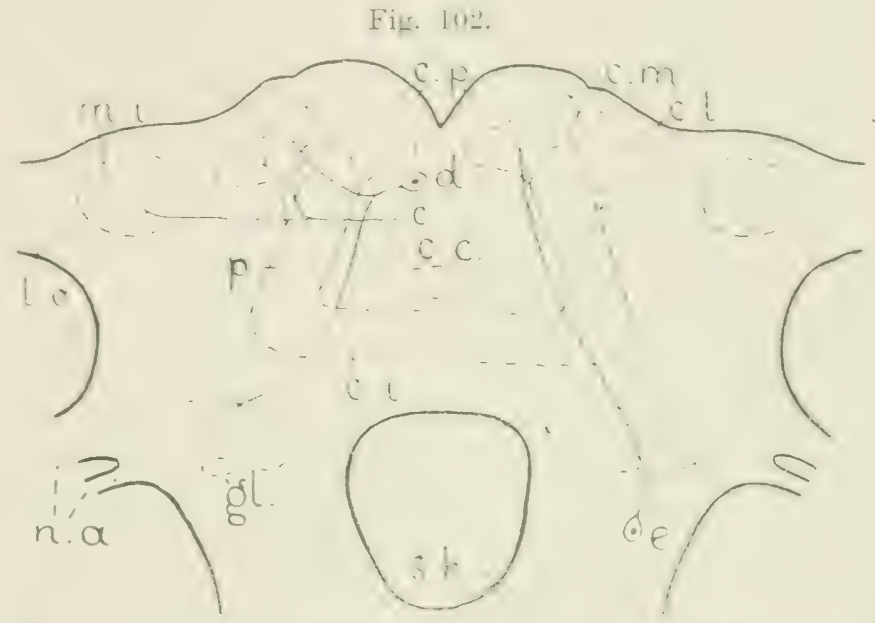

Schematischer Querschnitt durch das Hirnganglion von Periplaneta orientalis. Abgeändert nach BRETSCHNEIDER (1914), Textfigur 12.

$$
c=\text { Nervenfaser }
$$

$d, e=$ Ganglienzellen

c. $c .=$ corpus centrale

c. $i .=$ cornu internum

c. $l$. $=$ calyx lateralis

c. $m .=$ calyx medianus

c. $p_{0}=$ corpus pedunculatum

gl. $=$ glomerulus

l. $o .=$ lobus opticus

m. $i .=$ medulla interna

n. $a .=$ nervus antennarius

$p .=$ pedunculus

s. $k_{i}=$ Schlundkonnektiv

scheinen mir nur

die folgenden Leitungsbahnen. Große Ganglienzellen aus dem Vorderteil der pars intercerebralis senden einen Stammfortsatz aus, aus welchem Dendriten zum Neuropilem der Becher und ein Neurit im sensibelen Antennalnerven hervorgehen.

Lateral im Hirnganglion liegen Ganglienzellen (Fig. 101, a), welche mit ihrem Neuriten die medulla interna des lobus opticus suchen, während ihre - Dendriten zum Zentralkörper gehen. Diese Kommissurfasern laufen iiber dem corpus centrale.

Ganglienzellen des Antennalganglions (Fig. 101, b) senden cbenfalls 
Seitenäste des Neuriten in das corpus centrale, aber der Neurit selber endet in den glomeruli der anderen Seite und ist eine Nervenfaser der unter dem Zentralkörper gelagerten Kommissur.

Nervenfasern unbekannter Herkunft (Fig. 102,c) spalten sich in einen Ast zum Neuropilem der corpora pedunculata und einen Ast zur medulla interna des lobus opticus.

In der pars intercerebralis fand BRETSCHNEIDER Ganglienzellen (Fig. $102, d)$ mit dichotomisch geteiltem Fortsatz. Seine Aeste suchen das Neuropilem der corpora pedunculata und die glomeruli des Antennalganglions. Derartige Ganglienzellen, welche einen Fortsatz zu den glomeruli und einen anderen zu den Bechem senden, befinden sich auch im Antennalganglion (Fig. 102.e).

Mit dem sensibelen Antennalnerven treten Fasern ins Gehirn ein, welche sich in den glomeruli des Antennalganglions verzweigen und dort enden (Fig. $101, f)$. Kenyor hat solche Fasern auch bei der Biene beobachtet. Es enden auch noch Fasern aus anderen Hirnteilen als die bis jetzt genannten in den glomeruli. Die glomeruli werden umgeren ron Ganglienzellen. welche trilweise ihre Fortsätze in die Antennalkommissur senden. Darunter gibt es einen Ganglienzelltypus (Fig. 101, g), welcher seinen Neuriten durch die Antennalkommissur sendet und in den glomeruli des. Antennalganglions der anderen

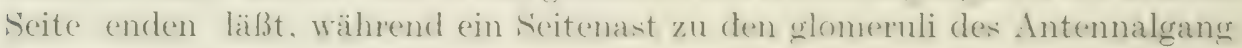
lions derselben Seite geht.

Ventral neben der motorischen Wrurzel des. Antemnalnerren liegen Ganglienzellen, welche ihren Fortsatz diesem Nerven beimischen (Fig. 101, h). Vielleicht gehen Seitenäste dieser Nervenfasern zu vier verschiedenen Abschnitten des Gehirns, aber, weil BRETSCHNEIDER solches nicht genau beobachtet hat, habe ich diese Aeste in der Fig. 101 fortgelassen.

Ueber das tritocerebrum bemerkt BRETSCHNEIDER, daß im Neuropilem desselben Nervenfasern des sensibelen Labralnerven sich verzweigen.

Die Fasern der Schlundkonnektive zeigten sich teilweise Fortsätze von Ganglienzellen des deuterocerebrum, teilweise zogen sie zum protocerebrum oder zu den glomeruli des Antennalganglions oder zum Bauchstrang.

Allo diese Sachen teilt Bretschneider uns über Periplaneta mit. Von den anderen Orthopteren sind die Heuschrecken in erster Linie untersucht worden. Hevsen (1866) und O. Schmid (1875) studierten ihr Gehörorgan und es ist nicht klar, ob sie darin Sinnesnervenzellen oder sensibele Ganglienzellen entrleckt haben. Ihre Untersuchungen sind schon alt und es ist sehr wïnschenswert, daß sie mit anderen Hilfsmitteln wiederholt werden, zumal weil auch Schös (1911) meiner Meinung nach keine klare Darstellung liefert. HeNsen beschrünkte sich auf Locusta. Die Hörleiste des Gehörorgans fand er aus Hörstiften zusammengesetzt. Jerler Hörstift besteht aus vier Zellen, der Deckzelle. zwei Seitenzellen und einer Basalzelle. Zwischen diesen Zellen und von der Basalzelle ringsum umgeben, findet man die , chorda". Nach HENSEx ist die chorda der periphere Fortsatz einer bipolaren (innglienzelle, welche zwischen den Zellen des Hörstifts endet, während die zentralen Fortsütze dieser Zollen den (iehörnerven bilden.

Schmot (1875) erkannte die chorda in den Stiftchen mancher Locustiden wieder. Sio befindet sich nach ihm (als Neurofibrille?) in dem peripheren fortsatz einer bipo. Isron Ganglienzelle, der Basalganglionzelle, deren anderer Fortsatz die Zelle mit einer Ganglienzelle des Hörnerven verbindet.

Scrös (1911) beschreibt den Bau der Hörorgane (Chordotonalorgane) der Ortho. 
pteren wie folgt. Die Fasern des Subgenualnerven setzen sich fort in die bipolaren , Sinneszellen" des Chordotonalorgans. Die Sinneszellen werden umgeben von anderen Zellen, welche Sснӧ刃 leider nicht scharf begrenzt sah. Die Sinneszellen werden in erster Linie umgeben von den Umhüllungszellen (Hexsexs Basalzelle?), welche besonders den ersten Teil des peripheren Fortsatzes der Sinneszelle umhïllen. Die Spitze dieses Fortsatzes, offenbar die ,chorda", dringt jedoch in die ,Kappenzelle" hervor, welche selbst sich in eine Endfaser verjüngt, welche zwischen den Hypodermiszellen endet. Nach Sснӧм ist die Kappenzelle nur eine Hilfszelle des Sinnesorgans und selbst nicht nervös. Die „Sinneszelle” wäre dann eine sensibele Ganglienzelle mit freien Nervenendungen und wahre Sinneszellen würden fehlen, aber ich bin fest überzeugt, daß weitere Forschungen nötig sind um die Struktur und Innervierungsweise dieser Gehörorgane aufzuklären.

BeLloxci (1883) hat als erster die Hodologie von Gryllotalpa vulgaris studiert. Das Antennalganglion (lobus olfactorius) hat einen inneren und einen äußeren Abschnitt. Letzterer enthält die glomeruli, worin Fasern des nervus antennarius enden. Das stimmt also mit Periplaneta (Fig. 101, f). Die dortigen Ganglienzellen senden ihre Fortsätze ins Neuropilem des Antennalganglions. Die beiden Antennalganglien sind durch die Antennalkommissur verbunden. Auch das stimmt mit Periplaneta überein (Fig. 101, g), aber wenn Belloxci sagt, daß aus den corpora pedunculata Faserbündel zum Antennalganglion derselben Seite ziehen um sich dort im Neuropilem zu lösen, können wir zwar vermuten, daß er Fasern beobachtet hat, wie die Fortsätze der Ganglienzellen $d$ und $e$ (Fig. 102), welche Bretschneider bei Periplaneta fand, aber Gewißheit darüber gibt es nicht. BeLloxcr sah aus jedem lobus opticus ein Faserbündel hervorgehen, welches sich teilte in ein kreuzendes und ein nicht-kreuzendes Büudel. Das kreuzende Biundel vereinigte sich wieder mit dem ungekreuzten Bündel der anderen Seite und zusammen endeten sie im Antennalganglion.

Fräulein Mostr (1892) hat Methylenblau-Präparate der Ganglien des Zentralnervensystems von Gryllotalpa vulgaris angefertigt, aber darin sehr wenig Besonders beobachtet. Sie lehrt uns, daß die Fortsätze der Ganglienzellen entweder sich im Ganglion verzweigen oder dasselbe verlassen. Daneben gibt es Nervenfasern, welche das ganze Ganglion durchziehen oder darin verzweigt enden.

Viallaves (1887b) hat das Gehirn von, zwei Grillen Oedipa coerulescens und Caloptenus italicus untersucht. Während auch hier die mikroskopische Anatomie sehr gut beschrieben wird, glaube ich seinen Angaben "iber-die Wege der Leitungsbahnen nur sehr geringen Wert beilegen zu müssen, weil VraLtaNes (18\$ $4 b$ ) auch bei Aeschna so große Fehler gemacht hat (siehe S. 282). Bei Aeschna haben spätere Forscher ViaLLAves korrigiert; Hiber das Gehirn der Grillen sind, so viel ich weiß, niemals andere Untersuchungen publiziert worden. Vrallaves hebt in dieser Arbeit das Verdienst Belloncrs hervor die medulla terminalis der Crustaceen, oder wenigstens den unteren Teil, mit dem corpus pedunculatum der Insekten homologisiert zu haben und er stimmt dieser Ansicht bei.

Der lobus opticus des protocerebrum enthält die medulla externa, worin die Ganglienzellen der äußeren und inneren Rinde (corona ganglionaris, ganglion cuneatum, u.s.w.) ihre Fortsätze tauchen. Ebenso ist die medulla interna mit einer Rinde von Ganglienzellen bekleidet, welehe ihre Ausläufer hineinsenden. Eine Kommissur verbindet nach VIALLANES die linke und rechte medulla interna.

Im protocerebrum unterscheidet Villanes die corpora pedunculata, das corpus centrale und die pons, welche man in den Figuren 101 und 102 abgebildet finden kann. Bemerkenswert ist nur, daß links und rechts nur ein Becher im corpus pedunculatum 
rorkommt. Dieser calyx ist mit Ganglienzellen gefiillt, welche ihre Fortsätze ins Neu. ropilem senden, das den Becher zusammensetzt. An der Oberfäche des protocerebrum liegen Ganglienzellen, deren F'ortsätze ins Neuropilem desselben eindringen. Das corpus contrale wird von einer Faserschicht umhüllt, deren Fasern nach VIaLlases teilweise aus vorn oder hinten im protocerebrum gelegenen Ganglienzellen hervorgehen. Dic Kommissuren, welche VIALLANES im protocerebrum sieht, habe ich nicht mit den Kommissurfasern, welche BreischiNerder bei Periplaneta fand (Fig. 101) homologisieren können. Li sind eine commissura protocerebralis superior, eine commissura inferior, welche laterale Teile des mittleren Abschnitts des protocerebrum verbindet und über dieser, aber unter dem Zentralkörper noch oine dritte Kommissur. Neben diesen Kommissuren verbinden auch die Fasern der Brücke die beiden Hälften des protocercbrum. Ganglienzellen des protocerebrum, welche unmittelbar vor der pons liegen, senden ihre Fortsätze hinein.

Das deuterocerebrum besteht aus einem lobus dorsalis und einem lobus olfactorius (oder Antennalganglion). Die beiden lobi dorsales sind durch eine vordere und eine hintere Kommissur verbunden und sie enthalten peripher gestellte Ganglienzellen, welche ihre Fortsätze ins Neuropilem senden. Im Antennalganglion liegen neben den glomeruli unipolare Ganglienzellen, deren Fortsätze ebenfalls ins Neuropilem eintreten.

Die Kommissur des tritocerebrum ist die äußerlich sichtbare 'Tritocerebralkommis. sur unter dem Oesophagus.

In seiner allgemeinen Uebersicht der Organisation des Nerrensystems der Arthropoden hasiert VIALLANES (1893) sich, was die Insekten anbelangt, auf seine oben genannten Grillen-Lintersuchungen. Sie bringt keine neue Leitungsbahnen zur Kenntnis.

Forficula auricularia hat in DuBosce (1897) einen Forscher ihrer Leitungsbahnen gefunden. Das Methylenblau verschaffte wiederum die P'äparate. In und unter allerhand Haaren über den ganzen Körper zerstreut, fand Durosce eine oder bei großen Haaren mehrere Haarzellen. Diese Haarzellen, welche das chitinöse Haar bildeten, sind wahre Sinneszellen, denn sie werden innerviert dureh die peripheren fortsütze bipolarer, sensibeler Ganglienzellen, welche niemals in das Haar selisst eindringen. Die zentralen Ausläufer dieser sensibelen Cianglienzellen vereinigen sich zu immer diekeren Nerven, welche keinen Nervenplexus bilden, sondern sich nur wiederholt dichotomisch teilen. Niemals waren dic zentralen l'ortsätze der sensibelen Ganglienzellen bis zum Bauchstrang zu verfolgen, aber in die Abdominalganglien des Bauehstranges treten mit dem vorderen Nerven des Ganglions Nervenfasern ein, welche sich dort verästeln und einen Zweig in das Konnektiv nach rorn zum vorhergehenden Ganglion senden. DuBosce betrachtet diese Fasern als sensibele Nervenfasern und Fortsätzo der sensibelen Ganglienzellen. Andere Nervenfasern der Abdominalganglien durchziehen die Ganglien und die Konnektive und stammen wahrscheinlich aus dem Gehim, wïhrend noch andere Fasern dus (ianglion durch das hintere Konnektiv verlassen und in den vorderen Nerven des nüehsten Gianglions austreten.

Vor kurzem hat KïHNL: (1913) das Gehirn von Forficula auricularia untersucht. Er behauptet darin ohne spezifische Nervenfïrhungsmethoden zahlreiche liaserbündel entcleckt zu haben, aber weder der 'Text noch seino Abbildungen ïberzeugten mich, daß diese. Bündel sich neneren Untersuchungsmethorlen gegenüber aufrecht erhalten werden. Am besten können sie zur Kenntnis der mikroskopisehen Anatomie des (iehirns beitragen. Die Hodologie wird nur gefördert durch die Mitteilung, daßB Ganglienzellen des corpus pedunculatum fortsiitze in die Berher und stiele und sogar zu den glomeruli des Antemalganglions senden.

leh mul3 zuletzt. noch cinige Angiloen melden, welche mir anderen . Vitteilungen

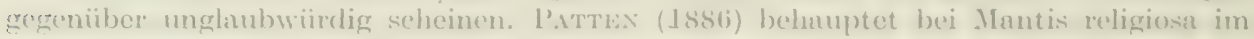
zusammengesetzten Auge Retinophoren mit axiaten und peripheren Nervenfasern ge-

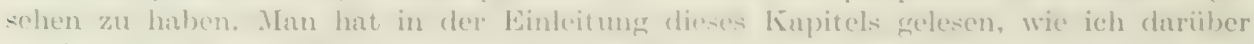

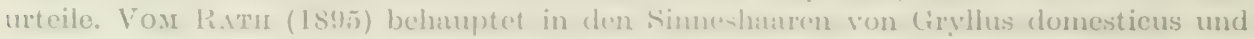
Locusta viridissimat Sinnesnervenzelten gresehen zu hatron, aber die Angaben Dunosegs

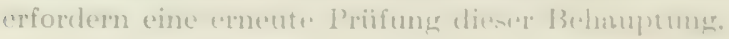


Die Insekten-Ordnung der Neuropteren hat nur in Hitтох einen Forscher gefunden, welcher den Wegen der Leitungsbahnen nachspiurte; dieser aber tat es in mustergültiger IVeise. Hintox arbeitete immer mit Corydalis cornuta. Er fing damit an (Hrtox 1902) zu zeigen, daß die schuppenförmigen Sinneshaare der Larven von Corydalis durch bipolare sensibele Ganglienzellen innerviert werden. Die Haarzellen sind also wahre Sinneszellen.

Später hat HiLtox (1911) im Zentrálnervensystem von Corydalis-Larven zahlreiche Leitungsbahnen u. a. mit Hilfe der vitalen Methylenblau-Methode zu Tage gefördert. Der Bauchstrang umfaßt drei Thorakal- und acht Abdominalganglien, welche durch Konnektive (Fig. 103, k.) verbunden werden. Die Thorakalganglien (Fig. 103, g.th.) besitzen drei Paare peripherer Nerven, die Abdominalgangłien zwei (Fig. 103, g.a. 7) mit Ausnahme deș letzten Abdominalganglions, aus dem vier Nervenpaare hervorgehen (Fig. $103, g . a .8)$. HiLtor entdeckte im Bauchstrang die nachstehenden sensibelen Bahnen, welche alle gebildet werden durch die zentralen Fortsätze der bipolaren sensibelen Ganglienzellen, welche, wie wir oben sahen, die Haarzellen der Sinneshaare innervieren. Frstens gibt es Fasern (Fig. 103, a), welche mit einem peripheren Nerven in ein Ganglion eintreten und dort enden ohne die
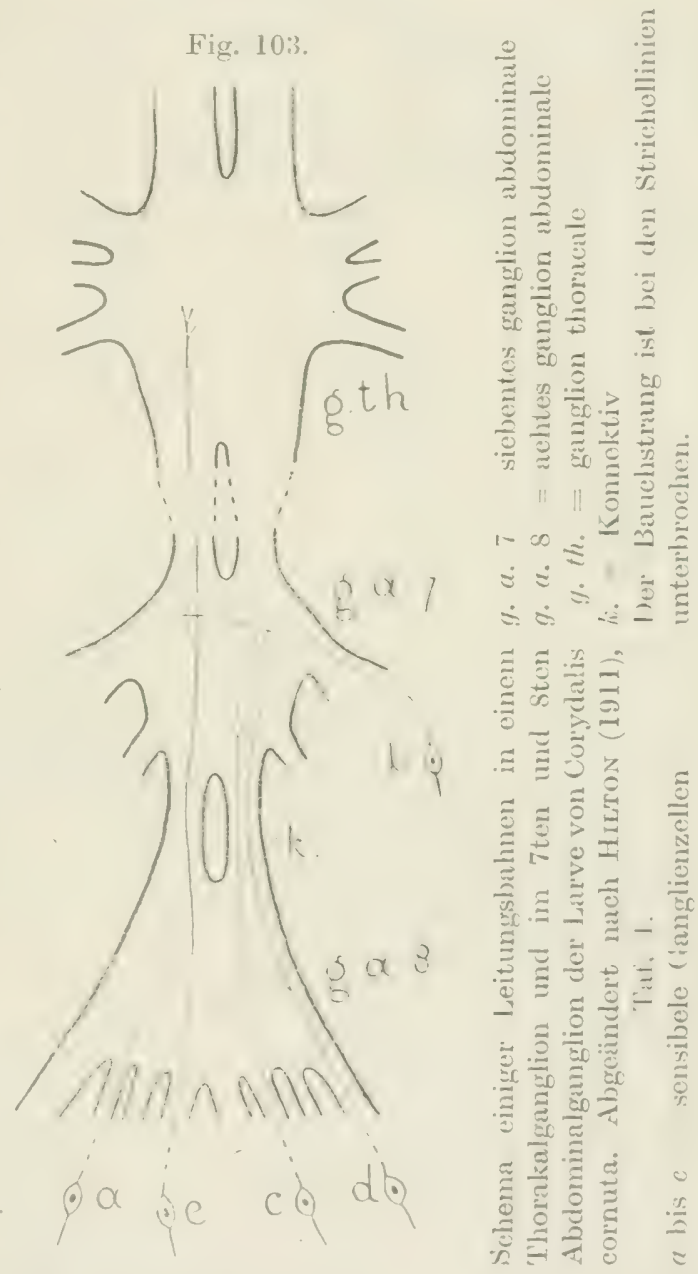
Medianlinie zu überschreiten. Andere tun dasselbe, aber sie kreuzen ïberdies (Fig. 103, b) und verzweigen sich also zu beiden Seiten. Noch andere Fortsätze der sensibelen Ganglienzellen aszendieren nach ihrem Eintritt in dem Bauchstrang und endigen im vorhergehenden Ganglion entweder auf derselben Seite (Fig. 103, c) oder auf der anderen Seite oder auf beiden Seiten. Diese Nervenfasern bilden besonders in den Abdominalganglien deutliche Bündel.

Es gibt auch Nervenfasern, welche dem Ganglion, worin sie eingetreten sind, einen Ast übermitteln, selbst aber zum vorhergehenden G'anglion aszendieren, um dort zu enden (Fig. 103, d) und dann fand HiLtox noch Nerven- 
fasern (Fig. 103. e). welche in den Bauchstrang eintreten und mehrere Ganglien durchziehen, bevor sie enden. Wie weit sie wohl ziehen können, ist unbekannt.

HiLton ist leider in seinen Beschreibungen sehr kurz, zu kurz möchte ich sagen. Ob die genannten Fasertypen in allen Abdominal- und Thorakalganglien wiederzufinden sind. ist nicht klar. Jedenfalls sind weit mehr als gerade die in der Figur 103 gezeichneten Nervenfasern von Hilton gesehen worden.

Die Bahnen, welche HiLTox im oberen und unteren Schlundganglion von Corvelalis-Larven entrerkte. will ich als Erläuterung zur Figur 104 beschreiben. Man sieht darin das Hirnganglion $(h . g$.$) mit dem unteren Schlundganglion$ (g. s.oe.) durch die Schlundkonnektive $(s . k$.) verbunden. Links im Hirnganglion sieht man ein corpus pedunculatum (c. p.) eingezeichnet. Das Hirnganglion geht vorn in die lobi optici $(l . o$.) über. Dahinter entspringt der nervus antennarius $(n . a$.$) . Noch mehr nach hinten geht aus dem Hirnganglion ein$ Nerv hervor, welcher sich bald verzweigt in den nervus clypeolabralis (n.cl.l.) und der nervus arcuatus ( $n$. arc.). Die beiden nervi arcuati kommen zusammen im Frontalganglion $\left(g . f r_{0}\right)$, welches mit dem ebenfalls medianen ganglion nervi vagi $(g . n . v$.) verbunden ist. Die beiden Schlundkonnektive sind hinter dem Oesophagus verbunden durch eine Kommissur, welche ich mit großer Wahrscheinlichkeit als die commissura tritocerebralis (c.tr.) deuten kann. Aus dem ganglion suboesophageum gehen unter anderen die nervi gustatorii $(n . g$.$) , die nervi labiales \left(n . l_{0}\right)$, die nervi maxillares $\left(n . m x_{0}\right)$ und die nervi mandibulares ( $u$. md.) hervor, während das Ganglion durch die Konnektive (k.) mit dem übrigen Bauchstrang verbunden ist.

HrLTox hat nun die folgenden Leitungsbahnen genau beobachtet, aber ich will gleich anfangs bemerken, daß er daneben verschiedene Nervenfasern ungenügend beschreibt und sonderbarer Weise manche Ganglienzellen und Leitungsbahnen in seinen Figuren abbildet ohne sie zu beschreiben, sodal3 ich nicht weiß, ob damit wirklich gesehene Elemente gemeint sind, warum ich sie hier lieber ïbergehe.

HiltoN erwähnt zuerst zwei Fasertypen unbekannter Herkunft, welche durch die hinteren Konnektive in das Unterschlundganglion eintreten und entweder dort enden (Fig. 104,f) oder durch die Schlundkonnektive ins Hirnganglion emporsteigen und da ihre Endverästelungen treiben (Fig. 104, q). HiLtox betrachtet diese Nervenfasern als sensibele Fasern ; es können jedoch ebensogut assoziative Elemente sein. Es gibţ auch Nervenfasern, welche das Unterschlundganglion mit dem Hirnganglion verbinden und im letzteren enden; sie passieren dabei die Tritocerebralkommissur (Fig. 104, $h$ ).

Ins untere Schlundganglion und ins Hirnganglion treten mit den peripheren Nerven sensibele Nervenfasern ein, welehe im Neuropilem dieser Ganglien enden. Hntox zeichnet derartige Fasern im Labialnerven (Fig. 104, i) im Maxillarnerven (Fig. 104, j) und im Mandibulamerven (Fig. 104, $k$ ) des unteren Schlundganglions. Der nervus antennarius des Hirnganglions führt sensibele Nervenfasern, welche im Neuropilem derselben Seite enden (Fig. $10 t$, l) oder nach Kreuzung im Neuropilem der anderen Seite (Fig. 10t, $m$ ). Ebenso enthält der nervus clypeolabralis sensibele Nervenfasern, welehe im Neuropilem des Hirnganglions sich verzweigen (Fig. 104, n). 
Fig. 104.

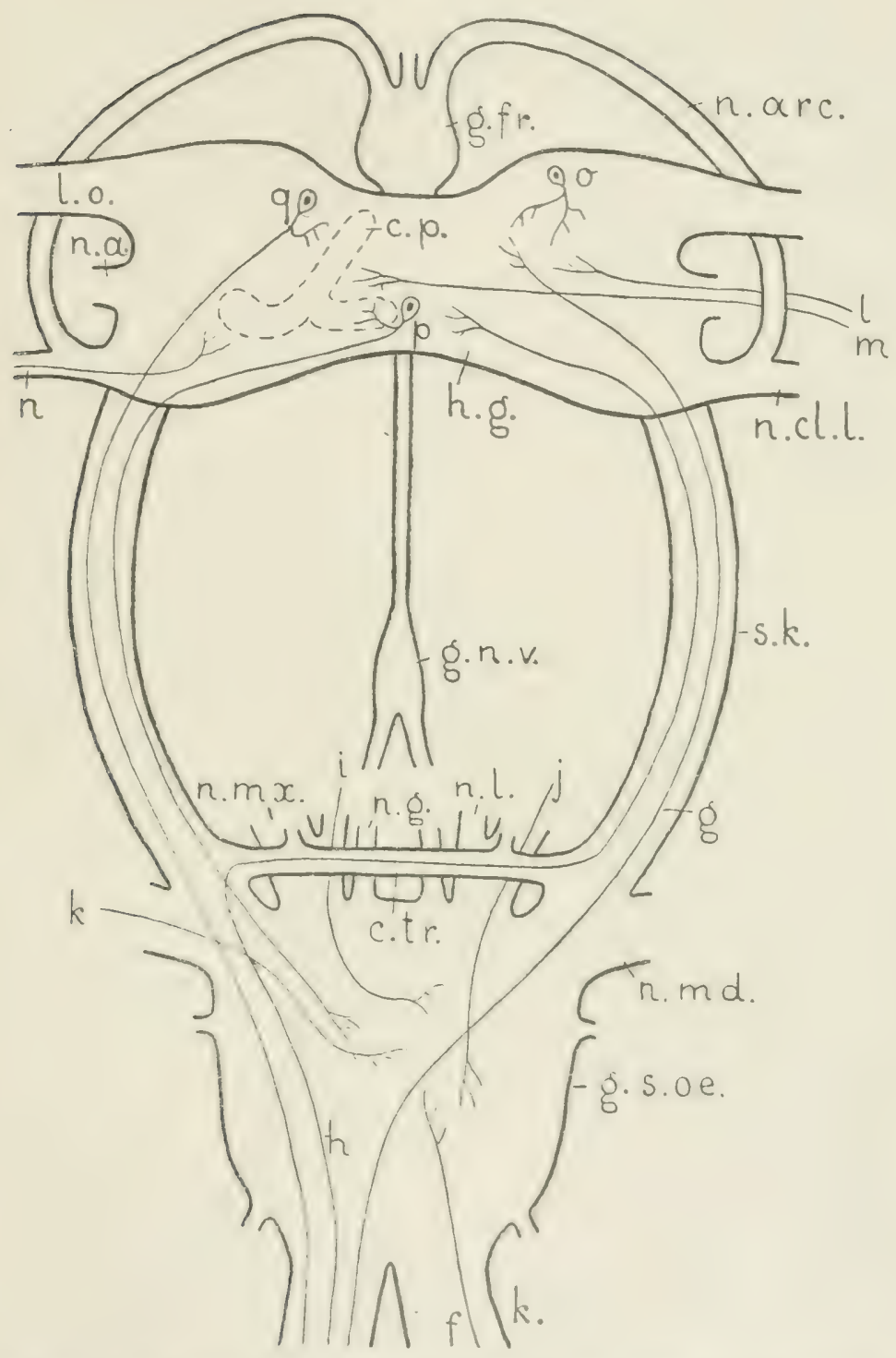

Schems einiger Leitungsbahnen im Schlundring der Larve von Corydalis cornuta. Abgeändert nach HrLtoN (1911), Taf. 2.

$f$ bis $n=$ Nervenfasern $\quad o, p, q=$ Ganglienzellen $\quad c . p .=$ corpus pendunculatum c. $t r .=$ commissura tritocerebralis $g . f r .=$ ganglion frontale $\ell_{0} n_{0} v \cdot=$ ganglion nervi vagi $g . s . o e .=$ ganglion suboesophageum $h_{0} g_{0}=$ Hirnganglion $k$. Konnektiv $l_{0} . o_{0}=$ lobus opticus $n . a_{0}=$ nervus antennarius $n_{0}$ arc. $=$ nervus arcuatus $n$. $c l . l$. = nervus clypeolabralis $n \cdot g \cdot=$ nervus gustatorius $n_{0} l .=$ nervus labialis $n . m d .=$ nervus mandibularis $n . m x_{0}=$ nervus maxillaris $s_{0} k_{0}=$ Schlunclkonnektiv 
Die sensibelen Bahnen des lobus opticus wurden von HuLtox ganz un. zureichend dargestellt.

HiLtox sagt in einer allgemeinen Beschreibung der motorischen Ganglienzellen des oberen und unteren Schlundganglions, daß der Stammfortsatz meistens dem Neuropilem Dendriten ïberliefert, während der Neurit entweder einen peripheren Nerven der gleichen oder der gekreuzten Seite sucht. Weil einige Konnektive des Bauchstranges, z. B. die Konnektive zwischen dem ersten und zweiten und zwischen dem zweiten und dritten Thorakalganglion, motorische Nerven aussenden, enthalten diese Konnektive motorische Nervenfasern, welche aus Ganglienzellen des vorhergehenden oder des nächsten Ganglions hervorgehen. HiLtox zeichnet manche motorischen Ganglienzellen in seinen Figuren, aber, wie ich glaube, nur als erläuterende Beispiele und ich lasse sie hier deshalb fort. Wer will, kann sie im Original nachschlagen.

Alle Ganglien zeigen nach Hiltox Assoziationszellen, deren Fortsätze das Zentralnervensystem nicht verlassen und entweder im selben Ganglion bleiben oder mehreve Ganglien verbinden. So befinden sich im Hirnganglion Ganglienzellen (Fig. 104, o) mit kurzen, das Ganglion nicht verlassenden Fortsätzen neben anderen, welche ihren Neuriten zum Unterschlundganglion senden, entweder um dort zu enden (Fig. 104, p) oder um weiter in den Bauchstrang zu deszendieren (Fig. 104, q). Solcher Assoziationszellen zeichnet HrLtox weit mehr, als er deren beschreibt. Die nicht-beschriebenen lasse ich als umzulänglich bekannt hier fort.

Die Coleoptera, obgleich eine sehr wichtige Ordnung der Insekten, sind relativ wenig auf ihre Leitungshahnen untersucht worden.

LAxDors (1868) hat wohl als erster versucht einen 'Teil der Leitungsbahnen darzustellen. Er wählte die Intennen von Lucanus cervus, dem Hirschkäfer, und von Doreus parallelepipedus als Ubjekt und fand darin Gruben, worin grol.se und kleine Haare standen, ebenso wie in der Umgebung der Gruben. LAxnors betrachtet alle Haare in den Gruben, ebenso wie die kleinen Haare ringsherum als Hörhaare, die großen Haare um die Gruben als 'Tasthaare. Die funktion dieser Haare könmen wir hier dahingestellt lassen (mir scheint die Hörfunktion dieser Haare nicht wahrscheinlich), wichtig aber ist es, was LAxpols iiber die Innervierung dieser Haare sagt. Er erzählt uns, daß unter den Haaren beider Arten eine bipolare Ganglienzelle liegt, deren peripherer Fortsat\% bis zur Basis des Haares vordringt, deren zentraler Fortsatz in den Antennalnerven ïbergeht. Es fragt sich, ob cliese Ganglienzelle eine sensibele (ianglienzelle oder eine simnesnervenzelle sci. Die großen Haare sind nach LA.tons hohl. Da hat man guten (irund zu erwaten, daß sie tatsächlich mit den Fortsitzen einer oder mehrerer Hatrzellen ausqufillt sind, wie es bei InsektenSimneshatren Regel ist und welche Hatrzellen wahre simncsellen sind, die durch eine sensibele Ganglienzelle innerviert werelen. Die kleinen Hatre scheinen jecloch solide zu sein und da wäre es möglich, dals die hipolare Ganglienzelle zugleicherzeit Haarzelle und also tatsächlich eine Sinnesnervenzelle wäre. Wie dem anch sei, Laxvors hat jedenfalls die Harbildungszellen nicht 
genau beobachtet und daraus geht der IT'unsch hervor, die Innervation dieser Haare möchte aufs neue studiert werden.

Es ist im Anschluß an das eben Gesagte bemerkenswert, daß Hintox (1902) viele Jahre später und mit modernen Hilfsmitteln bei Larven des Maikäfers Sinneshaare entdeckt hat, cleren Haarzellen durch bipolare sensibele Ganglie:...in innerviert wurden. Es hestehen also jedenfalls bei Käfern Sinneshaare mit sensibelen Ganglienzellen.

BERGEr (1878) hat sich, wie bei so manchen Arthropoclen, so auch bei einigen Käfern beeifert die Wege der Nervenfasern zu erforschen. So gelang es ilum bei Drytiscus und Hydrophilus das äußere und innere Chiasma im lobus opticus zu sehen und ebenso festzustellen, daß Fasern des Schlundkomnektivs in den Magennerven eintraten, aber genauere hodologische Angaben macht er nicht.

Im nächsten Jahre entdeckte GRExACHER (1879) eine Leitungsbahn, als er fand. daß in den ocelli der Larven ron Drtiscus und Acilius sulcatus, beide Wasserkäfer, die Retinazellen unter allmähliger Verjüngung in optische Nervenfasern übergehen und damit zeigen, daß sie Sinnesnervenzellen sind.

Pattex (1888) hat dieser Behauptung zwar widersprochen und gerade auch in den Ozellen der Larve von Acilius seine Retinophoren beschrieben, aber man weiß schon, daß ich ihm nicht glauben kann (vergl. S. 194). Jede Retinophore ist nach ihm durch Verschmelzung zweier Retinazellen und einer dazwischenliegenden Nervenfaser ent. standen. Die Nervenfaser wird dabei axial und ist scheinbar, aber auch nur scheinbar, die kontinuirliche Fortsetzung der Retinophore. Daneben gibt es nach PATtex Nervenfasern, welche die ganze Retinophore umspinnen. Die Retinophoren, oder die Retinnzellen, woraus sie hervorgegangen sind, würden also keine Sinnesnervenzellen, sondern wahre Sinneszellen sein.

Die genannten Nervenfasern sind nach Pattex iiberall wo Retinophoren sind anzutrefien. Daneben entdeckte er hier frei in der Retina enclendle Nervenfasern. Weil niemand anders je solche Fasern beobachtet hat, glaube ich die PAtrexsche Mitteilung bezweifeln zu müsson. Meine Bedenken gegen seine Meinung, daß diese frei endenden Fasern besonders hier Fortsätze unter das Epithel gesunkener Sinnesnervenzellen seien, habe ich schon S. 207 auseinander gesetzt.

Pattex beschreibt noch in der Rinde des ganglion opticum grol.je und kleine tripolare Ganglienzellen; ein Fortsatz verzweigt sich im Neuropilem des Ganglions, die beiden anderen verbinden wahrscheinlich die Zellen gegenseitig.

MicheLs (1880) hat einen merkwürdigen Versuch gemacht die Bahnen eines Käfers, Oryctes nasicornis, im Larven-, Puppen- und Käferzustande zu erforschen. Im Bauchstrang der Larve sah er Kommissuren und Längsbündel von Nervenfasern. Die Nervenfasern der Längsbündel durchziehen manche Ganglien und es sind Fasern dabei, welche in einem Ganglion kreuzen, zurücklaufen und am Ende in einen peripheren Nerven des Bauchstranges austreten. Oft waren in einem Gảnglion fünf Kommissuren übereinander zu unterscheiden. Sie bestehen überwiegend aus Fortsätzen von Ganglienzellen des Ganglions, welche in einen peripheren Nerven der gekreuzten Seite austreten. Die vorderen drei Einschnürungen zwischen den Ganglien des Bauchstranges sind im Gegensatz zu allen anderen frei von Ganglienzellen. Die zwei vorderen wachsen später zu langen Konnektiven aus. Nicht alle Ganglien des Bauchstranges zeigen denselben Bau. Dis untere Schlundganglion ist abweichend gebaut; die drei Thorakalganglien, aus denen die Nerven zu den Beinen hervorgehen, 
sind komplizierter als die Abdominalganglien und unter diesen besteht das letzte Ganglion des Bauchmarks aus drei verwachsenen Ganglien.

Der Bau des Bauchstranges der Puppe zeigt Uebergänge von der Larve zum Käfer.

Beim Käfer gleicht der Hinterteil des Bauchstranges noch am meisten demjenigen der Larve. Die Ganglien sind mehr miteinander verwachsen, aber die Stellung der Ganglienzellgruppen in den Ganglien weicht im allgemeinen nicht erheblich ab. Durch alle Ganglien des Bauchstranges ziehen drei Paar Längsbündel, welche sich in den Konnektiven zwischen den drei vorderen Ganglien zu einem Bündel vereinigen, welches bis ins Gehirn zu verfolgen ist. Vorn im Bauchstrang sind die Längsfasern am zahlreichsten, denn jedesmal überschreiten einige dieser Fasern die Medianlinie und treten in einen peripheren Nerven der anderen Seite aus. Wie bei der Larve senden auch jetzt die Ganglienzellen der Ganglien Fortsätze aus, welchegुdie Kommissuren bilden und in einem Nerven der gekreuzten Seite verschwinden. Jedes Ganglion zählt aber nur drei oder höchstens vier Kommissuren, statt fünf wie bei der Larve. Nur das Unterschlundganglion enthält mehr Kommissuren, worin es mit demjenigen der Larve übereinstimmt.

Fräulein Hoxт (1892) hat uns mit einem Ganglienzellplexus bekannt gemacht, welchen sie in Methylenblau-Präparaten in einigen Thorakalmuskeln der Larven von Lucanus cervus und Melolontha vulgaris, sowie auch in Muskeln der Imago ron Hydrophilus piceus entdeckt hat. Der Plexus, welcher auch mit den 'Tracheen zusammenhängt, wird von ihr als ein nervöser Endapparat betrachtet. Seine Natur ist mir nicht ganz klar, erinnert jedoch noch am meisten an einen sympathischen Ganglienzellplexus.

Das sympathische Nervensystem der Käfer ist auch fovon HalLER (1910a und $b$ ) bearbeitet worden. (Siche S. 330). Bei den Carabiden besteht es nach ihm $(1910 a)$ ans einer Reihe ron Riesenganglienzellen, welche untereinander durch eine breite Nervenfaser, den sogenannten Farveschen Nerven oder Mediannerven verbunden werden. Jede sympathische Ganglienzelle sendet Fortsätze in das Abdominalganglion, woneben sie gelagert ist und iiberdies ziehen zwei laterale Fortsätze die peripheren Nerven des Abdominalganglions entlang.

Eine detailliertere Beschreibung hat HALLer (19106) noch im selben Jahre gegeben und es waren GoLgi- und Methylenblau-Präparate, welche ihn dazu befähigten. Bei der Larve von Procrustes und ron Carabus sylvestris und ( $\therefore$ auratus befindet sich median ,oben in jedem Abdominalganglion" (das heißt innerhalh derselben bindegewebigen Scheide) eine sehr große Canglienzelle. Diese Zelle ist eine sympathische Ganglienzelle und sie repräsentiert nach HALIER für sich allein ein ganzes sympathisches Ganglion anderer Insekten. Wie gesagt, sind diese Zellen durch einen hreiten medianen Ausläufer gegenseitig verbunden und dringen kleine fortsätze dieser Zellen ins zugehörige Abdominalganglion ein. Der vorderen Ganglienzelle der Reihe entspringt ein medianer Fortsatz, welcher sich spaltet in zwei Aeste, welche den vorderen Nerven des ersten Thorakalganglions begleiten. Die medianen Fortsätze, welche die Zellen gegenseitig verbinden, spalten zwei Seitenäste ab, welche 
in derselben Hülle, wie die peripheren Nerven der Abdominalganglien laufen. Nach einiger Zeit verästeln sie sich und die Zweige gehen kontinuirlich über in die Fortsätze multipolarer Ganglienzellen, welche in peripheren Ganglien angehäuft liegen und auch gegenseitig mit breiten Fortsätzen zusammenhängen. Es fehlt aber jede Verbindung mit dem sympathischen Nervensystem des Kopfes.

HALler sieht, wie man weiß, immer bei Evertebraten die Ganglienzellen durch Fortsätze umittelbaar verbunden und, obgleich er sich darin wohl meistens irrt, ist gerade hier im sympathischen Nervensystem ein wahrer Ganglienzellplexus sehr gut denkbar, weil solches fast bei allen Tieren die Regel ist.

Ueber Meloe prosearabeus berichtet HaLler (1910b) uns noch, daß im plexus myentericus Ganglienzellen liegen, welche mit ihren Fortsätzen unmittelbar die Muskeln des Darmes innervieren.

Mitteilungen über das Zentralnervensystem der Carabiden findet man in der ersten Arbeit HaLlers (1910a). Auch hier in den Ganglien des Bauchstranges hängen nach ihm viele Ganglienzellen durch breite Fortsätze zusammen. Mit den peripheren Nerven treten sensibele Nervenfasern in den Bauchstrang um sich dort T-förmig zu teilen und in Fasern der Längsbündel, überzugehen, welche viele Ganglien passieren. Einige dieser Fasern lireuzen in einer Kommissur, bevor sie sich teilen. Aehnliche sensibele Fasern sind uns auch bei Chaetopoden und Crustaceen bekannt.

Die motorischen Nervenfasern der peripheren Nerven sind Fortsätze von Ganglienzellen derselben oder der gekreuzten Seite. Bisweilen sendet eine Ganglienzelle zwei Fortsätze in denselben peripheren Nerven. Seitenäste dieser Neuriten suchen das Neuropilem derselben oder der anderen Seite auf oder sie schließen sich nach 'I'-förmiger 'Teilung den Längsbündeln an um im nächsten Ganglion zu enden. Es gibt auch Ganglienzellen ohne Fortsatz in einem peripheren Nerven, aber mit einem T-förmigen Ausläufer in einem Längsbündel. Oft enden diese Längsfasern im nächsten Ganglion, bisweilen aber durchziehen sie mehr als zwei Ganglien. Die Zellen sind jedenfalls Assoziationszellen.

Der neueste Untersucher der Leitungsbahnen der Coleopteren ist wohl BRETSCHXEIDER (1914) gewesen, welcher sich nicht nur mit Periplaneta, sondern auch mit Tenebrio molitor, dem Mehlkäfer, beschäftigt hat. Der Bau des Gehirns gleicht im allgemeinen demjenigen von Periplaneta. Die corpora pedunculata der Larve und der Imago bieten nicht viele Unterschiede. Die drei Abschnitte des Gehirns haben jeder ihre eigene Kommissur : das protocerebrum eine Kommissur der lobi optici, das deuterocerebrum eine Antennalkommissur und das tritocerebrum die T'ritocerebralkommissur. Im Antennalganglion befinden sich nach Bretschyeider Ganglienzellen mit liortsätzen zum corpus centrale. Viele andere Bahnen werden beschrieben ohne genaueren Nachweis des Anfangs oder des Endes und daß Bretscirierder sich oft mit unzureichendem Beweis der Leitungsbahnen zufrieden stellt, geht auch wohl daraus hervor, daß er behauptet einige Neuronen, welche KExyos bei der Biene beobachtet hat, bei 'Tenebrio wiedererkannt zu haben, obgleich seine Methoden (keine spezifischen Nervenfärbungsmethoden) ihm solches kaum gestattet haben können. 
Wie man sieht, liegen über die Leitungsbahnen der Käfer nur wenige bestimmte Angaben vor.

Weit besser steht es gliicklicherweise mit der Ordnung der Hymenopteren, wozı die Insekten gehören, welche, wie die Bienen und Ameisen, die höchste psychische Entwicklung entfalten. Doch bleibt auch hier noch sehr vieles zu wiinschen: Von allen Hymenopteren ist wohl die Biene, Apis mellifica, am weitgehendsten untersucht worden.

Drete (1876) beschreibt schon im Gehirn der Biene die corpora pedunculata und manche (ianglienzellgruppen und Fasersysteme. Weil er niemals Beginn- oder Endpunkt dieser Fasern nennt und seine Methoden ihm auch nicht gestatteten die Fasern genau zu verfolgen, will ieh seine Angaben nicht wiederholen.

Ueber BERGEr (1878) liel3e sich das Gleiche sagen. Er sah in Gehirn ron Apis mellifica z.B. eine commissura optica und im lobus opticus cin äußeres und ein inneres Chiasma, ebenso wie manche Kommissuren im unteren Schlundganglion, aber dessenungeachtet blieben ihm die Wege der Nervenfasern völlig unbekannt, weil er die Mittel nicht besaß, sie einzeln oder auf längeren Abschnitten zu verfolgen.

Erst die Untersuchungen KExyoxs lieferten uns eine richtige Einsicht in manche Leitungsbahnen der Biene. Ls ist nur schade, daß diese vorzüglichen Arbeiten, welche von allen späteren Forschern gelobt werden und worauf mancher sich stiitzt bei dem Studium anderer Insektengehirne, so wenig Nachahmung und Erweiterung gefunden haben.

KExyox hat iiber das Gehirn der Biene drei Arbeiten publiziert. In der crsten (KEXYOX 1896a) bespricht er nur die corpora pedunculata, in der zweiten (KExyox 18966) das ganze Gehirn, das Unterschlundganglion mit. einbegriffen, aber nicht den lobus opticus und in der dritten (KENYOx 1897) nur den lobus opticus. Fch will mit den beiden cisten anfangen.

Zur Erklärung der Kexvoxschen Ergebnisse reproduziere ich hier zwei Figuren (Fig. 105 und 106), welche ich seiner zweiten Arbeit entlehne. In der ersten figur 105 sieht man das durchscheinend gedachte Gehirn der Bicne von vorn, in der zweiten Figur 106 sieht man es ron der Seite. Die lobi optici (Fig. 105, l.o.) des protocerebrum sind abgeschnitten worden, aber dennoch treten in der Figur Teile der medulla externa (Fig. 105, m.e.) und interna (m.i.) zum Vorschein. Ein pedunculuslohi optici fehtt also auch hier. wie bei so vielen Insekten. Das Hirnganglion (Fig. 106, h. g.) trïgt die ocelli (Fig. 105 und $106, o c$.) am Ende kurzer Ozellarnerven (Fig. $106, n . o c$.). In Inneren unterseheidet man wie immer das proto-, dentero- und tritocerebrum. Das protocerebrum cnthiilt die corpora pedunculata (Fig. 1(15. c. p.). Links und rechts ist ein corpus pedunculatum mit zwei hecherformigen Nemropilemen. Die zwei Becher, der calyx extermus (Fig. 105, e. e.) und der calyx internus (Fig. 105, c. i.) setzen sich in Sticle (pedunculi, lig. 1(15. p.) fort, welche sich vereinigen. Bald aber gehen ihe Fasern wiederum als cormu anterius (Fig. 10is. c. a.) und cornu internum (c. int.) anseinander. In der ligur 10; läuft das cornu anterius dem Beobachter entgegen und wird also stark verkiirzt gesehen. Dats linke Imnenhorn erreicht fast das rechte, aber, da keine Fasern hier die Hedianlinice iiberschreiten, kommt es nicht zur Bildung einer Kommissur. 
Calyces, pedunculi und cornua bestehen aus Neuropilem ; die Becher sind mit Ganglienzellen, den Zellen der corpora peduncalata, überfüllt. Zwischen den Becherstielen ,von rechts und links befindet sich das corpus centrale (Fig.

Fig. 105.

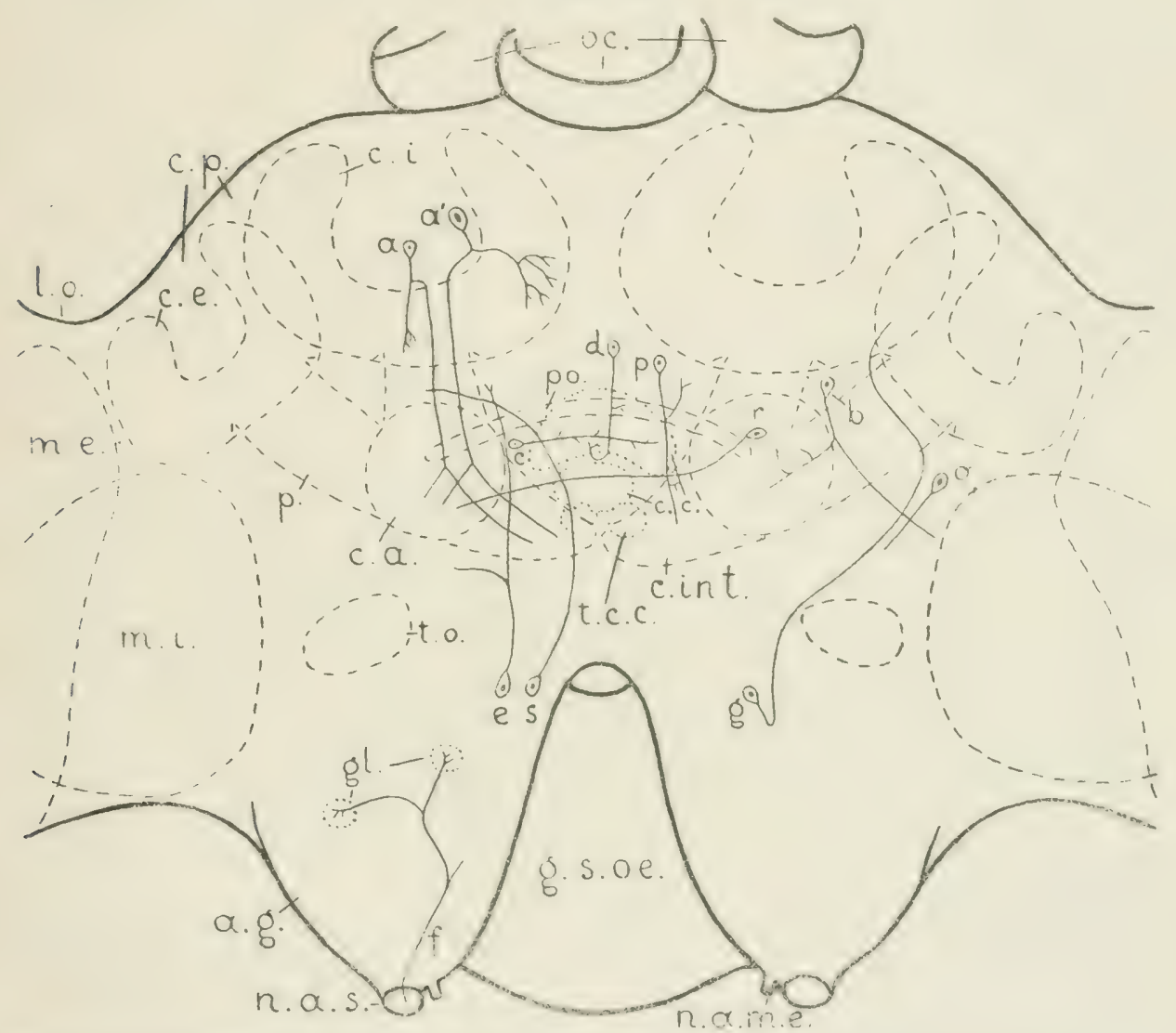

Einige Leitungsbahnen im Gehirn von Apis mellifica. Abgeändert nach KENYoN (1896b), Taf. 17. Das Gehirn wird von vorn gesehen und ist durchscheinend gedacht. Die Strichellinien begrenzen die Neuropileme. $a, a^{\prime}, b, c, d, e, g, o, p, r, s=$ Ganglienzellen $f=$ Nervenfaser
a. g. = Antennalganglion
c. $a .=$ cornu anterius
c. $c .=$ corpus centrale
c. $c$. $=$ calyx externus
c. $i$. $=$ calyx internus
c. int $_{\text {o }}=$ cornu internum
c. $p$. $=$ corpus pedunculatum

$g l .=$ glomerulus

g. s. oe. = ganglion suboesophageum

l. o. $=$ lobus opticus

$m . e .=$ medulla externa

m. $i$. = medulla interna

n. a. m. e. $=$ nervus antennarius motorius externus

n. a. $s .=$ nervus antennarius sensibilis

o. $c$. $=$ ocellus

r. = pedunculus

po. $=$ pons

t. c. $c$. $=$ tuberculum corporis centralis t. $o$. = tuberculum opticum

105 und 106, c.c.) aus einem größeren Oberteil und einem kleineren Unterteil aufgebaut. Darunter liegen die beiden tubercula corporis centralis (Fig. 105, 
t.c.c.), welche bisweilen ,Ozellarglomeruli" genannt werden. Hinter dem Zentralkörper ist die pons (Fig. 105 und 106, po.) von KExyox ,fibrillar arch", von VIALLAxes, ,le pont" genannt. Es ist keine Kommissur, sondern ein stabförmiges, ungepaartes Neuropilem. Zum protocerebrum sind auch noch die beiden tubercula optica (Fig. 105 und $106, \ell$. o.) zu rechnen, welche KENYOx "optic bodies" nennt, VIALLANES jedoch schon vorher als , tubercules optiques" bezeichnet hatte.

Dem protocerebrum schließt sich das deuterocerebrum an. Es enthält das Antennalganglion (oder den lobus olfactorius ) (Fig. 105 und 106, a.g.) mit seinen glomeruli (Fig. 105, gl.). Daraus gehen drei Nerven hervor : der sensibele Antennalnerv (nervus antennarius sensibilis, (Fig. 105 und 106, n.a.s.), der äußere motorische Antennalnerv (nervus antennarius motorius externus) (Fig. 105 und $106, n . a . m . e$. ) und der innere motorische Antennalnerv (nervus antennarius motorins internus) (Fig. 106, n.a.m.i.).

Das twitocerebrum grenzt unmittelbar ans deuterocerebrum. Der nervus labre's (Fig. 106, n.lbr.) entspringt daraus.

Die Schlundkonnektive, welche das Hirnganglion mit dem unteren Schlundganglion (Fig. 105 und 106, g. s.oe.) verbinden sind so kurz, daß man sagen kann: sie fehlen (vergl. Fig. 106). Das untere Schlundganglion (von KExyon ventrocerebrum genannt) sendet die Mandibularnerven (Fig. $106, n$. md.), die Maxillarnerven (Fig. 106, n. mx.), die Labialnerven (Fig. 106, n.lb.) und die nervi posteriores aus (Fig. 106, n. p.). Es ist durch Konnektive (Fig. 106, k) mit dem übrigen Bauchstrang verbunden.

Nach dieser allgemeinen, orientierenden Beschreibung kann ich mit der Aufzählung der von KENYoN (1896b) mit Hilfe der GoLgischen Methode entdeckten Leitungsbahnen anfangen. Daß3 er unter den Nervenfasern sensibele, motorische, assoziative und Kommissurfasern fand, braucht fast nicht erwähnt zu werden.

In den Bechern liegen zwei unipolare Ganglienzellarten, welche sich. wohl in Größe und Färbbarkeit, nicht aber durch den Lauf ihrer Dendriten und Neuriten unterscheiden und welche ich deshalb mit $a$ und $a^{\prime}$ (Fig. 105) bezeichnen will. Die Ganglienzellen im Zentrum des Bechers $(a)$ sind klein; jene, welche mehr dem Becher genähert sind $\left(a^{\prime}\right)$ sind größer. Beide Zelltypen haben einen Stammfortsatz, weleher in den Becher eindringt und dort Dendriten abspaltet, reich verzweigte Dendriten bei den großen Ganglienzellen $\left(a^{\prime}\right)$. weniger verästelte bei den kleinen Zellen $(a)$. Dèr Neurit der beiden Zellarten zieht in den pedunculus und spaltet sich in einen Ast im Vorderhorn und cinen Ast im Innenhorn.

Auch außerhalb des Bechers, aber noch zum corpus pedunculatum gehöriglicgen Ganglienzellen, welehe ihre F'ortsätze in das Neuropilen des Bechers senden.

In den calyees endigen Nervenfasern, welehe aus anderen Hirnteilen dahin gelangen. Sie alle dringren in die Unterseite des bechers cin und umschlingen teilweise den pedunculus. Diese Fasern gehören sechs oder sieben systemen an, zwei, welche vom lobus opticus herstammen, zwei von der ventralen Seite des Gehirns, zwei rom Antennalganglion und wahrscheinlich fürt sich dazu ein System von Kommissuriasern. 
Hinter und zwischen den pedunculi fand KEvyox Ganglienzellen, welche einen Fortsatz in das cornu anterius senden, wo er sich verästelt. Nach ihm hat VIALLANes (1887a) diese Ganglienzellen schon bei Vespa entdeckt. Genau genommen bildet Kexyox diesen Zelltypus nicht ab, aber in seiner Tafel 17 finde ich einen unbenannten Zelltypus (Fig. 105, b), welcher diese Zellart darstellen könnte mit dem Unterschiede jedoch, daß der Neurit dieser Zelle nicht in das Vorderhorn, sondern sonstwo hingeht. Im Vorderhorn enden noch andere Nervenfasern unbekannter Herkunft.

In seinem Aufsatz über die corpora pedunculata hat KENYoN (1896a) obigen Angaben noch hinzugefügt, daß Nervenfasern der calyces, welche sich zur Gegend oberhalb des Oesophagus begeben, dort mit Fasern des Bauchstranges in Verbindung treten.

KENYON (1896a) hat besonders gesucht die Bedeutung der corpora pedunculata ausfindig zu machen. Er weist darauf hin, daß F'LögEL schon zeigte, wie die corpora pedunculata besser entwickelt sind je höher die psychische Funktion des Insektes ist. Auch andere Forscher (unter denen ich Haller voranstellen möchte) haben immer die corpora pedunculata als den Sitz der Intelligenz betrachtet. Fest steht nach KENYoN, und gerne schließe ich mich dieser Ansicht an, daß die Ganglienzellen der calyces wichtige sensibele Reize empfangen aus allen Teilen des Gehirns und daß sie alle Assoziationszellen sind. Die corpora pedunculata sind somit das wichtigste Assoziationszentrum des Insektenhirns.

Das corpus centrale besteht, wie gesagt, aus einem Ober- und einem Unterteil. In den unteren Abschnitt treten Fasern unbekannter Herkunft neben Fasern, welche aus Ganglienzellen des Antennalganglions hervorgehen. Ich konnte sie nicht in die Figur einzeichnen.

Den oberen Abschnitt erreichen Fortsätze von median über dem corpus centrale oder dahinter gelegenen Ganglienzellen, ebenso wie Ausläufer von über dem Antennalganglion gelagerten Ganglienzellen. Sie sind nicht in der Figur.

Unmittelbar hinter dem corpus centrale ist eine Kommissur, welche gebildet wird durch. Fortsätze von Ganglienzellen des protocerebrum (Fig. 105, c), welche dem Zentralkörper Seitenäste überliefern. Diese Zellen sind in zwei Gruppen angehäuft, eine hinter dem cornu internum und eine neben dem corpus centrale.

Median über dem Zentralkörper entdeckte Kenyos Ganglienzellen (Fig. $105, d)$, welche ihren Fortsatz in einem Bogen nach hinten in den Raum zwischen den beiden 'Teilen des Zentralkörpers senden, wonach er sich im Oberteil verzweigt. Zuvor war der pons ein Seitenast abgegeben worden. Aehnliche Ganglienzellen befinden sich hinter dem Zentralkörper, oberhalb der pons.

Zum protocerebrum rechnet KExyos auch Ganglienzellen (Fig. 105,e), welche über dem Antennalganglion liegen und deren F'ortsätze median vom Vorderhorn laufen und in der Gegend dariber enden. Seitenäste spalten sich unter dem cornu anterius davon ab.

Wenn ich alle ungewissen Angaben und alle Fasern unbekannter Herkunft, welche doch für andere Forscher niemals genau wiedererkennbar sind, fort- 
lasse, bleiben mir über die Ganglienzellen des protocerebrum nur die folgenden Mitteilungen übrig. Bei der pons sind Ganglienzellen aufzufinden, welche ihre Fortsätze gerade nach vorn senden über den Zentralkörper hinweg. Ganglienzellen über und hinter dem Antennalganglion haben Fortsätze, welche den Vorder- und Hinterteil des protocerebrum vereinigen. Ein Ast dieser Fortsätze erreicht das Vorderhorn, ein anderer teilt sich in einen Ast zu den tubercula corporis centralis und einen Ast zum unteren Schlundganglion.

Deuterocerebrum. Der sensibele Antennalnerv führt Nervenfasern (Fig. $10 \tilde{5}, f)$, welche sich verzweigen und in den glomeruli des Antennalganglions enden. Die motorischen Antennalnerven enthalten teils Nervenfasern unbekannter Herkunft, welche ich hier fortlasse, teils Nervenfasern, welche aus Ganglienzellen des tritocerebrum entspringen und später beschrieben werden sollen.

Das protocerebrum wird durch verschiedene Fasersysteme einerseits mit dem lobus opticus, andrerseits mit dem deuterocerebrum verbunden. Neben dem tuberculum opticum sind Ganglienzellen gelagert, deren Fortsätze Aeste zum tuberculum opticum und zu anderen Hirnabschnitten abgeben. Einige dieser Aeste kreuzen die Medianlinie und enden im tuberculum opticum der anderen Seite. Sie bilden die commissura anterior, welche nach KENYON Vrallanes bei Vespa entdeckte.

Protocerebrum und lobus opticus werden durch den tractus opticus anterosuperior verbunden. Die Fasern dieses Bündels entspringen aus Ganglienzellen (Fig. 107, a), welche oberhalb des tuberculum opticum und unter dem calyx externus gelegen sind. Diese Ganglienzellen senden ihren Fortsatz zwischen die pedunculi des äußeren und inneren Bechers, wo er den calyces einen Seitenast überliefert. Der Fortsatz selber läuft weiter zum lobus opticus um in der medulla extema zu enden.

Die beiden medullae internae werden durch zwei Kommissuren, die commissura optica superior und die commissura inferior verbunden.

Oberhalb des corpus centrale läuft eine Kommissur, die commissura dorsocerebralis superior, worüber DIETL, BERger und BeLtoxer nach Kexrox mit Unrecht urteilten, daß sie die lobi optici verbände. Auch KExrox blieb der Ursprung und das Ende der Kommissur verborgen, aber dennoch glaubt er, es sei eine Kommissur der corpora pedunculata und er behauptet, daßer darin VIALLANes folgt. Ich meine, die Kommissuren sollen erst viel eingehender studiert werden, ehe man sie mit anderen homologisiert oder anderen gegenüberstellt und dazu kamn die Bemerkung KExyoxs beitragen, daß die Fasern dieser Kommissur teilweise vor und teilweise hinter den pedunculi laufen.

Die Antemnalganglien werden nach KExyox verbunden durch die commissura dorsocerebralis inferoanterior und inferoposterior. Wäre das nicht vielleicht die Antennalkommissur so vieler anderer Autoren? Um auf diese Frage zu antworten, sollte man die Ganglienzellen dieser Nervenfasem kennen und diese nennt kisyox uns nicht.

Die Antennalganglien werden nach KExYox bei der Biene durch drei tractus mit dem protocerebrum verbunden. Bei anderen Insekten wurden sie 
HEXAPODA, HYMEXOPTERA.

309

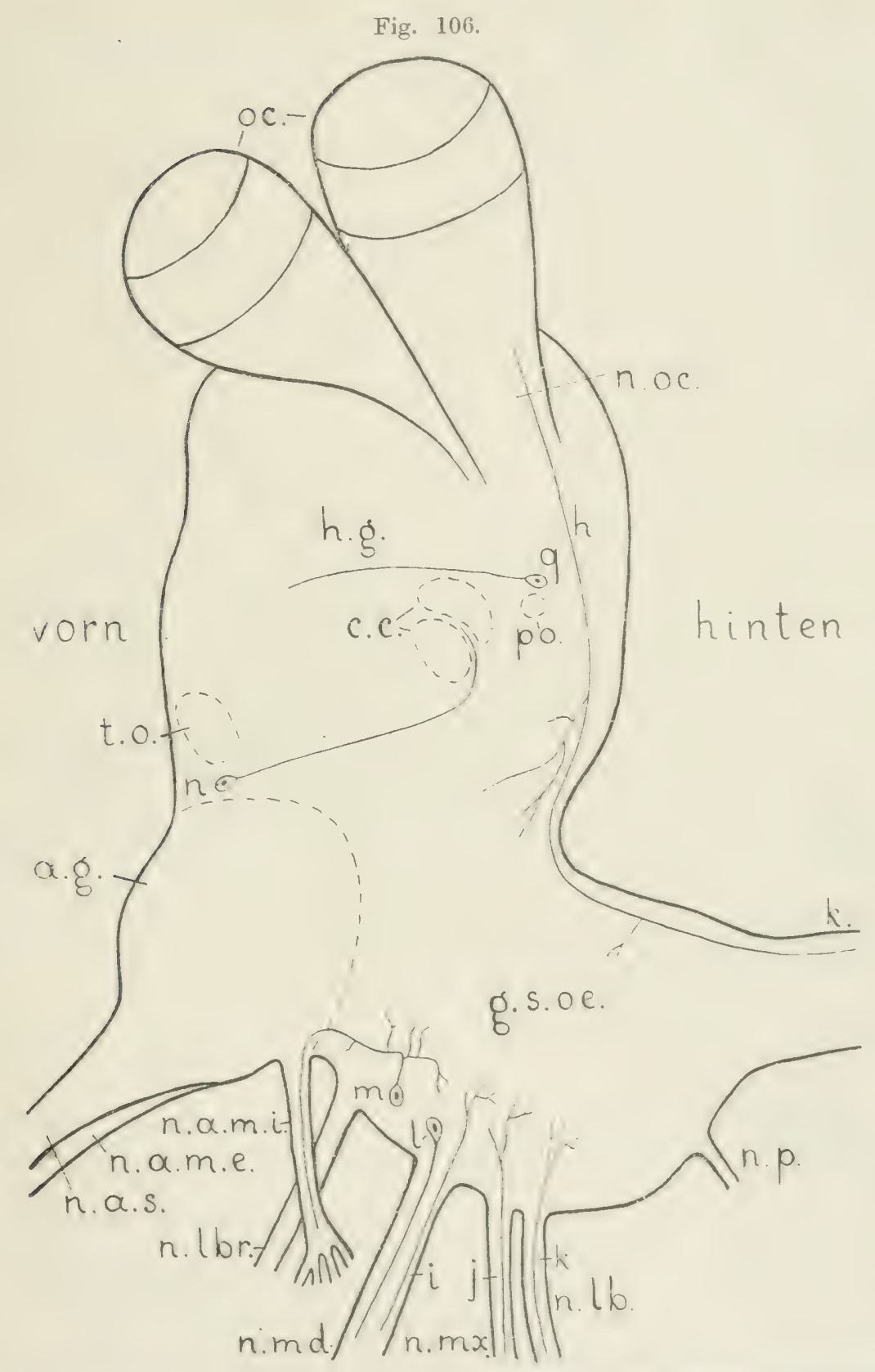

Einige Leitungsbahnen im Gehirn von Apis mellifica. Abgeändert nach KEvyoN (1896b), Taf. 20. Seitenansicht des durchscheinend gedachten Gehirns.

$h, i, j, k=$ Nervenfasern $l, m, n, q=$ Ganglienzellen $\quad a . g .=$ Antennalganglion c. c. = corpus centrale g. s. oe. = ganglion suboesophageum h. . $_{\text {. }}=$ Hirnganglion $k$. - Kontorius internus a $s_{s}=$ nervus antennarius sensibilis $n$. $l b$. = nervus labialis $n$. $l b r$. = nervus labralis $n$. md. = nervus mandibularis n. $m x_{0}$ = nervus maxillaris $n_{0} o c_{0}=$ nervus ocellaris $u_{0} \mu=$ nervus posterior oc. $=$ ocellus po. $=$ pons t. $0 .=$ tuberculum opticum 
immer unrichtig beschrieben, nur VIALlanes macht eine Ausnahme. Das erste System vereinigt die glomeruli mit dem calyx internus, das zweite das Antennalganglion mit dem calyx externus. Leider sind beider Ursprungszellen unbekannt. Das dritte läuft am meisten lateral und geht aus Ganglienzellen des Antennalganglions hervor (Fig. 105,g) um im äußeren, vielleicht auch im inneren Becher zu enden.

In den peripheren Nerven entdeckte KExyon die nachstehenden Leitungsbahnen. Die drei Ozellen liegen so dicht neben einander, daß die Ozellarnerven bald verschmelzen. Fasern des mittleren Ozellus enden in den tubercula corporis centralis (Fig. 105, t.c.c.) andere ziehen wahrscheinlich in die Briicke (Fig. 105, po.). Nervenfasern der lateralen ocelli (Fig. 106, $h$ ) gehen u. a. zum Unterschlundganglion und weiter in den Bauchstrang.

Fasern, welche mit dem Labralnerven ins tritocerebrum eintreten, bilden ihre Endverästelungen unter der Wurzel des motorischen Antennalnerven oder im unteren Schlundganglion. Sie sind also wohl sensibel.

Sensibel scheinen mir gleichfalls die Nervenfasern, welche mit dem nervus mandibularis. maxillaris und labialis mitkommen und sich bald nach ihrem Eintritt verästeln (Fig. 106, $i, j, k$ ). Neben der Wurzel des Mandibularnerven liegen außerdem einige Ganglienzellen (Fig. 106, $l$ ), welche ihre:Fortsätze dem Nerven beimischen, wie solches später von Joxescu (1909) bestätigt wurde.

Lateral im tritocerebrum wies Kexyox eine (xanglienzelle (Fig. 106, m) nach, deren Neurit in den inneren motorischen Antennalnerven überging.

Kenyos beschreibt in seiner übrigens so trefflichen Arbeit leider niemals Neuronen, sondern immer nur Fasersysteme oder Ganglienzellgruppen. Nur ziemlich selten erwähnt er, welche Fasern mit welchen Zellen zusammenhängen und nur dann sind nach meiner Ansicht sowohl Zellen wie Fasern für andere wicderzuerkennen. Die bis jetzt beschriebenen Neuronen sind seinen Angaben der Fasersysteme entlehnt; die nachstehenden sind unter seinen Beschreibungen der Ganglienzellgruppen zu finden.

Neben den Ursprungszellen des tractus opticus anterosuperior (Fig. 107, a) liegen Ganglienzellen, welche die Fortsiitze zur Medianebene des Gehirns sendert.

Halbwegs des tubereulum opticum und der medulla interna sind Ganglienzellen, deren Fortsätze oberhalb des Vorderhorns des pedunculus verzweigt enden.

Lateral neben und unter dem tuberculum opticum fand Kexrox Ganglienzellen mit Fortsätzen. welche unter dem cornu anterius liefen : median neben und unter dem tuberculum opticum Ganglienzellen mit Fortsätzen, welche die Außenseite des Vorderhorns entlang liefen.

Zwischen tubereulum opticum und Antemalganglion sind drei Ganglienzellgruppen. Die Zellen (Fig. 106, 11 ) senden die Fortsiitze zwischen die beiden Teile des corpus centrale.

Ganglienzellen unter dem ealyx externus (Fig. 105, o) fïgen die Fortsätze den Neuriten der Ganglienzellen y bei (lig. 105), aber weiter sind ihre lVege unbekannt.

Hinter den pedunculi ist eine Ganglienzellgruppe wahrnehmbar, deren 
Zellen Fortsätze zwischen den Stielen hindurch zum Vorderhorn schicken. Der Ganglienzelltypus p (Fig. 105) ist vor der pons gestellt und er sendet die Fortsätze mit mit dem Bündel, welches den calyx internus mit den glomeruli verbindet.

Fig. 107.

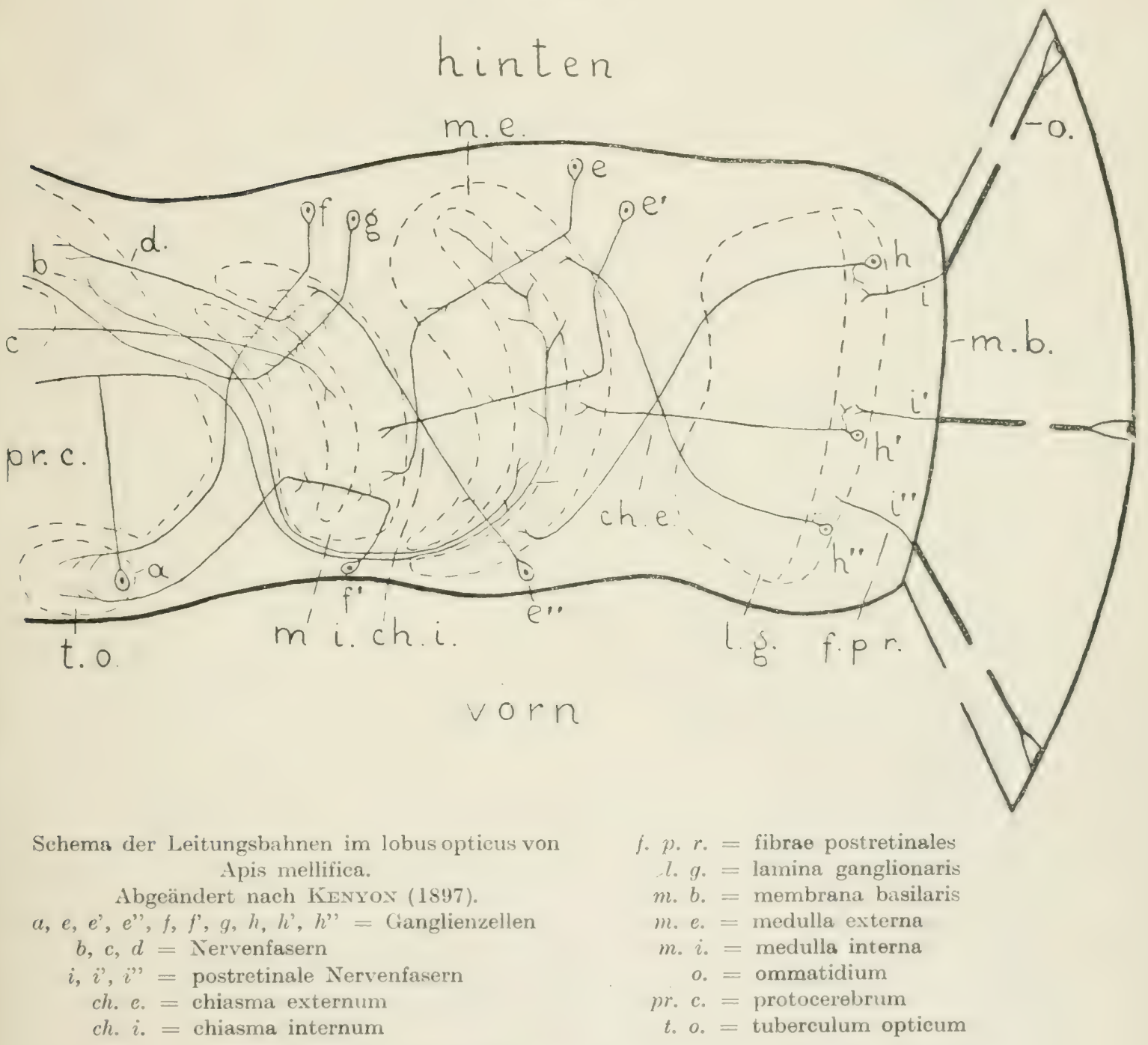

Der Ganglienzelltypus $q$ (Fig. 106) ist ïber dem Ende der pons gelegen und seine Fortsätze enden oberhalb des Vorderhorns.

Unter der pons sah Kexyox eine Ganglienzellgruppe, deren Zellen (Fig. $105, r)$ Fortsätze aussenden, welche, bisweilen in der commissura optica superior, kreuzen und zur Vereinigungsstelle der pedunculi und comua der corpora pedunculata der anderen Seite ziehen. 
Hinter den Ganglienzellen des Typus $p$ befinden sich Ganglienzellen, welche die Fortsätze nach unten richten, wahrscheinlich zum corpus centrale. Unter diesen Ganglienzellen liegen wiederum andere, deren kortsätze unter die commissura optica superior umbiegen und wahrscheinlich zu den ealyces ziehen.

Median im Antennalganglion gelagerte Ganglienzellen senden'ihre Neuriten median nach oben, wo sie über das Innenhorn hinbiegen. Ich betrachte die Kenyoxsche Zelle 9 als eine Zelle dieser Gruppe und bilde sie hier in Fig. 105 als Zelle $s$ ab.

Im unteren Schlundganglion endlich konnte KENYOx sieben Ganglienzellgruppen unterscheiden. Zwei liegen ventromedian neben den Wurzeln der Maxillar- und Labialnerven und ihre Zellen senden die Fortsätze zur dorsalen Seite.

Dem lobus opticus von Apis mellifica hat Kexyox (1897) einen Aufsatz für sich gewidmet und seine Resultate hat er wiederum mit Hilfe der GolgIschen Methode erworben. Die mikroskopische Anatomie des lobus opticus ist uns schon von anderen Insekten her bekannt. Die Ommatidien (Fig. 107, o). der Retina des zusammengesetzten Auges sitzen alle auf der Basalmembran (Fig. 107, m.b.). Darunter liegt die Schicht der postretinalen Nervenfasern (Fig. $107, f . p . r$.$) . Es folgen dann lamina ganglionaris (l . g$.$) , chiasma externum$ $\left(c h . e_{0}\right)$, medulla externa $\left(m . e_{*}\right)$, chiasma internum $\left(c h . i_{.}\right)$und medulla interna $(m . i$.) in der bekannten Ordnung. Wie Figur 105 uns gezeigt hat, schließt sich die medulla interna unmittelbar dem protocerebrum an (Fig. 107, pr.c.). In Fig. 107 sieht man das tuberculum opticum $(t .0$.$) darin angedeutet.$

KExyox fängt an mit der Beschreibung des tractus opticus anterosuperior, welcher ihm schon vordem bekannt war. (vergl. S. 308). Der tractus verbindet die calyces der corpora pedunculata der einen Seite mit dem Zentrum der medulla externa derselben Seite und es ergibt sich, daß jede seiner Fasern ein Teil eines 'T-förmigen Fortsatzes einer Ganglienzelle ist, welehe oberhalb des tuberculum opticum und unter dem calyx externus gelegen ist. (Fig. 107,a).

Es gibt auch einen tractus opticus anteroposterior, dessen Fasern (Fig. 107,b) sowohl im protocerebrum, wie in der medulla externa ihre Endverästelungen entfalten. Die Ursprungszellen dieser Zellen sind leider unbekannt.

In der medulla interna enden Nervenfasern (Fig. 107, c), welche sich in das protocerebrum begeben und dort wenigstens teilweise durch die commissura optica kreuzen und in die medulla interna der anderen Seite ïbergehen. Auch hier sind die Ganglienzellen, woraus diese Fasern hervorgehen noch zu suchen. Kexyox behauptet, daß3 VIALLAxes dieses Bündel schon gekannt habe, aber er hat den $\mathbf{W e g}$ dieser Fasem gewiß nicht genügend nachgewiesen.

Fasern unbekannter Herkunft sind auch die Fasern d der Figur 107 , welche in der medulla interna, sowie im protocerebrum enden. KExyos vermutet, daß ihre Ganglienzellen neben der medulla interna stehen.

Noch andere Fasersysteme gehen von der medulla interna zum tuberculum opticum oder von der medulla interna zu den calyces.

Vorn und hinten, auberhalb der medulla externa entdeckte li Exrox Gau- 
glienzellen (Fig. 107, $e, e^{\prime}$ und $e^{\text {") }}$, welche ihren Fortsatz in die medulla externa senden. Diese Fortsätze durchziehen die medulla auf dem kiirzesten WVege, wobei sie den Randschichten Kollateralen überliefern, bilden das chiasma internum und enden in der medulla interna.

Aehnliche Ganglienzellen (Fig. 107, $f$ und f') liegen neben der medulla interna. Ihre Fortsätze ziehen ebenfalls, wenn sie einmal in die medulla interna eindringen, geradewegs hindurch, den Randschichten Kollateralen abgebend, um im tuberculum opticum zu enden. Noch andere Ganglienzellen (Fig. 107,g) unterscheiden sich ton den vorigen nur durch die Tatsache, daß ihr Neurit zuletzt nicht zum tuberculum opticum, sondern zum Neuropilem des protocerebrum schreitet.

Das chiasma externum wird gebildet durch Nervenfasern, welche in der äußeren Schicht der medulla externa enden und Neuriten sind von Ganglienzellen der lamina ganglionaris (Fig. 107, $h, h^{\prime}, h^{\prime \prime}$ ). Die Stammfortsätze dieser unipolaren Ganglienzellen senden ihre Dendriten in die lamina ganglionaris, wo dieselben den Endverästelungen der postretinalen Nervenfasern (Fig. 107, $i, i$ und $i$ ") begegnen.

Aus obigen Angaben kann man mit Kexyox den Schluß ziehen, daß der optische Reiz durch die Retinulazelle des Ommatidium empfangen und in ihren Nervenfortsatz, der postretinalen Nervenfaser (i, Fig. 107), weitergeführt, entweder durch die Fortsätze der Ganglienzellen $h$ und $a$ zu den Bechern des protocerebrum geleitet werden kann, oder durch die Ganglienzellen $h^{\prime \prime}, e$ und f' zum tuberculum opticum oder endlich durch die Elemente $h, e^{\prime \prime}$ und $d$. zum Neuropilem des protocerebrum. Zweifelsohne sind dies nur Beispiele von optischen Leitungsbahnen und werden später noch weitere entdeckt werden.

Ich werde die Resultate Kenyoss, insofern sie den lobus opticus anbelangen, am Schluß meiner Besprechung der Inseliten (S. 332) mit denjenigen anderer Forscher vergleichen.

Haller (1905) hat eine Schilderung des Baues des Gehirns der , höheren Insekten" gegeben, welcher Schilderung hauptsächlich das Studium des Gehirns von Apis mellifica zugrunde lag. Weil es mir beim jetzigen Stande unserer Kenntnis noch nicht erlaubt scheint, was man hier und dort bei einigen wenigen Insekten beobachtet hat, $\mathrm{zu}$ verallgemeinern, bevorzuge ich es, die Angaben Hallers alle auf die Biene zurückzuführen. Manche treffen aber auch für andere Insekten (Vespa, Periplaneta) zu.

HaLler gibt eine Beschreibung des Bienengehirns, welche ganz gut zu der Kexyosschen stimmt und durch die Figuren 105 und 106 illustriert werden kann. Die corpora pedunculata (globuli nach HALLER) sind besonders groß und das Neuropilem derselben bildet zwei tiefe, durch eine Ganglienzellschicht getrennte Becher. Das corpus centrale (Zentralganglion nach HALI.ER) besteht aus einem dorsalen und einem ventralen Neuropilem mit einer Ganglienzellschicht dazwischen. Dorsal vom Zentralkörper läuft nach HALLER die dorsale Kommissur, ventral von demselben die ventrale Kommissur, mit der Antennalkommissur verbunden. Die Schlundkonnektive sind stark verkiirzt, sodal3 das untere Schlundganglion sich dem Hirnganglion unmittelbar anschliel3t und das tritocerebrum in den Hintergrund gerät. Auch ist die par's intercere- 
bralis, zwischen und vor den corpora pedunculata der beiden Seiten wenig entwickelt, weil die mediane Ozelle dem Gehirn unmittelbar obliegt. HALLER beschreibt auch den Bau des lobus opticus in einer Weise, welche mit der Kenyonschen Dảrstellung übereinstimmt und also durch Fig. 107 hinreichend wiedergegeben wird.

Die Fortsätze der Ganglienzellen der corpora pedunculata verästeln sich bald und stehen nach HALLER schon im Neuropilem der Becher mit Fortsätzen von Ganglienzellen aus anderen Hirnteilen in Verbindung. Das stimmt mit den Kenyonschen Angaben und geht auch aus der Figur 105 hervor. Einige Ganglienzellen der corpora pedunculata senden Fortsätze aus, welche in zwei Biindeln zum I nterschlundganglion ziehen, während umgelehrt hier Ganglienzellen aufzufinden sind, welche ihre Ausläufer in die Stiele der corpora pedunculata senden.

HALLER entdeckte bei der Biene Nervenfasern, welche aus dem corpus pedunculatum zur medulla interna des lobus opticus zogen. In der obengenannten dorsalen und ventralen Kommissur laufen nach ihm Fasern, welche die lobi optici von links und rechts vereinigen.

Die Ausläufer von Ganglienzellen der par's intercerebralis waren oft für HALLER auf größeren Strecken zu verfolgen. Einige dieser Zellen senden Fortsätze zu den lateralen oder medianen Ozelle, wobei letztere von links und rechts Nervenfasem bekommt. Die Fortsätze dieser Zellen verästeln sich und nach HALLER hängt jeder Zweig mit einer bipolaren Ganglienzelle zusammen, welche ihrerseits eine Sehzelle innervieren soll. Weil wir sicher wissen, daß die Sehzellen Sinnesnervenzellen sind, erregt diese Vorstellung HaLlers viel Zweifel. Dieselben intercerebralen Ganglienzellen, welche den Ozellen Fortsätze zusenden, senden andere Fortsätze zum Bauchstrang. Nach Haller hat schon KExyox diese Fasern (Fig. $106, h$ ) beobachtet.

In der pars intercerebralis fand HALLER andere Ganglienzellen, welche mit ihrem Fortsatz die medulla interna des lobus opticus derselben oder der gekreuzten Soite suchen, oder aber beiden medullae internae einen Ast überlieferten.

Noch andere Ganglienzellen der pars intercerebralis haben Fortsätze, welche durch den \%entralkörper oder daneben in die Stiele der corpora pedunculata ziehen. Achnliche Zellen sind mit Ausliufern ausgestattet, welehe sofort kreuzen und damn das Bündel, welches die corpora pedunculata mit dem Unterschlundganglion verbindet, benutzen um den pedunculus zu erreichen.

Ganglienzellen der pars intercerebralis senden Fortsätze in das Neuropilem des Antennalganglions derselben Seite oder durch die Antennalkommissur in das Intennalganglion der anderen Seite. Umgekehrt senden Ganglienzellen des Antemnalganglions die Fortsätze zur pars intereerebralis.

So ist auch die pars intercerebralis durch ein doppelläufiges Bündel mit dem unteren Schlundganglion verbunden.

Vicle Fasem verbinden verschiedene Teile des protocerebrum untereinander. So senden hateral im protocerebrum gestellte Ganglienzellen fortsiitze durch die dorsale Kommissur zu den corpora pedunculata der anderen Seite oder durch die ventrale hommissur zum Neuropilem der anderen Seite. 
Ventrale Ganglienzellen haben Ausläufer, welche zu dorsalen oder lateralen Teilen des Neuropilems derselben oder der gekreuzten Seite ziehen oder zum Zentralkörper.

Ueber das corpus centrale teilt Hallen uns Folgendes mit. Es ist durch ein Faserbündel mit dem unteren Schlundganglion verbunden und die Ursprungszellen dieses Bündels liegen wenigstens teilweise im unteren Schlundganglion. Seitenäste der Fortsätze dieser Zellen ziehen in einem Bogen zum protocerebrum und bilden so den , vorderen Bogen". Diesem vorderen Bogen mischen sich Fasern bei, welche Fortsätze sind von Ganglienzellen der pars intercerebralis und von medianen und lateralen Ganglienzellen des ganglion suboesophageum. Die Fortsätze der lateralen Ganglienzellen haben Seitenäste, welche kreuzen und im Neuropilem enden.

Ganglienzellen des Antennalganglions senden ebenfalls die Fortsätze ins corpus centrale und weil also der Zentralkörper mit manchen Gebieten verbunden ist, sieht HALLER darin ein Assoziationszentrum.

Es bleibt mir noch übrig die Bahnen des Antennalganglions zu beschreiben. Nach Haller suchen die Fortsätze mancher Ganglienzellen des Antennalganglions das Unterschlundganglion. während dort gelagerte Ganglienzellen Fortsätze aussenden, welche zwischen den glomeruli des Antennalganglions enden.

In der Antennalkommissur laufen Nervenfasern, welche Ganglienzellen des einen Antennalganglions mit dem Neuropilem des anderen verbinden.

Wiederum andere Ganglienzellen des Antennalganglions haben Fortsätze, welche in dem von HALLER entdeckten ,, hinteren Bogen” laufen, durch die dorsale Kommissur kreuzen und dann im Neuropilem enden.

Nach HalLER nehmen die glomeruli Fortsätze mancher Ganglienzellen des Antennalganglions auf und sind, wie er immer glaubt, auch die dortigen Ganglienzellen untereinander unmittelbar durch Fortsätze vereinigt.

In dem Antennalnerven befinden sich nach ihm solche Fasern, welche in den glomeruli enden (vergl. Fig. 105, f) neben solchen, welche aus Ganglienzellen des Antemnalganglions hervorgehen. Letztere sind vielleicht die Fasern, deren Ursprung Kexyox nicht erforschen konnte. (S. 308).

Ueber den Tritocerebralnerven meldet HALLer uns, daß er nur Fasern fïhrt, welche im tritocerebrum enden. Er wäre dann rein sensibel. Wenn man aber Jonescu (1309) glauben kann, hat HALLER nicht den richtigen Namen angewandt und nicht den nervus labralis (Kexyos, Fig. 106) oder labrofrontalis (JoNEscu), sondern den motorischen Antennalnerven Tritocerebralnerven genannt, in welehem Falle natürlich auch motorische Nervenfasern da sein würden.

Als letzter hat JonEscu (1909) Untersuchungen und zwar vergleichende über das Gehirn von Apis mellifica vollbracht. Ich ergreife diese Gelegenheit zu melden, daß diese Arbeit aus dem ZiegLersehen Laboratorium stammt, woraus viele wertvolle und gedankenreiche Studien iiber das Nervensystem der Evertebraten uns erreicht haben (Z. B. BoETTGER (1910), P'IETSCInER (1911) und BretschNeIDER (1914).

Jovescu hat Schnittserien verfertigt und Silbermethoden angewandt. Er fängt damit an das Gehirn der Bienenkönigin, der Arbeitsbiene und der 
Drohne anatomisch zu beschreiben und die Unterschiede aufzuzählen. Weil die Differenzen wohl in der Größe einiger Hirnteile, aber nicht oder sehr wenig in ihrem Bau zu finden sind (die Drohne hat z. B. weniger glomeruli im Antennalganglion als die Arbeitsbiene) sind die Leitungsbahnen im allgemeinen dieselben. Es wird für die anatomischen Besonderheiten auf das Original verwiesen.

Joxescu nennt das chiasma interna das mittlere Chiasma, weil er hinter der medulla interna noch eine dritte Kreuzung der optischen Nervenfasern zu sehen glaubt. Was er damit meint, lehrt uns schon die Figur 107. Zugleich aber geht daraus hervor, daß die dritte Kreuzung nicht den beiden anderen gleichzustellen ist, denn sie wird nicht gebildet durch gleichwertige Nervenfasern (wie $f$ und $f^{\prime}$ ), wio solches im chiasma externum und internum der Fall ist $\left(h, h ', h^{\prime \prime}\right.$ und $\left.e, e^{\prime}, e^{\prime \prime}\right)$ und ohne welche man nicht von einem Chiasma im lobus opticus reden darf. Ich erkenne hier also nur zwei chiasmata an, aber man wird sich erinnern, daß PARKER bei Astacus (S. 225) wirklich ein drittes Chiasma gleichwertiger Nervenfasern fand.

Die zwei corpora pedunculata, Assoziationszentra oder Intelligenzorgane, welche bei der Arbeitsbiene mehr entwickelt sind als bei der Königin und bei dieser wiederum mehr als bei der Drohne, enthalten wie bekannt, becherförmige Neuropileme. In diesen Bechern befinden sich nach Jon Escu Ganglienzellen (wie die Zelltypen $a$ und $a$ ', Fig. 105 nach KenYoN), deren Neuriten in den pedunculus und zu anderen Hirnteilen laufen. Ebenso bestätigte er den Kexyosschen Befund, daß an der Außenseite der calyces Ganglienzellen liegen, welche ihren Fortsatz ins Neuropilem des Bechers senden; nach ihm endet er daselbst verzweigt. Neben den Randteilen der Becher fand Jonescu Ganglienzellen, deren Fortsatz zum anderen Becher desselben Paares zog. Diese merkwiirdigen Zellen setzen also die beiden Becher desselben Paares in Verbindung, ebenso wié Fasern der dorsalen Kommissur die corpora pedunculata von links und rechts verbinden.

Daß es Nervenfasern gibt, welche die Becher mit dem lobus opticus verbinden, gibt Joxescu sowohl Kenyon als HALLer zu, aber iiber die Besonderheiten dieser Verbindung läßt er sich nicht aus.

Betreffs der Fasern der Ozellarnerven lehrt Joxescu uns wiederum etwas andres als Kexyox oder Halter. Er sagt, daß diese Fasern im Gehirn ein chiasma bilden und zwar in der ,Ozellarnervenbriicke", das heißt in der pons.

Ueber den lobus opticus teilt Jonescu uns Folgendes mit. In der lamina ganglionaris (äußeren Wibrillarmasse nach Joxescu) liegen nach ihm keine mipolaren Ganglienzellen, wie KExyox darin begegnete (Fig. 107, h), sondern bipolare Ganglienzellen, welche einen Fortsatz in die Bündel der postretinalen Nervenfasern senden und den zweiten durch die lamina ganglionaris hindurch in das chiasma externum. Diese Angabe stimmt ibberein mit dem was HarLeR bei der Libelle Gomphus (S. 283, Fig. 98, $a, b, c, d$ ) sah. Sonst haben alle Forscher in der lamina ganglionaris nur unipolare Ganglienzellen gefunden.

Im ganglion cuneatum (keilförmigen Ganglion), wie man weiß eine Ganglienzellgruppe zwischen den Fasern des chiasma externum vor der medulla externa gelegren und also zur äuberen Rinde dieser medulla grehörig, befinden 
sich nach Joxescu Ganglienzellen, deren Stammfortsatz sich spaltet in einen Ast, welcher in das chiasma externum tritt und einen anderen, welcher in die medulla externa (mittlere Fibrillarmasse) taucht oder selbst in das chiasma internum eintritt.

Nebon der medulla interna (immeren Fibrillarmasse) sah Joxescu Ganglienzellen mit geteiltem Stammfortsatz. Der eine Ast zog in das chiasma internum. der andere in die medulla interna. Die beiden letzterwähnten Ganglienzelltypen wurden weder bei Apis noch bei einem anderen Insekte von anderen Forschern gefunden.

Die beiden lobi optici werden verbunden durch Nervenfasern, welche in der hinteren Kommissur die Medianlinie überschreiten. JoNescu erkennt neben dieser Kommissur und der ebenfalls schon erwähnten dorsalen Kommissur eine ventrale und eine vordere Kommissur. In der vorderen Kommissur befinden sich nach ihm Fortsätze von Ganglienzellen des protocerebrum.

Ebenso wie Kexyox und HaLler sieht auch Jonesce Faserbündel, welche das Antennalganglion mit dem protocerebrum verbinden. Die Faseru, deren Ursprung JoxEscU erforschen konnte, gingen alle aus Ganglienzellen des Antennalganglions hervor. Sie sind in zwei Bündel zusammengefaßt, welche Joxescu den funiculus antennalis superior und inferior nennt.

Der funiculus antennalis superior spaltet sich in drei Bündel. Das erste geht zur medulla externa und interna des lobus opticus derselben Seite, das zweite zu den Stielen der Becher und das dritte zum lobus opticus der anderen Seite. Das zweite Bündel war wohl auch von Kenyon (Fig. 105, g) und Haller beobachtet worden, aber genaue Identifikation fällt mir schwer, weil nach JoxESCU auch der funiculus antennalis inferior zu den Bechern der corpora pedunculata geht und auch dieser wohl gemeint sein kann. Die Dendriten der Ganglienzellen, woraus der funiculus antennalis inferior hervorgeht, gehen zu den glomeruli. Nicht der ganze funiculus zieht in die Becher, sondern ein Teil bleibt im Neuropilem des protocerebrum und steht dort mit optischen Fasern in Verbindung.

Die motorischen Fasern des nervus antennarius sah Jovescu aus Ganglienzellen des Antennalganglions entspringen. Sie bilden zwei Bündel, eins zum basalen Gliede der Antenne und eins zu den anderen Gliedern.

Ueber die Nerven, welche aus dem deutero- und tritocerebrum, sowie aus dem Unterschlundganglion hervorgehen, herrscht sehr viel Uneinigkeit. JoNescu erkennt zwei Paar Antennalnerven, während KExyox im Stande war drei Antennalnerven (vergl. Fig. 106) zu unterscheiden. Aus dem tritocerebrum entspringt der 'Tritocerebrahnerv. Darunter versteht KENYON den Labralnerven, welchen Nerven Joxescu Labrofrontalnerven nennt, aber HALLER betrachtet nach Joxesce den motorischen Antennalnerven irrtïmlich als Tritocerebralnerven und JAxET nennt so bei der Ameise den Nerven, welcher den musculus dilatator inferior pharyngis innerviert. Auch werden Nerven des ganglion suboesophageum oft ungenau beschrieben. Ich brauche darauf nicht einzugehen, weil die Leitungsbahnen dieser Nerven doch nicht bekannt sind.

Nach Joxescu erhält der Labrofrontalnerv (Fig. 106, n. $l 6 r$.) motorische 
Nervenfasern aus Ganglienzellen, welche hinter dem deuterocerebrum und also im tritocerebrum gelegen sind. Ventral im unteren Schlundganglion befinden sich nach ihm Ganglienzellen, welche ihren Neuriten in den Mandibular-, Maxillar- oder Labialnerven senden und ihre Dendriten ins Neuropilem des Unterschlundganglions. Die Zellen des Mandibularnerven hat KENYON (Fig. 106, l) wahrscheinlich schon beobachtet.

Was JoNescu an Bruchteilen von Neuronen beschrieben hat, lasse ich wiederum fort.

Einige Teile des peripheren Nervensystems der Biene haben in jüngster Zeit Bearbeitung gefunden. So hat S.HöN (1911) den Bau des tibialen Chordotonalorgans untersucht. Weil er aber hauptsächlich Ameisen zu seinen Forschungen verwandt hat und er zwischen Bienen und Ameisen keine Unterschiede fand, verweise ich den Leser auf meine Behandlung der Ameisen (S. 321).

Mc INDoo (1914) hat in jeder der Riechporen, welche an versehiedenen Stellen des Bienenkörpers vorkommen eine Sinnesnervenzelle entdeckt, welche sich in eine Nervenfaser fortsetzt. Die Sinnesnervenzelle ist deutlich bipolar und oft liegen die Zellkörper in einiger Entfernung unter den Poren. Ich glaube, MIC INDoo hat hier unzweifelhaft Sinnesnervenzellen nachgewiesen.

Neben der Biene hat unter den Hymenopteren auch die Wespe (Vespa) oft die Aufmerksamkeit auf sich gezogen.

Grenacher (1879) hat konstatiert, daß bei Vespa communis und ebenso bei Crabro cribarius, welcher mit Vespa, Apis und Formica zu rien Aculeaten, einer Unterabteilung der Hymenopteren gerechnet wird, die Retinazellen der Ozellen sich in Nervenfasern fortsetzen und also Sinnesnervenzellen sind.

Buetschu (1885) hat gemeint in den Rieehorganen der Antennen von Vespa crabro bipolare Sinnesnervenzellen zu entdecken, welche durch ihren zentralen Fortsatz mit einem tiefer liegenden Gianglion in Verbindung ständen. Ebenso beschrieb Vom RaTr (1895) in den Antemen von Ichneumon (einem der 'Terebrantia), Vespa und Anthophora und Eucera (ebenso wie die Honigbiene Apiden) unter den Kegeln und Membrankanälen. wie gewisse Typen von Simmesharen genannt werden, bipolare Sinnesnervenzellen mit Simnesfortsïzen bis zu spitze des Hares. Man weiß, daß und warum ich die BuETschLIschen und Vow Ratuschen Angaben bezweifle (vergl. die Einleitung dieses Kapitels).

SCHOEN (1911) fand die Chordotonalorgane der Wespen ebenso wie diejenigen der Ameisen gebaut und ich verweise also abermals auf diese 'Tiergruppe.

Die Hodologie des Zentralnervensystems von Vespa ist nur von VIALLANes (1887a) studiert worden und auch dieser Gelehrte hat mehr die mikroskopisehe Anatomie des Gehirns beschrieben und mit schönen Abbildungen illustriert, als daß3 er dio Wege der Leitungsbahnen verfolgt hat. VIALLANEs arbeitete mit Vespa crabro und vulgaris ohne auch einen einzigen Unterschied im Hirnbau zwischen beiden zu beobachten. Natiorlich zeigt der Bau des Gehirns der Wespen die allgemeinen Verhältnisse der Hymenopteren, worauf ich nach meiner Beschreibung von Apis nicht einzugehen brauche.

Was Viatanes uns üher den Verlauf der Nervenfasem mitteilt, hat meistens nur geringen Wert. Veber den lobus opticus finde ich Folgendes erwïhnt. Die postretinalen Jervenfasern durchziehen nach ihm die laminn ganglionaris und werden fiasern des chiasma externum um in die medulla externn einzutreten. Dieses lïß3t sich bezweifeln auf Grund unserer Kenntnis dieser Nervenfasern bei anderen Insekten. Wahrscheinlich unclen die postretinalen Nervenfusern schon in der lamina ganglionaris. Daß3 die Zellen der ..masse ganglionaire antérieure", einer Ganglienzellgruppeneben der medulla externa, ihre fortsätze in die medulla externa senden, ist sehr glaubwirdig, aber nicht sehr wichtig, ebensowenig wie die Bemerkung, daß (ianglienzellen neben der medulla interna ihre

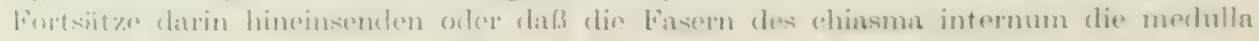


externa und interna verbinden. Wichtiger ist die Entdeckung, daß eine Kommissur di lobi optici und zwar die medullae internae von links und rechts verbindet.

Im protocerebrum sah V'LALLANFs die corpora peduneulata und in der Höhlung der beiden calyces Ganglienzellen, welche ihre Fortsätze ins Neuropilem der Becher sandten. Ein ähnliches Verhältnis also wie bei der Biene. aber Vidtuxes sah auch die pedunculi mit Ganglienzellen belegt, deren Fortsätze in clic Stiele eintraten und das war bei Apis nicht der Fall.

VIALlaxes sah die corpora pedunculata von links und rechts dureh eine verbunden und wir wissen, daß Kevros und Jostscu diese Kommissur bei der Biene beobachtet haben. Im protocerebrum fand er weiter eine obere und eine untere Kommissur erstere teils vor, teils hinter dem corpus centrale laufend.

In beiden Hälften des protocerebrum sah VIALLANES ein besonderes Neuropilem, daß er tuberculum opticum nannte, weil es durch Nervenfasern mit dem lobus opticus verknuipft war. Er entdeckte auch schon die Kommissur zwischen den beiden tubercula optica, welche später bei der Biene von KExyor commissura anterior genannt wurde.

In der Peripherie des protocerebrum liegen Ganglienzellgruppen. Was. VIALLAxes über die Wege ihrer Fortsätze sagt, bedarf der Bestätigung, weil seine Methoden unzureichend waren. So meldet er hinten im protocerebrum Ganglienzellen mit Fortsätzen in den pedunculi; median gestellte Zellen senden íhre Fortsätze ins corpus centrate, wiederum andere Zellen in das Antennalganglion (lobus olfactorius) oder in andere Hirnteile. So findet man nach VIALLANes bei Vespa auch Nervenfaserbündel in den Schlundkonnektiven, welche im jrotocerebrum kreuzen, aber gerade für Nervenfaserm. welche auf so langen Strecken verfolgt sein sollen, ist es sehr notwendig, daß sie auch mit anderen Methoden nachgewiesen werden.

Ueber das deutero- und tritocerebrum kann ich kurz sein. Das tritocerebrum der Wespe ist sehr mangelhaft entwickelt. In der Rinde des Antennalganglions sah VIALLAvEs Ganglienzellen mit Fortsätzen im Neuropilem, aber weiter konnte er ihnen nicht folgen.

Auch über die Ameisen liegen einige, sei es auch spärliche Angaben vor.

Vou RAti (1895) behauptet) auch bei Formica Sinnesnervenzellen unter' rer'schiedenen Sinneshaaren der Antenne gesehen zu haben.

Pietschker (1911) hat das Gehirn von Camponotus ligniperdus teilweise mit silbermethoden bearbeitet. Dessenungeachtet hat er wohl manche Besonderheiten der mikroskopischen Anatomie des Gehirns entdeckt und das Gehirn der Arbeiterin höher entwickelt gefunden als dasjenige des Weibchens und dieses wiederum besser als chs Gehirn des Männchens, was auf Größenunterschiede der lobi optici und corpora pedunculata zurückzuführen war, aber Reizleitungsbahnen hat er nicht nachgewiesen und ich beschränke mich darauf seine Arbeit als einen guten, modernen, aber nicht hodologischen Aufsatz anzuzeigen.

Mehr Resultate hinsichtlich der Leitungsbahnen hat Fräulein Thompsos (1913) gehabt, obgleich sie keine spezifischen Nervenfärbungen anwandte. Sie hat Puppen von drei Ameisenarten, Camponotus, Formica und Lasius als Naterial gewählt. Im protocerebrum erkennt sie nur zwei Kommissuren an. Die eine ist die commissura dorsalis anterior über dem corpus centrale gelegen, welche Fräulein Trompsox homologisiert mit der ,commissure cérébrale supérieure", welche VIALLAxEs, der "superior dorsocerebral commissure", welche Kexrox und der ,dorsalen Kommissur", welche Joxescu bei anderen Insekten beobachtet haben. Fräulein Trompsox weist jedoch den Lauf der Nervenfasern dieser Kommissur, das wichtigste Merkmal für jede Homologisierung, ganz unzureichend nach. Die zweite Kommissur nach 'l'rostesox ist die pons, wie bekannt ein medianes Neuropilem, aber gar keine Kommissur im iblichen Sinne des Wortes. Sie weist darauf hin, daß der Name „Uzellar- 
nervenbrücke", welche Joxescu und Pretschiker der pons zuteilen, nicht immer richtig ist und deshalb nicht mehr gebraucht werden soll; bei der Königin von Lasius niger z. B. haben die Ozellarnerven nichts mit der pons zu schaffen. Auch mir scheint der Name pons der beste.

Fräulein Thompsox hat den corpora pedunculata besondere Aufmerksamkeit gewidmet und Hig. 108, welche ein corpus pedunculatum der Arbeiterin von Camponotus darstellt, soll ihre Angaben illustrieren. Jeder calyx

Fig. 108 .

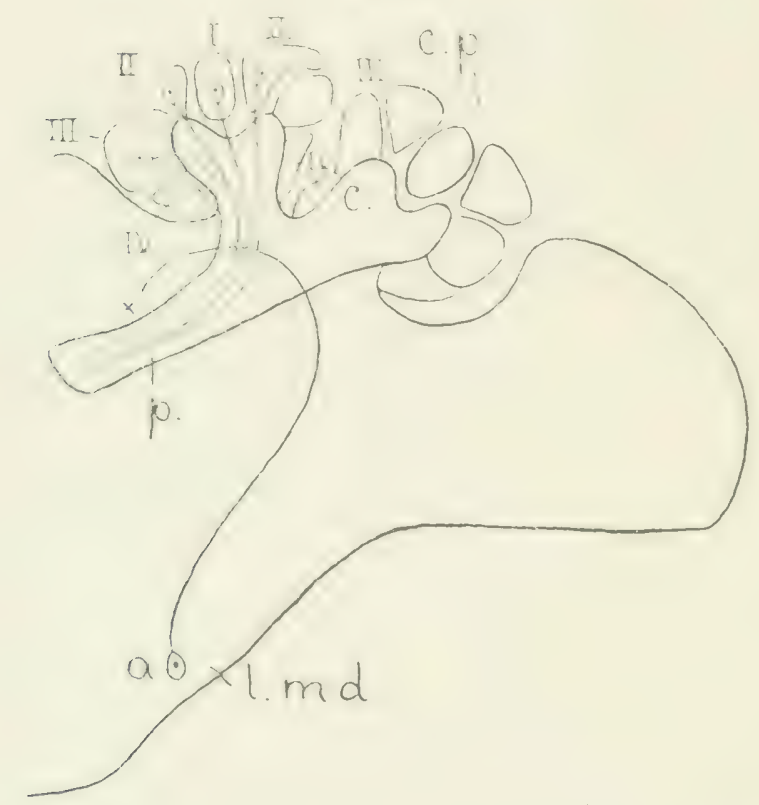

Schematischer Querschnitt durch einen Teil des Gelirns der Arbeiterin von Camponotus pennsylvanicus.

Abgeändert nach Thomrson (1913), Taf. 6, Tig. 33. $a=$ Granglienzelle

I bis $I V=$ Ganglienzellgruppen der corpora pedunculata

c. $=$ calyx

c. $p .=$ corpus peclunculatum

l. $m l$. $=$ lobus mandibularis des ganglion suboeso-

$p .=$ pedunculus

(Fig. 108, c.) wird umgeben von vier Ganglienzellgruppen (I bis IV); eine ist in der Höhlung des Bechers gelegen und die drei anderen liegen kreisförmig auf dem Becherrande und um den Becher herum. Die Ganglienzellen der Gruppe I, Fig. 108, sind groß und sie senden ihren Neuriten ins Zentrum des pedunculus. Fräulein Thompsox betrachtet diese Zellgruppe als ein wichtiges motorisches Zentrum. Dic Zellen der zweiten Gruppe (Fig. 108, II) senden ihre Neuriten so in den pedunculus, daß sie die Neuriten der Gruppe I umringen. Die 'Lellen selbst sind klein und haben ovale Kerne. Die Zellen der Gruppe III sind ebenfalls klein, aber sie haben runde Kerne. Ihre Neuriten dringen in den Becher ein, sind jedoch nicht weit zu verfolgen.

Man weiß, daß solche Zellen ron KExtox und Joxesct auch bei der Biene außerhalb der Becher gefunden worden sind. Die Ganglienzellen der vierten Gruppe (Fig. 108, IV) sind die kleinsten: wie ihre Nenriten laufen, wird nicht erwähnt. Die verschiedenen Typen der Ganglienzellen des Bechers werden also durch die Trompsoxschen Untersuchungen klarer dargestellt als ron anderen forsehern.

Sehr wichtig ist die merkwïrdige Entdeckung Trompsoss, daß einige Leitungsbahnen der corpora pedunculata nicht bei allen Erscheinungsformen 
derselben Art (Arbeiterin, Männchen und Königin) vorkommen. Das Gehirn der Königin hat mehr Bahnen als dasjenige der Arbeiterin oder des Männchens. Die Ameisen weichen darin ab von den Bienen, wenn man Joxescu glauben kann. Auch weichen die verschiedenen Ameisenarten untereinander in ihren Leitungsbahnen ab.

Bei den Arbeitsameisen von Camponotus und Formica fand Fräulein Thompsox im lobus mandibularis des unteren Schlundganglions Ganglienzellen (Fig. 108, a), deren Fortsätze ein Bündel bilden, welches vor dem pedunculus der corpora pedunculata hinläuft, in der commissura dorsalis anterior kreuzt und bis zum corpus centrale weiter geht. In der Figur 108 ist dieses Bündel bei $\times$ abgebrochen.

Das tritocerebrum bildet zwei ganz reduzierte lobi, welche in der Mitte dem Unterschlundganglion aufsitzen. Einige Ganglienzellen darin senden ihre Fortsätze in eine der beiden Wurzeln des ungepaarten Tritocerebralnerven.

Ich glaube hiermit die wiedererkennbaren Leitungsbahnen, welche Fräulein Thompsor erwähnt, zitiert zu haben, lasse aber manche ungenügend erforschte Bahnen ohne bekannten Beginn oder bekanntes Ende fort.

Finige Sinnesorgane der Ameisen haben in Schoen (1911) einen Forscher gefunden. ScHOEN erklärt sich, wie ich schon S. 200 bemerkte, hinsichtlich der Innervierung der Sinneshaare mit Vom Rath einverstanden. So sieht er in der Haut der Tibia von Lasius Sinneshaare, worin unter der Hypodermis gelagerte bipolare Simnesnervenzellen ihren peripheren Fortsatz senden, während ihr zentraler Fortsatz in einen Fortsatz einer Ganglienzelle eines in den Subgenualnerven eingeschalteten Ganglions übergeht. Die Membranenkanäle von Lasius (abgeänderte Sinneshaare) werden in gleicher Weise innerviert und nicht anders ist die Innervation der Sinneskegel der Tibia von Camponotus und Formica.

Von Schoes wurden auch die Gehörorgane oder Chordotonalorgane verschiedener Ameisenarten studiert. Leider sind seine Auseinandersetzungen nicht sehr klar. Der Subgenualnerv des Beines gibt, wie er sagt, seine Fasern den ,Simneszellen” des Organes ab. Wenn man näheren Aufschluß dariber verlangt, was er damit meint, kann man in seinen Abbildungen sehen, daß die Nervenfasern des Subgenualnerven unmittelbar in die bipolaren Sinneszellen übergehen, m. a. W., daß die Subgenualnervenfasern Fortsätze der Sinneszellen sind. Nach SchовN, gehen die Sinneszellen iiber" in die Umhül. lungszellen, woraus ich ableite, daß er die Zellgrenzen dieser Zellen nicht gut beobachten konnte. Die Umhüllungszellen umgeben den basalen Teil des peripheren Fortsatzes der Sinneszelle. Außerhalb der Umhïllungszellen liegen die Kappenzellen, worin die Spitze des Sinnesfortsatzes der Simneszelle eindringt. Neben den Kappenzellen liegen die keu. lenförmigen Zellen, welche in eine diinne Endfaser sich verjüngen, welche zwischen den Hypodermiszellen endet. Nach ScHoEN sind die Kappenzellen und die keulenförmigen Zellen Hilfszellen des Sinnesorganes und selbst nicht nervös. Wahre Sinneszellen wïrden also fehlen und die "Sinneszelle" wäre eine sensibele Ganglienzelle mit freien Nervenendungen, aber der Bau dieser Chordotonalorgane liefert noch zu viel Schwierigkeiten un zu diesem Schluß berechtigt zu sein.

Schoes fand die Chordotonalorgane der Bienen, Wespen, Hummeln und'Terebrantia ebenso gebaut, wie dasjenige der Ameisen.

Es bleibt mir jetzt noch übrig eine ScHENksche Arbeit zu erwähnen (ScHENK 1903), welche sich nicht nur mit Bienen. Wespen oder Ameisen beschäftigt, sondern zehn Hymenopterenarten behandelt und zwar die Innervierung ihrer verschiedenen Simneshare. Durch Wort und Bild erregt Schenk den Eindruck, als wenn in den Sinnesharen immer Sinnesnervenzellen gefunden wïrden, so z. B. in den sensilla basiconica von Vespa crabro, in den sensilla placodea (Porenplatten oder Membranenkanälen) von Vespa crabro und 
Apis mellifica u. s. w. Schenk schließt sich also in dieser Hinsicht Vom RAтu an, aber überzeugende Beweise für seine Ansicht gibt er nicht, es wäre nur weil er die Haarzellen fast immer verschweigt.

Ebenso, wie die Hymenopteren sind auch die Dipteren oft auf ihre Leitungsbahnen untersucht worden und zwar hat das Genus Husca immer im Zentrum des Interesses gestanden. Ich werde Musca daher getrennt behandeln und die übrigen Dipteren folgen lassen.

Es ist wiederum BERGER (1878), welcher uns schon in alten Zeiten Mitteilungen macht über die Leitungsbahnen im Gehirn einiger Muscarten. Er sieht im Gehirn die uns von anderen Insekten schon bekannten Gebilde wie corpora pedunculata, corpus centrale (von ihm fächerförmiger Körper genannt), Antennalganglion u.s.w. Ueber dem Zentralkörper beschreibt er einige riesengroße Ganglienzellen mit Fortsätzen, welche nach außen und nach hinten laufen. Die beiden Antennalganglien sah er durch eine Kommissur verbunden und üherdies bemerkte er daß die Nervenfasem darin aus dem Antennal. nerven stammen und meistens zum Antennalganglion der anderen Gehirnhälfte gehen. Im lobus opticus salı er das äußere und das innere Chiasma. Wie so mancher nach ihm, wie z. B. Bellonci (1886), konnte er nicht die Nervenfasern der chiasmata verfolgen. Solches blieb anderen vorbehalten. BERGER entdeckte auch eine commissura optica.

Aus dem unteren Schlundganglion sah BERgER einen Nerven zu den Mundteilen hervorgehen. Einige Fasern dieses Nerven sah er aus Ganglienzellen des ganglion suboesophageum entspringen, die meisten aber kamen aus dem Gehiru, wobei diejenigen, welche aus der anderen Himhälfte kamen, im unteren Schlundganglion die Medianlinie kreuzten.

Nach Berger hat Viallanes sich mit dem Nervensvistem der Dipteren befaßt. Hiex will ich nur dasjenige referieren, was er über Musea mitteilt; das übrige folgt später. Erstens hat VIALLANes (1882), weleher manchmal Vergoldung der Nervenelemente. anwandte, bei der Larve von Musca vomitoria unter der Hypodermis einen Ganglienzellplexus entdeckt. Die Zellen dieses Plexus anastomosieren mit ihren Fortsätzen; andere Fortsätze bilden Nerven, welche ihrerseits einen Nervenplexus bilden ; noch andere enden scheinbar frei. In den Nervenplexus waren Ganglien eingeschaltet, aber die Fortsätze dieser Ganglienzellen waren nicht verfolgbar.

Zweitens hat VIALLANes den Lauf der Nervenfasern im lobus optieus der Puppe von Musca vomitoria untersucht. Seine unzureichenden Methoden haben ihm dariber grundfalsche Vorstellungen gegeben, welche er zum Teil später selbst (ViaLLANES 1885) geändert hat. Es nuitzt nicht, seine damaligen Anschaumgen hier in extenso wiederzugeben.

Bevor noch VIALLANes Gelegenheit hatto seine Ansichten ïber den lobus opticus von IIusea zu verbessern, hatte Hickson (1885) seine Untersuchungen iiber den lobus opticus von IIusca vomitoria publiziert. Hicksov hat eine eigene Nomenklatur aufgestellt, welche bei vielen Gelehrten (so bei CAJAL) Eingang gefunden hat und welcho ich deshalb hier mit der meinigen, welche sich älteren Benennumgen anschließt, vergleichen will. Hoksos nun nennt die lamina ganglionaris das periopticon, die medulla externa mit umgebenden Ganglienzellen das epiopticon und die medulla interna mit umgebenden Ganglienzellen das opticon. Daß3 Hicksox auch die beiden chiasmata sieht. braucht fast nicht gesagt zu werden Was Hrcksox iblor die Wege der Vervenfasern sagt, liann heute im allgemeinen keinen (Alauben mehr finden. Wr sieht die beirlen medullae umgeben von einer linde von ..Nervenzellen", welche durch ihre geringen Cytoplas. mamengen von "(ianglienzellen” zu unterscheiden sind. Die Nervenzellen häingen gegenseitig mit Fortsiitzen zusammen. Die Nervenfasern anastomosieren nach ihm in jeglicher Weise, in welchem Falle man ïber anatomisch bestimmte Reizleitungsbnhnen tatsïchlich nicht sprechen könnte. Dennoch treten nach ihm die nachstehenden Leitungs. bahnen hervor. Die Nervenfasern. welche die retinulae des zusammengesetzten Auges immerieren, sind nach Hicksox fortsitze von Nervenzellen der lamina ganglionaris 
Wir wissen aber jetzt, daß diese Nervenfasern Fortsätze der Retinulazellen sind, wie bei allen Insekten erwiesen worden ist, bei IIusca besonders von CAJAL (1909). Andere Nervenzellen der lamina ganglionaris senden einige Fortsätze in das chiasma externum, während sie durch andere mit zylinderförmigen Netzen verbunden sind, welche in der lamina ganglionaris gelegen sind. Wie ich glaube, stimmen diese Netze in manchen Hin sichten mit den Neurommatidien von VLALtaves überein. Nach HICksox hängen sie untereinander zusammen und werden sie gebildet durch wiederholte Verzweigung von Nervenfasern, welche aus der medulla externa herstammen und also das chiasma externum passiert haben. Wahrscheinlich hat er darin nicht Recht (vergl. VIrIER, S. 330).

VIAllaxes (1855) lehrt uns schließlich Folgendes über die Bahnen im lobus opticus von Musca vomitoria. Weil aber Eristalis tenax und Stratiomys chamaeleon nach ihm von Musca nicht abweichen, sind seine Angaben wohl als für alle Dipteren gültig betrachtet. VIALLANES hat nur die Larven der genannten Insekten untersucht, wo das zusammengesetzte Auge nur noch Imaginalscheibe ist und jedes Ommatidium nach ihm von einer optogenen Zelle vertreten wird, wo aber der lobus opticus schon weit ausgebildet ist und die gleichen Teile zeigt wie bei der Imago nur etwas mehr zusammengedrückt. Die optogene Zelle verjüngt sich nach VIALLANEs in eine postretinale Nervenfaser. Weil später aus der optogenen Zelle sieben Retinulazellen mit sieben postretinalen Nervenfasern hervorgehen, wird die Vorstellung geweckt, wie wenn die eine postretinale Faser der optogenen Zelle sich der Länge nach in sieben Fasern teile. Es kann aber auch sein, daß VIALLANES irrtümlich sieben postretinale Fasern als eine einzige betrachtet hat, wie er solches auch vorher (1882) getan hat. Dieser Punkt soll also bestätigt werden.

Die lamina ganglionaris besteht aus drei Schichten, von denen die äußere Ganglienzellen enthält. Die postretinalen Fasern gehen nach VIALLANES wenigstens bis zur mitt. leren Schicht der lamina ganglionaris, wahrscheinlich aber weiter durch das chiasma externum in die medulla externa. Wir werden sehen, daß CAJAL (1909) beide Endigungsweisen verwirklicht gefunden hat. Die Zellen der äußeren Schicht der lamina ganglionaris sind unipolare Ganglienzellen, welche ihre Fortsätze zur mittleren Schicht senden, welche nur aus Fasern besteht. VIALLANES hat, wenn er diesen Fasern zu ihrem Ende hat folgen können, dieselben Zellen, wie CAJAL (Fig. 109, c) gesehen. Die medulla interna und externa haben beide Ganglienzellgruppen neben sich, deren unipolare Zellen die Fortsätze darin aussenden.

RADL (1902) hat nur oberflächlich und viel zu wenig genau die Struktur des Zentralnervensystems der Evertebraten studiert. Wenn er sagt, daß bei Musca und anderen Insekten die Leitungsbahnen des Auges unverzweigt und ununterbrochen die lamina ganglionaris durchsetzen, so mag das bei IIusca für einige Fasern (die langen von CAJAL (1909) endgiiltig nachgewiesenen postretinalen Nervenfasern) zutreffen, im allgemeinen ist solches gewiß nicht wahr.

Die letzte und zugleich bei weitem die beste Arbeit, welche mir über die Leitungsbahnen im lobus opticus von Musca vomitoria bekannt ist, wurde von CAJAL (1909) verfaßt. Er arbeitete mit der GoLGischen Methode und kontrolierte seine Resultate an Hämatoxylinpräparaten, fürwahr eine sehr gute Gewohnheit. CAJAL gibt manchmal andere Namen als die hier gegebenen. So rechnet er die lamina ganglionaris mit zur Retina. Die Schicht der postretinalen Nervenfasern kann demzufolge diesen Namen nicht beibehalten und wird von CAJAL lamina fenestrata genannt, weil Tracheen darin Oeffinungen bilden. Die Ganglienzellschicht der lamina ganglionaris nennt CAJAL lamina ganglionaris (sensu stricto), die Faserschicht der lamina ganglionaris (welche auch Stützzellen enthält) lamina plexiformis. CAJAL versucht mit diesen Namen die Uebereinstimmung der Retina der Vertebraten mit der „Retina” der Insekten zum Ausdruck zu bringen, so sagt er auch, daß die 
Nervenfasern, welche die lamina ganglionaris (Retina nach CAJAL) verlassen, den ,nervus opticus” bilden, aber mir scheint es so gesucht und dabei so verfehlt alles was man in der Retina der Vertebraten findet bei den Insekten wiederfinden zu wollen, daß ich ihm darin nicht folgen kann.

Jedes Ommatidium (Fig. 109, o.) wird nach CAJAL von sieben postretinalen Nervenfasern verlassen (Fig. $109, f . p . r$.), welche Fortsätze der sieben Retinulazellen des Ommatidium sind. Das war uns schon von anderen Insekten bekannt. CAJAL hat aber die wichtige Entdeckung gemacht, daß3 diese sieben Nervenfasern nicht alle einander gleich sind. Es befindet sich darunter eine

Fig. 109 .

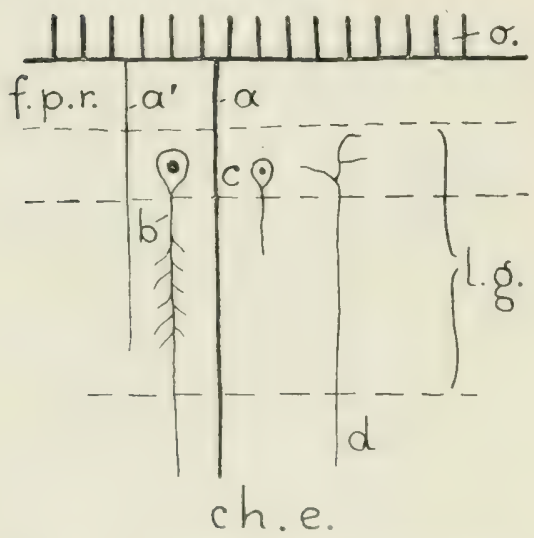

Schema einiger. Leitungsbahnen der lamina ganglionaris im lobus opticus von Musea vomitoria.

Abgeändert nach CAJAL (1909).

$a=$ lange postretinale Nervenfaser

$a^{3}=$ kurze postretinale Nervenfaser

$b, c=$ Ganglienzellen

$d=$ Nervenfaser

ch. $e$. = chiasma externum

1. $p . r .=$ fibrae postretinales

l. g. = lamina ganglionaris

o. = ommaticlium lange und zugleich dicke Nervenfaser (Fig. $109, a)$ und sechs kurze und diinne (Fig. $\left.109, a^{\prime}\right)$.

Die langen und dicken Fortsätze der Retinulazellen durchziehen ohne weiteres die lamina ganglionaris, werden $\mathrm{zu}$ Nervenfasern des chiasma externum und enden in der medulla externa (Fig. 109, a und Fig. 110,a).

Die kurzen Fortsätze der Retinulazellen enden schon in der lamina ganglionaris (Fig. 109, $a^{\prime}$ ). Die Ganglienzellschicht der lamina ganglionaris enthält zwei Zelltypen: große und kleine unipolare Ganglienzellen (Fig. 109, $b$ und $c$ ). Die großen Zellen haben einen Fortsatz, welcher durch das chiasma externum in die medulla externa tritt und dort endet (Fig. 109 und 110,b) und CAJAL bemerkt, wie Vigrer (1908) kurz vorher diesen Zelltypus sehon bei anderen Dipteren als Musea beschrieben hatte. Der Stammfortsatz dieser Zellen spaltet in der Faserschicht der lamina ganglionaris zahlreiche kurze Aestchen ab (Fig. 109) und es ist zwischen diesen Aestehen, daß die kurzen postretinalen Nervenfasern enden. Wahrscheinlich geht also hier der Reiz ron $a$ ' auf $b$ iiber. Q Quersehnitte durch die lamina ganglionaris lehrten CAJAL, daß jeder Stammfortsatz einer Zelle $b$ mit sechs bis acht kurzen postretinalen Nervenfasern in Verbindung steht. Diese Fasern stammen jedoch aus verschiedenen Ommatidien und CAJA stimmt Vigier bei, wenn er sagt, daB optische Reize aus benachbarten Ommatidien in dieser Weise in einer Ganglienzelle zusammengebracht werden. Der Fortsatz der Ganglienzelle b) mit seinen Seitenästchen bildet mit der Gruppe umgebender Nervenfasern ein Neurommatidium, wie solches VIALLAxes. Hicksox und Vigier bei Dipteren beobachtet haben und wie meiner Meinung nach auch ZaWARzix bei teschna gesehen hat.

Die kleinen Ganglienzellen der lamina ganglionaris (Fig. I09, c) haben 
einen Fortsatz, welcher noch innerhalb der lamina ganglionaris endet. In der lamina ganglionaris enden überdies zentrifugale Nervenfasern (Fig. 109, d), welche mit ihren Endverästelungen besonders die Ganglienzellen $c$ umspinnen. Ihre Herkunft blieb CAJAL unbekannt ; ZA WARZIN glaubt dieselbe in Ganglienzellen der medulla externa suchen zu müssen (vergl. S. 286).

Hinter dem chiasma externum folgt, wie bekannt, die medulla externa (Fig. $110, m . e$. .). Das Neuropilem derselben zeigt nach CAJAL vier Faserschichten (Fig. 110, 1 bis 4). Außerhalb derselben liegt eine Ganglienzellrinde, welche von den Fasern des chiasma externum durchzogen wird. Diese Fasern trennen die Ganglienzellen in drei Gruppen, deren mittlere das ganglion cuneatum (keilförmiges Ganglion) genannt wird, während der vordere und hintere Teil zusammen corona ganglionaris heißen. Weil die Ganglienzellen dieser Teile nicht verschiềden sind, CAJAL hat es bei Musca deutlich gezeigt, so fühle ich auch hier kein Bedürfnis ganglion cuneatum und corona ganglionaris zu unterscheiden und spreche also nur über die äußere Ganglienzellrinde der medulla externa.

Die äußere Ganglienzellrinde der medulla externa enthält zwei Ganglienzelltypen, welche nach CAJAL den Amakrinen der Vertebraten-Retina gleichen, aber

Fig. 110 .

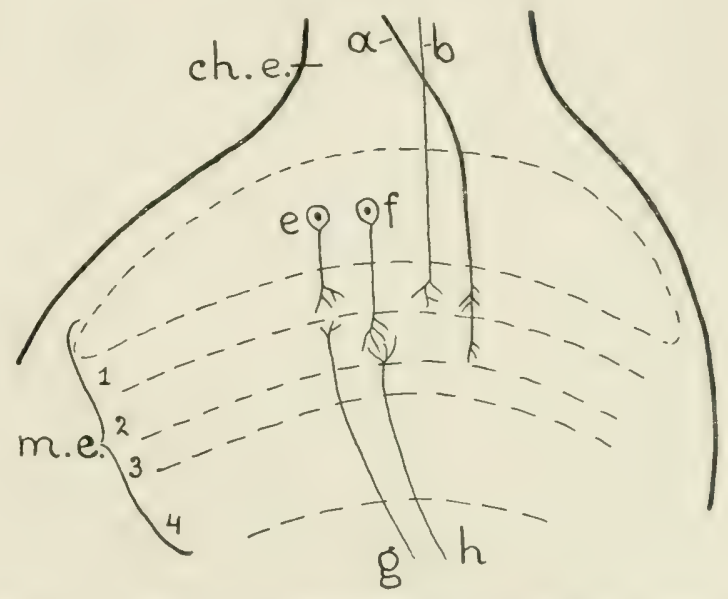

Schema einiger Leitungsbahnen der medulla externa im.lobus opticus von Iusca vomitoria. Abgeändert nach CAJAL (1909).

$a=$ lange postretinale Nerverifaser

$b, g, h=$ Nervenfasern

$e, f=$ Ganglienzellen

ch. e. = chiasma externum

$m . e_{0}=$ medulla externa

1 bis $4=$ Faserschichten der medulla externa das tun so manche der unipolaren Ganglienzellen der Evertebraten, daß solches keine nähere Verwandtschaft dieser Zellen mit Amakrinen beweisen kann. Der erste 'Typus (Fig. $110, e)$ hat einen zentral gerichteten Fortsatz, welcher nicht weiter geht als die Grenze der ersten und zweiten Faserschicht der medulla externa. Der zweite Typus (Fig. 110,f) besitzt Fortsätze, welche sich nur in einer Ebene verzweigen und jedenfalls bis in die zweite plexiforme Schicht, vielleicht auch bis zu der dritten und vierten sich erstrecken. Oft liegen die Endverästelungen dieser Ganglienzellen neben den letzten Verzweigungen von zentrifugalen Nervenfasern (Fig. 110, $g$. und $h$ ), welche vielleicht aus dem Gehirn stammen.

Man hat schon erfahren, daß auch die langen postretinalen Nervenfasein und die Fortsätze der Ganglienzellen $b$ der lamina ganglionaris in der medulla 
externa enden. Hier ist die geeignete Stelle zu bemerken, daß die postretinalen Nervenfasern (Fig. 110,a) erstens in der ersten Faserschicht der medulla externa und zweitens in der zweiten oder dritten Faserschicht Verästelungen treiben. Die erstgenannten Kollateralen sind dabei auf gleicher Höhe wie die Endverästelungen der Fasern $b$ (Fig. 110), welche in der ersten plexiformen Schicht und an der Grenze der ersten und zweiten enden.

In der dritten und vierten Schicht des Neuropilems der medulla externa

Fig. 111.

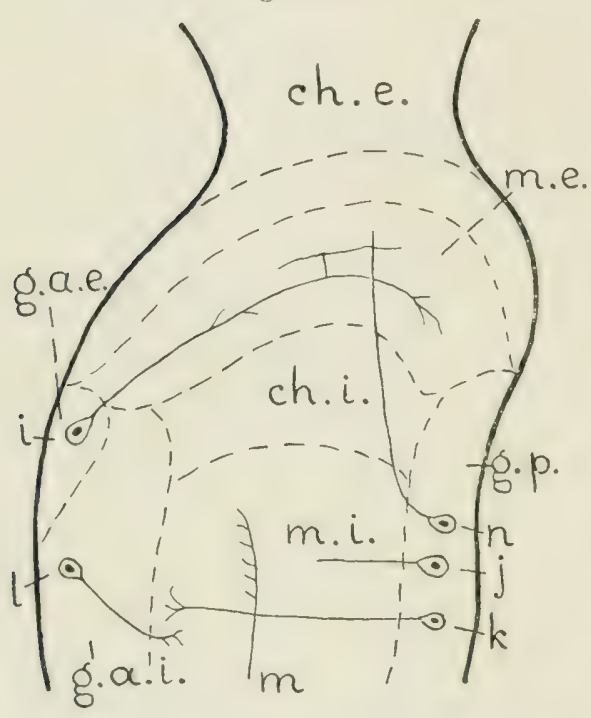

Schema einiger Leitungsbahnen im lobus opticus von Musca vomitoria.

Abgeändert nach CAJAL (1909).

$i$ bis $n=$ Ganglienzellen

$m=$ Nervenfaser

$c h . e .=$ chiasma externum

ch. $i_{0}=$ chiasma internum

g. $a . e .=$ ganglion anterius externum

g. $a . i .=$ gangtion anterius internum

$g \cdot p .=$ ganglion posterius

m. $e_{0}=$ medulla externa

$m . i$. = medulla interna verbreiten sich zarte Fasern unbekannter Herkunft.

Hinter der medulla interna trifft man das chiasma internum (Fig. 111, $c h . i$.) und dahinter die medulla interna (Fig. 111, m. i.). Es liegen, wie bekannt, einige Ganglienzellgruppen daneben, welche CAJAL ganglion posterius (Fig. $111, g . p$.$) , ganglion anterius externum$ $(g . a . e$.$) und ganglion anterius internum$ (g. a.i.) nennt.

Im ganglion anterius externum fand CAJAL große Ganglienzellen (Fig. 111, i). Thr Fortsatz tritt in die medulla externa ein und läuft in einer der vier Neuropilemschichten der Oberfläche parallel. Bisweilen verästelt sich eine Kollaterale in einer anderen Schicht als in derjenigen, wo der Neurit läuft; so z. B. kommt es vor, daß der Neurit in der dritten Faserschicht der medulla externa liegt und Kollateralen in der ersten oder zweiten sich befinden.

Das ganglion posterius enthält kleine Ganglienzellen (Fig. 111, j), deren Fortsätze sich zur medulla interna begeben, aber das Ende ist unbekannt. Andere Ganglienzellen (Fig. 111, k) senden ihre Fortsätze zur gegenüberliegenden Seite (der Vorderseite) der medulla interna, wo sie enden. In der Nähe dieser

Fortsätze enden auch Ausläufer von Ganglienzellen des ganglion anterius internum (Fig. 111, l). Noch andere Ganglienzellen des ganglion posterius (Fig. $111, n)$ senden den Fortsatz bis in die medulla externa. wo er in unbekannter Weise endet.

Es gibt manche Nervenfasern unbekannter Herkunft, welche die medulla interna, besonders den mittleren Abschnitt derselhen und das chiasma internum durchziehen um in der medulla externa zu enden. Dazu gehören \%. B. die Fasern $g$ und $h$ der Fig. 110. Neben Fasern, welche in einer Fasersehicht 
der medulla externa enden, liegen andere, welche in mehreren dieser Faserschichten Verzweigungen besitzen und noch andere, welche einen Seitenzweig weiter senden zu einer unbekannt gebliebenen Stelle.

Alle diese Fasern gehen mehr oder weniger fächerförmig auseinander und CAJAL trägt deshalb Bedenken das chiasma internum der Autoren hier auch noch chiasma zu nennen. Wenn sich schon darin Fasern kreuzen, so sind diese verschiedener Herkunft und in diesem Falle darf man nicht von einem Chiasma reden. Diese Bemerkung CAJALs ist ganz richtig. Nur möchte ich darauf hinweisen, daß sowohl bei Aeschna (Fig. 99, $k$ und $l$ ), wie bei Apis (Fig. 107, $e, e$ ' und $e^{\text {") }}$ gewisse Fasern des chiasma internum wirklich aus gleichwertigen Ganglienzellen hervorgehen und also bei ihrer Kreuzung ein wahres Chiasma bilden. Diese Ganglienzellen liegen jedoch in der äußeren Rinde der medulla externa und die Fasern sind zentripetal, nicht zentrifugal. Es scheint mir also, daß CAJAL, welcher mit Recht, die zentrifugalen Nervenfasern nicht als wahre Chiasmafasern betrachtet, die wahren Chiasmafasern des chiasma internum bei Musca nicht zu Gesicht bekommen hat, wie er auch in der äußeren Rinde der medulla externa wohl Ganglienzellen wie $e$ und $f$ (Fig. 110), aber keine mit längeren Fortsätzen beobachtet hat. Nähere Untersuchungen bleiben erwiinscht.

Neben Fasern, welche die medulla interna passieren, fand CAJAL bei Musca vomitoria auch Nervenfasern unbekannter Herkunft, welche in der medulla interna verzweigt enden (Fig. $111, m$ ). Auch hat er entdeckt, daß zentrifugale Nervenfasern, welche aus dem tuberculum opticum und aus der commissura optica des Gehirns kommen, ebenso wie zentripetale Nervenfasern aus der medulla externa in der medulla interna enden.

Am Schluß seiner vorzüglichen Arbeit macht CAJAL den Versuch die optischen Leitungsbahnen der Insekten, Cephalopoden und Vertebraten zu vergleichen. Er findet im allgemeinen die Schichten und Neuronen der Vertebratenretina im lobus opticus der Insekten und Cephalopoden zurück; für Einzelheiten verweise ich auf das Original. Ich gestehe, daß die zahlreichen von CAJAL aufgestellten Analogien bei mir durchaus keinen Anklang gefunden haben mit Ausnahme der Uebereinstimmung der Sehzellen (Stäbchenzellen, Zapfenzellen, Retinulazellen), welche in der Tat überall Sinnesnervenzellen sind, welche den optischen Reiz empfangen. Sie sind dies aber nicht nur bei den Cephalopoden, Insekten und Vertebraten, sondern überall im ganzen Tierreich, wo nur Sehzellen gefunden werden. Gegenüber Bestrebungen wie der CAJALschen möchte ich betonen, erstens, daß es sich doch nur um Konvergenzerscheinungen (welche im Auge der Cephalopoden und Vertebraten besonders häufig sind), niemals um Homologisationen handeln kann und zweitens, daß, so lange uns die Neuronen im lobus opticus der Cephalopoden und Insekten so mangelhaft bekannt sind, man besser tut die Entdeckung der unbedingt nötigen Tatsachen abzuwarten, bevor man sich an weitgehende Vergleichungen wagt.

Ueber andere Dipteren als Musca sind mir die nachstehenden hodologischen Angaben bekannt geworden. VIALLAxes (1882) beschreibt bei der Larve von Eristalis tenax einen subcutanen Ganglienzellplexus, worüber er mitteilt, daß die multipolaren Zellen unmittelbar mittels ihrer Fortsätze 
zusammenhängen. Ein wahrer Ganglienzellplexus befindet sich ebenfalls im Chylusmagen der Larve von Tipula gigantea zwischen den glatten Muskelfasern. Dieser Plexus weist die Eigentiumlichkeit auf, daß alle Ganglienzellen vier longitudinale, nicht gegenseitig verbundene Reihen bilden.

Bei der Larve von Stratiomys chamaeleon hat VIALLAxes (1882) unter der Haut einen Nervenplexus mit multipolaren Ganglienzellen entdeckt. Einige ihrer Fortsätze enden frei, andere Nervenfasern des Plexus enden in der Nähe der Basis eines Haares. Genauere Betrachtung lehrte ihn, daß unter der Basis des chitinösen Haares die Haarzelle liegt, welche mit ihrem Zytoplasma das Haar auffüllt. Wenn auch der Zellkörper oft nicht klar hervortritt, so ist doch immer der Zellkern sichtbar. Die Haarzelle nun wird innerviert durch eine bipolare, sensibele Ganglienzelle, deren zentraler Fortsatz eine Nervenfaser des subcutanen Nervenplexus wird und deren peripherer Fortsatz nach VIALLANES ohne Zweifel ins Innere der Haarzelle vordringt. Ich schließe daraus, daß die Haarzelle eine wahre Sinneszelle ist, welche durch eine sensibele Ganglienzelle innerviert wird.

CuCCATI (1888) hat die Organisation des Gehirns von Somomya erythrocephala studiert. Ich entlehne seiner Arbeit die folgenden hodologischen Angaben. Die Ganglienzellen der corpora pedunculata senden ihre Fortsätze ins Neuropilem der Becher und Stiele, wo sie, ebenso wie bei einigen Myriapoden, Spiralen beschreiben, bevor sie weitergehen zum Neuropilem des Gehirns. Lateral neben den corpora pedunculata fand CUCCATI Ganglienzellen mit Fortsätzen zum Neuropilem des Gehirns oder nach Kreuzung zum lobus opticus der anderen Seite. Mediodorsal im Hirnganglion sind Ganglienzellen mit Fortsätzen, welche neben der Medianebene geradewegs nach unten gehen und dann kreuzend die andere Hirnhälfte suchen. Dorsal liegende Ganglienzellen senden nach Kreuzung Fortsätze ins corpus centrale, aber diese Fasern verlassen den Zentralkörper wieder und ziehen ins Neuropilem. Ventral neben dem lobus opticus befinden sich Giangliensellen, woraus kreuzende Nervenfasern hervorgehen und andere, welche ihre Fortsätze ins Antennalganglion senden.

Im lobus opticus sah CuCCATr das äußere und innere Chiasma, aber er hat die Nervenfasern nicht genau verfolgt. Der lobus opticus ist durch ein Nervenfaserbindel mit dem Antennalganglion verbunden und dieses sendet ein Seitenbïndel zu den corpora pedunculata. Ueberdies verbindet ein kleineres Bündel das Antennalganglion mit dem lobus opticus der anderen Seite. Diese Angaben Cuccats bedürfen sehr der Bestïtigung, weil er. weder Anfang noch Ende der Biindel sah. Nach Cuccatr werden die beiden lobi optici durch frei Kommissuren verbunden, die dorsalen 'leile durch eine ganz dorsal laufende Kommissur, die ventralen durch eine etwas mehr ventrale, aber immerhin noch dorsale Konmissur. Die dritte Kommissur läuft zur halben Höhe des (iehirns. Manche Nervenfasern vereinigen den lobus opticus mit dem protocerebrum ohne zu lireuzen.

Neben diesen drei optisehen Kommissuren bestehen andere. Deutlich beschrieben werden nur zwei zarte Kommissuren hinter dem corpus centrale.

Ueber das Antennalganglion bemerkt Cuccatr Folgendes. Die dortigen Ganglien. zellen senden ihre Fortsätze ins Feuropilem des Ganglions. Einige Fasern des Antennalnerven bilden die commissura antennalis, andere ziehen ins protocerebrum, noch andere enden im Neuropilem des Antennalganglions. Nach Cuccati ziehen wiederum andere Nervenfasern des Antennalnerven in den motorischen Iabiahnerven, welcher übrigens fiortsätze von (i̊nglienzellen enthält, welche neben der Wurzel dieses Nerven liegen.

In den Nerven der Ozellen sah Cuccati Nervenfasern, welche in die Schlundkonnektive zogen. Es stimmt darn also Somomya mit der Biene ïberein.

PATTFx (1890) hat gemeint im zusammengesetaten Auge von 'Tabanus und Belo. stoma Retinophoren zu sehen, welche mit Sinnesharen darin ïbereinstimmen sollten, 
daß beide aus zmei nervösen Zellen beständen (beim Sinneshaare wären dies die Haarzelle und die sensibele Ganglienzelle, bei der Retinophore zwei Sehzellen). Man weiß schon aus der Einleitung dieses Kapitels, wie ich ïber diese PAtrexschen Ansichten denke. Die cinzige Mitteilung in diesem Aufsatz, welche mir glaubwürdig ?scheint, ist diejenige, daß die Retinulazellen von Belostoma sich kontinuirlich in Nervenfasern fortsetzen.

WeInLAND (1891) hat die Innervation der Halteren der Dipteren studiert. Er entdeckte auf den Halteren verschiedene Papillenfelder. Unter jeder Papille befindet sich eine hipolare Zelle. Der periphere Fortsatz dieser Zelle ist der Achsenfaden eines chitinösen Körpers, welcher unter zwei chitinösen Falten liegt. Der Achsenfaden ist von einigen verwandelten Hypodermiszellen umringt. Der zentrale Fortsatz der bipolaren Zelle ist eine Nervenfaser zum Thorakalganglion des Bauchstranges. Es fragt sich, ob die bipolare Zelle eine Sinnesnervenzelle oder eine sensibele Ganglienzelle sei. WEINLAND, welcher sich diese Frage gewiß nicht gestellt hat, nennt die \%elle Ganglienzelle, aber aus seinen Abbildungen schließe ich, daß die bipolare Zelle eine Hypodermiszelle ist und ich betrachte sie als eine Simnesnervenzelle. Die Papillen der Halteren wären somit nicht mit Sinneshaaren des üblichen. Typus zu vergleichen. Wie auch die Iodifikation der Papille sei, immer ist nach WEINLAND die Innervierungsweise die gleiche.

Lowve (1890-1892) hat über Calliphora erythrocephala eine schöne Monographie publiziert, worin über die Leitungsbahnen Folgenrles gesagt wird.

Unter der Haut hefinden sich, wie solches schon S. 201 gemeldet wurde, Ganglienzellen, welche einen Fortsatz senden in die Haarzelle eines Simneshares oder welche diese Zelle mit den Verästelungen ihres peripheren Fortsatzes umspinnen; sensibele Cianglienzellen also. Daneben-gibt es Sinneshare, welche eine oder mehrere Sinnesnervenzellen enthalten, wobei also die Haarzelle selbst cinen Nervenfortsatz aussendet. Solches ist z. B. in den Antennen der Fall. Auch andere Hypodermiszellen als Haarzel. len werden durch Fortsätze darunter gelagerter Ganglienzellen umsponnen und weil Lowne diese Zellen nicht besonders Sinneszellen nennt, meine ich, daß er hier Ganglienzellen mit freien Nervenendungen beschreibt, bei Arthropoden eine seltene Erscheinung. In den Halteren beschreibt Lowne verschiedene Sinnesnervenzellen, womit er sıch also in Uebereinstimmung mit WeINLAND befindet. Daß er auch in den Stäbchenzellen der ocelli und in den Retinulazellen des zusammengesetzten Auges Sinnesnervenzellen erkennt, ist beinahe selbstverständlich.

Ueber das Zentralnervensystem gibt Lowne mehr mikroskopisch-anatomische als hodologische Einsiehten. Was nicht gar zu unbestimmt ist, wird hier wiedergegeben. Im Unterschlundganglion nennt er Längsfasern, welche aus den Thorakalganglien stammen, Kommissurfasern, welche aus Ganglienzellen des unterer, Sch]undganglions hervorgehen und nach ihrer Kreuzing in Längsbündeln zum Ciehirn emporsteigen und Fasern, welche mit dem Maxillarnerven eintreten.

Die Antennalganglien, welche im Neuropilem die glomeruli enthalten, sind durch eine breite Kommissur verbunden und vier Pare Faserbindel verbinden sie mit dem protocerebrum. Ein Bündel endet in der Nähe der corpora perlumeulata, ein Bündel kreuzt und zieht in den pedunculus des corpus pedunculatum, ein drittes sucht den lobus opticus und ein viertes das untere Schlundganglion.

Hinter dem corpus centrale beschreibt Lowne das Pyramidalganglion, dessen Zellen Fortsätze zum Ozellarnerven aussenden.

Im lobus optieus unterscheidet LownE wohl die medulla externa und interna, das chiasma externum u. S. w. aher über die Wege der einzelnen Nervenfasern bemerkt er nur, daß eine Kommissur die beiden lobi optici verbindet.

Ich möchte betonen, daß es mir scheint, daß LownE seine Angaben hauptsächlich rlen Arbeiten anderer Autoren entlehnt hat. Vielleicht hat man darin den ( $x$ rund zu suchen, warum er in den Sinneshaaru bisweilen Sinnesnervenzellen, bisweileu sensibele Ganglienzellen sieht und in dieser Streitfrage keine Stellung nimmt.

Ueber die Ganglienzellen in der lamina ganglionaris der Dipteren im allgemeinen und von Calliphora erythrocephala im besonclern liegt uns eino wertvolle Arbeit vor, 
welche VIfIER (1908) abgefaßt hat. Fr zeigt darin, daß die lamina ganglionaris in ihrer äußeren Schicht unipolare Ganglienzellen enthält, welche ihren Fortsatz durch das chiasma externum zur medulla externa (epiopticon) senden. Fin Teil des Stammfortsatzes trägt kurze, birnenförmige Dendriten, welche mit den Endabschnitten der Nervenfortsätze der Retinulazellen in Verbindung stehen. Wo dies der Fall ist, wird ein neurommatidium gebildet in ähnlicher, aber nicht in gleicher Weise, wie VIALLANES es bei der Crustacee Palinurus beobachtete (vergl. S. 240) und in jedem neurommatidium hat der Stammfortsatz einer Zelle der lamina ganglionaris mit drei oder vier postretinalen Nervenfasern Kontakt. Man weiß schon, daß CAJAL (Fig. 109, $a^{\prime}$ und $b$ ) bei MIusea vomitoria ganz das nämliche sah und ich glaube, daß die zylinderförmigen Netzchen, von Hickson bei Musca beobachtet, eben dieselben Neurommatidien sind. Daß nicht nur die Dipteren, sondern auch andere Insekten ähnliche Vorrichtungen, wie VIGIER und CAJAI klar zu Tage gefördert haben, besitzen, zeigt die Arbeit ZawanzINs über die Libelle Aeschna (vergl. S. 286).

Es soll hier zuletzt noch ein Aufsatz Escherichs (1902) genannt werden. Wohl wird darin hauptsächlich die Entwicklung des Nervensystems der Muscide Lucilia caesar behandelt und werden darin nur wenige Leitungsbahnen erwähnt, aber aus dieser Arbeit geht gerade hervor wie wichtige Aufschlïsse über den Lauf der Nervenfasern in komplizierten Ganglien, wie das Thorakalganglion der Fliegen, das Studium der Ontogenie geben kann.

Der Bauchstrang von Lucilia und anderen Insekten entsteht aus zwei ektodermalen Seitensträngen, wozwischen ein Mittelstrang, welcher den Mediannerven oder nervus sympathicus Jiefert. Die Herkunft des Bauchstranges aus zwei Anlagen (es sei hier nebenbei bemerkt) ist in prinzipiellem ('egensatz zur Herkunft des Rüickenmarks der Vertebraten, womit einige Untersucher den Banchstrang vergleichen oder sogar homologisieren möchten. Daß so viele andere ausschlaggebende Tatsachen eine nähere Verwandtschaft der Vertebraten mit den Arthropoden ausschließen, darauf kann hier nicht weiter einge. gangen werden.

Der Bauchstrang konzentriert sich schließlich bei den Dipteren zusammen mit dem Mediannerven*) in einem einzigen Thorakalganglion, das folglich einen sehr verwickelten Bau aufweist. Aber in der Ontogenie konnte Eschericu im Mediannerven konstant vorkommende Ganglienzellen einzeln erkennen, sodaß er cie mit Buchstaben helegen konnte. (Man vergleiche HALI.ER über den nervus sympathicus der Carabiden, S. 302.)

Der Mediannerv ist segmentiert und mit Anschwellungen ausgestattet, welche zwischen den Ganglien des Bauchstranges liegen. Aus diesen Anschwellungen gehen Nerven hervor, jeder aus einem Fortsatz einer dorsal im Mediannerven gelagerten fianglienzelle (von Esсневіси mit me angedeutet) bestehend. Diese Fortsätze gehen wahrscheinlich zu den Tracheen.

In den Ganglien des Bauchstranges fand Escherich zwei Kommissuren, welche den Mediannerven unterbrechen und unipolare Ganglienzellen, welehe ihre Fortsätze entweder ins Neuropilem oder durch die Kommissuren zur anderen Seite des Bauchmarks senden. Eschericr meinte, aber dieses steht nicht ganz fest, daß Ganglienzellen des Mediannerven in der Nähe der Bauchstrangkommissuren ebenfalls Fortsätze in den Bauchstrang aussenden.

Die einzige Ordnung der Insekten neben den genannten, worüber mir hodologische 'Tatsachen zur Kenntnis gekommen sind, ist die Ordnung der Lepidopteren und, falls ich wirklich nichts übersehen habe, darf es erstaunlich heißen, daß über die Leitungsbahnen im Nervensystem der Falter und Raupen so wenig bekannt ist, wo die 'Tiere doch so bequem in großer Menge zu erhalten sind.

BERGER (1878), Welcher so viele Insekten studiert hat, hat im Gehirn von Pierjs

*) Dieser Mediannerv oder nervus sympathicus ist nicht das Homologon des Mediannerven oder Mediankonnektivs der Chatopoden. 
hrassicae corpora pedunculata und äußeres und inneres Chiasma im lobus opticus entdeckt, aber keine Nervenfasern in ihrem Lauf verfolgen können.

CAtTIE (1881), zeichnet in einer Abbildung des sechsten Bauchganglions der Raupe von Acherontia atropos zwei Kommissuren. Das ist aber alles, was in dieser Arbeit, worin das , centrale, peripherische und sympathische Nervensystem der Raupen" besprochen wird, über den Verlauf der Nervenfasern zu finden ist.

Benedicentr (1895) ist mit Bombyx mori glücklicher gewesen, aber er konnte ja auch die EHRLICHsche Methylenblau-Methode anwenden. Fr fand alle Granglien des Bauchstranges mit Ausnahme des Hirıganglions und des unteren Schlundganglions übereinstimmend gebaut und auch stimmten die Ganglien der Larve und der Imago überein. Die Ganglienzellen der Ganglien senden ihre Fortsätze ins Neuropilem derselben oder der gekreuzten Seite oder aber in die peripheren Nerven. In jedem Konnektiv fand er zwei Kolossalfasern, welche auch die Ganglien ganz durchsetzen können.

Am besten ist noch die Innervation der Sinneshaare der L.epidopteren studiert worden. E. HoLMGREN (1896), welcher mit Methylenblau arbeitete, berichtet, daß er in der Haut der Raupe von Sphinx ligustri Sinnesnervenzellen in Verbindung mit Haaren fand. Die Nervenfortsätze dieser Zellen haben Anschluß an einen subepithelialen Ganglienzellplexus. Die multipolaren Ganglienzellen des Plexus sind durch ihre Fortsätze mit einander und mit den Sinnesnervenzellen unmittelbar verbunden. Es ist also ein wahrer Ganglienzellplexus. Einige Ausläufer der multipolaren Ganglienzellen ziehen in die peripheren Nerven. Sehr merkwïrdig ist es, daß Houmgrax auch Sinnesnervenzellen entrleckte mit einem peripheren Fortsatz, welcher nicht in ein Haar, sondern zwischen den Epithelzellen der Haut zur Cuticula lief. Hier hat er jedenfalls wahre Sinnesnervenzollen entdeckt, während die Innervation der Sinneshaare m. E. nicht mittels Sinnesnervenzellen stattfindet, wie man sogleich motiviert finden wird.

GUENTHER (1901) hat die Innervation der Sinnesschuppen und Sinneskuppeln bei Saturnia pavonia und manchen anderen Faltern untersucht. In jungen Flügeln von Puppen liegen bei jeder Sinnesschuppe zwei Zellen, eine große, die Schuppenbildungszelle, und eine kleine, die sensibele Ganglienzelle. Guexther nennt diese Zelle Sinneszelle, aber weil sie die Schuppenbildungszelle innerviert, ist es eine sensibele Ganglienzelle und die Schuppenbildungszelle ist die wahre Sinneszelle. Später, wenn die Schuppe ausgebildet ist, sieht man unter der Schuppe zwischen den Hypodermiszellen eine bipolare Zelle. Der periphere Fortsatz dieser Zelle läuft in den Porenkanal in der Basis der Schuppe, dringt aber nicht in die Schuppe selbst hervor. Der basale Fortsatz ist eine Nervenfaser, welche sich einem Flügelnerven beimischt. Diese Zelle ist clie sensibele Ganglienzelle. Die Schuppenbildungszelle ist nach GuExTHER zu Grunde gegangen. aber ich frage mich, was denn wohl die hohle Schuppe ausfüllt, worin der Sinnesfortsatz der sensibelen Ganglienzelle nicht eintritt, wenn es nicht das Zytoplasma der Schuppenzelle ist. Kurz, ich glaube, wenn man die Ontogenie der Sinnesschuppen betrachtet, hat man Recht sie als Sinneshaare aufzufassen, deren Haarzellen (Schuppenbildungszellen) durch sensibele Ganglienzellen innerviert werden.

In den Flügelrippen liegen zahlreiche Sinneskuppeln. Das Chitin ist da zur Stelle dünn und kuppelförmig gewölbt. Unter jeder Sinneskuppel befindet sich eine bipolare Zelle mit einem Fortsatz in der Kuppel und einem Fortsatz im Fligelnerven. Weil der periphere Fortsatz das Chitin der Kuppel und also die Körperoberfäiche erreicht, scheint die bipolare Zelle eine Sinnesnervenzelle zu sein.

Hutow (1902) hat sich besonders mit der Innervation der Simeshaare der Lepidopteren befaßt. Obgleich die Gestalt der Haare sehr variiert, ist der Bau immer derselbe, wie ihn die vitale Methylenblau-Methode lehrte.

Bei der Larve vom Bombyx mori verzweigen sich die sensibelen peripheren Nerven wiederholt dichotomisch und endlich gehen ihre Fasern ïber in bipolare sensibele Ganglienzellen. Diese Zellen liegen bei Bombyx mori in großer Entfernung der Sinneshaare, aber bei anderen Lepidopteren wie Ampelophaga myron ist der Zellkörper neben der' Haarbasis gelegen. Der periphere Fortsatz der sensibelen Ganglienzelle schritt meistens nur bis zur Haarbasis; immer aber war das chitinöse Haar durch eine Haarzelle ausge- 
füllt, welche wie eine wahre Sinneszelle durch den peripheren Fortsatz der sensibelen Ganglienzelle innerviert wurde. Aehnliche bipolare sensibele Ganglienzellen wurden von Hriton bei den Sinneshaaren aller untersuchten Raupen, welche manchen Arten angehörten, gefunden.

Die zentralen Fortsätze der sensibelen Ganglienzellen der Raupen gehen nach HiLtoN über in einen Ganglienzellplexus unter der Hypodermis. Die multipolaren Ganglienzellen dieses Plexus anastomosieren mit ihren Fortsätzen und senden andere Fortsätze in die peripheren Nerven, welehe unter der Haut einen Nervenplexus bilden. Das stimmt also sehr gut mit dem was Hocmares über Sphinx ligustri bemerkte. HrLton sah den Ganglienzellplexus bei Bombvx, Ampelophaga, Datana, Papilio, Pieris, u. a. Bei Pieris bilden die zentralen Fortsätze der sensibelen Ganglienzellen der Haare, offenbar in Ver einigung mit anderen Ganglienzellen, Nerven, welche mit dem vorderen peripheren Nerven ins Abdominalganglion eintreten. Jedes Abdominalganglion hat nämlich zwei Paare peripherer Nerven. Nach ihrem Eintritt ins Ganglion biegen die sensibelen Nervenfasern nach vorne $u m$ und treten in das Konnektiv, wo sie sich dem Auge entziehen. Im Konnektiv laufen sie lateral, während mehr median Nervenfasern ziehen, welche das Ganglion passieren und wieder in clas nächste Konnektiv ïbergehen.

Bei allen untersuchten Raupen mit Ausnahme von Io wurlen auch bei den Drüsenhaaren bipolare Ganglienzellen entdeckt. Es werden nach meiner Meinung eher motorische (sekretorische) als sensibele Ganglienzellen sein.

In letziter Zeit hat auch Schenk (1903) die antennalen Sinnesorgane von vier Lepidopterenarten untersucht. Er versucht uns beizubringen, daß die versehiedenen Sinneshare Sinnesnervenzellen enthalten (ebenso wie HoLMGREN), was ihm jedoch nicht immer gelingt. Bei der männlichen Fidonia beschreibt ScHENK unter dem sensillum trichodeum (einem besonderen Sinneshaartypus) eine Sinnesnervenzelle mit einem peripheren Fortsatz im Haare. Wenn er aber unter dem sensillum coeloconicum (Grubenkegel) eine Grup. pe solcher Sinnesnervenzellen beschreibt, gestatten es sowohl seine Beschreibung, wie seine Abbildung, dnrin eine Gruppe von Haarzellen innerviert durch einen Fortsatz einer sensibelen Ganglienzelle zu sehen. Das wäre nur mit spezifischen Nervenfärbıugs• methoden, welche ScHF, nicht angervandt hat, zu entscheiden.

Die Beschreibung der Leitungsbahnen der Insekten ist zu Ende und da wird gewiß der Leser fragen, ob es nicht möglich sei, eine übersichtliche allgemeingiiltige :Darstellung der Leitungsbahnen des Insektenhirns zu geben. Man wird sofort einsehen, daß solches noch am ehesten für den so oft studierten lobus opticus gelingen wird und ich werde auch den Versuch dazu machen. Dabei meine ich nur dann einen gewissen Ganglienzelltypus allen Insekten zurechnen zu dürfen, wenn er von drei verschiedenen Autoren beobachtet worden ist. Stellt man sich mit zweifacher Beobachtung zufrieden, so stölst man noch oft auf ungelöste Streitfragen. Es ist erstaunlich und zugleich vielbezeichnend für den Stand unserer Kenntnis, wie wenig Ganglienzelltypen der gestellten Forderung entsprechen.

Der erste bei allen Insekten auftretende Zelltypus ist die Retinulazelle, welche sich in eine postretinale Nervenfaser fortsetzt, welche im Neuropilem der lamina ganglionaris endet. Dieses Neuron ist von VIALLAves bei Dipteren, von Kevrox bei Apis, von Vigier bei Calliphora, von CAJAL bei Musca und von ZaWARzix bei Aeschna beobachtet worden.

Der zweite Zelltypus ist eine unipolare Ganglienzelle in der äußeren Zellschicht der lamina ganglionaris gelegen. Der Stammfortsatz spaltet kurze Dendriten ab im Neuropilem der lamina ganglionaris, welche dort mit den postretinalen Nervenfasern in Beziehung treten, der Neurit geht aber durch 
das chiasma externum in die medulla externa, wo er endet. Es tragen diese Nervenfasern neben anderen durch ihre eigenartige Kreuzung zur Bildung des Chiasma bei. Dieser Zelltypus wurde von Hicksor bei ILusca, ron Kexyox bei Apis, von VIGIER bei Calliphora, von CAJAL bei Musca und von Zawarzix bei Aeschna wahrgenommen.

Der dritte Ganglienzelltypus, welchen man allen Insekten zuerkennen darf, gehört ebenfalls zur äußeren Zellschicht der lamina ganglionaris. Der Fortsatz dieser unipolaren Zelle endet bereits im Neuropilem der lamina ganglionaris selbst. Es wurden diese Zellen von VIALLises bei Dipteren, von CAJAL bei Musca und von Zawarzix bei Aeschna beschrieben.

Damit sind alle Neuronen des lobus opticus genannt, welche man ruhig als bei allen Insekten vorkommend betrachten kann. Die anderen sind entweder ungenügend bekannt oder nicht allen Insekten eigen.

Merkwürdig ist es, daß, wenn man den lobus opticus der Insekten mit demjenigen der Crustaceen vergleicht, man nur die Retinulazellen mit ihren in der lamina ganglionaris endenden Nervenfasern bei Crustaceen zurückfindet. Die damit in Beziehung stehenden Nervenfasern des chiasma externum gehen schon aus einem anderen Zelltypus, welcher nicht vor, sondern hinter der lamina ganglionaris gestellt ist (S. 224, Fig. 74, a) hervor.

Es lohnt sich nicht zu versuchen eine allgemeine Schilderung der anderen Neuronen des Insektenhirns zu geben. Das Resultat würde noch dürftiger sein als beim lobus opticus. Es kann nur zu neuen Untersuchungen anregen, wenn man sieht, wie unausgebeutet das Feld noch ist.

Die vierte und letzte Klasse der Arthropoden bilden die Arachnoidea, welche in drei Ordnungen geteilt werden: die Aranea oder Spinnen, die Arthrogastres oder Skorpione und die Acarina oder Milben. Ueber die letzte Ordnung sind mir keine hodologischen Angaben bekannt.

Grenacher (1879) hat bei den Aranea die erste Leitungsbahn entdeckt, als er sah, daß bei Epeira und Lycosa die Retinazellen der Augen ummittelbar und allmählich in Opticusfasern übergingen und diese Zellen also Sinnesnervenzellen sind.

Sсндикшттsсн (1884) hat sich später eine nicht sehr klare Vorstellung von der Retina von Epeira gebildet. Ich bekomme jedoch den Eindruck, daß auch er darin tatsächlich Sinnesnervenzellen gesehen hat. Sagt er doch, daß die Retina aus einer Sammlung von Endstücken von Opticusfasern besteht, welche Endstiicke Anschwellungen der Nervenfasern sind, welche ein doppeltes Stäbchen tragen und Keme enthalten. Sollten da nicht die Anschwellungen die Zellkörper der Retinazellen und die Opticusfasern ihre Nervenfortsätze sein?

ScHmkewitscu hat ebenfalls das Zentralnervensystem von Pholeus platangoides studiert. Er hat darin manche Ganglienzellgruppen beschrieben, aber nur wenige Leitungsbahnen. Lateral im Chelieerenganglion (vergl. S. 334) ist eine Ganglienzellanhäufung, woraus Nervenfasern entspringen, welehe sich mischen unter Vervenfasern, welche aus Ganglienzellgruppen des ( anglions des ersten Beinepares hervorgehen. Diese Nervenfasern bilden einen Ring um den Oesophagus herum. Jedes Ganglion des Zentralnervensystems enthält wenigstens eine Kommissur und im Neuropilem aller (ianglien enden Nervenfasern der peripheren Nerven. In beiden Hälften des Nervensystems laufen zwei Längsbïndel durch alle unter dem Oesophagus gelagerte Ganglien, welche nach ScHrmKEWITsCH wahrscheinlich vom Hirnganglion zu den Abdominalnerven gehen. 
Auch Bertkau (1886) ist nicht so glücklich gewesen, wie rirenacher und hat nur undeutlich gesehen, wie Retinazelle und Opticusfaser in Haupt- und Nebenaugen verbunden sind. BERTKAU glaubt beide miteinander verschmolzen und ich meine auch hier aus den Abbildungen schließen zu können, daß die Retinazellen Simnesnervenzellen sind.

Widiann (1908) hingegen hat den Grenacherschen Befund, daß die Sehzellen der Spinnen Sinnesnervenzellen sind, bestätigt. Bei den konvertierten Augen einiger Spinnen sah er die Retinazellen unmittëlbar in Nervenfasern iibergehen und das gleiche beobachtete er bei den invertierten Augen der freilebenden Spinnen. Die invertierten Augen der Netzspinnen zeigten die Merkwürdigkeit, daß der Nervenfortsatz (eine Opticusfaser) nicht basal aus der Retinazelle hervorging, wie bei den freilebenden Spinnen, sondern etwas höher, aus dem Zellkörper hervortrat. Wenn WIDMANN glaubt, daß ontogenetisch die Fasern des nervus opticus keine Fortsätze der Retinazellen sind, sondern Fortsätze ron Ganglienzellen, welche in die Retinazellen eintreten, so stimme ich darin gar nicht mit ihm iberein. Die Retinazellen sind wohl hier, wie bei allen Tieren Sinnesnervenzellen.

Die besten hodologischen Mitteilungen über das Nervensystem einer Spinne verdanken wir Haller (1912), welcher Epeira untersuchte. Haller gibt die folgende Beschreibung des Zentralnervensystems. Es besteht aus einem Paare Zerebralganglien, welche ich zusammen das Hirnganglion (Fig. 113, h.g.) nennen möchte, oberhalb des Oesophagus (Fig. 113, oes.) und fünf dicht beisammengestellten Ganglien unter dem Oesophagus. Das erste dieser Ganglien, das Chelicerenganglion, sendet Nerven zu den Cheliceren, die vier anderen zu den Schreitfüßen. Aus dem letzten Ganglion gehen überdies zwei Abdominalnerven hervor. Der abdominale Teil des Bauchstranges ist ganz reduziert und nach HALLER ins letzte Ganglion aufgenommen.

In den Ganglien des Bauchstranges, wovon Figur 112 einen Querschnitt darstellt, liegen nur wenige Ganglienzellen dorsal, um so mehr aber ventral. Ventral befinden sich zwei Gruppen großer unipolarer Ganglienzellen, eine laterale und eine mediane. Die Zellen der lateralen Gruppe senden ihren Fortsatz in den peripheren Nerven derselben Seite (Fig. 112,a) oder nach Kreuzung in der commissura dorsalis (Fig. $112, c . d$. .) in den peripheren Nerven der anderen Seite (Fig. 112,b) ; die Zellen der medianen Gruppe haben nur kreuzende Nervenfasern, welche durch die dorsale Kommissur in den peripheren Nerven der anderen Seite übergehen (Fig. 112,c). Neben den großen Ganglienzellen entedecte Hat.Ler ventral im Ganglion kleinere unipolare zellen. Einge derselben (Fig. 112, d) senden ihren Fortsatz nach oben. Bei der dorsalen Kommissur angelangt, spaltet sich der Fortsatz in einen Ast, welcher die Medianlinie iiberschreitet und im Neuropilem endet und einen Ast, welcher in den peripheren Nerven derselben Seite austritt. Bei anderen kleinen Ganglienzellen (Fig. 112, e) verästelt sich gerade der ungekreuzte Zweig des Stammfortsatzes und zieht der kreuzende in den peripheren Nerven. Die peripheren Nerven führen Fasern, welehe sich im Neuropilem derselben Seite (Fig. 112, f) oder nach Kreuzung in der commissura dorsalis im Neuropilem der anderen Seite des Ganglions verzweigen (Fig. 112,g). Dorsal im Ganglion fand Haller multipolare Ganglienzellen (Fig. 112, h). Ihre Dendriten verästeln sich im Neuropilem; ihr Neurit ïberschreitet die Medianlinie in einem besonderen Abschnitt der dorsalen Kommissur und endet dorsal im Neuropilem der anderen Seite. 
Unter der commissura dorsalis laufen drei Paare Längsbündel untereinander neben der Medianlinie. Sie erhalten ihre Fasern aus Ganglienzellen des basalen Teils des Ganglions. Auch ziehen darin Fortsätze von Ganglienzellen des Chelicerenganglions, welche jedem Ganglion Seitenäste überliefern.

Neben den kurzen Schlundkonnektiven, welche das Hirnganglion mit dem Bauchstrang verbinden, liegen die Ganglienzellen des Oberlippenganglions (Fig. 113, o. l.g.). Ihre Fortsätze werden wohl in die Oberlippennerven treten, aber HALLER hat dies nicht tátsächlich beobachtet.

HALLER beschreibt zu beiden Seiten im Hirnganglion zwei globuli oder corpora pedunculata, ein vorderes (Fig. 113, c. p.a.) und ein hinteres, welche mit den corpora pedunculata der Insekten übereinstimmen, deren Neuropileme aber nicht Becher genannt werden können, weil sie nicht becherförmig sind. Ich glaube, man

spricht am besten uiber corpora pedunculata ohne besondere Unterscheidung der Neuropileme.

Die Ganglienzellen der corpora pedunculata sollen nach HaLLER durch kurze Dendriten gegenseitig verbunden sein. Ihre NeuriFig. 112 .

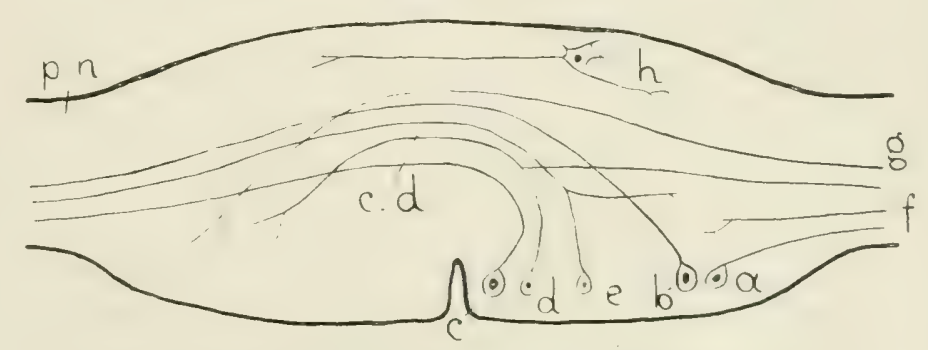

Schematischer Querschnitt eines Bauchganglions von Epeira. Nach Haller (1912).

$a$ bis $e$ und $h=$ Ganglienzellen

$f, g=$ Nervenfasern

$c, d .=$ commissura dorsalis

p. $n .=$ peripherer Nerv

ten bilden nach

ihm Netze in den, glomeruli" im Neuropilem der corpora pedunculata, bevor sie in den Stiel übergehen. Das lautet alles ein wenig sonderbar und bedarf der Bestätigung. Eher ist zu glauben, daß Ganglienzellen des vorderen corpus pedunculatum ihren Neuriten in den pedunculus senden und dann weiter durch das Schlundkonnektiv zum Bauchstrang, wo er nach oder auch ohne Kreuzung im Neuropilem endet (Fig. 113, $a$ und $b$ ). Andere Ganglienzellen senden Fortsätze aus, welche eine Kommissur zwischen den corpora pedunculata von links und rechts bilden (Fig. 113,c). Diese Kommissur ist ein Teil der commissura dorsalis, welche daneben Nervenfasern enthält, welche aus den peripheren Nerven des Bauchstranges stammend, im Neuropilem des corpus pedunculatum der anderen Seite enden (Fig. 113, d). Aehnliche sensibele Nervenfasern enden im corpus pedunculatum derselben Seite (Fig. 113,e).

Ganglienzellen des Bauchstranges (Fig. 113, f) senden bisweilen ihren Neuriten durch das Schlundkonnektiv ins Hirnganglion. Hier angelangt, spaltet sich ein Ast ab, welcher in der vorderen Kommissur des Hirnganglions kreuzt; ein zweiter Ast endet im Neuropilem derselben Seite und ein dritter endet im corpus pedunculatum derselben Seite. Dorsal im Hirnganglion sind 
schließlich noch Ganglienzellen gestellt (Fig. 113, g), welche mit ihrem Fortsatz das Neuropilem des Bauchstranges suchen.

Neben der commissura dorsalis und anterior entdeckte HALLER noch eine dritte Kommissur im Hirnganglion, die commissura posterior, aber es wurde nicht bekannt, woher die Nervenfasern derselben stammen.

Ueber die Leitungsbahnen der Arthrogastres ist fast gar nichts bekannt. Schroeder (1908) entdeckte auf den Kämmen der Skorpione Sinneskegel,

Fig. 113.

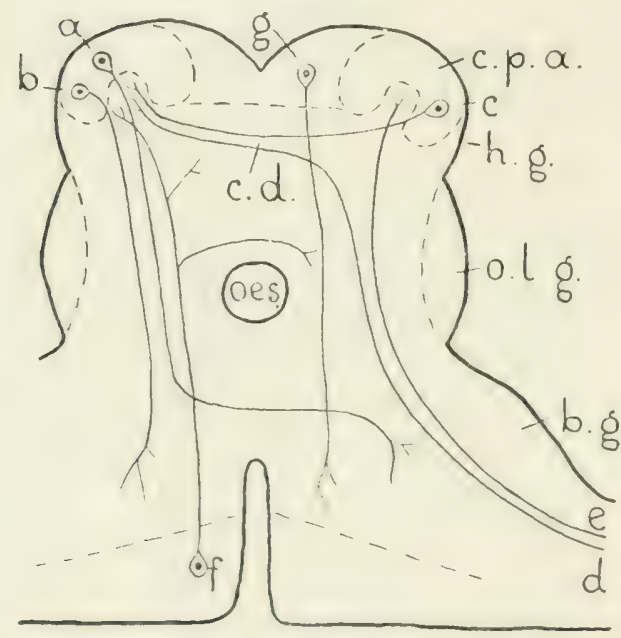

Schematischer Quersehnitt durch das Zentralnervensystem von Epeira. Nach HaLler (1912).

$a, b, c, f, g=$ Ganglienzellen

$d, e=$ Nervenfasern $\Rightarrow$

b. $g$. = Bauchganglion

c. $d_{\text {. }}=$ commissura dorsalis

c. $p . a .=$ corpus pedunculatuma anterius

h. $g .=$ Hirnganglion

oes. = Loch, wo der. Oesophagus hindurchtritt.

o. . $\%$. = Oberlippenganglion

Die Strichellinien begrenzen die (isng. lienzellgruppen.

Crustaceen, Jenaische Zeitschrift fiir Naturwisenschaft, 131. 45, 1909.

$\because$ Aldw $(1894 a)$, Studies on the Nervous System of Crustacea, 1. Some Serve-Elements of the Eubryonic Lobster, Quarterly Journal of Microscopical Science. Vol. 36, 18!4.

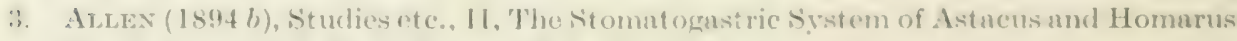
(Puart. Joumal of Mier. Sieienes. Vol. 36. 1s!9f.

1. Artax (1s96) Studies ete.. 15. Further Observations on the Verve-Filements of the Embryonic Lobster. (Quart. Joumal of Mier. Science, Vol. 39, 1897.

5. BAUER (19014), Zu innern Metamorplose des Centralnervensystems der Insecten, Zoologische Jahrbiicher. (Abth. Anut.), Bt. 20, 1904. 
6. Belionci (1880), Sui lobi olfattori del Nephrops norregicus, Memorie della Accademia delle Scienze dell' Istituto di Bologna, Serie 4, Tomo 1, 1880.

7. Belloncr (1882), Nuove ricerche sulla struttura del ganglio ottico della Squilla mantis, Memorie d. Accad. d. Scienze d. Istituto di Bolngna, Serie 4, Tomo 3, 1881.

s. Berconcr (1883), Sur la structure et les rapoorts des lobes olfactifs dans les arthropodes supérieurs et les vertébrés, Archives Italiennes de Biologie, Tome 3, 1883.

9. Belloncr (1886), Intorno al ganglio ottico degli artropodi superiori, Internationale Monatsschrift für Anatomie und Histologie, Bd. 3, 1886.

10. BenEDICENTI (1895), Recherches histologiques sur le système nerveux central et périphérıque du Bombyx mori, Archives Italiennes de Biologie, Tome 24, 1895.

11. Berger (1878), Untersuchungen iiber den Bau des Gehirns und cler Retina der Arthropoden, Arbeiten aus dem zoologischen Institute der Universität Wien, Bd. 1,1878 .

12. Bertkau (18\$6), Beiträge zur Kenntnis der Sinnesorgane der Spinnen, I, Die Augen der Spinnen, Archiv für mikroskopische Anatomie, Bd. 27, 1886.

13. Bethe $(1895 \%)$, Studien über das Centralnervensystem von Carcinus Maenas nebst Angaben über ein neues Verfąhren der Methylenblaufixation, Archiv fo mikrosk. Anatomie, Bd. 44, 1895.

14. Bethe (1895 b), Die Otocyste von Mysis, Zoolog. Jahrhüicher, Bd. 8, 1895.

15. Bетне (1896), Ein Beitrag zur Kenntnis des peripheren Nervensystems von Astacus fuviatilis, Anatomischer Anzeiger, Bd. 12, 1896.

16. Bethe (1897), Das Nervensystem von Carcinus Maenas, Archiv für mikroskopische Anatomie, Bd. 50, 1897.

17. Bethe (1898), Das Centralnervensystem von Carcinus Maenas, Arehiv f. mikr. Anatomie, Bd. 51, 1898.

18. Boettafr (1910), Das Gehirn eines niederen Insektes (Lepisma saccharina), Jenaische Zeitschrift für Naturwissenschaft, Bd. 46 N. F. 39, 1910.

19. Bretschnfider (1914), Ueber die Gehirne der Küchenschabe und des Melilkäfers, Jenaische Zeits. f. Naturwiss., Bd. 52, N. F. 45, 1914.

20. Buetschli (1885), Ueber die nervösen Endorgane an den Fïhlern der Chilognathen und ihre Beziehungen zu denen gewisser Insekten, Biologisches Centralblatt, Bd. 4,1885 .

21. Buetschli (1912), Vorlesungen über vergleichende Anatomie, 2te Lieferung, 1912.

22. CaJAí (1890), Coloration par la méthode de Golgi des terminaisons des trachces et des nerfs dans les muscles des ailes des insectes, Zeitschrift für wissenschaftliche Mikroskopie, Bd. 7, 1890.

23. CAJaL (1909), Nota sobra la estructura de la retina de la mosca (M. vomitoria L.), Trabajos del Laboratorio de investigaciones biologicas, Tomo 8, 1909.

24. Cajai y Sanchèz (1915), Contribucion al conocimiento de los centros nerviosos de los insectos, Trabajos del Laborat. de investig. biolog., T. 13, 1915.

25. CATTIE (1881), Beiträge zur Kenntnis der Chorda supraspinalis der Lepidoptera und des centralen, peripherischen und sympathischen Nervensystems der Raupen, Zeitschrift für wissenschaftliche Zoologie, Bd. 35, 1881.

26. Claus.(1875), Ueber die Entwicklung, Organisation und systematische Stellung der Arguliden, Zeits. f. wiss. Zoologie, Bd. 25, 1875.

27. Claus (1876), Zur Kenntnis der Organisation und des feineren Banes der Daphniden und verwandten Cladoceren, Zeits. f. wiss. Zoologie, Bd.27, 1876.

28. Claus (1879), Der Organismus der Phronimiden, Arbeiten aus dem zoologisehen Institute der Universität Wien, Bd. 2, 1879.

29. Claus (1891), Ueber das Verhalten des nervösen Endapparates an den Sinneshaaren der Crustaceen, Zoologisèher Anzeiger, Bd. 14, 1891.

30. Cuccati (1888), Ueber die Organisation des Gehims der Somomya erythrocephala, Zeits. f. wiss. Zoologie, Bd. 46, 1888.

31. Cunningtos (1903), Studien an einer Daphnide, Simocephalus sima; Beiträge zur Kenutnis des Centralnervensystems und der feineren Anatomie der Daphniden, Jenaische Zeits. für Naturwiss. Bd. 37, 1903. 
32. Dretl (1876), Die Organisation des Arthropodengehirns, Zeits. f. wiss. Zoologie, Bd. 27, 1876.

33. Diete (1878), Untersuchungen über die Organisation des Gehirns wirbelloser Thiere, II Abth., Crustaceen, Sitzungsberichte der Mathematisch Naturwissenschaftliche Classe der Akademie der Wissenschaften, Wien, Bd. 77, I Abth., 1878.

34. Dogrex (1894), Beitrag zur vergleichenden Anatomie und Physiologie des Herzens, Archiv f. mikr. Anatomie, Bd. 43, 1894.

35. Dubosce (1897), Sur le système nerveux sensitif des Trachéates (Orthoptères, Chilopodes), Archives de Zoologie Txpérimentale, 3me Série, 'Tome 5, 1897.

36. Dubosce (1898), Recherches sur les Chilopodes, Archives de Zoolog. Expér., 3me Série, Tome 6, 1898.

37. Escherich (1902), Zur Entwicklung des Nervensystems der Musciden mit besonderer Berücksichtigung des sog. Mittelstranges, Zeits. f. wiss. Zoologie, Bd. 71, 1902.

38. Fischel (1908), Untersuchungen über vitale Fürbung an Süßwassertieren, ins. besondere bei Cladoceren, Internationale Revue der gesamten Hydrobiologie und Hydrographie, Bd. 1, 1908.

3!). FLOEGEL (1878), Ueber den einheitlichen Bau des Gehirns in den verschiedenen Insecten-Ordnungen, Zeits. f. wiss. Zoologie, Bd. 30, Suppl., 1878.

4(1. Gerstakcker (1866 - 1879), Crustacea, Bronns Klassen und Ordnungen des Thierreichs. Bd.5, Abt. 1, Erste Hälfte, $1866-1879$.

41. Gerstafcker und Ortmann (1901), Crustacea Malacostraca, Bronns Klassen und Ordnungen des Tierreichs, Bd. 5, Abt. 2, Zweite Hälfte, 1901.

4:. Graber (1880), Ueber das unicorneale Tracheaten- und speciell das Arachnoideenund Myriopoden-Auge, Archiv f, mikr. Anatomie, Bd. 17, 1880.

43. Grenacher (1879), Untersuchungen ïber rlas Sehorgan der Arthropoden, 1879

44. Grenacher (1880), Leber die Augen einiger Myriapoden, Archiv f. mikr. Anat., Bd. 18, 1880 .

4.). Gïntuer (1901), Ueber Nervenendigungen auf dem Schmetterlingsfligel, Zoologische Jahrbuicher, (Abth. Anat.), Bd. 14, 1901.

46. Haller (1905), Ueber den allgemeinen Bauplan des Tracheatensyncerebrums, Archiv f. mikr. Anatomie, Bd. 65, 1905.

47. Halder (1907), Ueber die Ocellen von Periplaneta orientalis, Zoologischer Anzeiger, Bd. $31,1907$.

4ล. Haller (1910 a), Ueber das Bauchmark, Jenaische Zeits. f. Naturwiss. Bd. 46, N. F. 39,1910 .

4). Haller $(1910$ b), Weitere Beiträge zur Tehre von der Kontinuität des Nervensystems, Archiv f. milir. Anatomie, Bd. 76, $1910-1911$.

i). Hatler (1912), Ueber das Zentrahnervensystem des Skorpions und der Spinnen, Archiv f. milir. Anatomie, Bd. 79, 1912.

il. Hauser (1SS0), Physiologische und histiologische Untersuchungen iiber das Geruchsorgan der Insekten, Zeits. f. wiss. Zoologie, Bd. 34, 1880.

i2. Hr.sex (1863), Studien iiber das Gohörorgan der Decapoden, Zeits. f. wiss. Zoologie B3.l. 13, 1863.

i3. Hrisien (1866), Ueber das Gehörorgan von Locusta, Zeits. f. wiss. Zoologie, Bd. 16. 1866 .

it. Hesse (1901), Von den Arthropoden-Augen, Zeits, f. wiss. Zoologie, Bd. 70, 1901.

$\therefore$.i. Hickson (1855), The lye and Optic Traet of Insects, Quarterly Journal of Miero. scopical Science, Vol. $25,1855$.

iri. Hutox (1902), Tho Body Sense Hairs of Lepidopterous Larvae, The American Naturulist, Vol. 36, 1902.

i7. Hutrox (1911), Some Remarks on the Motor and Sensory 'Traets of Insects, 'The Journal of Comparative Neurology, Vol. 21, 1911.

is. Howk (1881), Nouvelles études sur les Pyenogonides, Arehives de Zoologie Expérimentale. 'lome 9. 1881.

i!). L. Howngrex (1 S!6), Zur Kenntnis des Hautnervensystems der Arthropoden, Anatomischer Anzeiger, Bd. 12, 1896. 
60. E. Holmgren (1898), Zum Aufsatze IV. Schrembres, ,Noch ein Wort iber das peripherische sensibele Nervensystem bei den Crustaceen", Anat. Anzeiger, Bd.14, 1898.

61. Nrus Holimane (1916), Zur vergleichenden Anatomie des Gehirns von Crustaceen etc. Kungl. Svenska V'etenskapsakademiens Handlingar, Bd. 56, 1916.

62. JoNEscu (1909), Vergleichende Untersuchungen über das Gehirn der Honigbiene, Jenaische Zeits. f. Naturwiss., Bd. 45, N. F. 38, 1909.

63. Kenyon $(1896 a)$, The Meaning and Structure of the So-called, ,Mushroom Bodies', of the Hexapod Brain, The American Naturalist, Vol. 30, 1896.

(j4. Kenyon $(1896 \mathrm{~b})$, The Brain of the Bee, The Journal of Comparative Neurology, Tol. 6, 1896.

65. Kenyon (1897), The Optic Lobes of the Bee's Brain, The American Naturalist, Vol. 31, 1897.

66. Kотте (1903), Beitråge zur Kenntnis der Hautsinnesorgane und des peripheren Nervensystems der Tiefsee-Decapoden, Zool. Jahrbücher, (Abth. Anat.), Bd. 17, 1903

67. KrIEger (1880), Die Organisation des Arthropodengehirns, Zeits. f. wiss. Zoologie, Bd. 33, 1880 .

68. KuEHNLE (1913), Vergleichende Untersuchungen über das Gehirn, die Kopfnerven und die Kopfdruisen des gemeinen Ohrwurms (Forficula auricularia L.) u. s. w., Jenaische Zeits. f. Naturwiss. Bd. 50, 1913.

69. Künckel et Gazagnatre (1881), Rapport du eylindre-axe et des cellules nerveuses périphériques avec les organes des sens chez les Insectes, Comptes rendus de l'Académie des Sciences, Paris, Tome 92, 1881.

70. LAndois (1868), Das Cehörorgan des Hirschkäfers (Lucanus cervus), Archiv f。 mikr. Anatomie, Bd. 4, 1868.

71. LEMOINE (1868), Recherches pour servir à l'histoirędes systèmes nerveux, musculaire et glandulaire de l'Ecrevisse, Annales des Sciences naturelles, 5 me Série, T. 9, 1868.

72. Leydig (1851), Ueber Artemia salina und Branchipus stagnalis, Zeits. f. wiss. Zoologie, Bd. 3, 1851 .

73. Leydig (1855), Zum feineren Bau der Arthropoden, Archiv für Anatomie, Physiologie und wissenschaftliche Medicin, 1855.

74. Leydig (1864), Vom Bau des thierischen Körpers, 1864.

75. Lerdig (1886), Die Hautsinnesorgane der Arthropoden, Zoologischer Anzeiger, Bd. 9, 1886.

76. I.OWNE (1890-1892), The Blowfly, 1890-1892.

77. MC INDoo (1914), The Olfactory Sense of the Honey Bee, The Journal of Experimental Zoology, Vol. 16, 1914.

78. Mrchers (1880), Beschreibung des Nervensystems von Oryctes nasicornis im Larven-, Puppen- und Käferzustande, Zeits. f. wviss. Zoologie, Bd. 34, 1880.

79. Monti (1892), Ricerche microscopiche sul sistema nervoso degli insetti, Rendiconti reale istituto lombardo, Serie 2, Vol. 25, 1892.

80. Nemec (1896), Zur Kenntnis des peripheren Nervensystems einiger Crustaceen, Anatom. Anzeiger, Bd. 12, 1896.

81. Newtox (1873), The Structure of the Eye of the Lobster, Quarterly Journal of Microscopical Science, Vol. 13, 1873.

82. NEwToN (1879), On the Brain of the Cockroach, Blatta orientalis, Quart. Journal of Micr. Science, Vol. 19, 1879.

83. Nowikof (1905), Ueber die Augen und die Frontalorgano der Branchiopoden, Zeits. f. wiss. Zoologie, Bd. 79, 1905.

84. Nusbauat (1899), Beiträge zur Kenntnis der Innervation des Gefäßsystems nebst einigen Bemerkungen über das subepidermale Nervenzellengeflecht bei den Crustaceen, Biol. Centralblatt, Bd. 19, 1899.

85. Nusbaum und Schreiber (1897), Beitrag zur Kenntnis des peripherischen Nervensystems bei den Crustaceen, Biol. Centralblatt, Bd. 17, 1897.

86. OwsJannikow (1861), Recherches sur la structure intime du systime nerveux des Crustacées, Annales des sciences naturelles, tme Série, 'T'ome 15, 1861.

87. OwsJANnikow (1863), Ueber die feinere Structur des Kopfganglions bei den Kreb. 
sen, besonders beim Palinurus locusta, Mémoires de l'Académie impériale des sciences de St-Pétersbourg, 7 me Série, Tome 6, 1863.

88. OwsJannikow (1900), Ueber die Nervenelemente und das Nervensystem des Flußkrebses, (Astacus fluriatilis), Mémoires de l'Acad. Impér. des sciences de StPétersbourg, 8me Série, Tome 10, 1900.

89. PACKARD (1884), On the Structure of the Brain of the Sessile-eyed Crustacea, I, The Brain of Asellus and the Eyeless Form Caecidotaea, Memoirs of the National Academy of Sciences, Vol. 3, Pt. 1, 1884.

911. PARKer (1895), The Retina and Optic Ganglia in Decapods, especially in Astacus, Mitteilungen aus der zoologischen Station zu Neapel, Bd. 12, 1897.

91. Patten (1886), Eyes of Molluses and Arthropods, Nitteil. a.d.zoolog. Station zu1 Neapel, Bd. 6, 1886 .

92. Pattex (1888), Studies on the Eyes of Arthropods, Journal of Morphology, Vol. 2,1889 .

93. Patten (1890), Is the Ommatidium a Hair-bearing Sense-Bud ?, Anatom. Anzeiger, Bd. 5, 1890.

91. Pattex (1894), On the Morphology and Physiology of the Brain and Sense Organs of Limulus, Quart. Journal of Microscopical Science, Vol. 35, 1894.

415. Pietschiker (1911), Das Gehirn der Ameise, Tenaische Zeits. f. Naturwiss., Bd. 47, N. F. 40, 1911.

94. RADL (1900), Untersuchungen über den Bau des Tractus opticus von Scquilla mantis und von anderen Arthropoden, Zeits. f. wiss. Zoologie, Bid. 67, 1900.

4). RADL (1902), Ueber specifische Strukturen der nervösen Centralorgane, Zeits. f. wiss. Zoologie, Bd. 72, 1902.

4s. Vou Ratir (1888), Ueber die Hautsinnesorgarie der Insekten, Zeits. f. wiss. Zoologie, Bd. $46,1888$.

!!!. Vour Ratri (1891), Zur Kenntnis der Hautsinnesorgane der Crustaceen, Zoologiseher Anzeiger, Bd. 14, 1891.

100. Vour RAtн (1895), Ueber die Nervenendigungen der Hautsinnesorgane der Arthropoden nach Behandlung mit der Nethylenblaumethode und Chromsilbermethode, Berichte der Naturforschenden Gesellschaft zu Freiburg i. B., Bd. 9, 1895.

111. Vour Ratir (1896), Zur Kenntnis der Hautsinnesorgane und des sensibelen Nervensystems der Arthropoden, Zeits. f. wiss. Zoologie, Bd. (i1, 1896.

111.2. REDIKORZEW (1900), Entersuchungen über den Bau der Ocellen der Insekten, Zeits. f. wiss. Zoologie, Brl. 68, 1900.

113. Reichesbacri (1888), Studien zur Entwieklungsgesehichte des Fluß3krebses, Abhandlungen herausgegeben von der Scnelienbergischen Naturforschenden (iesellschaft, Bd. 14, 1888.

114. Retzius (1890), Zur Kenntnis des Nervensystems der Crustaceen, Biologische Untersuchungen, N. F. Bd. 1, 1890.

115. Ritzius (1895), Das sensibele Nervensystem der Crustaceen, Biol. Untersuch., N. F. Bd. 7, 1895 .

1ui. Retzivs (1906), Zur Kenntnis des Nervensystems der Daphniden, Biol. Lintersuch., N. F. Bd. 13, 190\%.

107. Rulaxd (1888), Leber die Hautsinnesorgane der Insekten, Zeits. f. wiss. Zoologie, Bd. 46,1888 .

lu: SAmassa (1891), Lntersuchungen über das entrale Nervensystem der Cladoceren, Archis f. milir. Anutomie. Bal. 3s, 1s!91.

111., SonEsk (1903), Die antemalen Hautsinnesorgune ciniger Jepifopteren und Hymenopteren u. s. W., Zoologische Jahrbiicher (Abth. Anat. ), Bd. 17, 1903.

111. Schmkewrsen (1884), Etude sur l'anatomie de l'épeire, Annules des sciences naturelles. (jone série. 'Tome 17, 18 s.

111. Scmmaz (1914). Beitriïe zur Kenntnis des Nerven- und Blutgefü3systems von Lanceola, Vibilia, Rhabdosoma und Oxyecphalus, Jenaische Zeits. f. Naturwiss., BCl, 52, N. 1'. 45, 1914. 
112. Oscar Schurdot (1875), Die Gehörorgane der Heuschrecken, Archiv f. mikr. Anatomie, Bd. 11, 1875.

113. SchnetDer (1902), Lehrbuch der vergleichenden Histologie der Tiere, 1902.

114. Schoev (1911), Bau und Entwicklung des tibialen Chordotonalorgans bei der Honigbiene und bei Ameisen, Zoolog. Jahrbiicher, (Abth. Anat.), Bd. 31, 1911.

115. Schretber (1898), Noch ein Wort über das peripherische sensibele Nervensystem bei Crustaceen, Anatom. Anzeiger, Bd. 14, 1898.

116. Schroeder (1908), Die Sinnesorgane der Skorpionskämme, Zeits. f. wiss. Zoologie, Bd. 90,1908 .

117. Max Schultze (1867), Ueber die Endorgane des Sehnerven im Auge der Gliederthiere, Archiv f. mikr. Anatomie, Bd. 3, 1867.

118. Thompson (1913), A Comparative Study of the Brains of Three Genera of Ants with Special Reference to the Mushroom Bodies, The Journal of Comp. Neurology, Vol. 23, 1913.

119. Viallanes (1882), Recherches sur l'Histologie des Inseltes, Annales des sciences naturelles, 6me Série, Tome 14, 1882.

120. VIALlanes ( $1884 a$ ), Etudes histologiques et organologiques sur les centres nerveux et les organes des sens des animaux articulés, Première mémoire, Le ganglion optique de la langouste (Palinurus vulgaris), Annales des sciences naturelles, 6me Série, T. 17,1884 .

121. Viallanes ( 1884 b), Etudes histologiques etc. Deuxième mémoire, Le ganglion optique de la libellule (Aeschna maculatissima), Annales des sciences naturelles, 6me Série, T. 18, 1884.

122. Vrallanes (1885), Etudes histologiques ete., Troisième mémoire, Le ganglion optique de quelques larves de Diptères (Musca, Eristalis, Stratiomys), Annales des sciences naturelles, 6me Série, T. 19, 1885.

123. VIallanes (1887 a), Etudes histologiques etc., Quatrième mémoire, Le cerveau de la guêpe (Vespa crabro et V. vulgaris), Annales des sciences naturelles, 7 me Série, T. 2, 1887.

124. Viallaves (1887 b), Etudes histologiques ete., Cinquième mémoire, I, Le cerveau du eriquet (Oedipoda coerulescens et Caloptenus italicus), Annales des sciences naturelles, 7 me Série, T. 4, 1887.

125. Viallanes (1892 a), Recherches anatomiques et physiologiques sur l'oeil composé des Arthropodes, Annales des sciences naturelles, 7 me Série, T. 13, 1892.

126. Vrallanes $(1892 b)$, Contribution à l'histologie du système nerveux des invertébrés, La lame ganglionaire de la langouste, Annales des sciences naturelles, 7 me Série, T. $13,1892$.

127. Viallanes (1893), Etudes histologiques etc., Sixième mémoire, Annales des sciences naturelles, 7 me Série, T. 14, 1893.

128. VIGIER (1908), Sur l'existence réelle et le rôle des appendices piriformes'des neurones. Le neurone perioptique des Diptères, Comptes rendus de la Société de Biologie, Année 1908.

129. Max Weber (1881), Anatomisches iber Trichonisciclen, Archiv f. mikr. Anatomio, Bd. 19, 1881.

130. Weinland (1891), Ueber die Sehwinger (Halteren) der Dipteren, Zeits. f. wiss. Zoologie, Bd. 51, 1891.

131. Widmanx (1908), Ueber den feineren Bau der Augen einiger Spinnen, Zeits. f. wiss. Zoologie, Bd. 90, 1908.

132. YUNG (1878), Recherches sur la structure intime et les fonctions du systène nerveux central chez les Crustacés décapodes, Archives de Zoologie Expérimentale, T. 7,1578 .

133. YUNG (1879), De la structure intime du système norveux central des Crustacés décapodes, Comptes rendus de l'Académie des Sciences, Paris, T. 88, 1879.

134. Zawarzrn (1914), Histologische Studien über Insekten, 1V, Die optischen Ganglien der Aeschna-Larven, Zeits. f. wiss. Zoologie, Bd. 108, 1914. 


\section{BRYOZOA.}

Ueber die Hodologie des Nervensystems der Bryozoen sind mir nur zwei Arbeiten bekannt. HARMER (1885) entdeckte bei Loxosoma crassicauda im einschichtigen ektodermalen Epithel des ganzen Körper's hatrtragende Simnesnervenzellen, welche sich unmittelbar in eine Nervenfaser fortsetzten. Diese Nervenfaser ging ihrerseits in eine bipolare Ganglienzelle über, deren zentraler Fortsatz in einen peripheren Nerven des Zentralganglions trat, welches bei diesen Tieren das ganze Zentralnervensystem darstellt. Aus dem Zentralganglion geht links und rechts ein Nerv zum, hinteren Sinnesorgan" hervor. Nach. Harmer ist dieses Sinnesorgan eine große Sinnesnervenzelle, welche viele Haare trägt und kontinuirlich in einen Nerven übergeht, welcher ein peripheres Ganglion aufsucht, bevor er ins Zentralganglion eintritt. Ich bezweifle jedoch, ob HARMER hier die richtige Einsicht hat. Pedicellina stimmt mit Loxosoma betreffs der Sinnesnervenzellen und bipolaren Ganglienzellen iiberein.

Retzius (1905) hat zwanzig Jahre später bei Pedicellina echinata die haartragenden Sinnesnervenzellen im Epithel wiedergefunden und sie besonders in den Tentakeln angetroffen. Die anschließenden bipolaren Ganglienzellen konnte er aber nicht finden und er glaubt, daß sie nicht bestehen, denn er sah die Nervenfortsätze der Sinnesnervenzellen in Bündeln zum Zentralganglion laufen ohne Kernen oder Zellen zu begegnen.

Es bleibt also bei den Bryozoen noch fast alles auf hodologischem Gebiete zutun.

\section{I, I'T ER A T'U R.}

I. Harner (1885), The Structure and Development of Loxosoma, (uarterly Journal of Microscopieal Scirnce, V'ol. 25, 1885.

2. Retzius (1905), Das sensibelo Nervensystem der Bryozoen, Biologische Untersuchungen, N. F. Bd. 12, 1905. 


\section{TUNICATA.}

Die ältesten Mitteilungen über die Histologie des Nervensystems einiger Tunicaten, woraus einigermaßen der Lauf der Leitungsbahnen erhellt, danken wir Ussow und sie gelten für Ascidien. Bei diesen Tieren besteht das Nervensystem aus einem Hirnganglion, woraus die peripheren Nerven entspringen und welchem sich bisweilen ein dorsaler Ganglienzellstrang anschließt, der nichts anders als das reduzierte Rückenmark der Larve ist.

Ussow hat meistens russisch publiziert und daher ist mir nur eine seiner Arbeiten (Ussow 1875) zugänglich: Er sagt darin schon, was später so oft für alle Tunicaten von anderen wiederholt worden ist, daß im Hirnganglion die Ganglienzellen peripher und die Fasern, das Neuropilem, zentral gestellt sind. Unter dem Epithel fand er multipolare Ganglienzellen, deren Fortsätze sich mit den Nerven und mit Epithelzellen, welche Tastorgane sind ,,verbinden". Sollten diese Epithelzellen vielleicht Sinnesnervenzellen sein?

NAxsen (1886) hat das Hirnganglion verschiedener Ascidien untersucht und gefunden, daß oft Ganglienzellen darin ihre Ausläufer unmittelbar in die peripheren Nerven senden. Die Nerven selbst enthalten gleichfalls Ganglienzellen, welche ihre Fortsätze zur Peripherie des Körpers senden.

LoRLEBERG (1907) hat mit modernen Hilfsmitteln das Nervensystem der Ascidien untersucht, hat darin aber, wieviel er übrigens erforschte, den Wegen der Nervenfasern nicht folgen können. Auch melden SEelrger und HARTIEYER (1893-1911) in ihrem Sammelwerke keine weiteren Leitungsbahnen der Ascidien und erwarten diesbezüglich alles von der Zukunft.

Bei den Salpen sind die Retinazellen im Auge von Buetschli (1892) als Sinnesnervenzellen erkannt und, weil er ihren Nervenfortsätzen zum Hirnganglion folgen konnte, hat er auch eine Leitungsbahn genau erforscht.

Goeppert (1893) bestätigt im allgemeinen diese Bemerkungen BuEtschlis. Bei den solitären Salpen ist das Auge meist unmittelbar neben dem Hirnganglion gelagert und die Sehzellen (Retinazellen) können sogar eine Fortsetzung der äußeren Ganglienzellschicht des Hirnganglions sein. Die Sehzellen gehen kontinuirlich in Nervenfasern über, welche zum Hirnganglion gehen.

Bei den Kettensalpen von Salpa pinnata ist das Auge einigermaßen vom Hirnganglion entfernt und bilden die Nervenfortsätze der Sehzellen einen richtigen Nerven zum Hirnganglion. Die Kettensalpe von Salpa democratica- 
mucronata hat, wie die anderen Salpen, eine Schicht von Sehzellen, welche Sinnesnervenzellen sind, aber die Kettensalpen von Salpa africana-maxima und Salpa runcinata-fusiformis besitzen eine zweischichtige Retina. Neben den Pigmentzellen des Auges liegt eine Schicht kleiner Zellen, welche durch Fortsätze verbunden sind mit großen bipolaren Zellen, welche eine zweite Schicht bilden und ihre zentralen Fortsätze zum Hirnganglion senden. Ich meine, daß die kleinen Zellen vielleicht die Sehzellen sind und die großen bipolare Ganglienzellen, halte aber eine nähere Untersuchung für notwendig.

DoBER (1912) bemerkt noch, daß bei der solitären Salpe von Salpa pinnata einige Zellen des Leucht- oder Seitenorgans sich in Nervenfasern fortsetzen, woraus man schließen kann, daß sie Sinnesnervenzellen sind. Andere Leitungsbahnen macht auch dieser Aufsatz nicht näher bekannt.

Die Hodologie des Nervensystems der Appendicularien ist ebenfalls sehr dürftig bekannt. Das Nervensystem setzt sich zusammen aus dem Zentralganglion, dem dorsalen Nervenstrang mit den (audalganglien (dem Riuckenmarke) , und den peripheren Nerven. Nach Seeliger und Hartueyer (18931911) enthalten die Caudalganglien motorische Ganglienzellen, welche einen Fortsatz zu einem Muskel senden. In der Haut sind freie Nervenendungen angetroffen, soda 3 sensibele Ganglienzellen wenigstens bei den Appendicularien unter den Tunicaten vorkommen.

Im Sammelwerke über die Pyrosomen, welches Seeliger und Neumaxn (1909-1910) veröffentlicht haben, finde ich nur, daß Neumaxx an zwei Stellen oben im Munde von Pyrosoma Agassizi Sinnesnervenzellen im Epithel entdeckt hat, sonst fehlt jede hodologische Angabe.

Wie man sieht, ist es fast ganz künftigen Forschern überlassen die Leitungsbahnen der 'Tunicaten, dieser wegen ihrer Verwandtschaft mit den Vertebraten so wichtigen Tiergruppe, zu erforschen.

\section{I'T E R A I U R.}

1. Bütschli (1892), Einige Bemerkungen über die Augen der Salpen, Zoologiseher Anzeiger, Bd: 15, 1892.

2. Dober (1912), Beiträge zur Kemntnis des Nervensystems der Salpen, Zeitschrift für wissenschaftliche Zoologie, Bd. 101, 1912.

3. Goeprent (1893), Untersuchungen iiber das Sehorgun der Salpen, Morphologisches Jahrbuch, Bd. 19, 1893.

4. Lorlebera (1907), Untersuchungen iiber den feineren Bau des Nervensystems der Aseidien, Zeits. f. wiss. Zoologie, Bd. $88,1907$.

5. Naxsex (1886), Preliminary Communication on some Investigations upon the Histologieal structure of the Central Nervous System in the Ascidia and in Myxine glutinosa, The Annals and Magazine of Natural History, Yol. 18, 1886.

6. Sezbiger und Hartweyer (1893 - 1911), 'Tunicata, Brosss Klassen und Ordnun. gen des Tierreichs, Bd. 3, suppl., Abt. 1, 1893 - 1911.

7. Seetiger und Neumaxis (1909-1910), Pyrosomata, Broxss Filnssen und Ord. nungen des Tierreichs, Bd. 3, Suppl., Abt. 2, 1909-1910.

8. Lssow (1875), Zoologiseh - embryologische Lntersuchungen, Die Mantelthiere, Archiv für Aaturgeschichte, Bd. 41, 1875. 


\section{AMPHIOXUS.}

\section{(Branchiostoma lanceolatum.)}

Obgleich dieses Tier' sich in manchen Hinsichten den Vertebraten anschließt, hat es doch besonders in manchen Einzelheiten des Nervensystems so vieles mit den Evertebraten gemein, daß es mir passend erscheint, damit meine Auseinandersetzungen zu enden, unter Verweisung auf den folgenden Abschnitt dieses Buches, worin der allgemeine Bau des Nervensystems dieses Tieres eingehender behandelt werden wird. Aus der reichen Fülle der Aufsätze, welche dem Amphioxus gewidmet sind, wähle ich nur diejenigen zur Besprechung, welche hodologische Hitteilungen enthalten. Weil die Nervenfasern von Amphioxus wie diejenigen der Evertebraten marklos sind, kommen für die Untersuchung der Leitungsbahnen dieselben Methoden wie bei den Evertebraten in Betracht, nicht aber die WEIGERTsche Markscheidenfärbung, welche bei Vertebraten so gute Resultate liefert.

Das Nervensystem von Amphioxus hat die Gestalt eines Rohres, welches am vorderen Ende zu einem Bläschen angeschwollen ist. Das Rohr nennt man das Rückenmark (medulla spinalis), weil es dorsal gelegen ist und mit dem Rückenmark der Vertebraten übereinstimmt und die vordere Anschwellung nennt man das Gehirn. Mit welchen Teilen des Vertebratenhirms das Gehirn von Amphioxus homolog ist, ist noch immer ungeachtet zahlreicher diesbezüglichen Untersuchungen eine offene Frage, welche ich hier nicht erörtern will, umsoweniger als die tiefere Kenntnis des feineren Baues dieses Organs, wie man bald sehen wird, noch immer aussteht und ohne diese die rrage $\mathrm{m}$. E. nicht gelöst werden kann. Ueberdies wird davon auch im folgenden $A b$ schnitt dieses Buches die Rede sein.

Das Rückenmark (Fig. 114) hat auf einem Querschnitte mehr oder weniger die Gestalt eines Dreiecks. Die Lichtung darin ist ein feiner, runder Kanal, die canalis centralis (Fig. 114,c.c.), welchem sich aber dorsalwärts ein S'chlitz, der teilweise zu einer Naht oder Raphe (Fig. 114,r.) geworden ist, anschließt. Ursprünglich war der Zentralkanal schlitzförmig. Der dorsale T'eil ist während der Entwicklung des Tieres virtuell geworden, indem er von Ganglienzellfortsätzen und sogar Ganglienzellkörpern durchwachsen und teilweise ausgefüllt worden ist und so ist schließlich fast nur eine Raphe iibrig greblieben.

Aus dem Rückenmark treten zahlreiche Nerven hervor, welche mit den 
Spinalnerven der Vertebraten in dieser Hinsicht übereinstimmen, daß sie segmental angeordnet sind und daß man dorsale, überwiegend sensibele und ventrale, motorische Nerven unterscheiden kann. Die Unterschiede, welche die sensibelen Nerven von Amphioxus gegenüber denjenigen der Vertebraten aufweisen, werden später zur Sprache kommen. Ein ungepaarter Nerv zur Flimmergrube und drei Nervenpaare verlassen das Gehirn.

Ich werde nach einander die Leitungsbahnen des Zentralnervensystems, also des Gehirns und Rückenmarks, und des peripheren Nervensystems beschreiben.

OwSJANNIKow (1868) ist der erste Forscher gewesen, welcher eine Lei-

Fig. 114 .

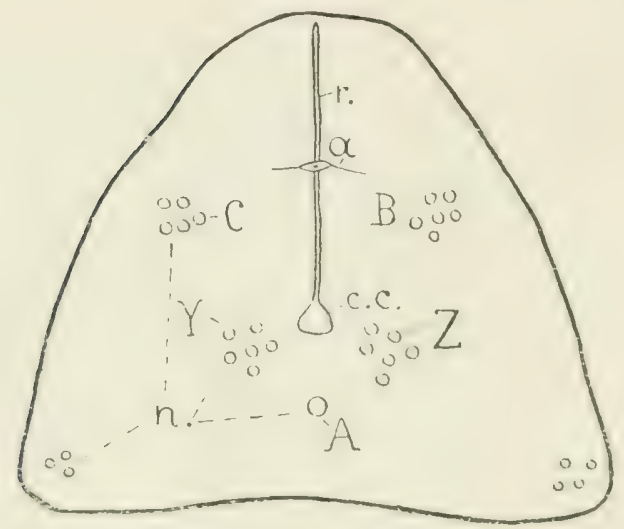

Schematischer Querschnitt durch das Riickenmark von Amphioxus.

$a=$ dorsalo Kommissurzello

A, B, C, $Y, Z=$ Neurochorde

c. c. = canalis centralis

$n .=$ Neurochordgruppe

$r$. $=$ Raphe tungsbahn des Zentralnervensystems beschrieben hat. Er erzählt uns, daß im Rückenmark Ganglienzellen liegen, welche einen Fortsatz in einen Spinalnerven senden. Andere, multipolare Ganglienzellen haben Fortsätze, welche Längsfasern des Rückenmarks sind. Ueher und unter dem Zentralkanal sah OwsJAxxikow Kommissurfasern ohne ihre Ursprungszellen entdecken zu können. Auch hat er dic gruppenweise longitudinal im Rückenmark verlaufenden Kolossalfasern oder Neurochorde ganz richtig als Nervenfasern betrachtet, obgleich er keinen Zusammenhang mit Ganglienzellen beobachten konnte.

Betreff's der Kommissurfasern und Neurochorde komnte schon bald STIEDA (1S73) vollständigere Mitteilungen machen. Er sah, daß viele

dorsale Komissurfasern Fortsätze von manchmal bipolaren Ganglienzellen sind, welche quer durch den spaltförmigen 'Teil des Zentralkanals gewachsen sind, und daß oft der Zellkörper dieser Ganglienzelle selbst die spalte überbriickt (Fig. 114, a). Woher die ventralen Kommissurfasern unter dem Zentralkanal stammen, sagrt er nicht.

In der Raphe fand er auch riesige multipolare Ganglienzellen, Neurochordzellen oder Kolossalzellen, liegen. Der dickste ihrer Fortsätze ist ein Neurochord, welcher longitudinal nach vorn oder nach hinten zieht. Die Neurochordzellen sind rom im Riiekemmark zahlreicher als hinten. STIEDA ist der Meinung, daß die Neurochorde nicht verzweigt enden, sondern zwei Neurochordzellen verbinden. Er hat dies aber nicht wahrenommen und später keine Bestätigung gefunden.

Einige Fasem der Spinalnerven sah STIEDA, ebenso wie OWSJNiKow, aus Ganglienzellen derselben Riickenmarkshälfte hervorgehen. Einige dieser 
Ganglienzellen liegen auf der Höhe der Nervenwurzel, andere scheinen mehr nach vorn oder nach hinten zu liegen; jedenfalls fuihren die Spinalnerven auch Nervenfasern, welche im Rückenmark umbiegen und nach vorn oder nach hinten ziehen. Ob die Nerven auch Ganglienzellfortsätze der gekreuzten Rückenmarkshälfte erlangen, darüber widerspricht sich STIEDA.

Rонох (1882) hat die bipolaren Ganglienzellen, welche die Raphe überbrücken (Fig. 114, a), wiedergefunden, will sie aber unbegreiflicherweise nicht Kommissurzellen nennen. Auch sah er im Rückenmark die multipolaren Ganglienzellen, welche einen Fortsatz in einen Spinalnerven senden und, weil er meldet, daß die Fasern der ventralen Spinalnerven aus diesen Ganglienzellen entspringen, hat er nachgewiesen, daß sie motorisch sind.

Ueber die Neurochorde hat Rонох einigermaßen sonderbare und unrichtige Vorstellungen. Es sollen darunter drei Arten unterschieden werden können, welche alle longitudinal laufen. Einige gehen aus vorn im Rüickenmark gelegenen Ganglienzellen (Neurochordzellen) hervor und enden frei irgendwo im Rückenmark. Dies hat später z. B. Rohde (1890) bestätigt. Andere Neurochorde sollen nach RoHоr stark verlängerte bipolare Ganglienzellkörper sein, welche ziemlich plötzlich in zwar dicke, aber keineswegs kolossale Nervenfasern übergehen. Eine dritte Art soll gar nicht mit Ganglienzellen verbunden sein !

Die übrigen Längsnervenfasern des Rückenmarks entspringen aus Ganglienzellen des Rückenmarks, wie schon OwsJansıkow uns lehrte, niemals aber aus Zellen des Gehirns. In Uebereinstimmung damit glaubt RoHоx, daß Gehirn und Rückenmark zwar durch kurze, schräge Nervenfasern verbunden sind, jedoch nicht durch lange longitudinale Fasern. Die vielen Längsfasern, welche das Gehirn mit dem Rückenmark vereinigen, sind nach RoHox Bindegewebsfasern, welche leicht mit Nervenfasern zu verwechseln sind. Es fragt sich, ob nicht RoHox dieses getan hat, denn es werden doch wohl auch längere Bahnen Gehirn und Rüickenmark verknüpfen.

Rонох begegnete in den vorderen zwei Dritteln des Gehirns kleinen, spindelförmigen Ganglienzellen, welche oft einen Fortsatz in einen Hirnnerven, worunter er die vorderen Nervenpaare versteht, sandten. Im hinteren Teil des Gehirns fand er große multipolare Ganglienzellen. Er selbst beschreibt uns nicht die Wege ihrer Fortsätze, sagt aber, daß W. MüLler schon $1875 \mathrm{im}$ Gehirn von Amphioxus multipolare Ganglienzellen entdeckte, welche einen Fortsatz einem sensibelen peripheren Nerven beimischten.

Die Neurochorde sind von RoHDE (1890) am besten studiert worden. Er bemerkte, was STIEDA und Rohox verneinten, daß sie konstante Gruppen bilden, welche am bequemsten in einem Querschnitt des Rückenmarks gesehen werden (Fig. 114). Der dickste aller Neurochorde läuft ventral median unter dem Zentralkanal und ist ungepaart. Die übrigen bilden drei geparte Gruppen. Die dünnsten Neurochorde laufen ganz lateral und ventral. Sie liegen deshalb in den Ecken des dreieckigen Querschnitts. Weiter gibt es noch zu beiden Seiten eine dorsale Gruppe und eine mediane Gruppe neben dem Zentralkanal.

RoHDE hat auch die Neurochordzellen, die Ganglienzellen, woraus die Neurochorde hervorgehen, genau beschrieben, mit Ausnahme derjenigen der ventrolateralen Gruppe, welche nicht entdeckt wurden. Die Neurochordzellen 
sind alle multipolare Riesenzellen, welche die Raphe überbrücken, wie STIEDA schon berichtete. Die Dendriten verästeln sich bald; der Neurit wird ein longitudinaler Neurochord, welcher eine nicht genau bekannte Strecke zurücklegt. Die Neurochordzellen selbst haben aber eine genau bestimmte Lage. Die vorderste Neurochordzelle (Fig. 115, A) ist die größte von allen und es ergab sich; daß sie den dicksten, ungepaarten, medianen Neurochord (Fig. 114, A) aussendet. Sie ist dicht hinter dem Ursprung des sechsten linken sensibelen Nerven im Rückenmark gelegen; ihr Neurochord biegt sich nach rechts bis er unter dem Zentralkanal angelangt ist und zieht dann median nach hinten (Fig. 115, A).

Die übrigen elf Neurochordzellen, welche vorn im Rückenmark liegen, haben Neurochorde, welche die beiden dorsalen Gruppen bilden. Die Neurochordzelle B (Fig. 115), welche der Zelle A folgt, liegt hinter der Abgangsstelle des sechsten rechten sensibelen Nerven, wobei man bedenken soll, daß bei

Fig. 115 .

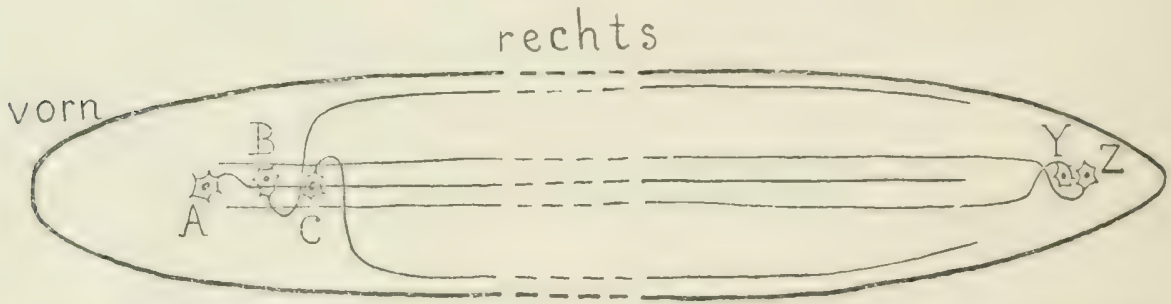

Schema der Neurochordzellen und Neurochorde im Rïckenmark von Amphioxus. Abgeändert nach ROHDE (1890), lig. 27a.

$A, B, C, Y, Z=$ Neurochordzellen

Amphioxus, der ja in so manchen Hinsichten asymmetrisch gebaut ist, die beiden Nerven desselben Paares nicht auf gleicher Höhe das Rückenmark verlassen (vergl. Fig. 116). Ihr Nemrochord (lig. 115 und 114, B) biegt erst nach links, Jäuft dann unter dem Zentralkanal nach rechts und steigt empor zur dorsalen Neurochordgruppe, worin er deszendiert. Die Neurochordzelle C (Fig. 115 und 114) ist hinter dem siebenten linken sensibelen Nerven gestellt. und ihr Neurochord tut nach der anderen Seite dasselbe, was der Neurochord $B$ nach der einen Seite tut. So folgen noch in bestimmten Entfernungen neun Neurochordzellen, welche ihren Neurochord abwechselnd linksum und rechtsum nach hinten senden.

Die Neurochorde der medianen Gruppen stammen aus Neurochordzellen, welche hinten im Rückenmark gelegen sind. Sie laufen also nach vorn. Die hinterste Neurochordzelle (Fig. 115, / $/$ ) liegt zwischen dem (ilsten rechten und dem 61 sten linken sensibelen Nerven. Mhr Neurochord biegt linksum, geht unter dem Zentralkanal hindurch und lïuft in der rechten medianen Gruppe nach vorn (Fig. 115 und 114, Z). Die vorletzte Neurochordzelle (Fig. 115, Y) findet man zwisehen dem blsten linken und dem fokten rechten sensibelen Nerven. [hr Neurochord biegt erst nach rechts und fïgt sich der linken medianen Neu- 
rochordgruppe bei (Fig. 115 und 114, Y). Die Zellen Y und Z bilden ein Paar. Die drei ihnen vorangehenden Körpersegmente enthalten keine Neurochordzellen, dann aber folgt wiederum ein Paar Zellen $\mathrm{X}$ und IV dicht beisammen beim 5̃ sten und 5ssten sensibelen Nerven. Ein drittes Paar $V$ und $U$ liegt beim 5̃sten und 54 sten sensibelen Nerven, ein viertes ( $\mathrm{T}$ und $\mathrm{S}$ ) beim 5 lsten und 52sten Nerven. Damn liegen die Neurochordzellen desselben Paares weiter auseinander. So liegt die Neurochordzelle $\mathrm{R}$ beim 49sten Nerven, die Zelle $\mathrm{Q}$ beim 47sten, $\mathrm{P}$ beim 45sten, $\mathrm{O}$ beim 43sten, $\mathrm{N}$ beim 41 sten und die Zelle $\mathrm{II}$ beim 39sten rechten sensibelen Nerven. Ihre Neurochorde mischen sich abwechselnd unter die rechten und linken medianen Neurochorden. Neben den genannten enthalten die medianen Neurochordgruppen auch Fasern, deren Zellen nicht auffindbar waren. RoHDE vermutet, daß sie ebenfalls hinten im Riuckenmark liegen. denn dort liegen noch andere multipolare Ganglienzellen quer durch die Raphe. Daneben hat RoHDE auch die bekannten kleinen bipolaren Ganglienzellen (Fig. 114, a), welche die Raphe überbrücken, gefunden. Retzios (1891) hat bald nach RoHDE das Zentralnervensystem von Amphioxus mit Methylenblau untersucht und darin auch die Neurochordzellen (Kolossalzel-

Fig. 116 .

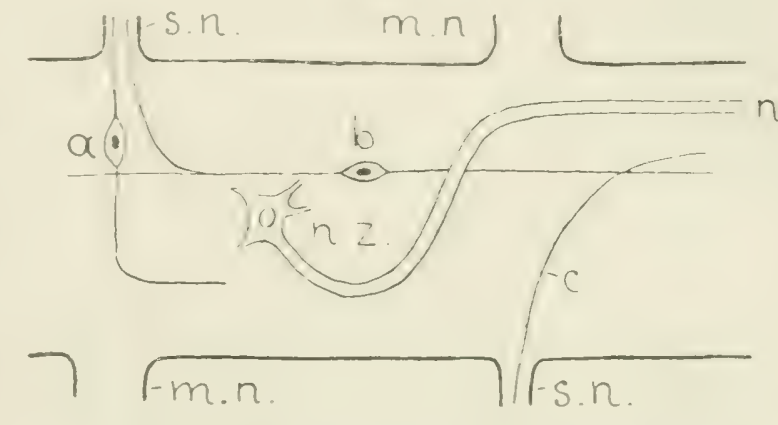

Schema einiger Leitungsbahnen im Rückenmark von Amphioxus. Horizontaler Längsschnitt. Abgeändert nach RETzius (1891).

$$
\begin{aligned}
a, b & =\text { Ganglienzellen } \\
c & =\text { Nervenfaser } \\
\text { m. } n . & =\text { motorischer Nerv } \\
n . & =\text { Neurochord } \\
n . z . & =\text { Neurochordzelle } \\
s . n . & =\text { sensibeler Nerv }
\end{aligned}
$$
len) gefunden. Seine Beschreibung dieser Zellen (Fig. 116, n. z.) stimmt ganz mit derjenigen Rowdes. Es sind in der Medianlinie gelagerte multipolare Ganglienzellen. Thre Dendriten enden bald; ihr Neurit, der. Neurochord (Fig. 116,n.), kreuzt unter dem Zentralkanal und wird eine longitudinale Faser, welche Kollateralen abspaltet.

Neben den Neurochordzellen hat Retzius andere Ganglienzelltypen entdeckt. Zuerst kleine, bipolare Ganglienzellen (Fig. 116, a) mit einem Fortsatz, welcher in den nächsten sensibelen Nerven eintritt nach oder ohne Abspaltung eines longitudinalen Seitenastes. Der andere Fortsatz lireuzt und zieht in ein Längsfaserbündel der anderen Pückenmarkshälfte. Einige Zellen dieser Art sind nicht bipolar, sondern uni- oder multipolar. Die multipolaren sind vielleicht dieselben wie die Kommissurzellen des dritten Typus, welche WoLfF (S. 352) beschreibt.

Ein zweiter Typus bipolarer Ganglienzellen (Fig. 116, b) ist ein wenig größer als der vorige und die Zellen bilden zwei longitudinale Reihen neben 
der Medianlinie des Rückenmarks. Einen Fortsatz senden sie nach hinten; sein Los ist nicht genau bekannt. Den zweiten senden sie nach vorn und dieser überliefert dem nächsten sensibelen Nerven einen Ast. In jeden sensibelen Nerven treten viele solcher Aeste und die Längsfasern, woraus sie hervorgingen, kamen sowohl von vorn als von hinten.

Andere Ganglienzellarten, welche sich mit dem Methylenblau färbten, sind weniger gut bekannt.

In die sensibelen Nerven sah Retzius auch Nervenfasern der anderen Seite (Fig. 116, c) übergehen, aber ihre Ursprungszellen blieben unbekannt. Ebensowenig gelang es ihm die Herkunft der Fasern der motorischen Nerven zu ermitteln.

Hexmans und vax der Stricht (1896), welche das Nervensystem von Amphioxus mit modernen Nervenfärbungen untersuchten, konnten erst im Rückenmark die motorischen Ganglienzellen wiederfinden, welche RoHow darin entdeckt hat, denn sie sagen, daß ventral in der medulla spinalis Ganglienzellen liegen, deren Fortsätze in Bündeln vereint, die ventralen, motorischen Nerven bilden. Diese Nervenfasern innervieren die Muskeln ihres Segments.

Vorn im Rückenmark erwähnen die genannten Autoren eine besondere Art großer, wahroheinlich multipolarer Ganglienzcllen. welche einen Fortsat\% in den dorsalen sensibelen Nerven senden. Neben diesen Nervenfasern führen die sensibelen Nerven Fasern, welche in GoLGI-Präparaten zeigten, daß sie sich nach ihrem Eintritt ins Rückenmark dichotomisch verzweigten in einen aszendierenden und einen. deszendierenden Ast. Noch andere Fasern der sensibelen Nerven, welche im Rückenmark Seitenäste in allen Rìchtungen abspalteten, waren Fortsätze von Ganglienzellen, welche neben der Raphe lagen.

Bei jungen Tieren von $15 \mathrm{~m}$.M. Länge konnten Heymans und vax DER Stricht offenbar die Ganglienzelltypen $a$ und $b$ (Fig. 116), welche Retzids entdeckt hatte, zurückfinden, aber sie kombinierten die beiden 'Typen mit allen ihren Fortsätzen zu einem einzigen 'Typus.

Ueber die Neurochordzellen teilen sie uns die wichtige 'Tatsache mit, daß sie Fortsätze (Dendriten) in die dorsalen sensibelen Nerven aussenden. Febrgens berchreihen sie die Neurochordzellen weniger genau als Ronde und Retzius es taten.

In der Arbeit Hesses (1898) wird wiederum eine neue Zellart des Rückenmarks als Anfang einer Leitungsbahn beschrieben. Es sind die iiberall zerstreuten Sehzellen, welche sich unmittelbar in eine Nervenfaser fortsetzen und daher Sinnesnervenzellen sind. Der Nervenfortsatz war leider nur eine kurze Strecke verfolgbar. Wir begregnen hier also Sinnesnervenzellen im Zentralnervensystem, was bei den anderen Evertebraten niemals der Fall war, bei Vertebraten aber für die Stäbchen- und Zapfenzellen der Retina und bei Amphioxus abermals fiur die Zellen des Infundibularorgans und einige Epithelzellen des Zentralkanals (vergl. S. 351) zutrifft. Das Merkwiirdige der mitten im Rückenmark eingebetteten Sehzellen ist, dal3 es solitare Sinnesnervenzellen sind, welche nicht die Körperoberfläche erreichen. Das haben sie aber mit den 
Sehzellen mancher Tiere gemein. Daß gerade nur die Sehzellen unter den Sinnesnervenzellen bisweilen nicht die Körperoberfläche erreichen, ist begreiflich, denn der Reiz des Lichtes weiß doch wohl zu ihnen zu gelangen.

Im SchNeIderschen Lehrbuche (ScHxeIder 1902) und im Sammelwerke von Loexnberg (1903) findet man viele der bis jetzt besprochenen Resultate der Forscher wiedergegeben.

Dogrex (1903) hat sich mehr mit dem peripheren als mit dem zentralen Nervensystem von Amphioxus beschäftigt. An dieser Stelle möchte ich daher nur bemerken, daß er die Neurochordzellen unipolar nennt und nur ihren Neuriten mit seinen Kollateralen beobachten konnte.

Neben dem Zentralkanal sah er einen noch nicht bekannten unipolaren Ganglienzelltypus. Sein Stammfortsatz spaltet Dendriten ab und geht dann zur Peripherie des Rückenmarks, wo er sich T-förmig teilt. Der eine Ast ist kurz und verzweigt sich bald ; der andere ist eine Längsfaser des Rückenmarks, welche nach DogIEL vielleicht in einen motorischen Nerven eintritt.

Das Gehirn von Amphioxus hat besonders in EDIxger (1906) einen Untersucher gefunden. EDINGer hat die Bielschowsky-Methode angewandt, aber damit nur Teile der Leitungsbahnen ans Licht gebracht. So sagt er, daß Fasern, welche unter der Oberfläche des frontalsten Hirnteiles laufen, zwei Bündel zum Auge, einer pigmentierten Stelle vorn im Gehirn, bilden, daß die Fasern der Hirnnerven im Gehirn einige Segmente nach hinten ziehen, ehe sie sich zum Zentralkanal umbiegen und daß der erste Hirnnerv, obgleich er ventral austritt, sensibel ist und seine Fasern von der dorsalen Seite hinten aus dem Gehirn herstammen. Zwischen dem zweiten und vierten dorsalen Nerven fand EDLrger dorsal eine Gruppe großer Ganglienzellen, welche Fortsätze nach vorn, nach hinten und nach der ventralen Seite aussandten und im Rückenmark sah er bipolare Ganglienzellen, welche nach vorn und hinten in eine Längsfaser übergingen. Vielleicht die Zellen $b$ der Fig. 116 nach Retzius.

Im Epithel des Zentralkanals des Rückenmarks entdeckte EDIxGER Sinnesnervenzellen mit basalem Nervenfortsatz und in den Zentralkanal hervorragendem Sinnesfortsatz.

Aehnliche Zellen sind bald darauf von BoEke (1908) im Epithel des Infundibularorgans, einer Vertiefung im Hirnboden von Amphioxus, entdeckt worden. Nach Bokke tragen diese Zellen Wimpern. Weil der Zellkörper selbst sich in eine Nervenfaser fortsetzt und nicht bloß durch eine herantretende Nervenfaser innerviert wird, haben die Zellen ganz den Charakter von Sinnesnervenzellen. Weder bei den Zellen des Infundibularorgans, noch bei den Zellen des Zentralkanals war der Nervenfortsatz weit verfolgbar.

WoLFF (1907) hat sich außerordentliche Mühe gegeben die Kommissurzellen des Rückenmarks von Amphioxus zu studieren. Er hat in erster Linie die uns schon von Stieda und Rohde bekannten dorsalen Kommissurzellen, welche die Raphe überbrücken, gesehen und darüber mitgeteilt, daß sie einen Fortsatz in das dorsale Bündel Längsfasern des Rückenmarks senden. Das war noch nicht bekannt. Auch sah er, daß diese dorsalen Kommissurzellen bisweilen paarweise anastomosierten mit jenem Fortsatz, welcher die Raphe 
überbriickte. WoLfF hat daneben ventrale Kommissurzellen unter dem Zentralkanal entdeckt. Erstens große Ganglienzellen mit einem Fortsatz nach vorn in dem ventralen Längsfaserbündel und mit einem Fortsatz nach hinten in der anderen Seite des Rückenmarks. Zweitens Kommissurzellen mit einem Ausläufer in dem ventralen Nerven der einen Seite und einem anderen in dem dorsalen Nerven der anderen Seite. Ein dritter Fortsatz dieser Zellen konnte nicht verfolgt werden. Drittens Kommissurzellen, welche vier Fortsätze besitzen, einen in einem dorsalen Nerven, einen in dem dorsalen Längsbündel der anderen Seite, einen im ventralen und einen im dorsalen Längsbündel der gleichen Seite. Zuletzt gibt es noch Kommissurzellen, welche nur einen ventralen Nerven und das dorsale Längsfaserbündel der anderen Seite durch ihre Fortsätze verbinden, während andere Ganglienzellen, welche man nicht Kommissurzellen nennen darf, einen Fortsatz haben, welcher sich spaltet in einen Ast zu einem ventralen Nerven und einen Ast zum dorsalen Längsfaserbïndel derselben Seite.

WoLfF macht am Schluß seines Aufsatzes einen Versuch das Medullarrohr der Vertebraten mit dem Schlundringe der Evertebraten zu homologisieren. Ein solcher Versuch scheint mir ganz verfehlt, denn ich schließe mich aus Gründen, welche hier verschwiegen werden mögen, jenen Forschern an, welche die Vertebraten nicht von den Würmern, Arthropoden oder Mollusken abstammen lassen, also nicht von jenen Tieren, welche einen Schlundring besitzen, sondern von den Tunicaten mit als nächsten Verwandten u.a. die Echinodermen und Ctenophoren. Betreffs des Nervensystems wird diese Hypothese gestützt durch die wichtige Tatsache, daß nur die 'Tunicaten unter allen Tieren ebenso wie die Vertebraten und Amphioxus ein röhrenförmiges Nervensystem aufweisen. Uebrigens ist, geschwiegen von den Echinodermen und Ctenophoren, der feinere Bau des Nervensystems der 'Tunicaten und der verwandten Enteropneusten (worüber ich sogar in diesem Buche nichts mitteilen konnte) viel zu wenig bekannt, als daß sich heute mit Erfolg detaillierte Homologisationen aufstellen ließen. Dafür soll auch Amphioxus viel eingehender studiert werden. Ueberdies möchte ich betonen, daß meiner persönlichen Meinung nach, alle mir bekannten Homologisationen des Vertebratennervensystems mit demjenigen der Würmer oder Arthropoden durchaus unglaubwiirdig scheinen. Wer die Phylogenese des Vertebratennervensystems studieren will, hat merkwïrdigerweise gerade das Nervensystem der am wenigsten erforschten Evertebraten zu untersuchen. Die relativ gut bekannten Würmer, Mollusken und Arthropoden werden ihm dabei nicht helfen können. Es liegt darin zugleich der Grund, warum richtige Homologisationen des Nervensystems der Vertebraten und Evertebraten fast völlig fehlen.

An einer Stelle, wo man solches wenig erwarten wïrde, hat auch HELD (1909) eine vollständige Reizleitungsbahn von Amphioxus veröffentlicht. Bei der 2.5 m.MI. langen Larve tritt aus Neuroblasten des Rückenmarks ein Bündel Neurofibrillen und diese Neurofibrillenbündel laufen in den ventralen Nerven bis zu den Zellen des Myotoms. Wahrscheinlich sind diese Neuronen dieselben, welehe beim erwachsenen Tiere von Hexmaxs ind VAX DER STRICH (1896) erforscht worden sind. 
'Die letzte Arbeit, welche iiber die Leitungsbahnen des Riickenmarks von Amphioxus handelt, hat Stexdect (1914) publiziert. Er huldigt darin sonderbaren Vorstellungen. So meint er, daß die EDIxG ERschen Sinnesnervenzellen durch Uebergånge mit den Neurochordzellen verbunden seien und daß es keine prinzipiellen Unterschiede zwischen beiden gäbe. Auch meint er, daß3 die anastomosierenden dorsalen Kommissurzellen, welche WoLfF entdeckte und er bestätigen konnte, wahrscheinlich EDIxGersche Sinnesnervenzellen seien. Dem kann natiirlich nicht so sein. Der Fortsatz einer Kommissurzelle ist kein Sinnesfortsatz einer Sinnesnervenzelle.

Weil Stexdell keine neuen Leitungsbahnen bekannt macht, genügen diese wenigen Worte über seine Untersuchungen.

Wenn ich mich frage, welche Ganglienzelltypen im Zentralnervensystem ron Amphioxus so bekannt sind, daß sie immer wiedererkennbar sind, so gelange ich $\mathrm{zu}$ den folgenden :

Motorische Ganglienzellen, welche ihren Neuriten in einen rentralen. motorischen Nerven senden (Rohor, Hexuaxs und vax der Stricht, Held).

Ganglienzellen, welche einen Fortsatz cinem motorischen Nerven beimischen und einen anderen dem dorsalen Längsnervenfaserbündel derselben Seite (WOLFF).

Bipolare Ganglienzellen (Fig. 116, a), welche einen Fortsatz in einen sensibelen, dorsalen Nerven und den anderen in ein Längsbündel der anderen Rückenmarkshälfte senden (Rerzios, vielleicht Heriaxs und VAx DER STRICHT).

Bipolare Ganglienzellen (Fig. 116, b), welche einer Längsfaser eingeschaltet sind, welche manchen sensibelen Nerven Seitenäste abgibt (RETzius vielleicht HEYMAXs und VAX DER STRICHT).

Große dorsale Ganglienzellen, vorn im Rückenmark, welche Fortsätze in den sensibelen Nerven haben (Hermaxs und VAx der STricitT).

Ganglienzellen neben der Raphe mit Dendriten im Rückenmark und einem Neuriten in einem sensibelen Nerven (Heymaxs und VAx DER Stricht).

Sehzellen (HESSE).

Sinnesnervenzellen im Epithel des Zentralkanals des Ruickenmarks (EDINGER).

Sinnesnervenzellen im Infundibularorgan (BовкE).

Neurochordzellen (StIEDA, Romox, Rohde, Retzils, Hermass und VAF DER STRIChT).

Unipolare Ganglienzellen mit Dendriten im Rückenmark und T-förmig geteiltem Neuriten unter der Oberfläche des Rückenmarks (DoGié).

Dorsale, die Raphe überbrückende Kommissurzellen (STIEDA, Ronde, Wolff, Stendell).

Ventrale Kommissurzellen, worunter vier'Typen unterscheidbarsind (WOLF).

Es liegt auf der Hand, daß diese relativ wenigen Ganglienzelltypen weit davon entfernt sind, alle vorhandenen Typen darzustellen. Sie geniigen nicht einmal ein einigermaßen ïbersichtliches Bild zu entwerfen, wie die Wege der Reize im Zentralnervensystem von Amphioxus sind und es werden also zu diesem Zweck immer neue Untersuchungen angestellt werden miissen. 
Teber die Leitungshahnen des peripheren Nervensystems von Amphioxus liegen uns folgende Beobachtungen vor. In erster Linie wurden Sinnesnervenzellen in der Haut entdeckt und zwar verdient LANGERHANS (1876) ihr erster genauer Beobachter genannt zu werden. Zuvor hatte wohl KowaLEwsky (zitiert nach Dogreu (1903)) gremeldet, daß in Epithelzellen der Körperoberfläche Nervenfasern enden (und OwsJaxnikow (1868) schloß sich dieser Meinung an), aber er meinte, daß alle Epithelzellen darin gleich seien und LANGGERmaxs war der erste, welcher die Simnesnervenzellen neben indifferenten Epithel zellen sah und dieselben somit richtig wahrnahm. LANGERHANs begegnete diesen Zellen nicht nur in der Haut, sondern auch im Epithel der Cirren des Mundes und auch am Boden der Riechgrube (Flimmergrube) fand er haartragende Sinnesnervenzellen.

-Rohon (1882) konnte die Langerhansschen Mitteilungen bestätigen und fïgte hinzu, daß die Nervenfortsätze der Simmesnervenzellen der Flimmergrube ins Gehirn eindringen, was seinerseits Конц (1890) bestätigte.

Fusari (1889) sah die Sinnesnervenzellen der Cirren besonders in Papil: len angehäuft. Ihre Nervenfortsätze verschwanden in darunterliegenden Nervenplexus.

VAN WiJhe (1893) konstatierte in der Vorderwand des Velums einen Nervenplexus, worin Simnesnervenzellen der Velartentakeln ihre Nervenfortsätze tauchten.

Es folgt dann eine Periode, worin das Vorkommen von Sinnesnervenzellen in der Haut verneint wird, so von Hermans und VAN DER STRIch't (1896) und von Retzius (1898). Weil DogreL (1903) abermals an verschiedenen Stellen Sinnesnervenzellen nachweisen konnte, glaube ich, daß HEyMars und vax der Stricht und Retzius darin nicht Recht haben.

Dogiel (1903) arbeitete mit der GoLgi-Methode und mit Methylenblau und er fand sowohl in der Haut als im Epithel der Cirren Sinnesnervenzellen (von ihm periphere Nervenzellen genannt), welche ihren Nervenfortsatz in einen subepithelialen Nervenplexus sandten. In den Cirren stehen diese Zellen in den Papillen gruppiert oder zwischen den Papillen zerstreut. In der Flimmergluhe traf Docitis neben indifferenten Epithelzellen simnesnervenzellen. welche ihren basalen Fortsatz in einem dicken Nerven zum Gehirn sandten. Auch dieses stimmt mit dem Bekannten iiberein, nur daß Dogrel einen bestimmten Nerven der Illimmergrube anerkenut, welchen ROHOx verneinte.

Der Leser hat schon erfahren, daß sich unter dem Epithel der Haut ein Nervenplexus befindet, in den die Nervenfortsätze der Simnesnervenzellen eintreten. Sie sind nicht die einzigen Fasem, welche diesen Nervenplexus bilden. Die Spinalnerven sind ebenfalls mit diesem Nervenplexus verbunden und treten ihm Fasern ab und iberdies enthält der Nervenplexus Ganglienzellen und gehen aus ihm sensibele Nervenfasern hervor, welche frei in der Hant enden.

Die hier gegebene Vorstellung fußt auf den folgenden Mitteilungen. RoHos (1882) ist der erste, welcher in der Haut von Amphioxus einen Nervenplexus mit interpolierten Ganglienzellen beschreibt, aus welchem Nervenfasern hervorgehen, welche frei in der Haut enden. Ihm folgen liusani (1859), welcher 
in der Haut einen Nervenplexus mit Ganglienzellgruppen sah und RETzius (1898), welcher in der Haut und im Epithel der Cirren freie Nervenendungen beobachtete: Schließlich meldet DogIel (1903), daß die sensibelen Spinalnerven sich verästeln und in einen subepithelialen Nervenplexus ïbergehen. Einige Fasern dieses Plexus verästeln sich zwischen den indifferenten Epithelzellen der Haut und enden dort frei. Aehnliche freie Nervenendungen wurden in den Cirren wahrgenommen.

Mit solchen Mitteilungen wird unsere Kenntnis der peripheren Leitungsbahnen von Amphioxus nur wenig gefördert. Will man sie genau kennen, so hat man die Nervenfortsätze der Sinnesnervenzellen bis zu ihrem Ende. die frei endenden sensibelen Nervenfasern bis zu ihrem Anfang und auch die Fortsätze der im Nervenplexus eingeschalteten Ganglienzellen zu verfolgen. Das bis jetzt Bekannte zeigt nur, daß die Nerven als solche nicht als einheitliche Leitungsbahnen betrachtet werden dürfen.

Daß ein Nervenplexus mit eingelegten Ganglienzellen nicht ausschließ- lich unter der Haut vorkommt, lehrt uns die Bemerkung Dogrels, daß ein solcher auch im Kiemenkorbe da ist.

Man hat sich große Mühe gegeben zu entscheiden, ob die Spinalnerven in ihren ersten Abschnitten, bevor sie eventuell in einen Nervenplexus ïbergehen, Ganglienzellen enthalten, weil man in dieser. Weise in den sensibelen Nerven die Homologa der Spinalganglien der Vertebraten zu finden hoffte. Die Ansichten der Autoren dariiber sind ziemlich verschieden.

LANGERHANS (1876) fand in keinem der Spinalnerven ein Ganglion mit Ausnahme der beiden vorderen Hirnnervenpaare (der ungepaarte Nerv zur Flimmergrube nicht mitgerechnet). Hier lagen einige Ganglienzellen in einer Kapsel beisammen in den peripheren Nerven.

RoHox (1882) entdeckte zahlreiche Ganglienzellen in den drei vorderen Hirnnervenpaaren.

FUSARI (1889) sagt, daß die beiden vorderen Hirnnervenpaare periphere Ganglien tragen. Die daraus hervortretenden Nerven enden nach ihm frei im Epithel der Haut, aber da sagt er wohl mehr, als er genau genommen verantworten kann, denn er folgt den einzelnen Nervenfasern nicht.

ROHDE (1890) sieht in den sensibelen Spinalnerven zahlreiche Kerne, deren nervöse Natur er anderen Autoren gegenüber, welche sie als Bindegewebskerne betrachten, verteidigt.

Hingegen leugnen Heymaxs und vax DER Strroht (1896), daß die sensibelen Spinalnerven je Ganglienzellen enthalten und sie erkennen folglich dem Amphioxus keine Spinalganglien zu. Schreider (1902) und LoExxBerg (1903) schließen sich in ihren Sammelwerken dieser Auffassung an.

Dogiel (1903), welcher den Bau der sensibelen Spinalnerven vielleicht am besten untersucht hat, hat darin die Nervenfasern genau verfolgen können. denn er beschreibt in den sensibelen Nerven diinne Nervenfasern unbekannter Herkunft, welche im Rückenmark angelangt, sich 'T'-förmig teilen in einen aszendierenden und einen deszendierenden Ast, welche hauptsächlich dorsal und lateral im Rückenmark gelegen sind und bisweilen anderen Nerven Seitenäste überliefern. Ich frage mich ob diese Fasern nicht die Fortsätze del 
von RetziUs entdeckten Ganglienzellen (Fig. 116, b) seien. Andere dünne Nervenfasern der sensibelen Nerven kreuzen die Medianlinie und enden verzweigt. Thre Ursprungszellen sind also in der Peripherie zu suchen. Noch andere Nervenfasern der sensibelen Nerven sind ein wenig dicker als die vorigen Sie biegen im Rückenmark ganz einfach in der Längsrichtung um. DogreL vermutet darin motorische Nervenfasern, welche auch in den sensibelen Nerven nicht fehlen würden.

Ganglienzellen mit verfolgbaren Fortsätzen hat DoGIEL in den sensibelen Nerven nicht finden können. So glücklich ist nur VAx WIJHE (1913) gewesen, welcher in letzter Zeit unter dem Atrialepithel, welches Leber, Mittel- und Enddarm bedeckt, eine große Henge multipolarer Ganglienzellen fand, welche ihre Neuriten mit den sensibelen Nerven zum Rückenmark sandten.

Zusammenfassend kann ich also sagen, daß vielleicht die Hirmmerven bald nach ihrem Austritt Ganglienzellen enthalten, daß jedenfalls die sensibelen Spinalnerven in ihren ersten Abschnitten keine Ganglienzellen führen, welche mit den Spinalganglionzellen der Vertebraten direkt vergleichbar wären. Man hätte sich vielleicht die Frage, wo die Homologa der Spinalganglionzellen der Vertebraten bei Amphioxus zu finden seien, nicht gestellt oder jederifalls ihre Lösung in anderer Richtung gesucht, wenn man sich genügend Rechenschaft gegeben hätte über die großen Unterschiede, welche die sensibelen Spinalnerven von Amphioxus gegenüber jenen der Vertebraten kennzeichmen. Die sensibelen Nerven der Vertebraten enthalten neben sympathischen Nervenfasern Fortsätze von Spinalganglionzellen, welche wahre Sinneszellen innervieren oder solche, welche frei im Epithel oder im Bindegewebe enden. Die sensibelen Nerven von Amphioxus gleichen in ihrer Zusammensetzung weit mehr den sensibelen Nerven der Evertebraten als jenen der Vertebraten, denn sie führen neben wenigen motorischen Fasern und sympathischen Nervenfasern, wozu ich vielleicht die von VAx WIJHE (1913) entdeckten rechnen darf. Nervenfortsäte von Simmesnervenzellen und frei in der Körperperipherie endende Nervenfasern, aber keine Fasern, welche wahre Simeszellen innervieren, denn solche Zellen wurden bei Amphioxus nicht gefunden. Der einzige lasertypus, welcher den sensibelen Nerven der Vertebraten und des Amphioxus gemeinschaftlich ist, sind also die frei endenden sensibelen Nervenfasern, welche bei den Vertebraten aus Spinalganglionzellen hervorgehen. Man wird also bei Amphioxus die Homologa oder wenigstens die Analoga der spinalganglionzellen entdeckt haben, sobald man die Ursprungszellen der oft crwähnten frei endenden sensibelen Nervenfasern erforscht hat. Heute kommen dafiir, so weit ich sehe, nur die Ganglienzellen des peripheren Nervenplexus. oder die Ganglienzellen des Rüclienmarks, welche einen Fortsat $\%$ in cinen sensihelen Nerven senden, (vergl.S. $353)$ in Betracht.

Wir haben schon im Riickenmark Ganglienzcllen kennen grelent, welche einem ventralen, motorischen Nerven einen fortsatz beimischten. Nach Dogiet (1903) wïrden diese Nervenfisern sich verästeln und ohne zu anastomosieren oder in periphere (ianglienzellen iiberzugehen, in motorischen Endapparaten der Fasern der Körpermusliehn enden. Bei diesen motorischen 
Nerven ist also ausnahmsweise der Weg des Reizes zugleich mit dem Laufe des Nerven völlig bekannt. Ebensowenig wie andere Autoren die Fortsätze der motorische Rückenmarkszellen bis zum Ende haben verfolgen können, ebensowenig konnte Dogrel den Ursprung der motorischen Nervenfasern ermitteln. Einige Fasern sah er im Rückenmark nach hinten umbiegen und ventral weiterziehen, andere sah er die Medianlinie überschreiten.

\section{I T E R A T UR.}

1. Boeke (1908), Over den bouw van de gangliencellen in het centrale zenuwstelsel van Branchiostoma lanceolatum (2de mededeeling), Verslagen der Koninklijke Akademie van Wetenschappen te Amsterdam, Wis- en Natuurkundige Afdeeling, 1908.

2. Dogiel (1903), Das periphere Nervensystem des Amphioxus (Branchiostoma lanceolatum), Anatomische Hefte (1ste Abt.), Bd. 21, Heft 66, 1903.

3. Edinger (1906), Einiges vom ,Gehirn" des Amphioxus, Anatomischer Anzeiger, Bd. 28, 1906.

4. FusARI (1889), Beitrag zum Studium des peripherischen Nervensystems von Amphioxus lanceolatus, Internationale Monatsschrift für Anatomie und Physiologie, Bd. 6, 1889 .

5. Held (1909), Die Entwicklung des Nervengewebes bei den Wirbeltieren, 1909.

6. Hesse (1898), Die Sehorgane des Amphioxus, Zeitschrift für wissensehaftliche Zoologie, Bd. 63, 1898.

7. Heymavs et van der Stricht (1896), Sur le système nerveux de l'Amphioxus, Mémoires couronnés et mémoires des savants étrangers publiés par l'académie royale de Belgique, Tome 56, 1898.

s. Kонц (1890), Einige Bemerkungen über Sinnesorgane des Amphioxus lanceolatus, Zoologischer Anzeiger, Bd. 13, 1890.

9. Langerhans (1876), Zur Anatomie des Amphioxus lanceolatus, Archiv für mikroskopische Anatomie, Bd. 12, 1876.

11). Loennberg (1903), Pisces, Bronss Klassen und Ordnungen des Thierreichs, Bd. 6, Abt. 1, 1903.

11. Owsjanvikow (1868), Sur le système central nerveux d'Amphioxus lanceolatus, Bulletin de l'Académie impériale des Ścienes de St.-Pétersbourg, T. 12, 1868.

12. Retzius (1891), Zur Kenntnis des centralen Nervensystems von Amphioxus lanceolatus, Biologische Untersuchungen, N. F. Bd. 2, 1892.

13. RetziUs (1898), Die Methylenblaufärbung bei dem lebenden Amphioxus, Biol. Untersuch. N. F. Bd. 8, 1898.

14. Rohde (1890), Histologische Untersuchungen übor das Nervensystem von Am. phioxus lanceolatus, Zoologische Beiträge, Bd. 2, 1890.

15. Rоном (1882), Untersuchungen über Amphioxus lanceolatus, Denkschriften der kaiserlichen Akademie der Wissenschaften, Wien, Math.-Naturw. Classe, Bd. 45, 1882.

li. SCHNeIder (1902), Lehrbuch der vergleichenden Histologie, 1902.

17. Stendell (1914), Zur Histologie des Rückemmarks von Amphioxus, Anatomischer Anzeiger, Bd. 46, 1914.

1ミ. Streda (1873), Studien über den Amphioxus lanceolatus, Mémoires de l'Académio impériale des sciences de St.-Pétersbourg, 7 me Série, Tome 19, 1873.

19. WolfF (1907), Bemerkungen zur Morphologie und zur Genese des AmphioxusRückenmarks, Biologisches Centralblatt, Bd. 27, 1907.

20. Van WiJhe (1893), Ueber Amphioxus, Anatomischer Anzciger, 13d. 8, 1893.

21. VAN WiJhe (1913), Over de metamorfose van Amphioxus lanceolatus, Verslagen der Koninklijke Akademie van Wetenschappen te Ansterdam, Wis- en Natuurkundige Afdeeling, 1913. 


\section{TIERNA婯EN-REGISTER.}

Acanthobdella 107, 111.

Acanthobdella peledina. 110.

Acanthocephala 57.

Acarina 333.

Acherontia atropos 331 .

Acilius 194, 207.

Acilius sulcatus 301 .

Actinia 22.

Aculeata 318.

Aeginidae 15, 16.

Aeschna 226, 287, 289, 295, 324, 327, 330, $332,333$.

Aeschna cyanea 285.

Aeschna grandis 285 .

Aeschna juncea 285 .

Aeschna maculatissima 282, 283.

Alciopa cantrainii 76 .

Alciopidae $59,75$.

Alcyonaria 24.

Alcyonium digitatum 23, 24.

Ameise 200, 304, 317, 318, 319-321.

Ammotrypane 61.

Ampelophaga 332.

Ampelophaga myron 331.

Amphineura 117, 118 .

Amphioxus 42, $345 \quad 357$.

Amphipoda 211-213.

Amphiporus 44.

Annelida $32,41,46,57,55-112$.

Anodonta 131 .

Anodonta anatina 130 .

Anomia ephippium 125, 126.

Anthophora 318.

Anthozon 22-24.

Aphrodite $67,69$.

Aphroditene 64, 67, 77.

Apidae 318.

Apis mellificn 275, 290, 294, 303, 304 $318,319,320,321,322,327,328$, $332,333$.

Aplysia 133.

Aplysia punctata 132.

Aporrhais pespelecani 135 .

Appendicularia 344 .

Apterygota 281.

Apus glacialis 211.

Arabella 64.
Arachnoidea 193, 197, 333

Aranea 333.

Arca barbata 123, 126.

Arca Noae 120, 121, 123, 126.

Arca tetragona 123, 126.

Arcacea 126.

Archiannelida 58.

Archiptera 281-289.

Arenicola 70 .

Arion 156, 158.

Arion empiricorum 149, 157.

Arion rufus 149.

Armandia 62.

Artemia salina 197, 208.

Arthrogastres 333, 336.

Arthropoda $2,3,11,12,13,77,81$, $94,120,133,147,156,191-336$, 352.

Ascandra arborea 6.

Ascaris $46-57$.

Ascaris Kükenthalii 55.

Ascaris lumbricoides 46, 48, 49.

Asearis megalocephala $46,47,48,49,51$.

Ascidia 343.

Asellus 213.

Asellus communis 214.

Astacus 151, 205, 213, 214, 217, 219. $221,223,224,227,228,229,230$, $231,233,234,235,236,237,238$, $239,240,241,243,246,248,251$, $25 \%, 253,254,259,272,316$.

Astacus fluviatilis 205, 219, 220, 221, 222, 223, 224, 232, 233, 234.

Astacus leptodactylus 224 .

Astacus marinus siehe Homarus.

Astarte fusca 126.

Asterins rubens 184.

Asteroiden 181-184. 185.

Asterope candida 76 .

Aulastomum gulo 102, 103, 105, 106, $107,109$.

Aurelia nurita 1!).

Auster siehe Ostrea.

Belostoma 328, 329.

Beroe oratus 25, 26

Biene siehe Apis mellifica. 
Blatta siehe Periplaneta.

Blutegel siehe Hirudo.

Bombyx 332.

Bombyx mori 203, 204, 331.

Botriocephalus $37,40$.

Brachyura 254, 272.

Branchiobdella parasita 110.

Branchiopoda 197, 207-211.

Branchiostoma lanceolatum siehe Amphioxus.

Branchipus 209.

Branchipus stagnalis 197.

Bryozoa 243.

Buccinum 132.

Bunodes 23.

Bythotrephes longimanus 209.

Caecidotaea stygia 214.

Calanella mediterranea 207.

Calliphora 332, 333.

Calliphora erythrocephala 201, 329.

Caloptenus italieus 295.

Campanularidae 16 .

Camponotus 319, 321.

Camponotus ligniperdus 319 .

Camponotus pennsylvanicus 320 .

Cancer 272.

Capitella 65.

Capitellidae 64, 65.

Carabidae 235, 302, 303, 330.

Carabus auratus 302 .

Carabus sylvestris 302 .

Carcinus 219, 257, 272.

Carcinus maenas 246, 251, 254, 255, $256,258,259,260,261,264,266$, $267,268,271,272,273$.

Cardita sulcata 126 .

Cardium 130.

Cardium edule 130.

Carinaria 139, 141.

Carinella 41, 44.

Carmarina 16.

Carmarina hastata 17.

Cephalopoda 119, 159-177, 289, 327.

Cerebratulus 41, 43, 44.

Cerebratulus marginatus 42 .

Cerianthus 23.

Cestodes 37-40.

Cetochilus 207.

Chaetoderma nitidulum 117, 118.

Chaetognatha 45,46 .

Chaetopoda 58-99, 235, 303, 330.

Chilognatha 198.
Chilopoda 202, 274.

Chiton 117, 118.

Chiton laevis 118.

Chiton siculus 118 .

Clepsine 107, 108, 109, 110, 111.

Codonium 17.

Coelenterata 2, 3, 4, 6, 7-28, 29, 31, $38,95,112,118,193,213,234,280$.

Coleoptera 197, 200, 207, 300-304.

Collembola 281.

Colossendeis 273.

Copepoda 198, 207.

Corethra plumicornis 197.

Corydalis 203.

Corydalis comuta 297, 298, 299.

Cotylorhiza 20.

Crabro cribarius 318 .

Crangon 200.

Craterolophus tethys 21.

Crinoidea 181, 186, 187.

Crustacea 41, 142, 192, 194, 197, 198, $199,200,201,203,204,205,207-$ $273,276,281,282,295,303,333$.

Ctenophora 25, 26, 352 .

Cyanea 9.

Cyanea annaskala 19.

Cyprina 138.

Cvprina islandica 130.

Daphnia 204, 207, 210.

Daphnia sima 208, 209.

Daphidae 198, 200, 208, 209.

Dasybranchus 65.

Datana 332.

Decapoda (Cephalopoda) 160.

Decapoda (Crustacea) 142, 199, 204, $207,211,215,219-273$.

Dendrocoela 31.

Dendrocoelum lacteum 32,34 .

Dentalium dentale 118.

Dentalium entalis 118.

Derostoma 32.

Dibranchiata (Cephalopoda) 160, 163.

Diplopoda 198, 214, 274.

Diptera 197, 198, 201, 239, 286, 322$330,332,333$.

Distomum 12.

Distomum eaudatum 35.

Distomum hepaticum 36 .

Distomum macrostomum 35.

Donax trunculus 130.

Dorcus parallelepipedus 300.

Dreissenia polymorpha 126. 
Drepanophorus 44,45 .

Dytiscus 301 .

Echinidre 188.

Echinodermata 1, 11, 181-189, 193, 352.

Echinoidea 181, 187, 188.

Echinorhynchus gigas 57 .

Electone 159, 160, 162, 163, 164, 165, $168,169,173,174,177$.

Eledone moschata 163.

Enteropneusta 352.

Entomostraca 207-211.

Epeira 333, 334, 335, 336.

Eristalis tenax $323,327$.

Fucera 318.

Eudendrium 16.

Euniceae 64.

Eunicidae 76 .

Eupolia 44, 45.

Falter $330,331$.

Fasciola hepatica 36 .

Fidonia 332.

Fissurella 135, 137, 138

Fliegen 201, 288, 330.

Flußkrebs siche Astacus fluviatilis

Forficula auricularia 201, 296.

Formica $318,319,321$.

Forskalia ophiura 18.

Frosch 169.

Gialathea 273.

(iammarus fluviatilis 213.

(iammarus pulex 213.

Ciastropoda 131-159.

Gieophilus 274.

Geophilus linearis 274.

(ieophilus longicornis 274 .

Ciephyrea 99.

fieryonidne 15, 16, 19.

iliedertiere siche Arthropoda.

rilomeridae 27.

rilossocodon 15 .

fiomphus 283, 284, 285, 290, 316.

(rordius 57.

(iraffia gemellipara 37 .

(irille 241, 295.

(iryllotalpa vulgaris 295 .

(iryllus domesticus 296.

Hamenteriฉ officinalis 107.

llaliotis 134, 135, 138 .
Haliotis tuberculata 135.

Halla 64,68 .

Helix 12, 146, 147, 152, 155, $156,157$. 235.

Helix aspersa $146,149$.

Helix pisena $146,149$.

Helix pomatia $146,149,150,156$.

Hemiptera 197.

Hermione 67, 69.

Hesione sicula 75 .

Hetereconchae 119, 130, 131.

Heteronemertina 45.

Heteropoda $138-145$.

Heuschrecken 294.

Hexapoda siehe Insekten

Hippocrene superciliaris 17.

Hirschkäfer siehe Lucanus cervus

Hirudinea 58, 61, 99-112.

Hirudo 101, 105, 106, 107, 108, 109, $110,251$.

Hirudo medicinalis $99,100,101,102$. $103,104,111$.

Holothuria 181, 188, 189.

Homarus $75,219,220,224,229,234$ $235,238,241,243,248,251,253$, $254,257,272$.

Homarus vulgaris 241, 242, 245, 247, $249,250,252,253$.

Hubrechtia 44.

Hummeln 321.

Hummer siehe Homarus vulgaris.

Hydra 9, 13, 16, 18.

Hydra fusca 14.

Hydra viridis 14.

Hydroidpolypen 16 .

Hydromedusen 14, 15, 16, 17, 18, 19, 20, 21

Hydrophilus 301.

Hydrophilus piceus 302.

Hydrozon $13-19,22$.

Hymenopter $197,198,200,203,304$ 322.

Ichneumon 318.

Idotea 214.

Ilex 16 (i3.

Inseliten 1, 2. 4, 77, 133, 193, 194. 197. 198. 199. 201, 202, 203. $211,218,222,225,226,235,239$, $240,243,261,27(6,279,280-333$. 335.

Io $33: 2$.

Irreguhares (Eehinoidea) $1 \mathrm{Ss}$.

1sopoda $211,213-215$. 
Iulidae 274.

Iulus $274,276,278$.

Käfer siehe Coleoptera.

Korallen 23.

Küchenschabe siehe Periplaneta.

Lanceola 213.

Landschnecken 145.

Langia formosa 44 .

Languste siehe Palinurus.

Lamellibranchia $119-131$.

Lasius $319,321$.

Lasius niger 320 .

Leberegel 36.

Lepidasthenia $65,66,67,80$.

Lepidonotus 70 .

Lepidoptera 197, 198, 200, 203, 330 332.

Lepisma saccharina 281.

Leptodora hyalina 209.

Leptomedusen 15.

Leptoplana 32.

Leucandra conica 6 .

Libelle 281, 282, 283, 284, 285, 288, 316

Ligula $37,40$.

Lima hians 126 .

Lima inflata 126 .

Lima squamosa 123 .

Limacidae $149,150$.

Linax 12, 36, 152, 153, 154, 155, 156 , 158.

Limax agrestis 151.

Limax maximus 146,149 .

Limax cinereoniger 157 .

Limax subfuscus 1.jl.

Limnadia 209.

Limnaeus stagnalis $145,146$.

Limulus 273.

Lineus gesserensis 44 .

Lithobius 274, 278, 279, 280, 290.

Lithobius Martini 274 .

Lithobius piceus 274 .

Lithodomus dactylus 126.

Locusta 294.

Locusta viridissima 296 .

Locustida 294.

Loligo 168, 169, 176.

Loxosoma crassicauda 342 .

Lucanus cervus $300,302$.

Jucernaria 19.

Lucernaridae 21 .

Lucilia caesar 330.
Lucinacea 126.

Lucina spinifera 120 .

Lumbriculus 96.

Lumbricus $13,32,84,85,86,87,89$, $90,91,92,93,94,95,96,97,98$, 106, 151 .

Lumbricus agricola 93.

Lumbricus terrestris 84 , Ss.

Lycosa 333.

Lysidica viridis $\mathbf{7 5}$.

Machilis 281.

Hacrura 241, 254, 25\%.

Nactra elliptica 131.

Maikäfer 203, 301.

Malacostraca 207, 211-273.

Mantis religiosa 296 .

Mastobranchus 65 .

Mehlkäfer siehe Tenebrio molitor.

Meloe proscarabaeus 303.

Melolontha vulgaris 302 .

Mesobdella gemmata 107.

Mesonemertina 45.

Metanemertina 44,45 .

Metazoa 6.

Milben 333 .

Mediola barbata $1: 26$.

Mollusca 2, 3, 10, 11, 13, 94. 117-17 . 181, 193, 206, 273, 352.

Moniezia expansi 39,40 .

Monoophorum striatum 32 .

Murex 138.

Nusca 286, 288, 322-327, 330, 332. 333.

Muscar vomitoria $322,323,324,325$, $326,327,330$.

Muscidae 330.

Myacea 130 .

Iyopsidae 176.

Irviapoda 193, 197, 202, 203, 214, $274-280,281,328$.

Mvriothela phrygia 16 .

Mysis 200, 215.

Mvtilacea 126.

Iytilus 119, 126, 127, 128, 129, 130.

Mytilus edulis 126.

Iyzostomum giganteum 62. $13.3,64$.

Nacella 138.

Nautilus $160,163$.

Nemathelminthes $46-57$.

Nematoda 46-57.

Nemertina $40-45$. 
Nephelis 107, 108, 109, 110, 111.

Nephelis vulgaris 108 .

Nephrops norwegicus 261, 273.

Nephthys 70, 71.

Nereis 11, 65, 72, 76, 78, 80, 246.

Nereis cultrifera 75 .

Nereis diversicolor $76,79,82,83$.

Nereis pelagica 72 .

Nereis virens $73,75,77,82$.

Neuroptera 197, 297-300.

Niphargus putaneus 213.

Notomastus $64,65$.

Nymphon 273.

Ocellatae 15, 17.

Octocorallineae 23.

Octopoda (Cephalopoda) 160, 170.

Octopus 160, 161, 162, 163, 170.

Oedipa coerulescens 295.

Oligochaeta 84-99, 108, 109.

Oliva 138.

Oncidium 156.

Oncidium verriculatum 156 .

Oncinella 133.

Oniscidae 214.

Ophelia 61.

Opheliaceae 60, 61, 6i2, 63.

Ophioglypha 186.

Ophiothrix 185, 186.

Ophiuroidea 181, 185, 186.

Ophrystroche puerilis 76 .

Op thobranchia 132-135.

Orchestria 213.

Orthoptera 197, 198, 289-296.

Oryctes nasicornis 301.

Ostrea edulis 126.

Oxycephalus 213.

Oxygyrus 141 .

Pagurus 200.

Palaemon 273.

Palaemon squilla 199.

Palinurus 151, 217, 219, 225, 238, 239. $241,272,330$.

Palinurus locusta 220, 2:38.

Palinurus vulgeris 194, 238.

Palolo-Wurm 75.

Paludina 134, 138.

Papilio 33:.

Parazoa fi.

Pecten 119, 121, 122, 123, 124, 126. $134,163$.

L'ecten incobnens 130.
Pecten maximus 119.

Pectunculus glycimeris 123, 126.

Pedicellina 342.

Pedicellina echinata 342 .

Pelagia noctiluca 22.

Penaeus 273.

Peripatus 274.

Periplaneta 289, 290, 291, 294, 295, $296,303,313$.

Periplaneta orientalis 289, 291, 292, 293.

Pholas dactylus 130 .

Pholcus phalangoides 333.

Phronima 211, 212, 213.

Physophora 18.

Pieris 332.

Pieris brassicae 330.

Piscicola 100, 101, 107.

Planaria 31, 32.

Planaria alpina 33.

Planaria montana $32,33$.

Planaria torva 32.

Planorbis 156.

Planorbis corneus 145.

Plathelminthes $31-45,117$.

Plesionika cottei 204.

Polychaeta 42, 58-84, 95.

Polycoelis brunnea 32 .

Polyelada 31 .

Polydesmidae 274.

Polygordius 58.

Polynoe 67.

Polynoe elegans 68.

Polyophthalmus 62 .

Polyophthalmus pictus 59, 60, 61 .

Polystomum 34.

Polystomum integerrimum 37.

Pontobdella 101.

Pontobdella muricata 106.

Porcellio 214.

Porcellio maculicornis 214.

Porcellio scaber 213, 214.

Porifera (i.

Potamohius astacus siche Astacus fluviatilis.

Procrustes 302 .

Prosobranchia 1:3:.

Protoconchue 119-130.

Protodrilus 58.

Protonemertina 45.

Protozon (i.

Protrachenta 274.

Psammobia vespertina 130 .

Pseudoneuroptera siehe Archiptera. 
Pterotrachea 139, 140, 141, 142, 143, 144,145 .

Pterotrachea coronata 140, 142.

Pterotrachea scutata 142.

Pulmonata 119, 132, 138, 145-159, 206.

Pyenogonida 273.

Pyrosoma Agassizi 344.

Pyrosomata 344.

Ranzania 76 .

Raubanneliden 75 .

Raupen $330,331,332$.

Regenwurm siehe Lumbricus.

Regulares (Echinoidea) 188.

Rhabdosoma 213.

Rhipidoglossa 134, 135, 136, 138 .

Rhizostoma Cuvieri 20, 21.

Sagartia parasitica 22.

Sagitta 45 .

Salpae 343,344 .

Salpa africana-maxima 344 .

Salpa democratica- mucronata 343.

Salpa pinnata 343,344 .

Salpa runcinata-fusiformis 344 .

Sarsia mirabilis 17.

Saturnia paronia 331.

Säugetiere 168 .

Scaphopoda 118

Schizopoda 211, 215.

Schlangensterne siehe Ophituroidea.

Schmetterlinge siehe Lepidoptera und Falter.

s'chwämme 6 .

Scorpio europaeus 336 .

Scutigera 274

Scutigera coleoptrata 274 .

Seyphomedusen 19

Serphozoa 19-22.

Sedentaria 70.

Seeigel siehe Echinoidea.

Seesterne siche Asteroidea.

Sepia $161,162,163,175,176,177$.

Sepia elegans 109.

Sepia officinalis $160,162$.

Sepia Rondeleti 169.

Sepiola 163, 176 .

Serpula 67.

Sida crystallina 208.

Sigalion 67,68 .

Simocephalus sima 209.

Siphonaria 133.

Siphonophoren 14, 17, 18 .
Sipunculus 99.

Skorpione 200, 333, 336.

Solecurtus strigillatus 130 .

Solen ensis 130.

Solen siliqua 130.

Somomya 275 .

Somomya erythrocephala 328.

Spatangidae 188.

Sphaeroma 214.

Sphinx ligustri 200,331, 332.

Spinnen $333,334$.

Spondylus 123.

Spondylus gaederopus 126.

Squilla mantis $215,216,217,218,219$, $225,226,240$.

Stachelhäuter siehe Echinodermata.

Staurostoma aretica 17.

Sthenelais $67,68,70$.

Stomatopoda 211, 215-219.

Stratiomys chamaeleon 201, 323, 328 .

Synapta 189.

Synaptidae 189.

Tabanus 328 .

Taenia 37, 39.

Taenia perfoliata 37.

Taschenkrebs siehe Careinus maenas.

Tellina nitida 130 .

Tellina planata 130 .

Tenebrio molitor 303 .

Terebellidae 70 .

Terebrantia 318,321 .

Teredo navalis 130 .

Tethys fimbria 132.

Tethys leporina 132

Tetrabranchiata (Cephalopoda) 160, 163.

Tetrarhyncha 37.

Thysanura 197.

Tipula gigantea 328 .

Tintenfische siehe Cephalopoda.

Titanethes 214 .

Tomocerus flavescens 281.

Tracheata 133, 192, 214, 273-336.

Trachynemidae $15,16$.

Trematodes $34-37$.

Travisia 60, 61.

Trichoniscidae 201,213.

Trichoptera 197.

Triclada 32.

Tristomum 34.

Trochus 134.

Tubularia 16.

Tunicater 343, 344, 352. 
Turbellaria 11, 31-34, 95, 112.

Turbo 138.

Unio 130.

Unio pictorum 130 .

Vanadis formosa 75 .

Velella 18.

Venus gallina 130.

Veretillum 23.

Vermes 2, 3, 11, 12, 13, 29-116, 124, $125,133,140,154,156,181,191$, $193,207,246,352$.

Vertebrata 1, 2, 3, 4. 7, 111, 11, 1:2. 13. $29,81,94,95,142,151,161,167$, $168,175,192,193,202,206,211$,
$216,241,289,323,324,325,327$, $330,345,346,350,352,355,356$. Vesiculatae $15,16$.

Vespa 282, 307, 308, 313, 318, 319.

Vespa communis 318.

Vespa crabro $198,318,321$.

Vespa vulgaris 318.

Vibilia 213.

Wespe 318, 319, 321 .

Wirbeltiere siehe Vertebrata.

Würmer siehe Vermes.

Xenia Hicksoni 23.

Zonites algirus 149 . 


\section{SACH-REGISTER.}

Augen $17,31, \quad 34, \quad 37, \quad 45, \quad 59, \quad 60$ $65, \quad 75, \quad 76, \quad 77, \quad 79, \quad 80, \quad 81$ $107,111,119,120,121,122,123$. $124,1: 2,134,135,140,141,155$, $156,163,164,165,166,167,168$, $182,183,184,192,193,194,206$, $207,208,209,210,212,214,215$, $225,244,254,271,273,274,281$, $284,285,286,291,296,301,304$, $305,309,310,311,312,314,318$, $322,323,327,328,329,333,334$, $343,344,350,351$.

corpora pedunculata $5,77,78,79,80$, $133,138,147,156,157,173,192$, $218,221,222,238,261,275,276$, $277,279,280,281,284,285,289$, $290,292,293,294,295,296,298$, $299,303,304,305,306,307,308$, $312,313,314,316,317,319,320$. $312,322,328,329,331,335,336$.

Epithelmuskelzelle 8.

Ganglienzelle

apolare - 100, 119, 134, 225.

entodermale - 16 .

primitive -3 .

sensibele $-10,11,12$.

Cianglienzellplexus 7, 13, 16, 18, 19, 20, $21,22,23,25,26,37,38$, $101,111,118,130,134,169,176$, $203,213,214,218,234,273,280$, $302,303,327,328,331,332$.

Gehörorgane 195, 197, 199, 272, 294, $295,300,318,321$.

globulus siehe corpora pedunculata. glomeruli olfactorii 192, 211, 218, 261, $273,275,276,277,278,285,292$. $293,294,295,296,305,306,308$, $310,311,315,316,317,329$.

glomeruli palpales 78 .

glomeruli pedunculi $276,277,278,279$ $280,281$.

Kettenbahnsystem 97, 98.

Kolossalfaser siehe Neurochord.

Kolossalzelle (keine Neurochordzelle)

$102,103,104,105,149,158,166$, $167,279,302,322$.

Kommissur 30, 191.
Konnektiv 30, 191.

lobus opticus der Cephalopoden 160, 161. $162,164,165,166,167,168,169$, 327 .

lobus opticus der Crustaceen 215, 216, $217,218,224,225,226,238,239$, $240,241$.

lobus opticus der Insekten 280, 281, 282, $283,284,285,286,287,289,290$. $292,293,295,298,299,300,301$. $303,304,305,306,308,311,312$. $313,314,316,317,318,319,322$. $323,324,325,326,327,328,329$, $331,332,333$.

lobus opticus der Myriapoden 276,277 , $278,279$.

Mediankörper 276, 277, 279.

Mediannerv (medianes Konnelitiv) 59. (i). $62,63,72,5 \%, 8(i, 10(1)$, $102,103,104,106,110,330$.

Mediannerv (FAIvrEscher Nerv) 302, 330 , Medianzelle $61,67,86,87,91,93,102$. $104,105,106,108,111$.

Nervensystem. entodermales - 14, 23. Evolution des - 3, 6, 8, 9, 10, 11 . $12,13,36,81,94,95,125,150$. $151,153,154,193,206,207,327$. $330,352,355,356$. mesodermales - 186 .

Ontogenie des - 9, 13, 14, 20, 111 , $124,125,146,223,241-254.280$. $285,297,298,299,301,302,303$. $319,322,323,327,328,330,331$. $332,334,352$. sympathisches - $1,4,37,51,85$, $99,101,108,111,146,161,235$, $241,259,276,302,303,330,356$.

Neurilemma 26, 197.

Neurochord 41, 42, 43, 57, 64, 65, 66, 67, 68, 69, 70, 71, 7:, 7:3.

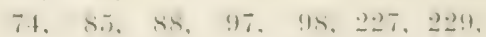
$231,232,233,234,242,243,241$. $346,347,348,249,350,351,35: 3$.

Neurofibrille 59, 105, 111, 120, 164, 219, 235, 239, 271, 272, 294, 352.

Teurommutidium $240,286,323,324,330$. 
Neuromuskelzelle 8 .

Neuron 3, 4, 29, 30, 51, 79, 80, 84, 112, $131,141,170,172,226,235,241$, $246,271,272,277,278,280,283$, $303,310,318,327,332,333,352$.

Neuronentheorie 3, 30, 170, 271, 272.

Neuropilem 3, 30.

NissL-körperchen 203.

Pilzkörper siehe corpora pedunculata Pinselzelle 118.

pons $279,280,292,295,296,305,306$, $307,308,309,310,311,316,319$, 320.

Punktsubstanz 29.

Retinophore 11, 120, 121, 122, 124, 135, $193,194,206,273,296,301,328,329$.
Sinnesnervenzelle 7, 12.

Sinneszelle (wahre) $7,11,12,81,124$, $163,193,195,196,200,201,202$, $204,205,206,207,211,213,272$, $274,295,296,300,301,321,328$, $331,332,356$.

statische Organe 25, 60, 139, 140, 142, $149,161,162,163,176,195,207$, $215,259,267,272,329$.

Vereinsgebiet 138, 157, 158.

Zentralkörper 211, 281, 283, 284, 285, $290,291,292,293,294,295,296$, $303,305,306,307,308,309,310$, $312,313,314,315,319,321,322$, $328,329$. 


\section{AUT OREN-REGISTER.}

Agassiz 14, 15.

Alexandrowicz 151, 235, 241.

Altex 220, 227, 229, 234, 235, 236, 237, $238,211,242,243,244,245,246$, $247,248,249,250,251,252,253$, $254,257$.

ANDRÉ 37.

Aратн: 3, 101, 106.

Ascoli 111, 112.

Ashworth 23, 24.

BABUCHIN 11, 118, 119, 156.

BAECkER 135, 156.

BAgLIONI 172, 173.

BAUER 171, 172, 280, 281.

BELLONCI 192, 214, 217, 218, 225, 226i. $240,261,273,295,308,322$.

BENEDICENTI 331.

Berger 208, 217, 218, 221, 222, 223, $238,282,301,304,308,322,330$.

BERTKAU 334.

Bethe 3, 4, 7, 13, 26, 51, 99, 133, 194, $200,205,213,214,215,234,235$, $246,254,255,256,257,258,259$, $260,261,262,263,264,265,266$, $267,268,269,270,271,272,273$.

BETTENDORF 34, 35, 36.

BIEDERMANN 72, 74, 102, 103, 104, 105, $109,110$.

Bielschowsiry 351.

Bisogin 151, 152.

BLANC 204.

Blochuay $32,34,38,39$.

BLUMrich 118.

BOEKE 351, 353.

Вӧнм 15.

BöнıIG $32,33,95,146,156$.

BolL 139, 140.

BöTtGer 281, 315.

BOUIN 12.

Brandes 46, 49, 57, 58.

BRAUN 34.

BraUSS 40.

BREtSCHNEIDER 290, 291, 292, 293, 294, $295,296,303,315$.

Bristol 106, 107, 108, 109, 111.

Brock 134.
BroNT 181.

BRUCH 99, 100, 101, 102, 103, 104, 105 106.

BUCHHOLZ 145.

Bürger 41, 42, 43, 44, 45.

Bïtschl $15,31,35,41,45,46,48,58$, $99,119,132,198,199,219,254$, $274,318,343$.

CAJAL 3, 97, 169, 280, 286, 288, 322, $323,324,325,326,327,330,332$, 333.

CARRIÈrE 123.

Catrie 331.

Cerfontaine 88, 89, 90, 91, 92, 97.

(HСх 6, 17, 18, 19, 25.

CLAPARÈDE 85.

Clarke 84.

Claus 19, 25, 139, 140, 198, 207, 208, $211,212,213$.

Совв 55.

Cuccati 328.

CÚ́NOT 182, 183.

CunNINGTON 209.

DEINEKA $49,51,52,53,54,55,56,57$. DewOLETZKeY* 41.

DietL 132, 162, 163, 173, 216, 217, 218, $221,222,304,308$.

DoBer 344.

DoGIEL 4, 49, 119, 134, 234, 351, 353. $354,355,356,357$.

Drost 130.

Dubosce 201, 202, 203, 274, 296.

Edinger 11, 124, 140, 351, 353.

EHRLICH 17, 38, 102, 331.

Eimer 15, 16, 19, 25, 26.

Eisig $30,64,65$.

Escherich 330.

FAIVRE 302.

Fischel 204, 210, 211.

Flemming $118,119,125,126,130,134$. $145,146,150$.

FLöGEL 289, 307.

FOI 118.

Fraipont 58. 
FRÉDÉRICO 188.

Freidenfelt 131.

Friedlaender $65,85,86,87,88,89,93$. Fröhlich 172, 173.

FusARI $354,355$.

\section{Gariatef 172.}

Gazagnatre 199, 201.

Gerstaecker 207, 21:3.

GILCHRIST 133.

Goldschmidt 49, 50,51,53, 54, 55, 57, 106.

GolgI 17, 33, 38, 42, 92, 93, 96, 106, $107,108,131,149,152,153,155$, $156,163,164,168,170,189,197$, $199,202,206,210,213,214,215$, $224,232,234,241,274,285,302$, $306,312,323,350,354$.

GöPPERT 343

Graber 193.

VON GRAFF 34.

GRANT SiIth 156.

GreefF 11, 35, 59, 76.

Grexacher $11,140,141,163,164,192$, $193,194,207,213,216,218,225$, $273,274,301,318,333,334$.

Girost.J 22, 23.

GÚÉRIN 170, 171.

Giinther 203. 3:31

\section{HADZI 14.}

HAECket $15,16,182$.

HALLER 3, $11,65,66,677,77,78,80$, $81,87.88,89,91,93,97,98,99$, $111,117,11 \mathrm{~s}, 13: 3,134,13: 5,134$. $137,138,147,156,157,158,159$, $161,162,173,174,175,176,177$. $214,273,274,275,283,284,285$. $286,290,291,293,302,303,307$. $313,314,315,316,317,330,3334$. $335,333(i$.

HAMAKE 72, 73, 74, 75, 77, 78, 82.

HAMAXX 11, 181, 182, 183, 184, 185. ISt, 187. 185, 184.

HAXSEX 101, 106i.

H.ARTY 16 .

HATMER :34:

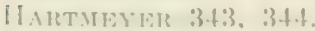

HATSE:R los, lom

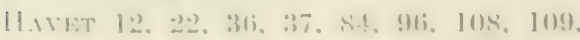
111. 111. 152, 153, 154t.

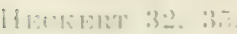

HeLd 352, 353
HeNChMAN 146.

HENSEN 11, 118, 119, 122, 156, 163, $197,272,294,295$.

HERMANN 101, 104, 106.

O. Hertwig 46 .

O. und R. Hertwig 8, 9, 10, 11, 12, 13, 14, 15, 16, 17, 14, 20, 2,2. 23. $25,36,81,94,95,124,206$.

R. Hertwig 25, 26.

Hesse $19,20,21,32,34,45,47,48,40$. $50,53,54,55,56,59,75,76,107$. $123,124,140,141,163,194,350$ 353.

HerMans $350,352,353,354,355$.

Hicksox 23, 322, 323, 324, 330, 333.

HiLtox 203, 204, 297, 298, 299, 300), 3111. 3:31. $3: 3: 2$

His 301

HOEK 273.

HOFFMANN 182, 188.

HofuANy 169, 170.

E. HoLMGREN 200, 213, 235, 331, 332.

N. Holmgren $76,77,75,79,811,81,82$. $83,84,211,214,261,274,275,276$. $277,278,279,280,281$.

JANET 317.

J.1TT.1 17:2. 17\%

JiCKeLI 14，16，182, 183.

JONESCU $310,315,316,317,31 \mathrm{~s}, 319$, 320,321 .

JOSEP 48, 54, 55, 56, 105.

KAHANF: 37

KASSIAXOW 19, 20,21, 22, 24.

Kefersteix 31

KENYON 281, 294, 303, 304, 305, 30(i, $307,308,309,310,311,312,313$. $314,31 \%, 316,317,318,319,332$. 3333

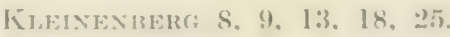

Kont, 3it.

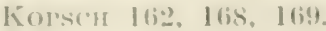

KоnотхеF 13, 17, 18, 19, 23, 23.4.

KoTTE :2114. 273.

KOWALEWSKY 4:, 16(0, 16i2, 16i3, 173. 175, 176.8354.

KnAsixskA 17, 20.

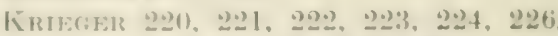
227, 228, 20!9, 2331, 231, 232, 233. $234,243,254$.

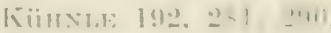

KïKEXTHAL, Go, (il, (i), lit 
KüNCKEL 199, 201.

LACAZE-DUTHIERS 132.

LACZKO 37.

LANDOIS 38, 200, 201, 300 .

LANG $31,32,34,36,37$.

LANGDON 93, 94.

LANGE 182, 183, 185.

LANGERHANS 354,355 .

LeMIOINE 221, 226.

VON LENDENFELD $6,9,16,19,20$.

VON LENHOSSEK $13,29,32,42,89,90$, $91,92,93,94,95,98,151,162$, $163,164,165,166,167,168,169$.

LeydiG $3,29,59,69,85,100,101,106$, $108,192,197,198,201,207,280$.

LINKO 17.

LINTON 37.

Livanow 105, 107, 110, 111.

LÖNNBERG $35 \mathrm{l}, 355$.

Looss 35 .

LORLEBERG 343.

LOWNE 194, 201, 203, 235, 329.

LUDWIG 181, 182, 183, 184, 185, 186, $187,188,189$.

MATLLARD 12.

MARCINOWSKI 36, 37.

Mayer $107,111$.

MC INDoo 318.

MencL 104, 105, 106, 111.

Merton 160, 163, 164.

E. Meyer $59,60,61,62$.

R. Meyer 184.

Michels 301.

MILNE Edwards 193.

Montgomery $41,43,44$.

MIonti 32, 33, 34, 95, 112, 295, 302.

F. MÜLLER 15.

IV. MüLLer 347.

De Nabias $132,133,146,147,148,149$, $152,156,157,158,159$.

NANSEN $62,63,64,106,343$.

Nemec 213, 214, 235.

NeUManN 344.

Newton 241, 289, 290, 291.

Nremite $37,40$.

NissL 203.

NotvikOFF 208, 209.

Nusbaum 203, 214, 218, 235, 273.

ORTMANN 213.
OWSJANNTKOW 160, 161, 162, 163, 173 , $175,176,220,221,223,226,231$, $232,233,238,241,346,247,354$.

PACKARD 214.

PARAVICINI 154, 155.

PARkER 6, 224, 225, 226, 239, 240, 316.

Patten 11, 12, 13, 119, 120, 121, 122 , $123,124,125,134,135,163,193$, 194, 206, 207, 273, 296, 301, 328, 329.

Pelseneer 148.

IV. Pfeffer 184.

Pietschker 315, 319, 320.

Plate 118.

Prenant 12.

RADL 192, 218, 219, 323.

RANKE 139, 140, 162 .

RANVIER 101, 146, 151.

volI RATH 196, 197, 198, 199, 200, 201, $202,203,204,205,213,234,272$, $273,274,281,296,318,319,321$, 322.

RAwTTZ 122, 123, 124, 125, 126, 127, $128,129,130,131$.

REDIKORZEW 194.

REICHENBACH 223.

REICHENSPERGER 187.

Retzius $3,7,11,69,70,71,72,73,74$, $76,77,78,79,80,81,82,90,91$, $92,93,94,96,98,102,103,104$, $105,106,107,108,109,110,112$, $145,149,150,152,155,199,205$, $207,208,209,210,211,223,224$, $228,229,230,231,232,233,234$. $243,246,248,252,253,273,342$, $349,350,351,353,354,355,356$.

Reupsch 142, 143, 144, 145.

ROHDE $48,49,54,55,56,64,67,68$, $69,77,104,105,106,108,347,348$, $349,350,351,353,355$.

Rоном $347,350,353,354,355$.

ROUGET 13.

RULAND 199.

SAMASSA $12,26,145,150,151,152,154$, $208,209,235$.

SANCHÈz 112, 280.

SCHAEPPi 18.

SCHAEFER 19.

SCHENK 200, 321, 322, 332.

SCHIMKEWITSCH 333. 
Friedo Schitid 110.

Oscar Schmidt 294.

A. Schneider $47,48,53$.

K. C. Schneider 9, 14, 16, 18, 22, 26, $40,46,73,96,105,110,117,189$, $234,235,253,351,355$.

SCHÖN 200, 294, 295, 318, 321 .

Schremer 203, 214, 235.

SCHRöDER 200, 336 .

H. Schultze 132 .

II. Schultze 192.

SEELIGER $343,344$.

SEMION 189.

Simroti $117,134,148$.

SMidt 146, 152, 155, 206.

Simrnow 11, 93, 94, 95.

SOMIMER 38.

SPENGEL $30,42,64,68$.

STANTSCHINSKY 156.

STENDFLL 353.

STIEDA 162, 163, 173, 176, 177, 346, $347,34 \mathrm{~s}, 351,353$.

VAN DER STRICHT $350,352,353,354,355$.

Teuscher 182, 183, 185, 188.

Thiele 126.

'I'Hompson 319, 320, 321.

'Tövösvary 275, 276, 280.

Tower 39, 40.

SchKafF $176,177$.

Schmalz 213, 272.

'Tschachotin 139, 140, 141, 142, 143, 144.
VON UExKüLL $172,173$.

Ussow 343 .

VERATTI 12, 95, 125, 150, 152, 153, 154 $155,206$.

VIALLANES 11, 192, 194, 201, 202, 203, $225,235,238,239,240,241,272$, $275,282,283,286,288,292,295$, $296,306,307,308,310,312,318$, $319,322,323,324,327,328,330$, $332,333$.

VIGIER 286, 323, 324, 330, 332, 333.

VIGNAL 85, 101, 106, 146.

Vosmaer 16.

IVALTER 32,35 .

MAx Weber 201, 213, 214.

WEIGERT 4, 345.

WEINLAND 329.

WhitMaN 107, 111.

WIDMANN 334 .

IVILL 26.

IVIRÉN 117, 118.

IVOLFF 8, 13, 19, 22, 349, 351, 352, 353. VAN WIJHE 354,356 .

YUNG $272,273$.

ZAWARZIN $282,284,285,286,287,288$. $289,324,325,330,332,333$.

ZERNECKE 38, 39.

Ziegler 315. 


QI Droogleever Fortuyn, Aemilius

925 Bernardus

D7 Die Leitungsbahnen im

Nervensystem der wirbellosen Tiere

BioMed

PLEASE DO NOT REMOVE

CARDS OR SLIPS FROM THIS POCKET

UNIVERSITY OF TORONTO LIBRARY 


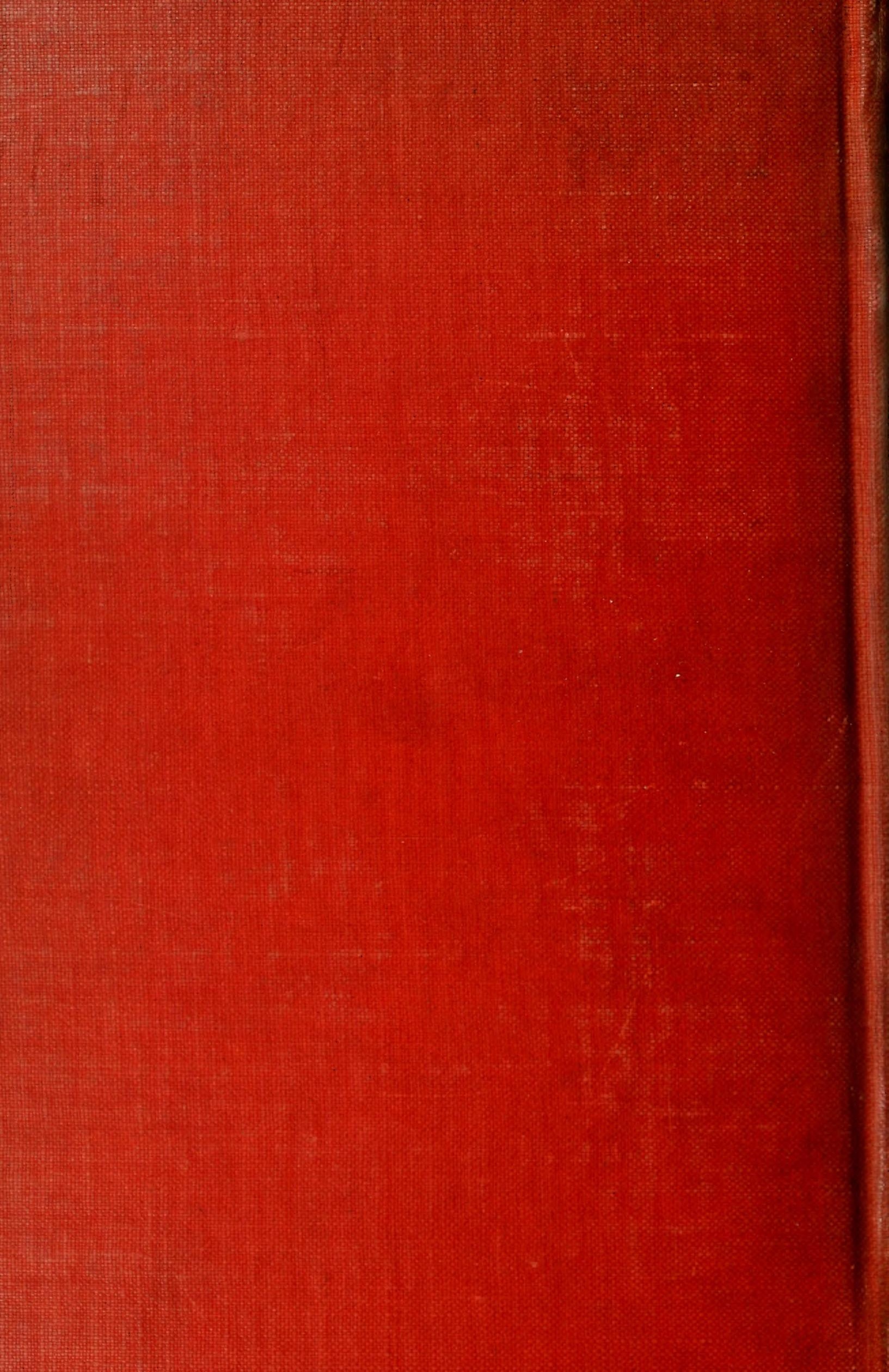

